\title{
Studies in Subject Didactics
}

\section{Nordic research in}

mathematics

education

Proceedings of NORMA14, Turku, June 3-6, 2014

Harry Silfverberg, Tomi Kärki \&

Markku S. Hannula (eds.) 


\section{Nordic research in mathematics education}

Proceedings of NORMA14, Turku, June 3-6, 2014 



\section{Publications of the Finnish Research \\ Association for Subject Didactics}

Studies in Subject Didactics 10

\section{Nordic research in \\ mathematics education}

Proceedings of NORMA14, Turku, June 3-6, 2014

Harry Silfverberg, Tomi Kärki \& Markku S. Hannula (eds.) 
Finnish Research Association for Subject Didactics

Chair:

Professor Arto Kallioniemi

Department of Teacher Education

P.O. Box 9

00014 Helsingin yliopisto

Publications of the Finnish Research Association for Subject Didactics - Studies in Subject Didactics

Publications in this series have been peer reviewed.

Studies in Subject Didactics 10

Nordic research in mathematics education

- Proceedings of NORMA14, Turku, June 3-6, 2014

Editorial board:

Harry Silfverberg, Tomi Kärki and Markku S. Hannula

Cover:

Katja Kontu

Publisher:

University of Turku, Department of Teacher Education

Printing:

Painosalama, Turku

ISBN 978-952-5993-17-2

ISSN 1799-9596 (painettu)

ISSN 1799-960X (verkkojulkaisu)

https://helda.helsinki.fi/

Turku 2015 


\section{Contents}

Nordic research in mathematics education - Proceedings of NORMA14, Turku, June 3-6, 2014

\section{PLENARY LESSONS}

Students' mathematical activity constrained by the milieu: A case of algebra

HEIDI STRØMSKAG (MÅSøVAL)

Making meaning of creativity and mathematics teaching MORTEN MISFELDT

How students own tendency to focus spontaneously on mathematically relevant phenomena predicts mathematical development?

ERNO LEHTINEN

A modeling perspective on the mathematical work of teaching HELEN M. DOERR

\section{REGULAR PAPERS}

\section{TEACHER DEVELOPMENT}

Pre-service mathematics teachers as researchers: the centrality of inquiry CLAIRE VAUGELADE BERG

Pre-service teachers developing lesson plans in field practice RAYMOND BJULAND, REIDAR MOSVOLD AND JANNE FAUSKANGER 51

Student teachers' work on reasoning and proving OLE ENGE AND ANITA VALENTA

The difficulties of measuring types of mathematics teachers' knowledge JANNE FAUSKANGER AND REIDAR MOSVOLD 
Educating Mathematics Teacher Educators: A Competency-Based Course Design

Using questioning diagrams to study teacher-student interaction MARKUS HÄHKIÖNIEMI

Mathematical knowledge for teaching among prospective teachers in Malawi

ARNE JAKOBSEN AND MERCY KAZIMA

Designing a research-based 'maths counsellor' program for Danish upper secondary teachers

UFFE THOMAS JANKVIST AND MOGENS NISS

Radford's layers of objectification as design principles in proving activities

ANDREAS LORANGE

Developing an identity as a secondary school mathematics teacher: A prospective teacher's narrative KIRSTI R $\varnothing$

Preschool teachers' perceptions of the role of videos in professional development OLA HELENIUS, MARIA L. JOHANSSON, TROELS LANGE, TAMSIN MEANEY, EVA RIESBECK AND ANNA WERNBERG

\section{CURRICULA, TEXTBOOKS AND RESOURCES}

How is mathematics teacher guides used for support and inspiration in teaching?

LINDA AHL, TUULA KOLJONEN AND LENA HOELGAARD

Teaching by the book: What kind of classroom practice do three different teacher guides for year 1 promote?

LENA HOELGAARD, KIRSTI HEMMI AND ANDREAS RYVE

Teachers' experience from using interactive e-books in the classroom ESBJÖRN HÄGERSTEDT, LINDA MANNILA, TAPIO SALAKOSKI AND RALPH-JOHAN BACK

Teachers' use of resources in and for mathematics teaching INGVILD LAMBERT GRAVE AND BIRGIT PEPIN 
How do teachers use teacher guides in mathematics?

GUĐNÝ HELGA GUNNARSDÓTTIR AND GUĐBJÖRG PÁLSDÓTTIR

An ethnomathematical study of play in Minecraft

LOUIS KØHRSEN AND MORTEN MISFELDT

Mathematics Textbooks' Impact on Classroom Instruction:

Examining the Views of 278 Swedish Teachers

JANNIKA NEUMAN, KIRSTI HEMMI, ANDREAS RYVE AND MARIE

WIBERG

Engineering students' use of web lectures in a linear algebra course RAGNHILD JOHANNE RENSAA

The hidden and salient messages of the mathematics curriculum about the changes in the culture of mathematics education HARRY SILFVERBERG

\section{PEDAGOGICAL SOLUTIONS}

Students' strategies for modelling a Ferris wheel METTE ANDRESEN

Preserving students' independence by encouraging students' selfevaluation

JONAS BERGMAN ÄRLEBÄCK AND HELEN M. DOERR

Upper secondary students appropriating the tool of harmonic oscillation: The issue of resistance MARTIN CARLSEN

Reflections on uncertainty aspects in a student project on traffic safety

KJELLRUN HIIS HAUGE AND RUNE HERHEIM

Mathematical agency in a traffic safety project

RUNE HERHEIM AND TORIL ESKELAND RANGNES

Mathematics in a literacy perspective: Meta awareness for all pupils

BODIL KLEVE

Supportive mathematics learning community

JÓNÍNA VALA KRISTINSDÓTTIR 
Building a local theory for the learning of experimental probability PER NILSSON

How to solve it: Students' communication when problem solving in groups

HANNA PALMÉR AND JORRYT VAN BOMMEL

Tasks of teaching mathematics in kindergarten

REIDAR MOSVOLD AND PER-EINAR SABBE

Coordinating the IC-model with a framework on communication in analysing student-to-student interactions in mathematics

MARIE SJÖBLOM

\section{SYMPOSIUM PAPERS}

Positioning of girls and boys in a primary mathematics classroom EVA NORÉN

Why Sarah left academia

LOVISA SUMPTER

Choosing mathematics in Norway and England: Discourses of gender, equity and choice

KATARINA WITH AND YVETTE SOLOMON

\section{WORKING GROUPS}

Working group on research on curriculum materials

GUĐNÝ HELGA GUNNARSDÓTTIR AND GUĐBJÖRG PÁLSDÓTTIR

Teaching mathematics at higher education

SIMON GOODCHILD AND FRODE RØNNING

Potential uses of social media in and for mathematics education research

REIDAR MOSVOLD 


\section{FOREWORD}

\section{NORMA 14 -CONFERENCE IN TURKU}

This volume contains the Proceedings of the Seventh Nordic Conference on Mathematics Education (NORMA 14), which took place 3-6 June 2014 in Turku (Åbo), Finland. The theme for the conference was "Nordic research in mathematics education". The first NORMA Conference on Mathematics Education NORMA-94 was also held in Finland, namely in Lahti in 1994. The second Norma conference was held four years later in Kristiansand, Norway and since then conferences have taken place every three years. The NORMA-conference provides a forum for discussions and constructive meetings of researchers, teachers, teacher educators, graduate students and others interested in research on mathematics education in the Nordic context, including also the Baltic countries.

The scientific committee of NORMA 14 represented all Nordic countries and had one representative from the Baltic countries. There was also a good mix of senior and junior researchers. The members of the scientific committee for NORMA $14-$ conference were

- Markku Hannula, University of Helsinki (chair)

- Jorryt van Bommel, Karlstad University,

- Martin Carlsen, University of Agder,

- Bettina Dahl Søndergaard, Aalborg University,

- Guðný Helga Gunnarsdóttir, University of Iceland,

- Cecilia Kilhamn, University of Gothenburg,

- Jüri Kurvits, Tallinn University,

- Tomi Kärki, University of Turku,

- Birgit Pepin, Sør-Trøndelag University College,

- Lisser Rye Ejersbo, Aarhus University,

- Harry Silfverberg, University of Turku.

The conference was hosted by the Department of Teacher Education at the University of Turku and organised in collaboration with NoRME - the Nordic Society for Research in Mathematics Education. The local organizing committee consisting of Harry Silfverberg (chair), Tomi Kärki, Aija Ahtineva, Satu Kankare and Anu Tuominen took care of the practical arrangements of the conference together with the Congress Office of the University of Turku.

In NORMA-conferences research has been presented in format of invited plenary talks, regular papers, short communications, and working groups. For this conference, we also opened a new presentation format, symposium, to allow deeper discussion across a number of related studies. At the conference, 4 plenary lectures, 31 regular papers, 21 short communications and one symposium with three separate 
papers were presented. Furthermore, three working groups were arranged: (1) Research on curriculum materials, (2) Teaching mathematics at higher education and (3) Potential uses of social media in and for mathematics education research. The total number of the authors of the presentations was 95. Eighty researchers participated personally in the conference. The official language of the conference was English and all the papers were written in English.

The vice dean of the Faculty of Education, professor Risto Rinne opened the conference by welcoming the participants to NORMA and to the University of Turku. The social program of the conference started with a Gathering together - party after the first conference day. On the second evening, we had an entertainment cruise with an old steamer Ukkopekka to a small island Loistokari located in the beautiful Turku archipelago. At Loistokari, an open air buffet table was served. The conference dinner was on the evening of the third conference day in the restaurant Koulu (School) which is actually situated in an old school building. After the conference dinner, several participants continued to have a dancing party in the Turku nightlife. Overall, the conference was not only scientifically invigorating event, but also a fruitful opportunity to build friendship across the Nordic community.

Most of the conference expenses were covered by the registration fees. We also thank the Federation of Finnish Learned Societes (Tieteellisten Seurain Valtuuskunta) for a significant support to the conference.

\section{THE REVIEW PROCESS OF THE PROCEEDINGS}

Prospective participants were invited to submit papers into four categories. All papers submitted to the conference went through a double-blind review process. Regular and symposium paper proposals were sent for review as full papers (10 pages). The review was done by two conference participants and the final conclusion regarding acceptance was made by an assigned scientific committee member. Some regular paper submissions were asked to be revised before acceptance and some were rejected as regular papers and asked to be presented as short communications. Short communication proposals were reviewed by two scientific committee members as one page abstracts and proposals for working groups were also reviewed by the scientific committee.

Regular papers were presented in parallel sessions at the conference (20 minutes for presentation and 20 minutes for discussion). Three symposium papers were presented in a separate symposium session (90 minutes). In working groups (60 minutes) the participants could raise questions and present topics they wanted to discuss and work on with other participants of the conference. Short communications were presented in parallel sessions (10 minutes for presentation and 10 minutes for discussion).

After the conference, there was one month time to prepare a final version of the accepted papers for the proceedings. All papers were reviewed again by the editors of the proceedings, in order to ensure that the reviewers' criticism and constructive comments were taken into account in the final versions appearing in this book. 


\section{THE PROCEEDINGS}

Heidi Strømskag's (Måsøval) and Morten Misfeldt's plenary talks form the first two papers of the proceedings. After these there are abstracts from the other two plenary speakers, Erno Lehtinen and Helen M. Doerr. The regular papers, symposium papers and summaries of the working group discussions have been arranged under three themes which seem to be emphasized in the papers: (1) teacher development, (2) curricula, textbooks and resources, and (3) pedagogical solutions. Regrettably, the abstracts of the short communications could not be included in this printed version of the proceedings but they will be published in an electronic version of the proceedings online.

The editors

Harry Silfverberg

Tomi Kärki

Markku S. Hannula 


\section{Plenary lessons}




\title{
STUDENTS' MATHEMATICAL ACTIVITY CONSTRAINED BY THE MILIEU: A CASE OF ALGEBRA
}

\author{
Heidi Strømskag (Måsøval) \\ Sør-Trøndelag University College, Norway
}

The theory of didactical situations in mathematics (Brousseau, 1997) is used in an a priori analysis of a task on algebraic generalisation of a shape pattern, and further, used in the analysis of two groups of students' engagement with the task. A formula for the general member of the sequence mapped from the pattern is established by the students, whereas the teacher's intention is the formulation of a theorem about a relationship between odd numbers and square numbers. The paper presents features of the adidactical milieu that contribute to the gap between the teacher's intention and the students' engagement with the task.

Keywords: Adidactical situation, milieu, shape pattern, algebraic thinking, mathematical statement.

\section{INTRODUCTION}

Research on students' processes of pattern generalisation suggests that it is not generalisation tasks in themselves that are difficult; the problems that students encounter are rather due to the way tasks are designed and limitations of the teaching approaches employed (Moss \& Beatty, 2006; Måsøval, 2011, 2013; Noss, Healy, \& Hoyles, 1997). It is therefore relevant to find out how design of tasks and the way pattern generalisation is taught, influence the outcome of students' engagement with tasks on shape patterns. I shall discuss this with data from student teachers' engagement with mathematical tasks at a university college. This is done from the perspective of the theory of didactical situations in mathematics (Brousseau, 1997). The research question addressed in this paper is: What features of the milieu contribute to the gap created between the teacher's intention with a task and the students' mathematical activity?

\section{THEORETICAL FRAMEWORK}

\section{The theory of didactical situations in mathematics}

The theory of didactical situations in mathematics (Brousseau, 1997) is a scientific approach to the problems posed by the teaching and learning of mathematics, where the particularity of the knowledge taught plays a significant role. This theory is about the didactical relationship between three elements: the teacher, the students, and a particular piece of mathematical knowledge. A situation where these elements interact is called a didactical situation (Brousseau, 1997). An adidactical situation is a situation in which the student takes a mathematical problem as his own and solves it on the basis of its internal logic without the teacher's guidance and without trying to interpret the teacher's intention with the problem. 
The students cannot be expected to engage in any adidactical situation; the teacher attempts to arrange an adidactical situation that the students can manage. She designs a milieu which reveals more or less clearly her intention of teaching to the students some particular knowledge. The milieu is a subset of the students' environment with only those features that are relevant with respect to the knowledge aimed at by the teacher in the didactical situation. The concept of milieu models the elements of the material and intellectual reality on which the students act; these elements are obstacles or conditions for the students' actions and reasoning. The mathematical task or problem given to the students refers to an important part of the milieu, the objective milieu (Hersant \& Perrin-Glorian, 2005). Further, the students' prior knowledge (that is relevant for the target knowledge) is part of the milieu, as well as manipulatives intended to be used when solving the given problem. Moreover, organisation of the classroom with respect to who is supposed to interact with whom, and how to interact, is also an important part of the milieu for a particular piece of mathematical knowledge (Brousseau, 1997). A milieu without any didactical intention with regard to the student is called an adidactical milieu. An appropriate adidactical milieu provides feedback to the students (whether their actions, formulations, and conjectures are appropriate) in situations where they are supposed to solve a problem without teacher intervention.

According to Brousseau (1997), the teacher has two main roles in a didactical situation: One is devolution of an adidactical situation to the students. This means to make the students accept the responsibility for an adidactical situation or to solve a mathematical problem, and the teacher accepts the consequences of this transfer of responsibility. The other main role is institutionalisation, which will be explained below. Besides these two main roles, it is the teacher's responsibility to manage the evolution of the different adidactical situations (these situations are explained below).

After devolution come four situations (or phases), where the role of the teacher and the status of the knowledge changes (Brousseau, 1997): Situations of action, formulation, and validation are (intentionally) adidactical situations, whereas the situation of institutionalisation is not adidactical. The situation of action is where the students engage with the given problem on the basis of its inner logic, without the teacher's intervention. The students construct a representation of the situation which serves as a "model" that guides them in their decisions. This model is an example of relationships between certain objects or rules that they have perceived as relevant in the situation. The situation of formulation is where the students exchange and compare observations and representations between themselves. The aim is to develop language to formulate their observations and agree on some common meanings. In this situation the teacher's role is to make different formulations visible in the classroom. The situation of validation is where the students attempt to explain some phenomenon or verify a conjecture. In this situation the teacher's role is to act as a chair of a scientific debate and (ideally) intervene only to structure the debate and try to make the students use more precise mathematical concepts. The situation of 
institutionalisation is where the teacher compares solutions or knowledge developed by different students or groups, and informs about formal mathematical terminology and highlights definitions and results that are important for the contextualised knowledge to become cultural knowledge that can be used in situations other than the original one set up by the teacher.

\section{Shape pattern generalisation}

A shape pattern is usually instantiated by some consecutive geometric configurations in an alignment imagined as continuing until infinity. Radford (2006) characterises algebraic generalisation of patterns when he proposes that

generalizing a pattern algebraically rests on the capability of grasping a commonality noticed on some elements of a sequence $S$, being aware that this commonality applies to all the terms of $S$ and being able to use it to provide a direct expression of whatsoever term of $S$. (Radford, 2006, p. 5)

The geometric configurations will be referred to as elements; the constituents of an element will be referred to as components. According to Måsøval (2011), there are two types of shape patterns: arbitrary patterns (Figure 1), and conjectural patterns (Figure 2).

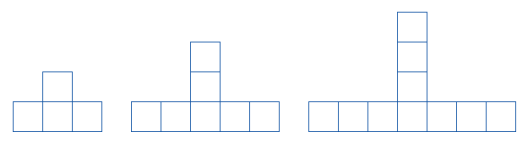

Figure 1. Example of the first three elements of an arbitrary pattern

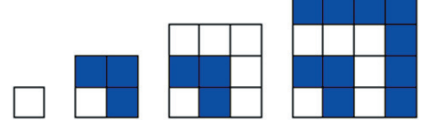

Figure 2. Example of the first four elements of a conjectural pattern

These patterns correspond respectively to two different mathematical objects aimed at in the process of generalising (Måsøval, 2011): formula (for the general member of the sequence mapped from the shape pattern; e.g., $a_{n}=3 n+1$ in Figure 1), and theorem (in terms of a general numerical statement; e.g., $1+3+5+\ldots+2 n-1=n^{2}$ in Figure 2). Institutionalisation of the knowledge in the case when algebraic generalisation aims at a formula is not institutionalisation of the formula per se. It is institutionalisation of how the formula can be derived through identification of an invariant structure in the elements of the pattern. Further, it is institutionalisation of how the invariant structure is interpreted into arithmetic relations and how these in turn are generalised algebraically in terms of a formula. The cultural, reusable knowledge in this case is the nature of the relationship between the algebraic expression and its referent (a generic element of the pattern). On the other hand, 
institutionalisation of the knowledge in the case when algebraic generalisation aims at a theorem involves decontextualisation of the general numerical statement from the shape pattern on the basis of which it is developed. The cultural, reusable knowledge in this case is a general relationship between sequences of numbers.

Måsøval (2011) has classified constraints to students' processes of pattern generalisation into three categories, drawing on the theory of didactical situations. The core categories are: 1) Constrained feedback potential in adidactical situations (which is about features of the milieu that constitute obstacles for the students when they are supposed to solve tasks without teacher involvement); 2) Complexity of turning a situation of action into a situation of formulation (which is about challenges students phase when transforming informal language expressions into mathematical symbols); and, 3) Complexity of operating in the situation of validation (which is about challenges students phase when trying to prove proposed conjectures). An overview of the theoretical construct with categories and subcategories is presented in Figure 1.

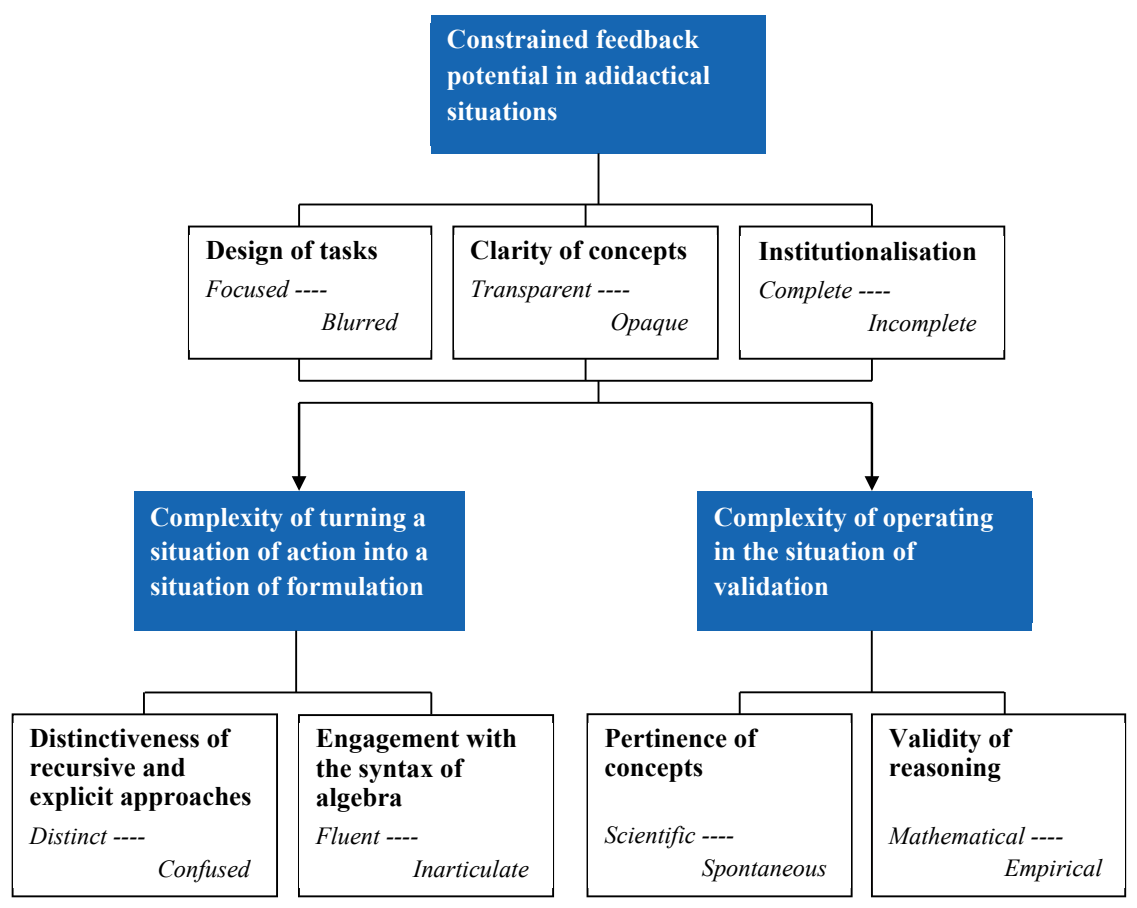

Figure 3. The theoretical construct in terms of a neutral setting out of the categories developed from the empirical material (adapted from Måsøval, 2011, p. 259) 
Here, core categories are placed in blue boxes; extreme values on the continuum of the dimension of a subcategory define the range of a property of the subcategory. In the flow chart, the arrows signify that the first core category contributes to the second and third core categories. This paper presents findings that fall under two of the subcategories of Constrained feedback potential in adidactical situations.

\section{METHODOLOGY}

The reported research is part of a larger study of student teachers' pattern generalisation at a Norwegian university college (Måsøval, 2011). In this chapter, I explain the methodology of the larger study, even if this paper reports only from a part of the larger study.

\section{Style of inquiry}

I wanted to expose evidence about 'how' and 'why' students' opportunities to establish algebraic generality in shape patterns are constrained. That is, to understand a phenomenon (constraints to students' pattern generalisation) in its natural setting. This called for a qualitative research methodology (Denzin \& Lincoln, 2005). The data I needed to understand the mentioned phenomenon were: mathematical tasks (designed by the teacher); information about the teacher's intention with the tasks; and, observations of students' engagement with the tasks at the university college. These were contemporary events over which I had little or no control. This fact, together with the above mentioned 'how' and 'why' questions, led me to the choice of a case study method (Yin, 2009). There are two cases, each constituted of a group of three students as they solve generalisation tasks (with some teacher intervention). This paper reports from the analysis of the two groups' engagement with Task 3.

\section{Research participants and data sources}

Research participants are Alice, Ida, and Sophie (Group 1), Anne, Helen, and Paul (Group 2), and their teacher of mathematics, Erik (names are pseudonyms). The students were in the first academic year on a teacher education programme for primary and lower secondary school. The observed teacher was my colleague, an experienced teacher educator of mathematics.

There are three sources of data for the larger project: transcripts from video-recorded group lessons at the university college (eight lessons in each group); four mathematical tasks; and three conversations with the teacher about the intention of the tasks. My role during data collection was to be a non-participant observer while video-recording students' group work (where the teacher had some interaction with the students).

\section{Methods employed for data analysis}

I conducted an a priori analysis of the four tasks, using Brousseau's (1997) theory as a conceptual framework. This was an epistemological analysis informed by Erik's intention with the tasks, which he had explained to me. Transcripts from the video recorded observations were partitioned into segments (represented by explanatory 
notes); each segment constituted a unit of meaning with reference to what the observed persons achieved or not achieved, related to the intentions of the tasks. The data chunks represented by the explanatory notes that were significant with respect to the research question (constraints to the generalisation processes), were coded using the constant comparative method (Strauss \& Corbin, 1998). From this process 41 codes emerged. The next step consisted of categorising the codes, a process from which seven categories emerged: design of tasks; clarity of concepts; institutionalisation; distinctiveness of recursive and explicit approaches; engagement with the syntax of algebra; pertinence of concepts; and, validity of reasoning.

The last step in the analytic process consisted of comparison of the seven categories and collection of them into groups, distributed with respect to the role each category played in the didactical situation. This interpretation was based on concepts and models from the theory of didactical situations. The result was emergence of three main groups, referred to as core categories, which are conceptualisations of key aspects of the data. The categories that were collected under the core categories are referred to as subcategories (see Figure 1). They explain the core categories in the way they offer purposeful interpretations of the phenomenon under investigation (constraints to students' algebraic generalisation of shape patterns).

\section{FINDINGS}

\section{A priori analysis of the mathematical task}

Task 3 (Figure 4) was the third of four tasks (during eight lessons of 45 minutes) on algebraic generalisation of shape patterns, designed by the observed teacher for students' collaborative self-engagement.

Task 3 (Part I)
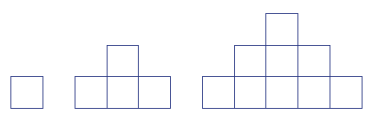

a) How many cubes will there be in the fourth shape? And in the fifth?

b) How many do you think there will be in shape number 10? And in shape number $n$ ?

c) What kinds of numbers are present in these shapes? In each row, and totally in the shape?

d) Can you express what the shapes seem to show, as a mathematical statement?

- In words? - In symbols?

\section{Figure 4. Task 3 (Part I)}

The teacher claimed in a conversation with me after the observed lesson that the aim of the first part of the task was to express in natural language, and then transform into algebraic notation, the mathematical statement that the sum of the first $n$ odd numbers is equivalent to the $n$-th square number (possibly represented by $1+3+5+\ldots+(2 n-1)=n^{2}$ or $\left.\sum_{i=1}^{n}(2 i-1)=n^{2}\right)$. Hence, the pattern is intended to be a 
conjectural pattern. The second part of Task 3 (not included in this paper) is designed to prove the intended statement of equivalence. Further, the teacher said that he had used 'mathematical statement' in the meaning of 'theorem'. His rationale for this was that the concept of mathematical statement was likely to appear easier for the students because it was closer to natural language than the word theorem.

The role of the shape pattern as an element of the milieu is that the pattern is not a "real milieu" for the statement of equivalence in the sense of Brousseau (1997), because the solution of the problem (proof of the theorem) can be reached by manipulation of the elements of the pattern. A generic example of a possible manipulation (made by me) is shown in Figure 5. An alternative shape pattern that would illustrate that the $n$-th square number is equivalent to the sum of the first $n$ odd numbers is the pattern shown in Figure 2 above.

The algebraic formulation, $1+3+5+\ldots+(2 n-1)=n^{2}$, is not a tool to construct the proof of the theorem; it is just a way to formulate a mathematical statement with symbols. However, as explained above, an additional aim of the task was the transformation of a natural language representation of the regularity of the pattern into algebraic symbolism.
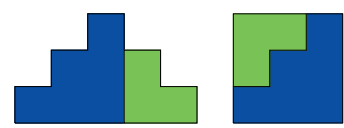

Figure 5. The third element manipulated into a $3 \times 3$ square

In this respect, the pattern is a real milieu in the sense that the elements of the pattern can be represented arithmetically $\left(1=1^{2}, 1+3=2^{2}, 1+3+5=3^{2}\right.$, etc. $)$ and serve as a "model" that can guide a process of algebraic thinking that aims at the equivalence statement $1+3+5+\ldots+2 n-1=n^{2}$. Here, the shape pattern is a context for algebraic thinking, where the elements of the pattern serve as referents for first arithmetic symbols and then algebraic symbols, the algebraic formulation being here only a tool to state the equivalence. Of course, once the statement is algebraically formulated, a possible manipulation of the algebraic expression can lead to find a proof. This can be done for instance by adding the first and last terms, then the second and last but one term, and so on, using the Gaussian method. Or, it can be done by manipulating the sigma sign of the sum as shown in (*), where $S_{n}$ represents the sum of the first $n$ natural numbers. But this is not the intention of this task, as the analysis of Part II of the task showed (presented in Måsøval, 2011, pp. 160-167).

$$
1+3+5+\ldots+(2 n-1)=\sum_{i=1}^{n}(2 i-1)=2 \sum_{i=1}^{n} i-\sum_{i=1}^{n} 1=2 S_{n}-n=n(n-1)+n=n^{2}(*)
$$


Of course, this last proof needs the knowledge that $S_{n}$ is equal to $n(n-1) / 2$, thus assuming that this is part of the milieu (which the teacher said he did indeed assume).

The two different aims of this task (establishing a general numerical statement which does not presuppose the use of algebra on the one hand, and algebraic thinking on the other) create a tension in the adidactical situation. Task 3 is not sharply focused on algebraic thinking with respect to a relationship between square numbers and odd numbers. This is a threat to the adidactical situation in the way it depends on the teacher's intervention. The analysis of the students' engagement with the task will show how the aim of formulating a mathematical statement is constrained. This is presented in the next section.

\section{Weaknesses in the milieu}

The teacher in the observed lesson presented the students with the task of formulating a mathematical statement (Task 3d, Figure 3). In the following I show how Tasks 3a, $3 \mathrm{~b}$, and $3 \mathrm{c}$ do not prepare an adequate milieu for the formulation of the mathematical statement aimed at. Both Group 1 and Group 2 counted components of the first few elements of the shape pattern and noticed that the numerical value of an element is equal to the square of its position (Task 3a). They conjectured that there will be 100 components in the tenth figure, and wrote a formula for the $n$-th element (Task $3 \mathrm{~b}$ ): $F n=n^{2}\left(\right.$ sic) (Group 1) and $a_{n}=n^{2}$ (Group 2). Both groups answered correctly that there are odd numbers in the rows and square numbers in the shape totally (Task 3c).

When they started to solve Task $3 \mathrm{~d}$, which is about expressing a mathematical statement based on what the shape pattern seems to show, they were insecure about the notion of 'mathematical statement'. After a while the teacher entered the room where Group 1 was placed, and the following conversation took place:

106 Ida: A mathematical statement? We have made a formula for... but how do you make a mathematical statement?

107 Teacher: Well, a formula is a mathematical statement if it...

108 Ida: Yes, because we have made it with symbols actually.

Ida's utterance in turn 108 suggests that she interprets the teacher's conditioning in turn 107 to mean that a formula is a mathematical statement if represented by mathematical symbols. The characteristics of a mathematical statement (in the task used in the meaning of theorem) are never made explicit by the teacher during the time spent on Task 3. The teacher's response to the conjectured formula, $F n=n^{2}$, is:

114 Teacher: Well ok, so it is... yes exactly, it, it is an expression for the total number of... squares in... in shape number $n$. Uh huh... ehm... that's fair enough... ehm but ehm then you could think, could you have expressed...?

115 Ida: The same thing with words?

116 Teacher: Well, or expressed the total number in another way, by thinking about how this shape is built up? 
Turns 114 and 116 show how the teacher tries to direct attention towards the structure of the elements of the shape pattern. However, the teacher's focus (in the same turns) on the total number of components may reinforce the students' conception that the task is about the numerical value of the general element of the shape pattern.

The next excerpt from the transcript shows how Group 2 (without teacher involvement) concludes that the mathematical statement is $a_{n}=n^{2}$ :

75 Anne: "Express what the shape seems to show as a..." [recites from the task] Well, it is the square then of... the shape [indecipherable]. Mathematical statement... Do you have any formulation of a mathematical statement?

87 Helen: Isn't that $n$ squared or? [laughs a bit]

88 Anne: $a_{n}$ is equal to $n$ squared?

89 Helen: Yes.

90 Paul: It has to be like that...

91 Anne: [Element] number $n$ is equal to $n$ squared. Well? Can't believe it is supposed to be more complicated?

The dialogue of Group 2 indicates that even if they are insecure, they find it unlikely that a mathematical statement should be more complicated than just an expression of the number of components of the general element.

There is a weak feedback potential in the adidactical milieu related to the concept at stake (equivalence of square numbers and sums of odd numbers); there is nothing that makes it necessary for the students to relate square numbers and odd numbers arithmetically. The students act as practical persons and produce solutions to Tasks $3 \mathrm{a}, 3 \mathrm{~b}$, and $3 \mathrm{c}$ in a most efficient way. This means that they count the components and reason inductively to find the answers for the tenth and $n$-th element. In doing so, they do not focus on the structure of the elements (that the total number of components of an element is equal to the sum of the components in each row).

Considered separately, the students' solutions to the first three subtasks are adequate. However, their solution to the question about the type of numbers in the rows and in the elements as a whole (presumably meant to draw attention to the concept aimed at) does not provide them with the possibility to adjust their actions towards the formulation of a mathematical statement about a relationship between square numbers and odd numbers. The only way their knowing the answer to this question might have contributed to the formulation of a mathematical statement, would have been if they had tried to discern the teacher's intention with the task. But that would have been a solution by didactical reasoning, and consequently, a threat to the adidactical situation. Hence, there is a problem with the design of the task: Task 3 does not provide the students with 'knowings' that enable them to appropriate the target mathematical knowledge: a generalisation of arithmetic relationships between odd numbers and square numbers (a theorem). 
Instead of producing the statement of a theorem, the students produce the statement of a function, where the numerical value of an element is given as a function of its position in the sequence. The students can be seen to make what Bills and Rowland (1999) refers to as empirical generalisations, rather than structural generalisations.

The lack of focus in the task on the target mathematical knowledge makes the objective milieu inappropriate. The outcome of the situation of formulation (Task $3 \mathrm{~d}$ ) was intended to be a conjecture about equivalence of two different expressions for the numerical value of the general element of the pattern. The actual outcome of the situation of formulation is a function. This is an inappropriate milieu for the situation of validation in the second part of the task (which is not included in this paper). For both groups, the adidactical situation of validation (designed to prove the intended theorem) becomes unsuccessful, due to the lack of a conjecture (equivalence statement).

In summary, a gap is created between the teacher's intention with the task, and the students' mathematical activity. The incomplete achievement in the situation of formulation can be explained by two factors. First, there is a problem with the design of the task: It does not provide the students with 'knowings' that enable them to formulate a conjecture about equivalence of two different expressions for the numerical value of the general element of the shape pattern. Second, there is a problem with the concept of a mathematical statement, which complicates the devolution of the adidactical situation: The teacher's meaning of this concept (a theorem) is different from the students' interpretation (a statement about the number of components).

\section{DISCUSSION}

The target mathematical knowledge in Task 3 is an equivalence statement decontextualised from the shape pattern. The knowledge developed by the students, however, is a formula for the general member of the sequence mapped from the shape pattern. Their formula is inductive knowledge contextualised by the shape pattern. A week before the observed lesson, these students engaged with two tasks on arbitrary shape patterns, where the aim was to find formulae for the general member of the sequence mapped from the shape patterns. Because Tasks $3 \mathrm{a}$ and $3 \mathrm{~b}$ are focused on counting components of elements (as were the previous tasks), it is not surprising that the students treat the pattern in Task 3 as if it were arbitrary (not conjectural). This is consistent with their interpretation of the concept of mathematical statement.

A milieu for generalisation of shape patterns (including the tasks) needs to be designed in accordance with the target mathematical knowledge: 1) If the target knowledge is a formula for the general member of the sequence mapped from the shape pattern, the pattern should be arbitrary and the focus should be on decomposition of the elements of the pattern in order to illuminate its invariant structure, and further, to make references between partitions of a generic element and mathematical symbols of the formula. 2) If the target knowledge is a general 
numerical statement, the pattern should be conjectural and the focus should be on the intended relationship between sequences of numbers. In this case, the aim is to find the numerical value of the general element in two different ways; the sought relationship is an equality between the two different algebraic expressions.

When both arbitrary and conjectural patterns are dealt with, it is important to know the distinction between the mathematical concepts at play, function or theorem. The above analysis showed that the concept of theorem (mathematical statement) was unclear to the students. It had not been institutionalised in previous lessons, and it was neither institutionalised (as a concept in its own right) during the observed lessons. The students interpreted it to mean a function, with which they were familiar. When the students asked the teacher how to make a mathematical statement, the teacher interpreted it to be about the equivalence statement itself (its substance), rather than it being about the general features of a theorem (that it is a conjecture about equivalence of two expressions which needs to be justified). That is, the teacher assumed that the concept of mathematical statement was known to the students.

An important feature of the milieu is the organisation of the interaction in the classroom: who is going to speak with whom? A possible way of handling the concept of theorem in the devolution phase of Task 3 would be to present it as a task of two collaborating groups: One group shall find the total number of components of each element by counting. The other group shall find out how many rows are needed to build the first few elements, and further, how many components are there in consecutive rows? Then the groups compare their data for the same elements, and potentially find out that: 1) the number of rows necessary to build the $n$-th element $(n)$ is equal to the square root of the total number of components found by the other group $\left(n^{2}\right)$; and 2) the sum of the components in the rows (odd numbers) is equal to the square of $n$. It is possible to use manipulatives, for example in the form of paper strips or centicubes, representing the rows of the staircase towers. This would also make it possible to figurally justify the conjectured relationship, by manipulating the rows of a staircase tower into a square (e.g. as shown in Figure 5).

The theoretical construct developed in the case study (presented in Figure 3) is based on algebra. I conjecture, however, that the three core categories are applicable for mathematical topics different from algebra, if subcategories of the second core category are developed separately, with respect to these mathematical topics (one at a turn). The second category, Complexity of turning a situation of action into a situation of formulation, is about transformation of informal language expressions (representing observations done by the students when acting on the milieu) into formal mathematical expressions. It would be possible to record group activity on tasks related to a particular mathematical topic and subject the data to an analysis based on the three core categories. This would mean to categorise segments from the data into the three core categories, and further, to code the events that fall under the second category in order to develop its subcategories. The point is to find out what factors that constrain students' opportunities to learn the target mathematical 
knowledge. It is necessary of course to conduct such of study to test if it is possible to develop the theoretical construct to make it applicable for a different mathematical topic. This is what my current research is about, but it is only in its early stages yet.

\section{REFERENCES}

Bills, L., \& Rowland, T. (1999) Examples, generalisation and proof. Research in Mathematics Education, 1, 103-116.

Brousseau, G. (1997). The theory of didactical situations in mathematics. Dordrecht, The Netherlands: Kluwer.

Denzin, N. K., \& Lincoln, Y. S. (2005). Introduction. In N. K. Denzin \& Y. S. Lincoln (Eds.), Handbook of qualitative research (3rd ed.) (pp. 1-32). Thousand Oaks, CA: Sage.

Hersant, M., \& Perrin-Glorian, M.-J. (2005). Characterization of an ordinary teaching practice with the help of the theory of didactical situations. In C. Laborde, M.-J. Perrin-Glorian, \& A. Sierpinska (Eds.), Beyond the apparent banality of the mathematics classroom (pp. 113-151). Dordrecht, The Netherlands: Springer.

Moss, J., \& Beatty, R. (2006). Knowledge building in mathematics: Supporting collaborative learning in pattern problems. Computer-Supported Collaborative Learning, 1, 441-465.

Måsøval, H. S. (2011). Factors constraining students' appropriation of algebraic generality in shape patterns: A case study of didactical situations in mathematics at a university college. (Unpublished doctoral dissertation). University of Agder, Kristiansand, Norway.

Måsøval, H. S. (2013). Shortcomings in the milieu for algebraic generalisation arising from task design and vagueness in mathematical discourse. In C. Margolinas (Ed.), Task design in mathematics education. Proceedings of ICMI Study 22 (pp. 231-239). Oxford.

Noss, R., Healy, L., \& Hoyles, C. (1997). The construction of mathematical meanings: Connecting the visual with the symbolic. Educational Studies in Mathematics, 33, 203-233.

Radford, L. (2006). Algebraic thinking and the generalization of patterns: A semiotic perspective. In S. Alatorre, J. L. Cortina, M. Sáiz, \& A. Méndez (Eds.), Proceedings of the 28th Annual Meeting of the North American Chapter of the International Group for the Psychology of Mathematics Education (Vol. 1, pp. 221). Mérida, México: Universidad Pedagógica Nacional.

Strauss, A., \& Corbin, J. (1998). Basics of qualitative research: Techniques and procedures for developing grounded theory (2. ed.). Thousand Oaks, CA: Sage.

Yin, R. K. (2009). Case study research: Design and methods (4th ed.). Los Angeles, CA: Sage. 


\title{
MAKING MEANING OF CREATIVITY AND MATHEMATICS TEACHING
}

\author{
Morten Misfeldt
}

\author{
Research Lab: ICT and Designs for Learning, Aalborg University
}

Creativity and innovation are important $21^{\text {st }}$-century skills, and mathematics education contributes to the development of these skills. However, it is far from clear how we as mathematics educators should respond to the need to contribute to our students' development of creativity and innovation. One reason is that it is not clear what relation such creative and innovative skills have to mathematics, and how we should teach them. In this paper, I review different conceptions of creativity in mathematics education and investigate what mathematical innovation and creativity "are" in the mathematical classroom. I show how different conceptions of mathematical innovation and creativity dominate different parts of the mathematics education literature, and explain how these differences can be viewed as framing mathematical creativity toward different domains.

\section{CREATIVITY AND INNOVATION IN THE MATHEMATICS CLASSROOM}

Enhancing students' creativity and innovation is an important educational goal within and across specific school topics. Enhanced creativity and innovation supposedly empower students to cope with their lives, increase their potential value in the labor market, and allow them to participate in aesthetic and joyful experiences (Loveless, 2002; Organization for Economic Cooperation and Development [OECD], 2010). Mathematics education thus faces the challenge of how to develop curriculum and teaching that enhance creativity and innovation.

The broad discussion of the goal of education simultaneously acknowledges mathematics as a core subject and suggests the need for a close connection between mathematics and valued general skills and competencies such as creativity and innovation (Partnership for 21st Century Skills, 2009). However, creativity and innovation have different meanings, and therefore, addressing creativity and innovation when teaching mathematics is not easy. In the Partnership for $21^{\text {st }}$-Century Skills (P21), creativity and innovation are defined as the ability to create new and worthwhile ideas (alone and in collaboration with others), and acting on these ideas to make useful contributions (Partnership for $21^{\text {st }}$-Century Skills, 2009). However, it is far from clear what makes an idea worthwhile and what constitutes a useful contribution. Creativity has previously been described as an innate property of an individual who is virtuous in a specific field, such as a psychological tendency to divergent thinking, as a situated tendency to act in interesting and non-foreseen ways (Joas, 1996), an acknowledgement of aesthetic and constructive considerations (Loveless, 2002), and as a matter of connecting disciplinary knowledge to practical 
and professional situations (Shaffer, 2004). These views of creativity are related to each other and to the P21 framework definition of creativity and innovation. When such fluffy concepts meet a national mathematics curriculum, many interpretations and practices are possible. "Creativity enhancing mathematics teaching" can thus signify everything from virtuous teaching of gifted students (Sriraman \& Lee, 2011) to an inclusive pedagogical trend that acknowledge aesthetic concerns and students as producers in the mathematics classroom (Resnick, 2012).

This situation calls for two questions to be answered: What is creativity in mathematics education? And how should we teach for and assess creativity in mathematics education? In this paper, I mainly address the first question by surveying the existing mathematics education literature on creativity in the classroom.

\section{Creativity as domain specific?}

An obvious starting point is to ask whether creativity and innovation are domainspecific or domain-independent abilities. In a review of the domain specificity of creativity in mathematics education research, Plucker and Zabelina (2008) revealed strong evidence that creativity to some extent is domain specific; no person is likely to be creative in all domains of life. However, in the same review, the researchers presented many arguments for the opposite position - namely, that creativity is an inert ability. The domain specificity that we observe can be explained by the fact that significant results of creativity require strong knowledge and skills in an area. Thus, creativity might very well be a general ability, but using this ability to obtain results acknowledged as creative requires the possession of skills and knowledge. As an example, using divergent thinking (Guilford, 1967; Torrance, 1963) as a measure of creativity takes domain independence for granted when the nature of creativity is addressed. Whether creativity is domain specific or domain independent, it makes sense to review mathematical creativity as a phenomenon in its own right, but this phenomenon might or might not be explainable as an independent ability or as the sum of skills in an area and a general creative ability.

\section{Mathematical creativity}

Poincaré's 1908 essay (1946) marks a starting point for deliberate investigation of the creative mathematical process. Introspectively, he describes how conscious and subconscious processes interact in the creation of mathematical insights. Hadamard (1954) builds on this essay and develops an explicit stage model for mathematical creative processes. The stages are preparation, incubation, illumination, and verification. Hadamard describes how when a creative individual, in the incubation stage, leaves his or her desk, is sleeping, or thinking about something other than the addressed problem, all of a sudden a solution or insight appears. Using such stage models gives a picture of mathematical practice as a lonely thinking process, where long periods of work and experiences of getting stuck are continued by not thinking about a certain problem and finally (perhaps) suddenly seeing a solution. 
If we use this stage model, we tend to view creativity in the mathematical field as problem solving where the problems are very hard and subconscious inspirational processes play an important role in their solution. The bestselling book How to Solve It by Polya (1945) is perhaps the most well-known account of mathematical thinking that follows this stage model. The book is a handbook for how to work with problems in the mathematics classroom, but the book's view on what creativity is is shared in the mathematical field by Poincaré and Hadamard.

Haylock (1987) reviews mathematical creativity in order to develop a framework for assessing creativity in the mathematical classroom. He notes several authors suggest that divergent thinking (Guilford, 1967; Torrance, 1963) is a good measure for creativity, whereas others build on the incubation model proposed by Hadamard, and again others are more focused on the nature of mathematical theory. In his description of mathematical creativity in schoolchildren, he suggests that there is a need to transcend what he calls algorithmic fixation (that creativity follows a certain recipe) and content universe fixation (you are creative in a specific area of knowledge), and suggests that this can be done by focusing on problem solving, problem posing, and redefinition situations.

Ervynck (1991) describes creative work in the context of undergraduate-level mathematics. He develops a stage model that relies to some extent on Hadamard, and distinguishes the first "technical stage" consisting of gaining familiarity with the involved concepts, followed by an "algorithmic" stage where more complex techniques related to the problem are performed, and finally a "creative" or constructive stage where a full-fledged mathematical construction is developed. Ervynck respects aspects of Hadamard's stage model but adds a conceptual focus on mathematical creativity, respecting concerns about the process object duality, and aligning reification processes (Sfard, 1991) and creativity. Ervynck thus defines mathematical creativity as:

the ability to solve problems and/or to develop thinking in structures, taking account of the peculiar logico-deductive nature of the discipline, and of the fitness of the generated concepts to integrate into the core of what is important in mathematics. (Ervynck, 1991, p. 47)

The focus on problems is explicitly supplemented by respect for the logical and theoretical nature of mathematics, which addresses theory building and problem solving. Furthermore, Ervynck suggests that the nature of mathematical creativity might differ according to the mathematical subjects involved.

Sriraman (Sriraman, 2008; Sriraman \& Lee, 2011) has investigated mathematical creativity among research mathematicians, and his empirical results confirm stage modes similar to the one described by Hadamard. Although Sriraman surveys 
different individual psychological and social approaches to creativity, his main empirical project is to challenge/confirm Hadamard's stage model. Sriraman finds:

In trying to better understand the process of creativity, the author finds that the Gestalt model proposed by Hadamard (1945) is still applicable today. This study has attempted to add some detail to the preparation-incubation-illumination-verification model of Hadamard (1945), by taking into account the role of imagery, the role of intuition, the role of social interaction, the use of heuristics, and the necessity of proof in the creative process. (Sriraman, 2008, p. 25)

In that sense, Sriraman considers mathematical creativity a complex phenomenon related to various possible constructs and theories, but maintains that the stage model is at the center of the consideration of mathematical creativity.

\section{Creativity and giftedness}

A research environment surrounds "creativity and gifted education." This environment can be followed in the conference series creativity and giftedness in mathematics education as well as in the ICME and CERME groups. A relatively large body of knowledge describes the relation between mathematical performance, divergent thinking, problem solving and problem posing (Leikin \& Pitta-Pantazi, 2012; Silver, 2013; Sriraman, Haavold, \& Lee, 2013), and on the relation between mathematical creativity and culture (Massarwe, Verner, \& Bshouty, 2011). In the Nordic community, a recent Norwegian dissertation has continued the discussion of mathematical creativity in this tradition (Haavold, 2013).

\section{Constructionism}

A review of the notion of mathematical creativity shows that research mathematicians' self-reported practices and experiences play an important role in the conceptualization of the field, and that the conception of mathematical creativity as "sudden insights solving hard problems" is important. However, at least one largescale project worked with a different conception of creativity in relation to mathematics. In the late '70s, Papert and his colleagues at the Massachusetts Institute of Technology introduced a different take on what primary and lower secondary mathematics education could be in a technological era. This approach, built on pupils' creative and aesthetic work in a computer-based mathematical environment, was developed by Seymour Papert in the context of primary and middle school pupils working with the Logo program (Papert, 1980). Papert developed the interpretive educational framework known as constructionism. According to constructionism, learning mathematics is especially effective when pupils develop and construct artifacts for which they care. Moreover, computer-based environments ("microworlds") can be designed in such a way that they are especially well suited to supporting such epistemic constructions. From the point of view of mathematical creativity, the Logo project is interesting for two reasons; rather than considering mathematical creativity as an end, creative and constructive work is considered a 
vehicle for learning mathematics, and technology is seen as a possible catalyst for this constructive and creative pedagogy.

Papert relates his educational ambition explicitly to creativity and to the workings of the research mathematician, by directly comparing an art class with the typical mathematics classroom:

In the math class students are generally given little problems which they solve or don't solve pretty well on the fly. In this particular art class they were all carving soap, but what each student carved came from wherever fancy is bred and the project was not done and dropped but continued for many weeks. It allowed time to think, to dream, to gaze, to get a new idea and try it and drop it or persist, time to talk, to see other people's work and their reaction to yours--not unlike mathematics as it is for the mathematician, but quite unlike math as it is in junior high school. I remember craving some of the students' work and learning that their art teacher and their families had first choice. I was struck by an incongruous image of the teacher in a regular math class pining to own the products of his students' work! An ambition was born: I want junior high school math class to be like that. (Harel \& Papert, 1991)

The vision can be realized by mathematics instruction in which children develop digital artifacts and during that work are guided toward powerful and important mathematical ideas.

\section{Epistemic games}

The vision of building things with mathematics and technology can be aligned with a competence and labor market-oriented approach to mathematics education that has had an increasing international influence during the last decade (Niss et al., 2002). In the labor market, the value of being able to create an artifact with technology and mathematics is increasingly important. Papert did not address this aspect, but the relation to work life has been systematically addressed by Papert's graduate student Shaffer (2006), who has systematically investigated and designed a didactical transposition from mathematical and scientific activities outside academia, into what he calls epistemic games. Shaffer's main idea is to copy professional working situations in computer-supported practice-simulating games, to create a new kind of learning that enhances important innovative skills. One example is the epistemic game Escher's World (2006) in which high school students, in an after-school activity, act as professionals in a design studio creating visual layouts by using the tool the Geometer's Sketchpad. Creating visual layouts in the Geometer's Sketchpad activates creative competencies and mathematical concepts (Shaffer, 2002, 2006), and the activity resembles an important work life activity involving mathematics. However, this activity has little to do with conceptualizing mathematical creativity as a sudden inspiration that leads to valuable solutions to existing problems. 


\section{OVERVIEW OF CONCEPTIONS OF MATHEMATICAL CREATIVITY}

I propose a conceptualization of creativity in mathematics education that contests two metaphors for creativity, as problem solving and as construction, as well as creativity enacted inside mathematics and with mathematics. These pairs of concepts should be understood as continuums spanning the field of creativity in mathematics education, rather than as dichotomies that classify mathematics education activities in a binary fashion. The overview builds on a pragmatist approach to categorization, valuing a continuous rather than a dichotomist approach to differences between phenomena.

By creativity and innovation as problem solving, I mean the idea that a creative/innovative mathematical activity involves finding new and valuable solutions to hard problems. This metaphor for creativity is predominant in the descriptions by Hadamard (1954) and Pólya (1945) and in the area of gifted education (e.g., Leikin \& Pitta-Pantazi, 2012). And it is present to a larger or smaller extent in much of the mathematics education literature (Silver, 2013; Sriraman, 2008).

The conception of creativity and innovation as construction signifies the development of new and valuable artifacts as the primary sign of creativity/innovation. Such artifacts can be conceptual as well as material. The conception is prevalent in parts of the general literature on creativity in education (Loveless, 2002), as well as in the constructionist program (Papert, 1980; Resnick, 2012). But it is also present in the contribution by Ervynk (1991), emphasizing the construction of conceptual or theoretical artifacts as a reification process crucial for mathematical creativity.

The distinction between creativity and innovation in and with mathematics deals with the specific role that mathematics has in framing students' activities. Activities described as with mathematics contain explicit references to domains outside mathematics, and mathematics is typically used as a tool for obtaining something else. Constructionism (Papert, 1980; Resnick, 2012) and the epistemic game project (Shaffer, 2006) explicitly address creativity/innovation with mathematics. However, the area of mathematical modeling and application typically also tends to consider mathematics as a tool for making a difference outside mathematics (Lesh \& Zawojewski, 2007). Opposed to this understanding, I will consider creativity/innovation in mathematics. Creativity and innovation in mathematics are used to describe situations where the problems and constructs that the students work with and the criteria for giving value to a certain construction, problem, or solution are internal to mathematics. 


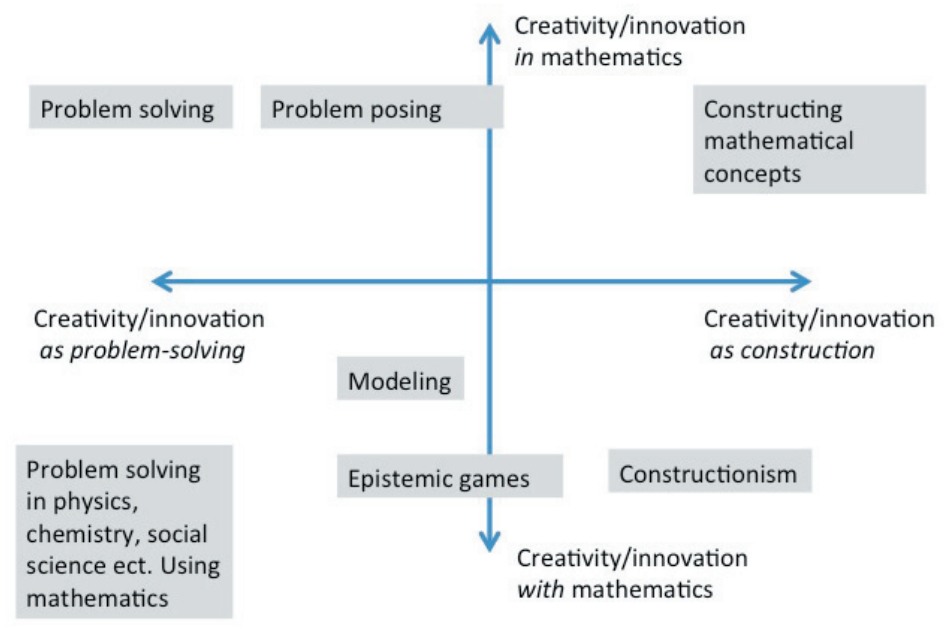

Figure 1: An overview of creativity in mathematics education.

If we look at the different and (partly conflicting) attempts to define creativity and innovation in relation to mathematics education, we can see that they are placed differently in the two-dimensional model. The discussions of the stage model for mathematical creativity are mainly framed as internal to mathematics and rely on a problem-solving metaphor for creativity. In contrast, Papert's constructionism is framed toward children's construction of artifacts meaningful in their own life worlds, and therefore, this conception can be viewed as creativity with mathematics building on a construction metaphor for creativity. The epistemic games project also mainly addresses creativity with mathematics. However, the domain for the students' activities is not their own interest and life world but a professional domain imported to the classroom from outside. Such a situation is typical, for example, in modeling activities where the problems dealt with are found outside mathematics. It is important to be sensitive toward how different domains frame mathematical activities in school, particularly if we want to improve our understanding of innovation and creativity in the mathematics classroom. Therefore, I suggest that we need more empirical knowledge about how various domains of knowledge frame students' work with mathematics in open scenarios related to problems and practices outside mathematics. 


\section{MATHEMATICS EDUCATION AS FRAMED TOWARD DIFFERENT DOMAINS OF KNOWLEDGE}

Any teaching situation involves a particular environment or situated task within which the students work. Since we focus on creativity and innovation, the environments are characterized by (1) a potential open-ended nature and (2) a relation to different situations outside school that the students somehow envision or relate to in their classroom work. The concept frame designates the socio-cognitive structures that make it possible for people to interpret their world and act within that world. In that sense, framing is the cognitive mechanism that allows the generation of a "situation" from the many and diverse sensory motor inputs that an individual receives (Goffman, 1974, p. 10). Thus, frames are crucial for making meaning in situations. Skovsmose relates frames to meaning in mathematics education (Kilpatrick, Hoyles, Skovsmose, \& Valero, 2005), and suggests that meaning must be considered situated and oriented toward the task that the students address, while the mathematics education literature tends to consider meaning as oriented toward abstract mathematical concepts. Relating meaning to situations and tasks (and not only "concepts") makes it imperative to relate meaning to the involved "spheres of practice," and the concept frame let us do that systematically. Frames relate to domains in the sense that any educational situation is framed by our understanding of the practices. Figure 2 illustrates the relationship between four domains common in education: (1) the domain of schooling, (2) disciplinary domains (mathematics, physics), (3) professional domains (agriculture, engineering), and (4) everyday domains (games, social media, family life; Hanghøj et al., n.d.).

\section{Disciplinary domains}

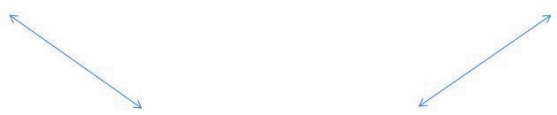

\section{Educational Scenario}

\section{Specialized domains}

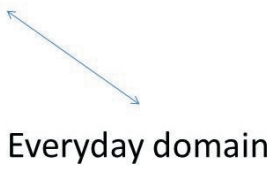

Everyday domain

\section{Figure 2: Relationship between the four domains (Hanghøj et al.).}

It is a valuable route for research to investigate how the different conceptions of creativity and innovation are framed toward different domains. When students act "as" designers of educational games, "as" researchers, or "as" engineers, the students" experience is related to their idea of this practice but is of course different from the lived experiences in these practices. Therefore, to answer the initial question of what 
creativity is in relation to the teaching of mathematics education, it makes sense to investigate examples where out-of-school practices and domains frame activities in the mathematics classroom and ask how such examples allow students to enact creativity and innovation in relation to mathematics.

\section{CONCLUSIONS}

The purpose of this paper was to address questions about what creativity and innovation is in mathematics education, as well as how we should teach for and assess creativity and innovation in relation to the teaching and learning of mathematics.

In the paper, the literature regarding creativity in mathematics education was reviewed and considered on two continuums (as showed in Figure 1). One of the proposed continuums goes from creativity in mathematics to creativity with mathematics, and the other one goes from a problem-solving metaphor for creativity to a construction metaphor. Furthermore, it was suggested that creativity in mathematics education is always enacted in relation to one or several domains. In that sense, mathematical creativity understood in some of the intrinsic definitions (Ervynk, 1991; Hadamard, 1954) cannot in any meaningful way be considered the same thing as the more general of artistic or professional activities involving the development of new ideas (Partnership for $21^{\text {st }}$-Century Skills, 2009; Resnick, 2012).

\section{REFERENCES}

Ervynk, G. (1991). Mathematical creativity. In D. O. Tall (Ed.), Advanced mathematical thinking (pp. 42-53). Dordrecht, the Netherlands: Kluwer Academic.

Goffman, E. (1974). Frame analysis: An essay on the organization of experience. New York: Harper \& Row.

Guilford, J. P. (1967). The nature of human intelligence. New York, NY: McGrawHill.

Haavold, P. Ø. (2013). What are the characteristics of mathematical creativity? An empirical and theoretical investigation of mathematical creativity (Unpublished doctoral dissertation). University of Tromsø, Norway.

Hadamard, J. (1954). An essay on the psychology of invention in the mathematical field. New York, NY: Dover.

Hanghøj, T., Misfeldt, M., Bundsgaard, J., Dohn, N. B., \& Fougt, S. S. (n.d.). Scenario-based education [Working paper]. 
Harel, I., Papert, S., \& Massachusetts Institute of Technology. (1991).

Constructionism: Research reports and essays, 1985-1990. Norwood, N.J: Ablex Pub. Corp.

Haylock, D. W. (1987). A framework for assessing mathematical creativity in schoolchildren. Educational Studies in Mathematics, 18(1), 59-74.

Joas, H. (1996). The creativity of action. Chicago, IL: University of Chicago Press.

Kilpatrick, J., Hoyles, C., Skovsmose, O., \& Valero, P. (2005). Meaning in mathematics education. New York: Springer.

Leikin, R., \& Pitta-Pantazi, D. (2012). Creativity and mathematics education: The state of the art. $Z d m, 45(2), 159-166$. doi:10.1007/s11858-012-0459-1

Lesh, R., \& Zawojewski, J. (2007). Problem solving and modeling. In F. K. Lester \& National Council of Teachers of Mathematics (Eds.), Second handbook of research on mathematics teaching and learning: A project of the National Council of Teachers of Mathematics. Charlotte, NC: Information Age.

Loveless, A. (2002). Literature review in creativity, technology and learning. Bristol, England: Futurelab.

Massarwe, K., Verner, I., \& Bshouty, D. (2011). Fostering creativity through geometrical and cultural inquiry into ornaments. In B. Sriraman \& K. Lee (Eds.), The elements of creativity and giftedness in mathematics $S E-14$ (Vol. 1, pp. 217-230). Sense. doi:10.1007/978-94-6091-439-3_14

Niss, M., Højgaard Jensen, T., \& Undervisningsministeriet. (2002). Kompetencer og matematiklcering : ideer og inspiration til udvikling af matematikundervisning $i$ Danmark. [Kbh.]: Undervisningsministeriet :

Organisation for Economic Cooperation and Development. (2010). Educational research and innovation; the nature of learning using research to inspire practice. Paris, France: Author. Retrieved from http://www.ucm.eblib.com/EBLWeb/patron?target=patron\&extendedid=P_5893 $68 \_0 \&$

Papert, S. (1980). Mindstorms: Children, computers, and powerful ideas. New York, NY: Basic Books.

Partnership for 21st Century Skills. (2009). P21 framework definitions. Retrieved from http://www.p21.org

Plucker, J., \& Zabelina, D. (2008). Creativity and interdisciplinarity: One creativity or many creativities? Zdm, 41(1-2), 5-11. doi:10.1007/s11858-008-0155-3 
Poincaré, H. (1946). The foundations of science: Science and hypothesis, the value of science, science and method. Lancaster, PA: Science Press.

Pólya, G. (1945). How to solve it; a new aspect of mathematical method. Princeton, NJ: Princeton University Press.

Resnick, M. (2012). Point of view: Reviving Papert's dream. Educational Technology, 52(4), 42-45.

Sfard, A. (1991). On the dual nature of mathematical conceptions: Reflections on processes and objects as different sides of the same coin. Educational Studies in Mathematics, 22(1), 1-36.

Shaffer, D. W. (2004). Pedagogical praxis: The professions as models for postindustrial education. Teachers College Record, 106(7), 1401-1421.

Shaffer, D. W. (2006). How computer games help children learn. New York, NY: Palgrave Macmillan.

Silver, E. A. (2013). Problem-posing research in mathematics education: Looking back, looking around, and looking ahead. Educational Studies in Mathematics, 83(1), 157-162. doi:10.1007/s10649-013-9477-3

Sriraman, B. (2008). The characteristics of mathematical creativity. Zdm, 41(1-2), 13-27. doi:10.1007/s11858-008-0114-Z

Sriraman, B., Haavold, P., \& Lee, K. (2013). Mathematical creativity and giftedness: A commentary on and review of theory, new operational views, and ways forward. Zdm, 45(2), 215-225. doi:10.1007/s11858-013-0494-6

Sriraman, B., \& Lee, K. H. (2011). The elements of creativity and giftedness in mathematics. Rotterdam, the Netherlands: Sense. Retrieved from http://site.ebrary.com/id/10490554

Torrance, E. P. (1963). Education and the creative potential. Minneapolis: University of Minnesota Press. 


\title{
HOW STUDENTS OWN TENDENCY TO FOCUS SPONTANEOUSLY ON MATHEMATICALLY RELEVANT PHENOMENA PREDICTS MATHEMATICAL DEVELOPMENT?
}

\author{
Erno Lehtinen
}

Centre for Learning Research, University of Turku

\begin{abstract}
According to the results of many longitudinal studies, inter-individual differences in mathematical achievement tend to increase in the course of formal schooling. Instead of attributing this entirely to the lack of (stable) abilities we should focus on the dynamic developmental factors, which might explain different learning trajectories. Our own studies from last fifteen years have highlighted the role of students' own focusing tendencies in the mathematical development. In our early studies we noticed that young children have generalized and relatively stable differences in their tendency to spontaneously focus on number of objects and events in their everyday surrounding. Longitudinal studies showed that these differences were in strong mutual interaction with early development of number concept and were a domain specific predictor of mathematical learning during early school years. Our recent studies have revealed that later in their development students have similar interindividual differences in their tendency to spontaneously notice quantitative relations situations that are not explicitly mathematical. First longitudinal studies on the "spontaneous focusing on quantitative relations" show that this tendency is a strong predictor of later learning of rational number concept. Earlier intervention studies show that it is possible to enhance children's spontaneous focusing on numerosity in a way, which has subsequent effects on the learning of number skills. In the presentation I will discuss if it is also possible to have similar intervention effects on the spontaneous focusing on quantitative relations.
\end{abstract}




\title{
A MODELING PERSPECTIVE ON THE MATHEMATICAL WORK OF TEACHING
}

\author{
Helen M. Doerr \\ Mathematics \& Mathematics Education, Syracuse University
}

\begin{abstract}
While much research over the past three decades has demonstrated the positive impact of mathematical modeling on student learning, progress has been slow in the widespread adoption of mathematical modeling as a classroom practice. A key factor in any change in classroom practice is the role of the teacher. Recently, researchers have investigated approaches to modeling that move beyond single modeling tasks to sequences of modeling tasks that facilitate the development of learners' mathematical ideas and modeling competencies. The mathematical work of teaching sequences of modeling tasks places new demands on the learners and new challenges for the teacher. The nature of teaching practices and the mathematical knowledge needed will be taken up in this presentation.
\end{abstract}




\section{Regular papers}

Teacher development 


\title{
PRE-SERVICE MATHEMATICS TEACHERS AS RESEARCHERS: THE CENTRALITY OF INQUIRY
}

\author{
Claire Vaugelade Berg \\ University of Agder, Kristiansand, Norway
}

This paper reports on pre-service mathematics teachers' reflections as they participate in an innovative course in teacher education. The course is based on a developmental research project currently running at University of Agder. One of its aims is to make the relationship between theory and practice visible through introducing the idea of inquiry at different levels. Results emphasise the importance of both the dialectical relationship between pre-service teachers' experiences while acting both as teachers and as researchers, and the emergence of students' awareness of their own professional development.

\section{INTRODUCTION}

Recent research publications have shown a growing interest both in the nature of inservice teachers' knowledge (Ball, Thames, \& Phelps, 2008; Carrillo, Climent, Contreras, \&Munoz-Catalan, 2013; Rowland, Huckstep \& Twaites, 2003) and in making explicit the complexity of mathematics teaching and learning in teacher education (Potari, 2012). At the last CERME 8 conference, evidence of this interest was brought to the fore as the working group labelled "From a study of teaching practices to issue in teacher education" attracted about 50 papers. Exploration of the nature of teachers' knowledge can be traced back to Shulman's (1986) seminal work where he emphasised the role of content in teaching and proposed to introduce pedagogical content knowledge (PCK) as one of the seven categories aiming at describing the different aspects which constitute, according to him, the knowledge basis for in-service teachers. His ideas have been developed further by Ball and colleagues (2008) who propose a practice-based approach and investigate the nature of teachers' subject matter in mathematics. Jaworski and Gellert (2003) offer a review of different models in teacher education and propose "critical apprenticeship" as a way of conceptualising teacher preparation. Based on these ideas I present in the article the main ideas of a developmental research project, "The Inquiry-Based Mathematics Teacher Education: preparing for life-long learning" project (IBMTE project) where the idea of inquiry is introduced as a means both to make visible and to strengthen the link between theory (results from research in mathematics education) and practice (pre-service teachers' experiences during their practice in schools) (see Berg, 2013). In the project inquiry is introduced as a means to encourage students to reflect on their experiences at a meta-level and to enhance their awareness concerning the complexity of mathematics teaching and learning. These ideas constitute the basis of an innovative course in teacher education which is currently running at University of Agder (UiA) and since fall 2011, I have been responsible for conducting the course, following students during their practice period 
in schools and supervising them as they write a research-based essay as an assessment for the course. In this article my focus is on students' experiences and reflections about the course, as reported in their essays, and I aim at answering the following questions: What kind of understanding of the idea of inquiry do the students develop? And how do the students experience being both a teacher and a researcher during their practice in school? The structure of the paper is as follows: First I present the theoretical perspective underlying the IBMTE project, then I explain methods used to collect and analyse data, and present results of the analysis. Finally I discuss possible implications of the research to models in teacher education while recognising the centrality of inquiry in students' professional development.

\section{Theoretical perspective of the IBMTE project}

The name of the project refers to "life-long learning". This aspect is understood as related to the issue of sustainability in student teachers' education. Considering teacher education as sustainable implies inviting student teachers in engaging in inquiry and research (Barnes and Solomon, 2013). I see a fundamental shift from considering student teachers as receivers of knowledge to inviting and recognising them both as producers of knowledge which might be relevant for their future teaching practice, and as valuable participants in a research project (Healey \& Jenkins, 2009). My interest in encouraging students to participate and engage actively in research originates from previous research (Grevholm, Berg, \& Johnsen, 2006) and from research into ways of making visible the relationship between theory (results from research in mathematics education) and (teaching) practice. Following Healey and Jenkins (2009) I understand discipline-based research and research-based teaching as being closely related and I consider that one of the most meaningful ways of making this linkage visible for student teachers is to encourage them to engage both in inquiry at different levels (see below) and in research (see Figure 1).

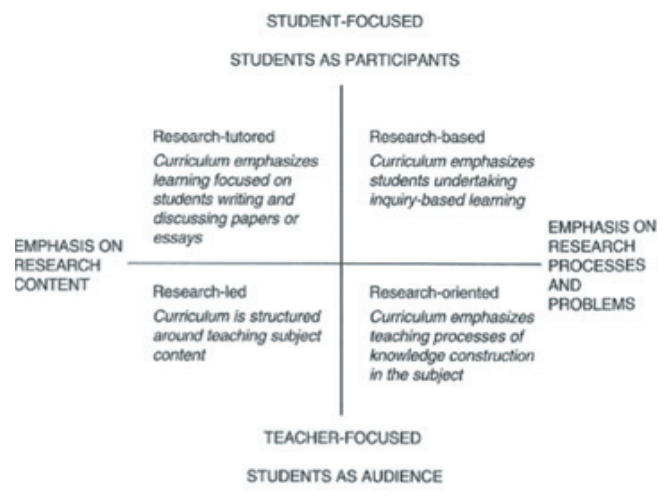

Figure 1: Students' different modes of participation (Healey and Jenkins, 2009) 
Thereby the IBMTE project is rooted in a desire to offer our student teachers the benefits and insights research-based education can provide and this is done through emphasising the deep interconnection and complementarity between theory (results from research in teacher education) and practice (teaching practice) and encouraging students developing awareness of this relationship. As Pring (2000) remarks

Therefore, to think of practice apart from theory (of some sort) is to create another false dualism. The dualism is created by the examination of theory as such and by asking how this or that theory relates to practice, as though practice were stranding outside a theoretical framework. On the contrary, to look at practice, to see how it is always open to a further account of what is being practiced and thus to the possibility of questions being raised which can be treated more theoretically, implies the logical inseparability of theory from practice. Theory here, then, refers to the articulation of the framework of beliefs and understandings which are embedded in the practice we engage in. (p.78)

Pring's words capture the philosophical attitude underlying the IBMTE project and I see a dialectical relationship between theory and practice since theory informs one's approach to (teaching) practice, and reflections on and analyses of practice nurtures new opportunities for conceptualising practice and developing theories of practice further. The challenge consists of making visible to the pre-service teachers the complementarity of theory and practice and during the course I invite them to explore this relationship further through the introduction the idea of inquiry. The origin of inquiry (Dewey, 1905) can be traced back to the seminal work of Polya in mathematics (Polya, 1945) and his ideas have developed further during the 1970s and 1980 s when an international movement in mathematics learning and teaching aimed at promoting problem-solving and conjecturing in mathematics classrooms (Mason, Burton, \& Stacey, 1982, Schoenfeld, 1985). In the IBMTE research project inquiry plays a crucial role and is understood as referring to a cyclical process consisting of the following elements: asking questions, recognising problems, exploring possibilities, investigating and seeking answers. Thereby this process opens for engaging in an inquiry cycle where development occurs (Berg, 2009, 2011, 2013a, 2013b; Jaworski, 2006, 2008). The cyclical process is understood and presented to students at three levels: at the first level inquiry in mathematics as the students are offered the opportunity to engage in mathematical tasks (Berg, 2013b); at the second level inquiry in teaching mathematics as students are invited to reflect on and to look critically at how to organise and prepare teaching in order to enhance their pupils' conceptual understandings of mathematics; and at the third level inquiry in student teachers' own reflections as they engage in considering their own development as future mathematics teachers. My aim is that student teachers gradually recognise inquiry as being a useful tool for investigating and reflecting on their teaching practice, and possibly adopt inquiry as a stance or as a way of being (Cochran-Smith \& Lytle, 1999; Jaworski, 2006, 2008). This approach enables the development of a "third space" in which students' roles as teachers and as researchers become hybridised (Barnes and Solomon, 2013). 
As explained above, one of the aims of the IBMTE project is to make the link between theory and practice visible to the students. In order to address this goal I presented during fall 2013 results from research in mathematics education related to the following three themes: the first theme addresses pupils' difficulties with word problems. Research shows that pupils engage in word problems while assuming the following assumptions: the problem proposed by the teacher makes sense, all information given in the problem is relevant and all numbers given must be used and only once. The answer of the problem should be with natural number, and algorithms recently taught are to be used. Here the importance of the didactical contract is emphasised, and it is defined as consisting of a set of implicit rules regulating the interaction between the teacher and his pupils. It is claimed that it is necessary to introduce another kind of didactical contract in the classroom as a means to encourage pupils to engage in word problems in a meaningful way. These results are important to be taken into account in teacher education and several student teachers decided to choose this issue as the focus of their research-based essay. After proposing different word problems to their pupils during their practice period, student teachers reflect on the consequences of their findings for their future teaching practice. The second theme relates to pupils' difficulties with engaging in algebraic thinking and the recognition of useful patterns in geometrical figures. Here preservice teachers are invited both to engage with mathematical tasks and to reflect on the way they solve these. The next step consists in introducing Stacey's results concerning the way pupils engage with these tasks and discussing how to stimulate pupils to recognise useful patterns in order to be able to observe and describe in a mathematical way linear patterns of the form $f(n)=\mathrm{a} n+\mathrm{b}$ with $\mathrm{b} \neq 0$. The last theme concerns the use of diagnostic tasks and pupils' misunderstanding in relation to decimal numbers, division and multiplication and reading graphs are addressed. Furthermore an important aspect of this course consists of making visible the specificity of mathematics, as subject matter (Berg, 2013a, 2013b). This is done through the introduction of the notions of semiotic registers, treatment and conversion between these (Duval, 2006). After the presentation of these results from research in mathematics education, the pre-service teachers are inviting to choose one of the themes and to formulate precise research questions. Furthermore they need to collect data during their practice period, analyse these and present their results and reflections in a written research-based essay.

\section{Methodological considerations and research setting}

In the IBMTE project I follow a developmental research approach. This methodology is rooted in ideas developed by Freudenthal (1991) and Gravemeijer (1994) in relation to curriculum development. Following a developmental approach in research implies that the researcher engages in observing, studying, and analysing student teachers' engagement and development through the course, and at the same time recognising that the research activity contributes to that development (Goodchild, 2008). In the research reported in this article, I follow an interpretative approach to 
data collected during 2011, 2012, and 2013. The data consists of interviews with students, questionnaires distributed both at the beginning and at the end of the course and research-based essays student teachers write as an assessment for the course. Due to limitation of space I will only examine evidence emerging from the essays. As explained above, students have to choose a theme, formulate well-defined research questions, present and explain relevant research findings in mathematics education (most of them are presented during the course), collect data during their three weeks practice period in school, and finally analyse it in order to answer their research questions. From the experience I have teaching this course for several years, nearly all students lack experience in writing an essay following scientific criteria and it results in an important need for supervision. In the following table, I present the number of student teachers who delivered their essays (in parentheses) and the number of essays where student agree that these might be used for research purposes. The analysis of essays is seen as investigating narratives by using a hermeneutic method of interpreting students' statements. The analysis is conducted through carefully reading the essays several times while searching for codes and patterns.

\begin{tabular}{|c|c|c|c|}
\hline Year & 2011 & 2012 & 2013 \\
\hline $\begin{array}{c}\text { Number of essays } \\
\text { which can be } \\
\text { used for research } \\
\text { purposes }\end{array}$ & $29(35)$ & $52(59)$ & $35(41)$ \\
\hline
\end{tabular}

Table 1: Number of essays delivered by the students (either individually or in groups) My aim in this article is to get insights both in student teachers' understanding of the idea of inquiry and in their experiences while acting both as teachers and as researchers during their practice in schools. In the following section I present excerpts from students' essays bringing evidence of students' experiences and reflections on both aspects as presented above.

\section{Student teachers' experience of inquiry}

In this section I present excerpts from students' essays concerning the meaning they give to the idea of inquiry and its relevance for them as future mathematics teachers.

Student 1 (2011): As I worked with my essay I learned a lot concerning what it means to be a teacher engaged in research and how important it is in order to become a better teacher. I have learned to ask myself critical questions about what I read and about my own teaching. I think that the word inquiry captures nicely what I have been through during my work with this essay

Student 2 (2011): We have learned a lot about the term inquiry. In the beginning this word was a little frightening and unknown, but it gives a good description of the course. This is just what we used in our research, 
that is to ask questions, to go deeper. This research-based essay gave us motivation to continue with research in mathematics education

Student 3 (2012): We have been through a process which gave us several perspectives which we can use in our work with pupils. It has opened our eyes for an inquiry approach and we believe that if we have such an attitude, as teachers, we will be able to influence our pupils to ask questions, to curious, to investigate. We used several teaching approaches during our period in practice and we could really see the effects of inquirybased approach to teaching.

Student 4 (2013): This course had some exciting aspects, but it was difficult in the beginning to understand it [inquiry]. It became clearer when I came to my practice period in school and it helped me to understand how pupils think

Student 5 (2013): My first impression was that this course was a little scaring with many new notions and inquiry was completely new. Now after my practice period, I can see it as an important part of my education as future mathematics teacher.

These excerpts bring evidence of the challenges students meet as the idea of inquiry is introduced during the course. It is a complex notion which meaning is difficult to grasp. In addition, the English term is used since there is no equivalent word in Norwegian, and this fact contributes to make this idea a frightening one. However it seems that as the students engage in their practice period and start the process of writing their essay, inquiry becomes more familiar and they are able to describe an attitude of "asking oneself critical question" (Student 1), "to go deeper" (Student 2), opening "our eyes for an inquiry approach" (Student 3). From these excerpts it seems that the students get inspiration to continue and explore further the possibilities offered by introducing inquiry both in mathematics teaching and learning and in reflecting on oneself development. I see this aspect as related to students' developing awareness of evolving in a "third space" (Barnes and Solomon, 2013) which might be characterized by an hybridisation of their roles both as teachers and researchers.

\section{Student teachers' experience of acting both as teacher and as researchers}

In this section I present excerpts from students' reflections about acting both as a teacher and as a researcher during their practice period in school.

Student 6 (2011): Looking at my own learning outcomes from this essay and from the course, I can see that I have been reflecting on things I haven't been thinking about before. It became more and more interesting to follow the course and to take part of the discussions and I am now much more interested in "didactics" and everything about a learning situation. I hope I can use this in a useful way when I become a teacher and I look forward to a future with even more reflections and discussions about "didactics".

Student 7 (2012): Writing a research-based essay is something new for me. Therefore it has been a huge challenge but at the same time a very rich learning process. Research by itself is one thing, but elaborating an essay where theory, methods and analysis fit is completely different. There 
is no doubt that this kind of awareness and reflections will be part of my profession as a teacher in future and I hope this will enable me to become a better leader for my pupils.

Student 8 (2013): It was exciting to be both teacher and researcher and to analyse different situations and try to relate these to the theory. At the same time, it gave me a lot of work because we were supposed to plan your teaching lessons and discuss our research plan. It was challenging. During my practice period I saw that the relationship between theory and practice was fruitful.

Student 9 (2013): It was a lot to do before, during and after our practice period, but I can see myself developing the ability to get relevant information from pupils' answer. However I see a huge difference between being a researcher and being a teacher. As a researcher you have to distance yourself from the pupils and analyse their thinking, as a teacher the contact with pupils is the most important. I see now clearly that there is a link between theory and practice and it is particularly relevant for my work as mathematics teacher - much more than what I thought in the beginning.

Pre-service teachers' reflections show evidence of the complexity of their role during the practice period. It seems that through experiencing this complexity they develop awareness concerning the meaning of acting both as a teacher and as a researcher. As a teacher, the focus is on planning for teaching lesson and building contact with pupils. As a researcher, the focus is on analysing pupils' answers and there is a need to distance oneself from the phenomena at stake. I understand this complexity as related to students developing awareness of acting in a "third space" (Barnes and Solomon, 2013). For the student teachers it consists of handling both roles at the same time while facing systemic constrains in terms of finding time for discussing and reflecting both with the practice teacher on teaching lessons, and with other students about conducting the research project. Furthermore I want to argue that it is during their practice period that the students become aware of the relevance of theory for their teaching practice and this recognition is crucial for their development as future mathematics teachers. The teaching practice helps them to understand further results from research in mathematics education. Likewise the discussions I have with the students during the course after their practice period and during the supervision meetings in addition to their engagement in writing their research-based essay, help them to understand further their practice period. I claim that it is in experiencing the dialectical relationship between theory and practice that pre-service teachers get the opportunity to move from being students as passive audience to becoming students as active participants in research-based teacher education (Healey \& Jenkins, 2009). During the course, they are offered the opportunity to act both as teachers and researchers, and thereby to reflect on their experiences, write a research-based essay, engage in critical apprenticeship (Jaworski \& Gellert, 2003) and experience the possibilities of evolving in a "third space" (Barnes and Solomon, 2013). 


\section{Discussion and conclusion}

My aim in this article was to explore both pre-service teachers' understanding of the idea of inquiry and the way they experience acting as a teacher and as a researcher during their practice period. Concerning the first research question, the analysis of pre-service teachers' reflections, as presented in their essays, show that inquiry is an idea which is complex to grasp and might seem frightening in the beginning. It is during their practice period that students get the opportunity to ask questions, to deepen pupils' answers, to reflect critically on their own teaching practice and I understand these aspects as crucial in operationalizing the notion of inquiry. As Student 5 (2013) explains "Now after my practice period, I can see it [inquiry] as an important part of my education as future mathematics teacher". Thereby engaging with the idea of inquiry enables the students to explore the dialectical relationship between theory and practice. The second research question aims at exploring preservice teachers' experiences during their practice period. Analysis of students' answers brings evidence both of the complexity they need to face as they are acting both as teachers and as researchers and of their own development as they gradually recognise the specificity and complementarity of these two roles. In addition, systemic constrains like time, opportunity to get supervision with their practice teacher and collecting relevant data for their essays are challenges students need to handle. However, I argue that the following important aspects emerge from the analysis: it is as they engage in their practice period that students develop awareness of the relevance of theory (results from research in mathematics education). Likewise writing a research-based essay offers them the opportunity of reflecting on their practice period and value how theory is helpful in conceptualising their teaching practice. Thereby a dialectical relationship between theory and practice is emerging and it constitutes a fundamental part of the IBMTE project. In the beginning of the article I presented Healey and Jenkins' (2009) model as a way of conceptualising one of the aims of the IBMTE project. However, the model offers a static picture while presented different modes of students' participation. I claim that inquiry is introducing a dynamical aspect which I consider as being at the core of teacher education, and through using inquiry as a tool, students gradually develop an attitude of recognising inquiry as a way of being. This recognition is central in making visible the deep relationship between theory and practice, or as using Pring's (2000) words "the logical inseparability of theory from practice". As a result of this research, I argue for considering inquiry as a means through which pre-service teachers engage in recognising the complexity of their future career as mathematics teachers, where theory (results from research in mathematics education) guides teaching practice and likewise, where teaching practice develops theory further. This recognition constitutes a crucial element in the emergence of students' awareness of their own professional development. Thereby the centrality of inquiry in teacher education needs to be recognised and emphasized and the research presented in this article is an attempt to move in that direction. 


\section{REFERENCES}

Ball, D. L., Thames, M., \& Phelps, G. (2008). Content knowledge for teaching: What makes it special? Journal of Teacher Education, 59(5), 389-407.

Barnes, Y. \& Solomon, Y. (2013). The discipline of noticing as a path to understanding. International Review of Qualitative Research, 6(3), 360-375.

Berg, C. V. (2009). Developing algebraic thinking in a community of inquiry: Collaboration between three teachers and a didactician. Doctoral dissertation at the University of Agder. Kristiansand, Norway: University of Agder.

Berg, C. V. (2011). Adopting an inquiry approach to teaching practice: the case of a primary school teacher. In M. Pytlak, E. Swoboda, \& T. Rowland (Eds.), Proceedings of the seventh congress of the European Society for Research in Mathematics Education, (pp.2580 - 2589). Rzeszow, Poland: University of Rzeszow, Poland.

Berg, C. V. (2013a). Introducing an inquiry-based approach in mathematics teacher Education: Focus on student teachers' reflections. In B. Grevholm, P. S. Hundeland, K. Juter, K. Kislenko, \& P-E. Persson (Eds.), Nordic research in didactics of mathematics: past, present and future, (pp. 61-76). Oslo: Cappelen Damm Akademisk.

Berg, C. V. (2013b). Enhancing mathematics student teachers' content knowledge: Conversion between semiotic representations. Proceedings of CERME8 conference, Antalya, Turkey, Feb. 2013.

Carrillo, J., Climent, N., Contreras L. C., \& Munoz-Catalan, M. C. (2013). Determining specialised knowledge for mathematics teaching. Proceedings of CERME8 conference, Antalya, Turkey, Feb. 2013.

Cochran-Smith, M., \& Lytle, S. (1999). Relationships of knowledge and practice: Teacher learning in communities. Review of Research in Education, 24, 249-305.

Dewey, J. (1905). How we think. Mineola, New York: Dover Publishers.

Duval, R. (2006). A cognitive analysis of problems of comprenhension in a learning of mathematics. Educational Studies in Mathematics, 61, 103-131.

Freudenthal, H. (1991). Revisiting mathematics education. Dordrecht, The Netherlands: Kluwer.

Goodchild, S. (2008). A Quest for 'Good' Research: The Mathematics Teacher Educator as Practitioner Researcher in a Community of Inquiry. In Barbara Jaworski and Terry Wood (Eds.), The Mathematics Teacher Educator as a Developing Professional (pp.201-220). Rotterdam: Sense Publishers.

Gravemeijer, K. (1994). Educational development and developmental research in mathematics education. Journal for Research in Mathematics Education, 25(5), 443-471.

Grevholm, B., Berg, C. V., \& Johnsen, V. (2006). Student teachers' participation in a research project in mathematics education. In E. Abel, R. Kudzma, M. Lepik, T. Lepmann, J. Mencis, M. M. Ivanov. \& M. Tamm (Eds.), Teaching mathematics: 
Retrospective and perspectives, 7th international conference May 12-13, 2006, (pp. 61-68). Tartu, Estonia: Tartu Ulikool.

Healey, M, \& Jenkins, A. (2009). Developing students as researchers. Linking Research and Teaching in Higher Education. In S. Haslett and H. Rowlands (Eds.), Proceedings of the Newport NEXUS Conference, Special Publication, 1, 711.

Jaworski, B. (2006). Theory and practice in mathematics teaching development: critical inquiry as a mode of learning in teaching. Journal of Mathematics Teacher Education, 9, 187-211.

Jaworski, B. (2008). Development of the mathematics teacher educator and its relation to teaching development. In B. Jaworski \& T. Wood (Eds.), International handbook on mathematics teacher education: Vol. 4. The mathematics teacher educator as a developing professional: Individuals, teams, communities and networks (pp. 335 - 361). Rotterdam, The Netherlands: Sense Publishers.

Jaworski, B., \& Gellert, U. (2003). Educating new mathematics teachers: Integrating theory and practice and the roles of practising teachers. In A. J. Bishop, M. A. Clements, C. Keitel, J. Kilpatrick, and F. K. S. Leung, Second International Handbook of Mathematics Education (pp. 829-875). Dordrecht: Kluwer Academic Publisher.

Mason, J., Burton, L. \& Stacey, K. (1982). Thinking mathematically. London: Addison-Wesley.

Polya, G. (1945). How to solve it. New Jersey: Princeton University Press.

Potari, D. (2012). The complexity of mathematics teaching and learning in mathematics teacher education and research. Journal of Mathematics Teacher Education, 15, 97-101.

Pring, R. (2000). Philosophy of educational research. London: Continuum.

Rowland, T., Huckstep, P., \& Twaites, A. (2003). The knowledge quartet. In J. Williams (Ed.), Proceedings of the British Society for Research into Learning Mathematics, 23(3), 97-102.

Schoenfeld, A. H. (1985). Mathematical problem solving. New York: Academic Press.

Shulman, L. S. (1986). Those who understand: Knowledge growth in teaching. Educational Researcher, 15(2), 4-14. 


\title{
PRE-SERVICE TEACHERS DEVELOPING LESSON PLANS IN FIELD PRACTICE
}

\author{
Raymond Bjuland, Reidar Mosvold and Janne Fauskanger \\ University of Stavanger
}

Previous studies indicate that lesson study can be used to stimulate the development of effective learning environments in prospective teacher education. In this paper, we present and discuss the results from a Norwegian project where lesson study was implemented in the field practice period in prospective teacher education. We analyze data from a pre-lesson mentoring session where three preservice teachers and one mentor teacher participated. Even though the lesson study intervention had serious limitations in this particular group, the results indicate an increased focus on content and learning. More focus on knowledge of the particular content to be taught is, however, necessary.

Keywords: Pre-service teachers; field practice; lesson study; proportional reasoning

\section{INTRODUCTION}

The demands on teachers are increasing, and the task of equipping all teachers for effective teaching in the $21^{\text {st }}$ century constitutes a significant challenge for teacher education (OECD, 2011). Pre-service teachers are faced with different challenges throughout their development from novices to experienced teachers; one challenge is to shift the focus from surviving in the classroom to student learning of a particular content (Richardson \& Placier, 2001). Among the other important aspects of teachers' skills are those of cultural awareness and regard for individual differences (Bransford, Brown, \& Cocking, 2000). It is important to develop a focus on learners' attitudes, skills and understanding - and not least to use this actively when designing and implementing teaching. The discussion of the components and role of teacher knowledge has been going on in the research literature for decades (e.g., Davis \& Simmt, 2006), and in order to design and implement high-quality teaching, teachers need a certain type of knowledge that is relevant for teaching (e.g., Ball, Lubienski, \& Mewborn, 2001).

Research on field practice experiences during teacher education (e.g., Ohnstad \& Munthe, 2010) indicates that there should be ample opportunity to support preservice teachers' learning during field practice. A collaborative inquiry model for teacher learning called lesson study has been reported to be promising (Murata \& Pothen, 2011; Stigler \& Hiebert, 1999). Lesson study is a Japanese professional development practice (Fernandez, 2002), and it has been adopted in several countries throughout the world. In a recent study, Fernandez and Zilliox (2011) investigated approaches to lesson study in prospective mathematics teacher education to stimulate effective learning environments. Their findings suggested 
that lesson study approaches did stimulate the prospective teachers "to participate in the professional developmental process of developing, analyzing and discussing lessons" (Fernandez \& Zilliox, 2011, p. 100). The prospective teachers also got support to begin implementing teaching practices and developing lesson plans which were related to reform-oriented mathematics.

The present study is a part of a larger project: "Teachers as Students" (TasS). This project aims at investigating pre-service teachers' learning in field practice through a time-lagged design experiment. Two groups of pre-service teachers from each of the subject areas mathematics, science, English as a foreign language, and physical education participated in a control- and intervention situation. Analysis of mentoring session(s) in the control group situation suggested that the dialogues between pre-service teacher(s) and mentor teacher(s) revealed low focus on reflecting about the choice of activities. The pre-service teachers in the four subjects were more concerned with practical doings than reflection about the subject content (Helgevold, Næsheim-Bjørkvik, \& Østrem, 2014). In this paper we investigate if it is possible to identify a more focused dialogue concerning students' learning of the mathematical topic in the intervention situation. More specifically, we pose the following research question: How can a lesson study approach influence pre-service teachers' ability to reflect about the content (mathematics) and students' learning of the content when preparing the lesson?

In order to answer this research question, we analyse transcripts from a pre-lesson mentoring session in a group of three Norwegian pre-service teachers and their mentor teacher using the framework of Bransford et al. (2000).

\section{THEORETICAL BACKGROUND}

As a result of their review of research, Bransford et al. (2000) distinguish between four attributes of high-quality learning environments. They suggest that such environments focus on the learner, knowledge, assessment and community.

Teachers in a learner centred environment recognize the importance of building on the conceptual and cultural knowledge that students bring with them to the classroom. Further, such teachers direct attention towards students' prior knowledge, skills, and attitudes. This includes students' preconceptions regarding subject matter - which in this case relates to proportional reasoning - as well as "a broader understanding of the learner" (Bransford, et al., 2000, p. 23), and students' cultural differences and students' theories about intelligence. The students in learner centred classrooms are invited into an environment where their continued thinking about development and adjustment of their ideas and skills is possible. The teachers in this environment pay close attention to each student's progress and devise appropriate tasks. 
An environment that is knowledge centred pays attention to what is taught, why it is taught, and what competence or mastery looks like and begins with concern for the students' initial preconceptions and "focus on the kinds of information and activities that help students develop understanding of disciplines" (Bransford, et al., 2000, p. 136). In this study, the focus was on proportionality and proportional reasoning. Proportionality is defined by Lamon (2007, p. 638) as: "a mathematical construct referring to the condition or the underlying structure of a situation in which a special invariant (constant) relationship exists between two covarying quantities". Understanding the constant is crucial for understanding proportionality. One reason why this is difficult is that the constant $(k$ in the linear function $y=k x$ ) changes mask in different situations: "In symbols, it is a constant. In a graph, it is the slope" (Lamon, 2007, p. 638). Conceptions and misconceptions are central aspects of the planning and teaching (Bransford, et al., 2000), and misconceptions might lead to errors. A common error relating to proportional reasoning - made by students of different ages - is to apply proportional methods to solve non-proportional problems (Fernández, et al., 2012). Another issue is that of the nature of the involved quantities. It has long been argued that students are able to visualize discrete quantities more easily than continuous quantities (Tourniaire \& Pulos, 1985), but more recent research has implied that the problem format can make a difference (Fernández, et al., 2012). Included in knowledge centred environments are activities as sense-making, meta-cognitive processing, and reflection. Adaptive teaching and inclusive practices are ways that teachers combine learner centred approaches with knowledge centred ones (Bransford, et al., 2000).

Having an assessment centred approach, the focus is on ongoing assessments designed to make students' thinking visible to both teachers and students. This assessment orientation helps teachers grasp the students' preconceptions, monitor students' progress, and help students identify their own progress (Bransford et al., 2000). Environments which invite students to learn from one another, to continually strive to improve, and to feel connected to one another and the larger community are referred to as community centred (Bransford, et al., 2000).

\section{METHODOLOGY}

The TasS project includes two data collection periods and two groups of participants: a control group (referred to in the project as the "business as usual condition") and an intervention group (referred to as the "lesson study approach condition"). Pre-service teachers in their second year of teacher education participated. In the "lesson study approach condition" data collection included video observations from pre-service teachers' planning lessons with their practice teacher (pre-lesson mentoring sessions), from carrying out lessons, from mentoring session after carrying out the lesson for a first time, carrying out the 
lesson for a second time, and from evaluating lessons (post-lesson mentoring sessions).

Three workshops on lesson study were organized as a preparation for the mentor teachers. As part of these workshops, a "Handbook for Lesson Study" was designed. The aim of the Handbook was to guide pre-service teachers and mentor teachers throughout a lesson study cycle. This cycle normally consists of: formulating a goal for the research lesson, planning, observing the research lesson and collect data, reflect and refine the lesson plan, and then often repeating this (Hart, Alston \& Murata, 2011). The topic of the research lesson was decided before field practice and in collaboration with campus teachers. Munthe and Postholm (2012) point to three crucial components in the process of planning for and carrying out the lesson study cycle: 1) the formulation of a research question to learn more about students' learning, 2) predictions about the chosen activities, and 3) observation of students' learning in the research lesson. These components were also highlighted in the Handbook.

In this study, the group of pre-service teachers in mathematics discussed the lesson plan for a mathematics lesson in grade 10. When analysing the data material, we focused on how the mathematical content of proportional quantities was discussed among three pre-service teachers and their mentor teacher, paying attention to students' learning of the topic. The four features of a high-quality learning environment from Bransford et al. (2000) were used to guide the analysis. Utterances were then identified and coded if they contained elements of a learner centred (L), knowledge centred (K), assessment centred (A), and community centred (C) orientation. In order to increase the reliability of the coding, two of the authors coded the data independently and reconciled. The overlap was close to hundred percent.

The duration of the pre-lesson mentoring session was about 21 minutes. We consider the transcribed text of this session as one on-going episode of utterances. Inspired by Wells (1999), the episode has been divided into thematic sequences of utterances. A new sequence starts when there is a natural shift of focus in the dialogue. It could be a question or a statement, what Wells calls a move, which initiates a new direction for the discussion. In the analysis below, we have selected some thematic sequences in which there is a clear focus on the mathematical topic, proportional quantities which is the theme and goal for the lesson.

\section{RESULTS}

In the dialogue below, we focus on a pre-lesson mentoring session of mathematics from the lesson study approach condition in order to investigate if such an approach can influence the pre-service teachers' development of ability to reflect about the content (mathematics) (K) and students' learning (L) of the content when preparing the lesson. 


\section{The theme and goal for the lesson}

The first thematic sequence of the dialogue has been selected from the beginning of the mentoring session. The reason for this choice is to illustrate how the preservice teachers present their goal and theme for the lesson. In the dialogue below, three pre-service teachers (PST 1, PST 2, PST 3) and their mentor teacher (MT) discuss the pre-service teachers' planning of the lesson:

1 MT: Ok, actually, then you can just say how you have thought you will do it.

2 PST 2: Yeah. We have written that the theme is, eh, the title is: Proportional quantities. (K)

3 MT: $\quad$ Mhm.

4 PST 2: Eh. And the learning goal for the lesson is to know more about proportional quantities. (L, K)

5 MT: Yeah.

6 PST 2: We have thought about starting with what they already know, that we should repeat $y=a x+b$ (equation of straight lines), and let them explain it to us, so it's easier for them to see the connection when we introduce $y=k x$ (straight line through origin). (L, K, A)

7 PST 1: We have understood that they know what the " $a$ " is (the slope of the line) and what the " $b$ " is (the intersection with the y-axis). Then they, when we introduce to them that $y$ is equal to $k$ multiplied by $x(y=k x)$, then they in a way can see the connection. (L, K)

8 MT: Will you use examples from everyday life?

9 PST 2: $\quad$ Mhm.

10 MT: Yes.

11 PST 2: We think that the introduction should focus on examples of prices, for instance the price of a text message (SMS) (...) (C)

The mentor teacher invites the pre-service teachers to explain how they have planned the lesson (1), and we learn that the theme for the lesson is about proportionality and the goal is to know more about proportional quantities (2), (4). These utterances illustrate that PST 2 has a knowledge- and learner-oriented perspective since she focuses on the mathematical content and what the students should learn. The dialogue illustrates that the mentor teacher's role in this sequence mostly is to listen and to let the pre-service teachers explain how they have planned to do the lesson (3), (5), (10).

PST 2 continues the explanation by focusing on the equation of a straight line, which seems to be previous knowledge for the students. In their lesson plan, the pre-service teachers will ask the students to explain this equation for them as a starting point in order to see the connection to the proportional function $y=k x$ (6). We clearly observe in the dialogue a concern for the students' preconceptions about the subject matter which is - according to Bransford et al. (2000) - when a 
knowledge centred perspective intersect with a learner centred perspective. There are also signs of an assessment orientation, since the students are invited to explain their understanding of the straight line, making the students' thinking visible to both pre-service teachers and students. In this way the pre-service teachers are probably able to grasp the students' preconception of a straight line. PST 1 (7) elaborates on PST 2's explanation by bringing in the fact that the students also know about the parameters of the straight line, but she does not explicitly express in the dialogue the role of these parameters. The students have been taught about the straight line. The students' own explanations will probably reveal whether or not this is prior knowledge to them.

Both PST 1 and PST 2 emphasize in the dialogue that the goal for the lesson is to let the students discover the connection between linear and proportional functions. However, we can wonder why they do not express this connection by giving the parameter " $b$ " the value of zero in order to come up with the straight line through origin $(y=a x)$. Both pre-service teachers are concerned with presenting proportionality by the constant, $k(y=k x)$, bringing in another parameter into the dialogue. One reason for this could be that the textbook may introduce this constant $(k)$, and the pre-service teachers want to stick to the textbook's way of presenting it. The mentor teacher does not comment on this. Instead she poses another question, inviting the pre-service teachers to consider if they will use examples from everyday life (8). She is then bringing in the community centred perspective in order to make connections to a context outside the school environment. From PST 2's response (11) we observe that the pre-service teachers have thought about connecting the mathematical content to a real life situation by considering the price for sending a text message with a mobile telephone.

\section{Elaboration of the goal of the lesson}

Between the first and second thematic sequence, the focus of the dialogue has been on the structure of the lesson (ways of teaching) and discussing tasks and differentiating tasks for students on different ability levels. In the continuation of the dialogue, the mentor teacher recapitulates and focuses on the beginning of the lesson:

87 MT: (...) it could be good to make it clear in the beginning of the lesson that the goal, eh, they should learn, the goal of the lesson is to learn about proportional quantities and show how it can easily be connected to everyday life. (L, K, C)

88 PST 3: Mhm.

89 MT: Mhm since it's a good way to find out what is most profitable if you put up such a diagram like this (points to the textbook with her pen). And if they see it, the students, then I think they maybe will be more motivated too. (L, K) 
90 PST 2: Mhm. Yes it seems as (.) when we asked: what do you know about proportional quantities, then they become afraid just of the expression. (L)

96 PST 2: What we had thought was that they should write down the rule (.) and then they should "think, pair, share" on y equals k multiplied by x. But then try to explain it to us in their own words what it actually means. $(\mathrm{C}, \mathrm{K}, \mathrm{A})$

In the first sequence of the dialogue, the mentor teacher listened to how the preservice teachers had planned the lesson. Here we observe that she plays a more active role in the dialogue. Her initiative (87) summarizes and elaborates on the goal of the lesson, helping the pre-service teachers to be aware of the fact that the mathematical content should be related to everyday life. To use the dimensions of Bransford and colleagues (2000), the mentor teacher initiates a discussion, stimulating for learner orientation (lesson goal), knowledge orientation (proportional quantities) and community orientation (connection to everyday life). PST 3 (88) indicates that she is listening. The mentor teacher goes on giving reasons for these dimensions by elaborating on the comparison of two lines in a diagram to see which of those that is most profitable (89).

In the continuation of the dialogue, PST 2 refers to some earlier experience from the classroom, indicating that the students had problems to understand what is meant by the term "proportional quantities" (90). Some utterances later (96), she/he goes on telling how they have planned to introduce this particular mathematical content. We observe that the students should focus on the rule $(y=k x)$ by thinking and discussing it, illustrating a knowledge and community centred perspective. The fact that they also should explain the rule to the preservice teachers indicates an assessment orientation since they then have the opportunity to monitor the students' progress.

Later in the dialogue, the pre-service teachers introduce the task they have planned to present for the students in the lesson. The task focuses on the price for sending text messages from two mobile subscriptions where the first one costs 0.99 (Norwegian "kroner") for each message (SMS), while the other one costs 0.29 plus 20 (Norwegian "kroner") a month. PST 1 expresses the connection between the proportional and the linear function:

142 PST 1: to find out that one of them is "plus 20 " $(y=0.29 x+20)$ and the other one is "plus 0 " $(y=0.99 x+0)$, and that is in the way the difference between a proportional function and a linear function. $(\mathrm{K})$

\section{DISCUSSION AND CONCLUSION}

In the data material that we have analyzed in this paper, we observe that the preservice teachers have formulated a goal for the lesson, and they indicate that they want to build on the students' previous knowledge. This can be seen as an indicator of a content-focused dialogue (Bransford, et al., 2000). The idea of 
defining a clear goal for the lesson is important in lesson study, and this is emphasized in the Handbook we developed for use in the project.

In the first dialogue presented in the results section, we observe how the preservice teachers wanted to build on the students' previous knowledge of the linear equation. The utterances then indicate a focus on the learners' conceptions highlighted by Bransford et al. (2000) as a central aspect of planning and teaching. Misconceptions related to proportional reasoning (Fernández, et al., 2012) were not, however, focused on by the pre-service teachers.

Although the pre-service teachers seemed to have a focus on the content as well as on the learners, we observe that they did not discuss some of the critical issues related to proportionality and proportional reasoning. They wanted to use the linear equation as a starting point for introducing $y=k x$. When doing this, however, they seemed to believe that the students would (immediately) "see the connection", or the relationship between the constant and co-varying quantities as described by Lamon (2007). The dialogue did not indicate that they were aware of the challenges many students face regarding different appearances of the constant. Lamon (2007) argues that an understanding of the constant is necessary in order for students to develop a proper understanding of proportionality. The pre-service teachers in our study did not, however, focus on connecting the constant $k$ with the slope. They also did not seem to find the conversion between $a$ (as slope in a graph) and $k$ as the constant.

It can be argued that the pre-service teachers in our study did not carry out a true lesson study since crucial components as research question, prediction and observation were lacking (Munthe \& Postholm, 2012). They were also not discussing possible problems that students might face, and they did not seem to use the Handbook in the preparation of the lesson. Still, the limited lesson study approach seemed to facilitate a stronger focus on content and goal orientation in the lesson-planning phase. They did formulate a goal for the lesson, although there was a lack of precision - both in the goal and their discussion of content. Deep knowledge of the content is, however, needed in order to design high-quality teaching (Ball et al., 2001). It is appropriate to ask if the pre-service teachers would have been able to go further in the content focused discussions if they had more mathematical knowledge for teaching proportionality, or if their mentor teacher would have drawn the focus of attention in a more content focused direction. In our Handbook, as a preparatory stage for the lesson study cycle, the pre-service teachers are challenged to explore and dig into the topic of the research lesson - which in lesson study refers to the lesson that is planned, observed, reflected on, etc. (Hart et al., 2011). Instead of blaming the pre-service teachers for their lack of delving into the topic of proportionality, our analysis suggests the importance of spending some weeks (e.g. Murata \& Pothen, 2011) for this 
exploratory stage as a preparation for the lesson study cycle carried out in the field practice.

The results from this study support the hypothesis that the implementation of lesson study in prospective teacher education has a potential to increase the preservice teachers' focus on knowledge and learners, and it thereby seems to be a relevant tool that can assist the pre-service teachers in their efforts to shift focus from surviving in the classroom to focus on the content to be taught and the students' learning. On the other hand, the results from our study also indicate that there is a need to focus on knowledge of the particular content that is to be taught. This particular focus has to be addressed in teacher education, and it is needed in order to support the pre-service teachers in their implementation of lesson study in field practice. More research is also needed in order to investigate how teacher education can facilitate even more successful implementations of lesson study.

\section{NOTES}

1. This research project is supported by the Research Council of Norway (project number: 212276).

\section{REFERENCES}

Ball, D. L., Lubienski, S. T., \& Mewborn, D. S. (2001). Research on teaching mathematics: The unsolved problem of teachers' mathematical knowledge. In V. Richardson (Ed.), Handbook of research on teaching (4th ed., pp. 433-456). New York, NY: Macmillan.

Bransford, J. D., Brown, A. L., \& Cocking, R. R. (2000). How people learn. Washington D.C: National Academy Press.

Davis, B., \& Simmt, E. (2006). Mathematics-for-teaching: An ongoing investigation of the mathematics that teachers (need to) know. Educational Studies in Mathematics, 61(3), 293-319.

Fernandez, C. (2002). Learning from Japanese approaches to professional development: the case of lesson study. Journal of Teacher Education, 53(5), 393-405.

Fernández, C., Llinares, S., Van Dooren, W., De Bock, D., \& Verschaffel, L. (2012). The development of students' use of additive and proportional methods along primary and secondary school. European Journal of Psychology of Education, 27(3), 421-438.

Fernandez, M. L. \& Zilliox, J. (2011). Investigating approaches to lesson study in prospective mathematics teacher education. In L. C. Hart, A. S. Alston \& A. Murata (Eds.), Lesson Study Research and Practice in Mathematics Education (pp. 85-102). New York, NY: Springer. 
Hart, L. C., Alston, A., \& Murata, A. (Eds.) (2011). Lesson study research and practice in mathematics education. New York, NY: Springer.

Helgevold, N., Næsheim-Bjørvik. B, \& Østrem, S. (2014). Veiledningssamtaler i lærerstudenters praksisperioder - innhold og prosesser. In A. B. Reinertsen, B. Groven, A. Knutas, \& A. Holm (Eds.), FoU i praksis conference proceedings (pp. 133-141). Trondheim: Akademika forlag.

Lamon, S. J. (2007). Rational numbers and proportional reasoning: toward a theoretical framework for research. In F. K. Lester (Ed.), Second handbook of research on mathematics teaching and learning (pp. 629-667). Charlotte, NC: Information Age Publishing.

Munthe, E. \& Postholm, M. B. (2012). Læreres profesjonelle læring i skolen. In M. B. Postholm, P. Haug, E. Munthe, \& R. Krumsvik (Eds.), Larere i skolen som organisasjon (pp. 137-156). Kristiansand: Cappelen Damm.

Murata, A. \& Pothen, B. E. (2011). Lesson study in preservice elementary mathematics methods courses: connecting emerging practice and understanding. In L. C. Hart, A. S. Alston \& A. Murata (Eds.), Lesson Study Research and Practice in Mathematics Education (pp. 103-116). New York, NY: Springer.

OECD (2011). Building a high-quality teaching profession: Lessons from around the world. Retrieved April 29, 2013, from http://www2.ed.gov/about/inits/ed/internationaled/background.pdf

Ohnstad, F. O, \& Munthe, E. (2010). Veiledet praksisopplæring og lærerstudenters kvalifisering. In P. Haug (Ed.), Kvalifisering til laereryrket (pp. 140-164). Oslo: Abstrakt.

Richardson, V. \& Placier, P. (2001). Teacher change. In V. Richardson (Ed.), Handbook of research on teaching (pp. 905-947) (4th ed.). Washington, DC: American Educational Research Association.

Stigler, J. W., \& Hiebert, J. (1999). The teaching gap: Best ideas from the world's teachers for improving education in the classroom. New York: The Free Press.

Tourniaire, F. \& Pulos, S. (1985). Proportional reasoning: a review of the literature. Educational Studies in Mathematics, 16(2), 181-204.

Wells, G. (1999). Dialogic inquiry: towards a sociocultural practice and theory of education. Cambridge: Cambridge University Press. 


\title{
STUDENT TEACHERS' WORK ON REASONING AND PROVING
}

\author{
Ole Enge and Anita Valenta \\ Sør-Trøndelag University College, Norway
}

In this study we are analysing student teachers' justifications of an algebraic conjecture. The study is based on student teachers' written work on investigation and justification of a statement about relation between multiples of 6 and multiples of 3 . Our research question concerns the type of justifications student teachers provide, the characteristic properties of their justifications and in particular the way they represent the generality in their work.

\section{INTRODUCTION}

Is it the case that all multiplies of 6 also are multiplies of 3 ? It is easy to check this question for particular numbers, 6, 12 and 18. One can check several numbers, hundreds of numbers, but, only by checking, we still cannot be sure that it is the case for all. How can we know whether the conjecture is true or false then?

Many researchers have argued that reasoning and proving should be a central part of school mathematics at all grades and in all topics (e.g. Kilpatrick, Swafford, \& Findell, 2001; Ball \& Bass, 2003). This implies that a mathematics teacher should be able to reason mathematically, to follow and assess others mathematical reasoning and understand the role of justification in mathematics (see e.g. Niss, 2004; Kilpatrick, Swafford, \& Findell, 2001; Ball \& Stylianides, 2008). From several studies it is known that teachers and student teachers have problem with proving mathematical claims and with understanding what counts as a mathematical proof.

From Scandinavian studies, when comparing Danish and French teacher education, Winsløw and Durand-Guerrier (2007) found that the French students in their study were more concerned with providing justifications of the mathematical results, whereas the Danish students are more inclined to accept things as "rules" and show several examples to pupils. Måsøval (2009) studied student teachers work on proving a generalisation of geometrical patterns and she identifies struggles the students have with understanding what it takes to give a valid mathematical proof, like they struggle with the notions "structure" and "relationships" on objects.

Lo, Grant and Flowers (2008) investigated student teachers' reasoning and justification in whole number multiplication and they found that students had problems with coordinating diagrams and strategies in their justifications. While they are interested in student teachers' reasoning about strategies in multiplication of particular numbers, we are concerned with student teachers' justification of a general property in multiplication. To address these questions we analyse the work of 140 student teachers, who provided written justifications as part of a homework assignment. 
We begin by discussing our theoretical framework and specifying our research question. Further, we discuss the methods of our study and present the context. In the main part the article, we present our findings and, finally, we discuss our findings and consider implications for teacher education.

\section{THEORETICAL FRAMEWORK}

There are several ways of approaching what is meant by justification and proof in school mathematics. We follow Stylianides (2008) notion of reasoning-and-proving as describing the overall process of "making sense of and establishing mathematics knowledge" (p. 9). He presents an analytical framework for studying such processes. The framework consists of three components; the mathematical component, the psychological component and the pedagogical component. Here we are interested in analysing student teachers justification of a mathematical claim, so the categories of providing a proof and providing a non-proof argument from the mathematical component, are central.

Stylianides (2008) divides the category of providing a proof into two classes; that of generic example and that of demonstration, the non-proof category is likewise divided into the class empirical argument and the class rationale.

A generic example is a valid argument in support of a claim which uses a particular example as a representative of a whole class, and presented such that its role is the "carrier of the general" (Mason \& Pimm, 1984, p. 287; see also Rowland, 1998). Schifter (2009) uses the notion of representation based proof to denote a type of proving where a generic example is illustrated in some representation in addition to numeric examples, for example drawings and/or real life situations. Cooper and Warren (2007) introduce the notion of quasi-generalisation to capture the process of moving from arithmetic to algebraic reasoning. Often the learner starts by checking the generalisation on several cases, then use one case as generic, before they use language and symbols to express the generality.

A demonstration on the other hand does not use a particular (representative) example. Valid arguments based on exhaustion, use of counterexample and mathematical induction are examples of demonstrations.

The non-proof argument category includes the well-known case of naïve empiricism, the claiming the truth of an assertion after just checking some cases, and also claiming the general case without showing how this is done. A rationale is a nonproof argument that omits explicit references to some key accepted truths that it uses, or uses statements that do not belong to a shared set of accepted truths in a given community. Consider for example a fifth-grader trying to justify that if you multiply any two numbers ending with 5 , the result will also end with 5 . Claiming that this is true because 5 times 5 is 25 is a rationale since there is no reference to the fact that there is only the digits in the one place that contribute to the digit in the result's one place. The psychological component plays an important role in the process of 
justifying and is concerned with how the learner perceives the mathematical object and task at hand.

Together with our professional interests in reasoning and proving in mathematics as mathematicians and mathematics teacher educators, these considerations lead to our question: "How do teacher students justify a claim in whole number multiplication? What are the characteristic properties of their justification? In particular, how do they represent generality in their work?" As teacher educators we consider these questions important to investigate as a part of the development of mathematics teaching in teacher education.

\section{METHOD}

\section{Participants and course}

The participants in this study were 140 student teachers on a study program for prospective teachers at 1 st to 7 th grade in elementary school. They will become general teachers after completing their education. We will use the name "student" for student teacher from hereon. The mathematics course is a compulsory course, lying in in the students' first, second and third semester. It was an integrated mathematics and mathematics didactics course, aiming to help students in developing mathematical knowledge for teaching. The underlying mathematical topic during the first semester was multiplicative thinking, and the emphasis was on different strategies, properties and reasoning in multiplication. Arguments and justification in mathematics had not been an explicit topic in the course so far. There were no clear discussion about what constitutes a valid argument or how to use generic examples as a tool in justification. However, there were frequent discussions on why strategies would or would not work for all numbers, and several tasks asked for general justifications. The data in this study are a part of responses to an individual homework assignment given at the start of the second semester. It was depersonalized concerning name, gender and class before we began the analysis.

\section{Task analysis}

The task presented to the students was the following problem:

Imagine that you are a teacher of fourth grade. You are working on multiplication, and a pupil says to you: "Look, all numbers which are in the 6times table are also in the 3-times table. That is strange."

a) Investigate the pupil's statement. Is it really true that all numbers in 6times table also are in 3-times table? Justify why it is or is not the case.

b) How would you adjust your reasoning and explain the relation to your pupils? Consider use of an appropriate context or/and an illustration.

We will only discuss part a) in this study. The task is about analysing and justifying a claim about a particular, but not special, number relationship. 
We wanted the wording in the task to be typical for a Norwegian fourth grader. In particular the words "6-times table" and "3-times table", which are familiar to every Norwegian fourth grader (the wording in Norwegian is "6 gangen" and " 3 gangen").

Any number in the 6 -times table, i.e. a multiple of 6 , can be written $6 \cdot k$, where $k$ is a whole number. We can interpret $6 \cdot k$ as 6 bags each containing $k$ objects. Let us say $k$ equals 4 . If we put two bags together in a bigger bag, we get 3 bags each containing 8 objects. Here we use 4 as a particular instance of the general case. Each multiple of 6 can be thought of this way, and by joining two and two bags, we have shown the general case. This is justifying the case by a generic example. Interestingly, a simple drawing of this situation, like the one below, is a representation based proof as stated by Schifter (2009).
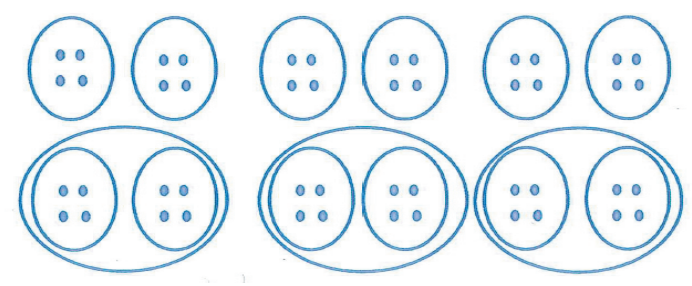

\section{Figure 1: Representation based proof}

A demonstration could be algebraically: Since $6=3 \cdot 2$, and multiplication is associative, $6 \cdot k$ can be written as $3 \cdot(2 \cdot k)$. That is, $6 \cdot k$ is a multiple of 3 . The same kind of demonstration can be done discursive. For example: " 6 can be written as 3 times 2, so a number in the 6-times table can be written as 3 times 2 times some number. That is, 3 times a number, since multiplication is associative."

Another demonstration is to use the repeated addition model of multiplication. All numbers in the 6 -times table can be written as $6+6+\ldots+6$ and since $6=3+3$, this is equal to $(3+3)+(3+3)+\ldots+(3+3)$, and this is a number in the 3 -times table.

\section{Data analysis}

Having our research question in mind, we started to analyse the written texts concerning the type of justification the students gave. We used a semi-grounded approach to the data with the categories from Stylianides (2008), and we individually started the analysis firstly by describing each justification and its properties in depth and gradually more in form of keywords referring to the predefined categories. After the first part with individual analysis, we discussed similarities and differences between the observations made and the keywords used. Based on the individual analysis and the comparison made, we developed a new set of keywords and categories, and started individually on the second cycle of analysis. In between we had discussions about particular justifications to compare the use of categories, define the boundaries and develop the categories further. 


\section{FINDINGS}

\section{Types of reasoning}

In this section we give an overview of the kind of reasoning students provided. We present typical reasoning of each kind and take a closer look at how student teachers represented the generality in their work. Later, we discuss student teachers' understanding of what is needed in order to justify a mathematical (general) conjecture and how they proceed in their justification.

1. The conjecture is considered as false

First, there were eight students who stated that the conjecture is false. Most of those misunderstood the wording and address the converse of the claim. The following is an example of this type:

It is not completely true. For example, 21 is not in 6-times table, but the double of it, 42, is. So, somehow we can find all numbers, but they are doubled. 6times table $=$ the double of 3-times table.

The student here states that not all numbers in the 3-times table are in the 6-times table, like $3 \cdot 7=21$. However, if we double all numbers in the 3 -times table we get a number in the 6 -times table, since $2 \cdot 3=6$.

2. The conjecture is considered to be about finitely many numbers

There were 18 students who interpreted the 6-times table as the numbers $6 \cdot 1,6 \cdot 2 \ldots$ up to $6 \cdot 10$, and similarly for the 3 -times table. This implies that the conjecture states a relationship between finitely many numbers. Thus these students had no need to express generality in their justification. Some of them concluded that the conjecture is true while others concluded not true. In both cases we find examples of justifying by using demonstration by exhaustion. Like this justification of the non-truth:

Not all numbers from the 6-times table are in the 3-times table because 3-times table go just up to 30. But up to 30 all numbers in the 6-times table are also in the 3-times table.

Other students "expanded" the 3-times table up to 60 and concluded that the conjecture is true by listing up and checking all cases as in the following case:

The statement is true for numbers up to 30. After 30, none of the numbers are in the 3-times table. But, if one continues 3-times table up to 60, the claim is true.

In some justifications by exhaustion where 3-times table is "expanded" to 60, the students in addition gave a reason for this by stating a relation between 3 and 6 . The following is a typical example:

Here I first wrote all numbers in the 6-times table and I expand 3-times table up to 60. Then I showed that all the numbers from 6-times table are in the 3times table too. 
6-times table: 6, 12, 18, 24, 30, 36, 42, 48, 54, 60.

3-times table: $3, \underline{6}, 9, \underline{12}, 15, \underline{18}, 21, \underline{24}, 27, \underline{30}, 33, \underline{36}, 39, \underline{42}, 45, \underline{48}, 51, \underline{54}$, $57, \underline{60}$

This shows that the pupil's statement is correct. The reason for this is that all numbers in the 6-times table can be divided by 3. 6:3=2, this again gives $3 \cdot 2$ in the 3-times table. And again 18:3=6, so 6.3 in the 3-times table and so on.

So this is demonstration by exhaustion and some kind of rationale. Here the student stated that six divided by three is equal to two, but the student did not discuss how this relation implies that the claim is true.

3. The conjecture is considered to be general and true.

The rest of the students considered the conjecture as stated for infinitely many numbers. Typically they justified that it is true by stating that 3 is a factor of 6 , or equivalently, that 6 is a multiple of 3 . The following justification is an example:

It is true that all numbers in the 6-times table also are in the 3-times table. This is because 3.2=6, so all numbers in the 6-times table becomes (and is) every second number in the 3-times table.

Like the previous example this is a rationale since a relation between 6 and 3 is mentioned, but no reasoning is given why this relation leads to the conclusion. However, many students tried to discuss how a relation between 6 and 3 could be used to justify the claim. A typical example is the following one:

3 is the half of 6, that is 6 divided by 3, and the numbers in the 3-times table are just steps by three. That is why every second number will simultaneously be in the 6-times table, since 3 is the half of 6 and in the 6-times table one have steps by six. The 6-times table and 3-times table then have a common factor.

The student used the repeated addition model of multiplication, the 3-times table is referred to as "steps of three". One can debate whether this is a rationale or a demonstration depending on what is assumed as known in a given community, in particular whether "steps of three" is understood as whole number multiples of 3.

Instead of relying on a representation of multiplication some students justified the claim using formal properties of multiplication. The following example is typical:

Since 3 is 6/2, all numbers in the 6-times table are in the 3-times table. This is because as long as the second factor is twice as big, the answer will be the same. We can show this by using algebra: 1. $a^{*} b=x$ is the same as 2. $1 / 2 a * 2 b=x$ because $1 * 1$ is the same as $1 / 2 * 2$. For example $4 * 8=32$ and $2 * 16=32$.

The student implicitly used the commutative and associative property of multiplication, but was not explicit about these properties, whether they were assumed known and how they were used in the justification. 


\section{Characteristic properties}

In this part we analyse in greater depth the characteristic properties of justifications where students considered the conjecture as general claim about infinitely many numbers.

Our analysis indicates that a common property in the justification is the use of natural language in order to represent the generality and justify the claim, like the first two examples of type 3. There are just a few students who attempted to use algebraic notation, as in the last example of type 3 . None of the students used an illustration, or a real life situation to interpret multiplication. Also, none of the students used a generic example in their justification. Dreyfus (1999) observes that in some cases the problem of reasoning and proving is "linguistic rather than conceptual". In many cases we observe that the students are stating the same claim or relation several times, in different words, often using several examples to explain what they mean. This can be observed in several justifications above, but here is one justification where this is even more striking:

Yes, all numbers in the 6-times table are also in the 3-times table. This has something to do with how numbers are build up, 6 is 3 two times, and likewise all numbers in the 4-times are in the 2-times, and the numbers in the 4-times are in the 8-times (sic). All these three examples I now have stated shows two numbers where one is twice as much as the other, that is if one multiply one number with 2 then one gets the other number. If one multiplies 3 with 2, one gets 6. Multiply 4 with 2, you get 8 . Let us look at an example:

$$
6 \times 63=378
$$

If we shall check if the number 378 also is in the 3-times table, we have to multiply 3 with $2 \times 63$. This is because 6 is $3 \times 2$, and then instead of multiplying $3 \times 2$ (which then would be 6 , and we are back with the same task) we move the number 2 over to the other side and multiply $63 \times 2$, and we can look upon it as in an equation:

$$
6 \times 63=3 \times(2 \times 63)
$$

It is difficult to give a more precise answer why this is so, maybe because I am thinking that this is something which just is like it is, however it can be shown again with another example with numbers in the same times, like 4 and 8:

$$
\begin{aligned}
& 70 \times 8=560 \\
& (70 \times 2) \times 4=560
\end{aligned}
$$

Reading this justification we get a feeling that the student understood the concept and could "see" what is happening, but struggled in finding a way to represent the thinking. The student used natural language to discuss the generality, repeated the same relation several times, used different examples in an attempt to justify the conjecture clearly, but the student did not try to use algebraic symbols. The two 
examples used, 6.63 and 70.4, could have been used as generic examples by discussing at the end that there is nothing particular in these examples, and that any multiple of 6 can be seen as a multiple of 3 (and every multiple of 8 can be seen as a multiple of 4) in the similar way. Instead, the examples are used to illustrate the thinking, and this type of use is strengthened by the fact that the student used two examples while one would be enough for justifying by generic example.

Importantly, none justified the claim by empirical arguments, by just checking some examples and then state the generality. All students gave some rationale for their justifications, they stated a relation between 3 and 6 , and indicated that this relation is the reason the claim is true. However, most students just stopped here, there was no attempt to point out how this relation implies the truth of the claim. Those who tried to go further did not define the concepts involved (e.g. multiples of 3) and were not clear about what was assumed to be known as a starting point.

\section{DISCUSSION}

Our analysis of the different forms of justification of a given number relation done by prospective teachers aligns with earlier research on the role of the mathematical language in justifying mathematical claims (see e.g. Ball \& Bass, 2003, Dreyfus, 1999). Our students struggle with the use of appropriate representation in their justifications. Since the conjecture is to be justified for an infinite number of cases, the appropriate representation would have to be algebraic, or use of a particular case as generic. In case of generic example, a representation used can be a numerical example and natural language, possibly an illustration or real life context in addition, as in representation based proof discussed by Schifter (2009).

There were just four students who tried to use algebraic notation. It seems that the students in the study do not have much experience with, or do not feel comfortable with using algebraic notation. As discussed above, using generic examples and representation based proof can be a way of proving without using algebraic symbols. As such this is a very useful knowledge about proving for elementary teachers when they engage their students in reasoning and proving situations. However, none of our students used a generic example in their work. This can indicate that the way of proving a general statement by use of a generic example is rather unnatural or unknown for the students. This implies a need of attention on this in teacher education.

There are some variations, but we observe that the students did not explicitly define the mathematical objects in use, for example what it means by a number in the 6times table. They were not explicit about what was taken for granted neither, what the starting assumptions were and what was regarded as known. This lack concerning explicit definitions and assumptions makes the reasoning and proving mathematically insufficient. Research has shown that teachers often have the misconception that empirical arguments constitute a proof (see e.g Simon, \& Blume, 1996; Knuth, 2002). 
All the student teachers in this study, even if they checked the claim on some examples, gave some reasoning by emphasizing some properties of the involved numbers and/or concepts. However they struggled with the language in their reasoning and how to represent their thinking in a mathematically valid way. Again, this can indicate that the students have poor experience with mathematical justifications and are not conscious on the precision needed in order to make a justification mathematically valid. The use of the analytical framework of Stylianides (2008) was fruitful in order to capture the challenges our students had with reasoning and proving. However, in some cases it was not easy to decide whether an example used was a generic example or not, and whether a justification is to be understood as a demonstration or a rationale.

Reasoning and proving in mathematics is demanding for student teachers (and teachers), as discussed by Stylianides and Ball (2008). On the other hand, it is a very important aspect in mathematics and also very important element in development of understanding in the process of learning mathematics. More research need to be done in order to understand why it is so hard for student teachers to provide mathematically valid reasoning within elementary mathematics, and how teacher educators can engage student teachers in this important topic.

\section{REFERENCES}

Ball, D. L., \& Bass, H. (2003). Making mathematics reasonable in schools. In J. Kilpatrick, W. G. Martin, \& D. Schifter (Eds.), A research companion to "Principles and standards for school mathematics" (pp 27-44). Reston, VA: National Council of Teachers of Mathematics.

Ball, D. L., \& Stylianides, A. J. (2008). Understanding and describing mathematical knowledge for teaching: knowledge about proof for engaging students in the activity of proving. Journal of Mathematics Teachers Education, 11, 307-332.

Cooper, T. J., \& Warren, E. (2007). The effect of different representations on Years 3 to 5 students' ability to generalise. ZDM Mathematics Education, 40(1), 23-37.

Dreyfus, T. (1999). Why Johnny can't prove. Educational studies in Mathematics, 38, 85-109.

Kilpatrick, J., Swafford, J., \& Findell, B. (Eds.). (2001). Adding it up: Helping children learn mathematics. Washington, DC: National Academies Press.

Knuth, E. J. (2002). Secondary school mathematics teachers' conceptions of proof. Journal for Research in Mathematics Education, 33, 379-405

Lo, J., Grant, T., \& Flowers, J. (2008). Challenges in deepening prospective teachers' understanding of multiplication through justification. Journal of Mathematics Teacher Education, 11, 5-22. 
Mason, J., \& Pimm, D. (1984). Generic examples: Seeing the general in the particular. Educational Studies in Mathematics, 15(2), 277-289.

Måsøval, H.S. (2009). Complexity of operating beyond naïve empiricism when proving a conjectured formula for the general term of a geometrical pattern. In C. Winsløw (ed.), Nordic Research in Mathematics Education: Proceedings from NORMA08 (pp. 24-33). Rotterdam: Sense Publishers.

Niss, M. (2004). The Danish "KOM" project and possible consequences for teacher education. In R. Strässer, G. Brandell, B. Grevholm, \& O. Helenius (eds.), Educating for the future. Proceedings of an international symposium on mathematics teacher education (pp. 179-190). Göteborg, Sweden: The Royal Swedish Academy of Science.

Rowland, T. (1998). Conviction, explanation and generic examples. In O. Alwyn and K. Newstead (Eds.), Proceedings of the 22nd Conference of the International Group for the Physology of Mathematics Education (pp. 65-72). Stellenbosch, S. Africa.

Schifter, D. (2009). Representation-based proof in the elementary grades. In D. Stylianou, M. Blanton, \& E. Knuth (Eds.), Teaching and Learning Proofs across the grades (pp. 71-86). New York: Routledge.

Simon, M. A., \& Blume, G. W. (1996). Justification in the mathematics classroom: A study of prospective elementary teachers. Journal of Mathematical Behaviour, 15, 3-31.

Stylianides, A. J. \& Ball, D. L. (2008). Understanding and describing mathematical knowledge for teaching: knowledge about proof for engaging students in the activity of proving. Journal of Mathematics Teachers Education, 11, 307-332.

Stylianides, G. (2008). An analytical framework of reasoning-and-proving. For the Learning of Mathematics, 28(1), 9-16.

Winsløw, C., \& Durand-Guerrier, V. (2007). Education of lower secondary mathematics teachers. Nordic Studies in Mathematics Education, 12(2), 5-32. 


\title{
THE DIFFICULTIES OF MEASURING TYPES OF MATHEMATICS TEACHERS' KNOWLEDGE
}

\author{
Janne Fauskanger and Reidar Mosvold
}

University of Stavanger

We present a critical discussion concerning the results from analyses of the connections between types of knowledge that are measured by the teachers' responses to multiple-choice items and open-ended questions. The data material consists of 30 teachers' responses to multiple-choice items and corresponding openended items. We used directed content analysis in our analysis of data, and cognitive types of teachers' content knowledge were used as analytical framework. The results indicate that the connection between teachers' responses to the multiple-choice items and the open-ended items is not always straightforward. In this paper, we discuss possible explanations for this.

\section{INTRODUCTION}

In the last decades, there has been a strong focus on the content knowledge needed for teaching mathematics (e.g., Ball, Thames, \& Phelps, 2008), and studies have indicated that teachers' content knowledge is important for students' learning (Hill, Rowan, \& Ball, 2005). Deborah Ball's research group at the University of Michigan has developed multiple-choice items to measure aspects of teachers' knowledge. Their measures are widely acknowledged and used. More recent work indicates that not only teachers' amount of content knowledge matters, but also the cognitive type of content knowledge they possess (Tchoshanov, 2011). Knowledge of facts and procedures - related to Skemp's (1976) notion of "instrumental understanding"-is referred to as Type 1 knowledge (Tchoshanov, 2011). In comparison, Type 2 knowledge, which is strongly related to Skemp's notion of conceptual or relational understanding, has a stronger influence on the quality of teachers' teaching and pupils' achievement. An example of Type 1 knowledge-which includes knowledge of number facts and operations - is the ability to multiply 35 and 25. Ball and colleagues (2008) refer to this as common content knowledge. They do, however, emphasize specialized content knowledge more, and this aspect of mathematical knowledge for teaching (MKT) includes an understanding of different algorithms. A teacher with a strong specialized content knowledge is thus able to assess whether or not particular algorithms can be used to e.g. multiply any two whole numbers. This is closely related to Tchoshanov's (2011) Type 2 knowledge, and the item in Figure 1 is an example of an item that is supposed to measure teachers' Type 2 knowledge.

In this paper, we acknowledge that development of measures can be useful for gaining more understanding of MKT as a construct (see e.g., Hill, Sleep, Lewis, \& Ball, 2007), and we also acknowledge the numerous studies that indicate that teachers' content knowledge is important. Instead of arguing about the measurement of teacher knowledge as such, we instead direct the focus towards the critical 
discussion about item format and the underlying assumptions in the theories of MKT and cognitive types of teacher knowledge.

The items developed by Ball and colleagues are multiple-choice items, and there are both advantages and disadvantages of using multiple-choice format in items. One advantage is that it takes less time to analyze these items when compared to openended items; another advantage is that multiple-choice items can be used at scale. A disadvantage can be that multiple-choice items might have a too narrow focus on recalling facts and procedures (Haladyna, 2004). Buchholtz and colleagues (2013) argued that multiple-choice items could not capture the depth of teachers' knowledge. Schoenfeld (2007) presented similar arguments in his criticism of the MKT items. In his article, he criticized the multiple-choice format and suggested to investigate the use of open-ended items. He also argued that there is a lot of work still to be done "in determining how well the items used actually reflect the desired competencies" (ibid., p. 204).

We build upon the recent research on types of teacher knowledge (Tchoshanov, 2011), in our attempts to investigate the perils and pitfalls of different item formats in measures of mathematical knowledge for teaching. We follow Schoenfeld's (2007) suggestion to 'open up' the MKT items, and we investigate the relationships between teachers' multiple-choice responses and their responses to corresponding open-ended questions (referred to here as long responses). Previous analyses of these issues have provided us with the following results: 1) there seems to be a mismatch between some teachers' responses to the MKT items and their long responses (Fauskanger \& Mosvold, 2012), 2) teachers might draw upon knowledge from various domains of MKT when responding to MKT items - different from the domains the items were developed to measure (Fauskanger \& Mosvold, 2013), and 3) it is difficult from the multiple-choice responses alone to judge what type of content knowledge the teachers possess in relation to the content the MKT items were developed to measure (Fauskanger, in review). In this paper, we use these results for a starting point in our attempt to answer the following research question:

How well do multiple-choice MKT items measure teachers' conceptual (Type 2) knowledge?

In our attempt to answer this research question, we also address one of the specific challenges that have been highlighted by the developers of MKT (Ball et al., 2008): The items might be managed by using different types of knowledge and the correct multiple-choice answer may be identified by utilizing procedural knowledge only (Hill, Umland, Litke, \& Kapitula, 2012). Answering this research question may provide evidence to support findings from other studies related to whether the MKT items measure teachers' superficial or procedural knowledge (Type 1), or deeper and more coherent teacher knowledge (Type 2) or both. Teachers' responses are in the present study elaborated upon from a cognitive perspective using directed content analysis (Hsieh \& Shannon, 2005), also called deductive category application, as an 
analytical approach. We discuss the multiple-choice responses and long responses from 30 teachers' responses to a testlet that includes three items with a focus on twodigit multiplication (see Fig. 1).

\section{METHODS}

In order to investigate the connection between the types of knowledge that teachers express when responding to multiple-choice items and corresponding open-ended questions, we analyzed data from a study where 30 in-service teachers participated. The teachers attended the same professional development course, and the data material was collected in connection with this course. The teachers taught different grade levels, and their formal education in mathematics/mathematics education as well as their teaching experience varied. The focus of attention in our study was on relationship(s) between types of knowledge as expressed in multiple-choice responses and long responses, and difference(s) between gender, grade level, formal education or experience were not discussed.

The instrument used in this study consisted of 28 MKT items that had been translated and adapted for use in Norway (Mosvold, Fauskanger, Jakobsen, \& Melhus, 2009; Fauskanger, Jakobsen, Mosvold, \& Bjuland, 2012). All items were originally developed by researchers at the University of Michigan as part of the Learning Mathematics for Teaching (LMT) project. The items we selected for use in our study had a focus on numbers and operations, and they were included in this study based on the assumption that teachers who identified the key would possess Type 2 knowledge (Tchoshanov, 2011) of the content measured. Therefore, teachers who identify the key in all three items in Figure 1 should thus possess Type 2 knowledge of two-digit multiplication. In this paper, this testlet will be discussed as a case.

In order to study how well multiple-choice MKT items do access teachers' conceptual (Type 2) knowledge, a group of researchers at the University of Stavanger developed open-ended questions to supplement the MKT items. These questions were developed to relate to the content of each item and therefore differed somewhat from item to item. The questions were also developed to investigate the type of content knowledge the teachers emphasized. 
3. Imagine that you are working with your class on multiplying large numbers. Among your students' papers, you notice that some have displayed their work in the following ways:

\begin{tabular}{|c|r|r|}
\hline Student A & Student B & Student C \\
35 & 35 & 35 \\
$\times 25$ & $\frac{\times 25}{175}$ & $\times 25$ \\
$\frac{+75}{875}$ & $\frac{+700}{875}$ & 150 \\
& & 100 \\
& & +600 \\
& & \\
\hline
\end{tabular}

Which of these students would you judge to be using a method that could be used to multiply any two whole numbers?

\begin{tabular}{|c|c|c|c|c|}
\hline & & $\begin{array}{l}\text { Method would } \\
\text { work for all } \\
\text { whole numbers }\end{array}$ & $\begin{array}{l}\text { Method would } \\
\text { NOT work for all } \\
\text { whole numbers }\end{array}$ & $\begin{array}{c}\text { I'm not } \\
\text { sure }\end{array}$ \\
\hline a) & Method A & 1 & 2 & 3 \\
\hline b) & Method B & 1 & 2 & 3 \\
\hline c) & Method C & 1 & 2 & 3 \\
\hline
\end{tabular}

Figure 1. A testlet from the LMT project (Ball \& Hill, 2008, p. 5).

The questions added to the testlet in Figure 1 were the following:

1) What do the students $A, B$ and $C$ know?

2) What, if anything, do they need to learn more about? (Please explain why.)

3) Does the testlet reflect a content that is relevant for the grade(s) you teach? (Please explain why or why not and provide an illustrating example from your classroom).

4) Would you recommend your students to use some of the algorithms used by student A, B and C? (Please state the reason(s) for your answer).

The long responses were provided for the entire testlet - not for each individual item $(a, b$ and $c)$. The teachers were also asked to provide in-depth reflections related to what knowledge they find important (and why) in order to be able to teach mathematics, and whether or not the $28 \mathrm{MKT}$ items represented important knowledge for them as teachers and they were asked to explain the reasoning behind all their responses. Previous analyses of teachers' long responses indicated that the questions are suitable for studying the relationship between multiple-choice responses and long responses (Fauskanger, in review; Fauskanger \& Mosvold, 2012). These initial analyses constituted an important part of the validation of the open-ended questions for use in this context.

The unit of analysis was the individual teachers' responses to the items. In order to study relationships between these two kinds of responses, the teachers' long 
responses were analyzed with qualitative content analysis. This approach is regarded as a flexible and systematic approach to classify and identify themes or patterns in analyzing text data (Hsieh \& Shannon, 2005). In directed content analysis, analytic coding categories are derived from existing theories (Hsieh \& Shannon, 2005), and we used categories of cognitive types of teachers' content knowledge in our study (Tchoshanov, 2011).

Excerpts from teachers' long responses reflecting memorization of facts or rules, procedural computations or other aspects related to instrumental understanding were coded as Type 1 knowledge, whereas excerpts reflecting understanding of concepts and connection between them, multiple solutions to non-routine problems or other aspects related to relational understanding were coded as Type 2 knowledge. Related to the testlet in Figure 1, excerpts emphasizing e.g. a standard algorithm for two-digit multiplication were coded as Type 1 whereas excerpts emphasizing e.g. novel strategies for two-digit multiplication were coded as Type 2. The hypothesis would then be that there should be consistency between teachers' long responses and the suggested solution selected. In this study, consistency occurs when teachers who possess the MKT that an item was designed to access (Type 1 and Type 2 knowledge) identify the key. Consistency might also occur when teachers, who explicitly write that they do not know, or whose long responses indicate Type 1 knowledge only, choose a suggested solution other than the key. Inconsistency occurs when a teacher with a proper understanding of the content to be measured gives an incorrect multiple-choice response or when a teacher without this proper understanding identifies the key.

\section{RESULTS}

When studying their responses to the multiple-choice items only, all teachers answered 7 items correctly. For the remaining 21 items, between 8 and 29 teachers identified the key for each item. However interesting it might be to compare the teachers' scores on the items, we find it more interesting to investigate the connections between the responses teachers gave to the multiple-choice items and their corresponding long responses.

The results from our analysis of the teachers' long responses indicate that they draw upon different types of content knowledge when responding to the multiple-choice items, and the type of content knowledge teachers utilize does not necessarily correspond to the multiple-choice response given. The testlet in Figure 1 was developed to measure teachers' specialized content knowledge (Ball \& Hill, 2008). As a reason, an underlying assumption in our study was that this testlet accesses teachers' conceptual knowledge about two-digit multiplication. When investigating the relationships between teachers' responses to the multiple choice items (see Figure 1) and the corresponding long responses, however, the connection was not always straightforward (group $1 \mathrm{~b}$ and 2a, table 1). 


\begin{tabular}{|l|l|l|}
\cline { 2 - 3 } \multicolumn{1}{c|}{} & Type 2 knowledge & Lack of/Type 1 knowledge \\
\hline All correct (a) & 11 teachers (group 1a) & 9 teachers (group 2a) \\
\hline One or more incorrect (b) & 2 teachers (group 1b) & 8 teachers (group 2b) \\
\hline
\end{tabular}

Table 1. Teachers' multiple-choice relative to their long responses regarding two-digit multiplication.

Some of the teachers (group 1b, Table 1) gave incorrect responses to the multiplechoice items, but their long responses indicated a relational understanding of twodigit multiplication. These two teachers seemed to value students' development of adaptive expertise (Hatano, 2003), and they displayed Type 2 knowledge (Tchoshanov, 2011) important for the quality of teaching this particular theme (e.g., Even \& Tirosh, 2002; Verschaffel, Greer, \& De Corte, 2007). A second group of teachers (the teachers in group 2a, Table 1) identified the key in the multiple-choice items. Our analysis of their long responses, however, told a different story. These nine teachers, in their long responses, appeared confused about the content of the items, and they had a strong focus on a particular preferred standard algorithm for two-digit multiplication. For the remaining teachers - the 11 teachers in group 1a and the 8 teachers in group $2 \mathrm{~b}$ - the connection between their multiple-choice responses and the long responses was like we expected. The teachers in group 1a identified the key in the multiple-choice responses, and their long responses indicated Type 2 knowledge. Correspondingly, the teachers in group $2 \mathrm{~b}$ either demonstrated a lack of knowledge or Type 1 knowledge in their long responses, and they did not manage to identify the key in the multiple-choice items. This is in accordance with the underlying hypothesis, and these are the kind of relationships we would expect to see between teachers' responses to these items. In the following, we present and discuss the results of our analyses in more detail - with a particular focus on the teachers who had multiple-choice responses with non-supporting long responses (i.e., group $1 \mathrm{~b}$ and group 2a, Table 1).

Ten out of the 30 teachers gave incorrect multiple-choice responses to one, two or three of the items included in Figure 1. Out of the 20 teachers who had correct responses to all three items, nine provided long responses that did not entirely support their multiple-choice responses (group 2a, Table 1). As an example, one of the teachers, Inga, identified the key in all three items. She identified the product as correct. However, Inga explicitly wrote that she did not understand any of the three methods used by the students. The other eight teachers whose long responses did not support their correct multiple-choice responses highlight routine expertise (Type 1 knowledge (Tchoshanov, 2011)) for the benefit of adaptive expertise (Hatano, 2003). One of these teachers, Brit, wrote: "They [the students] need to work towards a standard algorithm. Otherwise they will spend too much time adding long strings of large numbers. It can easily become a mess." Throughout her long responses Brit highlighted standard written algorithms for the benefit of novel strategies developed 
by students. Brit and the other nine teachers might not avoid "premature teaching of standard written algorithms", as highlighted by Verschaffel et al. (2007, p. 575).

There were also two teachers (group 1b, Table 1) who gave at least one incorrect multiple-choice response but whose long responses indicated Type 2 knowledge (Tchoshanov, 2011) of the MKT being measured. Ragna responded "I'm not sure" (coded as incorrect) to two of the items in Figure 1, but she highlights the importance for teachers to support students' development of adaptive expertise (Hatano, 2003) in her long responses. Oda responded that Students A and B (Fig. 1) use algorithms that could not be used to multiply any two whole numbers. From her long responses, however, it is evident that she possesses a relational understanding (Skemp, 1976, 1987), or Type 2 knowledge (Tchoshanov, 2011), about two-digit multiplication. She provides detailed step-by-step descriptions of what the students using all the three algorithms in Figure 1 have done. The reason why Oda provided incorrect multiplechoice responses to a) and b) seems to be embedded in her interpretation of what is meant by "would work". As can be seen from Figure 1 the items invite teachers' to figure out which out of the methods A, B and C that "would work" or "would NOT work" for multiplying any two whole numbers. Not working for Oda relates to the methods being cumbersome for the students if the numbers have more digits than two. Oda writes that she will guide her students towards an algorithm which is not time consuming and which can be used effectively, but highlight the importance of the calculation to be based on students' relational understanding (Skemp, 1987). She writes that an algorithm for two-digit multiplication should be based on an understanding of the distributive, associative and commutative properties of multiplication. Oda's long response indicates that she seems to avoid "premature teaching of standard written algorithms" which is also highlighted in research (Verschaffel et al., 2007, p. 575).

\section{CONCLUDING DISCUSSION}

Cognitive types of teachers' content knowledge seem to influence teaching as well as pupils' learning (Tchoshanov, 2011), and Type 2 knowledge appears to be particularly important. Specialized content knowledge, which is a category of MKT that has been particularly emphasized by Ball and colleagues (2008), is strongly related to the assumptions about Type 2 knowledge. The item discussed more indepth in this paper is an example of an MKT item that should access teachers' Type 2 knowledge. The present paper represents an attempt to investigate how well multiplechoice MKT items do measure teachers' Type 2 knowledge, and we investigate the relationships between types of teachers' content knowledge, as expressed through teachers' responses to MKT items, and their long responses.

Among the teachers who gave the correct answer to the multiple-choice items, some wrote in their long responses that they do not understand novel strategies for twodigit multiplication. Other teachers seem to understand novel strategies, but who still believe that a standard algorithm is always best (Type 1 knowledge). Finally there are 
teachers who understand and value novel strategies (Type 2 knowledge). Ideally, all teachers who provide the correct response to the multiple-choice item should be in the last category-if the item properly measures Type 2 knowledge. A possible implication of the findings from this study is that it might be difficult from the multiple-choice responses alone to judge what type of content knowledge (Tchoshanov, 2011) the teachers possess. A natural follow-up would then be to discuss why such an apparent inconsistency occurs.

There are different possible explanations for the inconsistency between teachers' responses to the multiple-choice item and the corresponding long-responses. One possible explanation is that the mismatch is related to the particular content in focus, and there was a testlet with a different focus that did not result in similar mismatch in our study (Fauskanger \& Mosvold, 2013). Still, the lack of connection between multiple-choice responses and long-responses seemed to be the rule rather than the exception in our study, so we suggest a different explanation.

A possible argument is that the inconsistency is related to issues that are embedded in the item format itself. It has been argued that multiple-choice items and open-ended items provide information about different aspects of teacher knowledge (e.g., Schoenfeld, 2007). Haladyna (2004) indicates that multiple-choice items are more suitable for measuring procedural knowledge (Type 1), and Hill and her colleagues (2012) indicate that a high MKT score might be obtained by utilizing procedural knowledge only. The results from this study seem to support the argument that multiple-choice format is not suitable for measuring cognitive types of teacher knowledge. In his criticism of the MKT items, Schoenfeld (2007) argued that more work needs to be done in order to determine how well the items reflect the competencies they are supposed to measure. The results from our study should not be interpreted as a refutation of the usefulness of the MKT items as such. Instead we suggest that our results indicate that some of the items actually measure a type of knowledge that is more procedural than what they were supposed to. When reading the definition of Type 2 knowledge (conceptual knowledge), one could argue that the item in Fig. 1 should measure such knowledge. Still, our study indicates that this is not necessarily the case.

In our study, we added open-ended questions to multiple-choice MKT items-as a response to Schoenfeld's criticism. The results indicate that the item in focus here seems to measure a more procedural knowledge than it is supposed to, and this can be seen as yet another criticism of the use of multiple-choice format in MKT items (cf. Fauskanger, Mosvold, Bjuland, \& Jakobsen, 2011). We want to emphasize, however, that adding open-ended questions does not automatically provide us with a better understanding of teachers' knowledge. Adding such open-ended questions does, however, make everything a lot more complex. Despite the added layers of complexity, we suggest that it is relevant to investigate responses to questions of other than multiple-choice format to learn more about cognitive types of teachers' 
content knowledge (Tchoshanov, 2011); using only multiple-choice items is not enough. More research is needed, however, to investigate the connection between teachers' responses to multiple-choice items and corresponding open-ended items. It is also relevant to further investigate the connection between teachers' responses to MKT items in a testing situation and their responses in e.g. cognitive interviews. Written responses do have some advantages over interview responses. With written responses, all teachers get the exact same questions in the same context, and they have time to think before responding. We suggest that the use of written responses enabled us to discover some patterns that might not have been discovered with other kinds of data. The themes that emerged from teachers' long responses also provided insight into types of content knowledge teachers might draw on when responding to the multiple-choice items.

\section{REFERENCES}

Ball, D.L., \& Hill, H.C. (2008). Mathematical knowledge for teaching (MKT) measures. Mathematics released items 2008. http://sitemaker.umich.edu/lmt/files/LMT_sample_items.pdf

Ball, D.L., Thames, M.H., \& Phelps, G. (2008). Content knowledge for teaching: What makes it special? Journal of Teacher Education, 59(5), 389-407.

Buchholtz, N., Leung, F.S., Ding, L., Kaiser, G., Park, K., \& Schwarz, B. (2013). Future mathematics teachers' professional knowledge of elementary mathematics from an advanced standpoint. $Z D M, 45(1), 107-120$.

Even, R., \& Tirosh, D. (2002). Teacher knowledge and understanding of students' mathematical learning. In English L. (Ed.), Handbook of international research in mathematics education (pp. 219-240). Mahwah, NJ: Erlbaum.

Fauskanger, J. (in review). Challenges in measuring teachers' knowledge. Educational Studies in Mathematics.

Fauskanger, J., Jakobsen, A., Mosvold, R., \& Bjuland, R. (2012). Analysis of psychometric properties as part of an iterative adaptation process of MKT items for use in other countries. ZDM, 44(3), 387-399.

Fauskanger, J., \& Mosvold, R. (2012). "Wrong, but still right". Teachers reflecting on MKT items. In L. R. Van Zoest, J.-J. Lo \& J. L. Kratky (Eds.), Proceedings of the 34th annual meeting of the North American Chapter of the International Group for the Psychology of Mathematics Education (pp. 423-429). Kalamazoo, MI: Western Michigan University.

Fauskanger, J., \& Mosvold, R. (2013). Teachers' mathematical knowledge for teaching equality. In A. M. Lindmeier \& A. Heinze (Eds.), Proceedings of the 37th Conference of the International Group for the Psychology of Mathematics Education (Vol. 2, pp. 289-296). Kiel, Germany: PME. 
Fauskanger, J., Mosvold, R., Bjuland, R., \& Jakobsen, A. (2011). Does the format matter? How the multiple-choice format might complicate the MKT items. Nordic Studies in Mathematics Education, 16(4), 45-67.

Haladyna, T.M. (2004). Developing and validating multiple-choice test items (3 ed.). New Jersey, USA: Lawrence Earlbaum Associates Inc.

Hatano, G. (2003). Foreword. In Baroody A. J. \& Dowker A. (Eds.), The development of arithmetic concepts and skills (pp. xi-xiv). Mahwah, NJ: Erlbaum.

Hill, H.C., Rowan, B., \& Ball, D.L. (2005). Effects of teachers' mathematical knowledge for teaching on student achievement. American Educational Research Journal, 42(2), 371-406.

Hill, H.C., Sleep, L., Lewis, J.M., \& Ball, D.L. (2007). Assessing teachers' mathematical knowledge. What knowledge matters and what evidence counts? In Lester F. (Ed.), Second handbook of research on mathematics teaching and learning (pp. 111-156). Charlotte, NC: Information Age Publishing.

Hill, H.C., Umland, K., Litke, E., \& Kapitula, L.R. (2012). Teacher quality and quality teaching: Examining the relationship of a teacher assessment practice. American Journal of Education, 118(4), 489-519.

Hsieh, H.-F. \& Shannon, S. E. (2005). Three approaches to qualitative content analysis. Qualitative Health Research, 15(9), 1277-1288.

Mosvold, R., Fauskanger, J., Jakobsen, A. \& Melhus, K. (2009). Translating test items into Norwegian - without getting lost in translation? Nordic Studies in Mathematics Education, 14(4), 101-123.

Schoenfeld, A.H. (2007). Commentary: The complexities of assessing teacher knowledge. Measurement: Interdisciplinary Research and Perspectives, 5(2), 198204.

Skemp, R.R. (1976). Relational understanding and instrumental understanding. Mathematics Teaching, 77, 20-26.

Skemp, R.R. (1987). The psychology of learning mathematics. Expanded American edition. Hillesdale, NJ: Lawrence Erlbaum.

Tchoshanov, M.A. (2011). Relationship between teacher knowledge of concepts and connections, teaching practice, and student achievement in middle grades mathematics. Educational Studies in Mathematics, 76(2), 141-164.

Verschaffel, L., Greer, B., \& De Corte, E. (2007). Whole number concepts and operations. In F. K. Lester Jr. (Ed.), Second handbook of research on mathematics teaching and learning (pp. 557-628). Charlotte, NC: Information Age Publishing. 


\title{
EDUCATING MATHEMATICS TEACHER EDUCATORS: A COMPETENCY-BASED COURSE DESIGN
}

\author{
Tomas Højgaard \& Uffe Thomas Jankvist
}

\author{
Department of Education, Aarhus University, Denmark
}

The paper argues for a three-dimensional course design structure for future mathematics teacher educators. More precisely we describe the design and implementation of a course basing itself on: the two mathematical competencies of modelling and problem tackling, this being the first dimension; the two mathematical topics of differential equations and stochastics, this being the second dimension; and finally a third dimension the purpose of which is to deepen the two others by means of a didactical perspective.

\section{INTRODUCTION AND CONTEXT}

In this paper we describe and discuss the design of a mathematics and didactics course as part of the master's degree in mathematics education at Aarhus University, mainly followed by future mathematics teacher educators. The guiding question of the paper is: how to best design and implement such a course? Our answer to this question is bound to be one of example, but as we provide this throughout the paper, we shall try to account for the various decisions related to design and implementation.

The design and implementation of the course is naturally framed by the design of the master's programme in total, which again is framed by an analysis of the pathway to become a teacher educator in Denmark. As opposed to the situation in the other Nordic countries, there are two fundamentally different paths to follow, depending on the kind of teachers being educated. Teachers in upper secondary school gymnasium - are educated from a university, with a master's degree in the subjects they teach. Hence, their teacher educators are university teachers holding a ph.d., typically in the same subject - e.g. mathematics - in which the teachers they educate get a master's degree. Teachers in primary and lower secondary school - the compulsory grades k-9, "folkeskolen" - are educated from teacher training colleges invented and designed for this particular purpose, with a vocational bachelor's degree as teachers in "folkeskolen". Hence, their teacher educators are employed for this particular task, and must hold a master's degree. Teachers of a specific subject, e.g. mathematics, in the folkeskole are supposed to (but need not) have a specialization in the teaching of that subject as part of their bachelor's degree from the teacher training college, and similarly for the teacher educators in the teaching of mathematics: It is often favoured if they hold a master's degree in mathematics education, of which we are the only providers in the country, but their degree can also be in mathematics.

\section{THE DANISH FRAMEWORK OF MATHEMATICAL COMPETENCIES}

The so-called KOM project (Niss \& Jensen, 2002; Niss \& Højgaard, 2011), running from 2000-2002 chaired by Mogens Niss with Tomas Højgaard Jensen (now just 
Tomas Højgaard) as the academic secretary, thoroughly introduced and exemplified eight mathematical competencies. In KOM, a mathematical competency is defined as: " $a$ wellinformed readiness to act appropriately in situations involving a certain type of mathematical challenge" (Niss \& Højgaard, 2011, p. 49, italics in original).

The eight competencies are usually illustrated by the so-called KOM-flower, depicting that one competency cannot be held and developed in isolation from the other competencies, but that competencies may be thought of as different 'centers of gravity'. The eight competencies are furthermore divided into two groups, dealing with being able to ask and answer in and with mathematics, and being able to deal with mathematical language and tools, respectively. See figure 1.

The content of the eight mathematical competencies may (cf. Højgaard, 2012) briefly be described as well-informed readiness to

... carry out and have a critical attitude towards mathematical thinking: Mathematical thinking competency.

... formulate and solve both pure and applied mathematical problems and have a critical attitude towards such activities: Problem tackling competency.

... carry out and have a critical attitude towards all parts of a mathematical modelling process:

Modelling competency.

... carry out and have a critical attitude towards mathematical reasoning, comprising mathematical proofs: Reasoning competency.

... use and have a critical attitude towards different representations of mathematical objects, phenomena, problems or situations: Representing competency.

... use and have a critical attitude towards mathematical symbols and formal systems: Symbol and formalism competency.

... communicate about mathematical matters and have a critical attitude towards such activities: Communicating competency.

... use relevant aids and tools as part of mathematical activities and have a critical attitude towards the possibilities and limitations of such use: Aids and tools competency.

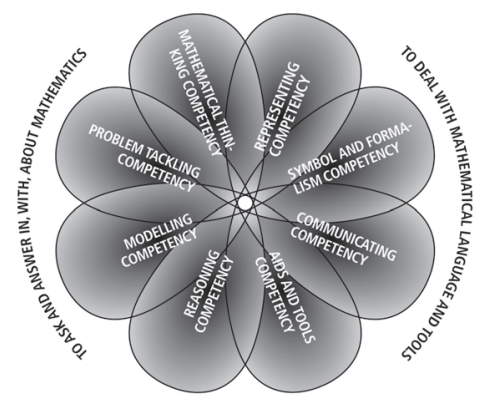

Figure 1. A visual representation - the "KOM flower" - of the eight mathematical competencies presented and exemplified in the KOM report (Niss \& Højgaard, 2011, p. 51). 
There were two main reasons for the initiation of the KOM project. One was to fight syllabusitis in mathematics education, cf. the explicit justification of the project in chapter three of the KOM report. Syllabusitis, conceptually introduced in Boisot (1972) and Jensen (1995), is a name for an educational disease consisting of identifying the mastering of a subject with proficiency related to its subject matter, and use that identification as the hub of educational processes from teaching to curriculum development (Blomhøj \& Jensen, 2007). It is a disease because it fails to acknowledge several important aspects of mastering a subject: Problem solving, reasoning and modelling, just to mention a few central ones from the subject of mathematics.

A second reason for the initiation of the KOM project - not least advocated by the Ministry of Education in Denmark - was to address the fundamental issue of coherence in an educational system, e.g. coherence between the educational approach in a given subject at primary, secondary and tertiary level. Hence, the fundamental idea of the KOM project was to apply the proposed set of mathematical competencies as a tool for developing mathematics education at all educational levels from primary school to university.

We - the mathematics education group at Aarhus University - have chosen to follow this idea in the development of the master's programme in mathematics education for two reasons. One is that we acknowledge the two fundamental challenges behind the KOM project - syllabusitis and lack of coherence - and agree that a set of mathematical competencies is a useful developmental tool to address these challenges. Another more pragmatic reason is that the eight mathematical competencies - at least on a rhetorical level - has been adopted by the mathematics program of the Danish public school system (cf. Undervisningsministeriet, 2009). So, from a coherence perspective it makes sense to use the framework of mathematical competencies as a basis for the design of the master's programme in general, and this mathematically focused course module in particular. Furthermore, the KOM framework addresses not only the development and possession of the competencies from a learner's and practitioner's point of view, but also from that of a teacher's (Niss \& Højgaard, 2011, part III).

\section{A TWO-DIMENSIONAL STRUCTURE FOR COURSE DESIGN}

When focusing on the development of competencies - with students, student teachers, or student teacher educators - it makes sense to rely on a two-dimensional structure for course design. The eight mathematical competencies were never meant as a 'stand alone' instead of a set of concept areas such as algebra and geometry; on the contrary, they only make sense in combination with mathematical concepts. But the conceptual basis for developing a specific competency, however, may be different. For instance, the problem tackling competency may be trained and developed within infinitesimal calculus as well as abstract algebra, number theory, or projective geometry. Of course, the further the reach in terms of concept areas the 
better. The KOM report refers to this as the 'radius of action' of a person's competency (Niss \& Højgaard, 2011, p. 72).

Nevertheless, when designing a specific course, not all concept areas of mathematics can be covered, of course. But when focusing on the development of competencies, it does make sense to include more than just one concept area. In the particular course that we are addressing in this paper (cf. Højgaard \& Jankvist, 2013, which on request can be emailed by one of the authors), the competencies in focus are mathematical modelling competency and mathematical problem tackling competency. And the concept areas chosen to accompany these competencies are calculus and stochastics. More precisely, the parts of calculus in focus are systems of differential equations and analytic versus qualitative solutions of such. A central topic in relation to this is that of so-called 'compartment models', which assists in translating from an extramathematical context to a system of differential equations. As for stochastics, the emphasis is on different models of distribution of probability and their use in hypothesis testing. The interrelation between the two competencies and the two concept areas may be depicted in a 2x2-matrix, as illustrated in figure 2 .

\begin{tabular}{|l|l|l|}
\hline \multicolumn{1}{|c|}{ Concept Area } & Calculus & Stochastics \\
Competency & & \\
\hline $\begin{array}{l}\text { Mathematical } \\
\text { Modeling } \\
\text { Competency }\end{array}$ & & \\
\hline $\begin{array}{l}\text { Mathematical } \\
\text { Problem } \\
\text { Tackling } \\
\text { Competency }\end{array}$ & & \\
\hline
\end{tabular}

Figure 2. A matrix structuring of the mathematical content in the educational module: 'Mathematics in a Didactical Perspective I'.

The problem tackling competency involves the ability to be able to detect, formulate, delimitate, and specify different kinds of mathematical problems, both pure and applied, as well as being able to solve mathematical problems in their already formulated form, whether posed by oneself or by others (Niss \& Højgaard, 2011, pp. 55-58). The important thing to notice about this competency is that the word 'problem' is relative to the person who is trying to solve it. What is a routine task for one person may be a problem for another and the other way round.

Firstly, the modelling competency consists of being able to analyse the foundations and properties of existing models and being able to assess their range and validity. Secondly, it involves being able to perform active modelling in given contexts (Niss \& Højgaard, 2011, pp. 58-60). Figure 3 shows our preferred model of this process, inspired by and quite similar to many other models of this process found in the literature. 


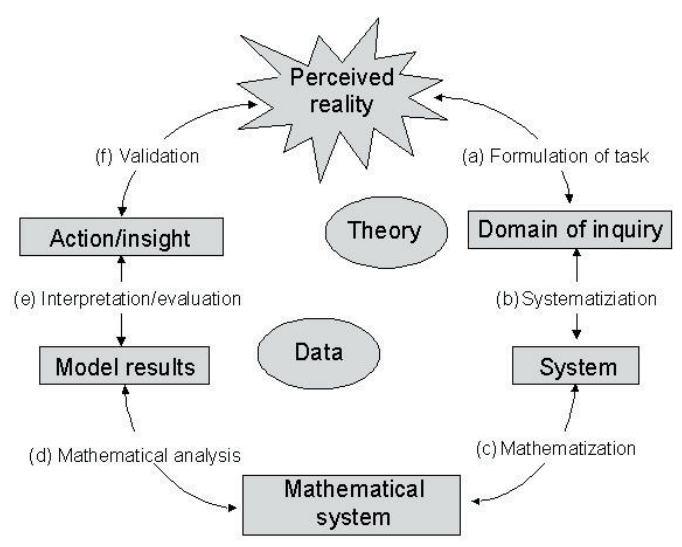

Figure 3. A visual representation of the mathematical modelling process (Blomhøj \& Jensen, 2007, p. 48).

This is not the place for an elaborated discussion of the different parts of this model of the mathematical modelling process (cf., e.g., Blomhøj \& Jensen, 2003; Jensen, 2007). Nor do we have room for a discussion of the differences and possible overlaps between the two competencies, but such a discussion is a central part of the course in focus here, based on the reading of Højgaard (2010) (in a Danish version) and Lesh $\&$ Zawojewski (2007) by the students.

\section{DIDACTICS - THE NEEDED THIRD DIMENSION}

From the point of view of educating mathematics educators, and in particular mathematics teacher educators, the $2 \times 2$ matrix structure in figure 2 runs short of one dimension, namely didactics of mathematics. Not only will the educators need to possess the two competencies themselves and be able to apply them within the two chosen concept areas; they also need to know about teaching perspectives, students' learning difficulties, etc. in relation to both the competencies and the concept areas. The KOM report also discusses the didactical and pedagogical sides of the eight mathematical competencies. As part of the third dimension, it is relevant to consider this for the problem tackling and modelling competencies, respectively.

As for problem tackling, the KOM report says that in order to launch and assist learning processes of investigative, experimental, and problem solving nature, it is crucial that the teacher (and thereby also the teacher educator) possesses the problem tackling competency him- or herself. As an organizer of teaching and other educational activities, the teacher must be able to pose and solve problems and questions which can give rise to problem tackling activities for students:

"Involved in this is being able to point out, select, formulate and define a variety of mathematical problems which can, in relation to different groups of students, give rise to such activity. [...] Considering that the students often have different intellectual, socio- 
economic and cultural backgrounds, it is also particularly important that the teacher is able to set up different strategies for dealing with the problem concerned and for helping the students to approach them from a range of different angles, depending on their backgrounds." (Niss \& Højgaard, 2011, p. 97)

In addition to the KOM report's treatment of problem solving, the students also encountered Schoenfeld's (1992) approach to this, and they were asked to time their own and each other's problem solving processes using Schoenfeld's schema. This again was used as a basis for self reflection regarding their possession of problem solving competency.

In relation to modelling, it is equally important for a teacher to possess the modelling competency in order to assist students in their modelling activities - in relation to analyzing and decoding already established models as well as in the process of actual model building:

"When it comes to the students' own work with mathematical modelling, it will in many situations often be necessary or appropriate to select certain parts of the modelling process (e.g. decoding elements in an existing model in relation to a given situation) as the object of teaching. The teacher must therefore master the part processes (structuring of the situation, mathematising, interpreting, validating, etc.) that make up a modelling process, and he/she must, with a view to selecting and evaluating the degree of difficulty of the individual processes, be able to have a general overview of the total process in concrete situations." (Niss \& Højgaard, 2011, p. 100)

The modelling cycle depicted in figure 3 acts as a fundamental didactical tool in the course. On the one hand, the students following the course in 2013-2014 relied on the cycle in their own modelling processes as well as the evaluation of these. On the other hand, the cycle served as a means for self-evaluation of their modelling competency - in a similar way as Schoenfeld's schema did for the problem solving part of problem tackling competency. In relation to this, the students were also introduced to Niss' concept of implemented anticipation, coining that

"[...] structuring of the extra-mathematical situation requires an anticipation of the potential involvement of mathematics, and the nature and usefulness of this involvement with regard to the modeling purpose [and that it] further requires an initial anticipation of which mathematical domain(s) might be used to represent the situation and the questions posed about it." (Niss, 2010, p. 54).

What Niss is pointing to is an implemented anticipation of "relevant future steps, projected 'back' onto the current actions" (Niss, 2010, p. 55) - an aspect of the modelling competency developing only with training and experience.

Hence, in summary, the two-dimensional matrix structure in figure 2 is expanded to include yet a dimension; one of didactics of mathematics. See figure 4 . 


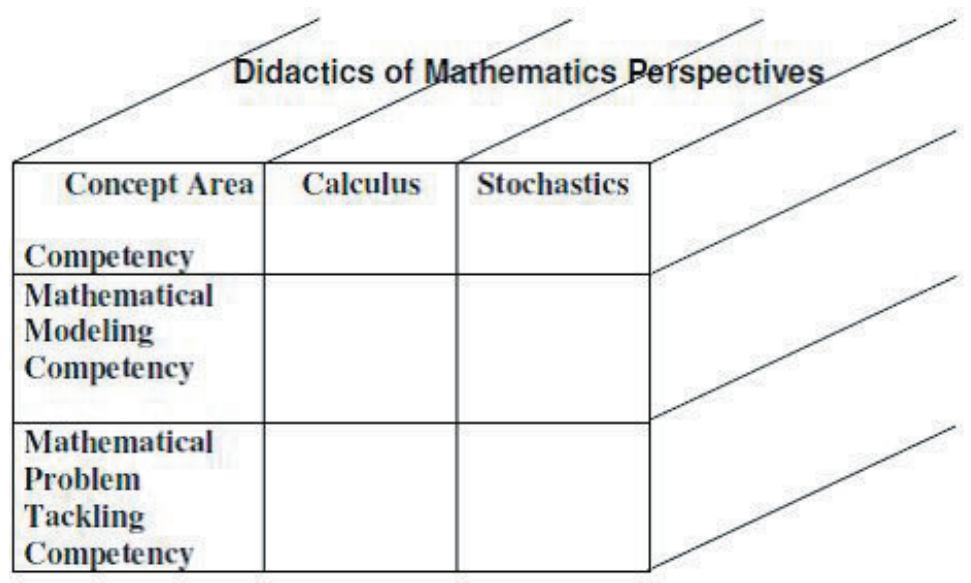

Figure 4. A visualisation of the content of the educational module: 'Mathematics in a Didactical Perspective I'.

In relation to the third dimension, yet a kind of competencies becomes relevant; what KOM refers to as a competency-based description of the profession of mathematics teachers, describing a set of six didactic and pedagogical competencies (Niss \& Højgaard, 2011, chapter 6), encompassing being able to

... evaluate and draw up curricula: Curriculum competency.

... think out, plan and carry out teaching: Teaching competency.

... reveal and interpret students' learning: Competency of revealing learning.

... reveal, evaluate and characterise the students' mathematical yield and competencies:

Assessment competency.

... cooperate with colleagues and others regarding teaching and its boundary conditions:

Cooperation competency.

... develop one's competency as a mathematics teacher: Professional development

competency.

Of course not every one of these six teacher competencies may enter into the course to the same degree - and nor did they make up a basis for the course design in a similar manner as the mathematical problem tackling and modelling competencies. Still, when relevant we have tried to focus on aspects of these six competencies. For example, as part of the final project in the course (to be explained in the following section), the students may think out and plan teaching activities in relation to problem tackling and modelling (teaching competency); the students may evaluate existing curricula in relation to these two competencies as well (curriculum competency); for the majority of students the project work involves cooperation with colleagues, dealing also with boundary conditions of problem tackling and modelling (cooperation competency); and when working with the development of their own 
problem tackling and modelling competencies, they indirectly also develop their competency as a mathematics teacher (professional development competency). As for the assessment competency, this was mainly dealt with by means of self-reflection on the students' own possession and development of the two mathematical competencies of the course. The competency of revealing learning was dealt with through literature such as Mellin-Olsen's distinction between instrumental and relational understanding as described by Skemp (1976), and also Heibert and Carpenter's (1992) discussion of teaching for understanding.

\section{STUDENTS' PROJECT WORK}

As mentioned above, at the end of the course the students are required to carry out a project work, preferably in groups, and hand in a project report, which make up the basis for their later oral examination (also in groups). As part of this project work, the students have to build a mathematical model relying on compartment modelling and the solving of systems of differential equations or stochastics in the form of hypothesis testing, or possibly both. This model, and not least the modelling process which the students have gone through, is then to be analysed from a didactic point of view relying on the mathematics education literature of the course. The didactical analysis serves the purpose of trying to address a certain didactical or pedagogical problématique or question, which the students themselves find intriguing. In this sense, the students' project work usually involves two questions; one that has to do with the actual mathematical model; and another that has to do with the didactical dimension. Everyone involved - us, the students and the external censor - found this double focus both challenging, interesting, very much in alignment with the intention of the course as a whole, and hence very relevant for the overall purpose of the educational programme as a whole.

Allow us to illustrate with a couple of brief examples from the implementation of the course in 2013-14. One group of students decided to model a price war between two fictive petrol stations. Hence the modelling question had to do with how this could be done. The students were able to carry out two different mathematical modelling processes; one relevant for upper secondary school students relying on compartment modelling, systems of differential equations and a qualitative solution of these, and another relevant for lower secondary school students relying only on functions. The group of students, all previous school teachers, had a hypothesis that Danish upper secondary school teachers expect a certain level of competency possession by the students when they begin, a level which is not necessarily reached by the end of lower secondary school, and that this could be one reason for the transfer problem between the two, in Denmark rather separated educational levels (in relation to mathematics). But if doing actual mathematical modelling in secondary school, although on a lower mathematical level, do students then develop these requested competencies to a higher degree? The students addressed this question by analyzing the two modelling processes by means of the modelling cycle and by looking at the 
way the problem tackling and modelling competencies entered into and differed between these two processes.

Another group of students asked themselves the open modelling question of how many people worldwide have AIDS/HIV in the year of 2030? The students performed a compartment modelling leading to a system of differential equations, which they were able to solve analytically. They then analysed their entire modelling process by means of the modelling cycle. Furthermore, they posed and solved a series of topic related questions to be dealt with from a stochastic point of view. The purpose was to enable them to address their didactic question about the relations between mathematical problem tackling and mathematical modelling. More precisely, they investigated the assumptions that a) it usually involves mathematical problem solving to work with tasks having the 'mathematical system' of a modelling process as the point of departure (cf. figure 2), and b) if 'travelling up' on both sides of the model of the modelling cycle, then at some point it will no longer be problem tackling which takes place, but 'something else' more special to a modelling process.

\section{CONCLUDING REMARKS}

In conclusion, we believe we have stated and exemplified the following two points of attention in relation to designing course modules as part of educating mathematics teacher educators: (1) that getting students to work with a two-dimensional, competency-based mathematical content holds a lot of potential in terms of developing a rich and deliberately complex picture of what it means to be good at mathematics; and (2) that such a matrix-approach also holds potential when it comes to incorporating didactical competencies as a third dimension in the content structure.

\section{REFERENCES}

Blomhøj, M. \& Jensen, T.H. (2003). Developing mathematical modelling competence: Conceptual clarification and educational planning. Teaching Mathematics and its Applications, 22(3), 123-139.

Blomhøj, M. \& Jensen, T.H. (2007). What's all the fuss about competencies? Experiences with using a competence perspective on mathematics education to develop the teaching of mathematical modelling. In W. Blum, P.L. Galbraith, H.W. Henn, \& M. Niss (Eds.), Modelling and applications in mathematics education - The 14"ICMI-study (pp. 45-56). New York, USA: Springer.

Boisot, M. (1972). Discipline and interdisciplinarity. In Interdisciplinarity: Problems of Teaching and Research in Universities (pp. 89-97). Paris: OECD.

Hiebert, J. \& Carpenter, T. P. (1992). Learning and teaching with understanding. In Grouws (Ed.), Handbook of Research on Mathematics Teaching and Learning (pp. 65-97). New York, USA: Macmillan Publishing Company.

Højgaard, T. (2010). Communication: the essential difference between mathematical modeling and problem solving. In Lesh et al. (2010), pp. 255-264. 
Højgaard, T. \& Jankvist, U.T. (eds.) (2013). Matematik i fagdidaktisk perspektiv I: Undervisningsplan. Copenhagen, Denmark: Department of Education, Aarhus University. Unpublished teaching plan.

Jensen, J.H. (1995). Faglighed og pensumitis. Uddannelse, 9, 464-468.

Jensen, T.H. (2007). Udvikling af matematisk modelleringskompetence som matematikundervisningens omdrejningspunkt - hvorfor ikke? Doctoral dissertation. Tekster fra IMFUFA 458. Roskilde, Denmark: IMFUFA, Roskilde University.

Lesh, R. \& Zawojewski, J. (2007). Problem solving and modeling. In F. K. Lester Jr. (Ed.), Second Handbook of Research on Mathematics Teaching and Learning (pp. 763-804). New York, USA: Information Age.

Lesh, R., P. L. Galbraith, C. R. Haines \& A. Hurford (Eds.) (2010). Modeling Students' Mathematical Modeling Competencies: ICTMA 13. New York, USA: Springer.

Niss, M. (2010). Modeling a crucial aspect of students' mathematical modeling. In Lesh et al. (2010), pp. 43-59.

Niss, M. \& Højgaard, T. (Eds.) (2011). Competencies and mathematical learning ideas and inspiration for the development of mathematics teaching and learning in Denmark. English translation of parts I-VI by Niss \& Jensen (2002). Tekster fra IMFUFA 485. Roskilde, Denmark: IMFUFA, Roskilde University. Cf. http://milne.ruc.dk/imfufatekster/.

Niss, M. \& Jensen, T.H. (Eds.) (2002). Kompetencer og matematiklaering - idéer og inspiration til udvikling af matematikundervisning $i$ Danmark. Uddannelsesstyrelsens temahæfteserie 18. Copenhagen, Denmark: The Ministry of Education. Cf. http://pub.uvm.dk/2002/kom.

Schoenfeld, A. (1992). Learning to think mathematically: problem solving, metacognition, and sense making in mathematics, in Grouws (Ed.), Handbook of Research on Mathematics Teaching and Learning (pp. 334-70). New York, USA: Macmillan Publishing Company.

Skemp, R. (1976). Relational understanding and instrumental understanding, Mathematics Teaching, 77, 20-26.

Undervisningsministeriet (2009). Falles mål $2009 \quad-\quad$ matematik. Undervisningsministeriets håndbogsserie, nr. 14 - 2009. Copenhagen, Denmark: The Ministry of Education. Cf. www.uvm.dk. 


\title{
USING QUESTIONING DIAGRAMS TO STUDY TEACHER- STUDENT INTERACTION
}

\author{
Markus Hähkiöniemi \\ University of Jyväskylä
}

Previous studies have often created question categories and studied frequencies of types of questions. The aim of this study is to develop a visual representation to capture how teacher questioning proceeds during a lesson. A group of 29 Finnish student teachers participated in a programme about inquiry-based mathematics teaching in grades 7-12. As part of the programme, they planned and implemented inquiry-based mathematics lessons. Data was collected by video recording the lessons. Data was analyzed by coding teacher questions into probing, guiding, factual and other questions. Questioning diagrams representing the flow of questions were created and used in identifying questioning approaches. Analysis of teacherstudent interaction gives further insights into the questioning approaches.

\section{INTRODUCTION}

Previous studies have often investigated teacher questioning by creating categories of questions, calculating frequencies of types of questions and by analyzing in depth the nature of questions in some episode (e.g., Hähkiöniemi, 2013; Sahin \& Kulm, 2008). For example, in Sahin and Kulm's (2008) classification, factual questions request a known fact, guiding questions give hints or scaffold solution, and probing questions ask for elaboration, explanation or justification. The studies categorizing questions give mainly two kinds of information. First, they give descriptive results about how often teachers, in certain conditions, ask different types of questions. For example, according to previous studies, teachers tend to ask low-level questions focusing on facts instead of explanations (e.g., Kawanaka \& Stigler, 1999; Myhill \& Dunkin, 2005; Sahin \& Kulm, 2008). Second, some of these studies have studied questioning in depth and created new data-based typologies of teacher questioning, and thus, help to understand the phenomenon of teacher questioning. For example, Hähkiöniemi (2013) identified different ways of asking students to explain.

What is lacking in previous research are ways to depict teacher questioning as it develops during an episode and questions cumulate on each other. When considering other parts of teacher-student interaction, there exist studies that have analysed sequences of interaction. Classical IRE interaction pattern consists of teacher Initiation, student Response and teacher Evaluation (Mehan, 1979). Further studies have found that this pattern can be broken up as instead of evaluating a teacher can ask a follow-up questions or prompts after student responses (IRFRFR or IRPRPR) (see e.g., Lehesvuori, Viiri, Rasku-Puttonen, Moate \& Helaakoski, 2013).

Another approach in studying classroom interaction, is examining larger interaction approaches. Several researchers have elaborated on two kinds of mathematics 
classroom interaction approaches in similar ways. One type of interaction guides students toward the desired goal or introduces information to them through questioning and the second type of interaction elicits students' thinking or supports them to explain (Lobato, Clarke \& Ellis, 2005; Franke et al., 2009; Temple \& Doerr, 2012). In science education, Mortimer and Scott (2003) have developed similar constructs as they divide classroom talk into dialogic and authoritative talk depending on whether the talk draws on multiple points of views or just one point of view, usually the teachers' view.

Lehesvuori et al. (2013) emphasize the need for temporal consideration of how teacher talk develops and progresses over time. They responded to this need by creating interaction diagrams which depicts the types of teacher talk as a function of time. Also researchers in mathematics education, have built visual representations of interaction. For example, Conner, Singletary, Smith, Wagner \& Francisco (2014) created argumentation diagrams which capture how an argument is built and include teacher input. However, the argumentation diagrams were complex and did not focus to teacher-student interaction in detailed level. Thus, the issue of representing teacher questioning more holistically is not yet satisfactorily examined.

The aim of this study is to design a graphical representation of teacher questioning which allows identifying holistic questioning approaches taking into account temporal development of questioning during seat work. This analysis gives insights into student teachers' ways to ask sequences of questions from the same students.

\section{METHODS}

\section{Context}

The participants of this study consist of 29 Finnish prospective secondary and upper secondary mathematics teachers. The student teachers were in the final phase of the teacher training program. They all had taught several school lessons during the program. The student teachers participated in an inquiry-based mathematics teaching unit taught by the author. The unit included nine 90 minutes group work sessions about the ideas of inquiry-based mathematics teaching. For example, the student teachers practiced how to guide students in hypothetical teaching situations (see, Hähkiöniemi \& Leppäaho, 2012). After the unit, each student teacher implemented one inquiry-based mathematics lesson in grades 7-12. All the lessons were structured in the launch, explore, and discuss and summarize phases. During the explore phase students usually worked in pairs or in three person groups. Altogether, there were 16 lessons in secondary school (grades 7-9) and 13 lessons in upper secondary school (grades 10-12). Lesson length was 45 minutes in the secondary school and either 45 or 90 minutes in the upper secondary school. Students used GeoGebra software to solve problems in 17 lessons. 


\section{Data collection}

The lessons were videotaped and audio recorded with a wireless microphone attached to the teacher. The video camera and the microphone were synchronized. The handheld video camera followed the teacher as he or she moved around the classroom. When the teacher discussed with a student pair, the camera was positioned so that students' notebooks or computer screens could be seen. Although the microphone was attached to the teacher, it captured also students' talk when the teacher discussed with a group of students. Students' written notes were collected after each lesson.

\section{Data analysis}

Data was analyzed using Atlas.ti video analysis software. All the teachers' questions were coded to probing, guiding, factual, and other questions. The definitions for these codes were constructed on the basis of Sahin and Kulm's (2008) characterizations. The shortened versions of the definitions are as follows:

- Probing questions (code 1): Questions which request students to explain or examine their thinking, solution method or a mathematical idea.

- Guiding questions (code 2): Questions which potentially give students hints or guides solving a problem. Potentially means that students do not have to understand the hint but the questions offers opportunity for this. Probing questions are excluded from this category.

- Factual questions (code 3): Questions that ask for a known fact such as an answer to a task, a definition, or a theorem. Guiding questions are excluded from this category. The difference to a guiding question is that students are not solving a problem and the question does not guide or give hint to solving the problem.

- Other questions (code 4): All other questions such as questions concerning classroom control.

A teacher utterance was considered as a question if it invited the students to give an oral response. For example, utterances such as "explain" were considered as questions even though grammatically they are not questions. On the other hand, grammatical questions were not coded as questions if the teacher did not give the students a possibility to answer the question. Inter-rater reliability for coding probing, guiding, factual, and other questions for a sample of 150 questions was $89 \%$ $($ Cohen's kappa $=.845)$.

In addition, lessons were coded to launch, explore, and discuss and summarize phases. The episodes when the teacher discussed with a certain student group during the explore phase were marked. After this, questioning diagrams of each student teacher were produced using SPSS and spreadsheet software (see, e.g., Fig. 1). In the diagrams, the horizontal axis shows the time in minutes and vertical axis shows the question type. The beginning and the end of the lesson as well as the lesson phases 
are indicated by vertical lines. In the exploration phase, the questions asked from a student group (or an individual student) are connected with a line. Questions are marked with red circles or blue triangles so that the symbol changes when the group changes. Questions asked during the launch and discuss and summarize phases are marked with green squares on connected with a line.

The questioning diagrams were scrutinized for different characteristics of teacher questioning. Besides numbers of different types of questions, it was attended to how the questions are chained and how long the chains are. Through this analysis five questioning approaches were identified. Episodes were selected for in-depth analysis to help to understand the questioning approaches.

\section{RESULTS}

Five different questioning approaches (see Fig. 1-5) were identified. These are presented in the following sections.

\section{Mainly other questions}

In this questioning approach, a teacher asks mainly other questions. For example, in a $7^{\text {th }}$ grade class where students worked using GeoGebra, the teacher circulated in the classroom and asked other questions about use of computers (Fig. 1). She asked many questions such as "is it working?"

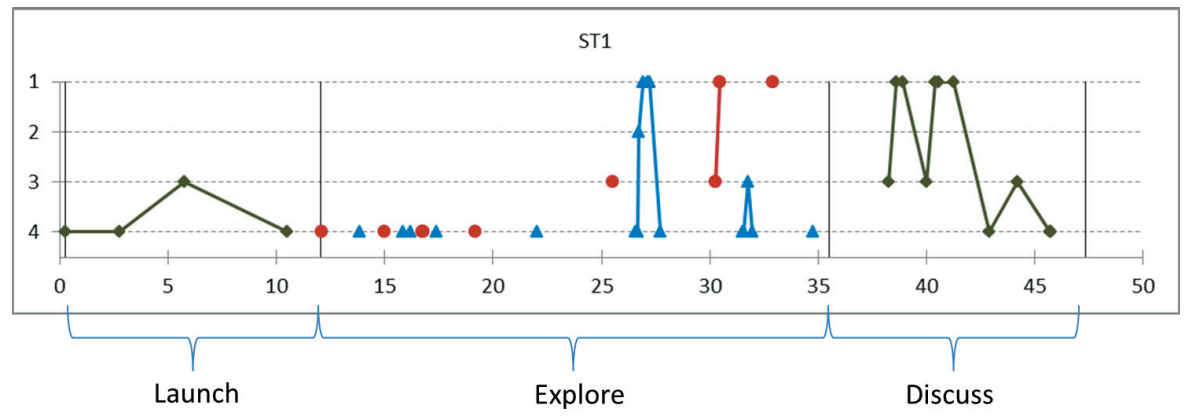

Figure 1: Questioning diagram of student teacher 1

As the questioning diagram indicates, mathematical discussions were rare in this lesson.

\section{Questions are rare}

The questioning diagram of student teacher 20 is an example of a lesson in which the teacher circulated in the class but asked only individual questions (Fig. 2). 


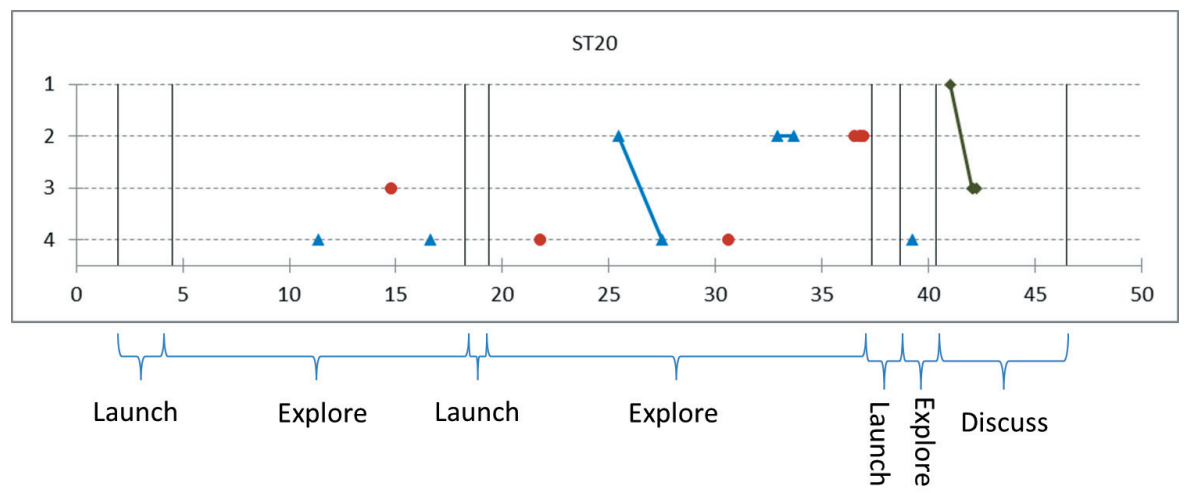

\section{Figure 2: Questioning diagram of student teacher 20}

The teacher circulated in the class, observed students' work and gave them advices. However, as the questioning diagram indicates, the teacher did not use questioning so often.

\section{Series of guiding questions}

Some questioning diagrams included a questioning approach in which a teacher asks series of guiding questions. There might be some other questions too but questions asked in a row from a student pair consist mainly of guiding questions as shown in the questioning diagram of student teacher 7 (Fig. 3).

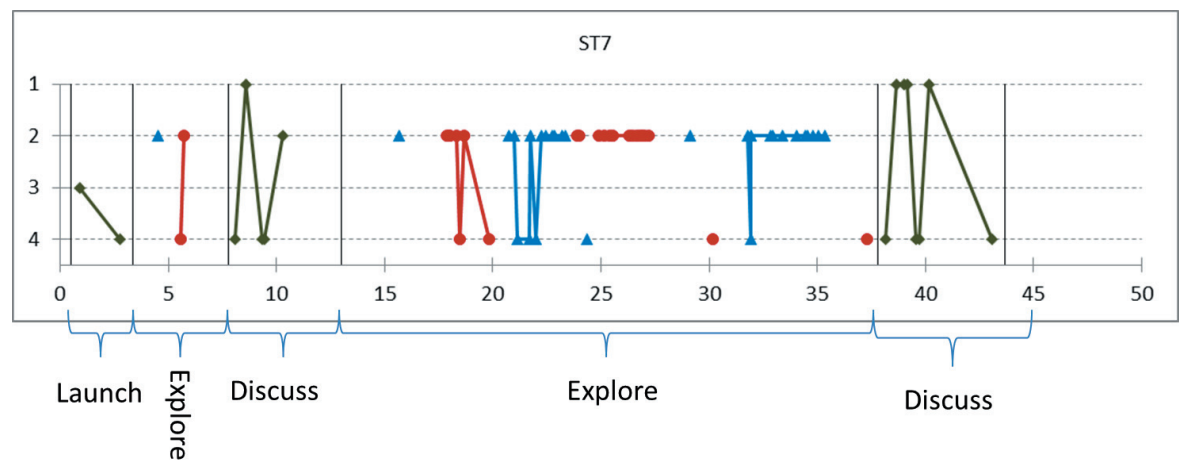

\section{Figure 3: Questioning diagram of student teacher 7}

The $8^{\text {th }}$ grade lesson of student teacher 7 was about percentages and interest. Students were solving how much money there is after a) 1 , b) 2, c) 3, d) 10 years if $3500 €$ is put in the account whose interest rate is $3.0 \%$. A series of guiding questions occurred when a student asked for advice:

Student: How is after 10 years calculated? 
ST7: So, now you have multiplied by 1.30 [money after 1 year], haven't you? Then, what have you done here [money after 2 years]? [Guiding]

Student: Multiplied this [money after 1 year] by 1.03 .

ST7: Mm. What about here [money after 3 years]? [Guiding]

Student: Multiplied this [money after 2 years] by 1.03 .

ST7: Yeah. So, uhm, what have you done like in total? [Guiding]

Student: Well, three times this times this. Does it go like that?

ST7: Yeah. So you have multiplied three times by 1.03 here, so how like mathematically? [Guiding]

Student: [In audible]

ST7: What? [Other]

Student: This is multiplied 10 times by this.

ST7: Uhm. Uhm. Uhm. Almost, but, that not times but? [Guiding]

Student: Raised to the 10th power.

In the above episode, the teacher guided the student to notice that after three years she has multiplied $3500 €$ three times by 1.03 . The questions guide the student straightforwardly toward the solution the teacher has in mind. The student seemed already to have the idea of multiplying 10 times by 1.03 but the teacher was heading toward the notion of exponent. As can be seen from the questioning diagram, this kind of strong guidance seemed to be typical for the teacher.

\section{Series of probing questions}

The questioning diagram of student teacher 2 is an example of questioning diagram including series of probing questions (Fig. 4). This means that the teacher asked a sequence of probing questions from the same student pair. The sequence may include also other types of questions.

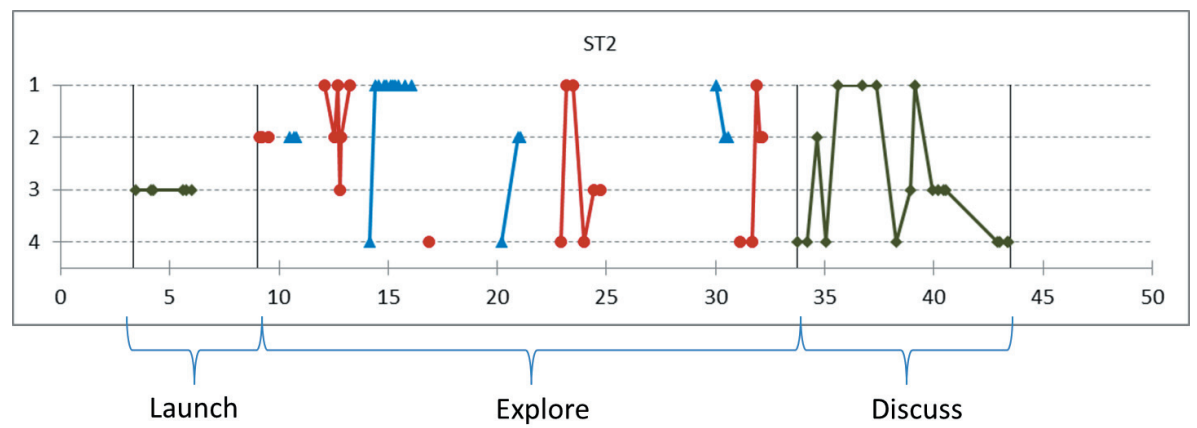

Figure 4: Questioning diagram of student teacher 2 
The $9^{\text {th }}$ grade lesson of student teacher 2 was about divisibility rules. A student had proceeded relatively fast. The teacher started a conversation about her claim that a number is divisible by two if the last digit is even. At first, when the teacher asked the reason for this property, the student only repeated the claim as if it was self-evident. For example, the student said that "Because they are divisible by two." The teacher continued asking for the reason in several probing questions such as "Why is it enough to look at the last digit?", "How do you know it?", and "But what if you look at the whole number?" Finally, the conversation started to turn toward mathematical explanation:

ST2: Do you mean that the previous digits can always be divided by two? [Probing]

Student: They can always be divided by two if the last [digit] is even.

ST2: Which can be divided by two? Which previous? What do you mean? I don't quite. [Probing]

Student: Well, if you have let's say, for example, 5, 3, 2, 4 [number 5324].

ST2: Yes.

Student: Then, if the last digit is even, you can divide them all by two. Or like the whole number by two. Of course you can't divide all of them separately by two.

ST2: What is the reason that you can divide the whole number by two? I can see that you can divide four [by two] [Probing]

Student: $\quad$ They are round thousands, round hundreds, round tens, to which only the digit in the end is added to. So it is the one digit which matters instead of the whole number. [...] They are complete thousands, hundreds, and tens, which all are divisible by two, and therefore, the whole number is divisible by two if the last one is not odd.

In the above example, the teacher continued asking probing questions in different ways until the student was able to give a mathematical explanation. The probing questions also helped the student to formulate the explanation. With only one probing question, the student would not have given so rich explanation. The discussion seemed to be open for the student's ideas and it was the student who took the number 5324 as an example.

\section{Long series of guiding and probing questions}

Some questioning diagrams included long series of guiding and probing questions. For example, student teacher 9 engaged in several long conversations with students and asked both probing and guiding questions (Fig. 5). The $7^{\text {th }}$ grade lesson of student teacher 9 introduced the notion of exponent to the students. The idea of the lesson was folding a paper once so that it forms two pieces. Then if you fold it again, you will have four pieces, then eight and so on. The students were asked to construct a 
rule by which you can calculate the amount of parts when the paper is folded a) 30, b) $x$ times. The teacher often asked probing questions when beginning the conversation. For example, he started the following conversation with two students:

ST9: Would you like to explain what you have done? Start to explain the principle from the beginning. [Probing]

Student 1: When you fold it, it always multiplies so that the previous result is multiplied by 2 . When it is folded once, it is divided into 2 and then when it is folded again, into 4 and then 8 . Then 16, 32, 64 .

ST9: $\quad$ Yeah. Well then what about here, in the task 3 a [folding 30 times], how does it go? [Probing]

Student 1: Well, it is calculated so that the previous result is always multiplied by 2 .

Student 2: Yes, like the preceding.

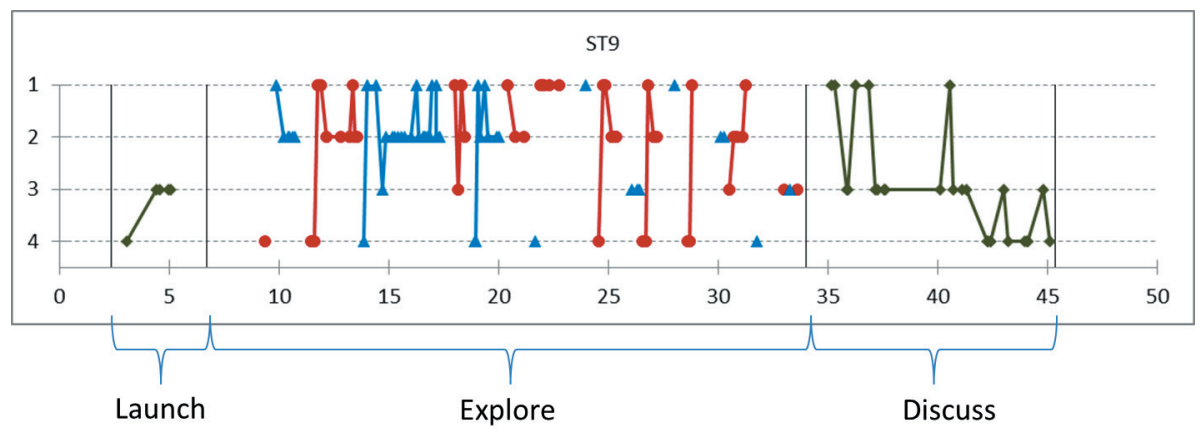

\section{Figure 5: Questioning diagram of student teacher 9}

The students seemed to have figured out the recursive rule. Then the teacher continued by guiding the students:

ST9: $\quad$ Could you write it in some other way? [Guiding]

Student 1: I don't know.

ST9: $\quad$ Could you think what is multiplied and how many times? [Guiding]

Student 2: Like the number of this multiplied by two. I can't explain.

ST9: $\quad$ Yeah. Could it be possible to invent a rule which only includes twos? [Guiding]

Student 1: Well, $2 x$. Like this, $2 x$ plus $2 x$ plus $2 x$.

ST9: Where does the $2 x$ come from? [Probing]

Student 1: Well, if it has to have only twos, then [I don't know].

ST9: $\quad$ Now it has also $x$ ? [Guiding] 
Student 1: Well, 2 times 2 times 2 times 2.

ST9: Uhm. How many time did you multiply the two? [Guiding]

Student 1: Well, $x$ times.

In the above episode, the teacher first found out students' ideas. Then, based on this, he guided the students to think about the explicit rule, probed their suggestions and guided them more. The teachers' guidance was building on the students' ideas.

\section{DISCUSSION}

In this study, a new visual representation of teacher questioning was developed: the questioning diagram. The questioning diagram makes it possible to observe teacher questioning holistically as it develops during the lesson. Similarly to Lehesvuori's et al. (2003) representation of communication approaches, the questioning diagrams allow observing questioning approaches. Previous studies that have reported frequencies of questions have identified what types of questions are common or rare (e.g., Kawanaka \& Stigler, 1999; Myhill \& Dunkin, 2005; Sahin \& Kulm, 2008). In addition to this, questioning diagrams allow identifying teachers' chaining of questions when talking to same student groups. Questioning diagrams add the possibility of observing how questioning develops in time. Thus, questioning diagrams add temporal consideration to analysing classroom interaction as called for by Lehesvuori et al. (2013).

In this study, five questioning approaches were found. Series of guiding questions indicate strong guidance toward a specific aim. Series of probing questions elicit students' thinking and support them in formulating an explanation. In other words, series of guiding questions direct students toward an answer whereas series of probing questions direct students toward an explanation. These two questioning approaches correspond to the two types of interaction reported in the research literature: (1) guiding students toward the desired goal or introducing information to them through questioning and (2) eliciting students' thinking or supporting them to explain (Lobato et al., 2005; Franke et al., 2009; Temple \& Doerr, 2012). The two approaches also bear some similarity to Mortimer and Scott's (2003) authoritative and dialogic communication approaches. Another questioning approach consists of asking long series of both probing and guiding questions. This kind of questioning guides students based on their ideas, and thus, combines elements of both guiding and eliciting interactions. In addition, the questioning approaches of asking questions only rarely or mainly other questions indicate lack of mathematical conversations.

The questioning approaches were identified from the questioning diagrams and confirmed by micro-analysis of the episodes. Thus, questioning diagrams may be used in identifying holistic questioning approaches and to select episodes for deeper analysis. So far questioning diagrams are used for research purposes but future studies could investigate use of them in giving holistic feedback for teachers. 


\section{REFERENCES}

Franke, M., Webb, N., Chan, A., Ing, M., Freund, D., \& Battey, D. (2009). Teacher questioning to elicit students' mathematical thinking in elementary school classrooms. Journal of Teacher Education, 60(4), 380-392.

Conner, AM., Singletary, L.M., Smith, R.C., Wagner, P.A., \& Francisco, R.T. (2014). Teacher support for collective argumentation: A framework for examining how teachers support students' engagement in mathematical activities. Educational Studies in Mathematics, 86(3), 401-429.

Hähkiöniemi, M. (2013). Probing student explanation. In A. Lindmeier, \& A. Heinze (Eds.), Proceedings of the 37th Conference of the International Group for the Psychology of Mathematics Education (Vol. 2, pp. 401-408). Kiel, Germany: PME.

Hähkiöniemi, M., \& Leppäaho, H. (2012). Prospective mathematics teachers' ways of guiding high school students in GeoGebra-supported inquiry tasks. The International Journal for Technology in Mathematics Education, 19(2), 45-58.

Kawanaka, T., \& Stigler, J. W. (1999). Teachers' use of questions in eight-grade mathematics classrooms in Germany, Japan, and the United States. Mathematical Thinking and Learning, 1(4), 255-278.

Lehesvuori, S., Viiri, J., Rasku-Puttonen, H., Moate, J., \& Helaakoski, J. (2013). Visualizing communication structures in science classrooms: Tracing cumulativity in teacher-led whole class discussions. Journal of Research in Science Teaching, 50(8), 912-939.

Lobato, J., Clarke, D., \& Ellis, A.B. (2005). Initiating and eliciting in teaching: A reformulation of telling. Journal for Research in Mathematics Education, 36(2), 101-136.

Mehan, H. (1979). Learning lessons: Social organization in the classroom. Cambridge, MA: Harvard University Press.

Mortimer, E.F., \& Scott, P. (2003). Meaning making in science classrooms. Milton Keynes, UK: Open University Press.

Myhill, D., \& Dunkin, F. (2005). Questioning learning? Language in Education, 19(5), 415-427.

Sahin, A., \& Kulm, G. (2008). Sixth grade mathematics teachers' intentions and use of probing, guiding, and factual questions. Journal of Mathematics Teacher Education, 11(3), 221-241.

Temple, C., \& Doerr, H. M. (2012). Developing fluency in the mathematical register through conversation in a tenth-grade classroom. Educational Studies in Mathematics, 81(3), 1-20. 


\title{
MATHEMATICAL KNOWLEDGE FOR TEACHING AMONG PROSPECTIVE TEACHERS IN MALAWI
}

\author{
Arne Jakobsen ${ }^{1}$ and Mercy Kazima ${ }^{2}$ \\ ${ }^{1}$ University of Stavanger, Norway; ${ }^{2}$ University of Malawi, Malawi
}

In this article we report on base line data that informed the development of a fiveyear project of improving quality and capacity of mathematics teacher education in Malawi (Kazima \& Jakobsen, 2013). 29 mathematics teacher educators at four different teacher colleges in Malawi answered a questioner about different aspects of prospective teachers' mathematical knowledge for teaching (MKT) - with a special focus on the subject matter knowledge. Our findings indicate that prospective teachers struggle with the same topics as Malawi pupils - as reported in two reports by The Southern and Eastern Africa Consortium for Monitoring Educational Quality (SACMEQ II and SACMEQ III).We also find that what prospective teachers struggle least with in College, is reported to be most difficult for them to teach at schools.

\section{INTRODUCTION}

Primary school in Malawi is eight years (Standards 1 to 8 ) and teacher education for prospective primary school teachers in Malawi takes a total of two years. The first year consist of full time taught courses followed by a second year of school based component in the form of teaching practice. This mode of teacher education was implemented in response to the huge demand for teachers that arose after the introduction of free primary education in 1994 and high population growth. From 1994 to 1995 enrolment in primary school increased by $50 \%$ from 1.9 million to 2.9 million (Ministry of Education, 2000) and has continued to grow. In 2008 primary school enrolment was at 3.6 million and in 2013 estimated at 4 million. This large increase in pupil enrolment in primary schools has put tremendous pressure on the already limited resources, including provision of qualified teachers, and the current average teacher to pupil ratio in Malawi primary schools is 1:88 (Ministry of Education, 2013).

Malawi is a member of The Southern and Eastern Africa Consortium for Monitoring Educational Quality (SACMEQ) - an independent intergovernmental non-profit organization with fifteen member states in the southern and eastern Africa. One of the missions of SACMEQ is to do educational policy research, both national wise and cross-national, and Mathematics is one of the subjects that is evaluated. The large increase in pupil enrolment in primary schools in Malawi appears to have an impact on both mathematics teaching and learning. According to the numeracy results in the assessments SACMEQ II (SACMEQ, 2006) and III (Hungi et. al., 2010), Malawi Standard 6 pupils attain only up to basic numeracy level which is level 3 out of 8 achievement levels measured by SACMEQ. Furthermore, the higher levels which 
include competent numeracy, mathematical skills and problem solving are not attained. Table 1 shows all the achievement levels and percentage of standard 6 pupils at each level in SACMEQ II (SACMEQ, 2006) and SACMEQ III (Hungi et. al., 2010).

\begin{tabular}{|c|l|c|c|c|}
\hline Level & Achievement & $\begin{array}{c}\text { SACMEQ II } \\
\text { Malawi }\end{array}$ & $\begin{array}{c}\text { SACMEQ III } \\
\text { Malawi }\end{array}$ & $\begin{array}{c}\text { SACMEQ III } \\
\text { Average }\end{array}$ \\
\hline 1 & Pre Numeracy & 12.4 & 8.6 & 3.9 \\
\hline 2 & Emergent Numeracy & 61.9 & 51.3 & 27.5 \\
\hline 3 & Basic Numeracy & 23.5 & 31.8 & 31.6 \\
\hline 4 & Beginning Numeracy & 2.1 & 6.6 & 20.2 \\
\hline 5 & Competent Numeracy & 0.2 & 1.3 & 8.3 \\
\hline 6 & Mathematics Skilled & 0.0 & 0.4 & 5.6 \\
\hline 7 & $\begin{array}{l}\text { Concrete Problem } \\
\text { Solving }\end{array}$ & 0.0 & 0.0 & 1.7 \\
\hline 8 & $\begin{array}{l}\text { Abstract Problem } \\
\text { Solving }\end{array}$ & 0.0 & 0.0 & 1.2 \\
\hline
\end{tabular}

Table 1: Percentage of standard 6 learners at each SACMEQ achievement level, numbers from Malawi and average of the 15 SACMEQ participating countries.

The poor achievement levels as shown in table 1 indicate that the teaching of mathematics in primary schools is not being effective. Increase in access for pupils has led to quantity, while quality has been compromised. After 20 years of free primary education (1994-2014) and a focus of quantity in terms of access for pupils, Malawi needs to strive for quality in education as well. Therefore we found it necessary to focus on primary teacher education and in particular the mathematical knowledge for teaching of prospective teachers. In 2013 we embarked on a project that is focusing on mathematics teaching and teacher education in Malawi. It is a five year (2013-2018) collaborative project between University of Malawi and University of Stavanger in Norway. The overall goal is to improve the quality of mathematics education in Malawi schools, through improving quality of mathematics teacher education as well as the capacity of mathematics teacher educators in Malawi. In February 2013 we conducted a small study and collected base line data that informed development of the five-year project. We present some of the findings from the base line data that was collected in February 2013 and how these informed the project (Kazima \& Jakobsen, 2013), and in this paper we address the research questions:

1. What are the mathematical topics prospective teachers find difficult in College?

2. How are these topics related to pupils' achievements and to what prospective teachers find difficult to teach at school? 


\section{THEORETICAL BACKGROUND}

Teacher's knowledge can be perceived in different ways and in the last decades a new trend of reflections and studies grounded in the works of Shulman and colleagues (Shulman, 1986, 1987; Wilson, Shulman, \& Richert, 1987) emerged. From among the different conceptualizations of teacher knowledge, attempts have been done both to describe (e.g., Petrou \& Goulding, 2011) and to measure the knowledge teachers need in order to teach mathematics effectively (e.g., Hill, Sleep, Lewis, \& Ball, 2007). Mathematical Knowledge for Teaching (MKT) (Ball, Thames, \& Phelps, 2008) is one example that captures the particular characteristics of mathematical knowledge needed for teaching - distinct from the mathematical knowledge needed in other professions using mathematics. MKT is knowledge that serves as a resource for specifically addressing the mathematical demands of teaching (Ball, et al., 2008), and several researches around the world are demonstrating the effectiveness of a teacher education centred on this specific knowledge (for a list of references, see Jakobsen, Thames and Ribeiro, 2013).

The existence of two domains of teachers knowledge - subject matter knowledge (SMK) and pedagogical content knowledge (PCK) - was introduced in Shulman's and colleagues work (e.g., Shulman, 1986, 1987; Wilson, Shulman, \& Richert 1987). Later on SMK and PCK was both further subdivided into three sub domains by Ball and colleagues (2008). SMK holds the knowledge teachers must have on the topics itself and contains (a) common content knowledge (CCK), perceived as the mathematical knowledge involved in teaching, but not unique to the teaching profession (e.g., being able to perform a certain calculation); (b) specialized content knowledge (SCK), that is mathematical knowledge unique to teaching and not used in professions outside teaching. In this respect, SCK is complementary to CCK, since it corresponds to the knowledge that allows the teacher to engage in tasks specialized to teaching, such as giving sense to students productions and comments or solving problems using multiple strategies; and (c) horizon content knowledge (HCK) - a knowledge about mathematics outside the curriculum (Jakobsen et al., 2013). The other domain, SMK consist of three sub domains holding knowledge of pedagogical aspects of instruction, with particular attention to students, means for presenting the content and to the curriculum. They call these sub domains: (d) knowledge of content and students (KCS); (e) knowledge of content and teaching (KCT); and (f) knowledge about content and curriculum (KCC).

One important contribution of Ball and colleagues' work is that the sub domains are defined in relation to the work of teaching. This kind of knowledge has been linked both to the quality of instruction (Charalambous, Hill, \& Mitchell, 2012; Hill, Ball, \& Schilling, 208; Hill, Kapitula, \& Umland, 2011; Lewis \& Blunk, 2012), as well as to student learning (Hill, Rowan, \& Ball, 2005; Kersting, Givvin, Sotelo, \& Stigler, 2011; Rockoff, Jacob, Kane, \& Staiger, 2011). In this discussion, it is also worth noting that, because MKT is intimately linked to teaching, it is different for different 
school levels and topics: MKT for kindergarten differs from MKT for upper elementary differs from MKT for secondary, and MKT for geometry differs for MKT for number and operation differs from MKT for algebra.

For this particular study where we report on mathematics topics prospective teachers found difficult in College, as reported by their mathematics teachers educators, and how these difficult topics are related to Malawi pupils' achievements, as reported in SACMEQ II and III. Our focus will primarily be on the CCK and SCK part of the mathematical knowledge for teaching.

\section{METHOD}

In February 2013 we spent one week visiting four out of six teacher education colleges in Malawi, all of the four located in the south and centre part of the country. All mathematics teacher educators that were available were interviewed, in total 29 teacher educators; 9 female and 20 male. Each of them completed a written questionnaire and also participated in a whole group discussion after answering the questionnaire. For the purposes of this paper, we will report on the responses to two of the items on the questionnaire. These were:

(i) List the topics that your student teachers find difficult in College.

(ii) List the topics that your student teachers find difficult to teach in schools.

Teacher educators were asked to respond to these two questions from their experience on teaching the prospective teachers in class during the taught course year and also the teacher educators' observation of prospective teachers teaching during the school based year (student teachers).

All responses were collected and analysed using frequency counts. Results are presented in table 2 and table 3 below.

\section{RESULTS}

For both questions, we grouped the answers in eight topics as listed in Table 2 and Table 3 below. There were more answers to question (ii) compared to question (i).

To the first question we got 56 answers, while we got 71 for the second one. The three most frequent topics for question (i) are: 1) Number systems and bases; 2) Fractions and decimals; and 3) 3d Shapes. In total these three groups make up 55\% of the answers to question (i).

For question (ii), the topics are different. The three most frequent mentioned topics to question (ii) are: 1) Rate, ratio and proportion; 2) Fractions; and 3) 3d and 2d shapes. In total, these three topics make up $69 \%$ of the answers to question (ii). We can see that only one topic is among the top three categories for both questions, and that is fractions. 


\begin{tabular}{|c|l|c|}
\hline & $\begin{array}{l}\text { Topics student teachers find } \\
\text { difficult in College }\end{array}$ & Frequency \\
\hline 1 & Number systems and bases & 12 \\
\hline 2 & Fractions and decimals & 10 \\
\hline 3 & 3 d shapes & 9 \\
\hline 4 & Progressions & 7 \\
\hline 5 & Scale drawing & 5 \\
\hline 6 & Inequalities & 4 \\
\hline 7 & Accounts and taxes & 3 \\
\hline 8 & Rate ratio and proportion & \multicolumn{2}{|c|}{} \\
\hline
\end{tabular}

Table 2: Topics student teachers find difficult in College

\begin{tabular}{|c|l|c|}
\hline & $\begin{array}{l}\text { Topics student teachers find } \\
\text { difficult to teach in schools }\end{array}$ & Frequency \\
\hline 1 & Rate, ratio and proportion & 24 \\
\hline 2 & Fractions & 17 \\
\hline 3 & $3 \mathrm{~d}$ and 2d shapes & 7 \\
\hline 4 & Capacity and volume & 5 \\
\hline 5 & Place value & 4 \\
\hline 6 & Simple accounts & 3 \\
\hline 7 & Data handling & 3 \\
\hline 8 & Scale drawing & \\
\hline
\end{tabular}

Table 3: Topics student teachers find difficult to teach in schools

\section{DISCUSION}

From the answers to question (i) we find that the most frequent mentioned topic that students find difficult in College is Number systems and bases; and Fractions and decimals. Both these topics belong to SACMEQ achievement level 4) and 5) listed in Table 1. This indicate that the content knowledge - CCK - that the prospective 
teachers struggle most with in College (as reported by their mathematics teachers educators); is at the SACMEQ achievement level where Malawi standard 6 pupils fails to perform, as indicated from the results of SACMEQ II and III listed in Table 1.

Fractions is also listed as number two on the list over reported topics that student teachers find difficult to teach at schools. This is not surprisingly - since a solid CCK about fractions is a requirement for development of SCK as well as the other components of MKT that is needed in the work of teaching fractions for students. Since fractions also are identified as a problematic area in SACMEQ II and III, it is not surprisingly that fractions remains as a problem both for prospective teachers in College, and for them to teach at schools. Fractions are indeed one of the most complex mathematical concepts that children encounter in their primary education (Newstead \& Murray, 1998) and needs special attention in teacher education (Jakobsen, Ribeiro, \& Mellone, 2014).

Another finding from our base line data is that the topic Rate, ratio and proportion; being the least of eight reported topics that the prospective teachers find difficult in College, is the most mentioned topics when it comes to what topics mathematics teacher educators report that student teachers find difficult to teach at schools. This shows that CCK alone does not make the work of teaching mathematics more easy for prospective teachers. The tasks teachers need to do in their work of teaching this topics involves much more than understanding the mathematics involved - it involves mathematical knowledge that is distinct to teaching and CCK alone is not sufficient to teach the topic efficiently to pupils. More focus on SCK in teacher education would most likely help prospective teachers when they are student teaching.

\section{SUMMARY}

From our collected base line data that we have found that prospective teachers struggle with many of the same topics as Malawi pupils struggle with in their primary school. We also find that topics that the same prospective teachers struggle with in college also are difficult for them to teach at schools. In addition, we see that even in a topic where teacher educators report that the prospective teachers have few difficulties (Rate, ratio and proportion), they report that student teachers find it difficult to teach the topic at school, telling us that CCK alone is not sufficient for effective teaching.

Our baseline data are limited, and we will need more data to get a better understanding of what constitute good and efficient teacher education in Malawi. It is a weakness of our study that we only have data from teacher educators and are lacking first hand data from the prospective teachers themselves. However, in our five year project, we intend to use measures of MKT (Hill et al., 2008) to pre- and posttest all prospective teachers in Malawi before and after their year of full time taught courses, in order to learn more about what is working/not working in teacher education in Malawi. In particular we are interested to learn more about mathematical 
knowledge for teaching teachers (MKTT, see Zopf, 2010) in Malawi, in order to improve mathematics teacher education.

\section{ACKNOWLEDGEMENT}

This work is supported by the Norwegian Programme for Capacity Building in Higher Education and Research for Development (NORHED).

\section{REFERENCES}

Ball, D. L., Thames, M. H., \& Phelps, G. (2008). Content knowledge for teaching: What makes it special? Journal of Teacher Education, 59(5), 389407.

Charalambous, C. Y., Hill, H.C., \& Mitchell, R. (2012). Two negatives don't always make a positive: Exploring how limitations in teacher knowledge and curriculum materials affect the quality of instruction. Journal of Curriculum Studies, 44(4), 489-513.

Chimombo, J. (2005). Quantity versus quality in education: case study in Malawi. International Review of Education, 51, 155-172.

Hill, H. C., Sleep, L., Lewis, J. M., \& Ball, D. L. (2007). Assessing teachers' mathematical knowledge. What knowledge matters and what evidence counts? In F. Lester (Ed.), Second handbook of research on mathematics teaching and learning (pp. 111-156). Charlotte, NC: Information Age Publishing.

Hill, H., Ball, D. L., \& Schilling, S. (2008). Unpacking "pedagogical content knowledge": Conceptualizing and measuring teachers' topic-specific knowledge of students. Journal for Research in Mathematics Education, 39 (4), 372-400.

Hill, H. C., Kapitula, L. R., \& Umland, K. L. (2011). A validity argument approach to evaluating value-added scores. American Educational Research Journal, 48, 794-831.

Hill, H. C., Rowan, B., \& Ball, D. L. (2005). Effects of teachers' mathematical knowledge for teaching on student achievement. American Educational Research Journal, 42(2), 371-406.

Hungi, N., Makuwa, D., Ross, K., Saito, M., Dolata, S., Cappelle, F., Paviot, L., \& Vellien, J. (2010). SACMEQ III results: Pupil achievement levels in reading and mathematics. Retrieved from

http://www.sacmeq.org/downloads/sacmeqIII/WD01_SACMEQ_III_Results.p df

Jakobsen, A., Thames, M. H., \& Ribeiro, C. M. (2013). Delineating issues related to Horizon Content Knowledge for mathematics teaching. In 
Proceedings of the Eight Congress of the European Society for Research in Mathematics Education (pp. to appear). Antalia, Turquia: ERME.

Jakobsen, A., Ribeiro, C. M., \& Mellone, M. (in print). Norwegian prospective teachers' MKT when interpreting pupils' productions on a fraction task. Paper submitted to Nordic Studies in Mathematics Education.

Kazima, M. \& Jakobsen, A. (2013). Moving from quantity to quality in mathematics education in Malawi. Proceedings of the 4th Africa regional congress of the International Commission of Mathematical Education (AFRICME), 11-14 June 2013, Lesotho College of Education, Maseru, Lesotho.

Kazima, M. \& Mussa C. (2011). Equity and quality issues in mathematics education in Malawi schools. In B. Atweh, M. Graven and P. Valero (Eds.) Managing Equity and Quality in Mathematics Education. New York: Springer Publications, 163-176.

Kersting, N. B., Givvin, K. B., Sotelo, F. L., \& Stigler, J. W. (2011). Teachers' analyses of classroom video predict student learning of mathematics: Further explorations of a novel measure of teacher knowledge. Journal of Teacher Education, 61(1-2), 172-181.

Lewis J. M. \& Blunk M. L. (2012): Reading between the lines: Teaching linear algebra, Journal of Curriculum Studies, 44(4), 515-536.

Ministry of Education (2000). Malawi government education statistics. Lilongwe: Education and Planning Division.

Ministry of Education (2013). Malawi government education statistics. Lilongwe: Education and Planning Division.

Newstead, K., \& Murray, H. (1998). Young students' constructions of fractions. In A. Olivier \& K. Newstead (Eds.), Proceedings of the 22nd Conference of the International Group for the Psychology of Mathematics Education (Vol. 3, pp. 295-303). Stellenbosch, South Africa.

Rockoff, J. E., Jacob, B. A., Kane, T. J., \& Staiger, D. O. (2011). Can you recognize an effective teacher when you recruit one? Education Finance and Policy, 6(1), 43-74.

SACMEQ (2006). SACMEQ II project results: Pupil achievement levels in reading and mathematics. Retrieved from www.sacmeq.org

Shulman, L. (1986). Those who understand: Knowledge growth in teaching. Educational Researcher, 15(2), 4-14.

Shulman, L. (1987). Knowledge and teaching: Foundations of the new reform. Harvard Educational Review, 57(1), 1-22. 
Wilson, S., Shulman, L., \& Richert, A. (1987). 150 different ways of knowing: Representations of knowledge in teaching. In J. Calderhead (Ed.), Exploring teachers thinking (pp. 104-124). London: Cassel.

Zopf, D. (2010). Mathematical knowledge for teaching teachers: the mathematical work of and knowledge entailed by teacher education. $\mathrm{PhD}$ thesis, University of Michigan. 


\title{
DESIGNING A RESEARCH-BASED 'MATHS COUNSELLOR' PROGRAM FOR DANISH UPPER SECONDARY TEACHERS
}

\author{
Uffe Thomas Jankvist \& Mogens Niss \\ Aarhus University; Roskilde University
}

The paper addresses how decades of mathematics education research results can inform practice by describing a developmental research project on designing and implementing an in-service upper secondary school teacher education program in Denmark. The program aims to educate a "task force" of so-called "maths counsellors"; mathematics teachers whose purpose it is to identify students with learning difficulties in mathematics, investigate the nature of these difficulties, and carry out interventions to assist the students in overcoming them. We describe the considerations made in relation to designing (and implementing for the first time) the program as well as the resulting components of the program.

\section{INTRODUCTION}

In Denmark, the present situation is that 7 out of 10 young people choose to enter into upper secondary school (the classical, the technical, or business upper secondary schools). Only a few decades ago, the number of young people choosing upper secondary school was significantly lower, and the increase has happened at the expense of apprenticeships in the crafts and trades, in retail, etc. Despite the fact that it was a governmental goal to increase the number of citizens with an upper secondary diploma, the upper secondary schools were not necessarily geared to the task of taking on this new population of students, not least because Danish upper secondary school teachers for the most part are traditionally trained with mainly an academic background in their subject not dealing with didactics.

From the point of view of upper secondary mathematics, one of the effects of the development has been that the number of students with learning difficulties in mathematics has increased. By learning difficulties in this context we are thinking about those obstacles and impediments which students may encounter in their learning of the subject - a kind of stumbling blocks - including also a wide range of often seen misconceptions and misinterpretations on the students' behalf (i.e. we do not include learning disabilities, so-called dyscalculia and the like). And as to the students, we are not concerned with those who are unmotivated for learning mathematics. On the contrary, the target group students are those who unsuccessfully try hard to learn mathematics and who are interested in getting help. Experience tells us that in every mathematics classroom there are a number of such students, who try their hardest to grasp the mathematics they are presented with, to figure out what is going on, but seem to be getting nowhere in their pursuit. And the number of such students has gone up as a consequence of the increased intake to upper secondary school. 
We have identified three areas within which Danish upper secondary students usually encounter difficulties, and which we deem particularly important in the Danish context (to be explained below). Hence, we have taken the accumulated research results and findings, related to three areas, described in the mathematics education literature, as our basis for developing an in-service teacher training "maths counsellor" program. That is to say, we find that mathematics education research over the past four decades or so have accumulated such a massive amount of knowledge in the form of its various findings, theoretical constructs, etc. - related to students' learning difficulties in these three areas that it justifies an initiative as the maths counsellor program. One indicator supporting this view is the series of articles by the EMS Committee of Education, reporting "solid findings" from mathematics education research. We should specify that what we mean by "maths counsellor" is an upper secondary mathematics teacher who has received extra training in assisting the type of students mentioned above. More precisely, the trained maths counsellors are to identify such students with learning difficulties in mathematics, investigate the nature of these difficulties, and carry out interventions to assist the students in overcoming them. Hence, our main question of this paper is:

How to design a research-based "maths counsellor" program for Danish upper secondary teachers?

As the background framework for working with students' learning difficulties, we draw on the Danish KOM-project of 2002, which defines mathematical competence as "a well-informed readiness to act appropriately in situations involving a certain type of mathematical challenge" (Niss \& Højgaard, 2011, p. 49). This overall mathematical competence is spanned by eight distinct, yet mutually related, competencies (each referred to as a competency in order to distinguish them from the overall competence). These are: the mathematical thinking competency; the problem tackling competency; the modelling competency; the reasoning competency; the representation competency; the symbols and formalism competency; the communication competency; and the aids and tools competency.

\section{THE IDENTIFITED AREAS OF STUDENTS' LEARNING DIFFICULTIES}

As mentioned above, we initially identified three areas related to students' learning difficulties in mathematics, taking into account also the Danish upper secondary school context: (1) concepts and concept formation in mathematics; (2) reasoning, proofs and proving in mathematics; and (3) models and modelling in mathematics.

Regarding the first area, mathematics education research studies and findings show that concepts and concept formation of any kind in mathematics make up stumbling blocks for students, and that this is so at all levels of mathematics education. As to the second and third areas, these are of course two of the eight competencies in the Danish KOM-framework. These two competencies are to do with different aspects of mathematics as a discipline; whilst the reasoning competency deals with internal 
mathematics, the modelling competency deals with mathematics for external use. Furthermore, the development and possession of these two competencies heavily rest on the possession of other competencies from the framework. In particular, some possession of the communication competency may be seen as a prerequisite for the reasoning competency, whereas aspects of problem tackling may be seen as a "subset" of the modelling competency. And both competencies, reasoning and modelling, are closely interwoven with the competencies of mathematical thinking, representation, and symbol and formalism. Furthermore, mathematical models and modelling is a topic which over the years has come to possess a central place in the Danish upper secondary mathematics programs, in particular that of the technical upper secondary schools, and for that reason, too, it is sensible to focus on it. On the other hand, mathematical reasoning and in particular mathematical proofs appear to be on the way out of mathematics in Danish upper secondary schools, a development which we find most deplorable because it disparages the internal aspects of mathematics as a discipline; aspects without which mathematics would not be mathematics!

In the designing of the maths counsellor program, the three identified areas of learning difficulties were transformed into three themes to make up the pillars of the program. The areas qualify as themes in the sense that they, so to speak, cut across mathematical topics. This we considered to be a strength in terms of design, not the least because mathematical topics may enter in and exit out of curriculum at any time.

\section{INITIAL DESIGN CONSIDERATIONS}

The development of the program was carried out during 2012 and early 2013, while both of us were employed at Roskilde University, the institution also responsible for offering and administer the running of the program. The development of the program was funded under a project supported by the European Social Fund (grant no. ESFK09-0024), and a pilot-run of the program began in September of 2012. In the following, we account for our initial design considerations regarding the maths counsellor program and its implementation.

As mentioned in the introduction, our intention was to base the program on the mathematics education research results and findings, which we believed could inform maths counsellors in their future work. While it was clear that the program could not be based on the teachers' own experiences and intuition alone - if so, students' learning difficulties would already have been resolved, or at least taken care of - it was also clear that we needed to find a way to transform research results, findings, theoretical constructs, etc. into practice in order to make them meaningful and relevant for the maths counsellors. Hence, a delicate balance needed to be struck between theory and practice.

Our way of dealing with this was to introduce an empirical dimension into the program. More precisely, we made it a condition that the teachers should observe and 
work with students with learning difficulties in mathematics during their training, as a way for them to gain actual experiences and be trained for their future job task, i.e. an element of "learning by doing" but also as a way of "putting theory into practice." The teachers would be asked to document difficulties of individual students, and through interactions with the students try to determine what the nature of the observed difficulties are. Based on this, they then were to design some kind of counselling sessions or units, the purpose of which is to assist the students in overcoming their difficulties. And finally, they would be asked to try to assess the level of success of these sessions or units.

The considerations above led us to describe the envisioned role of a maths counsellor by means of three phases (or components) of maths counselling. A maths counsellor should be able to:

- identify students with learning difficulties in mathematics;

$\circ$ diagnose a student's learning difficulties; and

o intervene according to the posed diagnosis.

In the identification phase the maths counsellors will drawn on a series of researchbased, specially designed instruments - to be named "detection tests" - the purpose of which is to detect students with (various kinds of) mathematics specific learning difficulties.

Once the counsellors have identified one or several students, the diagnostic phase begins. In this phase it is the job of the maths counsellor to find out what the detected difficulties actually consist in, and from where they might stem. As a simple example, say that a student shows difficulties in solving the equation, $3 x-1 / 2 x-17.5=\sqrt{ } 2$. The maths counsellor will now have to find out if the student's problem is one of lacking symbols and formalism competency, e.g. symbol manipulation, if it has to do with working with fractions, with decimal numbers, with negative numbers, with irrational numbers or some combination of these. Hence, the diagnostic phase, in this case, could (but does not have to) include a session where the student is interviewed about his or her attempt to solve the given equation and is presented with simpler equations varying over the above mentioned topics, making a diagnosis possible.

Based on the diagnosis arrived at, the intervention phase must offer the student some kind of activities which aim at remedying his or her difficulties in mathematics thus identified. How exactly such interventions are designed and implemented should be left up to the maths counsellors to decide - although the activities should draw on available research results, i.e. be research-based. However, in the design of the program, we were cautious in not predefining a series of intervention activities for at least the following three reasons. First, if predefining interventions, we would also have to predefine potential difficulties that could be remedied by such interventions. A potential danger in this is that the maths counsellors might only have eye for the predefined difficulties and their associated interventions, and thus perhaps miss out 
on other or deeper difficulties that a student may have. Second, various practical issues may come into play when having to implement the interventions under different circumstances within the different schools. Third, it is a well known fact that teaching - and hence also counselling - works better if the teacher possesses enthusiasm. Such enthusiastic teaching/counselling will surely be more likely to occur, if the maths counsellor implements interventions which he or she has a share in, i.e. has conceived, designed, etc.

Finally, it should be mentioned that although we have described the three phases of maths counselling as being disjoint, this is not necessarily true in practice. For example, in the process of diagnosing, minor elements of intervention may already occur. We may think of this as the phases occasionally overlapping or as if there may be a fluent transition from one phase to the next. This being said, it is also clear that in a given counselling of a student, the need for revisiting an earlier phase can occur. This will be the case if new difficulties suddenly reveal themselves in the process of either diagnosing or intervention. A reanalysis of certain detection test items or a rediagnosing may then be needed.

\section{THE PROGRAM}

We now give a description of the actual program as it was implemented in September 2012. To align the structure of the program with the three overall themes, it was decided to let it run over three semesters, thus the first implementation was to end in January 2014. Each semester of the program was estimated to 5 ECTS, i.e. the program counts 15 ECTS in total. This translates to approximately 400 hours of further training for the in-service teachers (including preparation, homework assignments, practical work, etc.). In hindsight, however, the amount of ECTS was severely underestimated.

Each semester consists of an introductory and concluding residential course, each of two days' duration. The reason for this is that it may be easier for the teachers to go away from their schools for four whole days in a semester instead of a number of hours per week. Also, it allows for teachers from all over the country to participate in the course in a quite manageable fashion. In the introductory courses the teachers are introduced to the theme of the semester, the associated curriculum literature of the semester as well as the detection test related to the theme and literature. In between the residential courses of a semester, the teachers carry out the three phases of maths counselling at their respective schools, i.e. they identify and diagnose students with learning difficulties and intervene accordingly. As mentioned, the teachers are asked to document and report everything. At the end of each semester they hand in a miniproject report applying theoretical constructs to their collected data and findings. They carry out and hand in this work in groups of 2-3 teachers. An important feature of these projects is that they are problem oriented, i.e. the teachers must, as part of their project, investigate a specific problem related to students' learning difficulties in mathematics within the theme of the semester. At the concluding courses, the 
teachers present their mini-projects, including their various findings, to each other and take turns acting as opponents (or reactors) of each other's projects. This idea is one taken from the Natural Science Basic Studies at Roskilde University, where every student group is given an opponent group and, similarly, acts as one as well. Experience shows that by having to critically evaluate another group's report (and work) the students learn equally much about their own project work and report writing. For the maths counsellors it is also a way of introducing a culture of constructive criticism, competent feedback, and professional discussion.

In each semester the teachers are provided with a list of literature, divided into three categories: general literature; specific literature; and supplementary literature. The general literature contains a selection of relevant theoretical mathematics education literature focusing on constructs, frameworks and solid findings. (The KOMdescription of mathematical competencies of course makes up an overall framework for all three semesters.) The specific literature deals with relevant issues, studies and findings related to the semester theme. And the supplementary literature list offers various additional texts related to the theme, e.g. more basic introductions, review and survey papers, suggestions for collections, handbooks, etc., but also papers on the role of frameworks, how to research in mathematics education, how to report findings, etc. Our criterion for selecting both general and specific literature was that it should motivate to understand the learning problems which arise with students in the teachers' everyday practice. One of our "philosophies" for choosing literature was to go to the original and classical texts. This was done in order to illustrate to the teachers how actual research is carried out in mathematics education, what constitutes a finding in mathematics education research, how data is collected, analyzed and interpreted using theoretical constructs, etc., since the teachers would be using similar techniques in their future job function as maths counsellors. Allow us to exemplify for one semester.

The general literature for the first semester consisted in an introduction to classical constructs from mathematics education research, which may be used to articulate students' difficulties with mathematical concepts and concept formation. Examples of the constructs used are: Mellin-Olsen's and Skemp's notion of instrumental, relational and logic understanding (Skemp, 1979); the process-object duality by Sfard (1991); Vinner's notion of concept definition and concept image (e.g. Tall \& Vinner, 1981; Vinner \& Dreyfus, 1989); and Duval's (2006) multifunctional and monofunctional registers. The specific literature addressed mathematical concepts and topics relevant for upper secondary school, but also more basic ones. Examples are students' difficulties with the concept of function (e.g. Tall, 1992), concept of limits (e.g. Cornu, 1991; Juter, 2005), and concept of derivative (e.g. Zandieh, 2000), all topics which show up during the mathematics program at upper secondary school. However, knowing that the type of students we were aiming to help often encounter difficulties related to symbols and formalism as well as representation, the specific literature also dealt with algebra and in particular equation solving (e.g. Davis, 1975; 
Filloy \& Rojano, 1989; Vlassis, 2002). If students have difficulties with simple algebraic equations, one of the potential roots of these difficulties is an underdeveloped concept of number. For that reason the specific literature also encompassed studies on students' number concepts, especially fractions (e.g. Fischbein et al., 1995; Sirotic \& Zazkis, 2007; Markovich \& Sowder, 1991). The supplementary literature consisted of the NCTM handbooks (Grouws, 1992; Lester, 2007) and Tall's (1991) Advanced Mathematical Thinking.

Drawing on the available research findings (including the literature mentioned above), one of our first tasks as designers of the program was to devise the previously mentioned instruments for "screening" students for their cognitive understanding as well as their degree of possession of mathematical competencies in those aspects of mathematics which are necessary for upper secondary school. More precisely, three "detection tests" were devised, one for each of the semester themes. The tests were presented to the students under the title of " $N$ Questions from the Professor" (a joke on the phrase "20 questions for the professor"). The number of questions, $N$, in the tests vary from 57 in the test on mathematical concepts, conventions, symbols, etc. through 23 on mathematical arguments, reasoning, proofs and proving to 13 on models, modelling and mathematizing. These numbers are primarily indicative, since questions sometimes contain sub-questions, but they clearly illustrate the difference in nature of the three themes based on how many questions an upper secondary student is able to answer in approximately 90 minutes (the duration of a typical double-session in Danish upper secondary school) without time pressure. We shall not enter into the specific questions of the three detection tests, since a proper treatment calls for three independent papers. However, it should be mentioned that the tests were devised in such a manner that cross referencing within one test as well as between tests to some extent is made possible. For example, if a student in the second detection test shows difficulties in following a certain proof, a cross reference may be made to the first detection test regarding the mathematical concepts involved in the proof in order to find out, if it is the mathematics of the proof that constitutes a stumbling block or not.

Groups of participants, preferably from the same school, do the 3 mini-project together adhering to the theme of the semester. As mentioned, every report is centred on a relevant problem oriented question, which the teachers' practical investigations and work during the semester are to bring insights to. These questions can be of various different types. As an example, one might ask if there are any significant differences in how a first year class of upper secondary students do on the first detection test as opposed to a third year class - if "yes," what are the differences and why exactly these differences, and if "no," how come not? To answer the first part of this question, the teachers would have to approach it quantitatively to see if there are any significant differences. However, the second part of the question could be answered by qualitative methods and data collection during the maths counselling work of phases 2 and 3, i.e. diagnosing and intervention with identified students. As 
an example related to the second semester theme, one question could concern the connections between a specific student's beliefs about mathematics and the proof schemes he or she possesses? Such a question would require no quantitative measures, but in-depth qualitative ones.

Hence, it is quite clear that the groups' choice of a problem oriented question has a clear impact on the methods which they are to apply. And not only this, the questions - and the answers - will also be closely connected to the relevant theoretical constructs of the semester specific literature. Although the teachers may not do actual "research" in mathematics education by means of their project work, it is clear that the approach of their mini-projects is not that different from usual mathematics education research, which they will have encountered in the specific semester literature. And although the teachers may not obtain real research results, they have valuable and valid "findings", many of which will be of an existence type - e.g. that this student had these specific learning difficulties for those reasons - but nevertheless findings that may be quite interesting and sometimes even surprising. As previously touched upon, another commonality with usual research is that the teachers are asked to document and report everything from their diagnostic and intervention work in the schools, whether stemming from field notes, audio recordings, video recordings, students' hand-in assignments, etc.

During the semesters, i.e. in between the introductory and concluding residential courses, the teachers receive supervision. Usually each group has a couple of supervisor meetings, where we discuss everything from their problem formulation, the detection test results, method, use of theory, the writing of the mini-project report, to transcriptions of data, or we watch their video recordings together with them to assist them in their analysis of these.

At the end of the concluding course of third semester, after the groups have presented their own reports and have been reactors to the other groups' mini-projects, they are further asked to put all three mini-projects together into one final report which is to make up the basis for their final exam. The intention here is neither that they just staple all three mini-projects together and hand them in, nor that their write up an entirely new report based on the previous three; but something in between. More precisely, it is expected that the teachers write an extra "chapter" in which they attempt to make some considerations across the three mini-projects, different as they may be.

The final exam follows the usual convention of a Roskilde University group exam, where the group members first take turns presenting different aspects of their projects. This takes up the first half of the examination, and the next half is then followed by an academic discussion, where supervisors and the external examiner are free to ask questions based on the hand-in report. It all ends with the students receiving a grade from the Danish seven point scale $(-3 ; 0 ; 2 ; 4 ; 7 ; 10 ; 12$, where 2 
and up are passing grades) - and in this case also a certificate of having become a maths counsellor for upper secondary school.

\section{CONCLUDING REMARKS}

As explained in the introduction, our overall motivation has been to find ways to assist the kind of students who try hard to learn mathematics, but for whom nothing seems to really happen. Our approach to addressing this question was first to narrow down the areas related to upper secondary students' learning difficulties in mathematics to three specific ones: concepts and concept formation; reasoning, proofs and proving; and models and modelling, since the mathematics education literature and previously conducted research in these three areas are massive. As for the main question of this paper - how to design a research-based maths counsellor program for Danish upper secondary teachers - obviously, the answer is bound to be of an exemplary nature, i.e. an example of an actual design as well as the considerations behind this. In our description, we have accounted for the delicate balance between theory and practice which we have aimed at striking in the design of the program. Also, we have described the three phases of maths counselling initially envisioned and later implemented, including the initial practical considerations, and we have provided a detailed account of the final design of the program, involving detections tests, literature lists, mini-projects, etc. Hence, these accounts make up the answer to the question.

We shall round off with a small status report. As already mentioned, the first maths counsellors graduated in January 2014. The second run of the program began in September 2013, and already 6 months before this, it was over-booked (and we operate with a waiting list for a third run). This illustrates the fact that there is a need felt for a program like this. Hence, the initiative has indeed been justified. So, counting on for the benevolence of the "administrative and financial powers", we hope to continue the program. Denmark has around 200 upper secondary schools, and if each of them is to have one or two maths counsellor, then the program would be guaranteed participants for at least the next 10 years.

\section{REFERENCES}

Cornu, B. (1991). Limits. In D. Tall (Ed.), Advanced Mathematical Thinking (pp. 153-166). Kluwer Academic Publishers.

Davis, R. B. (1975). Cognitive processes involved in solving simple algebraic equations. Journal of Children's Mathematical Behavior, 1, 7-35.

Dreyfus, T. \& Vinner, S. (1989). Images and definitions for the concept of function. Journal for Research in Mathematics Education, 20, 356-399.

Duval, R. (2006). A cognitive analysis of problems of comprehension in a learning of mathematics. Educational Studies in Mathematics, 61, 103-131. 
Filloy, E. \& Rojano, T. (1989). Solving equations: The transition from arithmetic to algebra. For the learning of mathematics, 9, 19-26.

Fischbein, E., Jehiam, R. \& Cohen, D. (1995). The concept of irrational numbers in high-school students and prospective teachers. Educational Studies in Mathematics, 29, 29-44.

Grouws, D. A. (Ed.) (1992). Handbook of Research on Mathematics Teaching and Learning. New York: Macmillian Publishing Company.

Juter, K. (2005). Limits of functions: traces of students' concept images. Nordic Studies in Mathematics Education, 10(3-4), 65-82.

Lester Jr., F. K. (Ed.) (2007). Second Handbook of Research on Mathematics Teaching and Learning. Charlotte, NC: Information Age Publishing.

Markovich, Z. \& Sowder, J. T. (1991). Students' understanding of the relationship between fractions and decimals. Focus on learning problems, Winter Edition.

Niss, M., \& Højgaard T. (Eds.). (2011). Competencies and mathematical learning ideas and inspiration for the development of mathematics teaching and learning in Denmark. English Edition, October 2011. IMFUFA tekst no. 485. Roskilde: Roskilde University. (Published in Danish in 2002).

Sfard, A. (1991). On the dual nature of mathematical conceptions. Educational Studies in Mathematics, 22, 1-36.

Sirotic, N. \& Zazkis, A. (2007). Irrational numbers: The gap between formal and intuitive knowledge. Educational Studies in Mathematics, 65, 49-76

Skemp, R. R. (1979). Goals of learning and qualities of understanding. Mathematics Teaching, 88, 44-49.

Tall, D. (Ed.) (1991). Advanced mathematical thinking. Dordrecht: Kluwer.

Tall, D. (1992). The transition to advanced mathematical thinking: functions, limits, infinity and proof. In D. A. Grouws (Ed.) Handbook of Research on Mathematics Teaching and Learning (pp. 495-514). New York: Macmillian Publishing Company.

Tall, D. \& Vinner, S. (1981). Concept image and concept definition in mathematics with particular reference to limits and continuity. Educational Studies in Mathematics, 12, 151-169.

Vlassis, J. (2002). The balance model: Hindrance or support for the solving of linear equations with one unknown. Educational Studies in Mathematics, 49, 341359.

Zandieh, M. J. (2000). A theoretical framework for analyzing student understanding of the concept of derivative. In Dubinsky, E., Schoenfeld, A. H. \& Kaput, J. (Eds.): Research in Collegiate Mathematics Education. IV. Published by CBMS: Issues in Mathematics Education, 8, 103-127. 


\title{
RADFORD'S LAYERS OF OBJECTIFICATION AS DESIGN PRINCIPLES IN PROVING ACTIVITIES
}

\author{
Andreas Lorange \\ NLA University College, Norway
}

The aim of this paper is to give an example of how Radford's factual, contextual and symbolic layers of objectification can be used as design principles in connection with proving activities related to arithmetic relations. Because concrete actions are central in Radford's description of the factual layer of objectification, physical artefacts will be important in the design of the learning activities. In this case study, I follow four groups of student teachers in their first year of their education, and the analysis of their response to the learning activities is based upon a semiotic-cultural framework.

Key words: Design of learning activities, physical artefacts, layers of objectification and semiotic contractions.

\section{INTRODUCTION}

Within the semiotic cultural framework, Radford has formulated learning in terms of objectification (Radford, 2008a). An important point in this theory is that learning is closely connected to actions aimed at noticing different aspects of the mathematical activity the students are engaged in. Within this theory, Radford (2010a) has introduced the factual, contextual and symbolic layer of objectification in connection with the generalisation of number patterns. Both the theory of objectification and the layers of objectification will be explicated in the next section. Koukkoufis and Williams (2006) have applied Radford's layers of objectification to integer addition and subtraction in connection with the "dice games instruction method". Furthermore, Lorange and Rinvold (in press) have applied these layers to students' strategies for expanding two fractions to a common denominator. In both of these studies, Radford's layers were used as an analysing tool in connection with the students' mathematical activity. My first aim in this paper is to investigate whether Radford's layers might be applied to other fields than those mentioned above. My second aim is to investigate how these layers can be used in connection with the design of learning activities. This means that Radford's theory of objectification, which is a theory of learning, is used as a theory of teaching. As far as I know, no research has been carried out in connection with this second aim. The two aims I have described above are combined in the following research question: How can Radford's layers of objectification be used as design principles in proving activities concerning arithmetic relations for student teachers?

\section{THE THEORY OF OBJECTIFICATION}

The theory of objectification (Radford, 2006b, 2008a) is made to account for the way in which students engage with something in order to notice and make sense of it. The 
process of objectification is closely linked with actions aimed at bringing something to the front of someone's attention or view (Radford, 2006a, p. 6):

The term objectification has its ancestor in the word object, whose origin derives from the Latin verb obiectare, meaning "to throw something in the way, to throw before". The suffix - tification comes from the verb facere meaning "to do" or "to make", so that in its etymology, objectification becomes related to those actions aimed at bringing or throwing something in front of somebody or at making something apparent - e.g. a certain aspect of a concrete object, like its colour, its size or a general mathematical property.

Since mathematical objects are general, they cannot be fully displayed in the physical world. Therefore, the students resort to signs and different kinds of artefacts to express their mathematical experience.

Together with the theory of objectification, the concept of semiotic contraction (Radford, 2008b) will play an important role in the analysis of the students' proving activities. According to Radford, the semiotic contraction is an essential part of the objectification process. As the semiotic contraction takes place, the semiotic activity of the students is condensed into more compact forms. This results in a concentration of meaning and a reduction of the number of actions, words or signs in the mathematical activity, which enables the students to focus on the central elements of the mathematical experience.

\section{RADFORD'S LAYERS OF GENERALITY}

The factual, contextual and symbolic layer of generality (Radford, 2006a, 2010a, $2010 b$ ) emerged in connection with the generalisation of number patterns. Therefore, Radford usually refers to them as layers of generality. Nevertheless, he also refers to them as layers of objectification because his theory of objectification is a general theory. In this section, I will describe these layers, and therefore it is natural to refer to them as layers of generality. However, apart from this section, I have chosen to refer to these layers as layers of objectification. The reason for this is that I find the term "layers of objectification" more appropriate for my study than "layers of generality" because I am generalising these layers to encompass proving activities, which are a more comprehensive issue than the generalisation of number patterns.

The factual, contextual and symbolic layers of generality correspond to generalisation through actions, language and mathematical symbols. The students Radford referred to were to generalise a number pattern that was expressed by a visual representation, see the left part of figure 1.

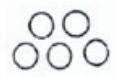

Figure 1

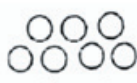

Figure 2

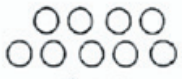

Figure 3
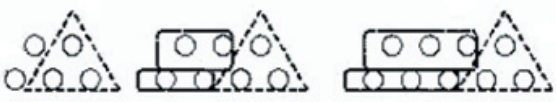

Figure 1: One of the patterns in Radford's studies. The grouping of circles is indicated to the right. 
An example of a way to determine the number of circles in a figure on the factual layer of generality was: "One plus one plus three, two plus two plus three, three plus three plus three" (Radford, 2006a, p. 11). Here the circles were grouped by pointing gestures of the students, see the right part of figure 1. The grouping of the circles intimated that a pattern of actions underlay this generalisation. According to Radford, a factual generalisation is "a generalization of actions in the form of an operational scheme (in a neo-Piagetian sense). This operational scheme remains bound to the concrete level [...]" (2003, p. 47). The crucial element of the factual generalisation is to express the variable quantity, i. e. the figure number, in some way. On the factual layer of generality, this quantity is not articulated in a direct way, but it "is expressed in concrete actions" (Radford, 2006a, p. 9).

Like the factual generalisation, the contextual generalisation also originates from a visual approach to the process of generalisation, but now "the previously constructed operational scheme is generalised through language" (Koukkoufis \& Williams, 2006, p. 165). An example of a contextual generalisation of the number pattern shown in figure 1 is: "You double the number of the figure and you add three" (Radford, 2006a, p. 13). The pattern of action associated with the grouping of circles is no longer in focus, and no gestures were involved. Hence, this is a semiotic contraction of the factual generalisation of the number pattern. A new abstract object, expressed by the formulation "the number of the figure" is introduced and has replaced the previously concrete objects associated with the factual generalisation. The crucial element of the contextual generalisation is to express the variable quantity, i. e. the figure number, in some way. On the contextual layer of generality, this quantity reaches the level of enunciation. In the example above, this was done through the formulation "the number of the figure". According to Radford (2010b), the explicit mentioning of the figure number is a hallmark of the contextual layer of generality.

On the symbolic layer of generality, the generalisation is expressed through mathematical symbols, and a formula for the number of circles in a figure is obtained. In connection with the number pattern that is shown in figure 1 , an example of a symbolic generalisation is " $\mathrm{n} \times 2+3$ " (Radford, 2006a, p. 14). About this layer of generality Radford (2010a, p. 56) says: "The understanding and proper use of algebraic symbolism entails the attainment of a disembodied cultural way of using signs and signifying through them." Here, the symbolic letter " $n$ " is the semiotic contraction of the "number of the figure", and the formula is a semiotic contraction of the contextual generalisation.

\section{METHOD}

The case study was carried out in the autumn of 2013 on my own teacher students in the first year of their education. The field work was conducted in the beginning of the semester. All the students participated voluntarily. The students were given a questionnaire where they were asked to assess their own proficiency in mathematics by placing themselves in one of five categories: "very low", "low", "medium", 
"strong" and "very strong". I did not choose students that had categorised themselves as "very low" because proving is considered as demanding. Neither did I choose "very strong" students because I wanted the students to meet some challenges. I put together four groups, and each group consisted of three students. One group had five sessions, two groups had six, and one group had seven. The reason for this is that the groups had different progression. As an introduction, the groups were working with the generalisation of different number patterns. After that, the groups were working with proving activities related to the following arithmetic relations: The sum of three consecutive integers divided by three is always the middle number, the sum of two odd numbers is always en even number, the sum of two consecutive odd numbers is always divisible by four, and different arithmetic relations related to hundred charts.

Each proving activity consisted of four sub-activities which will be described in more detail in the next sections: one introductory, one factual, one contextual and one symbolic. In these sub-activities the researcher presented a problem to the students in written form. Normally the students were working with the problem without intervention from the researcher. The researcher could intervene if for example there were points in the formulation of the problem that needed to be clarified. When the students had finished the task, they were asked to explain how they reasoned as they were solving the problem. Often the students were asked to write down their explanation before they presented it orally. The researcher did not evaluate the students'solutions. If the students came up with different solutions, the students were asked to discuss between themselves. This worked quite well because the correctness of an answer or the validity of an explanation could be checked against the physical context of the task. After the students had presented their solutions and explanations, the researcher could intervene, for example by summarising some important points in the task. Apart from this, the researcher did not normally teach the students. An exception from this took place when, for example, a student was hampered because he did not know how to factorise an algebraic expression. Then the researcher helped him.

All of the sessions were videotaped. Research notes and a synopsis were written after each session, and all the salient episodes were transcribed. This constituted the raw material of my analysis. Radford's framework as described in the previous sections was used in the analysis. I chose four excerpts from one group which will be analysed in forthcoming sections. These excerpts were chosen because I consider them to be typical examples of responses to the sub-activities that will be described.

\section{THE INTRODUCTORY SUB-ACTIVITY}

Gravemeier and Cobb (2006) state that the instructional starting points have to be "experientially real for the students". This means that one has to "present the students problem situations in which they can reason and act in a personally meaningful manner" (p. 33). In line with this, I wanted to start with an activity where the students 
could experience the arithmetic relation they were to prove later. The following task was given to the students:

Draw a $3 \times 3$ square in the hundred chart. To the right is shown an example of how such a square can be drawn. The square shall be drawn at another place than the squares of the other students in your group. Add the corners in the $3 \times 3$ square and divide by four. What do you discover?

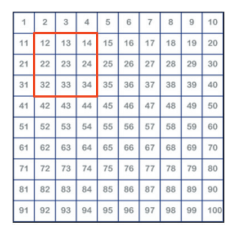

The reason for asking the students to place their $3 \times 3$ squares in different places was that I wanted them to notice the generality of the arithmetic relation they were investigating. Emma chose 75 as the number in the upper left corner in the $3 \times 3$ square, Lisa chose 2 and Jane 38. They all made the same conclusion. For example, Emma wrote: "We discovered that by adding the corners in the $3 \times 3$ square and divide by four, you get the middle number in the square."

\section{THE FACTUAL SUB-ACTIVITY}

Based upon Radford's description of the factual layer of objectification, I worked out the following design principles: The mathematical structure in the problem should be noticed through artefact-mediated kinaesthetic actions. These actions should constitute an operational scheme, and the artefacts combined with these actions should be the semiotic means through which the objectification takes place. Furthermore, the variable should be implicitly expressed through actions. To meet these requirements, I designed the following activity. In figure 1, the counter, cube, stick and big $3 \times 3$ square is reproduced.

Choose one of the three $3 \times 3$ squares that you made. Write the number in the upper left corner in the $3 \times 3$ square on a counter, and put this counter in the upper left corner of the big $3 \times 3$ square. The cube stands for the number 1 , and the stick stands for the number 10 . The same number shall be written on all the counters. Put counters, cubes and/or sticks in the four corners and in the middle square so that the counters, cubes and/or sticks in a square add up to the number in that square. Can you use what you now have done to explain why the sum of the four corners in a $3 \times 3$ square divided by four always equals the middle number in the square?

The purpose of this activity was to bring a certain feature of the $3 \times 3$ square to the front of the students' attention, namely how the numbers in the upper right, lower left, lower right and middle square could be expressed by the number in the upper left corner. The students chose Lisa's number in the upper left corner of the $3 \times 3$ square. After some discussion, the students agreed on the following explanation, which Lisa utters in the excerpt below.

Lisa: We understood that in this diagonal (gliding pointing gesture, picture 1) it is increasing by nine for every number. And in this diagonal (gliding pointing gesture, picture 2) it is increasing by eleven. [...] And we found out that if we move nine from the greatest number to the smallest number in this diagonal (moving one stick from the lower corner of the diagonal to the 
upper, picture 3, and moving one cube from the upper corner of the diagonal to the lower, picture 4), then you have the same number in all three. And here (pointing gesture indicating the other diagonal), there were eleven more. And if you move eleven from the greatest number to the smallest (moving one stick and one cube from the lower corner of the diagonal to the upper, picture 5), then you have the same in all (gliding pointing gesture around the four corners, picture 6). And if you multiply thirteen by four and divide by four, you get thirteen which is in the middle.
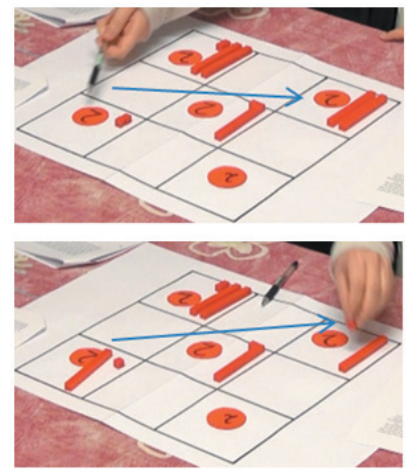
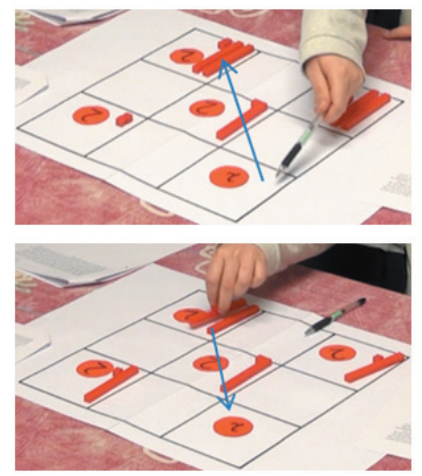
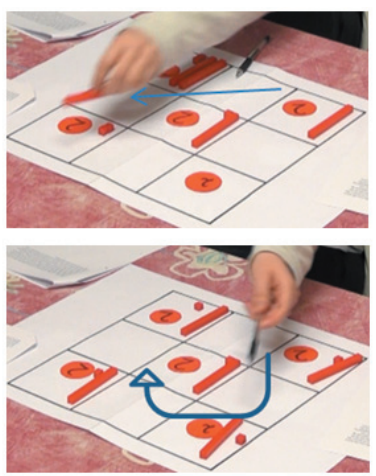

Figure 2: Picture 1 to 3 is on the first row, and picture 4 to 6 on the second.

I will now argue that Lisa's explanation corresponds to a factual layer of objectification. The objectification of the relation between the number in the upper left corner and the numbers in the rest of the corners and in the middle of the $3 \times 3$ square is based upon the placements of the counters, sticks and cubes in the $3 \times 3$ square, and upon kinaesthetic actions with these artefacts. These actions correspond to an operational scheme which is crucial in the objectification of the mathematical structure of the arithmetic relation. Furthermore, her argument is based on the number 2 in the upper left corner of the $3 \times 3$ square. Therefore, the variable in her argument is implicit. Still, there is some generality beneath the surface in her explanation because she consistently refers to the numbers in the corners without actually mentioning these numbers.

\section{THE CONTEXTUAL SUB-ACTIVITY}

From Radford's description of the contextual layer of objectification, we can work out the following design principles: The previously constructed operational scheme from the factual activity should be objectified through language, the variable should be explicitly expressed through language, and the contextual objectification should be a semiotic contraction of the factual objectification. This means that the students must go beyond particular cases and reason in a general way. Therefore, it was important to avoid references to particular cases in the students' explanations. Also, figures could make it possible for the students to elude the challenge of explicit enunciating 
the variable. In order to facilitate a contextual objectification and obtain a higher degree of clarity, Radford recommends that the students should write down an explanation to a generic addressee. This entails that: "Implicit and mutual agreements of face-to-face interaction (e.g., gestures, clue words) need to be replaced by objective elements of social understanding [...]" (Radford, 2003, p. 50). To meet all these requirements, I designed the following task:

Work out together and write down an explanation as to why the sum of the corners in a $3 \times 3$ square divided by four always equals the middle number in the $3 \times 3$ square. Imagine that a fellow student not present today shall be able to understand the explanation. You shall not use figures or mathematical symbols. The explanation shall not refer to particular cases, but it shall be general.

After some discussion between the students, they wrote down their explanations, and afterwards they were asked to read them aloud. As an example of their explanations, I recount Lisa's written explanation below.

Lisa: $\quad$ Mark a three times three square on a hundred chart. Add the four corners and divide by four. Then you see that you get the middle number in the square. In the diagonal from the upper left corner to the lower right, you see that it increases by eleven. In the opposite corner, from the upper right to the lower left, you see that it increases by nine. If you in the diagonal towards right, move eleven from the greatest number to the smallest, you get the same number in all the squares. If you in the diagonal towards left, move nine from the greatest number to the smallest, you get the same number in all the squares in the diagonal. Then you see that there is the same number in all the four corners, which equals the middle number in the square. If you then add the four corners (the same number) and divide by four, you get the same number as the middle.

Now, the variables in the arithmetic relation are explicitly expressed as "the four corners" and "the middle number". Furthermore, the previously constructed operational scheme is objectified through written language. Therefore, no gestures or artefact-mediated kinaesthetic actions were involved. Consequently, Lisa's written message is a semiotic contraction of her factual objectification which was described in the previous section.

\section{THE SYMBOLIC SUB-ACTIVITY}

Based upon Radford's description of the symbolic layer of objectification, I worked out the following design principles: The symbolic objectification should be a semiotic contraction of the contextual objectification, and the symbolic objectification should be expressed through mathematical symbols. To meet these requirements, I designed the following task:

Work out together and write down an explanation as to why the sum of the corners in a $3 \times 3$ square divided by four always equals the middle number in the $3 \times 3$ square. Algebraic symbols shall be a part of the explanation. 
After some discussion, the students wrote down their explanations. As an example, I recount Jane's written explanation. Under this explanation, she wrote: "Where $\mathrm{x}$ is an arbitrary integer, and the number which is topmost left in the square."

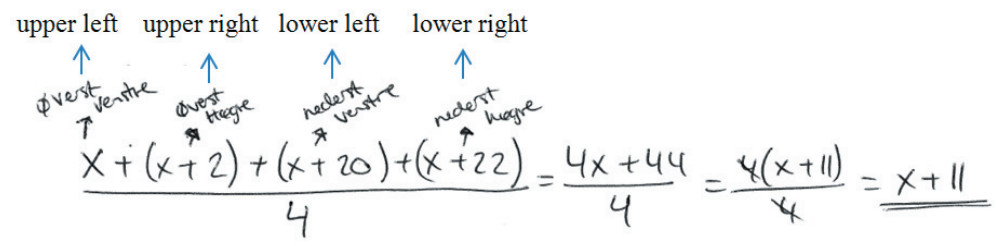

Figure 3: Jane's symbolic explanation. The handwritten words are translated.

The arithmetic relation is now expressed through mathematical symbols. Although the signs are used in a disembodied way, some remnants of the context are still visible, namely the references to the four corners expressed in the handwritten words in figure 3. The variable " $x$ " is the semiotic contraction of "the number which is topmost left in the square". However, this calculation is not a semiotic contraction of the contextual objectification. The reason for this is that this calculation corresponds to the act of collecting the four counters, sticks and cubes, and then dividing this collection into four equal parts. In connection with the contextual objectification eleven or nine was "moved" from the greatest numbers to the smallest in the two diagonals in the $3 \times 3$ square.

$$
\frac{(x+22-11)+(x+11)+(x+20-9)+(x+2+9)}{4}=\frac{(x+11)+(x+11)+(x+11)+(x+11)}{4}
$$

Figure 4: "Moving" of 11 and 9 expressed with mathematical symbols.

This "moving" of eleven and nine could have been expressed through mathematical symbols as shown in figure 4, but the students did not do it this way. In their symbolic explanation, this "moving" of numbers is not visible.

\section{CONCLUSION AND FURTHER RESEARCH}

In this paper, I have given an example of how Radford's layers of objectification can be used as design principles in proving activities concerning arithmetic relations for teacher students. In the factual activity, the objectification of the relation between the number in the upper left corner and the numbers in the rest of the corners and in the middle of the $3 \times 3$ square was based upon artefact-mediated kinaesthetic actions, and the variables in the arithmetic relation were not explicitly enunciated. This was facilitated by asking the students to place counters with the number of the upper left corner, cubes and sticks in the four corners and in the middle of the $3 \times 3$ square so that the counters, cubes and sticks in a square add up to the number in that square. In the contextual activity, the previously constructed operational scheme was objectified through written language, the variables were explicitly expressed, and the contextual objectification was a semiotic contraction of the factual objectification. This was facilitated by asking the students to write down a written explanation to a fellow 
student not present without using figures and mathematical symbols. In the symbolic activity, the arithmetic relation was expressed through algebraic symbols. However, the symbolic objectification was not a contraction of the contextual objectification, because the symbolic objectification had another mathematical structure than the contextual objectification.

This case study has been a first attempt to use Radford's layers of objectification as design principles of learning activities. One of the design principles of the symbolic activity was that the symbolic objectification should be a semiotic contraction of the contextual objectification. In the excerpt from one of the symbolic activities I have analysed in this paper, this was not the case. One area of further research is therefore to find out more about to what degree this design principle is fruitful. In connection with the factual sub-activity, the written instruction to the students helped the students and guided them to solve the problem in a special way. Another question for further research is therefore how the factual activity could be designed in a more open-ended way, leaving more of the work to the students.

Radford's descriptions of the factual, contextual and symbolic layers of objectification were developed in connection with the generalization of number patterns which are discrete problems. Therefore, one constraint of Radford's work for the design of learning activities is that it is difficult to use these layers in connection with problems where the variable is not an integer. The applicability of Radford's layers would be greatly increased if one could modify the descriptions of these layers so that they also could encompass continuous problems. One question for further research is how such a modification could be done.
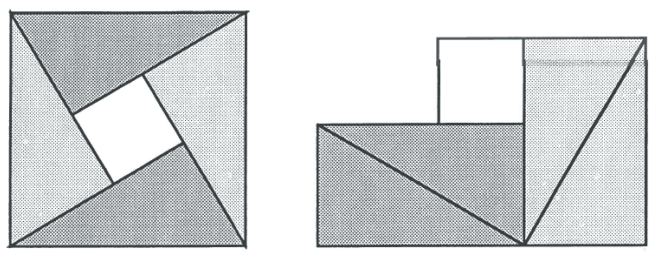

Figure 5: A visual representation of Bhaskara's first proof of the Pythagorean theorem.

As an example of this, let us consider Bhaskara's first proof of the Pythagorean theorem, see figure 5. According to Radford's description of the factual layer of objectification, the sides in the right-angled triangles should not be expressed explicitly. In this context such a design principle might seem rather artificial, and it will be difficult to describe the parts of the figure without explicitly referring to the sides of its components. Therefore, I suggest that this design principle is removed in connection with continuous problems. In this generalization of Radford's layers, I retain that the mathematical structure in the problem should be noticed through artefact-mediated kinaesthetic actions as an operational scheme on the factual layer. I also retain the design principles I have worked out from Radford's description of the contextual and symbolic layers. The main point is that the objectification takes place 
through semiotic means such as physical artefacts, language and mathematical symbols, and that semiotic contractions take place.

\section{REFERENCES}

Gravemeier, K., \& Cobb, P. (2006). Design research from the learning design perpective. In v. d. Akker, K. Gravemeijer, S. McKenney \& N. Nieven (Eds.), Educational Design research: The design, development and evaluation of programs, processes and products (pp. 45-85). London: Routledge.

Koukkoufis, A., \& Williams, J. (2006). Semiotic objectifications of the compensation strategy: En route to the reification of integers. RELIME. Revista latinoamericana de investigación en matemática educativa, 9(1), 157-176.

Lorange, A., \& Rinvold, R. A. (in press). Students' strategies of expanding fractions to a common denominator - a semiotic persepective. Nordic Studies in Mathematics Education.

Radford, L. (2003). Gestures, Speech, and the Sprouting of Signs: A SemioticCultural Approach to Students' Types of Generalization. Mathematical Thinking and Learning, 5(1), 37-70.

Radford, L. (2006a). Algebraic Thinking and the Generalization of Patterns: A Semiotic Perspective. In S. Alatorre, J. L. Cortina, M. Sáiz \& A. Méndez (Eds.), Proceedings of the 28th Conference of the International Group for the Psychology of Mathematics Education, North American Chapter, Mérida: Universidad Pedagógica Nacional, November 9 - 12 (Vol. 1, pp. 2-21).

Radford, L. (2006b). Elements of a Cultural Theory of Objectification. Revista Latinoamericana de Investigación en Matemática Educativa, Special Issue on Semiotics, Culture and Mathematical Thinking, 103-129.

Radford, L. (2008a). The ethics of being and knowing: Towards a cultural theory of learning. In L. Radford, G. Schubring \& F. Seeger (Eds.), Semiotics in mathematics education: epistemology, history, classroom, and culture (pp. 215-234). Rotterdam: Sense Publishers.

Radford, L. (2008b). Iconicity and contraction: a semiotic investigation of forms of algebraic generalizations of patterns in different contexts $Z D M, 40(1), 83-96$.

Radford, L. (2010a). Layers of generality and types of generalization in pattern activities. $P N A, 4(2), 37-62$.

Radford, L. (2010b). Signs, gestures, meanings: Algebraic thinking from a cultural semiotic perspective. In V. Durand-Guerrier, S. Soury-Lavergne \& F. Arzarello (Eds.), Proceedings of the Sixth Conference of European Research in Mathematics Education (CERME 6) (pp. XXXIII - LIII). Lyon: Université Claude Bernard. 


\title{
DEVELOPING AN IDENTITY AS A SECONDARY SCHOOL MATHEMATICS TEACHER: A PROSPECTIVE TEACHER'S NARRATIVE
}

\author{
Kirsti Rø \\ University of Agder, Norway
}

The paper discusses the case of Benedicte, a prospective secondary school mathematics teacher undergoing a one-year teacher training program at university. A narrative interview conducted at the end of the first semester of her teacher training reveals a story of a student teacher in mathematics acting as a broker when crossing boundaries between communities of practice in university teacher education and school. The case of Benedicte is further an example of learning during boundary crossing in terms of reflection, which appears as changes in her relationship with mathematics and mathematics teaching.

Key words: identity, narrative, community of practice, boundary crossing, brokering

\section{INTRODUCTION}

Research on mathematics teacher identities has expanded in recent years with the mutual goal to better understand and support the needs of (pre-service) mathematics teachers (Beijaard, Meijer, \& Verloop, 2004; Ponte \& Chapman, 2008). The increased number of studies on professional identity has coincided with what Lerman (2000) denotes as the social turn in mathematics education. He stresses the need for extending the unit of analysis from concerning the individual mathematics teacher to also including the social practices in which the teacher participates. Thus, researchers have begun to draw on situated or sociocultural perspectives by proposing that teachers' learning should be understood as increasing participation in socially organised practices that develop the teachers' professional identities (Lerman, 2000; Peressini, Borko, Romagnano, Knuth, \& Willis, 2004).

The paper is part of a Ph.D. study of novice mathematics teachers' experiences of undergoing the transition between mathematics teacher education at university and a professional debut at school. By listening to their voices, I explore how prospective mathematics teachers develop their identities, as they participate within and at the boundaries of various communities of practice in university and school (Akkerman \& Bakker, 2011; Wenger, 1998). Further, my attention is directed towards the teachers' descriptions of selected areas of mathematics content and how these descriptions are changing in relation to the teachers' experiences of undergoing the transition. This last dimension of the Ph.D. project is not covered in the current paper. The longitudinal research design includes a series of semi-structured interviews distributed across a group of prospective teachers in their last year at university and in their first year at school. It contains teachers' narratives of the transition between university and school, in addition to discussions about mathematics problems related 
to a selected content area of mathematics. This paper stems from the first part of the data collection, taking place in the pre-service mathematics teachers' last year at university. Based on a narrative interview concerning a pre-service teacher's experiences from university teacher education, I present the case of Benedicte. The research question is:

- What characterises a prospective mathematics teacher's experiences of participation at the boundaries of communities of practice in university teacher education and school?

The paper addresses a limited research field on Norwegian mathematics teacher education and mathematics teachers' early careers, and on secondary mathematics education and teaching (Bulien, 2008; Ensor, 2001). Related Nordic research is Palmér's (2013) study of primary school mathematics teachers' professional identity development, Persson's (2009) study of changes in prospective primary school mathematics teachers' approaches to mathematics and mathematics education, and Häll's (2006) investigation of novice teachers' arguments for mathematics teaching in compulsory school.

\section{THEORETICAL FRAMING}

My point of departure is viewing the process of becoming a mathematics teacher as a learning process where mathematics teachers grow into the practice in which they engage (Jaworski, 2006). This entails participating in a number of different communities: in mathematics courses at the university, teacher education courses and school placement, in the teacher common room and in the classroom. Further, teacher learning is a process of identity development, since it transforms the teacher's ability to participate in the world by changing all at once who the teacher is, her practices and her communities (Wenger, 1998). In order to explore how prospective mathematics teachers enter, learn from and contribute to various communities in the transition between university and school, I build on Wenger's (1998) theory of communities of practice. According to him, becoming a knowledgeable participant in a community involves a process of interaction between the competence that the community has established over time (i.e. what it takes to act and to be recognised as a competent member), and one's on-going experience of the world as a member. It is within this interplay of social competence and personal experience that learning takes place - a dynamic, two-way relationship between people and the social learning system in which they participate. The result is both personal transformation in terms of identity development, and evolution of social structures.

For prospective mathematics teachers, learning can take place when they enter communities of practice during teacher training as peripheral participants and gradually develop as central participants (Lave \& Wenger, 1991). A gradual change in participation, from the periphery towards the centre, can be described in terms of modes of belonging: engagement, imagination and alignment (Wenger, 1998). Within the community, the prospective mathematics teacher engages with ideas about 
mathematics and mathematics teaching through engagement in communicative practice and develops the ideas through exercising imagination. Further, the prospective teacher aligns with conditions or characterisations of the practice. The term alignment has later been modified by Jaworski (2006) into critical alignment, a means of not just aligning with practice as established in the community, but of looking critically at that practice while aligning with it. Further, the boundary of a community is constitutive of what counts as central participation and what does not. Other learning opportunities will therefore occur at the boundaries, as the prospective mathematics teacher is exposed to foreign competences when she enters other communities in school and may try to create bridges across them and former communities (Wenger, 1998). Based on Wenger's notion of boundaries, I explore transitions between communities of practice at university and at school in terms of boundary crossing, as prospective mathematics teachers do the work of reconciliation of different forms of memberships in various communities.

Continuities across boundaries can be created from brokering, which is provided by people who can introduce elements of one practice into another (Wenger, 1998). The prospective mathematics teacher may act as a broker when bringing ideas of mathematics teaching stated in teacher education into communities of mathematics teachers in school. But acting as a broker is challenging and uncomfortable, since it requires enough legitimacy to influence the development of practice within a community, and enough courage to address conflicting interests. Hence, entering school as a student teacher can be described as an experience of confrontations between one's own expectations about teaching and expectations stated by teacher education, students in the classroom or tutors.

In Akkerman and Bakker's (2011) review of research literature on boundary crossing, boundaries are defined as "sociocultural differences leading to discontinuities in action and interaction" (p. 133). The definition highlights that boundaries are not about sociocultural differences per se, but instead, boundaries are being "real in their consequences" (Akkerman \& Bakker, 2011, p. 152). Thus, unlike describing sociocultural differences between university and school, I study how the differences across communities play out in and are being shaped by the process of developing mathematics teacher identities. By overcoming discontinuities, boundary crossing carries a potential to learn about practices and about one's own identity. Akkerman and Bakker present potential learning mechanisms that may occur when crossing boundaries, two of them concerning processes of making sense of practices in multiple contexts. Identification entails a renewed sense of practices and related identities, by encountering and reconstructing boundaries but not being able to overcome discontinuities. Learning in terms of reflection will result in an expanded set of perspectives and a new construction of identity, which in turn will have an impact on future practice. In terms of brokering (Wenger, 1998), I view reflection as the desirable learning outcome when one is reconciling memberships across communities, and consequently, is trying to establish continuity across boundaries. 


\section{METHODOLOGY}

In order to make an operational approach to the concept of identity, I follow Elliott (2005), who claims that narratives provide the means to understand oneself as living through time. In cases of prospective mathematics teachers, they can make sense of their experiences from participating in different communities of practice by creating narratives composed of recollections of the past and perceptions of the present (Jansen, Herbel-Eisenmann, \& Smith III, 2012). I search for narratives being categorised as reflective (Bjuland, Cestari, \& Borgersen, 2012), meaning that the mathematics teachers "look back and consciously reflect about personal experiences" (p. 407) and relate those experiences to the present situation. Hence, I choose a retrospective point of view on mathematics teachers' experiences of the transition from university to school. However, the presented definition of boundaries and boundary crossing entails a longitudinal research design when investigating how the transition between university education and professional debut in school plays out in and is shaped by the process of developing mathematics teacher identities. Due to the progression of the Ph.D. study, the transition between education and work is not covered in this paper.

In the Ph.D. study, I am concerned with identifying narratives told by a group of preservice mathematics teachers through a series of interviews distributed across their last year at university and their first year as mathematics teachers at school. Inspired by Elliott (2005), the interviews start with an invitation to talk about specific instances and situations from the informant's experiences of being a student teacher in mathematics. An example of an invitation is: "Can you tell me about your time in university? Please, start with your first year as a university student, describe experiences from university studies in mathematics, and continue with experiences from the teacher training program". During this session I should avoid interrupting the story, giving the informant time to elaborate on important instances. The storytelling is followed by questions outlined in an interview guide, to go into details in important sections of the story.

This paper is based on data from an interview with one prospective mathematics teacher, carried out at the end of her first semester in a one-year full time teacher training program at the university. From inductive coding of the interview transcripts (Miles \& Huberman, 1994), I have investigated current communities of practice based on Wenger's (1998) three dimensions: mutual engagement, joint enterprise and shared repertoire. Further, different forms of participation are distinguished in terms of modes of belonging: engagement, imagination and alignment (Wenger, 1998). This is supposed to provide evidence of learning possibilities within and at the boundaries of various communities of practice at university and at the practice school. In order to detect experiences of boundary crossing, I have compared descriptions of memberships, having different locations in communities, with experiences of discontinuities. According to Jansen et al. (2012), a sociocultural difference has led to experiences of discontinuities if the teacher has experienced a 
change in his or her attitudes over time and concurrently reports a meaningful difference between settings. Hence, I have searched for reported differences between settings at the university and at the practice school which are frequently mentioned, with magnitude terms (such as "a lot", "very", "much more"...) and/or with a high level of details in the descriptions. Further, I have located attitude statements, as indicated by expressions of feelings and emotions, and preference statements, such as desires for learning activities. Since the data stems only from the first of a series of interviews, it is not possible to make comparisons of statements over time, and consequently, the description of the prospective mathematics teacher's identity development is limited. Nevertheless, the informant's reflections of personal experiences may reveal a shift in identifying oneself as a pre-service mathematics teacher.

\section{THE CASE OF BENEDICTE}

In Norway, there are two university teacher education programs which qualify for teaching in secondary school: a five-year Master's program including teacher training (LUR), and a one-year, post-graduate teacher training program (PPU). Benedicte started on a five year Master's program in science and mathematics teaching with a great amount of scepticism. Even though she had developed an interest for the subjects in her own schooling, the choice of applying to teacher education was made due to motivation problems with her original plan of becoming a music therapist. Hence, becoming a mathematics teacher was not Benedicte's first choice. After one year of mathematics and physics studies, she went through a personal crisis, which also had implications for her studies. Having failed on a series of exams, she came back to teacher education after one year of leave and with a goal of finishing her teacher studies. She met a new defeat when not being approved for the first teacher training semester within the LUR-program, due to failures on earlier exams. Hence, she chose to leave the five-year teacher education program, and instead finish a Bachelor's Degree in physics. After having resumed exams from her first year with university mathematics and physics, she is at present a student at the one-year teacher training program (PPU). Due to a non-approvable combination of subjects in physics, her teaching subject is mathematics. Benedicte's story includes experiences of demanding studies, undesirable changes in plans and mixed feelings towards mathematics and mathematics teaching. However, the story also reveals changes in the way she look at herself as a student teacher in mathematics. In the following, I will elaborate on her work of reconciliation of different memberships across community boundaries, and how being a broker contributes to changes in her mathematics teacher identity.

The narrative reveals memberships in two communities of practice during university teacher education: the community of student teachers in science and mathematics, and the community of teachers and students in the practice school. Benedicte describes the former as both comforting and fascinating. 
12 Benedicte: I came into a very nice class, so I have brought this class environment with me, even after leaving them (...) so even though I changed the study program, I had, they were my student friends, the handsome guys in physics that [laughs] were a race of their own, in which I belonged (...) It created a kind of affinity and identity.

By aligning with the community of fellow students, Benedicte's scepticism towards the teacher education program was transformed into a feeling of familiarity and safeness. Although she left the class due to changes in her study progression, Benedicte still feels connected to the group of former fellow students. However, her relationship towards mathematics and mathematics teaching is double edged. On the one side, she finds the subject interesting and appealing, and she has had good experience of communicating mathematics to peers during her own schooling. Further, having a genuine interest for students and their needs, her dream is to become a teacher in school with the possibility of deriving advantage of an additional educational background in psychology. On the other hand, becoming a teacher in mathematics remains a second choice for Benedicte. As university studies did not turn out the way she had wished for, her reconsideration of future plans includes a dream of becoming a teacher in physics. Being a student teacher in mathematics was therefore an experience of defeat, but this changed during her school placement:

64 Benedicte: It was a defeat, because physics has always been my favourite subject. [I: Ah, I see...] And then, suddenly I am going to be a math teacher [laughs] [I: Ok] I have always thought that I may teach other subjects, but... physics is what I have found the most interesting. [I: Yes, $\mathrm{mhm}]$. (...) the starting point was, yuck, I'm going to have forty hours of teaching practice in mathematics, it will never turn out well, eh... and, when I was sitting in the lectures... for instance the math didactician that is saying, Skovsmose and landscapes of investigation (...) thinking, yeah, sure! I will never have use for this. (...) Then, I decided, yes, I'm going to have practice in mathematics, and... I can at least try to use some of the things they are talking about, and decide what I think about it, although, I'm critical (...) and I have to say, I have become kind of redeemed as a mathematics teacher.

Through peripheral participation in the community of the tutor and students during school placement, Benedicte finds a leeway of trying out tools and methods from teacher education. She aligns with the joint enterprise of facilitating mathematical discussions among students, and she negotiates her classroom practice through dialogues with the students.

80 Benedicte: I was quite lucky with my tutor, I will say (...) he and I... we matched. He was quite strict and he knew what he thought was best, and he preferred... ten minutes of summing up and theory, then tasks and closing. (...) So he was strict, and I found out that, ok, then I have to work within these frames and at the same time try to use drips and drops. And I was quite concerned with, that I had a good starting point, because he had worked with the class in that they were quite used to be questioned. 
In return, she gains feedback from the students in the shape of engagement in the mathematics activities.

117 Benedicte: And... in the beginning they were like, ah... I don't get it. But I let them talk in pairs, so then, I tried to create some verbal activity, because I thought I wanted to try this thing of approaching rich problems and approaching an, eh... investigation, even though it was a quite theoretical investigation, it was at least a start. And when I saw how it worked out, I became surprised, because... they caught it. (...) and it was very nice to see that, at that point, they understood it, and they found, kind of understood how I worked.

Benedicte's engagement is related to her imagination of being a mathematics teacher who communicates mathematics as an applicable and varied subject, and which is available for student at all levels. Her preference for seeing the relevance of mathematics also appears in her attitudes of being a mathematics student teacher.

860 Benedicte: So, the thing of... being able to develop myself in understanding math, it has during the practical parts of mathematics education lessons been very useful and in a way given me more insight in and belonging to mathematics, because I see now that I can be a part of it, too. (...) This I can handle, and this I can use. And I see the usefulness, that it is nice to put it into school, let the students experience something different and this interests me as well.

The story also reveals a position at the boundary of the community of prospective mathematics teachers and teacher trainers at university. By viewing a mathematics teacher career as a second choice, she initially established a distance towards the lectures in mathematics education in the teacher training program and threw it away as something useless. However, she describes a shift in her relation with mathematics teaching in terms of "before and after" teaching practice. She is now able to see the practice of one of the setting in light of the other, and hence, she discovers new aspects of mathematics teaching and learning and a new initiative to become a mathematics teacher in school.

148 Benedicte: So I have kind of seen that suddenly, from throwing away the nonsense which was before practice, to say that, yes, I give it a chance, it has been so fun to see that, wow; this has given me new initiative.

925 Benedicte: I see a very clear division, before practice, this is just nonsense and the resistance, to become able to see more from what has happened, it is easier to relate it to something and you become prepared for what is being talked about, that you see more connections there. So I think that for the spring semester I will be more positive, look at it as something useful, than what I did in the beginning, hopefully.

In parallel with reporting a change in her relation towards mathematics, Benedicte is talking positively about the meeting with students during school placement. Glimpses of progress in the students' work give her confirmation and support in developing her teaching practice. 
421 Benedicte: You see it in the hidden, that heh, there are things which have worked out, and it is an affirmation, a confirmation, that I am on the right track. And that is inspiration to move forward.

These positive experiences of teaching mathematics have brought her closer to both the subject and the mathematics teacher role.

337 Benedicte: (...) now that I have worked and been out in practice, the mathematics has in a way returned to me, and I have actually, I am able to acknowledge and smile and accept and say yes, I am a mathematics teacher and I am therefore kind of a mathematician even though it feels a bit strange to say that.

The renewed interest in mathematics and mathematics teaching can further be connected to Benedicte's work of brokering. She is crossing the boundary of the community of prospective mathematics teachers and teacher trainers by forcing herself to try out "drips and drops" during practice, and she finds this encouraging. Nevertheless, it is her genuine interest in students and their needs that creates continuity across boundaries, and hence, enables brokering. She has experienced positive outcomes when focusing on trustful relations with students during school placement. Consequently, her main interest is mathematics in the context of teaching, rather than mathematics as a subject in itself.

160 Benedicte: And... it is an everyday challenge (...), I am so happy I do not need to twist my head and think about solving triple integrals. [I: Mhm] But I get to twist my head in thinking how should I work with trustful relations in order to make a safe classroom so that it is ok to ask, it is ok to make mistakes, so I can hear how they are thinking to be able to make progress (...).

By being a broker, Benedicte is also able to critically align with her tutor in school. This act of reflection, when evaluating one practice against another, and simultaneously expanding one's perspectives on the practices, is a significant contribution in her shift in attitudes towards mathematics teaching.

895 Benedicte: So I found it nice to come away from all the talking, to be in school, and actually see that, eh, I did catch something, the part of being critical. Thinking that, ok, I am not fully agreeing with what you are doing as well. So that, there are some drips and drops that has come along, that has in a way influenced my attitude during practice.

In the case of Benedicte, it is not a well-built interest in mathematics which makes up a basis for developing a mathematics teacher identity. Contrarily, positive experiences of mathematics in the context of teaching has resulted in new initiative for developing her teaching practice, and consequently, strengthened her interest in mathematics. The continuity along this developmental process is her engagement for students' learning. Benedicte summarises her teacher role in the following utterance:

250 Benedicte: (...) a math teacher with focus on relations and trust, as an approach for achieving learning. 


\section{DISCUSSION}

The paper draws on a framework in which learning is understood as identity development, when a person participates within and at the boundaries of communities of practice (Wenger, 1998). In addition to recognise the learning potential that resides in a community, the framework takes into account learning during boundary crossing, where reflection is the desirable learning outcome (Akkerman \& Bakker, 2011). Analysis of a prospective teacher's narrative in terms of participation in communities of practice at university and at school has showed a possibility for a peripheral participant to act as a broker. Further, the study shows that the learning potential from being a broker is substantial. Even though Benedicte is not likely to make permanent change of the practice in either of the communities, the learning outcome from creating continuities across boundaries is powerful enough to develop her mathematics teacher identity in terms of a changed relation towards mathematics and mathematics teaching. From being a sceptical student teacher in mathematics in advance of teaching practice, she now reports that she has become a prospective mathematics teacher with engagement in further developing her mathematics teaching practices. The continuation of this paper is a longitudinal investigation of Benedicte's and an additional group of prospective mathematics teachers' way throughout teacher training and into school as mathematics teachers. It thus remains to be seen whether and how brokering takes place when undergoing the transition between university education and the professional debut in school.

\section{REFERENCES}

Akkerman, S. F., \& Bakker, A. (2011). Boundary crossing and boundary objects. Review of Educational Research, 81(2), 132-169.

Beijaard, D., Meijer, P. C., \& Verloop, N. (2004). Reconsidering research on teachers' professional identity. Teaching and Teacher Education, 20(2), 107128.

Bjuland, R., Cestari, M. L., \& Borgersen, H. E. (2012). Professional mathematics teacher identity: Analysis of reflective narratives from discourse and activities. Journal of Mathematics Teacher Education, 15(5), 405-424.

Bulien, T. (2008). Matematikkopplevelser $i$ loererutdanningen: En fenomenologisk orientert narrativ analyse av studenttekster [Mathematical experiences in teacher education: A phenomenological oriented narrative analysis of student texts] (Doctoral dissertation, University of Tromsø). Tromsø: University of Tromsø.

Elliott, J. (2005). Using narrative in social research. London: Sage Publications.

Ensor, P. (2001). From preservice mathematics teacher education to beginning teaching: A study in recontextualizing. Journal for Research in Mathematics Education, 32(3), 296-320.

Häll, M. B. (2006). Allt har förändrats och allt är sig likt: En longitudinell studie av argument för grundskolans matematikkundervisning [Everything has changed 
and all remains the same: A longitudinal study of arguments for mathematics teaching in compulsory school] (Doctoral dissertation, Linköping University). Linköping: Linköping University.

Jansen, A., Herbel-Eisenmann, B., \& Smith III, J. P. (2012). Detecting students' experiences of discontinuities between middle school and high school mathematics programs: learning during boundary crossing. Mathematical Thinking and Learning, 14(4), 285-309.

Jaworski, B. (2006). Theory and practice in mathematics teaching development: Critical inquiry as a mode of learning in teaching. Journal of Mathematics Teacher Education, 9(2), 187-211.

Lave, J., \& Wenger, E. (1991). Situated learning. Legitimate peripheral participation. Cambridge: Cambridge University Press.

Lerman, S. (2000). The social turn in mathematics education research. In J. Boaler (Ed.), Multiple perspectives on mathematics teaching and learning (pp. 19-44). Westport, CT: Greenwood Press.

Miles, M. B., \& Huberman, A. M. (1994). Qualitative data analysis: An expanded sourcebook (2nd ed.). London: Sage Publications.

Palmér, H. (2013). To become - or not to become - a primary school mathematics teacher: A study of novice teachers' professional identity development (Doctoral dissertation, Linnaeus University). Växjö: Linnaeus University.

Peressini, D., Borko, H., Romagnano, L., Knuth, E., \& Willis, C. (2004). A conceptual framework for learning to teach secondary mathematics: A situative perspective. Educational Studies in Mathematics, 56, 67-96.

Persson, E. (2009). Det kommer med tiden: Från lärarstudent till matematiklärare [It will improve with time: From student teacher to mathematics teacher] (Doctoral dissertation, Stockholm University). Stockholm: Stockholm University.

Ponte, J. P., \& Chapman, O. (2008). Preservice mathematics teachers' knowledge and development. In L. D. English, M. B. Bussi, G. A. Jones, R. A. Lesh, B. Sriraman \& D. Tirosh (Eds.), Handbook of international research in mathematics education (pp. 223-261). London: Routledge.

Wenger, E. (1998). Communities of practice: Learning, meaning and identity. Cambridge: Cambridge University Press. 


\title{
PRESCHOOL TEACHERS' PERCEPTIONS OF THE ROLE OF VIDEOS IN PROFESSIONAL DEVELOPMENT
}

\author{
Ola Helenius ${ }^{1}$, Maria L. Johansson ${ }^{2}$, Troels Lange ${ }^{3}$, Tamsin Meaney ${ }^{3}$, \\ Eva Riesbeck ${ }^{3}$, Anna Wernberg ${ }^{3}$ \\ ${ }^{1} \mathrm{NCM},{ }^{2}$ Luleå University of Technology, ${ }^{3}$ Malmö University
}

This paper presents the results of a pilot study using questionnaires on the role of video case studies in professional development material for preschool and preschool class teachers in Sweden. Although the analysis of the results show that some questions in the questionnaire need adapting, generally it seems that it is possible to find out information about the impact of specific aspects of a PD programme. The results of the pilot study suggest that teachers found videos particularly useful in developing their understandings of mathematics in preschools and children's learning of mathematics in preschools. They found it difficult to make connections between the videos and the relationships that they were developing with other preschool teachers, with the children and with others at their preschools.

\section{USING VIDEOS IN PROFESSIONAL DEVELOPMENT}

In this paper, we report of the findings from a small pilot study investigating Swedish preschool and preschool class teacher's opinions on the use of videos in a large scale professional development (PD) programme on mathematics. Although the use of video in preservice and inservice PD has been documented for several decades, there are few research studies that have documented the impact of the video component in these programmes. Where the use of video has been evaluated, it is often the teachers' own teaching which is videoed (see for example, Meaney, Trinick \& Fairhall, 2011; Borko, Jacobs, Eiteljorg, \& Pittman, 2008; Sherin \& van Es, 2009).

An alternative use of videos in professional development is that of videopapers.

A videopaper is therefore a marriage of the traditional paper written by researchers and academics (but not exclusively so) and videotaped classroom footage of teachers and students working in real classroom situationsCombining the video with the text creates a fluid document that is more explicit than the text or video alone, while remaining contained and controlled by the author. (Oliviero, John, Sutherland, 2004, p. 183)

Although videopapers include a range of resources that participants can use in any order, it is the combination of video case studies with written material which has shown interesting results. Nemirovsky, DiMattia, Ribeiro, and Lara-Meloy (2005) suggested that the way that teachers discussed videoed case studies was more reflective than when only written descriptions of the case studies were provided. However, teachers watching video case studies remained unsatisfied with the 
background information provided about what they were watching and this affected their understanding about what was happening in the case study.

As designers of materials that were to be used in a large PD for preschool and preschool class teachers, we had included the watching of videos with written materials with the expectation that this would support teachers to reflect on their teaching. As part of a larger study to investigate how these materials were received and used by teachers, we wanted to find out about how the videos were received. This pilot study describes the methodology we used to gage teachers' perceptions. The results suggest that questionnaires do provide more than "happiness indicators" (Sarama, \& DiBiases, 2004, p. 417) as the teachers provided specific details about the role they considered the video material had in their PD.

\section{PROFESSIONAL DEVELOPMENT OF PRESCHOOL TEACHERS}

As a result of international comparisons, concern about school students' mathematics achievement have become common place in discussions in many countries (see for example, Clements \& Sarama, 2007). Sweden is no exception and with continuing poor results (Skolverket, 2013), a significant amount of money has been put into providing professional development to teachers in preschools through to the adult education section in order to ultimately raise Swedish students mathematics results (Skolverket, 2012).

However, in a review of the international research on continuing professional development (CPD) in mathematics education Joubert and Sutherland (2008) arrived at the conclusion that the impact of preservice and inservice programmes is very limited. As well, there is little research on professional development in mathematics for preschool teachers. In a literature review for the US Department of Education, Zaslow et al. (2010) found only seven studies in which the impact of professional development in mathematics for preschool teachers was evaluated. Often when these programmes are evaluated, the criteria against which they are compared was to do with how easily children were eased into school mathematics. For example, Perry, Dockett and Harley (2007) worked on numeracy development, something heavily emphasised in the first years of school, with a small group of preschool teachers in Australia. In the United States, specific intervention studies are set up to ensure that children started school with appropriate mathematical knowledge and included teacher professional development as one component (for example Clements \& Sarama, 2008; Baroody, Eiland, Thompson, 2009).

Given that the Swedish preschool curriculum (Skolverket, 2011) has no outcomes for children but rather has outcomes for preschools, evaluating the impact of PD for preschool and preschool class teachers against student outcomes was not appropriate. Therefore, in evaluating the impact of the PD, we wanted to compare teachers' perceptions of the materials and their usefulness in developing their mathematical 
teaching practices against our design principles (Helenius et al., 2014 forthcoming). The videos were included to support teachers to reflect on their current practices, as well as present examples of new practices and so it seemed valuable to begin our evaluation of the materials by looking at this component.

Skolverket provides strict guidelines for the structure of the web-based PD material as well as indications of the content to be covered (see Skolverket, 2012). However, it was our choice to include videos of young children engaged in mathematical activities that we had filmed, with specifically written texts, reflection questions and tasks to undertake in their own preschool or preschool class (see http://matematiklyftet.skolverket.se). In this paper, we use questionnaires to explore teachers' perceptions of the video case studies, in relationship to whether they were responding to them in the way that we had anticipated, using our model for designing professional development material.

\section{QUESTIONNAIRES FOR DATA GATHERING}

Sarama and DiBasis (2004) were extremely critical of the use of questionnaires in evaluating the effectiveness of professional development because "this information tends to be highly subjective and not particularly reliable" (p. 417). However, Desimonde (2009) queried such judgements. From her secondary analysis of previous research, she found that:

Answers to survey questions are best used to answer defined, discrete questions about frequencies and trends, specific features of professional development, and instructional time spent on specific content and practices. Teacher surveys that ask behavioral and descriptive, not evaluative, questions about the teachers' professional development experiences and teaching have been shown to have good validity and reliability (Desimonde, 2009, p. 190)

Therefore, in designing our questionnaire, we took into consideration Desimonde's (2009) stipulations. However, before listing the actual questions and results, we describe the framework for the design of the professional development materials, and on which we based the questions for the questionnaire.

\section{DESIGNING WEB MODULES FOR PRESCHOOL AND PRESCHOOL CLASS TEACHERS}

In previous research (Helenius, et al., 2014 forthcoming), we outlined the model that we developed retrospectively from examining our own decision making in the first third of the development of the material. The model can be seen in Figure 1 and has 3 components. These were tasks for the teachers to undertake, content that deemed as important for teachers to understand and the relationships that needed to be developed, if the PD was to have an impact on children's engagement in mathematical tasks. The principles that guided the material development can be seen 
in the questions in Figure 1. We consider that the model is relevant for the development of a range of PD material.

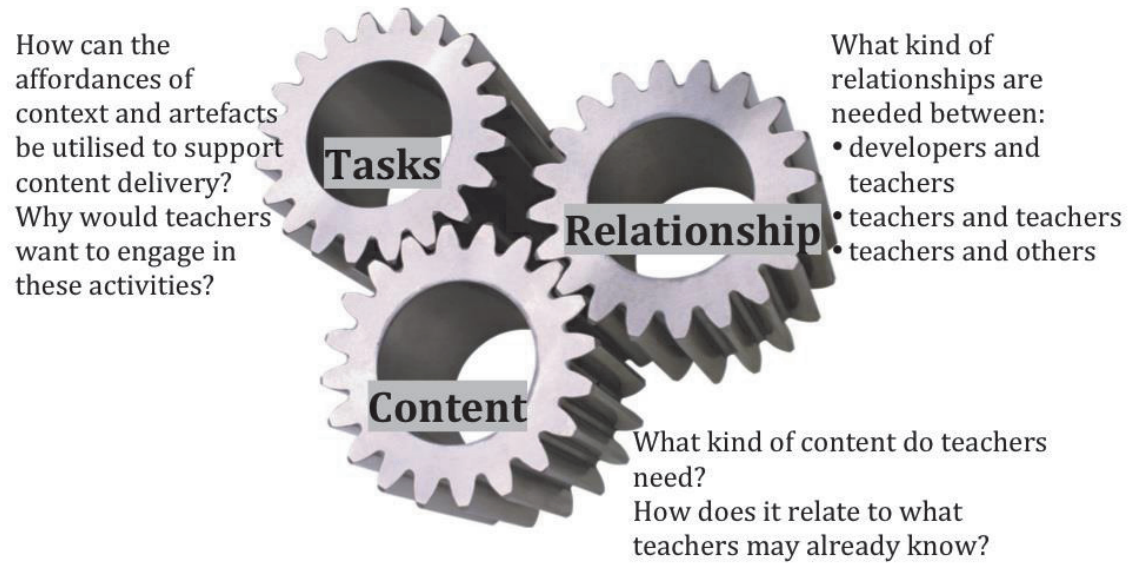

\section{Figure 1: Model for designing professional development material}

For the Skolverket project, specific decisions were taken about content, tasks and relationships that fitted the context of the Matematiklyftet project. Bishop's 6 mathematical activities (Bishop, 1988) was the basis for the content, the cog that drives the other two. Although not formally acknowledged, the mathematical objectives in the revised Swedish preschool curriculum can be traced back to Bishop's (1988) 6 mathematical activities (see Utbildningsdepartementet, 2010). Therefore, with Skolverket's approval, we chose to base the PD materials on these understandings. The preschool and preschool class materials are connected into webbased modules. Each module consists of three sections, with each containing four parts. Each section deals with two of Bishop's 6 mathematical activities.

The tasks connect the content to the relationship. Different tasks were presented in the four moments of each of the 12 parts. For example, in the preschool module, part 2 is about the mathematical activity, play. In the first moment, teachers read an article about play as a mathematical activity and then watch a video where four preschool children are engaged in a hypothetical play. The teacher is requested to write down some thoughts about this mathematical activity. In Moment B, the preschool teachers meet in a group to discuss the article and the video. After this discussion, they plan together what they will do with the children in their preschools, based on some suggestions (set up a shoe store, play with cards, or observe when children negotiate about rules etc.). In Moment $\mathrm{C}$, they implement these tasks. In the final moment, the teachers talks with their group about what they learnt from 
implementing the task. The relationships that the materials need to nurture are those between the preschool teachers and between the preschool teachers and the children. As the preschool teachers may not have a mentor to guide their discussions, we decided to talk directly to teachers, rather than use a passive voice (Helenius, et al., 2014 forthcoming).

\section{THE STUDY}

Questionnaires were completed by 29 teachers and 2 facilitators. 18 were preschool teachers and 9 were preschool class teachers. All participants were involved in a municipality-organised PD programme which used the Skolverket materials as their basis. The questionnaire first asked for details about whether the teachers were teaching in preschool or preschool class and what parts of the module, they had completed. Most teachers had only worked on parts 1 or 2 of the modules.

In the main part of the questionnaire, there were 13 questions concerning the videos used in the professional development programme. Seven of the questions had likert scale responses and the other six questions were open-ended. All questions were about one of the three components, task, relationship and content, in relation to the use of video in the professional development. The 7 likert-scale questions were:

- How much do you think that the films have helped to increase your understanding of the mathematical content of the modules?

- How much do you think that the films have helped to increase your understanding of children's mathematical development?

- How much do you think that the films have the help you when it comes to planning and implementing the information in moment $\mathrm{C}$ ?

- How much do you think that the films have contributed to the talks and discussions in moment $\mathrm{B}$ and moment $\mathrm{D}$ ?

- How much has the films helped to develop relationships between you and the children in the preschool?

- How much has the films helped to develop relations between you and other preschool teachers?

- How much has the films helped to develop relationships between you and others that you encounter in your work as a preschool teacher?

The open-end questions were:

- How have the films contributed to your professional development in the work of the module?

- In what way do you think that the films contributed to your understanding of the mathematical content? 
- In what way do you think that the films contributed to your understanding of children's mathematical development?

- How have the films helped you when it comes to planning and implementing the information in section $\mathrm{C}$ ?

- In what way do you think the films contributed to the talks and discussions?

- What do you think of the films as a whole?

\section{RESULTS}

The analysis made us aware of issues to do with using questionnaires to evaluate the role of videos in a PD programme. Particularly, in relationship to the open-ended questions about the tasks we could see that the teachers had interpreted them differently to what we had intended. Several wrote about lack of time for discussions and reflections. Consequently, there may be a need to rephrase the question since out intention was for teachers to reflect on if and how the videos helped them in their planning of tasks. However, as lack of time is a commonly identified impediment to teachers adopting new approaches suggested by professional development (Meaney, et al., 2011), it may be that any questions would be misconstrued so that teachers could express their feelings about this. Instead it might be better to have a separate question, which asks specifically about impediments to their participating in PD.

Another issue was that some teachers did not answer the specific question but answered more generally, often in a positive manner. For example, regardless of the question, the teachers described how they had started to see mathematics in the preschool with new eyes.

De har öppnat ögonen på mig och lärt mig se på verksamheten på ett nytt sätt. (They have opened my eyes and taught me to look at the preschool business in a new way)

We did not consider that answers like these provided us with a deep enough understanding about the use of videos in the PD, and therefore excluded them from our analysis. Instead we used answers that had concrete examples or were more explicit. In modifying the questionnaire, it would be better to ask for specific examples to illustrate the answers to the open-ended questions.

However, on the whole it seemed that the questionnaire could gather appropriate data to ascertain whether teachers make use of the videos as we had anticipated when we included them in the Skolverket modules. Figure 2 shows clear differences in the results for the likert-scale questions connected to the content, task, relationship components. Teachers were much more positive about the impact of the videos on their content knowledge and much less certain about the impact on developing relationships. These differences indicate that the teachers were not simply providing positive answers but able to distinguish between the different components in relationship to the videos. 
In the next sections, we discuss the results, mainly from the open-ended questions, in relationship to the three cogs.

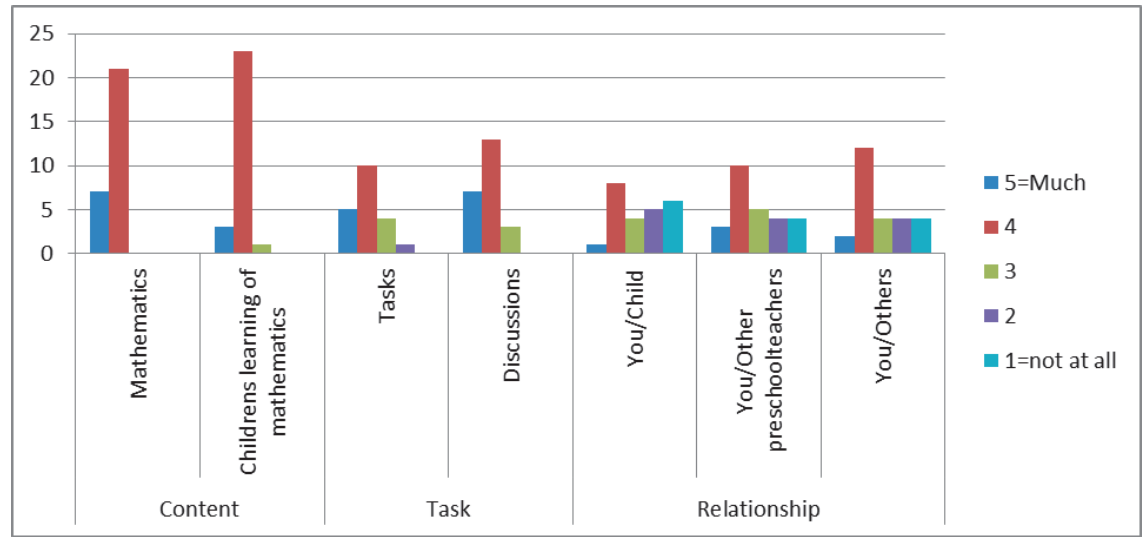

\section{Figure 2: Responses to likert-scale questions}

\section{Content}

The teachers wrote that the videos gave them inspiration, new ideas and different ways of thinking about mathematical activities. Specifically, they indicated that the videos made them notice mathematics in situations they had not been aware of previously. In regard to the article that they read, they felt that video acted as a link between the theory and the practice.

Det gör om det teoretiska tillpraktiskt och gör det lättare att se hur mycket matte vi faktiskt har $i$ vår vardag (This makes the theoretical to the practical and makes it easier to see how much math we actually have in our everyday lives)

The teachers gave different examples of how the videos has helped them. They considered watching the children gave them a deeper understanding of the kind of mathematics they engage with in pre-school. This provided them with insights into how children understood mathematics. An example which was given was about how they before had not thought about body language as a way to interpret children's understanding.

Att koppla till konkreta exempel ger en djupare förståelse (Linking to specific examples gives a deeper understanding)

Öppnat upp nya sätt att se och förstå matematik och dess innehåll och arbetssätt (Opened up new ways to see and understand mathematics and its contents and methods) 
Gett mig verktyg för att se barnens utveckling (Given me the tools to ensure the children's development)

The examples in the videos inspired them to think about mathematics in different ways and therefore also see their teaching practice in a new ways.

Matematik är så mycket mer än siffror och ekvationer. Barnen är fulla av matematik (Mathematics is so much more than numbers and equations. The children are full of mathematics.)

\section{Task}

The teachers saw many of the tasks as being intimately connected to the videos. For example, the teachers indicated that the reflection and discussions around the concrete examples in the videos made them see the children's mathematical understandings in ways that they had not previously considered. This had an impact on their own teaching practices.

Vi diskuterar mer om matematikens betydelse och hur vi kan möjligen bli bättre på att förmedla våra mattekunskaper (We discussed more about the importance of mathematics and how we could possibly be better able to convey our math skills)

Intressanta diskussioner som belyser Bishops matematiska aktiviteter (Interesting discussions highlighting Bishop's mathematical activities)

Inspiration, reflektion, givande diskussioner - kritiskt granskat min egen verksamhet (Inspiration, reflection, fruitful discussions - critically reviewed my own business)

Some teachers wrote about how documentation were discussed, helped them 2103 develop their understanding of how documentation could be used to understand and challenge children's mathematical thinking in their everyday life.

These answer are more implicit answers about the role of the videos, but explicit about the impact the videos had on the teachers.

Öppnat upp nya sätt att se och förstå matematik och dess innehåll och arbetssätt (Opened up new ways to see and understand mathematics and its contents and methods)

Vi diskuterar mer om matematikens betydelse och hur vi kan möjligen bli bättre på att förmedla våra mattekunskaper(We discuss more about the importance of mathematics and how we could possibly be better able to convey our math skills)

Det gjorde det lättare att se de olika matematiska aktiviteterna (It made it easier to see the various mathematical activities)

\section{Relationship}

In the last category, relationship, the teachers wrote that it was valuable for everyone to watch the same video because it made them focus on the same situation. When 
their familiarity with it meant that they all had the same basis for their discussions. This supported them all to see different ways of thinking about mathematical activities and allowed them to value the different interpretations.

Bra diskussioner genom att alla har en gemensam upplevelse (Good discussions, because everyone has a shared experience)

Bra samtal eftersom man ser olika saker i filmerna (Good call because you see different things in the movies)

\section{CONCLUSION}

In our investigation of the impact of the Skolverket professional development webbased modules, we need to find effective methods of data gathering and analysis. This pilot study shows us that questionnaires can be used to gather useful information. However, some questions need revising. Some of the teachers responded to the questions about tasks by complaining about a lack of time for involvement in the professional development. This suggests alternative questions are needed. It also seemed that to do an appropriate analysis, we needed the teachers to provide answers that discussed specific situations. Thus in the open-ended questions, there needs to be requests for this level of detail.

The results of the pilot study indicate that teachers found the videos useful for their understanding about what mathematics could be in and also how children can participate in mathematical situations. They found the videos less useful in contributing to them developing their relationships, both within the preschool and with their colleagues who were also completing the professional development. However, for a more reliable result a larger study with rephrased questions is needed.

\section{REFERENCES}

Baroody, A. J., Eiland, M., \& Thompson, B. (2009). Fostering at-risk preschoolers' number sense. Early Education and Development, 20(1), 80-128.

Bishop, A. J. (1988). Mathematical enculturation: A cultural perspective on mathematics education. Dordrecht: Kluwer.

Borko, H., Jacobs, J., Eiteljorg, E., \& Pittman, M. E. (2008). Video as a tool for fostering productive discussions in mathematics professional development. Teaching and teacher education, 24(2), 417-436.

Clements, D.H., \& Sarama, J. (2007). Early childhood mathematics learning. In F.K. Lester (Ed.), Second handbook of research in mathematics teaching and learning (pp. 461-555). Charlotte, NC: Information Age.

Clements, D. H., \& Sarama, J. (2008). Experimental evaluation of the effects of a research-based preschool mathematics curriculum. American Educational Research Journal, 45(2), 443-494. 
Ginsburg, H. P., Jang, S., Preston, M., Appel, A., \& Van Esselstyn, D. (2004). Learning to think about early childhood mathematics education: A course. In C. Greenes \& J. Tsankova (Eds.), Challenging young children mathematically, (pp. 40-56). Boston, MA: National Council of Supervisors of Mathematics.

Helenius, O., Johansson, M. L., Lange, T., Meaney, T., Riesbeck, E., Wernberg, A. (2014 forthcoming). Theorising the design of professional development web modules. Proceedings of MADIF 9 Linköping: Svensk Förening för Matmematikdidaktisk Forskning.

Meaney, T., Trinick, T. \& Fairhall, U. (2011). Collaborating to meet language challenges in Indigenous mathematics classrooms. New York: Springer.

Nemirovsky, R., DiMattia, C., Ribeiro, B., \& Lara-Meloy, T. (2005). Talking about teaching episodes. Journal of Mathematics Teacher Education, 8(5), 363-392.

Olivero, F., John, P., \& Sutherland, R. (2004). Seeing is believing: using videopapers to transform teachers' professional knowledge and practice. Cambridge Journal of Education, 34(2), 179-191.

Perry, B., Dockett, S., \& Harley, E. (2007). Preschool educators' sustained professional development in young children's mathematics learning. Mathematics Teacher Education and Development, 8, 117-134.

Sarama, J., \& DiBiase, A-M., (2004). The professional development challenge in preschool mathematics. In D. H. Clements, J. Sarama \& A-M DiBiase (Eds.) Engaging young children in mathematics: Standards for early childhood mathematics education (pp. 415-446). Mahwah, NJ: Lawrence Erlbaum.

Sherin, M. G., \& van Es, E. A. (2009). Effects of video club participation on teachers' professional vision. Journal of Teacher Education, 60(1), 20-37.

Skolverket (2012). Matematiklyftet [Mathematics lifting]. Stockholm: Skolverket. Available from:

http://matematiklyftet.skolverket.se/matematik/faces/training/aboutTraining? afr WindowId $=45 \mathrm{kyulmxz} 46 \&$ afrLoop $=2182108876032000 \&$ afrWindowMode $=0$ \&_adf.ctrl-state $=45 \mathrm{kyulmxz} 49$

Skolverket (2011). Curriculum for the Preschool Lpfö 98: Revised 2010. Stockholm: Skolverket. 
Curricula, textbooks and resources 


\title{
HOW ARE MATHEMATICS TEACHER GUIDES USED FOR SUPPORT AND INSPIRATION IN TEACHING?
}

\author{
Linda Ahl, Tuula Koljonen, Lena Hoelgaard \\ Mälardalen University, Sweden
}

In this study we investigate how teachers talk about their use of mathematics teacher guides, for support and inspiration in teaching. We aim to broaden the knowledge of how teachers use mathematics teacher guides in and for teaching. Our second aim is to try out if guidelines for designing educative curriculum material can serve as an analytical tool. The results show that less experienced teachers demand for a wider scope of content in the teacher guide. More experienced teachers demand for support in design of teaching in classroom practice. Common for all teachers, despite prior experience, is that they want the teacher guide to provide connections between theory and practice. The analytical tool served well for analysis of interviews. It helps us to pay attention to the features of the content discussed in the interviews.

Keywords: Mathematics teacher guides, analytical tool, curriculum materials, support, inspiration

\section{INTRODUCTION}

The impact of mathematics teaching recourses ${ }^{1}$, on teaching and learning, is a growing research area in mathematics education. It is well known that the designs of resources have strong impact on how teaching, learning and classroom practice will be orchestrated. Notwithstanding their strong position, this area is short of research. Especially the design and use of teacher guides come short of research (Lloyd, Remillard \& Herbel-Eiselmann, 2009). We know about possible impacts from the design of teacher guides through studies by Remillard (2000, 2005, 2012), Brown (2009), Davis and Krajcik (2005), among others. Brown (2009) describes how classroom instruction relies on collaboration between curriculum materials, as tools that convey curricular forms, concepts and practices and the teacher's personal resources. How the teachers use the teaching materials depend on their experience, intentions and abilities. This is crucial for our expectations about what can be accomplish in classroom practice with teacher guides. They can promote a teacher's pedagogical design capacity, or her ability to use personal resources to adapt the curriculum to achieve productive instructional ends. Further they can support the teacher's ability to act in practice by suggestions with respect to the design and

\footnotetext{
${ }^{1}$ All the resources, which are developed and used by teachers in their interaction with mathematics for teaching and learning, inside, and outside classroom. (Pepin, Gueudnet \& Trouche, 2013)
} 
enactment of lessons, tasks, formative assessment, individualization of teaching, homework, etc. (Hemmi, K., Koljonen, T., Ahl, L., Hoelgaard, L., \& Ryve, A., 2012). In line with Brown (2009) we emphasize that teachers and curriculum material participate together in a collaborative relationship, whereby teachers are viewed as active agents in developing and constructing the planned and enacted curriculum. All together this knowledge gives us high expectations of the potential that is embedded in teacher guides. The focus in this study is the mathematics teachers' guides; more precisely how and what teachers talk about their use of teachers guides in and for teaching. The results of this study could be seen as one piece in the building of an understanding of how teachers and teacher guides are related to, and constitute, each other. In this study we search to broaden the knowledge of how teacher's use mathematics teacher guides for support and inspiration in their teaching practice. We also aim to try out if guidelines for how to design educative curriculum material can serve as an analytical tool for interviews. Our research questions are:

- What content do teachers use from their teacher guide, when planning lessons?

- Can guidelines for how to design educative curriculum materials work out as an analytical tool for interviews about how teachers use their resources - in this case the teacher guide?

\section{METHODOLOGY}

\section{Context}

This study is a part of a comparative project examining similarities and differences between teachers' use of mathematics teacher guides in Sweden, Iceland and Finland. Researchers in Iceland and Finland are conducting similar studies about how teachers use their teacher guides. The next step in the project is to compare the results from the different countries. Such findings could contribute to the international research discourse on aspects of curriculum materials and their influence on teaching. Teachers in all three countries are free to choose what curricular materials they want to use; since the beginning of the 1980s in Finland and 1991 in Sweden, there is no state control over curricular materials (Pehkonen et al., 2007; Jablonka \& Johansson, 2010). Iceland has an informal state control. Because the market for teaching material is small, it is hard for publishers to produce textbooks and teacher guides with profit (Gunnarsdottir, 2013). As a consequence there is a state publishing house that provides most of the Icelandic materials, but they are not compulsory.

\section{The analytical tool}

In the analysis we use the analytical tool we developed from Davis \& Krajcik (2005), in a study by Hemmi, et al. (2012). It contains five categories of content in educative curriculum materials (Table 1). By using the tool to analyse the interviews we want to try out if the tool helps us to draw attention to what kind of support the teachers consider to be useful and what kind of shortcomings they perceive from their teacher 
guides. We use the tool to label the support and lack of support that teachers talk about in the interviews.

\begin{tabular}{|l|l|}
\hline $\begin{array}{l}\text { 1a) General knowledge } \\
\text { of students ideas and } \\
\text { strategies }\end{array}$ & $\begin{array}{l}\text { Describes why students might hold particular ideas about } \\
\text { mathematical concepts and exemplifies common strategies } \\
\text { among students. }\end{array}$ \\
\hline $\begin{array}{l}\text { 1b) Suggestions for } \\
\text { how to encounter } \\
\text { students ideas and } \\
\text { strategies }\end{array}$ & $\begin{array}{l}\text { Gives suggestions for how to deal with/encounter various } \\
\text { ideas and strategies of students and how to enhance their } \\
\text { learning and prevent future difficulties. }\end{array}$ \\
\hline 2) Concepts and facts & $\begin{array}{l}\text { Describes concepts and facts within mathematics such as } \\
\text { history, field of application, derivations, methods, proofs, } \\
\text { and correct terminology. }\end{array}$ \\
\hline $\begin{array}{l}\text { 3) Progression and } \\
\text { connections }\end{array}$ & $\begin{array}{l}\text { Shows the mathematics progression throughout the school } \\
\text { years as well as connections between mathematical topics; } \\
\text { for example, explains the future development of methods } \\
\text { and concepts. }\end{array}$ \\
\hline $\begin{array}{l}\text { 4) Connecting theory } \\
\text { and practice }\end{array}$ & $\begin{array}{l}\text { Supports the teacher's actions in practice beyond the } \\
\text { curricular materials by connecting theory and practice. } \\
\text { Exposes the central ideas in national curriculum and } \\
\text { research results for promoting teachers' autonomy. }\end{array}$ \\
\hline 5) Design of teaching & $\begin{array}{l}\text { Supports the teacher's ability to act in practice by } \\
\text { suggestions with respect to the design and enactment of } \\
\text { lessons, tasks, formative assessment, individualization of } \\
\text { teaching, homework, etc. }\end{array}$ \\
\hline
\end{tabular}

Table 1: Five categories for data analysis

Data

Data is collected through semi-structured interviews of five early years mathematics teachers. Our selection of teachers was based on the criteria that they represent both teachers with long teaching experience and teachers with only some years in the profession; and that the teachers use one of the most commonly used teaching material in Sweden. They use either Eldorado or Matte Safari, which are the most common teaching materials in grade 1 to 3 in Sweden.

All participating teachers teach children in grade 1 to 3 . They volunteered for the interview, knowing that the study was about how they use teacher guides. In advance the teachers were asked to copy pages in the teacher guide that they had used the week before the interview. Same researcher conducted all interviews. All interviews are filmed with a laptop. We, the authors, made a joint analysis of the films and the copied pages from the teacher guide to ensure that we reached mutual understanding of the data. Here follows a short description of the participating teachers: 
Annika has 30 ECTS in mathematics. She has taught for less than two years.

Beret has 90 ECTS in mathematics. She has taught for more than ten years.

Camilla has 30 ECTS in mathematics. She has taught for more than ten years.

Doris has 60 ECTS in mathematics. She has taught for more than ten years.

Erika has 30 ECTS in mathematics. She has taught for less than two years.

Swedish, Icelandic and Finnish researchers decided on the interview questions together, in the collaborative project referred to above in the section context. We worked out 11 interview questions altogether. The questions concern how the teachers start their planning; how they use their teacher guides; what parts of the guide they usually are using; what they value in the teacher guides and what they would like to see in the guide. In short, all questions concerned what they use and how they use it; as well as the important issue, what support they miss that they would like to see in their teacher guides.

The teaching material the teachers use in practice is:

- Matte Direkt Safari (Falk et al., 2011), a Swedish textbook and teacher guide that has been on the market for several years, (used by teacher 2, $4^{2}$ and 5) and

- Matte Eldorado (Olson \& Forsbäck, 2011), a Swedish textbook and teacher guide that has been on the market only a few years (used by teacher 1 and 3 ).

As a foundation for the analysis we give you a brief description of the two teacher guides:

Matte Direkt Safari: (S) In the beginning of the Teacher's guide there are four pages with information to the teacher about the structure of the students' textbook and the teacher's guide. Each chapter in the teacher guide starts with goals for the chapter. The students' textbook has a picture as an introduction to each chapter. The teacher is given suggestions of questions to ask the children, from the teacher guide. The picture is meant to engage the children and make them curious about the content in the upcoming chapter. There are also practical exercises, work sheets and a page with activities that can be carried out both indoors and outdoors. Some chapters, but not all, have one page with descriptions and explanations about the presented methods in the students' textbook.

Eldorado: (E) The information to the teacher is extensive. Around 40 pages in the beginning of each teacher guide deals with different aspects of mathematics such as algorithms, teaching methods and assessments. The authors of this teacher guide have emphasised to visualise clear connections between the content in the textbook and the national curricula. After this introduction the teacher guide follows the structure in

\footnotetext{
${ }^{2}$ Teacher 4 use a range of Teacher guides, different guides for different grades.
} 
the textbook. Each chapter starts with two pages of additional information to the teacher about what to pay extra attention to, in teaching towards the goals with the chapter. Goals for working with the chapter, worksheets and concrete practical materials are represented in every chapter. There are also suggestions for how to individualize teaching for those who need more challenge and those who need easier tasks.

All three authors of this paper are familiar with both Matte Direkt and Eldorado, so we can picture what the teachers are referring to in the interviews. We believe that it is both strength and a weakness when conducting the analysis. We can easily visualise what the teachers are talking about but at the same time we cannot disregard our own experiences with the teaching materials, even though we want to. This might influence our analysis. To avoid bias as far as possible, we conducted the analysis together, checking each other's understanding of the interviews. We first discussed the categories in Table 1 in relation to the interview data. This process was followed by a collective analysis in relation to the data.

\section{ANALYSIS AND RESULTS}

The data in our study shows that the more experienced teachers use the teacher guides differently from the less experienced teachers. All teachers search the teachers guide for support and inspiration in designing classroom practice but there are a difference between the more experienced and the less experienced teachers' answers. Most of the experienced teachers answers is labelled as category 5: Design of teaching. The answers from the less experienced teachers are more widely spread among the categories in the analytical tool. They want support for design of teaching as well as support for how to understand students thinking, concepts, and progression in different grades (Category 1, 2 and 3). The following excepts illustrate how the more experienced teachers use their teacher guides ${ }^{3}$.

Interviewer: How do you use the teacher guides? Describe?

Beret (S): We use the pictures and talk about them. I use practical exercises. I want more of those.

Camilla (E): I read the information to the teacher and then I choose exercises that are suitable for the group. I use the pictures and talk with the children about the mathematics... in the picture. I pick stuff from the teacher guide.

Doris (E): I use copy materials. I construct booklets with different difficulty levels from them.

All three experienced teachers use the teacher guide as a source to pick material from. They use the teacher guide as a toolbox for designing teaching. We labelled this as

\footnotetext{
${ }^{3}$ All the excerpts from the interviews are translated from Swedish by the authors of this paper.
} 
category 5: Design of teaching. Regard the difference in this excerpts from the less experienced teachers:

Interviewer: How do you use the teacher guides? Describe?

Annika (E): We work with addition and subtraction now; it's increase and decrease. And I think the teacher guide had a good way to present it. That you should name it increases and decreases and introduces it at the same time. I think that was good because I must admit to having worked with only addition or only subtraction... though I know they are connected.

The support in the teacher guide inspired Annika. She got reminded of the inverse relationship between addition and subtraction and used it in her classroom. We labelled this as Category 2: Concepts and facts.

Interviewer: What parts of the teachers guide (the whole guide) are you usually using?

Erika (S): The guide doesn't cover everything needed. It's mostly count, count, count and it is not much problem solving. It doesn't cover enough, I think, or it has shallow descriptions. I want one that covers all the topics. I want to know: When you teach this you must pay attention to this and so on... I want tips and tricks and hints about what ideas the students might have.

Erika asks for content that supports her as a teacher. She wants support to be able to foresee difficulties. We labelled this as category $1 \mathrm{a}$ and 1b: General knowledge of students' ideas and strategies and Suggestions for how to encounter student' ideas and strategies. The less experienced teachers also want support for professional development in teaching practice. This is different from the more experienced teachers that use the teacher guide as a toolbox.

Some of the teachers' answers covered two categories at the same time. Category 3: Progression and connections and Category 4: Connecting theory and practice was especially hard to label as one or the other. The answers concerning these categories divided the teachers in two groups, depending on which teacher guide they use. Both the more and the less experienced teachers using Eldorado are happy with the clear connections to the Swedish national curricula. On the contrary the teachers using Matte Safari think that the teacher guide lacks in information about progression and theoretical connections to the national curricula. Here follows some excerpts from the interviews to illustrate our results.

Interviewer: How do you start your planning?

Annika (E): The guide is clear about the connections to the national curricula. It helps when planning. Then you have to adjust to the group you working with. There are suggestions in the guide for how to individualise in the group. 
Camilla (E): Now I looked at the guide thinking of the new curricula. They have decomposed $\operatorname{Lgr~} 11^{4}$ and tried to cover it. And I think they made a really good overview in this guide. They have different topics with relevant content. It's a good support.

Above both the less experienced Annika and the more experienced Camilla says that the clear connections to the national curricula is a support in their planning.

In the following excerpt the less experienced Erika talk about support from the teacher guide for planning the progression from year 1 to year 3 .

Interviewer: What other sources do you use for lesson planning?

Erika (S): The national curriculum is the starting point. It's a bit... the goals for grade 3 in is quite clear but what shall you do in grade 1 and grade 2? How much are you supposed to do in grade 3 ?

Interviewer: Would you be helped by clear connections to the curricula?

Erika (S): Yes! Now I start with the curricula and compare with Matte Safari to see what's there and what's missing. It could be clearer in the teacher guide and save me some time.

Erika thinks it is hard to know the expected progression though the school years 1 to 3. When the interview asks if she would be helped by clear connections to the curricula in the teacher guide she agrees that it would be supportive. Here Erika talks about both category 3: Progression and connections and category 4: Connecting theory and practice.

Connections to research are a part of category 4: Connecting theory and practice in the framework. None of the interviewed teacher's said that they want more connections and information about research in teaching methods and student learning. The interviewer additionally asked all teachers if they would be inspired by connections to research about what works in the area of mathematics education. They all agreed that it would be an inspiration with connections to research, but they had not thought about it before the interviewer asked.

\section{CONCLUSION AND DISCUSSION}

The teachers in our study express that they use the teacher guides as a source for support and inspiration in planning and enacting teaching. The answer to our first research question is that the more experienced teachers use the teacher guide as a toolbox, for support and inspiration in classroom practice. They are focused on instructions for design of teaching in classroom practice (cf. Ball \& Cohen, 1996; Davis \& Krajcik, 2005). The less experienced teachers demand for content from

\footnotetext{
${ }^{4}$ Sweden has a new national curriculum called Lgr 11, since 2011.
} 
several categories. We believe that they use the teacher guide as a toolbox as well as a source for teacher learning (cf. Remillard, 2000; Brown, 2009). The different needs between the less and the more experienced teachers harmonise with Brown's (2009) theory of the teacher tool relationship. Brown describes that teachers will use their tool in different ways due to their experience, intentions and abilities. A new contribution to the research in how teachers participate with their teacher guides is that the findings indicate that there are issues that unite the teachers in their demand for support, despite their differences in experience, intention and abilities.

Swedish teachers are facing the reality of a national reform from year 2011. The learning goals in the curricula are explicit for grade 3,6 and 9. In between the teacher has autonomy to choose the path for progression. The teachers might still struggle to interpret the new curricula and search for support in doing so. Both the more experienced and the less experienced are novice in teaching by the new national curriculum. This can explain the appreciation of the clear connections to the curricula, which is emphasised in one of the teacher guides.

The new Swedish curriculum is also a plausible explanation for our difficulties to separate categories 3 and 4 . The progression (category 3 ) for each school year is not explicit in the national curriculum; therefore the teachers want support from the teacher guide to convey the intentions in the national curricula (category 4). The progression throughout school years, and the connection with the national curricula interweaves with each other. Despite some difficulties with separation category 3 and 4 our framework seems to cover all content that is discussed in the interviews. The answer to our second research question is that the framework for designing educative curriculum materials work out well as an analytical tool for interviews about how teachers use their teacher guides. We experienced some methodological difficulties to separate data but we believe that the framework covered all content discussed in interviews.

We were a bit downhearted as researchers, when none of the teachers mention that they would get support from research findings. On the other hand, traditionally Swedish teaching materials do not convey research findings. The authors are in general teachers, not researchers. The teachers know this and consequently they do not expect to find research findings in the teacher guides. When the interviewer additionally ask if the teachers would want more connections to research they are overall positive to that idea, but they did not bring it up without a question from the interviewer. This indicates that it is hard to miss something you are not used to meet in the teacher guide. This is something to consider in future studies. Is the teacher's demand for content in the teacher guide an expression for the support and inspiration they need or a manifestation of what they are used to work with?

Our findings contribute to the knowledgebase about how teacher use their tools in planning and enacting teaching. A question raised during the work is what teachers consider to be the characteristics of a teacher guide and what impact these interpretations have for how they are used? The view that teachers use their recourses 
in a participatory relationship proposes that the features of the teacher guides matter as much as the teachers' characteristics (Pepin et al., 2013). Our hypothesis is that teachers approach a collection of copy materials, with extra tasks, different from a bridge to research findings, about how to design classroom practice.

\section{ACKNOWLEDGMENTS}

We thank NORDFORSK (project 45321) for funding Nordic Network, which creates opportunities for us to collaborate with our Nordic colleagues.

\section{REFERENCES}

Ball, D. L., \& Cohen, D. K. (1996). Reform by the book: What is: or might be: the role of curriculum materials in teacher learning and instructional reform? Educational researcher, 25(9), 6-14.

Brown, M. (2009). Toward a theory of curriculum design and use: Understanding the teacher-tool relationship. Mathematics teachers at work: Connecting curriculum materials and classroom instruction, 17-37.

Collopy, R. (2003). Curriculum materials as a professional development tool: How a mathematics textbook affected two teachers' learning. The Elementary School Journal, 287-311.

Davis, E. A., \& Krajcik, J. S. (2005). Designing educative curriculum materials to promote teacher learning. Educational Researcher, 34(3), 3-14.

Falk, P., Picetti, M., \& Elofsdotter Meijer, S. (2011). MatteDirektSafari $1 A \& 1 B$. Lärarhandledning. Stockholm: Bonniers Utbildning.

Gunnarsdottir, G. H., (2013). NORDIC NETWORK Seminar. Tallin 2013-12-05

Hemmi, K., Koljonen, T., Ahl, L., Hoelgaard, L., \& Ryve, A. (2012). Analyzing mathematics curriculum material in Sweden and Finland: Developing an analytical tool. Submitted for publication.

Jablonka, E., \& Johansson, M. (2010). Using texts and tasks: Swedish studies on mathematics textbooks. In Sriraman, B., Bergsten, C., Goodchild, S., Palsdottir, G., Søndergaard, B.D., \& Haapasalo, L. (Eds.). The sourcebook on Nordic research in mathematics education. Charlotte, NC: Information Age Publishing, p. 363-372.

Lloyd, G. M., Remillard, J. T., \& Herbel-Eisenmann, B. A. (2009). Teachers' use of curriculum materials: An emerging field. Mathematics teachers at work: Connecting curriculum materials and classroom instruction, 3-14.

Olsson, I., \& Forsbäck, M. (2011). Matte Eldorado Lärarbok $1 A$ \& 1B. Stockholm: Natur och Kultur. 
Pehkonen, E. Ahtee, M., \& Lavonen, J. (Ed.). (2007). How Finns learn mathematics and science. Helsinki University, Finland.

Pepin, B., \& Haggerty, L. (2003). Mathematics textbooks and their use by teachers: a window into the education world of particular countries. In Curriculum landscapes and trends (pp. 73-100). Springer Netherlands.

Pepin, B., Gueudet, G., \& Trouche, L. (2013). Re-sourcing teachers' work and interactions: a collective perspective on resources, their use and transformation. ZDM, 45(7), 929-943.

Remillard, J. T. (2000). Can curriculum materials support teachers' learning? Two fourth-grade teachers' use of a new mathematics text. The Elementary School Journal, 331-350.

Remillard, J. T. (2005). Examining key concepts in research on teachers' use of mathematics curricula. Review of Educational Research, 75(2), 211-246.

Remillard, J. T. (2012). Modes of engagement: Understanding teachers' transactions with mathematics curriculum resources. In From Text to'Lived'Resources (pp. 105122). Springer Netherlands. 


\title{
TEACHING BY THE BOOK: \\ WHAT KIND OF CLASSROOM PRACTICE DO THREE DIFFERENT TEACHER GUIDES FOR YEAR 1 PROMOTE?
}

\author{
Lena Hoelgaard, Kirsti Hemmi \& Andreas Ryve \\ Mälardalen University
}

This paper investigates three Swedish commercial mathematics teaching materials for Year 1, covering more than 80 percent of the market. We specifically focus on the teacher guides and the classroom practice they construe. Taking an educative curriculum materials perspective, the analysis of these three mathematics teaching materials reveals substantial differences in their support for designing classroom practice.

Keywords: mathematics teacher guides, support, classroom practice, primary school

\section{INTRODUCTION}

In this paper, the potentials of teacher guides for promoting certain qualities in mathematics classrooms are studied. There are indications that teaching materials, such as students' textbooks and teacher guides, have a substantial impact on classroom practices (Davis \& Krajcik, 2005; Stein, Remillard \& Smith, 2007). For instance, a report in Finland (Joutsenlahti \& Vainionpää, 2010) shows that 88.4 percent of Finnish mathematics teachers regard teacher guides as important or very important for their mathematics teaching, while only 0.8 percent do not consider them important at all. Yet, few studies, especially in the Nordic countries, investigate the characteristics of teacher guides. In this study we aim to contribute to the curriculum materials research area by focusing on how classroom practices are construed in three teacher guides covering more than 80 percent of the Swedish market.

In Sweden, many teachers teach mathematics in primary school (Year 1-5) without having any formal university education in either mathematics education or mathematics. For instance, an analysis of the Swedish TIMSS study shows that although 90 percent of Year 4 students have teachers with a teacher education, only 15 percent of these teachers are educated in mathematics (Skolverket, 2012). Further, according to the same report, almost 90 percent of Swedish Year 4 teachers use the curriculum materials as a basis for their teaching, harmonizing with findings that quiet, individual work with students' textbooks dominates the classroom practices (Boesen et al., 2014). Since 1991, there is no state control over teaching materials in Sweden (Jablonka \& Johansson, 2010) and teachers are free to choose the materials they want. Teachers rely heavily on the mathematical content and students' learning objectives in the textbooks, assuming that the content is consistent with the current syllabus (Jablonka \& Johansson, 2010). However, recent studies show 
that there are clear discrepancies between the many textbooks in Sweden and the national syllabi (Johansson, 2006).

In Hemmi, Koljonen, Ahl, Hoelgaard and Ryve (2013), we began to analyse teacher guides from Sweden and Finland using an analytical tool derived from Davis and Krajcik (2005). This analytical tool focuses on opportunities for teachers' professional development through using curriculum materials, a socalled educative curriculum materials focus (Ball \& Cohen, 1996; Davis \& Krajcik, 2005; Remillard \& Bryans, 2004). When examining the kinds of support offered for teachers' professional development, we discovered clear differences between the four teacher guides (two each in Sweden and Finland). This study deepens the results of the pilot study, by characterizing the support three Swedish teacher guides offer for designing classroom practice. One of the guides is produced in Finland, and has recently been adjusted to and used in the Swedish context.

\section{METHODOLOGY}

In this study, the teachers and teacher guides are seen as participants in a collaborative relationship (Brown, 2009), with both teacher and guide playing a role in mediating this relationship. The teaching materials are conceptualized as artefacts which have the potential to influence the practice in a mathematics classroom, and we aim to study this potential. From this perspective, we focus on three different teaching material series available on the Swedish market. Two are the most commonly used Swedish teaching material series; the third, from Finland, is new to the Swedish market, but the Finnish version is well-known and largely used in Finland (Joutsenlahti \& Vainionpää, 2010).

- Matte Eldorado ${ }^{1}$ (ME), Year 1 (autumn, A, and spring, B)

- Matte Direkt Safari² (MDS), Year 1 (autumn, A, and spring, B)

- Favorit Matematik ${ }^{3}$ (FM), Year 1 (autumn, A, and spring, B)

Matte Eldorado (Olsson \& Forsbäck, 2011) and Matte Direkt Safari (Falk, Picetti, \& Elofsdotter Meije, 2011) are used by the vast majority of practicing teachers in Swedish primary school, Years 1-3. Both have been available on the Swedish market for many years, and are revised based on Curriculum for the compulsory school, preschool class and the recreation centre, 2011 (Skolverket, 2011). The Curriculum represents the part of the Swedish policy documents that relates to educational aims and content, and is referred to as Lgr11. Favorit Matematik (Haapaniemi, Mörsky, Tikkanen, Vehmas, \& Voima, 2012) has also been revised in accordance with Lgr11. The reason we chose to analyse Favorit

\footnotetext{
${ }^{1}$ English translation: Math Eldorado

${ }^{2}$ English translation: Math Direct Safari

${ }^{3}$ English translation: Favorite Mathematics
} 
Matematik, even though it is new on the Swedish market, is that this teaching material series was one of the two Finnish materials analysed in Hemmi et al. (2012), as well as the fact that a growing number of teachers seem to be interested in it. Further, studying materials from different countries might help us notice features we otherwise might have missed; they therefore serve as useful cases in contributing to the research discourse on educative curriculum materials.

In Hemmi et al. (2013) we conclude that ME and FM could be classified as more educative curriculum materials than MDS, according to the framework derived from Davis and Krajcik (2005). Further, in Hemmi et al. (2013) we suggest that all three teacher guides offer support in designing classroom practice, but we do not focus the on the ways this was accomplished. In this study, we deepen the results and practically focus on resources for the design of classroom practice. In examining and characterizing the various teaching materials in terms of what kind of support they offer for designing classroom practices, we particularly aim to find recurring activities and routines that the teacher guides (henceforth TGs) construct.

\section{Method of analysis}

When analysing and conceptualizing the TGs in terms of the support they offer for designing mathematics practices, we acknowledge that different types of analysis could be used. In this study, we draw upon Clarke et al. (2007), understanding lessons as being composed of "lesson events" (p. 287) that are carried out in certain forms and have certain functions. Form illustrates the visual features and social participation of an activity, while function illustrates its intention, action, inferred meaning and outcome. We stress that we are studying the potential of TGs in supporting certain classroom practices, and the current study does not inform us about how teachers implement the suggested activities in their classroom teaching.

As a first phase, the TGs for ME and MDS were studied to clarify which part of the TGs was appropriate to study in order to understand the potential for supporting the design of classroom lessons. FM already had a pronounced split in lessons, and there was thus no need to perform this first analysis on it. Relatively quickly we discovered a recurring pattern which could serve as a lesson unit in both ME and MDS, centred around explicit objectives for students' learning as stated in the TGs. Each objective comprised two to three pages in the student textbook (henceforth called textbook). In a second step in analysing the support for designing classroom practices, all TGs were studied in units of lessons, looking for any recurring classroom episode forming an activity or routine (cf. Franke, Kazemi, \& Battey, 2007). These patterns of activity constitute the object of analysis in the next phase of the study. 
A second phase of the analysis was then conducted, based on the activities stressed as central within the TGs. This analysis aimed to make explicit the justifications for and explanations of these activities. We were particularly interested in describing the activities in terms of not only form (group work, solving tasks, etc.) but also the function (Clarke et al., 2007) of the lesson events. When we present the results below, we will give examples that further illustrate how we interpret the categories of form and function.

\section{RESULTS}

The results are structured so that the TGs are presented one at a time. Recurring activities are described briefly in terms of form and function, followed by an analysis of the support teachers receive in realizing the purpose of the activities and routines.

\section{Math Eldorado}

Each lesson follows a certain pattern of activity: 1) The teacher presents the learning objectives of today's lesson; 2) The teacher suggests activities for the students to work with in groups/pairs; 3) The students work in their textbook; 4) Simplify, Challenge, Notice, Further work. First, the TG presents the overall learning objectives (1) for the students, which are not visible in their textbook.

This is followed by suggestions for different activities (2) the teachers and students can participate in together. In terms of form, the teacher introduces the content, which is dealt with on the textbook pages associated with the current lesson. Communicating and working in groups and/or in pairs is advocated. The function of these activities is that the students have the opportunity to build an understanding before starting to work in the textbook.

Then, the students are expected to work in their textbook (3) with the pages (often two) dealing with the current content. All students are expected to work with the same pages in the textbook. The teacher's assignment in this part of the lesson is presented as active and reflective. The analysis shows four recurring routines in connection to the lesson to support this active role: A) Simplify, B) Challenge, C) Notice, and D) Further work.

The activities of Simplify (A) and Challenge (B) aim to provide teachers with support for interacting with the students who, for various reasons, need more support. The form of these activities advocates an active teacher, who adapts the content of the textbook tasks to meet different students' needs. The activities' function is to individualize and differentiate (in connection to students' work in their textbook). The support the TG gives the teacher in Simplifying (A) often takes the shape of suggesting how to use concrete materials, or how to break the tasks down into smaller parts and let the student work with one part at a time. Challenge (B) offers the teacher support in enabling students to challenge 
themselves to develop their mathematical thinking beyond the content of the tasks in the textbook by, for instance, using an expanded range of numbers and constructing their own tasks based on what they themselves consider challenging. The teacher's central role is also illustrated in Notice (C), in the form of questions to ask him-/herself, to reflect on issues that are important for students' understanding. "Can students describe the differences between the various quadrangles? Do they understand that the square is also a rectangle?" (ME 1B, p. 115). The function of Notice (C) is to make the teacher aware of common misconceptions and difficulties the students might have regarding the content in question (cf. Davis \& Krajcik, 2005). However, the support is typically not designed to suggest how the teacher should act in the classroom, and few suggestions for how to work with these misconceptions and difficulties are introduced. Further work (4) offers support for the teacher through suggestions for different types of activities, games and tasks connected with the lesson's content and objective. Analysis of the form of these activities shows that they are practical in nature and suitable to be executed in pairs or small groups, inside as well as outside the classroom. The function is to engage the students with the mathematical content they have just worked with through further practice, e.g. concrete materials or games.

The form of all the activities may facilitate the teacher in taking active role in designing lessons, as the TG offers information about the function of the lesson content rather than simply instructions for how the teacher should proceed with the teaching. Support for the teacher consists of information, e.g. what tasks the textbook contains and how they should be implemented, and has a character of descriptive text rather than instructions the teacher is to follow. All information is not available in directly connection to the lesson; the teacher must read the information pages at the beginning of the TG to find all the information in terms of function. This means that the TG might also play an important role in the teacher's planning prior to the lesson and support him/her in seeing the content from a larger perspective, rather than simply in connection to the specific lesson. The support also includes a list of the concrete materials needed for the exercises and activities.

\section{Math Direct Safari}

Each lesson follows a specific pattern of activity: 1) Joint introduction; 2) Review box in textbook; 3) Students work in their textbook.

To support the teacher in designing the lesson, the TG briefly presents the content the textbook tasks represent. After this, the TG proposes a joint introduction (1) of the lesson's content. The joint introduction is linked to the corresponding pages in the textbook (usually 2-3 pages). The form of this introduction is that the teacher introduces laboratory exercises to the whole class, first showing the students and then instructing them to perform the same exercises in pairs. The analysis of this activity shows that the introduction is 
directly linked to the content of the tasks the students are then expected to work with in their textbooks. The function of the activity is, therefore, that the students are given the opportunity to build an understanding of the procedures presented by the textbook tasks before starting to work in their textbook, with the pages dealing with the current content.

Before the students start working in their textbooks, the teacher is encouraged to make them aware of the review box (2) that often appears at the beginning of the textbook pages. The form is that the teacher and students read the box together and the entire class discusses the content presented. The function of this box is not explicitly stated in the TG, but the analysis shows that the information in the box is addressed to the students and is designed to support their further work in the textbook. The box is also directly related to the content of the joint introduction (1). The last event is the students' work in their textbook (3). The form is that the teacher supports them as they work individually in their textbook. The TG presents the tasks and gives the teacher instructions regarding what the students are to do. The function of the individual work is to let the students practice the content presented by the teacher in the introduction (1) and by the review box (2). The analysis shows that the textbook supports selfteaching, since the tasks can be solved by referring to the review box. Students can learn what to do in order to solve the textbook tasks. There are tasks in which they are encouraged to work together as well, in sections where the TG tells the teacher "At the bottom of the page [in the textbook] is a 'Work Together'. The students can certainly solve this individually, but here the idea is that you should stop and let them think about..." (MDS1A, p. 120).

The analysis emphasizes the important role of the textbook in the mathematics classroom practice, as all lesson events are linked to the textbook. The form of all activities assigns the teacher an active role in helping the students work with their textbook tasks and explains how these should be implemented in classroom practice. The functions of all the activities are focused on the students and their work and learning in direct connection to the textbook content. Support for the teacher consists of instructions, e.g. how the teacher can introduce and implement exercises with the students. The instructions are specific, and do not explicitly force the teacher to reflect on how to establish them in the classroom practice. The support for the teacher thus becomes more of a script or "recipe" that he/she can either follow or deviate from in designing the teaching.

\section{Favorite Mathematics}

In FM the teacher is given suggestions for lesson plans for every individual lesson. The form of the lesson plan is a numbered list that suggests a certain working path for the lesson. The function is to facilitate the teacher's work by offering support for planning the classroom practice as well as for implementing the content of each lesson. 
The analysis of the lesson plan reveals five recurring events: 1) Story; 2) Questions and mental arithmetic; 3) Work on the whiteboard; 4) Activities; 5) Students' textbook tasks.

A short story (1) is presented in the TG, as well as questions and three mental arithmetic tasks (2) per lesson, all in connection to an introduction picture (in the textbook). The support for the teacher for working on the whiteboard (3) consists of an image in the TG and instructions for how to draw the image on the board and present it to the students. In terms of form, the teacher is expected to implement all the events with the whole class. The function of all three events is to alert the students to the content of the current lesson.

The form of the activities (4) is that the teacher is to use additional activities to be performed by the class as a whole. The function of these activities is, like the previous ones (1-3), to offer the students the opportunity to encounter the current lesson content, but now in a more hands-on manner using concrete materials and games. The TG supports the activities through detailed explanations of how they can be implemented in the whole class.

Finally, students are expected to work in their textbooks (5). Support for the teacher consists of information (for Lesson 1 in FM 1A, p. 6) about how the tasks in the textbook are organized and how the textbook's pages offer different challenges and increased difficulty levels.

For each lesson other activities are presented in the TG, such as problem-solving and advice about additional activities. The form is that the teacher initiates these in the whole class, and the function is for the students to encounter the current lesson content in different ways. Similarly, the heading Knowledge Base is recurring (not in connection to every lesson, but about $30 \%$ of them). The form of this heading is directed at the teacher's own knowledge, while the function is to provide the teacher with "...valuable information and a brief introduction to the area the lesson addresses" (FM 1A, p. 4).

The form of all the events assigns the teacher an active role, and gives him/her the opportunity to choose routines and activities by providing a lesson plan as well as additional activities for designing the teaching. The function of the activities is described in direct connection to the lesson, and includes information on both the lesson-specific content as well as how the teacher can view the content of the lesson from a larger perspective. The TG thus supports the teacher by offering an opportunity to design the lesson beyond the lesson plan, by providing deeper information about the content of the lesson. This can entail, for example, an explanation of the difference between numbers and digits or the historical perspective regarding a certain concept. 


\section{CONCLUSIONS AND DISCUSSION}

The teacher plays a central role in all three TGs for designing classroom practice. They all provide support to teachers in forming their classroom practice, but in different ways. Both ME and FM offer teachers support in actively designing their teaching, by giving suggestions and information directly related to each lesson. ME and FM construe a classroom practice whereby the teacher is expected to be active and is given great flexibility to do so, introducing activities beyond the tasks included in the students' textbooks. This information, we conjecture, also supports the teacher's learning as it can help expand his/her ability to see and make visible the mathematics from a wider perspective, for both him-/herself and the students.

MDS supports another type of classroom practice, in which the textbook constitutes a more important part of teaching. Certainly, MDS supports the teaching design because the instructions it gives are intended to support teaching; however, the focus is on the students' work with the textbook rather than on the teacher as an active designer. The support for the teacher is found in instructions on how to get the students working in their textbooks, and the teachers are given more of a controlling role. Based on the link between the joint introduction, the review box and the tasks in the textbook, this teaching material encourages a more speed-individualized classroom. The textbook supports selfteaching, as the students themselves can figure out what to do and how the tasks should be solved. The fact that the TG additionally indicates that the joint introduction can be carried out "when convenient" (MDS 1A and 1B, p. 7) reinforces this assumption.

From a Swedish perspective, in which the majority of teachers who teach mathematics in primary school have no education in mathematics (see Skolverket, 2012), these results are interesting. Teachers need support in order to teach, but depending on what their prior experience is, they need different types of support. We therefore need further studies examining not only the potential for support but also how different teachers draw upon and establish classroom practices using different textbook series.

The FM and MDS TGs are well structured, which we conjecture facilitates the teacher's work. FM offers the teacher a complete lesson plan to follow or use as the foundation for teaching, while MDS offers the teacher a script to follow or deviate from in the classroom practice. The structure is not as obvious in the $\mathrm{ME}$, where the information to the teacher is contained in the running text. Further studies need to examine when and how teachers interact with the three textbook series in planning and enacting classroom practices. For instance, are FM and MDS more suitable in the process of enacting classroom practice while ME is designed for supporting teachers in planning lessons?

Our study contributes to the collective knowledge about teachers' various resources for planning and implementing the teaching of mathematics. Our 
contribution, which can be seen as a case study based on Swedish conditions, helps in the understanding of the TG as one such resource. To better understand the interaction between teachers and TGs, research must be conducted focusing on both the personal and the material resources.

One aspect that caught our interest through this study is the way the TG speaks to the teacher. This aspect is not captured by the framework used here, but reasonably forms an interesting area for further research. The ways TGs speak to the teacher include aspects of positioning, and reasonably also affect how teachers read, interpret and use the guides. Seen from the perspective that educative curriculum materials should support teacher learning, it would be of interest to look further into this aspect.

\section{REFERENCES}

Ball, D.L., \& Cohen, D.K. (1996). Reform by the book: What is - or might be the role of curriculum materials in teacher learning and instructional reform? Educational Researcher, 25(9), 6-14.

Boesen, J., Helenius, O., Bergqvist, E., Bergqvist, T., Lithner, J., Palm, T., \& Palmberg, B. (2014). Developing mathematical competence: From the intended to the enacted curriculum. The Journal of Mathematical Behavior, 33, 72-87. doi:10.1016/j.jmathb.2013.10.001.

Brown, M.W. (2009). The teacher - tool relationship. Theorizing the design and use of curriculum materials. In J.T. Remillard, B.A. Herbel-Eisenmann \& G.M. Lloyd. (Eds.), Mathematics teachers at work. Connecting curriculum materials and classroom instruction, pp. 17-37. New York: Routledge.

Clarke, D., Mesiti, C., O'Keefe, C., Hua Xu, L., Jablonka, E., Ah Chee Mok, I., Shimizu, Y. (2007). Addressing the challenge of legitimate international comparisons of classroom practice. International Journal of Educational Research, 46 (5), 280-293.

Davis, E.A., \& Krajcik, J.S. (2005). Designing educative curriculum materials to promote teacher learning. Educational Researcher, 34(3), 3-14.

Falk, P., Picetti, M., \& Elofsdotter Meijer, S. (2011). Matte Direkt Safari $1 A$ \& $1 B$ Lärarhandledning. Stockholm: Bonniers Utbildning.

Franke, M.L., Kazemi, E., \& Battey, D. (2007). Understanding teaching and classroom practice in mathematics. In F.K. Lester (Ed.), Second handbook of research on mathematics teaching and learning (pp. 225-256). Charlotte, NC: Information Age Publishing.

Haapaniemi, S., Mörsky, S., Tikkanen, A., Vehmas, P., \& Voima, J. (2012). Favorit matematik Lärarhandledning $1 A \& 1 B$. Lund: Studentlitteratur.

Hemmi, K., Koljonen, T., Ahl, L., Hoelgaard, L., \& Ryve, A. (2012). Analyzing mathematics curriculum material in Sweden and Finland: Developing an 
analytical tool. Proceedings of CERME8

http://cerme8.metu.edu.tr/wgpapers/wg11_papers.html

Jablonka, E., \& Johansson, M. (2010). Using texts and tasks: Swedish studies on mathematics textbooks. In Sriraman, B., Bergsten, C., Goodchild, S., Palsdottir, G., Søndergaard, B.D., \& Haapasalo, L. (Eds.). The sourcebook on Nordic research in mathematics education. Charlotte, NC: Information Age Publishing, pp. 363-372.

Johansson, M. (2006). Teaching mathematics with textbooks (Doctoral dissertation). Retrieved from http://epubl.ltu.se/1402-1544/2006/23/

Joutsenlahti, J., \& Vainionpää, J. (2010). Oppimateriaali matematiikan opetuksessa ja osaamisessa (Learning materials in the teaching and learning of mathematics). In E.K. Niemi \& J. Metsämuuronen (Eds.), Miten matematiikan taidot kehittyvät? Matematiikan oppimistulokset peruskoulun viidennen vuosiluokan jälkeen vuonna 2008 (How do pupils' mathematical skills develop? The learning outcomes in the end of the fifth grade in compulsory school). Helsinki: Opetushallitus (The Finnish National Board of Education).

Olsson, I., \& Forsbäck, M. (2011). Matte Eldorado Lärarbok $1 A$ \& $1 B$. Stockholm: Natur och Kultur.

Remillard, J.T., \& Bryans, M.B. (2004). Teachers' orientations toward mathematics curriculum materials: Implications for teacher learning. Journal of Research in Mathematics Education 35(5), 352-388.

Skolverket (2011). Curriculum for the compulsory school, preschool class and the recreation centre, 2011 . Retrieved from http://www.skolverket.se/publikationer?id=2687

Skolverket (2012). TIMSS 2011. Retrieved from http://www.skolverket.se/publikationer?id=2942

Stein, M.K., Remillard, J.T., \& Smith, M.S. (2007) How curriculum influences student learning. In F.K. Lester Jr. (Eds.). Second handbook of research on mathematics teaching and learning (pp. 319-369). Charlotte, NC: Information Age. 


\title{
TEACHERS' EXPERIENCE FROM USING INTERACTIVE E-BOOKS IN THE CLASSROOM
}

\author{
Esbjörn Hägerstedt ${ }^{1}$, Linda Mannila ${ }^{1}$, Tapio Salakoski ${ }^{2}$, Ralph-Johan Back ${ }^{1}$
}

${ }^{1}$ Åbo Akademi University, Turku, Finland, ${ }^{2}$ University of Turku, Turku, Finland

The availability of computers and tablets at school level has increased during recent years. Nevertheless, studies show that teachers experience a lack of pedagogically viable material to use together with the technology in the classroom. This is the case in particular for mathematics. In this paper we discuss teachers' experience from using a given kind of interactive learning material in their mathematics classroom for the first time. Our findings suggest that teachers appreciated the opportunity to use new, flexible and interactive instructional methods for teaching and coaching students as well as the possibility to modify the material themselves. Challenges experienced were e.g. technical problems and the increase in time needed for teaching (both for getting used to the new material as well as using new tools etc.).

\section{INTRODUCTION}

Information and communication technology (ICT) is part of everyday life in schools, where computers are used for diverse purposes: writing essays, finding information online, producing multimedia and taking part of interactive exercises and electronic exams. In general, the last decade has shown an increasing switch from pen and paper to computers and tablets, and from printed textbooks to digital learning materials. Exams, which traditionally have been taken using pen and paper, are also currently undergoing a transition towards the use of ICT. In Finland, exams are already sporadically arranged using computers in some subjects, and this will increase dramatically in upcoming years in preparation for the matriculation examination ${ }^{1}$ being digitised starting in 2016 (http://www.digabi.fi).

Despite an increased availability of computers and other devices in Finnish schools, these are hardly utilized to their full potential in the classroom. Reports from official working groups emphasize the importance of integrating ICT in teaching and learning (Ministry of Employment and the Economy, 2013), but studies indicate that Finnish teachers experience a lack of pedagogically viable computer supported material to use in the classroom (European Commission, 2013). In addition, professional development is needed in order to increase the use of ICT in teaching and learning activities. The situation is not representative of Finland alone; research has indicated several barriers that teachers face related to ICT integration in the classroom. For instance, Kopcha (2012) summarizes these as related to the following five aspects:

\footnotetext{
${ }^{1}$ The Finnish matriculation examination is a nation-wide exam taken by all students finishing upper secondary school. The purpose of this examination is to find out whether the students have acquired the "knowledge and skills required by the curriculum for the upper secondary school and whether they have reached an adequate level of maturity in line with that school's goals." (http://www.ylioppilastutkinto.fi/en)
} 
- access (no computers available or available computers not working properly)

- vision (lack of vision often results in teachers abandoning ICT very easily)

- beliefs (using ICT is difficult or of no use)

- time (planning how and learning to use ICT takes time)

- professional development (not enough relevant training)

If the situation of using ICT in the classroom in general needs improvement, the need is even larger for mathematics. Although the thought of using computers in the mathematics classroom is nothing new, as it was introduced already in the 1960s (Suppes, 1965), current studies show that mathematics is the subject in which ICT is utilized the least (Skolverket, 2013).

One of the biggest challenges in creating sophisticated digital learning material for mathematics is related to the extensive need for special characters that cannot be produced using a regular keyboard. As a result, students have seldom been able to, for instance, write solutions on the computer in a straightforward way.

Van de Walle (as discussed by Wiest (2001)) has presented three ways, in which mathematics education is changed by the introduction of ICT:

1. Which skills to invest time in is changed. Instead of using time on paper-andpencil computations and constructions, more time and effort can be invested in problem solving and reasoning.

2. The ways in which mathematics is taught change, as new types of material (visualizations, simulations, etc.), learning opportunities and problems are introduced.

3. ICT makes it easier to support learning various mathematical skills and topics.

Pierce and Ball (2009) studied teachers' perceptions on technology use in secondary mathematics classes and found that teachers believe that the use of technology motivates the students as well as makes the math more enjoyable. They also think that use of technology helps the students gain deeper understanding and help them learn how to work with real world problems. The study also showed that only $15 \%$ of the teachers thought that learning new technology would take up too much of their personal time, whereas $24 \%$ felt that using more technology would result in them not having time to cover all material for the entire course.

In this paper, we present the results from an analysis of mathematics teachers' experience when using interactive e-books in their teaching. The e-books can be viewed as a learning environment, as they contain not only material (theory, examples, exercises) but also functionality and tools that have been tailored for learning and teaching mathematics. For instance, the format provides an editor that makes it easy to produce mathematical text on a regular keyboard.

In the following, we briefly describe the interactive e-books and some of its features. Next we will present the study settings as well as the results, which are discussed in a separate section. Finally, the paper is ended with some conclusions and final words. 


\section{INTERACTIVE E-BOOKS}

Interactive e-books for high school mathematics were developed within E-Math, a project that ran during the period 5/2011 - 12/2013 and was funded by the EU within the Central Baltic Interreg IV A 2007-2013 programme. The aim of the project was to enhance mathematical understanding amongst students on high school level, using a new format for presenting mathematical solutions and arguments called structured derivations combined with interactive e-books. For details on the project, the participants and the published e-books, please visit http://www.emath.eu.

Structured derivations is a standardized format that can be used for writing proofs and solutions within all areas of mathematics, regardless of difficulty level. The format was introduced by Back and von Wright (Back \& von Wright, 1999; Back, 2010) and has been empirically evaluated in education with encouraging results starting in the early 2000s (see e.g. Peltomäki and Back, 2009; Mannila, 2009).

Structured derivations provides a way of presenting mathematical solutions and proofs in an easily readable and well-structured format, where each step is explained. This helps students understand how a solution is constructed and why a problem is solved in a given way. An example of the basic structure is given in Figure 1.

$$
\begin{array}{ll}
\bullet & (x-1)\left(x^{2}+1\right)=0 \\
\Leftrightarrow \quad & \text { zero product rule: } a b=0 \Leftrightarrow a=0 \vee b=0\} \\
& x-1=0 \vee x^{2}+1=0 \\
\Leftrightarrow \quad & \text { add } 1 \text { to both sides in left disjunct }\} \\
& x=1 \vee x^{2}+1=0 \\
\Leftrightarrow \quad & \{\text { add }-1 \text { to both sides in right disjunct }\} \\
\Leftrightarrow \quad & x=1 \vee x^{2}=-1 \\
& \left\{\text { a square is never negative: } a^{2}<0 \Leftrightarrow F\right\} \\
& x=1 \vee F \\
& \{\text { disjunction rule: } p \vee F \Leftrightarrow p\} \\
& x=1
\end{array}
$$

$$
\begin{array}{r}
(x-1)\left(x^{2}+1\right)=0 \\
x-1=0 \vee x^{2}+1=0 \\
x=1 \vee x^{2}=-1 \\
x=1 \vee F \\
x=1
\end{array}
$$

Figure 1: Example of structured derivations finding the real roots of an equation. For reference, the same solution is presented in a more traditional way to the right.

The standardized format makes it easier to create computer support both for writing mathematics and analysing mathematical arguments. In the e-books the format is used for presenting examples and theory, as well as a basis for the mathematics editor. A more in-depth review of the format and examples including other features is available in, e.g, the articles by Back \& von Wright (1999) and Back (2010). 
The interactive e-books are based on a tailor-made framework developed within the project. The framework includes three book types: 1) an author book that serves those creating new content, 2) a teacher book with functionality and tools specifically developed for teachers' needs, and 3) a student book, which serves as an integrated text- and workbook for students. During a course, the teacher book is connected to student books through a server. A screenshot from the e-book is given in Figure 2.

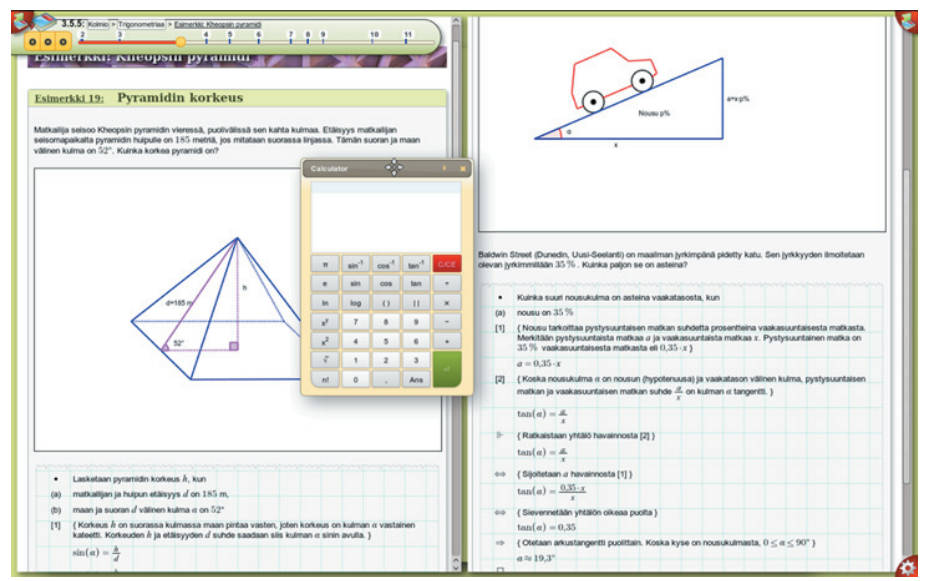

Figure 2: Overview of the interactive e-book.

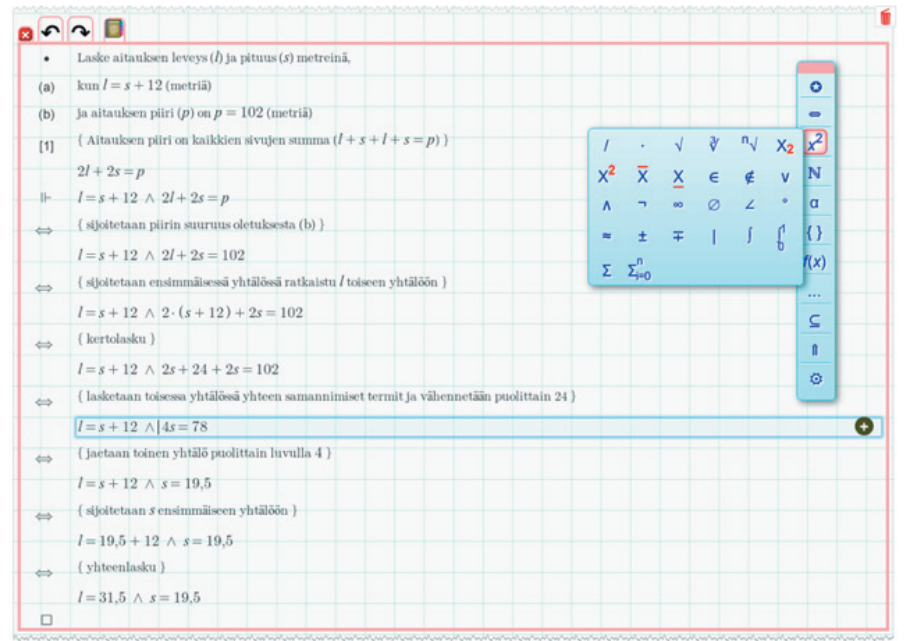

Figure 3: Overview of the editor for writing mathematical text.

The e-book framework offers teachers and students a range of tools and functionality: 
- Teachers can, for instance, add own material, examples and exercises using different types of editors; mark home assignments directly in the book, give individual feedback on students' solutions, go through examples step-by-step, and create PowerPoint-like presentations by picking material from the book.

- Students, on the other hand, can read theory, take part of interactive examples, solve assignments using a set of editors (Figure 3) and submit solutions to the teacher, discuss using a chat allowing mathematical content, etc.

The e-books can be used both online and offline, and all solutions and teacher response are saved in a local file - hence, the student does not lose any information e.g. when the course ends and the connection to the server is no longer available.

In the remainder of the paper, we will focus on teachers' experience of the IT-related parts of the e-books, i.e. using the technology in the classroom.

\section{STUDY SETTINGS ${ }^{2}$}

The e-books mentioned above were empirically evaluated in a pilot study during 2012-2013 in 15 schools with 18 teachers and roughly 1000 students in Sweden (Stockholm, two schools), Estonia (Tallinn, eight schools) and Finland (Mariehamn and Turku, five schools). Students were equipped with personal laptops, which were used on a regular basis during lectures. As part of these pilots, we conducted a qualitative study aiming at bringing light on the benefits and challenges experienced by teachers when using the interactive e-books. The study was based on semistructured interviews conducted with 18 teachers (7 Finnish, 3 Swedish, 8 Estonian).

The interviews were transcribed and the resulting data were analysed and summarized into emergent themes using content analysis (Cohen et al., 2007). The analysis resulted in five (5) categories describing the benefits and equally many describing the challenges related to using IT in the classroom.

\section{RESULTS}

In this section, we will present the findings from the analysis described above. Each category is exemplified with a quotation.

\section{Experienced benefits}

The main benefits found related to technology and the number of teachers mentioning the respective benefits are listed in the following:

- New instructional methods for mathematics (18/18)

- Supportive functionality and tools (17/18)

- Increased flexibility and interactivity $(14 / 18)$

- Possibilities to influence the study material (4/18)

- Opportunities for individualisation $(2 / 18)$

\footnotetext{
${ }^{2}$ For a more detailed description of the study settings and the methodology, please see the thesis by Hägerstedt (2014).
} 
These categories are presented in more detail below.

New instructional methods for mathematics: Teachers clearly appreciated getting new methods for use in the classroom - both for teaching and for coaching. Structured derivations is seen as an interesting new pedagogical approach, which helps students see the importance and benefits of justifications. Computers and the e-book, on the other hand, give teachers long-awaited tools for modernizing their teaching.

Teachers particularly liked the ability to coach students individually by giving feedback on solutions directly in the e-book. This opportunity was appreciated for making it easier to see what - and how - the students were doing as well as a way of increasing the amount of teacher-student communication. The possibility to glance at students' solutions to homework also helps the teacher decide what should be repeated during the next lesson before moving forward to new material.

"A big change is the ability to give feedback outside lecture hours. That way it is possible to give more personal feedback, as others are not listening from the side."

Supportive functionality and tools: Teachers appreciated the tailored tools and functionality available for use in the classroom. The most popular one was the stepby-step functionality that enables showing examples in the e-book one step at a time - this makes it possible to go through examples in the classroom in an interactive manner and also leaves more room for reasoning. Similarly, teachers liked the editor, which makes it possible to create examples and solutions in a straightforward way on the computer.

"The e-book got an add-on so you can show step- by-step. Now it is suitable for showing examples."

Increased flexibility and interactivity: Teachers liked that everything was in one place eliminating the need for a separate book, notebook and calculator. In addition, they found the interactive graphs and other similar illustrative material useful.

"...topics that had interactive content, e.g. graphs that you could easily change, they motivated the students and they understood better."

Possibility to influence the study material: Teachers liked the possibility to add their own content and distribute it to their students, as it made them in control over the material used.

"When the e-book feels like your own making it is much more pleasant to teach with"

Opportunities for individualisation: Closely related to the possibility to influence the material are different ways for individualisation provided in the e-book. Teachers mentioned, for example, having exercises of different difficulty levels and the tools that make it possible to follow up on students' progress.

"A huge benefit has been that I now notice much sooner if someone falls behind or misses something. Thanks to the fact that it is so easy to go through exercises that have been handed in." 


\section{Experienced challenges}

As mentioned above, the analysis also revealed five categories describing challenges related to the technology in one way or another:

- Technical problems (18/18)

- Initial learning curve (both for the teacher and the student, 18/18)

- Increased time consumption (16/18)

- Practical problems $(12 / 18)$

- Motivating students (12/18)

In the following, we describe these categories in more detail.

Technical problems: All teachers reported having had technical problems - some more, some less. The technical problems were mainly related to two things: 1) computer issues involving aspects such as slow computers or other problems with the computer environment, and 2) peculiarities found in the editor used for writing mathematics in the e-book, for instance, getting used to switching between writing normal text and writing mathematics.

"... dealing with all those computers and computer problems."

Initial learning curve for teachers and students: Learning to use new technology naturally requires some effort in order to learn to use new tools and work with new functionality. This is the case regardless of the situation in which the technology is introduced. For the teachers the initial learning curve involved feelings of insecurity of their own skills, additional time needed for preparing lessons and mastering new teaching situation. Some teachers, however, pointed out that this is the case when starting to use a new traditional paper book as well.

"It is always tough the first time you use them [a new book], the second and third time it gets easier and I think it is the same thing here."

Increased time consumption: A natural consequence of the learning curve is that preparations etc. take more time in the beginning. When teachers have learnt to use the basic features of the e-book, they naturally want to go on to use more advanced functionality as well. Giving personal feedback to students, writing structured examples to be included in the e-book material, etc. are all features provided by the ebook, but that require more time and effort from the teacher.

"It [giving individual feedback] is time consuming for the teacher, but from the student's viewpoint it is good."

Practical problems: In addition to strictly technical problems, teachers also mentioned practical problems of various types. For instance, in some schools students' desks were too small for fitting both a laptop and a notebook at the same time. Other things mentioned were empty batteries, laptops being heavy to carry around and lack of video projectors in all classrooms. In addition, some teachers 
expressed their worry about the computer making it more difficult for students to focus on what they should be doing.

"Of course it is a little dangerous when the computer is there on the table and we know that it has Internet and the Facebook profile could be updated"

Motivating students: Closely related to this type of practical problems, some teachers found it challenging to motivate students. As with all groups of students, they have various backgrounds, e.g. some being more digitally literate and others less.

"Those who are comfortable with using computers, and most of them are very positive.

Those who have less interest in computers, are a bit inefficient, they are negative."

\section{DISCUSSION}

As pointed out by van de Walle (Wiest, 2001), when using computers less time has to be invested in laborious tasks, such as calculating and creating constructions with pen and paper. All of the freed up time cannot, however, be directly used for a larger focus on the mathematical content, as there is also a need to learn to use the new tools. It takes time both for teachers and students to become familiar with new technology and this can be particularly challenging for teachers, who need to feel "on top" of what goes on in the classroom. Even after the new material has become familiar, the use of tools and other functionality can still result in no extra time being won from getting rid of the pen and paper. Professional development is needed in order to help teachers become confident with new material - regardless of whether it is computer-based or unplugged. One problem seems to be a question of supply and demand - publishers do not want to make digital learning materials before there is a big enough demand and teachers cannot ask for it before they know how to use it in a meaningful way.

The interactive e-books were developed for mathematics and hence include tools and functionality specifically aimed at teaching and learning this specific subject. Both the tools as well as the increased flexibility they bring to the classroom, were among the largest benefits experienced by the teachers in our study.

It is common for teachers to have their own favourite examples, assignments or other material that is not part of the course book, but that they would still like to include in their teaching. This is particularly true for mathematics teachers for a number of reasons: 1) Compared to other subjects it is pretty easy and straightforward to make own examples without it taking too much time. 2) There are close to infinite many ways of solving a certain math problem but only a few ways of describing e.g. Napoleon's life. 3) If the teachers use their own examples as a complement to the course book, the students get double the amount of practice. This was also pointed out by one of our pilot teachers. Traditionally, this has involved distributing separate documents to students, as it is not possible to add material to a printed textbook. In the e-book, however, such additions and modifications are supported; a feature that was highly appreciated by the teachers. 
When using traditional material in the classroom, such as printed textbooks and pen and paper, one does not have to worry about technical problems. As computers or other technology is introduced, so are technical problems. As discussed above, this is one of the most common barriers for teachers wanting to use ICT in the classroom in theory technology is available, but in practice it does not work as it should. Consequently, both teachers and students can experience a lack of access to the technology. Luckily, the project was able to supply quick technical support to those in need, and problems related to the e-books were easily solved. Problems with the hardware or user rights on individual computers were naturally out of the project personnel's control.

The use of personal laptops in the classroom has been found to increase students' motivation, improving problem-solving skills and diminishing digital divides, e.g. based on gender (Mackinnon \& Vibert, 2002; Finn \& Inman, 2004). Similarly, research points out drawbacks of using laptops in educational settings. One of these is clearly the same as the fear also pointed out by the teachers in our study: students might be doing something completely different from what they should (Fried, 2008). Some level of distraction may always be involved, but by making the material available for in-class topics as good and motivating as possible, the number of students finding the need for doing something else may be decreased.

\section{FINAL WORDS AND FUTURE WORK}

In this paper we have presented teachers' experiences from using interactive textbooks in the classroom. Despite the e-book providing increased functionality compared to a traditional textbook, which results in preparations taking more time, teachers still expressed interest in having access to even more tools and features.

When conducting our analysis of the interview data, we were able to create a wish list of things teachers would like to see in the e-book. This list included for instance increased possibilities for making modifications, tools for drawing different types of figures as well as a solution making it possible to also organize exams in the e-book. When the second pilot started in fall 2013, the e-book contained much new functionality and consequently the wish list had been significantly reduced. The data from this pilot are still being collected, and we look forward to continuing our study on the use of interactive textbooks in the mathematics classroom.

As computer based learning tools make their way into our education institutions teachers face a tremendous challenge in reinventing their teaching (Khan, 2012). Our study has shown that teachers are more then happy to take on this challenge - given the right training and tools as well as a possibility to have an influence.

\section{REFERENCES}

Back, R-J. Structured Derivations: a Unified Proof Style for Teaching Mathematics. Formal Aspects of Computing, 22(5): 629-661, 2010. 
Back, R-J \& von Wright, J. (1999). Structured Derivations: a Method for Doing High-School Mathematics Carefully. Technical Report 246, TUCS, Finland.

Cohen, L., Manion, L. \& Morrison, K. (2007). Research Methods in Education. 6th Edition. London: Routledge New York.

European Commission. (2013) Survey of Schools: ICT in Education. Benchmarking Access, Use and Attitudes to Technology in Europes' Schools. Final Study Report.

Finn, S. and Inman, J.G. (2004). Digital Unity and Digital Divide: Surveying Alumni to Study Effects of a Campus Laptop Initiative. Journal of Research on Technology in Education, 36(3), pp. 297-317.

Fried, C. B. (2008). In-Class Laptop Use and Its Effects on Student Learning. Computers and Education, 50, pp. 906-914.

Hägerstedt, E. (2014) Teachers' Experience from Using Interactive E-Books and Structured Derivations in the Classroom: Advantages and Challenges. Master's thesis, Abo Akademi University.

Khan, S. (2012). The One World Schoolhouse: Education Reimagined. Twelve.

Kopcha, T. J. (2012). Teachers' Perceptions of the Barriers to Technology Integration and Practices with Technology under Situated Professional Development. Computers and Education, 9, pp. 1109-1121.

Mackinnon, G. R., and Vibert, C. (2002). Judging the Constructive Impacts of Communication Technologies: A Business Education Study. Edcucation and Information Technologies, 7(2), pp. 127-135.

Mannila, L. (2009). Teaching Mathematics and Programming - New Approaches with Empirical Evaluation. Doctoral dissertation, Åbo Akademi, November 2009.

Ministry of Employment and the Economy (2013). 21 Polkua Kitkattomaan Suomeen. ICT 2015 -työryhmän raportti, 4, February 2013.

Peltomäki, M. and Back, R-J. (2009). An Empirical Evaluation of Structured Derivations in High School Mathematics. In Proceedings of $19^{\text {th }}$ ICMI Study Conference on Proof and Proving in Mathematics Education. Taiwan.

Pierce, R. and Ball, L. (2009). Perceptions that May Affect Teachers' Intention to Use Technology in Secondary Mathematics Classes. Educational Studies in Mathematics, 71, pp. 299-317.

Skolverket. It-användning och it-kompetens i skolan. Rapport nr. 386. Stockholm, 2013.

Suppes, P. Computer-based mathematics instruction. Bulletin of the International Study Group for Mathematical Learning, 3, pp. 7-22. 1965. 
Wiest, L. R. The Role of Computers in Mathematics Teaching and Learning. Computers in the Schools, 17(1-2), pp. 41-55, Taylor \& Francis, 2001. 


\title{
TEACHERS' USE OF RESOURCES IN AND FOR MATHEMATICS TEACHING
}

\author{
Ingvild Lambert Grave and Birgit Pepin \\ Sør-Trøndelag University College, Trondheim, Norway
}

There is an increasing amount of resources available for teaching and learning mathematics, traditional as well as digital. However, we know relatively little about how teachers work with them in detail. In this study we have studied how four Norwegian primary teachers used resources in/for their mathematics teaching. Anchored in the analyses of lesson observations, interviews and particular documents, three (out of five) "usage categories" are discussed in this paper: (1) management of teaching objectives; (2) teachers ' use of resources for inspiration; and (3) resources teachers use for student work. These categories emphasize the importance of understanding interactions between teachers and resources; and the ways resources influence many different aspects of teachers' work.

\section{INTRODUCTION}

In past decades resources have been heralded as important for mathematics teaching and learning, but it is only relatively recently that the focus has been on how these resources are/should be used (Cohen, Raudenbush, \& Ball, 2003, p. 120). One reason for this change in focus is likely to be the increased availability of digital resources (e.g. Gueudet \& Trouche, 2012). But simply having access to resources is not enough to impact on teaching. The literature (e.g. Cohen et al., 2003, p. 122) claims that what impacts on students' learning most is how resources are used by teachers (and not only their availability). Hence, it seems reasonable to investigate how teachers use resources in and for mathematics teaching.

In Norway, where the study was carried out, the national curriculum consists of objectives that are expected to be achieved after $2^{\text {nd }}, 4^{\text {th }}, 7^{\text {th }}$ and $10^{\text {th }}$ grades. However, there are no instructions for teaching, and teachers organize their teaching according to those goals. Since 2000, textbooks do not have to be approved by the ministry and there is a free market for mathematics textbooks in Norway. This gives a strong influence to those producing textbooks and other text resources (Juuhl, Hontvedt \& Skjelbred, 2010). In terms of research, both the "minimalistic format" of the National Curriculum and the situation of "free" textbook production, make it both challenging and interesting to investigate how mathematics teachers in Norway use resources, including textbooks, in and for their teaching.

\section{THEORETICAL BACKGROUND FOR THE STUDY}

In this article resources are understood as curriculum resources in mathematics teaching, according to the definition by Pepin \& Gueudet (2013): 
- text resources, such as textbooks, teacher curricular guidelines, websites, student sheets and syllabi;

- other material resources, such as manipulatives and calculators;

- ICT based resources, such as computer software. (Pepin \& Gueudet, 2013)

In terms of theoretical frameworks (relating to teachers' use of resources) used in this study, we identified two different categories: (1) use of curriculum/text resources, such as textbooks (e.g. Brown, 2009; Remillard, 1999; Sherin \&Drake, 2009); and (2) use of resources including all three elements of Pepin \& Gueudet's definition (e.g. Gueudet \& Trouche 2012; Gueudet et al., 2013). Both provide the theoretical background for our research, but in this paper we will mainly report on the use of text resources.

In terms of teachers' use of curriculum resources, Brown (2009) coined the term Design Capacity for Enactment (DCE). He conceptualizes the interaction between the resource and the teacher as an adaptation of the resource by the teacher, and this adaptation is characterized by the following: offloading; adapting; and improvising. These adaptions are three different ways of distributing agency amongst the teacher and the resource, and both the teacher and the resource influence this usage. Characteristics of both the teacher and the resource influence the interaction (Brown, 2009, pp. 26), and the outcome of the interaction is the teaching with the resource. The ways the teacher uses the resource to achieve lesson objectives is termed as pedagogical design capacity (Brown, 2009, pp. 24). The DCE is useful as a theoretical background, since it shows different ways in which teachers can use resources, and provides reasons for these differences (Brown, 2009).

Another theoretical framework for teachers' interaction with curriculum resources is provided by Remillard (1999): she contends that teachers use resources in three different arenas: (1) the design arena involves choosing and designing tasks for the students; (2) in the construction arena the teacher enacts the plans in the classroom and responds to what happens in the classroom; and (3) the curriculum mapping arena refers to the organization of the curriculum (Remillard, 1999, p. 322). In these different arenas resources are used quite differently by teachers.

As a third frame, Sherin \& Drake (2009) assert that teachers' adaptation of resources can be understood as a continuum, the curriculum adaptation spectrum (Sherin \& Drake, 2009, p. 486-487). At one end (of the spectrum) teachers create, they use resources and create new components for their teaching. Along the "middle", teachers replace, they "substitute one component of a lesson with something different"; and at the other end teachers adapt the resources when they omit components of a lesson without replacing them (Sherin \& Drake, 2009, p. 486-487). 


\section{THE STUDY}

The design of the study was akin to qualitative case study, which provided opportunities to research the complex contexts in which teachers used resources (Creswell, 1998, pp. 61). Four "ordinary" teachers were the case units of analysis: Lillian; Cathrine; Sandra; and Torgeir. They were "sampled" based on their involvement with mathematics teaching in their school: they were in charge of the mathematics teaching (team) of the particular grade they were teaching.

To investigate the practises of these teachers with respect to resources, we used multiple data collection strategies: (1) we collected documents and papers from the teachers' work; (2) we observed them in their classrooms with students; and (3) we interviewed them. The documents and papers collected were the following: teaching plans; half year plans; copies from the textbooks (used for teaching); the tasks/activities they gave to the students; and "arbeidsplan" (a work plan for students produced by the teacher for a set period of time, will be described more closely later). We also asked them to draw schematic representations of the resource system (SRRSs) (Gueudet \& Trouche, 2012, pp. 28). These gave us information about which resources were important for the teachers, how they linked their different resources; and one teacher even numbered the resources to show how she ranked the resources. The SRRSs gave additional information to observations and interviews.

In terms of observations, these provided information about how the teachers used resources in their teaching, whilst the SRRSs and the interviews gave information about how resources were used in/for teaching. The interviews were conducted after the observations to make use of what we had observed.

The analysis was conducted in two steps. First we did a within-case analysis where we looked in detail at each teacher's case: this was a descriptive analysis. Then we conducted a cross-case analysis: this was "a thematic analysis across the cases" (Cresswell, 1998, pp. 63). In both the within-case as well as the cross-case analysis we used the constant comparative method in order to develop categories (Cohen, Morrison \& Manion, 2007, pp. 493): the analysis resulted in the identification of five categories (of which three are discussed in this paper).

After the within-case analysis we also conducted respondent validation, in order to

... assess intentionality, to correct factual errors, to offer respondents the opportunity to add further information or to put information on record; to provide summaries and to check the adequacy of the analysis. (Cohen et al., 2007, pp. 136)

\section{FINDINGS}

Our investigation of how the four teachers used resources in and for mathematics teaching revealed five different usage categories. These usage categories showed how the resources influenced almost all aspects of mathematics teachers' work: planning 
the lessons and pupil learning progressions over several weeks; cooperation with other teachers; the teaching in the mathematics lessons; and the students' homework; to name but a few. Figure 1 shows how the five usage categories were linked.

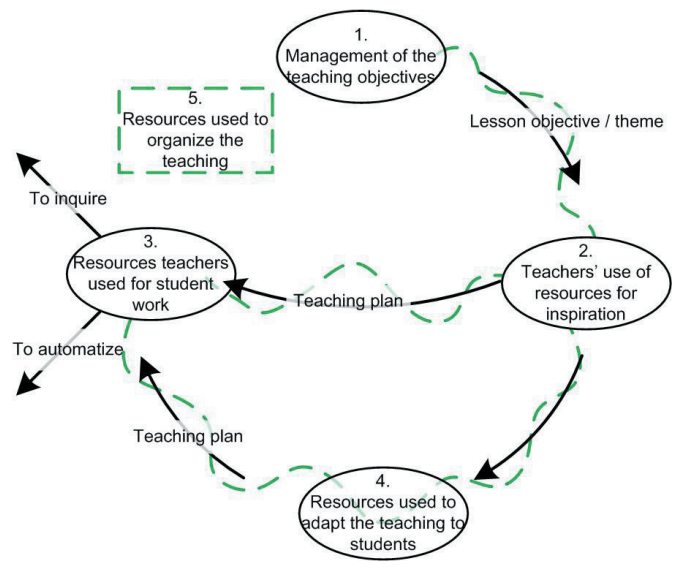

Figure 1: The five usage categories and how they are connected

In this paper three of the five categories will be presented. These categories are:

1. Management of the teaching objectives

2. Teachers use of resources for inspiration

3. Resources teachers use for student work

We choose to present only these three categories because these three are most prominent among the four teachers, both in interviews, observations and in their SRRSs.

\section{Management of the teaching objectives}

The first usage category that the study revealed was how teachers use resources to manage their teaching objectives. This usage category seemed very important and prominent in Norway, because of the organization of the national curriculum in objectives, without providing any pedagogical guidelines.

The study revealed that there were two main resources that helped to manage the teaching objectives, both the long-term objectives and short-term lesson objectives. These two resources were: the national curriculum and the textbook with its' teacher guide. However, the four teachers in the study used these two resources differently. For one of the teachers, Cathrine, the textbook was the most important resource to manage the teaching objectives, to the extent that the textbook back-grounded the 
national curriculum almost completely for Cathrine. Both in her long-period planning and in her daily planning, she followed the textbook.

For another teacher, Lillian, the national curriculum was the most important resource to manage the teaching objectives. She had recently changed from one school to another, and in her new school they used a textbook that she did not particularly like, for different reasons. The result of this disliking was that the textbook was backgrounded, and the national curriculum foregrounded, which meant that the national curriculum was the resource she used to manage her teaching objectives, both longterm objectives and lesson objectives.

These two different ways to use resources to manage teaching objectives can be understood in terms of Remillard's (1999) mapping arena. The textbook's role in the mapping arena can be understood in the following way:

Textbooks offer a curriculum map that organizes mathematical topics into sections, each including specific concepts or skills. Teachers map the curriculum when they decide how or whether to use these structures. (Remillard, 1999, p. 334)

The second teacher, Lillian, is an example of a teacher that did not follow the structures of the textbook, whilst Cathrine used them and followed them very closely ("teaching by the book").

To manage the short-term teaching goals, at first sight, it appeared that the arbeidsplan was the main resource for these two teachers: in Norway many schools and teachers use what they call arbeidsplan. This is a document the teachers (typically in group discussions linked to a particular grade) produce for a set time period to organize the students' work (e.g. arbeidsplan for a two-week period). The arbeidsplan provides what is supposed to be taught in the lessons, and the students' homework.

However, at closer investigation we found other resources that appeared to be more important for setting short-term teaching objectives. In Cathrine's practice the arbeidsplan was completely directed by the textbook. This showed that for Cathrine the textbook managed both long term and short-term objectives. Referring to Brown (2009), it can be argued that she "offloaded a large degree of agency for guiding instructional activity onto the materials" (Brown, 2009, pp. 24). Cathrine allowed the textbook to decide (1) the pace and progress in her teaching; (2) which activities to use; and (3) how to present the mathematical explanations/introductions.

This practice was in contrast to Lillian's. For her instruction we found that the national curriculum was the main resource to manage also her short-term teaching objectives. In her case, the arbeidsplan was structured according to the national curriculum, and the arbeidsplan guided her short-term teaching objectives. The activities she used in her teaching, and the ways she presented the mathematics in her 
teaching, was directly in accordance with the objectives from the national curriculum on which she based the arbeidsplan.

These teachers' use of resources to manage their teaching objectives can be understood in terms of Remillard's (1999) different arenas. When the teachers used resources to manage long-term teaching objectives, we argue that they were working in the mapping arena. However, when the teachers used resources to manage their short-term goals, they appeared to work on the borderline between mapping arena and the design arena. This was because the curriculum was already organized in half-yearly plans, but in their work with the arbeidsplan they continued to organize the curriculum. Because of this, we contend that when they used resources to manage their short-term teaching objectives, they were following a path from mapping arena to design arena.

\section{Teachers' use of resources for inspiration}

This usage category is both about the teachers' planning phase, and their implementation phase, as the interaction of the teacher and the resource is assumed to lead to the teaching (Brown, 2009). The teachers in the study used different resources for inspiration, and they used them differently to get inspiration.

The study showed that among the four teachers, the textbook was most frequently used for inspiration. Also in this usage category, the two teachers Cathrine and Lillian had quite opposite practices. If we use the continuum from Sherin \& Drake (2009), Cathrine can be placed on one end, as her adaptations of the textbook mostly involved omitting parts from the textbook. Lillian can be placed on the other side of the continuum, as her adaptations mostly involved her creating components, and even new lessons, based on themes from the textbook (Sherin \& Drake, 2009, p. 486-487).

Whether these teachers used the textbook as an inspiration is arguable. However, in terms of Remillard's (1999) design arena, it can be argued that the teachers use the textbook for their planning, more precisely to choose and create exercises and tasks for their students. In this way the teachers used the textbooks to get inspiration for their own teaching.

Another resource that was widely used for inspiration was the Internet, and the Internet was used both for inspiration for the teacher, and for the students. An example of how they used the Internet as an inspiration for the students was: they found tasks and games on the Internet for the students; especially on the publishing firms' own Internet pages. The teachers reported that their students got more motivated when they were allowed to do tasks on the Internet, than from tasks in the textbook. One of the teachers in the study, Sandra, also used to find youtube-films of teachers giving lessons. She gave these films to her students as homework, to watch as a preparation for her lessons. Both when the teachers assigned Internet tasks for students and when they use YouTube lessons, they used the Internet mainly to inspire their students. 
However, we also found examples of how they used the Internet to inspire themselves as mathematics teachers. Sandra for instance, used google.no to find lesson plans, half year plans and arbeidsplans of other teachers, in other schools, when she was planning her own teaching.

Among these different resources for inspiration, one can say that when the teachers used resources to inspire the students, they used the resources in the construction arena. But when they used the resources to inspire themselves, they worked in the design arena (Remillard, 1999).

\section{Resources teachers use for student work}

The students also used many of the resources the teachers used for inspiration, and one can argue that there were many connections between these two usage categories. But in the usage category called "Resources teachers use for student work", the resources were not used to inspire the students. They were used either to automatize skills, or for inquiry. It was the teacher who decided how the resources were to be used in this category. In the study we only studied what the students did at school, not how they used resources at home for homework.

To automatize skills, the teachers mainly used textbooks. For example, Cathrine said that in her opinion the students needed "peace" and a chance to get concepts presented in a "structured way", and "step-by-step", to be able to learn mathematics. Hence, she followed her textbook quite closely, and in most of her lessons the students spent their time working on tasks to automatize skills. When the textbook gave the students a possibility to choose between methods and recommended that the students used both methods to inquire how these methods worked (Alseth Nordberg, \& Pedersen, 2008, pp. 14-15) (see figure 2), she decided (not the students) which method they should use.

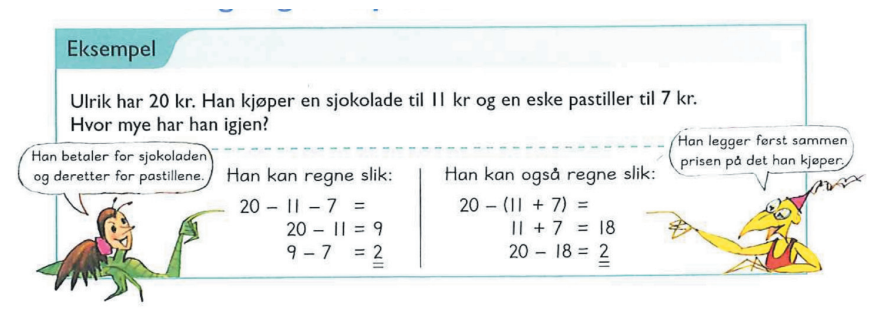

Figure 2: An excerpt from Cathrine's textbook. (Alseth et al., 2008, pp. 14)

The way Cathrine used the textbook and teacher guide, can be understood related to DCE (Brown, 2009). DCE emphasizes the interaction between teacher and resources, and that "features" of both the teacher and the resources influence this interaction. In this case a feature of the resource was that it gave the students a chance for inquiry of 
two different methods. A feature of the teacher, Cathrine, was that, according to her beliefs about how students learn mathematics, they needed to learn small parts/steps at a time, that they needed peace to concentrate, and that they needed to work individually to trust in their own skills. The way she used the resource here, the interaction between the teacher and the textbook, can be called adaptation (Brown, 2009). The adaptations she did were influenced by her own belief about teaching and learning mathematics, and therefore she did not follow the advice from the teachers' guide.

An example of how students used resources for inquiry was from one of Sandra's lessons. In this lesson, the lesson object was that the students should be able to "find a common denominator and to add and subtract by using the common denominator". To manage this she had prepared fraction strips that the students used to solve fraction tasks from their textbook. The teachers' guide also suggested using fraction strips instead of finding a common denominator (Pedersen, Pedersen, Skoogh, Johanssson, \& Ahlström, 2006, pp. 53). Sandra wanted the students to discover connections by using the fraction strips.

Her students managed very well to use the fraction strips to solve addition tasks. But when they had to solve subtraction tasks, they had problems. This can be understood in terms of the following: if the students considered the fraction strips as a new algorithm and not a way to discover connections, as was Sandra's intention. Galen, Feijs, Figueiredo, Gravemeijer, Herpen \& Keijzer (2008), say the following about the use of fraction strips:

Working with fraction strips can only contribute to the intended development if the teacher makes sure that the students test their solutions by explaining the relationships between the measurements they used. Good mathematics education involves more than the quality of the concrete materials; it also involves the quality of the students' discussions of the reasoning behind their solutions. (Galen et al., 2008, pp. 66)

In her lesson Sandra gave the students the opportunity to discuss and explain what they did, when they were working in pairs, and the textbook and the teachers' guide asked the students to explain what they did for every task (e.g. Pedersen, Pedersen, Skoogh, Johansson \& Ahlström, 2006, pp. 52-53). However, the aim of the students appeared to be to work as quickly as possible, to finish the tasks as quickly as possible, to get their break quicker, and hence they used the minimum time to discuss. Even though Sandra's intention was inquiry, one can say that the lesson ended in "automatizing", since the students hurried and did not take time to discuss to make it an inquiry.

This example of how Sandra's class used the fraction strips for inquiry can be understood in terms of Brown's DCE (Brown, 2009). It was clear that Sandra was convinced that students needed to inquire and find connections to be able to learn this 
mathematical topic. At the same time affordances of the fraction strips provided opportunities to inquire, but they also demanded students' explanations of their thoughts and reflection on their findings. The interaction between Sandra and the resources can be called adaptation, because she was not able to utilize the potential of the fraction strips. It can also be seen as a result of the context and of the choices she made: for example, that students had to finish all the tasks in order to go for their break; rather than a result of her beliefs.

This category, connected to student work, can be seen to be related to the construction arena (Remillard, 1999). The examples above showed how the teachers taught by using the plans they had already made. But the work in the construction arena also involves the teachers making decisions in the moment, as Remillard (1999) points out. Decisions both Sandra and Cathrine took in the moment directed the lessons in particular ways.

\section{RESULTS}

In this paper we have presented three (out of five) identified categories of how teachers used resources in/for their mathematics teaching. These three categories do not cover all aspects of the teachers' practice, but they show that resources influence many aspects of teachers' pedagogic choices and practice.

The presentation of these three categories also showed the crucial importance of developing a deeper understanding of the interaction between the teacher and the resource. This was shown in terms of Brown's DCE (Brown, 2009) and Remillard's (1999) three arenas. Teachers interacted with resources, and the "results" of these interactions were the lesson plans (as lesson preparation), and their pedagogic practice in the classroom. Teachers brought with them their own knowledge, beliefs about how students learn mathematics, and their own experience, which influenced the interactions between teachers and resources.

In the first category, we showed that the teachers used different resources to guide teaching objectives. One extreme situation appeared when teachers let the textbook back-ground the national curriculum completely in their management of the teaching objectives. In the second category we showed that the main resource for inspiration were the textbook, but that the Internet also had an important role. And in the third category, we showed how the teacher and the interaction between teacher and resource influenced the teaching results. Interestingly, the identification of the "usage categories" also showed not only that they could be assumed to inhabit different places on Sherin \& Drake's (2009) continuum, but also that the same resource may have different roles depending in which context it is used, and by which teacher. The textbook is one very good example of this, since the textbook was present in all three categories. 


\section{REFERENCES}

Alseth, B., Nordberg, G., \& Røsseland, M. (2008). Multi 7a: Laererens bok. Oslo: Gyldendal Norsk Forlag AS.

Brown, M. W. (2009). The teacher-tool relationship: Theorizing the design and use of curriculum materials. In J. T. Remillard, B. A. Herbel-Eisenmann \& G. M. Lloyd (eds.), Mathematics teachers at work: Connecting curriculum materials and classroom instruction (pp. 17-36). New York: Routledge.

Cohen, L., Morrison, K., \& Manion, L. (2007). Research methods in education (6. utg.). London: Routledge.

Cohen, D. K., Raudenbush, S. W., \& Ball, D. L. (2003). Resources, instruction and research. Educational Evaluation and Policy Analysis, 25(2), 119-142.

Creswell, J. W. (1998). Qualitative inquiry and research design: choosing among five traditions. Thousand Oaks, Calif.: Sage.

Galen, F. v., Feijs, E., Figueiredo, N., Gravemeijer, K., Herpen, E. v., \& Keijzer, R. (2008). Fractions, percentages, decimals and proportions: A learning-teaching trajectory for grade 4,5 and 6. Rotterdam: Sense Publishers.

Gueudet, G., \& Trouche, L. (2012). Teachers' work with resources: Documentational geneses and professional geneses. I G. Gueudet, B. Pepin \& L. Trouche (red.), From text to "lived"' resources: Mathematics curriculum materials and teacher development (pp. 23-42). Dordrecht: Springer.

Juuhl, G. K., Hontvedt, M., \& Skjelbred, D. (2010). Laremiddelforsking etter LK06: Eit kunnskapsoversyn. Utdanningsdirektoratet. Retrieved from: http://www.udir.no/Tilstand/Forskning/Forskningsrapporter/Hogskoler/Laremiddel forsking-etter-Kunnskapsloftet---rapport-2010/

Pedersen, B. B., Pedersen, P. I., Skoogh, L., Johansson, H., \& Ahlström, R. (2006). Abakus: Larerens ressursbok 7A. Oslo: H. Aschehoug \& Co. (W. Nygaard).

Pepin, B., \& Gueudet, G. (2013 - online). Curricular resources and textbooks in mathematics education. I S. Lerman, (red.), Encyclopedia of Mathematics Education. Berlin Heidelberg: Springer-Verlag. Retrieved from: $\mathrm{http}: / / \mathrm{www}$. springerreference.com/docs/html/chapterdbid/313219.html

Remillard, J. T. (1999). Curriculum materials in mathematics education reform: A framework for examining teachers' curriculum development. Curriculum Inquiry, 29(3), 315-342. 
Sherin, M. G., \& Drake, C. (2009). Curriculum strategy framework: investigating patterns in teachers' use of a reform-based elementary mathematics curriculum. Journal of Curriculum Studies, 41(4), 467-500. 


\title{
HOW DO TEACHERS USE TEACHER GUIDES IN MATHEMATICS?
}

\author{
Guðný Helga Gunnarsdóttir and Guðbjörg Pálsdóttir \\ University of Iceland
}

Curriculum materials in mathematics are an important tool for teachers in preparation, instruction and evaluation. The aim of this study is to determine how Icelandic teachers use teacher guides in preparing for their mathematics teaching and analyse how they support teacher learning. Five teachers in lower grades (1-6) were interviewed and asked about their use of teacher guides. The guides the teachers were using and the interviews were analysed according to a framework developed by Hemmi, Koljonen, Hoelgaard, Ahl and Ryve. The framework was developed for analysing teacher guides but in this study we also test whether it can be used to analyse the interviews. The study is done in collaboration with researchers in Sweden and Finland. The Icelandic teachers used two different types of teacher guides, which provide different opportunities to develop professionally. The findings indicate that the structure and content of the teacher guides influence how the teachers think of and prepare their teaching. They also support the idea that teacher guides can play an important part in teachers' professional development.

Keywords: teacher guides, teacher learning, curriculum materials

\section{INTRODUCTION}

Research on curriculum materials is a growing field within mathematics education research. The main focus had been on the textbook itself: its structure, content and its influence on reform. On the other hand, teacher guides play an important role in mediating ideas about instruction and can contain materials teachers can use as a basis for their reflections and decisions. Teachers interpret these guides from their knowledge, understanding and analysis of their situation (Brown, 2009). That means that they do not necessarily plan their teaching in line with the authors' intentions. Therefore it is important to study both the content and structure of teacher guides and teachers' ideas about their usefulness. The aim of this study is to determine how Icelandic teachers use teacher guides when preparing for their teaching and whether the guides provide opportunities for teacher learning. We are collaborating with researchers in Finland and Sweden who are conducting similar studies. We are all participants in a Nordic network for research on mathematics textbooks (http://textbookstudy.wordpress.com). In this paper we report on the analysis of interviews with five Icelandic teachers and the teacher guides they used.

\section{THEORETCAL BACKGROUND}

Teacher guides are part of all mathematics curriculum materials and are used by teachers in their planning and actions (Stein, Remillard \& Smith, 2007; Jablonka \& Johansson, 2010). A recent study in Iceland shows that Icelandic teachers use 
teacher's guides and find them useful (Haraldsdóttir, 2013). The authors of curriculum materials interpret the curriculum guidelines and represent them in textbooks and teachers guides (Gunnarsdóttir \& Pálsdóttir, 2010). It is important to understand how teachers understand these representations and how they constrain and afford their practice (Brown, 2009). Teachers interact and develop their relationship with resources like teacher guides in a different way according to their ideology and characteristics of the resource (Brown, 2009; Remillard, 2013). To be able to understand the teachers' interaction with the teacher guides it is necessary to analyse the guides themselves as well as the teachers expressed usage. Teachers adjust their ideas and ideas from teacher's guides to the socio-cultural settings of their classroom based on their experience, goals and competences. This process indicates that teacher guides can contribute to teachers' learning and professional development (Doerr \& Chandler-Olcott, 2009).

According to Davis and Krajcik (2005), teacher learning involves developing and becoming able to use one's knowledge base about content and its teaching and learning. It also involves participation in the discourse of teaching and various teacher practices. Teacher learning is always situated in teachers' practice. Curriculum materials/teacher's guides can be a tool that teachers use to support their learning and professional development on their own or in collaboration with others.

Davis and Krajcik (2005) point out what characterizes curriculum materials that are designed for promoting teacher learning. They present five main ideas:

- The materials give teachers ideas on learners' thinking and how they might react to activities.

- They sometimes give the teachers new ideas on how to approach subject matter and help them to develop their own understanding of the matter.

- They help teachers to connect different mathematical ideas and see the larger curricular picture from reflection on objectives, tasks and discussion in teacher guides.

- They help the teachers to make their choices in teaching more visible.

- They support teachers in developing their teaching design building on their personal resources embedded in the materials.

Davis and Krajick (2005) have used these ideas to develop Design Heuristics for Educative Curriculum Materials for Science Teaching. Hemmi, Koljonen, Hoelgard, Ahl and Ryve (2012) have on the basis of the work of Davis and Krajick (2005) developed a framework for analysing curriculum materials in mathematics. The framework is modified to fit the purpose of analysing teacher guides in mathematics and has been tested by analysing Finnish and Swedish teacher guides. We are in this study testing and developing it further in cooperation with the authors. The framework focuses on the opportunities for teacher learning provided by the teacher guides. It consists of five categories and is described in Table 1. 


\begin{tabular}{|l|l|}
\hline Categories & Categories for data analysis \\
\hline $\begin{array}{l}\text { 1a) General knowledge of } \\
\text { students' ideas and } \\
\text { strategies }\end{array}$ & $\begin{array}{l}\text { Describes why students might hold particular ideas } \\
\text { about mathematical concepts and exemplifies common } \\
\text { strategies among students. }\end{array}$ \\
\hline $\begin{array}{l}\text { 1b) Suggestions for how to } \\
\text { encounter students' ideas } \\
\text { and strategies }\end{array}$ & $\begin{array}{l}\text { Gives suggestions for how to deal with/encounter } \\
\text { various ideas and strategies of students and how to } \\
\text { enhance their learning and prevent future difficulties. }\end{array}$ \\
\hline 2) Concepts and facts & $\begin{array}{l}\text { Describes concepts and facts within mathematics such } \\
\text { as history, field of application, derivations, methods, } \\
\text { proofs, correct terminology. }\end{array}$ \\
\hline $\begin{array}{l}\text { 3) Progression and } \\
\text { connections }\end{array}$ & $\begin{array}{l}\text { Shows the mathematics progression throughout the } \\
\text { school years as well as connections between } \\
\text { mathematical topics; for example, explains the future } \\
\text { development of methods and concepts. }\end{array}$ \\
\hline $\begin{array}{l}\text { 4) Connecting theory and } \\
\text { practice }\end{array}$ & $\begin{array}{l}\text { Supports the teacher's actions in practice beyond the } \\
\text { curricular materials by connecting theory and practice. } \\
\text { Exposes the central ideas in national curriculum and } \\
\text { research results for promoting teachers' autonomy. }\end{array}$ \\
\hline 5) Design of teaching & $\begin{array}{l}\text { Supports the teacher's ability to act in practice by } \\
\text { suggestions with respect to the design and enactment } \\
\text { of lessons, tasks, formative assessment, } \\
\text { individualization of teaching, homework, etc. }\end{array}$ \\
\hline
\end{tabular}

Table 1: Categories for data analysis

In the study we use this framework to analyse Icelandic teacher guides and test it in analysing interviews with teachers in lower grades. Using the same framework to analyse both the guides and the interview enable us to shed light on how teachers interact with particular features and characteristics of teacher guides (Remillard, 2005). The aim is to find out if the teacher guides provide opportunities for teacher learning and professional development and how the teachers are making use of them.

\section{METHODOLOGY}

In the study we collected data by interviewing five teachers who taught mathematics in lower grades in compulsory school and by analysing the teacher guides they were using. We contacted math teachers we knew in some schools in Reykjavík and surrounding area and asked them to find for us teachers from the lower grades who were willing to talk to us about teacher guides in mathematics. The first five teachers 
who volunteered were interviewed by the first author. The sample was chosen by convenience. The teachers taught in four different schools and their experience in teaching in the lower grades was 5-8 years. Two of them taught in third grade and the others in grades one, five and six. None of the teachers had specialized in teaching mathematics. All the teachers were female and were given pseudonyms to protect their privacy. In semi-structured interviews, the teachers were asked how they prepared their mathematics lessons, how they used the teacher guides and about important characteristics of the guides. All interviews were transcribed and analysed according to the framework. The content of the teacher guides was also analysed and categorised.

\section{ANALYSIS OF THE TEACHER GUIDES}

Two types of curriculum materials are used in grades 1-4 in Icelandic schools. The first series Eining 1-8 are materials translated from Danish $\left(F_{a k t o r}\right)$ and adapted to the Icelandic context. This series was published in Iceland in 1998-2001 and considerable text on mathematics teaching and learning was added to the teacher guides in the Icelandic edition. The second series Sproti $1 a-4 b$ is translated from Norwegian (Multi $\left.{ }^{2}\right)$ and published in 2009-2012. In grades 5-7 teachers either use an Icelandic series called Geisli 1-3 first published in 2002-2004 and revised in 201012 or Stika $1 a-3 b$ which is a continuation of Sproti and published in 2011-13.

The teacher guides for Eining each have introductory chapters (20-26 pages). Here there are texts about mathematics teaching and learning and important issues on teaching mathematics in the lower grades. An overview of the materials is also given, as well as a list of important manipulatives and suggestions for further readings. In each guide new topics are introduced, so together all eight guides form a kind of a handbook on important aspects of teaching mathematics to young children. There is also a page-by-page guide to the student textbook where the goals for each page and suggestions for how to work with the topic are listed. Emphasis is put on hands-on activities and discussions before the students solve the problems in the book.

The guides for the series Geisli have a six-page introductory chapter for each school year where the ideas behind the materials are explained and some important aspects for teaching in the middle grades are discussed. For each chapter in the student book the guide provides the teachers with goals for the chapter, information on the topic where the teachers can deepen their own knowledge on its teaching and learning and get ideas about how to plan the teaching of the topic.

The guide for the curriculum materials Sproti and Stika have a similar structure. For each school year there is an eight-page introduction with information about the curriculum materials and the ideas behind it. It also includes goals and a suggested plan for the school year. This introduction is the same for each school year. In the guide there is also a page-by-page guide for the student textbook. The emphasis is on guiding students through the problems on the pages. There are also suggestions for 
how to differentiate the students' work. Suggested easier work often includes handson activities, and more difficult tasks include work with higher numbers or games to play. There are ideas about how to make problems more real by linking them to practical activities or games.

When the teacher guides are analyzed according to the framework by Hemmi et al. (2012) the introductory chapters in Eining and Geisli and the introduction to each chapter in Geisli provide the teachers some insight about students' ideas and strategies (Category 1a), how to encounter those strategies (Category 1b) as well as background knowledge about mathematical concepts and facts (Category 2). The progression (Category 3) throughout the school year is also shown, including connections between theory and practice (Category 4). There are also clear references to the Icelandic national curriculum and to literature on mathematics teaching and learning. The page-by-page guide in Eining and the chapter guide in Geisli also support teachers in their design of teaching (Category 5). In Geisli the guide is not as detailed as in Eining. The teachers are given some ideas about how to work with each chapter but the planning of each lesson is left for the teachers to do.

The introductions for Sproti and Stika give teachers some insight into the ideas behind the materials, but they do not provide the teachers with much theoretical text about mathematics teaching and learning. The page-by-page guide for the student textbook gives some insight into students' ideas and strategies (Category $1 \mathrm{a}$ and $1 \mathrm{~b}$ ) and also some knowledge about mathematical concepts and facts (Category 2), but this information is often superficial and the space for elaborating on these issues is limited. In the introduction, the main ideas to be dealt with each year are listed, but there are no direct references to the Icelandic national curriculum (Category 3 ). The main emphasis in these guides is on the page-by-page guide, and teachers get support on how they can work through the pages with the students and are given ideas about individualisation of the teaching. There are also many suggestions for games and some practical activities (Category 5).

Based on this analysis, it can be concluded that the guides to Eining and Geisli give the teachers more opportunities for teacher learning than those for Sproti and Stika. Sproti and Stika are focused on the design of teaching and support teachers in individualizing the teaching and provide the teachers with ideas for games and extra activities. The page-by-page guide to Eining also supports teachers in planning each lesson, but in Geisli more is left to the teacher to decide.

\section{ANALYSES OF INTERVIEWS}

In the interviews the teachers discussed how they used the teacher guides while preparing and reflecting on their teaching. Anna, Birna and Dóra used the curriculum materials Sproti and Stika, and Eva and Freyja used the curriculum materials Eining and Geisli. Teachers can choose which materials they use and in the study they were not asked to give reasons for their choice. 
In analysing the interviews with teachers, we looked for quotes that could be categorized according to the five categories in the framework. Did the teachers mention things that indicated that what they were looking for in the guides was material that supported them in a way suggested by the framework? Could we for instance find evidence that the teachers were looking for material that gave them ideas about how to encounter students' ideas and strategies (Category 1a and 1b), material that provided them with knowledge about mathematical concepts and facts (Category 2), or were they primarily looking for ideas about the design of teaching (Category 5)?

All the teachers were using the guides extensively and had them at hand at all times. They expressed the understanding that the key to the curriculum materials was through the teacher guides.

Birna: I read it at home this summer - this is a brand new book - and saw that it had lots of suggestions for more difficult or more easy problems. I saw right away that this is a bit individualized book.

The guides are a source of ideas and support the teachers in many ways. Birna finds it important that the guide she is using explains every problem in the students' book. It "guides the teacher through the book". Eva and Freyja both point out that they find the theoretical introductions that can be categorized as general knowledge of students ideas and strategies (Categoryla) and suggestions for how to encounter students ideas and strategies (Category 1b) useful.

Eva: I find it good to have a short introduction about something that is important for this stage - but not too much.

Freyja: I find it good to have something theoretical or like an introduction where I can see things from the children's point of view. ... The guide often pointed out what you have to emphasize with the children.

Freyja also mentions that the guide offers her opportunities to deepen her knowledge about the topics she is teaching (Category 2) and she also mentions that it helps her to identify what can be difficult for the children and how to deal with that.

Freyja: $\quad$... and often more depth for me in the topic, I find that good but that is of course special for me

Freyja: $\quad$ Now I look up things in the guide I feel I am not sure about how to teach or things I can see the children find difficult

Dóra also mentions that the guide gives good support for a teacher who is not "mathematically minded". She feels she has been "given a treasure to use in her teaching" and it helps her to connect theory and practice (Category 4). The same can be said about Freyja who often refers to the theoretical part and how it helps her in her practice. 
Freyja: What I find best about this guide is that there is a theoretical part that helps you to see things from the students' point of view and makes sure you do not forget the big ideas

Freyja: $\quad$ For each topic or chapter I read carefully the theoretical part and reflected on how to approach it

According to Freyja, the guide makes sure that she does not forget the big ideas and suggests that the guide helps her to see progression and connections. Dóra mentions that the guide gives a good overview of main ideas, and Anna points out that she and her colleagues compare the national curriculum guidelines in mathematics and the material in Sproti to see how it is delft with within the curriculum materials. These three teachers feel that the teacher guides support them in making connections and seeing the bigger picture (Category 3 ).

In the interviews it was evident that the teachers were mainly using the teacher guides to get ideas to use in their design of teaching (Category 5). They are looking for some practical ideas like games and hands-on activities, as well as for ideas about how to deal with important topics and to structure the lessons.

Anna: $\quad$ This is more like ideas, what ideas I can use, how I can use them and how I can adjust the ideas in the book to my context

Birna: $\quad$ To each page in the book, the guide often has some stories and starters and all the extra problems that are there

Dóra: The biggest advantage I feel are the practical problems and the more difficult problems that we often have used in work stations ...They also sometimes take you out of the box...

All the teachers plan their teaching in cooperation with colleagues who teach the same age group, and usually they plan at least a week ahead. In the planning the main reference is the teacher guide and materials suggested by the guide. However, other materials are used as well, for instance ideas from other curriculum materials or web pages. The teachers find it important to have some variation in their teaching and are looking for ideas that offer other approaches than traditional work in textbooks.

Eva: I read them through and look at both the goals and if there are any extra ideas or problems I can use when introducing the topic, and I also look at the additional ideas that the guide refers to ... What do they say about concrete work? What can I make them do? What is good to say, sometimes? It is not a problem for me - it is often: What more can I do they are good at this - what can I do that is more exciting? Then I look at the additional ideas.

It is clear from the analysis of the interviews that the teacher guides are important tools for the teachers and they seem to influence how they plan their teaching. The 
teachers also see the guides as an important source of knowledge about mathematics teaching. They both serve them as practical guides and have an educative purpose.

\section{DISCUSSION}

In this study a framework for analysing teacher guides in mathematics (Hemmi et al., 2012) was tested on Icelandic curriculum materials and interviews with teachers. According to the analysis, the framework serves well to show differences in teacher guides. It is evident that the guides for Eining and Geisli provide more opportunities for teacher learning than those for Sproti and Stika, which are more focused on the design of teaching and supporting the teachers in individualizing their teaching. The categories in the framework get different priorities in different guides and that indicates that authors can have different intentions when writing the curriculum materials. From the interviews it can also be concluded that the content of the teacher guides influences how the teachers use them and what they find important. Eva and Freyja focus on the theoretical parts, while Anna, Birna and Dóra find the practical ideas most valuable. The content also influences their discourse on preparations and reflections on teaching. It seems like the teachers want more of the same kind of materials as they already have in the guides. The teachers using Sproti and Stika find all the practical ideas very useful and like to have each problem in the student book explained. They do not miss the theoretical part in Geisli and Eining which the teachers who use those materials highly value. The interviews reveal that the teachers reflect and choose on the basis of what is emphasized in the guides they have chosen.

The interviews also provide insights into the participants' teaching practices and how or if they use the opportunities for teacher learning. It can be seen through the interviews that the teacher guide is the key to curriculum materials and what to emphasize in practice. The teachers value the teacher guides and rely on them when planning their teaching. All the teachers use them as their main resource but the less experienced teachers follow them more closely. Therefore, if the material is educational, its use should lead to teacher learning. The analysis shows that both types of teacher guide provide opportunities for teacher learning even though they focus on different things and lead the teachers to consider different matters when preparing for their teaching. The format of the page-by-page guide to Sproti and Stika is always the same and limits what can be said in connection with each page. Sometimes the authors put in theoretical aspects but the space does not allow them to elaborate on topics. In Eining and Geisli the format is also always the same but the space for theoretical and practical information is flexible.

The categories in the framework help to analyze whether the teacher guides incorporate opportunities for teacher learning and how the opportunities provided are used by the teachers. Through the interviews we have developed an understanding of how the teachers adjust ideas from the teacher guides to their context based on their experiences. 


\section{CONCLUSION}

The framework proved to be a good tool in analysing both the teacher guides and the interviews. The questions for the semi-structured interviews where made before the decision was taken to use the framework for analysis. The framework was useful to discover what the teachers were looking for in the guides and for what purpose. By using the framework we saw some examples of how the teachers used opportunities provided for teacher learning.

As has been mentioned earlier, this study is being carried out in collaboration with Finnish and Swedish scholars doing similar research in their countries. It will be interesting to discuss and compare our results and to develop the framework and its further use. It is useful for those who write and publish curriculum materials to know how teachers use teacher guides and whether they are an important tool to provide accessible opportunities for teachers' learning. This study indicates that this can be the case and that curriculum materials can be a valuable resource in teachers' professional development.

\section{NOTES}

1. Danish publication. Faktor i første - Faktor i tredje. Authors: Silla Balzer Petersen and Arne Mogensen. Publisher: Malling Beck A/S

2. Norwegian publication. Multila-7b. Authors: Bjørnar Alseth, Ann-Christin Arnås, Henrik Kirkegaard, Gunnar Nordberg and Mona Røsseland. Publisher: Gyldendal Norsk Forlag.

\section{REFERENCES}

Alseth, B., Arnås, A. C., Kirkegaard, H., \& Røsseland, M. (2012). Sproti 3. Kópavogur: Námsgagnastofnun.

Alseth, B., Nordberg, G., \& Røsseland, M. (2011). Stika 1. Kópavogur: Námsgagnastofnun.

Brown, M. W. (2009). The teacher - tool relationship. Theorizing the design and use of curriculum materials. In J.T. Remilard, B.A. Herbel-Eisenmann \& G.M. Lloyd. (Eds.), Mathematics teachers at work. Connecting curriculum materials and classroom instruction (pp. 17-35). New York: Routledge.

Davis, E. A., \& Krajcik, J. S. (2005). Designing educative curriculum materials to promote teacher learning. Educational Researcher, 34(3), 3-14.

Doerr, H. M., \& Chandler-Olcott, K. (2009). Negotiation the literacy demands of standard-based curriculum materials: A site for teachers' learning. In J.T. Remillard, B.A. Herbel-Eisenmann \& G.M. Lloyd. (Eds.), Mathematics teachers at work. Connecting curriculum materials and classroom instruction (pp. 283301). New York: Routledge.

Angantýsdóttir, G., Gunnarsdóttir, G. H., Kristinsdóttir, J. V., \& Pálsdóttir, G. (2011). Geisli 2, Kennsluleiðbeiningar. Kópavogur: Námsgagnastofnun. 
Gunnarsdóttir, G. H., \& Pálsdóttir, G. (2010). The implementation of the intended curriculum in teaching mathematics. In B. Sriraman, C. Bergsten, S. Goodchild, G. Pálsdóttir, B. Dahl \& L. Haapasalo (Eds.) The first sourcebook on Nordic research in mathematics education (pp. 539-549). Charlotte, NC: Information Age Publishing.

Haraldsdóttir S. H. (2013). Kennsluleiðbeiningar: „, Dar geta verið góðar, ef paer eru góðar". [Teacher's gudies: ,, They can be good, if they are good"]. Unpublished Master thesis. Reykjavík: University of Iceland, School of Education. Available at http://hdl.handle.net/1946/16067

Hemmi, K., Koljonen, T., Hoelgaard, L., Ahl, L., \& Ryve, A. (2012). Analyzing mathematics curriculum materials in Sweden and Finland: Developing an analytical tool. In B. Ubuz, Ç. Haser \& M. A. Mariotti (Eds.) Proceedings of the Eight Congress of the European Society for Research in Mathematics Education Ankara: Middle East Technical University. Available at http://www.mathematik. uni-dortmund.de/ erme/doc/CERME8/CERME8_2013_Proceedings.pdf

Ingimarsdóttir, S., \& Pálsdóttir, G. (1999). Eining 2, kennarabók. Reykjavík: Námsgagnastofnun.

Jablonka, E., \& Johansson, M. (2010). Using texts and tasks: Swedish studies on mathematics textbooks. In B. Sriraman, C. Bergsten, S. Goodchild, G. Pálsdóttir, B. Dahl \& L. Haapasalo (Eds.). The first sourcebook on Nordic research in mathematics education (pp. 363-372). Charlotte, NC: Information Age Publishing.

Remillard, J. (2005). Examining key concepts in research on teachers' use of mathematics curricula. Review of Educational Research, 75(2), 211-246. Available at http://rer.sagepub.com/content/75/2/211

Remillard, J. (2013). Examining resources and re-sourcing as an insight to the teaching. ZDM 45(7), 925-927.

Stein, M. K., Remillard, J. T., \& Smith, M. S. (2007). How curriculum influence student learning. In F. K. Lester Jr. (Ed.), Second handbook of research on mathematics teaching and learning (pp. 319-369). Charlotte, NC: Information Age. 


\section{AN ETHNOMATHEMATICAL STUDY OF PLAY IN MINECRAFT}

Louis Køhrsen and Morten Misfeldt

\section{Metropolitan University College and Aalborg University}

This paper explores how children engaged in playing Minecraft in an afterschool program develop mathematical approaches. The investigation is framed as ethnomathematical in the sense that, rather than searching for specific curricular concepts, it explores the problem situations and explanatory systems that children develop. Aesthetics, symmetry, collaboration, copying, and efficient building strategies all lead to local problem-solving and explanatory systems and can therefore be characterised as steps towards ethnomathematics. In the explored example, collaboration between the children and the afterschool program's attitude towards children's collaborative gaming are crucial factors in the way Minecraft supports the development of mathematical thinking.

Keywords: Ethnomathematics, Game based learning, Minecraft,

\section{INTRODUCTION: MINECRAFT AS CHILD CULTURE AND EDUCATIONAL DREAM}

Minecraft is a widespread phenomenon, with more than 13 million individual purchases of the game. There have been several attempts by educators to use Minecraft in formal mathematics teaching (Miller, 2012; see also www.minecraftedu.com), and the Lego-like block structures are sometimes identified as a reason for Minecraft being well suited for mathematics education. In this paper we aim at providing empirical knowledge which might inform such claims, by exploring the mathematical aspects of activities engaged in by children playing Minecraft.

Minecraft can be played alone or with others on a local area network or as a massively multiplayer online game. The Minecraft world consists of one meter cubic blocks, generated in a world to create landscapes that may include mountains, meadows, deserts, lakes, and oceans. In the game, you can break, collect, and place the blocks, using them to construct buildings and landscapes or transforming them into other materials or tools. However, playing Minecraft is not a well-defined and uniform activity. With its open-world gameplay, the game itself allows players to design not only their physical surroundings but also their own narratives - for example, surviving in a world with limited food resources, going on adventures, building huge castles, or brewing potions that enable one to fly (Duncan, 2011). For teaching purposes, there is also an educational version called 'MinecraftEdu', which is a modification of the original game that allows for a more controlled game environment, in which teachers can prepare lessons and can more easily follow students' activities. The game is typically used as a replacement for concrete materials when children are to work with areas, volumes, ratios, scale, histograms, and types of graphs. Children's gaming activities are not included as activities in 
these learning resources, nor is the premise that the children are present in the virtual world taken into account (Miller, 2012).

\section{QUESTION}

The data presented in this paper were collected during a project that explored the question, "What mathematics do children use and develop when they play Minecraft in an afterschool program?" (Køhrsen, 2013). In this paper, we look for situations that can be considered mathematical, in the sense that systematic approaches are applied or problems are addressed, and we ask what situations may be characterised as mathematical in children's free time play with Minecraft.

\section{THEORY}

According to d'Ambrosio (2001), different cultures, including nationalities, tribes, genders, organisations, and professions, develop knowledge systems and problemsolving strategies that can be understood as parallel to those of western mathematics, and should be recognized as such. In line with Devlin (2011), we also understand children's gaming culture as a legitimate culture, where mathematics activities and problem solving may occur.

In our research, we are looking for situations that can help to clarify whether children's activities when playing Minecraft foster a unique ethnomathematics, and how it might be characterised (d'Ambrosio, 2001). Any such investigation of children's gaming culture, as a legitimate culture in which an ethnomathematics can be developed, is likely to encounter the problem of recognising a mathematics that differs from scholastic mathematics (Millroy, 1991). Bishop (1997) offers a framework in which mathematics can be analysed as a cultural phenomenon, offering a way of recognising core mathematical activities as part of the culture in their own right.

In his analysis of mathematics as a cultural phenomenon, in which he searches for mathematical similarities, Bishop describes six forms of activity that seem to occur across all cultures.

1. Counting - referring both to the development of number systems and to actions around counting (for instance, using objects to support counting);

2. Locating - referring to different ways of coding and symbolising special environments, and to different ways of describing and understanding physical space and/or objects in space;

3. Measuring - referring both to the words used to describe different measurements and to the tools or body parts used for measuring;

4. Designing - referring to the development from imagined form and shape and to the reshaping of the environment;

5. Playing - both strategic games and gambling games;

6. Explaining - where questions and answers are part of extending human cognition beyond experience and environment (Bishop, 1997). 
Following Bishop, the aim of this paper is to find and describe examples of mathematical situations and activities in children's informal play and construction work in Minecraft. We would expect such situations to provide relevant focal points for an empirically based understanding of the systems and problem-solving strategies constituting a Minecraft ethnomathematics.

\section{METHOD}

An ethnographic methodology was employed to investigate this question. This mend, that rather than describing and analysing the children's products or measuring their conceptions or competencies, we attempted to gain access to their practice and culture in a longer term way. This was done with a view to developing a holistic description of the mathematical activities that these children engage in and how these activities are contextualised when they play Minecraft in an afterschool program (Hastrup, 2010).

To this end, we followed seven 10-year-old boys over a period of three weeks as they played Minecraft in their afterschool program. They were selected on the basis of availability and high levels of gaming activity. In this particular program, playing Minecraft was mainly a boys' activity, and no girls were available who met these criteria. The data collected include interviews, hand-held camera recordings of situations where Minecraft is played, and observations (field notes). The video data were analysed in three steps: first, the events captured on video were summarised in written form (with time codes); second, using Bishops framework, the mathematical aspects of Minecraft play were summarised; and third, two cases where children perform activities that we interpret as mathematical were fully transcribed and analysed in depth (Rønholt, Holgersen, Fink-Jensen \& Nielsen 2003).

The interviews were video-recorded, comprising an oral record of the child's relation to the game and an action record based on the strategies and preferences observed during gameplay. The oral part of the interviews was transcribed, and action reports were compiled for each sub-question.

\section{FINDINGS AND ANALYSIS}

This section is presented in three parts. First, the context of the findings is described by describing the gaming culture of the afterschool program; second, a range of examples is given of mathematical constructions in the children's gameplay; and finally, the analysis of findings, using Bishop's categories of mathematics activities, is presented.

\section{Context for mathematical actions in Minecraft}

Observations during the afterschool program showed that the program endorse that children play computer games, and that the physical environment enabled friends to play these games together. In the interviews, the children explained that they play less at home than in the afterschool program. They also explained that gameplay in the 
afterschool program tends to involve larger constructions and longer-lasting games than when they play at home. This highlights the fact that the findings from this study are bound to these specific players in this specific context. Here, when the children played Minecraft, they often played together in larger groups, over an extended timespan of days or weeks. During such games, large constructions were often built by collaborating and working for several days towards a certain goal - for instance, to finish a bridge or a castle. In the observed games, these large constructions were demanding to construct as the children took account of both symmetry and proportions.

\section{Mathematical activities}

The mathematics-related activities that we found in the children's play fell into several categories. These included construction activities involving symmetries, geometric reflections, approximations of round shapes in a cubic virtual environment, and decorative patterns; activities involving mining, including the use of compound numbers when referring to large amounts of a material (e.g. 'don't stop [digging] until you have at least two times 64 iron [blocks]'); and ways of finding materials and navigating through the mines. In this section, we will elaborate on the mathematics and methods used when constructing, and on the acquisition of new knowledge about construction. The data include many more observed examples of mathematical activity, but here we will focus solely on the activities around constructing because construction is the dominant form of activity in the game.

Designing houses: All the houses built by the children used three blocks ( 3 meters in game scale) from ground to ceiling. Since an avatar in the game is 1.7 meters in game scale, it is possible to enter a building that has a height of only two blocks. The children explained the chosen height by saying that it "looks right", and that inside it they can jump, which would not be possible in a house with a height of only two blocks.

Symmetry: This matters when constructing a house, and the children spent a lot of time making patterns and other adornments. The houses, which tended to imitate family houses, were clearly designed with an understanding of symmetry, as the children explained that where they placed doors and windows was not coincidental or random. In one example, where three children built a house together, the width of the house was adjusted to accommodate three windows of equal size on one side, equidistant to each other. The colour of the house's corner pillars differed from that of the walls, making it possible to develop a pattern with one block between each window on both the interior and exterior of the structure.

The only observed quadratic house was built at the top of a tree, using the crown of the tree as a guide to measurement to ensure a perfect quadratic form for the pyramidal roof, and to ensure that the roof would require only one block rather than four at its highest point. In fact, oak trees in Minecraft have a quadratic crown of an odd side length. The boy in question didn't seem to know that, but explained that he 
could not build a house with only one block at its peak without using an oak tree for guidance.

Interior decoration: In most of the constructions observed, the children devoted a lot of time to interior design. In one case, three boys built a house together, in four storeys, with an internal measurement of $3 \times 7$ game scale meters. Each storey had its own purpose (processing of materials, keeping valuable materials, keeping other materials and tools, and a sleeping quarters). In the middle of one of the gables, a ladder connected all the floors of the house. Each storey was decorated along two axes of symmetry, shown in Figure 1 left. The figure shows the floor plans of the sleeping quarters. The room needs a bed and a coffin to be in perfect symmetry; one of the children mentioned this, saying that he hoped a new player would join their game so that the sleeping quarter could be completed.

Construction of castles and circles: Unlike the houses, the children used different rules for the choice of height in other buildings, such as castles, which generally have a larger height from floor to ceiling. When asked, the children did not have exact words for the proportional relation between the ground and the height of the castle, except to say that it just "looks right". In effect, this means that a castle may have a height of ten blocks to the roof, as compared to the three blocks used for houses.

The castles provided a few examples of approximations of round towers. Not all the children succeeded in building round towers, and when asked most would build a quadratic shaped tower diagonal to the game grit instead (Figure 1, top right). The children could see that this shape was not round, but could not see what needed to be changed. One child learned to use approximate circle shapes (Figure 1, bottom right) by copying the shape, block by block, from another child. A third child had knowledge of how to construct two sizes of a circle, but he could not apply that knowledge to construct circles of other radiuses.
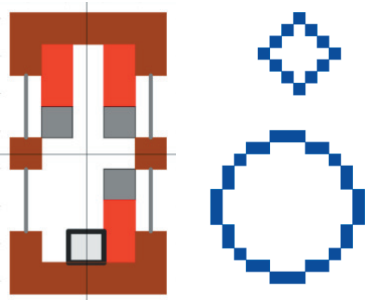

Figure 1: Symmetry in design of house interior (left), diamond shape (top right) and approximated circle shape used to construct round towers (bottom right).

The propagation of strategies for the construction of circle shapes is one example of knowledge sharing and sharing of strategy, and of the need to learn new things.

Constructions of known measures: Certain constructions in the game require exact measurements. This provides other challenges beyond constructing on the basis of 
aesthetics or the approximation of sizes and shapes. One example of this was seen in the construction of a fountain. Based on his knowledge of how far water falls from a water source, the child knew the radius of the fountain but not the circumference. This led him first to place tree blocks on top of each other to form the centre of the fountain; then, from the centre he counted the radius of the fountain in four directions, placing a block each time, and completing the circumference by connecting the four blocks.

Bridge structures: Minecraft generates worlds with mountains, ravines, valleys, and lakes, requiring the children to construct bridges. In the next example, a group of children constructed a series of bridges between mountain peaks. When two bridges met in the air, two approaches were used to determine how they should intersect. One method was to ensure that the bridges were at the same height. The children did this by using the avatar's ability to fly without changing altitude to measure the correct height, placing the head of their avatar at the same height as a bridge and then flying in a straight line required for the bridge. The other approach involved creating a suspension bridge with stairs at both ends, adjusting the height by creating the necessary steps at each side. In this second approach, however, the children expressed concerns about their wish to have identical stairs at each end of the bridge.

Construction methods: The game player's perspective created an extra challenge for the children in their desire for identical or mirroring constructions because it is impossible to see the construction being mirrored while building the new one. In this section, two observed methods will be examined in more detail: a 'trial and error method' and a method that involves copying by memorising segments of a larger construction.

In one example of 'trial and error', a child was attempting to build a spiral staircase in an approximate round tower. His strategy can be described as continuous adjustment by correcting an ongoing construction, but it also indicates a realisation that certain strategies were not working, as he started again from scratch with the knowledge acquired without yet having a plan for the construction as a whole.

- First he attempted to create steps in a straight line. Every step has a left edge and a depth of one block; when he reached the first corridor where he had to turn, he realised that his strategy did not work and made attempts to adjust the steps to follow the turn (Figure 2, left).

- After the turn, he continued with a strategy in which every new block in forward direction was a block higher than the previous one. At the next turn, this led to further problems (Figure 2, left), and he decided to remove the whole staircase and start over.

- This time, he started a little closer to the turn. He kept a straight left edge on the stair while attempting to build the staircase up in height to fit the turn. Afterwards, he investigated the construction, and adjusted the steps (Figure 2, right). 
- As seen on the right in Figure 2, the adjusted step causes him to start again a bit lower down the staircase, adjusting the steps at the beginning of the staircase to accommodate the new knowledge obtained.
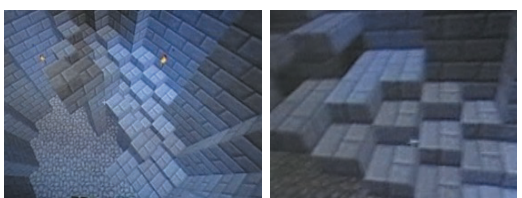

Figure 2: first attempt to create a spiral staircase (left), and the process of readjusting the staircase (right).

In this case, the boy explained that he was not sure how the stairs was going to look like, and that he was experimenting to find a strategy for building the staircase.

In an example of the second method (copying by memorising segments of a larger construction), another boy wanted to copy the approximated round tower and its spiral staircase. It was not possible for him to see the staircase he was copying when building, and he had to not only turn his head, but run across to another tower to investigate the construction he was copying. Given the complexity of the construction, it was not possible for him to memorise it in its entirety. As he started to copy the stair, the boy memorised how many blocks would be required for a given step. Memorising each step would take some time, counting while focusing on one block at a time, making it possible for him to memorise two or three steps at once (Figure 3). After building the steps, he could not be sure whether or not it was correctly built, running one more time to check. Searching for a more effective method, the boy discovered a three step pattern in the steps, which he continued, calling it 'One-One-Tee' as a reference to the shape of the steps (Figure 3). The use of segment names made the construction of the rest of the staircase much faster, in the end enabling the boy to repeat the pattern four times without checking the original construction.
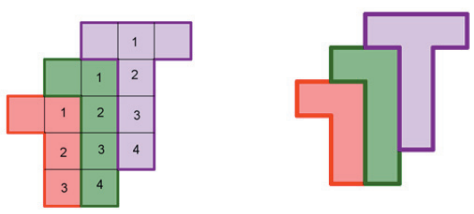

Figure 3: Method of memorising by counting blocks on each step (left), and method of memorising segments 'One-One-Tee' (right). 


\section{Table 1}

Findings relating to Bishop's categories

\begin{tabular}{|c|c|c|}
\hline Category & Example & Analysis \\
\hline Counting & Mining & $\begin{array}{l}\text { Counting objects occurs regularly in the game. Because } \\
\text { of the game design the player has a maximum number of } \\
\text { items they can hold in each slot. A new form of } \\
\text { compound number is used when talking about huge } \\
\text { amounts: } 64 \text { for 'many', counting by saying } 2 \text { times } 64 \\
\text { as opposed to } 128 \text {, or more than } 64 \text { to signify a lot of an } \\
\text { item, giving } 64 \text { the same function as } 100 \text { in normal use. }\end{array}$ \\
\hline Measuring & $\begin{array}{l}\text { Fountain \& } \\
\text { bridge } \\
\text { building }\end{array}$ & $\begin{array}{l}\text { Two aspects of measuring become clear from these data. } \\
\text { When constructing objects of specific size, the children } \\
\text { tend to measure objects as an area, or in terms of the } \\
\text { width of the empty space between the blocks. They have } \\
\text { an idea of the empty space in the middle, but not of the } \\
\text { outer length or of the number of blocks necessary to } \\
\text { build the object, and use the empty space to create the } \\
\text { rest of the construction. } \\
\text { When connecting bridges or building outer walls of } \\
\text { castles and other huge or tall buildings, altitudes are } \\
\text { measured by use of the in-game ability to fly at an } \\
\text { unchanging level. }\end{array}$ \\
\hline Locating & $\begin{array}{l}\text { Construction } \\
\text { of circles, } \\
\text { bridges }\end{array}$ & $\begin{array}{l}\text { In the many collaborative construction projects, visual } \\
\text { block design is used to explain the construction process. } \\
\text { Words are used to locate and describe objects or } \\
\text { placement of single building blocks, along with use of } \\
\text { the cubic design. }\end{array}$ \\
\hline Designing & $\begin{array}{l}\text { Houses, } \\
\text { castles, } \\
\text { bridges }\end{array}$ & $\begin{array}{l}\text { Altering of landscape and constructions is a key game } \\
\text { feature in Minecraft, so that designing is a common } \\
\text { activity in the observed games. } \\
\text { The children's culture of the afterschool program } \\
\text { favoured huge constructions such as castles and extra } \\
\text { detail, making these important aspects of designing. } \\
\text { Symmetry and recurring design elements were part of } \\
\text { almost every observed construction. } \\
\text { Unlike Lego, the game design challenges the design } \\
\text { process by making it impossible for the player to see } \\
\text { anything other than the immediate area they are } \\
\text { building, requiring the children to develop strategies for } \\
\text { remembering construction parts and design patterns. }\end{array}$ \\
\hline Explaining & $\begin{array}{l}\text { Spiral } \\
\text { staircase, }\end{array}$ & $\begin{array}{l}\text { Explaining is one of the social norms in the group. } \\
\text { Constructing together demands language and ways of }\end{array}$ \\
\hline
\end{tabular}




\begin{tabular}{|l|l|l|}
\hline & $\begin{array}{l}\text { build a } \\
\text { circle, } \\
\text { collaboration }\end{array}$ & $\begin{array}{l}\text { telling and showing to explain different methods of } \\
\text { construction, usually involving a high degree of showing } \\
\text { to provide visual support for words of location and } \\
\text { amounts of different blocks used. }\end{array}$ \\
\hline Playing & $\begin{array}{l}\text { As the frame is a game in itself, and no specific game or play activities } \\
\text { were observed within the game, there is no analysis under this heading }\end{array}$ \\
\hline
\end{tabular}

\section{CONCLUSIONS}

The mathematical actions discovered in the investigation are influenced both by the design of the game and the social and cultural conditions in the afterschool program. The game challenges the children to visualise and systematise constructions, as they try to realise their desire for unity, symmetry and aesthetics. New constructions and construction methods are learned from other children, by showing and telling as well as through trial and error. Demanding constructions originate from the children's own game narratives, which they often develop in groups and in admiration of each other's work.

The game culture in the club differs from the children's experience of playing alone at home, influencing the complexity of the children's constructions, their collaboration and knowledge sharing. The children explain that if they play at home, they create smaller constructions, and they create them alone. If they lack the knowhow to create specific constructions they wish to build, they use the Internet but are limited by having to comprehend English. In this manner, the after school program is where Minecraft itself becomes a place for shared actions and mutual challenges, impacting both on what is played and how it is played.

Two aspects of the game's design play a central role in providing challenges for the children's construction activities. The game's first-person perspective means that the player can see only that part of their construction that is directly in front of them. In relation to their idealised forms for identical staircases, towers, and so on, it means that the children cannot see the construction they are mirroring or copying while building. They are therefore forced to develop strategies in how to memorise the original construction, and this mediation of their actions changes the premise for construction in relation to, for example, working with building blocks.

Because the game only features three-dimensional cubic elements or blocks, it is impossible to construct circles, lines and points. When the children compare widths, they often describe the width as the distance between the two outer lines of the blocks. This is problematic when, for example, determining the number of blocks needed for a construction with an inner spacing of $2 \times 3$, where the perimeter of the structure has a size in itself, going against their school knowledge of perimeters as having zero size. Building with cubes also changes how the children construct a circle, which is a difficult shape that has to be learned. 
In conclusion, it is worth reflecting on whether these data constitute evidence of an actual ethnomathematics, in line with d'Ambrosio's (1985) descriptions of distinctive mathematical actions of indigenous people. This question is not easily answered. If Minecraft-mathematics is to be seen as an ethnomathematics, it is because it mediates the children's actions, requiring problems to be solved in a different way than in the surrounding reality. It remains an open question whether the observed methods and systemisation constitute a coherent mathematical approach to the Minecraft world, or whether they are merely fragments of various approaches used by different children in different situations.

\section{REFERENCES}

d'Ambrosio, U. (1985). Ethnomathematics and its place in the history and pedagogy of mathematics. For the learning of Mathematics, 5(1), 44-48.

d'Ambrosio, U. (2001). General remarks on ethnomathematics. ZDM - The International Journal on Mathematics Education, 33(3), 67-69.

Bishop, A. J. (1997). Mathematical enculturation: A cultural perspective on mathematics education. Dordrecht: Kluwer Academic.

Chesler, N. C., Arastoopourarastoopour, G., D'Angelo, C. M., Bagley, E. A., \& Shaffer, D. W. (2013). Design of a Professional Practice Simulator for Educating and Motivating First-Year Engineering Students. Advances in Engineering Education, $3(3)$.

Devlin, K. J. (2011). Mathematics education for a new era : video games as a medium for learning. Natick, MA: A. K. Peters.

Duncan, S. C. (2011). Minecraft, beyond construction and survival. Well Played: a journal on video games, value and meaning, 1(1), 1-22.

Hastrup, K. (2003). Ind $i$ verden: En grundbog $i$ antropologisk metode[In to the world: A course book in anthropological method]. Copenhagen: Hans Reitzel.

Miller, A (2012) Ideas for Using Minecraft in the Classroom. Retrieved January 20, 2014 from http://www.edutopia.org/blog/Minecraft-in-classroom-andrew-miller

Millroy, W. L. (1991). An ethnographic study of the mathematical ideas of a group of carpenters. Learning and Individual Differences, 3(1), 1-25.

Køhrsen, L. (2013). Minecraft Matematik—et etnomatematisk studie af børn der spiller Minecraft på en fritidsklub [Minecraft Mathematics - an ethnomathematical study of children who play Minecraft in an after-school program](Unpublished Master's thesis). Aalborg University.

Rønholt, H., Holgersen, S.-E., Fink-Jensen, K., Nielsen, A. M., \& Københavns Universitet. (2003). Video i padagogisk forskning: Krop og udtryk i bevagelse[Video in pedagogical research: body and expression in movement]. Højbjerg: Hovedland. 


\title{
MATHEMATICS TEXTBOOKS' IMPACT ON CLASSROOM INSTRUCTION: EXAMINING THE VIEWS OF 278 SWEDISH TEACHERS
}

\author{
Jannika Neuman ${ }^{1}$, Kirsti Hemmi ${ }^{1}$, Andreas Ryve ${ }^{1,2}$ and Marie Wiberg ${ }^{2}$ \\ ${ }^{1}$ Mälardalen University and ${ }^{2}$ Umeå University, Sweden
}

For mathematics teachers to achieve an instruction where students have the opportunity to develop different mathematical competencies is difficult without access to adequate support. The most commonly used supportive tools are by far mathematics textbooks. However, in Sweden, there is very little research available on the characteristics of these materials. In this paper we aim to examine the relationship between teachers' $(K-6)$ perceived support from the curriculum materials and their mathematics instruction, looking for patterns associated with commonly used textbooks. Our analysis of teachers' responses to a questionnaire $(n=278)$ showed major differences regarding perceived support for teachers using different textbooks. This pattern was also evident when the teachers were to report about their mathematics instruction.

\section{INTRODUCTION}

National evaluations in Sweden (e.g. Skolinspektionen, 2009) of over 200 mathematics classrooms indicate that a majority of the mathematics lessons consist of students' individual work in textbooks and many teachers experience difficulties in designing instructional approaches offering students affordances to develop several mathematical competencies. This pattern of classroom practices is also common in several countries such as the US (Hiebert, 2003). Teachers' mathematical knowledge for teaching is often put forward as a key aspect for improving classroom teaching. However, recent research stresses the role of tools for supporting mathematics teachers (Cobb \& Jackson, 2011, 2012). Examples of such tools are teacher guides and textbooks, of which the latter is used as the primary base for instruction in a large part of the world (Arora, Foy, Martin, \& Mullis, 2012). In fact, textbooks often serve as the main information source when teachers decide how to present the content and their pedagogical strategies are often affected by the material's instructional approach (Johansson, 2006). Thus, textbooks can serve as a support for teachers when designing mathematics instruction. However, in the Swedish debate, this possible supporting role is barely mentioned. Mathematics textbooks are often talked about in negative terms and teachers' textbook-dependence is partly used as an explanation for the declining results. Nevertheless, when teachers are planning for mathematics instruction they use textbooks to a high extent. Further, research has begun to conceptualize teaching materials in terms of their potential for teachers' learning (Davis \& Krajcik, 2005; Remillard, Herbal-Eisenmann \& Lloyd, 2009). It is therefore important to try to nuance the picture of curriculum 
materials and adhere to what kind of support, but also restraint, teachers receive from the materials.

In Sweden, teachers may choose freely among commercial curriculum materials to use in their mathematics instruction. There is, however, very little research available on the characteristics of the available materials. Research in the area is currently underway and initial analyses of different teacher guides with associated textbooks show that they offer different and varying degrees of support to teachers (Hemmi, Koljonen, Hoelgaard, Ahl, \& Ryve, 2013). However, merely studying the curriculums potential to support teachers in their mathematics instruction does not offer the complete picture. How teachers use text-based curriculum materials depends on a number of factors like the characteristics of the materials, what teachers choose to read and the teachers' knowledge and beliefs (Stein, Remillard, \& Smith, 2007). Regarding the latter this includes teachers' beliefs about mathematics teaching and learning, but also teachers' views of curriculum materials in general and the particular curriculum being used (Remillard \& Bryans, 2004). This means one must also look at how teachers perceive the materials since these beliefs will greatly influence whether and how they use them. In line with Furinghetti and Pehkonen (2002) we consider mathematics teachers' beliefs about teaching and learning as belonging to subjective knowledge. This involves teachers' conceptions, views and personal ideologies which are also considered to be affected by contextual factors such as school culture, educational policy and the teacher-student relationships (Hannula, Lepik, Pipere, \& Tuohilampi, 2013).

This paper contributes to research on curriculum materials by taking the perspective of the teachers. We aim at examining the relationship between the teachers' (K-6) perceived support from the mathematics curriculum material and their mathematical classroom practices. Two research questions are formulated to cover this aim:

- How do the teachers perceive the support they receive from the curriculum materials and are there any differences between teachers using different textbooks?

- What are (if any) the differences in how teachers who use different textbooks perceive how they organize their mathematics instruction?

\section{CURRICULUM MATERIALS AND TEACHERS' CURRICULUM USE}

Regarding the concepts of curriculum materials, textbooks, tools, teacher resources etc. there seems to be no unambiguous definition. Rather the concepts seem to have different meanings in different contexts and are sometimes used interchangeably (Stein, Remillard, \& Smith, 2007). However, instead of trying to formulate a comprehensive definition we merely point out that from here forth we apply the concept of curriculum material narrowly. The terms textbook 
and curriculum material will be used somewhat synonymously when referring to students' written mathematics textbooks with the accompanying teacher guides.

As with curriculum materials the notion of teachers' 'curriculum use' is also framed differently across studies (Remillard, 2005). In this paper we regard teachers' curriculum use as participation with the text where teachers are seen as collaborators with the curriculum materials in designing the enacted curriculum. In line with Brown (2009) we understand curriculum materials as artefacts products of sociocultural evolution which can extend human capacitates as well as mediate action by both emphasizing affordances and constraints on an activity. For instance, a teacher guide can offer teachers support on multiple ways to structure a lesson (affordance), but also guide teachers' choices by setting up parameters for the activity (constraint). So, briefly one could say that artefacts like curriculum materials can support teachers in achieving goals that they would probably not be able to accomplish by themselves.

Moreover, Brown (2009, p. 18) employs the notion of 'teaching as design' where "teachers must perceive and interpret existing resources, evaluate the constraints of the classroom setting, balance tradeoffs, and devise strategies - all in the pursuit of their instructional goals". This implies that the resulting instruction is not only dependent on the capacity of the teacher but also on the affordances of the artefact she uses. The instructional outcomes result from an interplay between the characteristics of the curriculum material as well as the teacher's skills, goals and beliefs. This means that in studying the resulting instruction one must pay attention to both the written curriculum as well as how teachers perceive, interpret and make use of these representations. In this paper we will focus on teachers' perceptions and stances towards different curriculum materials. These aspects are considered to be of particular relevance as they are examples of influential factors in the teacher-curriculum relationship responding directly to the curriculum material as a cultural artefact (Remillard, 2005). Further, the resulting classroom instruction will also be explored, although only in terms of the teachers' perceived instruction. We want to stress that although the curriculums potential to support teachers in designing their mathematics instruction along with the teachers' perceived support may have a strong impact on the resulting instruction, also other features are of importance. For example, both Remillard (2005) and Brown (2009) reflect upon further aspects which can influence instruction, such as students' reactions and contextual factors. This means that the results of this study can be seen as one piece in trying to understand the participatory relationship between the curriculum materials and teachers along with the resulting instruction.

\section{METHODOLOGY}

The reported study was conducted in the context of a large-scale, longitudinal research and development program aimed at improving classroom teaching in mathematics. The project is carried out in a larger city in Sweden and conducted 
in cooperation between the municipality and university. Special focuses within the project is placed on developing, but also productively use existing artefacts which can support teachers in planning, conducting and evaluating high-quality mathematics instruction.

At the very beginning of the project all mathematics teachers in the municipal elementary schools attended a meeting and in conjunction with this a questionnaire was distributed. Hence, almost all teachers in the municipality, teaching mathematics in grades $\mathrm{K}-6(\mathrm{n}=329)$, responded to the questionnaire. The questionnaire was developed building on the MIST-project (Vanderbilt University, n.d.) and we especially added several questions about teachers' perceived support from curriculum materials and they were asked to rate their agreement with these statements on a five-point scale. We also posed questions about their mathematics instruction. On a four-point scale the teachers were to state how often they conduct certain activities in their classrooms. Regarding instruction there were also some questions which were to be answered by yes or no. Most of the survey questions presented in this paper were created by one of the authors and piloted several times with Swedish teachers.

In this study we focus on teachers' perceived support from curriculum materials along with their mathematics instruction, looking for patterns associated with particular materials. A total of 278 of the 329 teachers responded to the question about which textbook they mainly use in their mathematics instruction. The two most commonly used textbooks were Eldorado $(\mathrm{n}=48)$ and Matte Direkt $(\mathrm{n}=$ 131), whereby we compare the two groups of teachers using the respective textbooks.

For questions on a Likert-scale, the non-parametric Mann-Whitney U test was used to detect any statistically significant differences between the two groups of teachers. This test is used for data with two independent samples with one categorical variable and a minimum of one ordinal variable (Cohen et al., 2011). However, one could argue that the intervals between data points on the Likertscales are equal and therefore should be seen as interval scales. Hence, also independent sample t-tests were run which showed the same results as the Mann Whitney U-test and are therefore not reported due to lack of space. Further, to assess the strength of the differences between the groups the effect size was calculated with Cohen's d. For interpreting the results the guidelines proposed by Cohen (1988) were used with .2 representing small effect, .5 representing moderate effect and .8 representing large effect. Finally, to detect possible associations between two categorical variables Cohen et al. (2011) suggest the chi-square test of independence, which we used on questions that were to be answered by yes or no. On these questions, the phi-coefficient $(\varphi)$ which indicates small effect for .10, medium effect for .30 and large effect for .50 , was calculated to determine the effect size between the two distributions. 


\section{RESULTS}

One of our research questions concerns teachers' perceived support from the curriculum material, looking for possible differences between teachers using different textbooks. The results are summarized in table 1 .

\begin{tabular}{|c|c|c|c|c|c|}
\hline \multirow{2}{*}{ Statements about perceived support } & \multicolumn{2}{|c|}{ Eldorado } & \multicolumn{2}{|c|}{ Matte Direkt } & \multirow[t]{2}{*}{$d$} \\
\hline & Mean & SD & Mean & SD & \\
\hline $\begin{array}{l}\text { It contains useful information for me about } \\
\text { underlying mathematical ideas }\end{array}$ & 4.70 & .51 & 4.19 & .61 & .87 \\
\hline $\begin{array}{l}\text { It provides me with useful information } \\
\text { about how to teach particular mathematical } \\
\text { ideas, concepts and procedures }\end{array}$ & 4.62 & .61 & 4.07 & .71 & .81 \\
\hline $\begin{array}{l}\text { It provides me with useful information } \\
\text { about what students typically know, can } \\
\text { do, or have difficulties with }\end{array}$ & 4.20 & .89 & 3.45 & .98 & .84 \\
\hline $\begin{array}{l}\text { It gives me ideas on how I can } \\
\text { individualize instruction }\end{array}$ & 4.22 & .84 & 3.52 & .99 & .82 \\
\hline $\begin{array}{l}\text { It gives me ideas on how I can vary the } \\
\text { instruction to awaken students' interest. }\end{array}$ & 4.39 & .92 & 3.62 & .91 & .75 \\
\hline $\begin{array}{l}\text { It gives me ideas on how I can concretize } \\
\text { instruction }\end{array}$ & 4.63 & .53 & 3.85 & .81 & 1.05 \\
\hline $\begin{array}{l}\text { It offers enough challenges to students who } \\
\text { need extra stimulation. }\end{array}$ & 3.96 & 1.00 & 3.11 & 1.16 & .76 \\
\hline $\begin{array}{l}\text { It offers mathematical problems that are } \\
\text { relevant to the level the students are at }\end{array}$ & 4.28 & .87 & 3.48 & .93 & .88 \\
\hline $\begin{array}{l}\text { It gives me ideas on how to support } \\
\text { students who have difficulties with certain } \\
\text { elements }\end{array}$ & 3.82 & 1.01 & 3.09 & .97 & .75 \\
\hline $\begin{array}{l}\text { It gives me ideas on how to evaluate } \\
\text { students' knowledge }\end{array}$ & 3.98 & 1.06 & 3.20 & 1.02 & .76 \\
\hline
\end{tabular}

Table 1: Means, standard deviations (SD) and effect size (d) between teachers using Eldorado and teachers using Matte Direkt for perceived support of the textbook. Maximum value of the scale is 5 .

The analysis showed that for all statements, non-parametric Mann - Whitney U tests reveals significant differences $(\mathrm{p}<.001)$ between teachers using Eldorado and teachers using Matte Direkt, where teachers using Eldorado experienced more support from the textbook. The effect size is considered moderate or large for all statements. The largest difference can be seen regarding if the teachers 
perceive that the textbook gives them ideas on how to concretize instruction. Cohen's $d$ for this statement is 1.05 which indicates a non-overlap of about $57 \%$ for the two distributions. For both categories of teachers statements about the textbook offering challenges to students who need extra stimulation and providing ideas on how to help struggling students received the lowest means.

Further, significant differences were found on the subject of textbooks' consistency with teachers' beliefs about effective mathematics teaching. Teachers using Matte Direkt $(\mathrm{M}=2.99, \mathrm{SD}=.48)$ found to a lesser extent that the textbook was consistent with their personal beliefs compared to those using Eldorado $(\mathrm{M}=3.35, \mathrm{SD}=.71 ; \mathrm{p}<.005, \mathrm{~d}=.66)$. Moreover, teachers using Eldorado $(\mathrm{M}=3.56, \mathrm{SD}=.59)$ also considered the textbook more consistent with the teaching approach advocated in the syllabus than those using Matte Direkt $(\mathrm{M}=3.00, \mathrm{SD}=.51 ; \mathrm{p}<.001)$. The effect size $(\mathrm{d}=1.07)$ for this question is seen as large, indicating that the similarity between the two groups of teachers is smaller than $43 \%$.

On the matter of how teachers using different textbooks perceive that they organize their mathematics instruction we detected a significant difference for one of the statements; see table 2.

\begin{tabular}{|c|c|c|c|c|c|c|}
\hline \multirow{2}{*}{$\begin{array}{l}\text { Statements about mathematics } \\
\text { instruction }\end{array}$} & \multicolumn{2}{|c|}{ Eldorado } & \multicolumn{2}{|c|}{ Matte Direkt } & \multirow[t]{2}{*}{$p$} & \multirow[t]{2}{*}{$d$} \\
\hline & Mean & $\mathrm{SD}$ & Mean & SD & & \\
\hline $\begin{array}{l}\text { Students discuss their solutions } \\
\text { with other students }\end{array}$ & 2.84 & 1.02 & 2.69 & .88 & .28 & .16 \\
\hline $\begin{array}{l}\text { Students solve mathematical } \\
\text { problems in small groups / pairs }\end{array}$ & 2.74 & .87 & 2.54 & .84 & .12 & .23 \\
\hline $\begin{array}{l}\text { Students tell about their } \\
\text { mathematics work for the whole } \\
\text { class }\end{array}$ & 1.95 & .90 & 1.76 & .80 & .23 & .23 \\
\hline $\begin{array}{l}\text { Students explain mathematical } \\
\text { concepts / procedures to each other }\end{array}$ & 2.57 & .95 & 2.39 & .95 & .23 & .19 \\
\hline $\begin{array}{l}\text { Students present their solutions to } \\
\text { problems for the whole class }\end{array}$ & 2.44 & .92 & 2.19 & .92 & .10 & .27 \\
\hline $\begin{array}{l}\text { Several students present different } \\
\text { solutions to the same problem for } \\
\text { the whole class }\end{array}$ & 2.27 & .96 & 2.05 & .81 & .15 & .26 \\
\hline $\begin{array}{l}\text { The teacher leads whole-class } \\
\text { discussions focusing on key } \\
\text { mathematical ideas based on } \\
\text { students' different solutions to a } \\
\text { problem }\end{array}$ & 2.33 & 1.10 & 2.13 & .93 & .28 & .24 \\
\hline
\end{tabular}


The teacher leads whole-class discussions with focus on mathematical concepts

The teacher leads whole-class discussions focusing on methods to solve mathematical tasks and then students practice at similar tasks Students work individually in the mathematics textbook / other materials *

\begin{tabular}{|ll|ll|l|l}
2.86 & .92 & 2.62 & .89 & .14 & .26 \\
2.91 & .97 & 2.76 & .92 & .35 & .16 \\
3.27 & .90 & 3.85 & .38 & .00 & -1.04 \\
& & & & &
\end{tabular}

Table 2: Means, standard deviation (SD), p-value and effect size (d) between teachers using Eldorado respectively Matte Direkt on how they perceive that they organize their mathematics instruction. Maximum value of the scale is 4 .

A significant difference in how often teachers perceive that they let students work individually in their textbooks or with other materials was found. This is also supported by the fact that teachers using Matte Direkt $(\mathrm{M}=3.75, \mathrm{SD}=$ 1.16) more often than those using Eldorado $(\mathrm{M}=2.88, \mathrm{SD}=1.40 ; \mathrm{p}<.001, \mathrm{~d}=$ -.71), feel that they during mathematics instruction let their students work at their own pace in the textbook while they go around and help them individually. For this question the similarity between the two distributions is around $57 \%$. Regarding the other statements about mathematics instruction no significant differences were found. However, the mean for teachers using Eldorado is slightly higher on all statements except the one about students' individual work in textbooks.

Finally, a Chi-square test for independence (with Yates Continuity Correction) showed a significant association between teachers using different textbooks and if they let their students adhere to the same mathematical area and do the same tasks, $\chi^{2}(1, \mathrm{n}=167)=29.14, \mathrm{p}=.00$. More than half of the teachers using Eldorado (52\%) agreed to this statement compared to $11 \%$ of those using Matte Direkt. The effect size was calculated $(\varphi=.43)$ and is considered as moderate.

\section{CONCLUSION AND DISCUSSION}

Our findings show that there are major differences associated with the curriculum materials the teachers use and the level of support they feel that they receive from them in terms of their mathematics instruction. On the whole, teachers using Eldorado perceive that they get more support from the material than those using Matte Direkt. Hence, teachers' beliefs about the different curriculum materials seem to be relatively consistent with the commenced teacher guide analysis done by Hemmi et al. (2013). This analysis revealed that the teacher guide for Eldorado can be regarded as a resource for potential teacher learning in practice for aspects like encountering students' ideas in a 
productive manner and making visible the demands of the practice concerning the curricular goals, whereas the teacher guide for Matte Direkt cannot.

Although the compared groups of teachers differ regarding survey questions on experienced support from the materials they still show similar trends on them. For example, both teachers using Eldorado and teachers using Matte Direkt gave the lowest scores on perceived support for questions on how to support struggling students and students who need extra stimulation. This can be linked to recent results from PISA (OECD, 2013) which show that, compared to the results from 2003, 17 countries display increase in the share of low performing students or decrease in that of top performing students. In Sweden the results are even worse with the share of low performing students increasing by 12 percent and the share of top performers being cut in half. As mentioned before, Cobb and Jackson (2011) argue for the importance of supporting tools for teachers when striving to improve mathematics teaching at scale. Further, they also stress the need for providing additional support for struggling students. Our study shows that teachers find scant support in their curriculum material to support struggling students.

Concerning how the teachers organize their mathematics instruction we also discovered some significant differences, mainly regarding the amount of time students work individually in their textbooks and if they are adhering to the same mathematical area. Teachers using Matte Direkt, in contrast to those using Eldorado, perceive that they more often let students work individually in their textbooks and to a smaller extent feel that they let them adhere to the same mathematical area. This kind of "speed individualization" is what has also been criticized in national evaluations (e.g. Skolinspektionen, 2009) for taking too much of instructional time, with the result of students not being given enough opportunities to develop mathematical abilities like problem solving, reasoning and communication. Teachers using Eldorado on the other hand seem to have a slightly more varied teaching. This is perhaps not too surprising considering that textbooks often serve as the primary source for teachers when designing mathematics instruction (Johansson, 2006) and teachers using Eldorado perceived more support from the curriculum material on subjects like how to vary and concretize instruction.

However, one could argue that the differences found between the two groups of teachers are not due to the curriculum materials being used, but that it is instead those differences that contribute to teachers choosing different materials. What is cause and what is effect cannot be answered by this first study. Nevertheless, our results suggest that teachers using Matte Direkt are less satisfied with the material, both in terms of how well they perceive that it corresponds to the syllabus (Skolverket, 2011) and their personal beliefs about effective mathematics instruction. At the same time, they spend more instructional time on letting students work individually in the textbook. The initiating analysis 
done by Hemmi et al. (2013) show that the teacher guide for Matte Direkt represents material that is very much dependent on the students' textbook. These relationships are worth further investigating.

Teachers' use of curriculum materials is of course affected by the characteristics of the material, but also by their beliefs about effective mathematics instruction and views of the materials being used (Brown, 2009; Davis \& Krajcik, 2005; Remillard, 2005; Remillard \& Bryans, 2004). Additionally, teachers' use of the materials is also dependent on what is happening in the classroom, like norms and students' reactions (Remillard, 2005; Stein et al., 2007). In this paper we have focused on teachers' beliefs of curriculum materials along with their perceived mathematics instruction and found interesting differences between teachers using different textbooks. This is an important first quantitative step that we now intend to follow up with additional analyses of the characteristics of these textbooks along with teacher interviews and classroom studies on how they are used in instruction.

\section{REFERENCES}

Arora, A., Foy, P., Martin, M. O., \& Mullis, I. V. S. (2012). TIMSS 2011: International results in mathematics. Chestnut Hill, MA: TIMSS \& PIRLS International Study Center.

Brown, M. (2009). The teacher-tool relationship: Theorizing the design and use of curriculum materials. In J. Remillard, B. A. Herbel-Eisenmann \& G. M. Lloyd (Eds.), Mathematics teachers at work - Connecting curriculum materials and classroom instruction. New York: Routledge.

Cobb, P., \& Jackson, K. (2011). Towards an empirically grounded theory of action for improving the quality of mathematics teaching at scale. Mathematics Teacher Education and Development, 13(1), 6.

Cobb, P., \& Jackson, K. (2012). Analyzing educational policies: A learning design perspective. Journal of the Learning Sciences, 21(4), 487-521.

Cohen, J. W. (1988). Statistical power analysis for the behavioral sciences (2 ed.). Hillsdale, NJ: Lawrence Erlbaum Associates.

Cohen, L., Manion, L., \& Morrison, K. (2011). Research methods in education (7 ed.). London: Routledge.

Davis, E. A., \& Krajcik, J. S. (2005). Designing educative curriculum materials to promote teacher learning. Educational Researcher, 34(3), 3-14.

Furinghetti, F., \& Pehkonen, E. (2002). Rethinking characterizations of beliefs. In G. C. Leder, E. Pehkonen \& G. Törner (Eds.), Beliefs: A hidden variable in mathematics education (pp. 39-58). Dordrecht: Kluwer.

Hannula, M. S., Lepik, M., Pipere, A., \& Tuohilampi, L. (2013). Mathematics teachers' beliefs in Estonia, Latvia and Finland. Paper presented at the Eighth 
Congress of the European Society for Research in Mathematics Education, Antalya, Turkey.

Hemmi, K., Koljonen, T., Hoelgaard, L., Ahl, L., \& Ryve, A. (2013). Analyzing mathematics curriculum material in Sweden and Finland: Developing an analytical tool. Paper presented at the Eighth Congress of the European Society for Research in Mathematics Education, Antalya, Turkey.

Hiebert, J. (2003). Teaching mathematics in seven countries : results from the TIMSS 1999 video study. Washington, D.C.: US Govt. Printing Office.

Johansson, M. (2006). Teaching mathematics with textbooks: A classroom and curricular perspective. Doctoral Thesis, Luleå University of Technology, Luleå. (2006:23)

OECD. (2013). PISA 2012 results: What students know and can do (Volume I). PISA: OECD Publishing.

Remillard, J. T. (2005). Examining key concepts in research on teachers' use of mathematics curricula. Review of Educational Research, 75(2), 211-246.

Remillard, J. T., \& Bryans, M. (2004). Teachers' orientations toward mathematics curriculum materials: Implications for teacher learning. Journal for Research in Mathematics Education, 35(5), 352-388.

Remillard, J. T., Herbal-Eisenmann, B. A., \& Lloyd, G. M. (2009). Mathematics teachers at work: Connecting curriculum materials and classroom instruction. New York: Routledge.

Skolinspektionen. (2009). Undervisningen i matematik - utbildningens innehåll och ändamålsenlighet. (2009:5). Stockholm: Skolinspektionen.

Skolverket. (2011). Curriculum for the compulsory school, preschool class and the recreation centre, 2011. Stockholm: Skolverket.

Stein, M. K., Remillard, J., \& Smith, M. (2007). How curriculum influences student learning. In F. Lester (Ed.), Second handbook of research on mathematics teaching and learning (Vol. 1, pp. 319-369): Information Age Publishing.

Vanderbilt University. (n.d.). Vanderbilt University study of middle school mathematics and the institutional setting of teaching (MIST) survey. Retrieved December 10, 2013, from http://peabody.vanderbilt.edu/docs/pdf/tl/Generic_Teacher_Survey_2010_Plu s_Sources_100803.pdf 


\title{
ENGINEERING STUDENTS' USE OF WEB LECTURES IN A LINEAR ALGEBRA COURSE
}

\author{
Ragnhild Johanne Rensaa \\ Narvik University College
}

The present paper investigates how engineering students use recorded lectures published on the web as part of their studying and learning of linear algebra. The investigation shows that students utilize the free access to web lectures mostly by consulting sequential parts. There is, however, a preference to attend live lectures rather than watch lectures on the web in real time.

Keywords: web lectures, support in learning, engineering students, linear algebra

\section{INTRODUCTION}

An evaluation report from the Ministry of Education from 2008 concludes that in our country there are some areas within engineering education that need higher standards. Research based teaching is one of these areas. In addition to include recent results from research in the professional disciplines, such teaching ought to comprise research results about teaching and learning of the disciplines. What teaching formats are offered to engineering students and which learning strategies the students emphasise are important questions to be answered, and many aspects may be considered if searching for answers. Focus of the present paper is a mathematics course in linear algebra given to students in their fourth year of a Master of engineering programme. A particular tool for learning; web lectures, is investigated in order to obtain knowledge about how engineering students utilise available course material as part of their learning of mathematics. The research questions are formulated to be: What characterises engineering students' approach to web- and live- lectures when being provided with real-time recordings of lectures in linear algebra? How may access to web lectures support their learning of mathematics?

\section{THE RESEARCH STRUCTURE}

The perspective of the present study is a quantitative, descriptive investigation, in which a collection of numerical data from a questionnaire distributed to all students is supported by selected statements given by individual students and my own experiences. Due to the focus of the study, three conceptions need to be clarified: The use of web lectures for different purposes, the lecture format and the engineering students' interests. These aspects form the setting of the mathematics course studied.

Online technology for education is increasingly used in higher education (Le, Joordens, Chrysostomou, \& Grinnell, 2010). This technology is designed for different purposes. Some record and publish lectures as supplement to classroom lectures (Brecht, 2012). Such videos may offer slower and more step-by-step explanations to meet students' difficulties. Others seek to enhance the learning experience in the 
classroom by using web lectures to introduce students to the course material prior to class (Day, 2008). Then in-class time can be used for 'learning by doing'-activities. The mathematics course in the present study was intensively taught for two nonconsecutive weeks, each with a 5-days-8-hours-schedule. Thus, a third approach was sought, to augment traditional lectures by posting recordings of the lectures online. In the current course setting this was the most practical approach. It is the same structure as Le and colleagues (2010) used in their videotaping of classes in calculus, where the researchers investigated students' use of pause and seek features of the recordings and related this to performance in the course. They found that whether the flexibility that such available recordings provide is beneficial to students is dependent upon the students' learning strategies. Some students utilised the pause and seek functions as part of a deeper strategy to learning while others paused mainly to memorise the content. Le and her colleagues concluded that students should be instructed on how web lectures should be used in order to be beneficial. The teaching format in the present class was what may be denoted as 'traditional', with large group lectures followed by task solving sessions where students worked in groups. Awareness of what takes place in mathematics lectures at universities is important. Bergsten's research, asking 'why do students go to lectures?' (2011) showed that students find it easier to understand the mathematics content when it is presented in lectures rather than given in a textbook. With such emphasis put on lectures, repeatable access to lectures provided by recordings should be valuable. Engineering students consider mathematics to be a routine practice of their profession (Steen, 2001). Kümmerer (2001) gives an account of what he denotes the 'workman approach' to mathematics that many students of science and engineering have. Mathematics is then perceived as a machine which automatically produces the correct answer if following a set of rules. If having such an approach, the formalism of linear algebra may be difficult to grasp, and the possibility to virtually return to lectures about concepts could provide useful.

\section{METHOD}

\section{The course setting}

The present investigation took place in a linear algebra course which I was teaching. Small adjustments of the lecturing format resulted in a smooth and well-functioning recording system where lectures were published online in real time. For detailed description of this system, see Collin (2013). The linear algebra course was offered to students in their fourth year of study in a Master of Engineering programme. Previously, in their first year of study, the students had completed a combined calculus- and linear algebra course in order to learn the basic 'tools' needed for the professional disciplines. However, in this precourse the linear algebra part was small compared to the calculus part, and students mainly got acquainted with basic concepts and operations on matrices. Therefore, a more extensive course was included in the fourth year of the master studies. Such postponing is in accordance 
with Carlson (1993), who lists the course being taught too early in their studies as one of four reasons why many students have difficulties in linear algebra.

\section{The questionnaire and data collection}

Data for the study was collected by distributing a questionnaire electronically to all students after the mathematics course was finished. The reason why it was decided to wait until the end was to have a complete summary from the students, including utilisation of web lectures when preparing for the final exam. A disadvantage of the postponement was that students were busy with their subsequent courses and did not feel obliged to contribute further to the linear algebra course. Only 27 out of 49 students submitted anonymous answers, and two of the responses were blank. Thus, no attempt to generalize the results is done and the inquiry may be regarded as a case study. In each question in the questionnaire, only one category could be chosen. Since the course was given in English, the data is genuine.

Initially, themes for questions in the questionnaire were designed based on hypotheses about students' ways of studying. From previous experiences I knew that giving too many open questions, which expect that students write down own explanations, may reduce the response rate - simply because students feel it is too time-consuming. Thus, I tried to design questions with different types of responses. However, throughout the linear algebra course the questions were adjusted as a consequence of observations and informal conversations with the students. For instance, when asking students how they preferred to use the web lectures, the alternatives were composed as I observed which strategies they employed during task solving sessions. Another question presented different statements to which students should agree or not, and these statements were developed and adjusted as students explained how they exploited the web lectures. An example was one student who called upon me in a pause between lectures. He wanted to tell me that his previous problem of simultaneously managing to take notes and being attentive to the lecture content had disappeared. This was since lecture notes were readable in the web lecture format, thereby eliminating the need to write notes. This information was the origin of the statement "I did not need to make lecture notes since I could see the writings on the web" included in the questionnaire.

The final part of the questionnaire was about learning. Initially, an open question was designed simply by asking the students to describe what they mean by learning linear algebra. However, I was aware that this - if properly answered - could give a wide range of responses which could be difficult to summarise. Thus, the work by Marshall and colleagues (Marshall, Summers, \& Woolnough, 1999) gave the idea to a question asking students to select one out of 5 conceptions for learning that best described their own opinion. I used the same notions as the ones Marshall and colleagues identified in their study of engineering students' conceptions of learning.

Distributions of responses to the questionnaire will be discussed. In addition, a crosstabulation of survey items is given to provide additional analysis of data. 


\section{The insider researcher}

Being both a teacher and a researcher gave some methodological advantages - as pointed out in the previous section. Also, exploring my own teaching practice may produce outcomes that can be used to develop the practice. However, being an insider researcher is also very challenging because of the risk of subjectivity. Two main inputs in the development of the questionnaire were observations and conversations with students. Did I interpret these inputs differently due to my role as class teacher? Did I develop questions and statements to accentuate certain parts of my teaching? To meet such objections I tried to be conscious about my role when developing the questions and I asked a colleague in the computer department to read through and give me feedback on the questions. He did not find them problematic.

\section{RESULTS WITH INTERPRETATIONS}

The first question in the questionnaire asked students if they found the teaching style that was needed to make the recordings in a proper manner to be satisfactory. Most of the students; $74 \%$, confirmed this to be ok and out of these $67 \%$ even stated it to be better than the traditional use of the blackboard. Among the positive comments that students gave in informal conversations was that the teacher was facing the students and could observe their reactions to explanations. For an illustration of this, see Collin (2013, p. 27). In addition, the possibility of going back to earlier arguments by picking up sheets of paper that had been written earlier was regarded as positive.

The second question in the questionnaire asked the students "How do you prefer to use the lectures published on the web (mark what you prefer the most)?" The frequencies (\%) of answers are given in Figure 1. The figure shows that about a quarter of the students did not utilise the access to web lectures. However, $67 \%$ of the students took advantage of the web-lectures as a whole or by parts, and the most preferred way of doing this was by concentrating on sequences - which are easy to single out in the particular web facility.

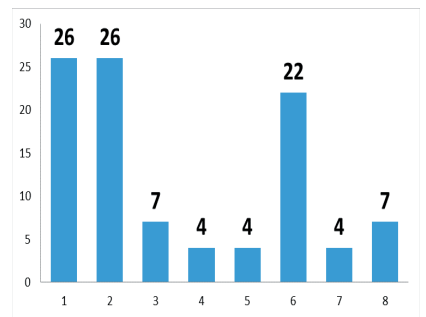

1: Look at a whole lecture about a topic

2: Look at parts within lectures by skimming through sequences

3: Let the whole lecture play as I do something else and then look if something interesting occurs

4: Mainly listen to arguments

5: Mainly look at how things are derived

6: Not look at web lectures

7: Others

8: No answer

\section{Figure 1: Frequencies of preferences in use of web lectures}

Students preferred to actively look up these sequences and pay attention when interesting parts occurred. This is in accordance with Le and colleagues (2010) who emphasise the possibility to virtually return to lectures if some steps are forgotten perhaps with a task to be solved at hand - as a beneficial approach. 
The third question consisted of 12 statements, S1 to S12, for which students were to choose their level of agreement. Rounded off frequencies of responses are given in Table 1. Additionally, the actual number of student responses is included in parenthesis in the agreement-column since these numbers are further analysed in Table 2. Selected statements are discussed subsequently. The statement about learning, S6, is postponed to the later discussion of Figure 2.

\begin{tabular}{|c|c|c|c|c|}
\hline & $\begin{array}{c}\text { Agree } \\
\%\end{array}$ & $\begin{array}{c}\text { Neutral } \\
\%\end{array}$ & $\begin{array}{c}\text { Disagree } \\
\%\end{array}$ & $\begin{array}{l}\text { No } \\
\text { opinion } \\
\text { /answer }\end{array}$ \\
\hline $\begin{array}{l}\text { S1: I found the speed of the live lectures } \\
\text { too high, thus I preferred web lectures }\end{array}$ & $\begin{array}{l}15 \\
(4)\end{array}$ & 41 & 29 & 15 \\
\hline $\begin{array}{l}\text { S2: I appreciated the freedom access to } \\
\text { web lectures implies }\end{array}$ & $\begin{array}{c}63 \\
(17)\end{array}$ & 30 & 0 & 7 \\
\hline $\begin{array}{l}\text { S3: I did drop some live lectures since } \\
\text { knowing that they could be watched on the } \\
\text { web }\end{array}$ & $\begin{array}{l}26 \\
(7)\end{array}$ & 7 & 48 & 19 \\
\hline $\begin{array}{l}\text { S4: I did not need to make lecture notes } \\
\text { since I could see the writings on the web }\end{array}$ & $\begin{array}{l}26 \\
(7)\end{array}$ & 11 & 56 & 7 \\
\hline $\begin{array}{l}\text { S5: I have used web lectures frequently } \\
\text { when preparing for the final exam }\end{array}$ & $\begin{array}{l}30 \\
(8)\end{array}$ & 33 & 30 & 7 \\
\hline $\begin{array}{l}\text { S6: The possibility of repeating lectures on } \\
\text { the web was important for my learning of } \\
\text { linear algebra }\end{array}$ & $\begin{array}{c}41 \\
(11)\end{array}$ & 29 & 15 & 15 \\
\hline $\begin{array}{l}\text { S7: I was nervous about asking questions } \\
\text { during live lectures when knowing that } \\
\text { they were recorded }\end{array}$ & $\begin{array}{c}4 \\
(1)\end{array}$ & 26 & 48 & 22 \\
\hline $\begin{array}{l}\text { S8: I rarely got the time to watch the web } \\
\text { lectures }\end{array}$ & $\begin{array}{l}30 \\
(8)\end{array}$ & 26 & 33 & 11 \\
\hline $\begin{array}{l}\text { S9: I did not like that the writing of lecture } \\
\text { notes became jagged (not continuous) on } \\
\text { the web }\end{array}$ & $\begin{array}{l}11 \\
(3)\end{array}$ & 22 & 52 & 15 \\
\hline $\begin{array}{l}\text { S10: If I attended a live lecture, I did not } \\
\text { find it necessary to watch the same web } \\
\text { lecture }\end{array}$ & $\begin{array}{l}22 \\
(6)\end{array}$ & 22 & 37 & 19 \\
\hline $\begin{array}{l}\text { S11: If I had to choose between being } \\
\text { introduced to a linear algebra topic by a }\end{array}$ & 52 & 22 & 19 & 7 \\
\hline
\end{tabular}




\begin{tabular}{|l|c|c|c|c|}
\hline $\begin{array}{l}\text { live lecture or a web lecture, I would prefer } \\
\text { a live lecture }\end{array}$ & $(14)$ & & & \\
\hline $\begin{array}{l}\text { S12: Web lectures cannot replace live } \\
\text { lectures }\end{array}$ & $\begin{array}{c}56 \\
(15)\end{array}$ & 18 & 15 & 11 \\
\hline
\end{tabular}

\section{Table 1: Frequencies of responses to statements about web lectures}

S2: Not surprisingly, quite many students appreciated the freedom given in knowing that lectures are recorded, $63 \%$. Le and colleagues (2010) point to the benefits of web lectures being that they allow students to never miss a lecture but also to return to previous lectures if they have forgotten or not really understood the content. According to Table 1, 37\% found this necessary since disagreeing to S10. In some cases the physical conditions may necessitate catching up with the progress of lectures by revising recordings. One student commented on this in an open question in the questionnaire, where students were to describe their work with the course:

I missed all the lectures of the first week due to late arrival in Norway. But the web lectures became so helpful to me.

S4: The presentation format of lectures on the web was designed to give primary space on the screen for what was written during class while a minor area was devoted to the movements of the teacher, see (Collin, 2013, p. 27). Thus, written material from lectures was easily read when watching web lectures. Still, the responses to Statement 4 show that $56 \%$ of the students did make notes - despite the possibility to look them up the web. This confirms results in other investigations, showing that students regard lecture notes as more important than the textbook (Randahl \& Grevholm, 2010), they consult their notes frequently (Rensaa, 2014) and they find them vital for what they gain from attending the lectures (Bergsten, 2011). With such emphasises, S4 confirms that it becomes important to make notes.

S5: The statement about use of web lectures when preparing for exam gave mixed answers. About 33\% accounted for neutrality in this, while the rest split equally between agreeing and not agreeing to the statement. The students of Day's investigation, who were to watch web lectures with presentations of lecture material in advance of class, stressed that these lectures were not equally useful as means to review for exam (Day, 2008, p. 45). These students' explanation was that the web lectures were too long and geared towards introducing the material, not reviewing it. This may to some extent be the case in the present mathematics course, even if the web facilities offer a sequential approach and thereby makes it easier to look up specific parts of the lectures.

S11: As seen from Table 1, more than $50 \%$ of the students preferred to attend live lectures and be physically present in class. One student provided the following explanation in the open question about the students' ways of working: 
I went to lectures, then I did some task solving after every lecture. For the exam preparation it's great to have some old exams to work with. Though some kind of hand in or likewise with related tasks is also a good way to get prepared for exams

For this student, attending lectures and doing tasks was found to be more important than the access to web lectures. Such approaches are often observed. It may be connected to students' cognitive strategies, as explained by Bassili (2008b) who showed that students who monitor their learning and like learning with peers prefer to go to lectures. The respondents in the present investigation were experienced students, and they may thereby have found such strategies valuable. Additionally, students go to lectures rather than watch online recordings when the content is perceived to be difficult (Bassili, 2008a). The present mathematics course was one in linear algebra, a subject which is commonly claimed to be cognitively and conceptually difficult to students (Carlson, 1993; Dorier \& Sierpinska, 2001). It is likely that students taking such a course are particularly ready to attend live lectures. Another reason for preferring live lectures may simply be that going to lectures in real time means that studies cannot be postponed. The freedom that lies in having web access to lectures can create problems with keeping progress if not disciplined.

Combinations: To compare preferred teaching facilities to statements, a crosstabulation was developed, given in Table 2. In this table, appreciation of web lectures in S2 and live lectures in S11 are displayed, given by the number of students agreeing to the statements. Selected results are subsequently discussed.

\begin{tabular}{|c|c|c|c|c|c|c|c|c|c|c|}
\hline & S1 & S2 & S3 & S4 & S5 & S6 & S8 & S9 & S10 & S12 \\
\hline S2 & 4 & - & 7 & 6 & 7 & 10 & 5 & 3 & 4 & 11 \\
\hline S11 & 4 & 9 & 1 & 1 & 3 & 6 & 7 & 3 & 5 & 13 \\
\hline
\end{tabular}

Table 2: Relationship between agreed statements; number of replies

S2-S3 \& S2-S5: Seven students have taken advantage of web lectures by skipping live lectures, S3. Some students told me that it was more comfortable to stay in bed in the morning and follow the lectures in real time from the bedside. Also, seven students state to have benefitted from repeating the mathematics content by watching web lectures before the exam, S5.

S2-S12 \& S2-S11: A total of eleven students appreciated the access to web lectures but still thought that live lectures cannot be replaced. One student provided the following explanation in the open question:

I took live lectures.. then spent some time at home with web lectures to reassure my concepts are good.. then attempted solving tasks.. if there was some problem.. again referred to web lectures.

This student combined attendance in class with reviews done by utilizing the web facilities afterwards. Such approaches are probably shared by the other students agreeing to both S2 and S12, but also the nine students who agreed to S2 and S11. 
S11-S8 \& S11-S10: The seven students that agreed to both S11 and S8 have not found time to watch web lectures. They have preferred going to live lectures and in cases of time constraints, watching web recordings have been skipped. Three of these students have also agreed to S10, emphasizing that since they attended live lectures they did not need to consult the web. However, from Table 1 it follows that $37 \%$ of the students who attended live lectures found it useful to watch the demonstrations again later since disagreeing to $\mathrm{S} 10$, thus the strategies vary.

Statement 6: This statement is about the students' learning processes. As seen from Table $1,41 \%$ or eleven students found that the possibility to watch lectures several times on the web was important to their learning of the mathematical content. Out of these, ten students connected it to S2 - the freedom that access to web lectures offers. The combination S6 and S11, connecting learning to live lectures, was emphasized by six students. It shows that students have different learning approaches in mathematics.

Web lectures offer flexibility and convenience, but this is not necessarily beneficial to the learning. In the study by Le and colleagues (2010), most of the students who used the online pause and seek features also preformed most poorly in the mathematics course. The researchers' explanation was that these students paused to memorise, not to understand. Students should be taught how to exploit the web lectures to profit their learning and not for memorizing (Le et al., 2010).

Statement 6 may be connected to a final question in the questionnaire asking students to mark out the conception for learning that best fits with their opinion about what it means to learn mathematics. Figure 2 presents the conceptions, from which the students could choose one, together with the distribution of answers.

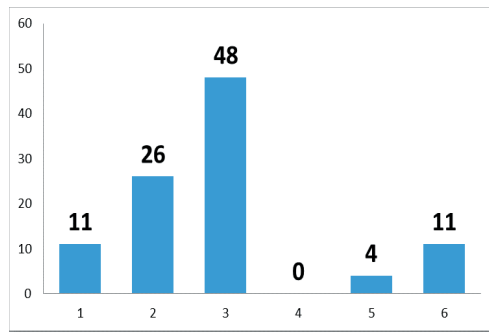

1: Learning as memorising definitions, equations and procedures

2: Learning as applying equations and procedures

3: Learning as making sense of physical concepts and procedures

4: Learning as seeing phenomena in the world in a new way

5: Learning as a change as a person

6: No answer

\section{Figure 2: Frequencies of responses to conceptions for learning}

The figure shows that nearly half of students took learning of mathematics to be making sense of physical concepts and procedures. This alternative is about familiarising oneself with the mathematical concepts that are introduced. This is particularly important in linear algebra, since it is a domain that has had lack of success in many countries in term of what is learned by the students (Dubinsky, 1997). Students find it cognitively and conceptually difficult - having problems grasping the formalism (Dorier \& Sierpinska, 2001). With reference to the results in 
Statement 6, some of the present students make sense of the mathematical content by utilising the web lecture features while others do not.

\section{CONCLUSION}

Web lectures offer an opportunity for students to decide their progress in dealing with the introduction of new mathematical material, and it offers a possibility to pause and consult other learning sources while being introduced to new concepts. The smooth technical organisation of the present course suggests that web lectures could be greatly utilised. The study confirms that students appreciated the free access to web lectures, but that the type of use varied. The most popular application was to consult sequential parts. However, the results also show that the students preferred to attend the traditional live lectures and be present in class when new material was introduced. This suggests that web lectures were drawn upon more for sequential follow-up use. An answer to the first research question is therefore that it seems as if access to web lectures is not extensively utilised in real time, but that many students draw upon the web access at later occasions for support.

As to the research question regarding how web lectures may support students' learning of linear algebra, an advantage that seemed to apply to some students was the possibility to repeat arguments for deeper understanding. "Linear algebra is an 'explosive compound' of languages and systems of representation" (Dorier \& Sierpinska, 2001, p. 270), and this may be hard to grasp in a first presentation. Thus some students can benefit from having the possibility to repeat lecture parts at later occasions. The exam results in linear algebra for the year that the present study was conducted were rather good. The percentage of A's and B's was higher than previous years, and the share of failures was smaller. This may be due to a number of reasons like the particular group of students, the particular teaching style, the set of exam tasks etc. Still, it was reassuring to have such results when introducing a new feature in class. It suggests that some students may take advantage of web lectures with a better understanding as outcome; at least in terms of what a summative, written exam may be interpreted to measure. It encourages further investigations in future courses to try to single out more details about the use of web lectures and their relation to exam results.

\section{REFERENCES}

Bassili, J. N. (2008a). Media richness and social norms in the choice to attend lectures or watch them online. Journal of Educational Multimedia and Hypermedia, 17(4), 453-475.

Bassili, J. N. (2008b). Motivation and cognitive strategies in the choice to attend lectures or watch them online. Journal of distance education, 22(3), 129-148.

Bergsten, C. (2011). Why do students go to lectures? Paper presented at the Cerme 7, Rzeszow, Poland. 
Brecht, D. H. (2012). Learning from online video lectures. Journal of Information Technology Education: Innovations in Practice, 11, 227-247.

Carlson, D. (1993). Teaching linear algebra: Must the fog always roll in? College Mathematics Journal, 24(1), 29-40.

Collin, K. (2013). Sonicfoundry Mediasite BCU+ Handbook: A Guide to Establish Virtual Cross-Border Campus for BCBU Network (pp. 23-28). s.1.: University of Lapland Printing Centre.

Day, J. A. (2008). Investigating learning with web lectures. (PhD thesis), Georgia Institute of Technology.

Dorier, J.-L., \& Sierpinska, A. (2001). Research into the teaching and learning of linear algebra. In D. Holton (Ed.), The teaching and learning of mathematics at university level: An ICMI study (pp. 255-273). Dordrecht: Kluwer Academic Publishers.

Dubinsky, E. (1997). Some thoughts on a first course in linear algebra on the college level. In D. Carlson, C. Johnson, D. Lay, D. Porter, A. Watkins \& W. Watkins (Eds.), Resources for Teaching Linear Algebra (Vol. 42, pp. 107-126): MAA Notes.

Kümmerer, B. (2001). Trying the impossible: Teaching mathematics to physicists and engineers. In D. Holton (Ed.), The teaching and learning of mathematics at university level: An ICMI study (pp. 321-334). Dordrecht: Kluwer Academic Publishers.

Le, A., Joordens, S., Chrysostomou, S., \& Grinnell, R. (2010). Online lecture accessibility and its influence on performance in skills-based courses. Computers \& Education, 55, 313-319.

Marshall, D., Summers, M., \& Woolnough, B. (1999). Students' conceptions of learning in an engineering context. Higher Education, 38, 291-309.

Randahl, M., \& Grevholm, B. (2010). Learning opportunities offered by a classical calculus textbook. Nordic Studies in Mathematics Education, 15(2), 5-27.

Rensaa, R. J. (2014). The impact of lecture notes on an engineering student's understanding of mathematical concepts. Journal of Mathematical Behavior, 34, 33-57.

Steen, L. A. (2001). Revolution of stealth: Redefining university mathematics. In D. Holton (Ed.), The teaching and learning of Mathematics at university level (pp. 303-312). Dordrecht: Kluwer Academic Publishers. 


\title{
THE HIDDEN AND SALIENT MESSAGES OF THE MATHEMATICS CURRICULUM ABOUT THE CHANGES IN THE CULTURE OF MATHEMATICS EDUCATION
}

\author{
Silfverberg Harry \\ University of Turku, Finland
}

The study examines by textual and linguistic analysis at to what extent the Finnish mathematics curriculum texts reflect and promote (1) the social turn in mathematics education, and (2) the different components of student's mathematical proficiency like procedural fluency, conceptual understanding, strategic competence, adaptive reasoning and productive disposition. The main means in the linguistic analysis is a so-called verb analysis.

\section{INTRODUCTION}

In the article, we mean with the term social turn in mathematics education (e.g. Lerman 2000) the turning of the individual, cognitive constructivist point of view of mathematics education to the social constructivist point of view. Actually, Lerman considers in his article particularly the social turn happened in the research of the mathematics education. However, there are good reasons why we can expect that same trend can be noticed also in the practice of mathematics education in schools. Some attempts to promote the social turn in mathematics education would be found in the national level curriculum texts of mathematics guiding the mathematics teaching at Finnish upper secondary schools as well. The still holding National Core Curricula published in 2003 by the Finnish National Board of Education is at least at the general level explicitly committed to the social-constructivist conception of learning. Its conception of learning is based on a viewpoint that learning is seen as “... a result of a student's active and focused actions aimed to process and interpret received information in interaction with other students, teachers and the environment and on the basis of his or her existing knowledge structures." (Anon. 2003, 14.)

Contrary to the above said, there are as well reasons to suspect that especially in the subject specific part of the curriculum where the objectives for mathematics education are stated the trend toward to the more social approach of learning mathematics would not be detectable. The learning of mathematics is often seen primarily as an individual effort and the meaning of the social activities have been diminished. In addition to that often the writers of the national curriculum texts are par excellence the experts of the mathematics subject and not as well familiarized with the theories of learning and the international trends of mathematical education which may cause the issue that role of the produced text is more focused on regulating what content and skills should be learnt than how the learning will happen. Following Singer and Moscovic (2008) also the mathematics curriculum should promote the development of the learning culture where the classes are especially communities of the learners of the mathematics in addition to fact that where the 
learners are independent thinkers and researchers who present their own views courageously, are asking spontaneously, argue for their opinion, change ideas and solve problems together. The social aspect should be seen also in the objectives given in the curriculum texts and that way in the verbs used in the curricula as well. The National Research Council pointed its importance out in the report 'Everybody counts' public already two and a half decades ago as follows

"...or students to understand what they learn "they must enact for themselves verbs that permeate the mathematics curriculum: 'examine', 'represent', 'transform', 'solve', 'apply', 'prove', 'communicate'." (National Research Council 1989, 58-59.)

In addition to the social point of view, our interest is directed in the examination of the objective texts of curricula to how the objectives emphasize the five components of the mathematical proficiency. In the report Adding It Up: Helping Children Learn Mathematics (Kilpatrick et al. 2001) they are characterised in the following way

1. Procedural fluency is defined as the skill in carrying out procedures flexibly, accurately, efficiently, and appropriately.

2. Conceptual understanding refers to the "integrated and functional grasp of mathematical ideas", which "enables them [students] to learn new ideas by connecting those ideas to what they already know."

3. Strategic competence is the ability to formulate, represent, and solve mathematical problems.

4. Adaptive reasoning is the capacity for logical thought, reflection, explanation, and justification.

5. Productive disposition is the inclination to see mathematics as sensible, useful, and worthwhile, coupled with a belief in diligence and one's own efficacy. (Kilpatrick et al. 2001, 116).

Our main means in the analysis of the curriculum texts is a so-called verb analysis. The analysis of the verbs contained by the objective sentences is not anyhow new as such. For instance, in Bloom's taxonomy on the so-called action verbs had a central role (Bloom 1956). The taxonomy of the objectives was essentially based on the grouping of the learning performances indicated just by the verbs from its demands on different hierarchical classes. The taxonomy of the objectives was essentially based on the grouping of the learning performances indicated just by the action verbs in the hierarchical classes demanding different cognitive capacity from the learner. Lately several attempts have been made to modernize the Bloom's taxonomy when the out-come based formulation of the objectives is becoming a general standard (cf. Anderson \& Krathwohl 2001; Krathwohl 2002; Moon 2002).

\section{RESEARCH QUESTIONS}

1. What kind of hidden messages do the choice of verbs in the curriculum texts transmit about the possible changes which were happening in the culture of mathematics teaching in nine years period 1994-2003 (actually up to today because the curricula of the year 2003 are still valid)? 
2. Especially, what does the choice of the verbs tell about

a) the promotion of a social turn in upper secondary school mathematics education in the curricula examined, and about

b) the possible change in the emphasis of the components of mathematical proficiency?

\section{METHOD}

\section{The analysed texts}

In this study, the strength of the promotion of different components of mathematical proficiency mentioned above are technically examined by looking the differences in the selection of verbs characterizing the learning objectives of mathematics in the two consecutive National Core Curricula for Finnish general upper secondary schools. As in Finland each upper secondary school offer two optional syllabuses of mathematics, short and long syllabus, in the years 1994 and 2003 four different mathematics curricula were published which in the following we refer with abbreviations Short94, Short03, Long94, Long03.

\section{Verb analysis of the texts}

In the quantitative analysis of verbs, we first separated all the verbs from the sentences in those many separate forms and tenses found in the Finnish language, grouped the verbs to the classes in accordance with the basic forms of verbs and calculated then the appearance frequency of each different verb. The slightly simpler version of the method used in this study was pre-tested in the author's earlier study (Silfverberg 2010). From each text Short94, Short03, Long94, and Long03 one text at a time, all the verbs appeared in them was picked to the examination. Totally 459 verbs consisting of 233 main verbs and 226 auxiliary verbs were analysed. From the verbs, we first examined of all the main verbs of sentences and after that those possible verbs and actions to which the main verbs were referring.

For instance, from the expression " ...learn to illustrate discrete and continuous statistical distributions." as the main verb naturally the verb "to learn" was picked as the main verb and as an action to which this verb referred a verb "to illustrate". However, the structure of all objective sentences in the curriculum was not equally explicit. In those sentences where the subject of the action had not been indicated in a verb form but where it was, however, clearly referring to an action like in the following objective "A learner is encouraged to an experimental and investigative approach, to the inventing of solutions and to the critical evaluation of solutions", the subjects of the actions were encoded in the analysis as verbs. In this particular case, actions were encoded as four verbs "to experiment", "to investigate", "to invent" and "to evaluate".

The preliminary analysis of verbs was simply done with the function "sort" in the word processing program Microsoft ${ }^{\circledR}$ Word. From the objective sentences, we first distinguished the parts beginning with the main verb, for instance "to learn 
something..." etc. After this, we sorted the parts into an alphabetical order and the frequencies of the main verbs were calculated. Furthermore, the objective sentences were analysed qualitatively and collected in the groups in accordance with their contents.

\section{RESULTS}

\section{Main and auxiliary verbs}

The main verbs found at least four times in some of the examined texts are presented in Table 1.

\begin{tabular}{lcccccccc}
\hline & \multicolumn{1}{c}{ Short94 } & \multicolumn{2}{c}{ Short03 } & \multicolumn{2}{c}{ Long94 } & \multicolumn{2}{c}{ Long03 } \\
Verb/action & $f$ & $f \%$ & $f$ & $f \%$ & $f$ & $f \%$ & $f$ & $f \%$ \\
\hline learns, can & $\mathbf{5}$ & $\mathbf{9 . 3}$ & $\mathbf{1 0}$ & $\mathbf{2 6 . 3}$ & $\mathbf{5}$ & $\mathbf{8 . 9}$ & $\mathbf{4 0}$ & $\mathbf{4 7 . 1}$ \\
is trained, practices & 4 & 7.4 & $\mathbf{6}$ & $\mathbf{1 5 . 8}$ & 4 & 7.1 & $\mathbf{1 2}$ & $\mathbf{1 4 . 1}$ \\
studies & $\mathbf{5}$ & $\mathbf{9 . 3}$ & 1 & 2.6 & 4 & 7.1 & 6 & 7.1 \\
understands & 0 & 0.0 & $\mathbf{3}$ & $\mathbf{7 . 9}$ & 0 & 0.0 & $\mathbf{1 1}$ & $\mathbf{1 2 . 9}$ \\
becomes acquainted & $\mathbf{5}$ & $\mathbf{9 . 3}$ & 2 & 5.3 & $\mathbf{7}$ & $\mathbf{1 2 . 5}$ & 0 & 0.0 \\
examines & 2 & 3.7 & 1 & 2.6 & 4 & 7.1 & 6 & 7.1 \\
gets used to & 4 & 7.4 & 1 & 2.6 & 4 & 7.1 & 1 & 1.2 \\
deepends & 0 & 0.0 & 0 & 0.0 & 1 & 1.8 & 4 & 4.7 \\
is guided to & 0 & 0.0 & 0 & 0.0 & $\mathbf{5}$ & $\mathbf{8 . 9}$ & 0 & 0.0 \\
\hline Altogether & $25 / 54$ & 46.3 & $24 / 38$ & 63.2 & $34 / 56$ & 60.7 & $80 / 85$ & 94.1 \\
\hline
\end{tabular}

Table 1. Main verbs used in the curricula Short94, Short03, Long94, Long03. The three highest frequencies from each column have been marked by bold characters.

Correspondingly, the main and auxiliary verbs which were found at least four times in some of the examined texts are presented in Table 2. 


\begin{tabular}{lcccccccc}
\hline & \multicolumn{2}{c}{ Short94 } & \multicolumn{2}{c}{ Short03 } & \multicolumn{2}{c}{ Long94 } & \multicolumn{2}{c}{ Long03 } \\
Verb/action & $f$ & $f \%$ & $f$ & $f \%$ & $f$ & $f \%$ & $f$ & $f \%$ \\
\hline learns, can & $\mathbf{7}$ & $\mathbf{5 . 3}$ & $\mathbf{1 0}$ & $\mathbf{1 4 . 7}$ & 5 & 4.1 & $\mathbf{4 0}$ & $\mathbf{2 9 . 4}$ \\
solves/determins & $\mathbf{6}$ & $\mathbf{4 . 5}$ & $\mathbf{8}$ & $\mathbf{1 1 . 7}$ & 6 & 4.9 & $\mathbf{2 1}$ & $\mathbf{1 5 . 4}$ \\
uses & $\mathbf{1 5}$ & $\mathbf{1 1 . 4}$ & $\mathbf{5}$ & $\mathbf{7 . 4}$ & $\mathbf{1 3}$ & $\mathbf{1 0 . 6}$ & 7 & 5.1 \\
examines & $\mathbf{9}$ & $\mathbf{6 . 8}$ & 3 & 4.4 & $\mathbf{1 0}$ & $\mathbf{8 . 1}$ & $\mathbf{1 4}$ & $\mathbf{1 0 . 3}$ \\
is trained, practices & 4 & 3.0 & $\mathbf{6}$ & $\mathbf{8 . 8}$ & 4 & 3.3 & $\mathbf{1 2}$ & $\mathbf{8 . 8}$ \\
understand & 3 & 2.3 & 3 & 4.4 & 3 & 2.4 & 11 & 8.1 \\
becomes acquainted & 5 & 3.8 & 2 & 2.9 & $\mathbf{7}$ & $\mathbf{5 . 7}$ & 0 & 0,0 \\
studies & 5 & 3.8 & 1 & 1.5 & 4 & 3.3 & 6 & 4.4 \\
models & 5 & 3,8 & 3 & 4.4 & 2 & 1.6 & 1 & 0.7 \\
gets used to & 4 & 3.0 & 1 & 1.5 & 4 & 3.3 & 1 & 0.7 \\
arguments/deduces/ & 2 & 1.5 & 0 & 0.0 & $\mathbf{9}$ & $\mathbf{7 . 3}$ & 4 & 2.9 \\
proves & & & & & & & & \\
evaluates & 4 & 3.0 & 2 & 2.9 & 3 & 2.4 & 0 & 0,0 \\
deepens & 0 & 0.0 & 0 & 0.0 & 1 & 0.8 & 4 & 2.9 \\
\hline Altogether & $59 / 132$ & 52.3 & $44 / 68$ & 64.7 & $71 / 123$ & 57.7 & $121 / 136$ & 89.0 \\
\hline
\end{tabular}

Table 2. All verbs used in the curricula Short94, Short03, Long94, Long03. The three highest frequencies in each column have been marked by bold characters

Because in the forming of Table 2 the data has been based on the data of the Table 1, partly the same trends are seen on both tables. It is noteworthy and somewhat strange as well that in the objectives given in the L03 curriculum it is less often referred to the justifying, reasoning and proving than in the L94 curriculum.

With this quantitative indicator, the format of objective descriptions used in 2003 seems to have become more strongly to emphasize such actions as learning, knowing and training than nine years earlier. To a certain extent, one can see a shift to a more traditional outcome-based and even a kind of the "neo-magerian" style of objective setting. Especially that was seen in the curriculum of a long syllabus of mathematics. However, at the same time, also the demand for the understanding would seem to be strengthened on the last round of renewing the curricula. The inquiry-based approach 
to study mathematics is brought up a little more emphatically in a curriculum of the long syllabus than of the short syllabus.

\section{The promotion of the social turn in mathematics education}

Surprisingly students' collaborative working or co-operation is not seen almost anywhere among the objective sentences. One explanation for this can be the fact that traditionally teachers have in Finland had a so-called didactical freedom to decide by themselves what methods they use in their teaching. So an old tradition has also been that the curriculum writers do not intervene willingly in the methodological questions of the teaching. We suppose that also in the texts examined in this study the style of the language of objective sentences was probably intentionally left didactically neutral. Though the objective sentences can be understood as such guiding both the individual and social learning processes, their formulations in the curricula like "a student learns..." or "a student familiarizes..." etc. were literally referring to the learning process of an individual.

\section{The emphasis of the mathematical proficiency}

\begin{tabular}{lcccc}
\hline & Short94 & Short03 & Long94 & Long03 \\
The type of mathematical proficiency & {$[f \%]$} & {$[f \%]$} & {$[f \%]$} & {$[f \%]$} \\
\hline $\begin{array}{l}\text { Procedural } \\
\text { Strategic }\end{array}$ & 39.4 & 41.0 & 28.3 & 50.6 \\
Contentual meta-knowledge & 31.0 & 48.7 & 54.3 & 24.7 \\
Mathematical thinking & 8.5 & 23.1 & 34.8 & 5.6 \\
$\begin{array}{l}\text { Conception of the self as a mathematical } \\
\text { learner }\end{array}$ & 14.1 & 10.3 & 17.4 & 13.5 \\
Conceptual & 8.5 & 15.4 & 2.2 & 3.4 \\
Concept forming & 9.9 & 10,3 & 8.7 & 22.5 \\
Knowing of the properties & 7.0 & 10.3 & 8.7 & 20.2 \\
$\begin{array}{l}\text { Perceiving of the connections } \\
\text { Others }\end{array}$ & 1.4 & 0.0 & 0.0 & 2.2 \\
\hline
\end{tabular}

Table 3. The relative frequencies of the actions (the verbs) referred in the texts. 
After the verb analysis, we analysed the objectives further with a more qualitative manner by classifying each objective sentence into the components of mathematical proficiency to which it according to their whole contents seemed to belong. So that the reader would get a better idea of what was done, we present an example of how the objective sentences were divided into the components of the mathematical proficiency. When the contents of the objectives of a text Long03 were analysed, a collection of 23 objectives seemed to form three subcategories Concept formation, Knowing of properties and Perceiving of connections to the same way as before in the analysis of verbs. The subcategories together formed a category closely resembling the component Conceptual understanding of the mathematical proficiency in the model presented by Kilpatrick et al. (2001). In the same way, we found that 12 objectives in the text Long03 formed a quite homogenous group which we resembled the component Adaptive reasoning in the model of Kilpatrick et al. Some examples of the objectives which formed the mentioned categories are presented below

Conceptual understanding (23)

Concept formation (18)

Examples: understands the integral function concept; deepens the function concept's understanding; understands the concepts of absolute and relative error and with their help the rules; concerning the exactness of approximation in the case of basic calculations; studies the concept of the probability

Knowing of properties (2)

Adopts an illustrative idea of the limit value, continuity and derivative of the function; knows the properties of the root functions, exponent functions and logarithm functions

Perceiving of connections (3)

Understands how analytic geometry creates connections between geometric and algebraic concepts; deepens his/her knowledge of the theoretical basics of differential calculus and integral calculus; knows the connections of the trigonometric functions $\sin ^{2} \mathrm{x}+\cos ^{2} \mathrm{x}=1$ and $\tan \mathrm{x}=\sin \mathrm{x} / \cos \mathrm{x}$

Adaptive reasoning (12)

...to estimate the validity of the arguments and the generalizability of the results; learns to see mathematical knowledge as a logical structure; learns principles of proving and practices proving. 
Table 4. Distribution of the objective sentences classified to the components of the mathematical proficiency in the model presented by Kilpatrick et al. (2001).

\begin{tabular}{lcccccccc}
\hline & \multicolumn{2}{c}{ Short94 } & \multicolumn{2}{c}{ Short03 } & \multicolumn{2}{c}{ Long94 } & \multicolumn{2}{c}{ Long03 } \\
& $f$ & $f \%$ & $f$ & $f \%$ & $f$ & $f \%$ & $f$ & $f \%$ \\
\hline Procedural fluency & 28 & 39.4 & 16 & 41.0 & 26 & $\mathbf{2 8 . 3}$ & 45 & $\mathbf{5 0 . 6}$ \\
Strategic competence & 6 & $\mathbf{8 . 5}$ & 9 & $\mathbf{2 3 . 1}$ & 32 & $\mathbf{3 4 . 8}$ & 5 & $\mathbf{5 . 6}$ \\
Conceptual understanding & 7 & 9.9 & 4 & 10.3 & 8 & $\mathbf{8 . 7}$ & 20 & $\mathbf{2 2 . 5}$ \\
Adaptive reasoning & 10 & $\mathbf{1 4 . 1}$ & 4 & $\mathbf{1 0 . 3}$ & 16 & 17.4 & 12 & 13.5 \\
Productive disposition & 6 & $\mathbf{8 . 5}$ & 6 & $\mathbf{1 5 . 4}$ & 2 & 2.2 & 3 & 3.4 \\
Others & 14 & 19.7 & 0 & 0.0 & 8 & 8.7 & 4 & 4.5 \\
& 71 & 100.0 & 39 & 100.0 & 92 & 100,0 & 89 & 100,0 \\
\hline
\end{tabular}

In the objectives of the long syllabus, the procedural fluency and the understanding about the concepts is more strongly emphasized in the objectives of the 2003 curriculum than in the 1994 curriculum. In the short syllabus, the significance of the strategic know-how seems to have increased at least relatively in the whole collection of the objectives. The student's conception of herself as a learner of the mathematics is supported distinctly than before and the so-called contentual meta-skills as among others skills to illustrate, skills to interpret the data and skill to construct definitions are emphasized. Surprisingly, in newer curricula the focus of the objectives seems to lie more strongly than before on the promotion of the strategic know-how in the short syllabus and in the securing of the procedural fluency in the long syllabus.

\section{DISCUSSION}

By examining the verbs of the curriculum texts we can get information from the conceptions of the learning and teaching mathematics which the texts less or more explicitly transmit. The method, how we have done a verb analysis here, was simple but if the texts are long it is moderately troublesome. At the following stage the purpose will be to carry out the verb analysis of the English versions of the curriculum texts with the software particularly developed for the quantitative analysis of the linguistic properties of the texts.

It seems that its own rhetoric has formed in the writing of the objective sentences of the national framework curriculum where the primary task of the objective sentences is to specify the contents to be learned and taught. The secondary decision is to choice the verbs giving the hints of the learning processes and of the recommended didactical choices. 
The stylistic matters of the language, such as the suitable variation of verbs and the avoiding of the repetition may after all become more important in the writing process than the thinking about what kind of message the text transmits of the learning paradigms, which it in a latent way expresses. From the point of view of the hidden messages it is not insignificant, whether the most frequent verbs appearing in the objective sentences are the verbs learn, are trained, be acquainted, solve, determine, studies and determine or for example the verbs examine, argue, justify and cooperate. Perhaps in the subject-specific parts of the curricula it has been too much trusted that the paradigmatic bonds of this kind have been sufficiently described in the general parts of the framework curricula and the real purpose has not been an intentional strengthening of the "drill and kill" method.

The verb analysis of the curriculum texts showed that the first examined shift "social turn in mathematics education" cannot be detected from the linguistic surface level of the subject specific curriculum texts. In this respect, the examined subject specific curriculum texts are quite traditional and do not seem to promote any notable changes in the culture of mathematics teaching and learning. Nevertheless, that is not in a line with the main message of the national framework curricula.

The answer to the question about how curriculum texts promote the possible change in the emphasis of the components of mathematical proficiency is more complex. The comparison of the framework curricula published in the years 1994 and 2003 revealed some clear changes in the emphasis of the components of mathematics proficiency. In the objectives of the long syllabus, the emphasis of the procedural fluency, strategic competence and conceptual understanding were strengthening. In the short syllabus, the significance of the strategic competence and the productive disposition seemed to increase and adaptive reasoning to decrease their significance. Nevertheless, whether it is a question of the change of the politics or if the observation caused primarily of the textual analysis method we used, leaves unsolvable in this context.

\section{REFERENCES}

Anderson, L.W., \& Krathwohl, D.R. (Eds.) 2001. A Taxonomy for Learning, Teaching and Assessing: A Revision of Bloom's Taxonomy of Educational Objectives. Complete Edition, New York: Longman.

Anon. 2003. National Core Curriculum for Upper Secondary Schools 2003. Regulation 33/011/2003. Helsinki: Finnish National Board of Education. www.oph.fi/download/47678_core_curricula_upper_secondary_education.pdf .

Bloom B.S. 1956. Taxonomy of Educational Objectives, Handbook I: The Cognitive Domain. New York: David McKay Co Inc.

Kilpatrick, J., Swafford, J. \& Findell, B. (Eds.) 2001. Adding It Up: Helping Children Learn Mathematics. Washington, DC: National Academy Press. 
Krathwohl, D.R. 2002. A Revision of Bloom's Taxonomy: An Overview. Theory Into Practice, 41(4), 212-218.

Lerman, S. (2000). The social turn in mathematics education research. In J. Boaler (Ed.), Multiple perspectives on mathematics teaching and learning (pp. 19-44). Westport: Ablex Publishing.

Mager, R.F. 1962. Preparing Instructional Objectives. Palo Alto., CA: Fearson Publ.

Moon, J. 2002. The Module and Programme Development Handbook. London: Kogan Page Limited.

National Research Council. 1989. Everybody counts: A report to the nation on the future of mathematics education. Washington, DC: National Academy Press.

Silfverberg, H. 2010. Opetussuunnitelmatekstien verbianalyysi - lukion matematiikan oppimäärät opetussuunnitelman perusteissa 1994 ja 2004 [in Finnish]. In E. Ropo, H. Silfverberg \& T. Soini (Eds.) Toisensa kohtaavat ainedidaktiikat (pp. 369-382). Department of Teacher Education, Tampere University, Report A31.

Singer, F.M., \& Moscovici, H. 2008. Teaching and learning cycles in a constructivist approach to instruction. Teaching and Teacher Education 24(6), 1613-1634. 
Pedagogical solutions 


\title{
STUDENTS' STRATEGIES FOR MODELLING A FERRIS WHEEL
}

\author{
Mette Andresen \\ Department of Mathematics, University of Bergen, Norway
}

This study of students' strategies for modelling was based on an episode where two upper secondary students in an inquiry based setting model the movement of a Ferris wheel with the use of GeoGebra. The aim of the study was to identify students' strategies for creative inquiry and to learn about their beliefs.

Keywords: GeoGebra, Ferris wheel, creative mathematical reasoning, mathematical inquiry

\section{OBJECTIVES AND PURPOSE}

This paper was based on an episode taking place in a mathematics classroom where two students made a joint effort to model the movement of a Ferris wheel. The aim of the paper's study was to see what strategies students may unfold for modelling in a setting designed for problem-solving. The episode was chosen as an example of students' modelling activity, picked out from data from a larger, running research and development project (2013-2015). The larger project focused on students' strategies for inquiry and problem solving and was carried out by a group consisting of eight mathematics teachers from five upper secondary schools in Bergen and one university researcher (Mette Andresen) in mathematics education. The teachers shared a wish to find ways to support and stimulate students' creativity and students' ability to think mathematically in an intellectually independent way. They wanted the students to be able to do mathematics on their own, meaning to model, solve problems, and to inquire and argue. As a researcher I wanted to conceptualize and deepen the term 'inquiry teaching and learning' in accordance with research trends in the whole Europe, where 'inquiry' and 'creativity' are supported and implemented in a variety of understandings and conceptualizations (Andresen, 2013). In particular, I was keen on getting insight into students' inquiry strategies, to propose answers to questions like: What does it mean to inquire, what signs of inquiry and creativity can be seen and what are the outcomes?

This paper interprets two students' activity in terms of modelling for concept formation and seeks to identify their strategy. The aim of the paper's study was to see how these two students managed to reach a solution to the modelling task, in an experimental setting with more open tasks and less strict guidance than they were used to in the classroom. Insight into students' problem solving strategies, in general, should enable our group to direct teaching designs in problem solving towards the realisation of the students' learning potentials. The two students in the actual episode were chosen because they, in advance, seemed to have good potentials for solving the task within the limited time assigned for this particular observation. 


\section{THEORETICAL FRAMEWORK}

The theoretical framework of this study was inherited from the larger project.

\section{Inquiry based activity in the classroom}

The overall theoretical framework was a sociocultural understanding of teaching and learning. It takes as its basis the interpretative framework for analysing individual and collective activity in classrooms developed by Paul Cobb et al. and described in (Cobb, 1999). This framework coordinates both individual (psychological) and collective (sociological) perspectives. According to (Yackel \& Rasmussen, 2002)), p 316 the framework offers an interpretation of 'inquiry based' activities in the classroom; 'inquiry' is indicated by the social norms that students are expected to develop personally meaningful solutions. They are expected to explain and justify their thinking, to listen to and attempt to make sense of the thinking of others, and to raise questions and challenges when they disagree or do not understand. These norms are, according to (Yackel \& Rasmussen, 2002), indicative of the students' beliefs. In this interpretation, any change towards 'inquiry' in the mathematics classroom must imply development of new or adjusted social and socio-mathematical norms, and it must also imply some development of the students' beliefs about what constitutes mathematical activity, about their own role and about the teacher's role.

\section{Modeling}

In general, analysis of students' modeling activities can take place at either of the following two levels depending on the research goals:

1) Modelling at functional level, which means expressive modelling, aiming at problem solving and involving certain applications of mathematical concepts, methods etc. This interpretation of mathematical modelling is in accordance with (Blum, 1991). Modelling at functional level requests modelling competence in the meaning described by (Niss, 2002)

2) Modelling at the level of concept formation following the ideas described in (Gravemeijer, Cobb, Bowers, \& Whitenack, 2000): the main design heuristics are the horizontal and vertical mathematizing. In this interpretation, 'horizontal mathematizing' happens by moving from situational to referential level with creation of 'emergent models'. Symbolizing is a main issue for these moves. The modelling for concept formation continues during 'vertical mathematising', moving from referential to general level.

In this study the modeling activity was interpreted mainly in accordance with 2) whereas 1) was included in the paper's final discussion of mathematical modelling as a means for supporting students' creative inquiry.

\section{The teaching of mathematical problem solving}


A central theoretical contribution of Alan Schoenfeld's problem-solving research was his framework for analysis of mathematical problem-solving behavior. Based on discussions in our group of (Schoenfeld, 2011), the teaching experiments were divided into two separate parts. In every classroom experiment, the first session contained an introduction to an inquiry, problem solving working style. The other part was the main problem solving session. The teaching of mathematical problemsolving was planned to include explicit use of Polya's scheme (Polya, 1985). The teachers did not in advance see this as a major change in their classrooms because they felt that problem-solving strategies would also be taught normally, although implicitly. But they had the general impression that their students were in need for elementary problem solving tools like for example strategies based on Polya's scheme. The teachers wanted to enable the students to make progress on their own hand rather than call for help as soon as they felt lost. In particular, some of the teachers also wanted to get rid of the students' very close use of the textbook's list of answers to the tasks. The experiment aimed to widen the students' picture of mathematics in the direction of a subject open for ideas and including discussions based on mathematical knowledge and imaginations. The teachers wanted to change the students' beliefs about mathematics and about their own roles, and the project intended to contribute to a change of the classroom's norms and practices.

The teachers felt comfortable with the preparation of materials for both parts of the teaching experiment, supported by discussions in the group and in smaller meetings.

\section{Students' inquiry strategies}

According to (Lithner, 2008) p 257, solving a task can be seen as carrying out four steps: 1) A (sub) task is met, which is denoted problematic situation if it is not obvious how to proceed. 2) A strategy choice is made. It can be supported by predictive argumentation: Why will the strategy solve the task? 3) The strategy is implemented, which can be supported by verificative argumentation: Why did the strategy solve the task? 4) A conclusion is obtained. Further, Lithner discerns between different types of reasoning involving strategy choice and strategy implementation. The two main types of reasoning are IR (Imitative Reasoning) and CMR (Creative Mathematically founded Reasoning). IR encompasses i) memorised reasoning where the strategy choice is founded on recalling a complete answer and the strategy implementation consists only of writing it down, and ii) three subtypes of algorithmic reasoning where the strategy choice is to recall a solution algorithm without creating a new solution; hereafter the remaining parts of the strategy implementation are trivial. In contrast, CMR fulfils all of the following criteria (Lithner, 2008) p 266:

1. Novelty. A new (to the reasoned) reasoning sequence is created, or a forgotten one is re-created.

2. Plausability. There are arguments supporting the strategy choice and/or strategy implementation motivating why the conclusions are true or plausible 
3. Mathematical foundation. The arguments are anchored in intrinsic mathematical properties of the components involved in the reasoning.

Lithner's studies were carried out at undergraduate level. Our group decided to take students' CMR as a goal for the teaching experiment meaning that we added CMR in connection with problem solving as an indicative of 'inquiry'.

\section{THE STUDY OF AN EPISODE}

This study was carried out as analysis of an episode cut out of data from the larger research and development project. The episode was chosen as an example of students' modeling for problem solving. This paper only brings a summary of the episode, with excerpts from the transcripts etc. First, the students' activity was interpreted in terms of modeling for concept formation. Then it was analyzed with the aim to identify students' strategies for modeling the movement of the Ferris wheel, which was the task they had to solve. Finally, mathematical modelling was evaluated as a scene for students' creative inquiry.

\section{DATA}

\section{The episode}

The task (in the episode) was to make a graph and create a function which models the distance above the ground as a function of time, task e) - f), based on data about the wheel (Figure 1) and on the results from tasks a) to d).

\begin{tabular}{ll}
$\begin{array}{ll}\text { Facts about the Ferris wheel } \\
\text { Height limits: }\end{array}$ & $\begin{array}{l}\text { Accompanied: } 0-129 \mathrm{~cm} \\
\text { Alone over } 130 \mathrm{~cm}\end{array}$ \\
\hline Tickets: & 1 \\
\hline Type of item: & Rotating vertically \\
\hline Made by: & Anton Schwarzkopf, Germany \\
\hline Year: & 1967 \\
\hline Name: & Reisenrad \\
\hline Number of passengers: & 120 persons, 20 gondolas with 6 persons each \\
\hline Main rotation: & 2,4 rounds per minute \\
\hline Main dimensions: & Height: 25 meters \\
\hline
\end{tabular}

\section{Figure 1: The Ferris wheel data}

\section{The tasks}

Imagine that you insert a coordinate system on the Ferris wheel with origo in the centre of the wheel and positive $x$-axis horizontally (and positive $y$-axis upwards). You enter the gondola when it is on the bottom, meaning at $-90^{\circ}$

a) You enter gondola number 8 . After you come 12 gondolas which must be filled. What is the angel between you and the positive $\mathrm{x}$-axis when they load gondola number 20? How high above the ground are you? 
The Ferris wheel starts to move with 2,4 rounds per minute. It stops after 3 minutes.

b) How high are you after 1 minute?

c) When will you be 20 meters above the ground?

d) Outline (by hand) a graph which describes you distance to the ground as a function of time

e) Use ICT and trace for making a graph showing distance to the ground as a function of time.

f) Can you create a function which models the distance above the ground as a function of time? (...)

\section{The episode}

The episode consisted of two boys, B1 and B2, working on task e) and f). It started under the group work following the presentation of results from previous lessons including answers to tasks a) to d). Prior to the previous lesson's group work, the teacher had introduced Polya's problem solving scheme to the students and encouraged them to make use of its principles. In this way, and with his open questions, inquiry reflections and comments during the presentation of results and answers, the teacher intended to set the scene for students' inquiry based activities under the subsequent group work.

When the episode started, the boys had sketched the curve with paper and pencil. The teacher $\mathrm{T}$ encouraged the boys to open GeoGebra; they agreed and graphed cosine. The graph was fitting the extreme points horizontally but not vertically.

195 T: $\quad$ Little too fast...

196 B1: $\quad$ (Repeats) Little too fast (stretches the graph horisontally)

198 B1: Okay what is happening here? (points to the graph in his paper) we used this (points to the midpoint of the curve on the paper) but what time is it here?

B1 referred to the answers to task a) - d). The boys continued, focusing on time as the parameter.

231 B2: It is like if you start in the bottom .. if you start on the top, I mean, like I did here, if you start on the top, time is zero, and then it will be 90 times this, okay? Because, then you start on the top (moves his hands like turning around) and 90 times as much then you reach zero. (refers to his paper $)(. .$.

248 B1: (referring to the graph on the screen) too fast! We try again.

249 B1: $\quad$ what if we substitute one... $\mathrm{x}$ (writes)... divided by..

251 B1: Oi! (see Figure 2, picture P1020784)Maybe, maybe... (...) 


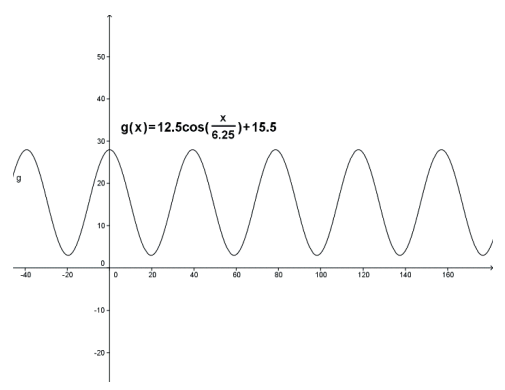

Figure 2: (P1020784, reconstruction)

326 B1: (stretches the graph vertically) what do we have to find?

328 B2: (points to the screen) we probably have to find the distance between these two (points to the distance between two top points on the curve)

332 B2: we can start with writing the distance between two wave tops

334 B1: yes, then we need... (draws the line $y=28$ and uses intersection between curves and the line, marks two top points A $(0,28)$ and B(39.48,28), (see Figure 3 Picture P1020789)

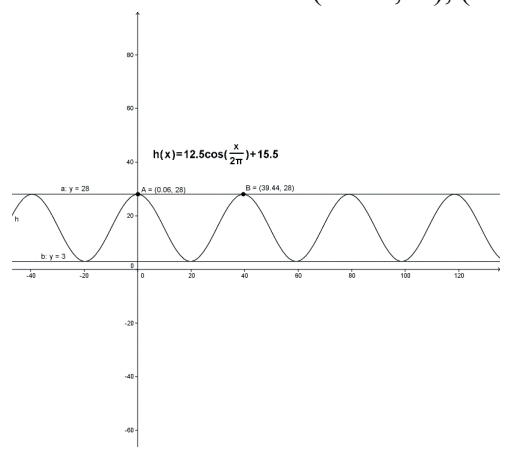

Figure 3: (P1020789, reconstruction)

340

341

342

B2 must it take 25

B1 it should take 25

B2 yes because that is the full rotation from the top (points to the top, bottom and next top of the curve on the screen) (...)

The two boys spent the next 20 minutes on attempts to fit the curve horizontally. Suddenly:

506 B2:

(counts) one, two three four, four

507 B1:

we had like 19 , like..

508 B2:

it is 4 times as fast as the other..

509 B1:

4 times as fast?

510 B2: yes, because there is one, no, there is one, two, three, four (points to the screen and counts) (they count together) 
513 B1: $\quad$ what do we multiply with 4 - here, maybe

514 B2: $\quad$ yes, try (see Figure 4 Photo P1020795)

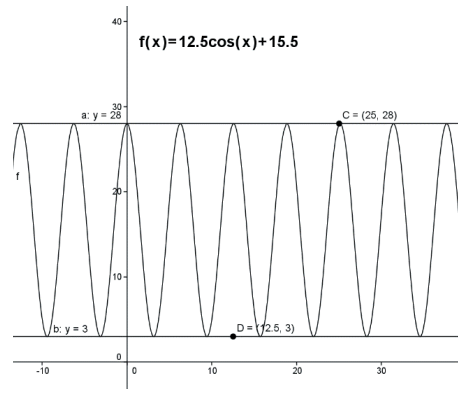

Figure 4: (P1020795, reconstruction)

515 B1: maybe

516 B2: $\quad$ good to find it exactly

517 B1: yes good (both) Hahahaha! Yes! Yahoo! (see Figure 5 Photo P1020796) (end of episode)

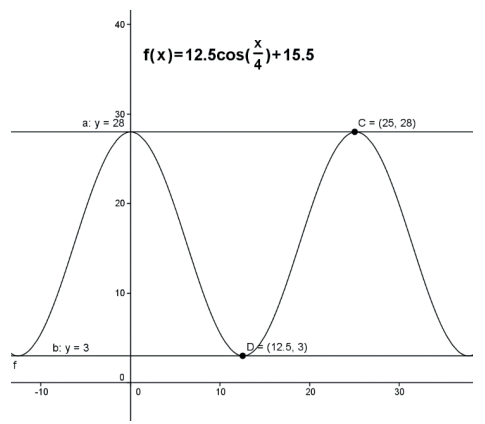

Figure 5: (P1020796, reconstruction)

\section{RESULTS}

\section{Students' modelling activity}

Before the experimental lessons on the Ferris wheel, the two boys knew about sine and cosine but they knew nothing about the harmonic oscillator or its expression $\mathrm{f}(\mathrm{x})$ $=\mathrm{r} \sin (\mathrm{cx})+\mathrm{h}$. From a concept-formation point of view, the goal was to reach and understand an expression of harmonic oscillator. When the episode started, the students had decided to use cosine and determined the extremes 12.5 and -12.5 of the curve. They intended to determine the time when the curve intersects the axis but did not succeed. By the use of GeoGebra they fixed the graph starting with $(0,28)$, and extremes $\mathrm{y}=3$ and $\mathrm{y}=28$. 
During the episode they aimed to introduce time as the variable $\mathrm{x}$, and connect time with periodicity. The teacher gave a hint for connection between the graph and the speed by saying 'Little too fast'(L195) but the students did not react immediately (L196 - 198). B2 tried to somehow intuitively express the relation between number of rotations and angular velocity (L 231ff), referring to his paper where the graph was symmetric around the $\mathrm{x}$-axis. He might suggest (in my interpretation) that the period of time from the wheel started (called zero) until the wheel had turned 90 degrees would be equal to the $\mathrm{x}$-value of graph's intersection point with the $\mathrm{x}$-axis (denoted zero too!). In that case, that $x$-value could be determined by multiplying the angular velocity by 90 , according to B2, in my interpretation. Neither of the boys, though, followed this idea. Instead, they went back to GeoGebra and graphed 12,5 $\cos (\mathrm{x} / 6,25)+15,5$. (L248-249, Figure 2, P1020784). They could not explain why they choose 6,25. Apparently, this was a guess supported by the calculation of the half height of the wheel $(12,5 / 2)$ and one fourth of the period (25/4), successively. A little later they changed the value into $2 \pi$ (not in this except).

After a while they seemed to start over again, maybe inspired by Polya's scheme (L326-338, Figure 3, P1020789). They decided to take the distance between top points as their starting point and used GeoGebra to measure this distance by the construction of $\mathrm{B}$, the intersection point between the curve and the line $\mathrm{y}=28$. They were aware that the distance might fit with the period but they did not manage to fit the graph by moving B. Suddenly, more than twenty minutes later, B2 counted the curve's tops, and grasped a new connection between curve and speed (L $506-517$, Figures 4 and 5, P1020795 and P1020796). Neither the students' dialogue nor their experiments with the curve on the screen reveals any signs of emergent understanding or inspiration for this idea prior to B2's sudden statement.

At the end of the episode, B1 and B2 had reached the expression $\mathrm{f}(\mathrm{x})=12,5 \cos (\mathrm{x} / 4)$ $+15,5$ of harmonic oscillator. They seemed to understand the meaning of 12,5 and 15,5 in relation to the curve, as well as the physical meaning of these constants (obvious from their dialogue not quoted in the excerpts here). The two students were convinced that they had found a constant $1 / 4$ which made the curve fit with its fixed values. It was obvious from the preceding trials (see the four reconstructions) that they had grasped the connection between values of the coefficient to $\mathrm{x}$ and stretching the curve horizontally. Their struggle with fitting the curve revealed that they did not understand the physical meaning of this coefficient, or its relation with, for example, the rotational speed.

\section{Students' strategies in the episode}

The main question for the students in the episode was how to apply the main rotation, 2,4 rounds per minute, to the model of the harmonic oscillator.

They chose a strategy which, according to common experience, is often seen amongst experienced GeoGebra users: They switched between the graphical interpretation and the algebraic expression, supported by formulas or examples from the textbook. 
During the episode B1 and B2 took only little notice of the textbook, though. By using this strategy the two students automatically merged the tasks e) and f).

Even if their work resampled guessing and trying, they did not make a systematically try out. None of them suggested, for example, introducing a slider for the expression's constants. The value of the coefficient of $\mathrm{x}$ was not determined by deduction, only by 'luck' under the visual inspection of the graph which counted as a sufficient argument. Neither did they give arguments for the value $1 / 4$ after it was determined. The two boys did not follow the instructions from Polya's scheme strictly. For example, they never mentioned making a plan. Neither did they discuss the meaning of their results or give arguments. But when they got stuck during their work they several times asked questions like: What are we supposed to find? (L 326). So, they might still be inspired by the lesson on Polya.

\section{Mathematical modelling evaluated as a scene for students' creative inquiry.}

The task and the setup intended to invite for inquiry. Modelling the Feris wheel at a functional level gave good opportunities for concept formation thanks to the imaginative character of the wheel and because the two boys had appropriate tools in the form of GeoGebra and, maybe, of knowledge about Polya's scheme. Mathematically, they were well prepared for the task by knowing about trigonometry whereas their complete lack of knowledge about harmonic oscillator gave room for novelty in their reasoning, which was one criteria for CMR. The plausibility rested on the sociomathematical norm that visual inspection might play a major role as argument for a solution or strategy choice. This also pointed to the close connection between norms and the individual student's beliefs about mathematics and mathematical relations, and to the strong influence of GeoGebra as the student's tool. The mathematical foundation was based on the tight connection between curve and algebraic expression. During the episode none of the boys, for example, gave arguments based on knowledge about transformations or change of variables for functions which would have counted for relevant, intrinsic mathematical properties. It was revealed during their initial work (not in the excerpt) that they were aware of the similarity between sine and cosine which would both be useful. It was apparent that they were capable of interpreting the task's data but they did not know about or apply basic physics, i.e. mechanics.

All in all, the episode demonstrated a case of creative inquiry in our study's meaning of the term.

\section{CONCLUSIONS AND PERSPECTIVES}

This study aimed to bring new knowledge about students' strategies when they worked in an inquiry based learning environment, and about their learning outcome and beliefs. It appears manifest from the results that one important factor of influence is the tools. The students' strategy choices are determined by the tools they have at 
their disposal. This means that if we want students to inquire and create they must have the opportunity to build appropriate tools, for example like in this study in the form of GeoGebra and Polya's scheme. The fact that students will not be able to be inquiry and creative just because they are told not to do things in the usual way points to new research in strategies and to development of 'toolboxes' useful for inquiry.

\section{REFERENCES}

Andresen, Mette (2013). European Aims to Stimulate Inquiry in School Mathematics. In: Grevholm, Hundeland, Juter, Kislenko \& Persson (Eds.), Nordic research in didactics of mathematics: Past, present and future. (pp. 41 -60). Cappelen Damm Akademisk 2013.

Blum, W. (1991). Applications and modelling in mathematics teaching - a review of arguments and instructional aspects. In Niss, Blum \& Huntley (Eds.), Teaching of mathematical modelling and applications. (pp. 10-29). Chichester: Ellis Horwood

Cobb, P. (1999). Conducting teaching experiments in collaboration with teachers. In A. E. Kelly and R. Lesh (Eds.), Handbook of research design in mathematics and science education, (pp. 307- 333). Mahwah, NJ: Lawrence Erlbaum.

Gravemeijer, K., Cobb, P., Bowers, J. \& Whitenack, J. (2000). Symbolising, Modeling and instructional design. In Cobb, P., Yackel, E. \& McClain, K. (Eds.), Symbolising and communicating in mathematics classrooms. Perspectives on discourse, tools, and instructional design. (pp. 225-274). Mahwah, New Jersey: Lawrence Erlbaum Associates Publishers.

Lithner, J. (2008). A research framework for creative and imitative reasoning. In Educational Studies of mathematics (2008) 67:255-276. Springer.

Niss, M. (2002). Mathematical competencies and the learning of mathematics: The Danish KOM project. IMFUFA Roskilde University

Polya, G. (1985). How to solve it. New aspects of mathematical method. Princeton University Press.

Schoenfeld, Alan H. (2011). How we think. A Theory of Goal-Oriented Decision Making and its Educational Applications. Routledge

Yackel, E., \& Rasmussen, C. (2002). Beliefs and norms in the mathematics classroom. In G.C. Leder, , E. Pehkonen, \& G. Törner (Eds.) . Beliefs: A hidden variable in mathematics education? (pp. 313 - 330). Dordrecht, the Netherlands: Kluwer Academic Publishers. 


\title{
PRESERVING STUDENTS' INDEPENDENCE BY ENCOURAGING STUDENTS' SELF-EVALUATION
}

\author{
Jonas B. Ärlebäck \\ Helen M. Doerr \\ Linköping University, Sweden \\ Syracuse University, USA
}

Over the past twenty years, reform efforts in mathematics teaching have emphasized the importance of listening to and developing student ideas in order to achieve the conceptual understanding needed for problem solving and mathematical reasoning. As teachers have worked to enact practices that build on student ideas, they have encountered many tensions and dilemmas. In this paper, we put forward the notion that supporting and preserving student independence should be a central principle in guiding teaching practices, potentially providing new ways to address the tensions and dilemmas of in the moment decision making and actions. We provide empirical evidence of teaching practices that encourage students' self-evaluation of modelling activities in ways that preserve their independence as learners and problem solvers.

\section{INTRODUCTION}

If we want students to be productive independent individuals and problem solvers with the abilities to apply mathematical thinking in the various situations they encounter in their professional and personal lives, they need to have a range of possibilities for acting mathematically readily at hand when faced with a problem. Mason and Davis (2013) argue that this readiness is not fostered by teaching and pedagogies that keep students dependent on their teachers rather than supporting students to act in ways that can become part of their own repertoire of mathematical ways of thinking and acting. Students' mathematics learning needs to develop productive dispositions, flexible strategies, and foster persistence and independent thinking (National Research Council, 2001). The characteristics of mathematical modelling problems, with the competencies needed for success, would appear to be a particularly rich site for developing these attitudes while learning and using mathematics in realistic problem situations. However, this poses many challenges for the teacher, especially about how to tackle classroom discussions, to structure group interactions, and to provide effective feedback to students (Brodie, 2010; 2011; Magiera \& Zawojewski, 2011). In this paper, we provide empirical evidence of teaching practices that encourage students' self-evaluation of their modelling activities in ways that preserve their independence as learners and problem solvers.

\section{BACKGROUND}

Adequately describing and theorizing about what teachers actually do in and around their classrooms is a complex task - one in which research has been slow and sometimes elusive in providing a holistic and comprehensive picture of teaching practices (Even \& Ball, 2009). One important strand of research has emphasized and seriously acknowledged the important role of giving voice to and using students' own work and ideas in the teaching and learning of mathematics. Recently, Stein and 
colleagues (2008) proposed a model of five practices (anticipating, monitoring, selecting, sequencing, and making connections between student responses) that can be taken up by novice K-12 teachers, as they learn to orchestrate productive mathematical discussions by simultaneously building on students' ideas and important mathematics. Stein et al. argue that this model gives guidance to teachers so that "the teacher remains in control of which students will present their strategies, and therefore what the mathematical content of the discussion will likely be" (p. 328). However, by centering the control of the mathematical discussion with the teacher, these novice teaching strategies may not help students become more independent learners and, as such, offer little guidance for experienced teachers in managing more complex learning situations. Such situations occur when the teacher has to respond to unanticipated student ideas and manage the emergence of student interactions that cannot be fully anticipated ahead of time. Mason and Davis (2013) refer to these situations as requiring teachers to make "in the moment" pedagogical decisions, something that presents a dilemma and tension for experienced teachers.

A common response to this dilemma is for the teacher to engage in telling or explaining to the students the intended content. Lobato, Clark and Ellis (2005) suggest a reconceptualization of the telling or not-telling dilemma by distinguishing between the teacher action of telling as initiating and the action of eliciting. According to Lobato et al., telling as initiating refers to teacher actions "that serve the function of stimulating students' mathematical constructions via the introduction of new mathematical ideas into a classroom conversation" (p. 110). The teacher's intention is to promote student sense making by introducing "ideas, images, connections and underlying meaning for mathematical symbols, rather than procedures." (p. 110). This teacher initiating is often followed by eliciting students' ideas. Brodie $(2010 ; 2011)$ elaborates the dilemmas faced by experienced teachers when, having elicited students' ideas, they must make in the moment decisions about when and how long to press individual student for making meaning and giving justifications. Shifting their practices to make learners' thinking more central, teachers are faced with pedagogical dilemmas and in the moment decision making about how to move students' mathematical learning forward. In this paper, we want to put forward the notion that student independence should be one of the most central principles in teaching, guiding both planning and in the moment pedagogical decisions and actions. The focus of this paper is on elaborating this latter aspect.

\section{THEORETICAL FRAMEWORK}

Our research is situation in the models and modelling perspective on teaching and learning mathematics (Lesh \& Doerr, 2003). Within this framework the notion of model development is central. Models are externally represented conceptual systems that consist of objects, operations, relations, and interaction-governing rules used to predict, explain, describe, or understand some other system. By engaging in learning activities, students' models are repeatedly developed, modified, extended and revised 
through "multiple cycles of interpretations, descriptions, conjectures, explanations and justifications that are iteratively refined an reconstructed by the learner" (Doerr \& English, 2003, p. 112). From this perspective, learning is equated with model development. The ability to develop, apply, and adapt a generalized model to be used in new situations or contexts is the essence of what it means for students to be independent learners and problem solvers.

\section{METHODOLOGY AND SETTING}

The following two episodes come from a six week summer mathematics course for beginning engineering students, designed around a model development sequence centred on the concept of average rate of change (Ärlebäck, Doerr, \& O'Neil, 2013). Model development sequences are sequences of structurally related activities that are intended to engage students in multiple opportunities to describe, interpret, make conjectures, explain, develop and iteratively refine their models while interacting with other students (Lesh, Cramer, Doerr, Post, \& Zawojewski, 2003). A model development sequence begins with a model eliciting activity where students' ideas about a problem situation are elicited and made explicit in forms that can be tested, revised and refined. Following the model eliciting activity are one or more model exploration activities and model application activities. In the model exploration activities, the underlying mathematical structure and representations (such as tables, interactive graphics, diagrams, or animations) of the elicited model is further investigated and developed. In the model application activities, the students apply and adapt their previously elicited and explored models in new contexts and situations.

The model development sequence in this study consisted of a model eliciting activity using the context of bodily motion along a straight path; a model exploration activity using a computer simulated walking-world (cf., Kaput \& Roschelle, 1996); and, two model application activities. In the first model application activity the students developed a model for how light intensity varies with the distance from a light source, and in the second model application activity, the students modelled how the voltage changes over a fully charged discharging capacitor in a simple circuit (cf., Ärlebäck et al. (2013)). In this paper, we report on our analysis of the video recordings of the lessons focusing on two particular teacher moves or actions identified in the data.

\section{Independence preserving moves}

An independence preserving move, is a teacher move whose intention and consequence is that it preserves students' independent on-going work. A teacher move that provides students with a tool or strategy to facilitate the students' independence in a future activity/situation would be considered independence preserving. Encouraging student persistence ("keep thinking", "keep talking”, "keep working") and collaborative work ("talk to your partner") is considered to be independence preserving. As well as being independence preserving, a teacher move can be neutral or non-independence preserving. A non-independence preserving 
move typically implicitly suggests that meeting external expectations ("label your columns") is valued rather than independent thinking and work.

\section{Encouraging self-evaluation moves}

Teacher moves that either implicitly or explicitly encourage students to be evaluators of the correctness, appropriateness, usefulness or goodness of their work are called encouraging self-evaluation moves. Examples of encouraging self-evaluation are moves that support students in having confidence in their solutions, in validating solutions with a partner, in giving reasons or justification about why their solution has to be correct. Encouraging self-evaluation also occurs when the teacher simply responds to the student "think more" about a particular result, representation, relationship, object or idea. We take encouraging self-evaluation to be a particular category within the more general category of independence preserving moves.

\section{RESULTS}

We give two examples of where independence preserving moves occurred within a model development sequence focused on the concept of the average rate of change. In both of these examples, the teacher encourages students' self-evaluation within a larger goal of supporting and preserving student independence. In the first example, the teacher preserves student independence by engaging them in collecting data that they can use to resolve a question that was left unresolved in a class discussion. In the second example, the teacher supports student independence by engaging them in developing a tool that they can use to distinguish between exponential and linear function, when given a data set.

\section{Example 1:}

The first example is from a model application activity, where students investigate how the rate at which light intensity changes varies with the distance to a light source. At the beginning of the activity, the students are asked the following question (using "clickers" or a student response system). This question was given as part of their homework prior to this particular lesson to elicit their thinking about changing light intensity:

Imagine the tail light of a car moving at a constant speed away from you. Is the light intensity: 1 . fading at a constant rate

2. fading slowly at first then quickly

3. fading quickly at first and then slowly

4. unsure

The results from the students were 1) $60 \%$; 2) $27 \%$; 3) $7 \%$; 4) $7 \%$. The teacher commented: “ $\ldots$ lots and lots to talk about [...] why did you choose the answer you chose?" She arranged the students in groups and asked them to discuss their answers. After a few minutes, while the teacher was walking around in the classroom listening to students' reasoning, the teacher pulled the class together for discussion. Each of these teacher moves -- eliciting their ideas with the clicker question, asking them to engage in peer discussion, and listening to their reasoning -- served to encourage the students to self-evaluate their response to the question on changing light intensity. The ensuing 
whole class discussion began as the teacher asked S1, a member of one group, to start the discussion:

Tutor: Okay, let's get started. S1, can you start us off? What where you guys talking about from your observations and past experiences?

S1: $\quad$ My other group members, they voted for number two, but I voted for number one because I explained that the car is going away at constant speed, so I thought like the light would go away at a constant speed too. But then I don't know if that's the same thing. It would be like how you see the light and the intensity of the light, if they drop in the same way.

The teacher re-stated S1's comment and invited students to consider S1's argument or offer their own:

Teacher: Okay. So, the question is, even though the car is going away constantly, it's the way you see the light - if that behaves the same way [as the car]? Okay. Other arguments, because there are a lot of people [pointing to the display of the question results] who said it was fading at a constant rate. Are you guys thinking similarly to S1 or why did you think it was at a constant rate? [several students mumble] S2, what did you say?

S2: $\quad$ The car is moving away at a constant speed so I think the intensity decreases at a constant speed.

Teacher: $\quad$ S3

S3: The light travels at a different speed...

S4: $\quad$...than the car...

S3: $\quad$...than the car...

S4: So, it would actually be different.

S5: Isn't the speed of light constant?

S6: If the speed of light is constant, why...

S4: $\quad$...why is the car moving? - because it creates a variable!

All: $\quad$ [Laughter and many students talking at the same time]

S7: $\quad$ But yeah [inaudible] the speed of light and speed of...

S3: $\quad$...S7, what do you think the answer is?

The students were actively engaged in arguing whether or not the light was fading at a constant rate. Many of those who thought the rate was constant were arguing that it had to be constant because the speed of light was constant. However, the intensity of light with respect to distance is not related to the speed of light with respect to time, as S1 had suggested in her initial argument. What is striking about the conversation above is that the teacher is not mediating, restating, or directing the discussion. She is listening, off to the side. The argument takes a turn in a new direction as S3 asked S7 what she thought:

S7: $\quad$ Me?

S3: Yeah!

S7: $\quad$ I put two, but I'm not sure that, but I don't know what the ratio is between light intensity and [S7 starts gesturing]...

S2: I mean for instance, if the speed of light's constant, and the cars' constant...

S7: $\quad$...Yes, but the speed of light is the travelling speed of light. We're talking light intensity which is what you see 


\section{S2: $\quad$ Right...}

In this segment, S7 has made the critical distinction (which was foreshadowed in S1's initial argument) between the speed of light and the intensity of the light. S2 seemed to acknowledge this, with his comment "right." But it is not entirely clear what he meant by this. But the next response to S7 is from S3, who had asked S7 for her answer in the first place. The teacher brief interjected a re-statement of S3's claim to have an example, which was then immediately followed by S4's example. From the teacher's perspective, it is not possible to fully anticipate what these examples might be, what they would mean, and how they would relate to the central question about the rate of change of intensity of light.

S3: Oh, I have the perfect example for this!

Teacher: You have a perfect example for this?

S3: $\quad$ Yes, so in $7^{\text {th }}$ grade we were studying the change of motion and stuff and whatever. And so, we found out, like if you're in, okay, I'm from New York City, we're doing that, like, if you're walking in a train, like running inside of a train, at, you know let's say your running like, 20 feet per second or whatever, whatever, that's unrealistic, but just say you're doing that, right. And the train is going at, like 100 feet per second, then the total would be 120 feet per second. That's how fast it would seem you're running, because the train is like moving, and then you're moving...

S4: $\quad$...I think I have a better example, of how you know that light is not travelling at a constant rate. Why do they put the inty-twinty-tiny lights on the top of buildings that planes aren't gonna be able to see from 50 yards away? [inaudible] explain that to me - why are runway lights so small, you see the guy [starts gesturing as if he was taxiing a plane to its gate]

ALL: [many students talking at the same time]

The discussion was ended by the teacher, but not by resolving the issue or drawing a conclusion. Instead, the teacher continued to engage the students in self-evaluating their emerging models of light intensity by collecting real data enabling them to resolve the problem based on empirical evidence.

The elicited results from the clicker question showed that $60 \%$ of the students thought that the relationship between light intensity and distance from the car was linear; only $7 \%$ of the students had answered with the correct relationship. To resolve this, the teacher encouraged the students to self-evaluate their models, and as the episode unfolds the students unpack their models by themselves, first in small group discussion and then in what can be characterized as a student-lead and student-driven whole class discussion. S1 raised the core question about the relationship between the constant speed of the car and the rate of change of the light intensity. The discussion then revolved around the speed of light and its constancy, prompting many students to express their ideas on this matter. However, S7 tried to focus the discussion back on S1's core question. S3 and S4 both draw on personal experience in trying to understand the situation. S3 remained focused on the role of the constancy of the speed of light, whereas S4 in argued about the rate of change of the light intensity. The teacher functioned as an observer throughout the discussion. The teacher broke off the discussion and initiated the next activity where students were to collect real data to resolve the issue. This latter activity was a key move in encouraging student 
self-evaluation of their emerging model for how the light intensity varies with the distance from the light source and in preserving student independence.

\section{Example 2:}

This second example comes from a model exploration activity that occurred midway in the model development sequence. The students had already explored the constant average rate of change as a structural characteristic of linear functions and the linked relationship between the position and velocity graphs for constant motion along a straight path (cf., Ärlebäck et al., 2013). An upcoming model application activity within the model development sequence would engage the students in applying and extending their model of constant average rate of changes to changing sequences of average rates of change over unit subintervals for exponential functions. The teacher's primary goal in this model exploration activity was for the students to explore and compare the underlying structure of linear and exponential functions in order to develop a "tool" that they could use to distinguish between linear and exponential functions given in a table format. A secondary goal for the teacher was to engage the students in making sense of the table representation and its relationship to the symbolic forms of the function, while drawing on their language for expressing these meanings. Our analysis of this example, which lasted about 33 minutes, revealed segments that were teacher-directed and where the students were engaged in routine work (e.g. computing entries in a table of values). In other segments, the teacher actively encourages the students to make meaning of the patterns that can be seen in the table. We divided the example into four segments and report on our analysis of the teacher moves in the two categories of independence preserving moves and encouraging student self-evaluation

In the first segment, the students calculated and filled out a table of values for the function $\mathrm{f}(\mathrm{x})=2 \mathrm{x}+3$ and $\Delta \mathrm{f}(\mathrm{x}) / \Delta \mathrm{x}$ for integer values between 0 and 5 . The teacher called their attention to the table and asked "What does it mean for this average rate of change to be two?" One student immediately responded "It's the slope" and this was followed by silence. The teacher then asked the students to talk with their peers to "brainstorm other things: what does that [the average rate of change] mean? What does it mean for the average rate of change to be two all the way down that column?" In this move, the teacher was encouraging the students to think further about the numerical representation and to express their ideas about the meaning of the constant two. After a minute of peer discussion, the teacher recorded several student contributions on the board and observed that the fact that the average rate of change was two tells us a lot about the function.

In the second segment, the teacher asked the students to consider the function $f(x)=$ $3(2)^{x}$ and to "do the same thing." The students completed the routine work of computing the table of values, shown in Figure 1, which the teacher recorded on a document camera for display. The teacher turned to the class and asked "What patterns do you notice about the average rate of change here?" 


\begin{tabular}{|l|l|l|l|}
\hline $\mathbf{x}$ & $\mathbf{f}(\mathbf{x})$ & Ave. rate of change & Succ. ratio \\
\hline 0 & 3 & ---- & ---- \\
\hline 1 & 6 & 3 & 2 \\
\hline 2 & 12 & 6 & 2 \\
\hline
\end{tabular}

\begin{tabular}{|l|l|l|l|}
\hline $\mathbf{x}$ & $\mathbf{f}(\mathbf{x})$ & Ave. rate of change & Succ. ratio \\
\hline 3 & 24 & 12 & 2 \\
\hline 4 & 48 & 24 & 2 \\
\hline 5 & 96 & 48 & 2 \\
\hline
\end{tabular}

Figure 1: The table of values for $f(x)=3(2)^{x}$

A student offered that the average rate of change is "half of the y-value" and that the average rate of change "doubles." The teacher mis-heard this student idea; she had been anticipating an observation about the function values doubling, not the sequence of average rates of change doubling. This points to the difficulty of hearing student ideas in the moment of teaching. The teacher recast the student's idea to refer to the function values, and named the doubling of the function values as the "successive ratio" and, with the students, completed the column shown in Figure 1. The teacher then formalizes and records this ratio as $\mathrm{f}(\mathrm{x}) / \mathrm{f}(\mathrm{x}-1)$. After she named the doubling of the function values as the successive ratio and had given its formal notation, the teacher called the students' attention to the table and, as with the linear table, asked "What else do you notice?" This segment concluded as the teacher recorded the students' observations about the function values ("increasing"), the sequence of average rates of change ("increasing"), and the successive ratios ("constant"). This segment was largely driven by the teacher's goal of identifying the successive ratios of the exponential function as constant, naming this constant, and formalizing the symbolic representation. We see this segment as largely neutral in terms of fostering students' independence. Rather, this segment served to set the stage for the next segment, where the primary goal of the example is foregrounded.

The third segment in this example began as the teacher engaged students in comparing and contrasting the tables associated with the two functions. It is here that the teacher set the primary goal of this example; she asked "how do you know if you're dealing with something that is linear or something that is exponential?" Her intention with this task was to engage the students in creating a tool that they could use to distinguish between a linear function and an exponential function when given a data set and to support the development of students' understanding of the structural features of linear and exponential functions -- namely the constancy of the average rate of change in a linear function and the constancy of successive ratios in an exponential function. Not surprisingly, the first student to respond to the teacher offered that "A linear function is a straight line, and an exponential function is an curved line." While this was not the intention of teacher's question (which implied a focus on the table values rather than on the graphs which had not been part of the representations in this segment), the teacher recorded this comment. Other students continued to contribute that the slope of the linear function and its average rate of change are constant and that exponential function has "successive ratios that are constant." This segment continued as the students worked independently to investigate the average rates of change and the successive ratios of two further examples, one where they were given a function in symbolic form $\left(f(x)=2(3)^{x}\right)$ 
and another where they were given a table of values and needed to find the symbolic function. In the final segment of this example, the teacher engaged the students in making the link between the patterns in the table and the symbolic form of the linear and the exponential function. One student pointed out that the successive ratio is the same number as the base of the function. The teacher highlighted these numbers and columns and asked the students where the constant property could be seen in the case of the linear function, thus drawing students' attention to the comparison of a linear and an exponential function. The teacher asked the students to identify where the yintercept can be "seen" in the symbolic form of a linear function and to consider the exponential function analogously. The students recalled the general form of the exponential function, $f(x)=a \cdot b^{x}$, and identified "a" as the y-intercept and " $\mathrm{b"}$ " as the successive ratio. By the end of this final segment, the students had developed a tool for distinguishing between linear and exponential functions that moved beyond references to the shapes of the graphs but rather reflected the structural characteristics (the constancy of the average rates of change and the successive ratios, respectively) that could been seen in a data table and linked to the symbolic form of the function. It is this development of a tool that students could use (and subsequently did use) in a range of situations that led us to characterize the teaching practice across the whole of this example as an independence preserving move. Throughout the example, the teacher encouraged students' self-evaluation of the meaning of the constants and values in the table by engaging them in peer conversations and in using their descriptive language for what they had noticed in the table.

\section{DISCUSSION AND CONCLUSION}

In this paper, we wanted to further the research on using students' thinking in mathematics lessons and the dilemmas connected with this practice, as reported in the literature, to forefront an argument and empirical evidence of teaching practices that encourage students' self-evaluation of their modelling activities in ways that preserve their independence as learners and problem solvers. This focus presents a shift in emphasis on students' and teachers' roles and responsibilities. For example, the essence of sequencing in the Stein et al. (2008) model is for the teacher to be in control of the form and content in a whole class discussion. An independence preserving stance would instead advocate sharing with students the responsibility for the sequencing of contributions in the discussion in order to engage them in the selfevaluation of their ideas and their emerging models. The first example suggests the importance and benefits of encouraging students' self-evaluation by having them collect data that can be used in evaluating the goodness of their emerging models and making adaptations to that model. This practice seemingly resolved the teaching dilemma that would otherwise have confronted the teacher as to how to resolve students' conflicting ideas. The second example illustrates the role of the teacher in using students' language and ideas about patterns to make connections between numerical and symbolic representations, while developing a tool that students can subsequently use in a range of situations to self-evaluate their thinking and work. 
This too supports the students in becoming more independent learners and problem solvers. We offer these examples as ways of thinking about the notions of students' independence and students' self-evaluation, with the hopes of contributing to the on going and evolving discussion of teaching practices.

\section{REFERENCES}

Ärlebäck, J. B., Doerr, H. M., \& O'Neil, A. H. (2013). A modelling perspective on interpreting rates of change in context. Mathematical Thinking and Learning, 15(4), 314-336.

Brodie, K. (2010). Pressing dilemmas: meaning- making and justification in mathematics teaching. Journal of Curriculum Studies, 42(1), 27-50.

Brodie, K. (2011). Working with learners' mathematical thinking: Towards a language of description for changing pedagogy. Teaching and Teacher Education, 27(1), 174-186.

Doerr, H. M., \& English, L. D. (2003). A modeling perspective on students' mathematical reasoning about data. Journal for Research in Mathematics Education, 110-136.

Even, R., \& Ball, D. L. (Eds.). (2009). The professional education and development of teachers of mathematics: The 15th ICMI study. New York: Springer.

Kaput, J. J., \& Roschelle, J. (1996). SimCalc: MathWorlds. [Computer program].

Lesh, R. A., \& Doerr, H. M. (Eds.). (2003). Beyond constructivism: Models and modeling perspectives on mathematics problem solving, learning, and teaching. Mahwah, NJ: Lawrence Erlbaum Associates.

Lesh, R. A., Cramer, K., Doerr, H. M., Post, T., \& Zawojewski, J. S. (2003). Model development sequences. In R. A. Lesh \& H. M. Doerr (Eds.), Beyond constructivism: Models and modeling perspectives on mathematics problem solving, learning, and teaching (pp. 35-58). Mahwah, NJ: Lawrence Erlbaum Associates.

Lobato, J., Clarke, D., \& Ellis, A. B. (2005). Initiating and eliciting in teaching: A reformulation of telling. Journal for Research in Mathematics Education, 101-136.

Magiera, M. T., \& Zawojewski, J. S. (2011). Characterizations of social-based and self-based contexts associated with students' awareness, evaluation, and regulation of their thinking during small-group mathematical modeling. Journal for Research in Mathematics Education, 42(5), 486-520.

Mason, J., \& Davis, B. (2013). The importance of teachers' mathematical awareness for in-the-moment pedagogy. Canadian Journal of Science, Mathematics and Technology Education, 13(2), 182-197.

National Research Council. (2001). Adding It Up. (J. Kilpatrick, J. Swafford, \& B. Findell, Eds.). Washington, DC: National Academic Press.

Stein, M. K., Engle, R. A., Smith, M. S., \& Hughes, E. K. (2008). Orchestrating productive mathematical discussions: Five practices for helping teachers move beyond show and tell. Mathematical Thinking and Learning, 10(4), 313-340. 


\title{
UPPER SECONDARY STUDENTS APPROPRIATING THE TOOL OF HARMONIC OSCILLATION: THE ISSUE OF RESISTANCE
}

\author{
Martin Carlsen \\ University of Agder, Norway
}

This study analyses four upper secondary school students' collaborative small-group problem solving in order to illustrate the role resistance may play in a process of appropriating the mathematical tool of harmonic oscillation. From a sociocultural perspective students' appropriation of mathematical tools is characterised by resistance. The study reveals that resistance unfolds as problems of recalling facets of the mathematical tool and difficulties in holding various elements together when using the tool in a mathematical problem context. The students experience difficulties in making sense of the relationships between mathematically theoretical descriptions of parameters involved in a functional expression of harmonic oscillation and their counterparts in a problem situation.

Keywords: Appropriation, Harmonic oscillation, Resistance, Tool

\section{INTRODUCTION}

This study aims at analysing the learning difficulties four upper secondary school students encountered when being involved in mathematical small-group problem solving. Particularly, I want to study how the issue of resistance unfolds in these students' processes of solving tasks concerning the mathematical tool of harmonic oscillation. The students were in their final year of upper secondary school and were 17-18 years old. They studied an optional mathematics course meant for further studies in mathematics at university level, i.e. the course was theoretically and mathematically advanced.

Following a sociocultural perspective, I adopt the neo-Vygotskian term appropriation as a metaphor of learning to describe how students gain from participation in interactional contexts (Mercer, 2000; Wells, 1999). The term appropriation is used in accordance with Moschkovich (2004) and Rogoff $(1990,1995)$ to do in-depth analyses of how the learning process evolved when the four students engaged with an advanced mathematical topic. According to Wertsch (1998), appropriation denotes an individual process of "taking something that belongs to others and making it one's own" (p. 53) (see e.g. Carlsen, 2010 for a detailed analysis of the appropriation process). In this study, however, I analyse resistance as an issue involved in the students' processes of making the mathematical tool of harmonic oscillation their own. I have therefore formulated the following research question:

How does resistance unfold in four upper secondary school students' process of appropriating the mathematical tool of harmonic oscillation? 


\section{THE PROCESS OF APPROPRIATING MATHEMATICAL TOOLS}

In this study I have adopted a sociocultural perspective on learning (Rogoff, 1990, 1995; Vianna \& Stetsenko, 2006; Vygotsky, 1978, 1986; Wells, 1999). More particularly, a sociocultural perspective has been used and elaborated within mathematics education research by for instance Moschkovich (2004) and Radford (2003). When studying students' mathematical appropriation process, it is remarkable how they are significantly dependent on the use of several cultural tools, e.g. language, paper and pencil, mathematical terminology and notations. Individuals use cultural tools to mediate their thinking and to collaborate, i.e. they are active agents in their own processes of learning as apprentices in sociocultural activity (Rogoff, 1990). Learning is thus in a sociocultural perspective seen as a situated, mediated, and distributed process where the individual person, the sociocultural context, and the social interlocutors are indivisible elements.

From a sociocultural perspective it is particularly interesting to analyse in what ways humans learn to handle and use cultural tools to solve emerging problems. People are dependent on and handle their surroundings by using cultural tools in everyday practices. Through the use of such tools, individuals mediate and distribute their knowing. Mediation is a term used to describe how humans interact with cultural tools in action and to denote what various tools do when used by persons. A mathematical tool, such as harmonic oscillation, is in this context seen as a cultural and communicative tool by which students interact and mediate their knowing.

According to Rogoff (1995), "[A]ppropriation occurs in the process of participation, as the individual changes through involvement in the situation at hand" (p. 153). Moreover, the appropriation process is about performing and contributing through participation in continuing collaborative practices (Vianna \& Stetsenko, 2006). The students in my study contribute with ideas and arguments in their on-going mathematical problem solving. Previous research on students' appropriation of mathematical tools has shown that the appropriation process is neither straightforward nor linear (Moschkovich, 2004; Radford, 2003; Rogoff, 1990).

\section{The issue of resistance}

The appropriation process always involves some sort of resistance (Wertsch, 1998). The term resistance may be interpreted in at least four different ways. Firstly, resistance may be seen as political resistance. Secondly, resistance may be seen as opposition regarding the learning of mathematics. This interpretation is connected with students' motivation and intentionality. Students' intentions and investments heavily affect processes of appropriating mathematical tools (Hannula, 2006; Op't Eynde, De Corte, \& Verschaffel, 2006). Thirdly, resistance may be seen as active opposition adopted by students towards learning new ideas and actions in school (Nunokawa \& Kuwayama, 2004). Students may create hybrids between old and new mathematical ideas due to resistance against abandoning already established methods 
of solving mathematical problems in favour of new methods introduced by fellow students.

Fourthly, resistance may be seen as a term to denote an intermediary element between a tool per se and the process of appropriating this tool. Thus, in this study I take the fourth meaning of the term as point of departure. Metaphorically, Wertsch (1998) addresses this issue by claiming that the appropriation process is loaded with "'friction' between mediational means and unique use in mediated action" (p. 54). This use of the term addresses the micro dynamics of the appropriation process. Resistance is seen as an adherent to the appropriation process itself, as pinpointing tensions between the mediational means and the agent's use of these means.

Radford (2003) analyses to what extent students use semiotic means of objectification to appropriate mathematical knowing. According to Radford (2003, p. 41), the semiotic means of objectification are defined as "objects, tools, linguistic devices, and signs that individuals intentionally use in social meaning-making processes to achieve a stable form of awareness, to make apparent their intensions, and to carry out their actions to attain the goal of their activities". He focuses particularly on how students relate to tensions between individually and culturally made meanings and how the students use these semiotic means of objectification. Radford's (2003) study reveals that resistance manifests itself as an issue that emerges between the student and the mathematical tool in question, as an intermediary problem between the mathematical tools per se and the students' use of semiotic means in situ, e.g. deictics (this, that, top row, bottom row), signs, and letters.

In Carlsen (2010) I analyse the issue of resistance as an emerging element of upper secondary school students' appropriation processes with respect to the mathematical tool of geometric series. The study shows that there is a theoretical and practical difference between being able to define in general what a geometric series is and to be able to utilise such a tool productively in a specific situation. The resistance is an inevitable element of the process of appropriating the tool of geometric series. In particular, the resistance is exemplified through students being bogged down in problems of recalling exponents within the sum formulae and expressions of the general term of a geometric series, the syntax of these algebraic expressions, elementary mathematical calculations, and difficulties in rounding off numbers.

Resistance therefore denotes tensions and impediments experienced by students as an emerging issue between the meaning of a mathematical tool and its use in a situated context. However, the resistance fades and disappears as individuals come farther in their process of appropriating the tool. Evidently, resistance as a constituent of the appropriation process vanishes, since "[i]t is the overcoming of such resistance that is part of the core of appropriation" (Carlsen, 2010, p. 98). 


\section{METHODS AND EMPIRICAL SETTING}

This study was designed as a case study (Stake, 1995, 2000). This design was chosen because I wanted to give an account of the role of resistance as an emerging issue within the appropriation process. This design gave me the opportunity to conduct a detailed and intensive analysis of students' mathematical small-group work. I closely followed a group of four upper secondary school students for several weeks of mathematics teaching, both lectures and group sessions. This approach to data collection reveals opportunities to uncover the group's way of interacting and communicating in their collaborative problem solving. Therefore, I took an overt, but passive researcher role. Video data of authentic classroom activity was collected and transcribed [1] in detail, making it possible for me to study how resistance unfolds within the students' process of appropriating the mathematical tool of harmonic oscillation.

The data analysis was done following a dialogical approach (Linell, 1998), an approach derived from dialogism as an epistemological stance focusing at how people make sense and learn on the basis of interaction, language, context, and contributions of others. Interthinking (cf. Mercer, 2000) and collaborative learning are hence crucial foci of dialogism (Linell, 1998). The dialogical approach is based on three dialogical principles, sequentiality, joint construction, and interdependency. Sequentiality concerns the argument that each of the students' contributions to the problem-solving process gets its meaning from its positioning in the flow of talk. In analysing the students' utterances, interpretations are made based on what have been said previously and what is said in the continuation of the utterances. Secondly, each dialogue is a collaborative endeavour by the students. Thirdly, the 'local' discursive components and the 'global' dialogical activity are interdependent (Linell, 1998). The dialogical approach used in my study was complemented by taking into account the students' use of semiotic means of objectification (Radford, 2003), such as gestures, voice, mathematical language of harmonic oscillation, deictics, and the text book.

The teaching was organised as lectures in a classroom followed by small-group collaborative problem solving in designated rooms with blackboards. The groups were homogeneously composed by the mathematics teacher according to the students' previous marks in mathematics. The group that I followed and videotaped consisted of four high-achieving students (best or second best mark) well attuned to each other, one female (Aud) and three males (Are, Jan and Pål). The observed students discuss and work collaboratively to make sense of a general algebraic expression of a function describing harmonic oscillation. They also work collaboratively to make sense of a corresponding graph which visualises harmonic oscillation. However, this small-group work and collaborative efforts are filled with communicative as well as collaborative challenges. In addressing such discrepancies the students need to clarify and make their thinking explicit in order to achieve shared meanings for terminology and symbols. 
The tool of harmonic oscillation was chosen in this study because of its interior complexity, making it particularly suitable for scrutiny when focusing at the issue of resistance. Four different parameters are involved which define the trigonometric function. Resistance thus may occur at various occasions in the students' collaborative problem solving as regards this tool.

\section{ANALYSIS AND RESULTS}

In the two excerpts below the students deal with a task where they are supposed to apply their knowing of harmonic oscillation in a given situation, here algebraically formulated as a cosine function, $f$, in the format $f(x)=A \cos (c x+\varphi)+d$. $A$ is the parameter used to label the function's amplitude, $c$ is the parameter used to label the function's angular frequency (the period of the function is $2 \pi /|c|), \varphi$ is the parameter used to label the function's angular position of oscillation, and $d$ is the parameter used to label the function's mean value. The students thus have to estimate the values of the four involved parameters (the students' estimations of the parameters $d$ and $\varphi$ are omitted due to space limitations). The students discuss 6.22a (Erstad et al., 2002, p. 233, my translation):

\subsection{2}

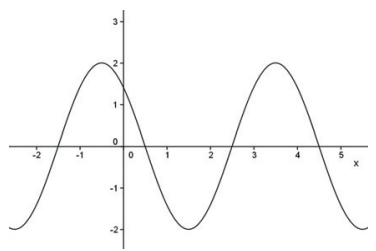

a Compose an expression for a cosine function that fits the given graph.

Figure 1: A task involving the concept of harmonic oscillation

\section{Excerpt 1 Estimation of $\boldsymbol{A}$ - the amplitude}

1 Jan:

2 Pål:

3 Jan:

4 Pål:

5 Aud:

6 Jan:

7 Pål:

8 Jan:

9 Aud:

10 Jan:

11 Pål:
The amplitude is one and a half

Why is it one and a half?

Because the amplitude is larger than eh one

Why one and a half?

The amplitude?

Because it goes

Why isn't it two?

Because it goes, what do you see there? (Points in his book)

The amplitude is two

Oh, it is perhaps two

IT IS TWO 
12 Jan: Yes, then it is two.

Jan (1) initiates the dialogue by claiming that the value of the amplitude is one and a half, an assertion Pål (2) obviously disagree with considering the fact that he repeats his question in (4). Jan (3) gives an argument where he indirectly claims that the amplitude is 1.5 because the amplitude is larger than 1. Jan's peculiar argument indicates that he believes Pål has 1 as the value of the amplitude in mind. However, from Pål's subsequent contributions (7) and (11) he estimates the value of $A$ to be two. Pål (4) is not satisfied with Jan's explanation of the amplitude's value. He repeats his previous question and demands to be convinced that the parameter in this case takes on the value 1.5. Following Jan's emphasis in (3), Aud (5) asks a clarifying question, just to be sure that they are discussing the value of the amplitude. Jan (6) initiates an elaborated explanation about the amplitude's value, but he is cut off by Pål (7) who offers an alternative value of the parameter. Pål advocates that the correct value of $A$ is 2 and not 1.5. Jan (8) continues his explanation from (6) and he asks a question with a reference to the graph. Jan uses the deictic word "there" simultaneously as he points at the graph. Jan points at one of the graph's maxima, and thus he misreads the unit of the $y$-axis. Jan is corrected by Aud (9), who claims that the amplitude has the value two. This utterance makes Jan (10) reconsider his standpoint. Pål (11) claims with emphasis that the value is two. He raises his voice to convince Jan that the value of $A$ equals two. Jan (12) then becomes convinced.

This short excerpt exemplifies how the issue of resistance emerges in a particular collaborative problem-solving setting. The resistance unfolds as uncertainty in reasoning and temporarily difficulties in drawing conclusions from a graph. The students seek to coordinate and objectify their theoretical knowing with respect to the harmonic function $f$ through the use of semiotic means (cf. Radford, 2003) such as emphasised words, pointing gesture, and repeated questions. To estimate the value of the parameter $A$ in a given case is challenging for the students. This shows that there is friction between the mathematical tool and its unique use in situ (cf. Wertsch, 1998).

\section{Excerpt 2 Estimation of $\boldsymbol{c}$ - the angular frequency}

The group starts to discuss the value of the parameters $c$ and $\varphi$. They discuss this for quite a long time because their estimated values do not coincide with the results given in the Answer section [2] in the back of their text book. As opposed to the parameters $A$ and $d$, the values of the parameters $c$ and $\varphi$ are only indirectly observable from the graph and thus have to be calculated.
103 Are:
Aren't there eh any rules about how to find $c$ and so on?
104 Jan:
Well, yes, wait a second
105 Pål:
It is that that rubbish
106 Jan:
Yes, the period is different 


$\begin{array}{lll}107 & \text { Pål: } & \text { Yes } \\ 108 \text { Jan: } & \text { That's the thing } \\ 109 \text { Are: } & \text { Aha } \\ 110 \text { Jan: } & \text { AHA } \\ 111 \text { Aud: } & \text { Period? How come? } \\ 112 \text { Jan: } & \text { No, well the period. That is the distance between every time that, like } \\ & & \text { every top } \\ 113 \text { Aud: } & \text { Twentytwo (Looks in her text book) } \\ 114 \text { Jan: } & \text { And it is going to be equal to two pi } \\ 115 \text { Are: } & \text { Two pi divided by } c\end{array}$

Are (103) addresses the value of $c$ by asking the other students about the existence of a rule of how to estimate $c$. Are's use of the word "rule" here is interpreted as another way of asking for a relationship or formula where $c$ is present. Jan (104) apparently considers Are's question, but he is thinking about something else. Jan's comment "wait a second" is foremost a thinking aloud comment for himself. Pål (105) indicates that he knows of a relationship where $c$ is involved. However, Pål's way of speaking signals that he cannot recall it. The word "rubbish" is interpreted as a way of expressing difficulties in remembering the relationship. Jan (106) continues his reasoning from (104) and claims with emphasis that the period is different, i.e. the period is different from $2 \pi$ - the period of the general cosine function. Jan emphasises the term "period", indicating that their difficulties have been buried in an inaccurate assumption about the function's period. Jan's contribution concerns the period of the function while Are's question concerns the parameter $c$. However, this apparent inconsistency shows Jan's awareness of the relationship between $c$ and the period, even though this is not made explicit. Pål (107) agrees to what Jan says, before Jan (108) argues about the essentiality of realising that the period of their function is different from the period of the general cosine function. There has been an error in the foundation of their calculations. Are (109) and Jan (110) make explicit their revelation and their breakthrough.

However, Aud (111) is unconfident about what Are and Jan are talking about, and she asks for an explanation and a warrant for their assertion. Jan $(112,114)$ externalises his thinking and makes it gradually more explicit. He explains and elaborates what the period is in practical terms and not factual, as the distance between two maxima of the function. Aud (113) does not listen to Jan's elaboration but searches the Answer section [2] of her text book. Anyway, Jan (114) says that the period is supposed to be $2 \pi$. Are (115) corrects him and demonstrates the key issue in the group's difficulty as regards the value of the parameter $c$. The group's reasoning is that the parameter $c$ constitutes the function's period. However, as Are (115) accentuates, the period $p$ is equal to $2 \pi$ divided by $c$. Implicitly Are realises that $p=2 \pi /|c| \Leftrightarrow|c|=2 \pi / p$. Since they may evaluate the period explicitly from the graph, he identifies how to estimate the value of $c$. 
The issue of resistance manifests itself in this dialogue as difficulties in coordinating their knowing of the general cosine function, their knowing of the general function of harmonic oscillation, $f$, and their knowing of internal relationships between parameters and the function's period. The students' process of achieving shared meanings for the parameter $c$ is characterised by this resistance. Resistance unfolds amongst the students' objectification of knowing as problems of recalling mathematical relations. Resistance also emerges as inaccurately made mathematical assumptions.

\section{DISCUSSION}

In this study I set out to come up with possible answers to the role resistance may play in four upper secondary school students' process of appropriating the mathematical tool of harmonic oscillation. From a sociocultural perspective (Moschkovich, 2004; Rogoff, 1990, 1995; Wells, 1999; Wertsch, 1998), appropriating the cultural tool of harmonic oscillation is a process of taking over and mastering the tool and how the students make this tool their own by using it for communicative and problem-solving purposes. From the analysed dialogues it is demonstrated that the appropriation process is characterised by resistance. Resistance plays a substantial role in these students' processes of making the concept of harmonic oscillation their own. The students' objectifications of their knowing reveal that hesitance, inaccuracy, and problems of recalling correctly are impediments and intermediary problems the students face. The issue of resistance unfolds as these students are supposed to hold everything together when solving a task where identifications of the parameter values are under scrutiny. Resistance is in this study seen as a constituent element of the appropriation process, unfolding as friction between the mediating tool and a person's use of this tool (cf. Wertsch, 1998). The resistance emerges as intermediary problems and impediments between the mathematical tool per se and the students' use of semiotic means in situ (cf. Radford, 2003). Particularly, resistance unfolds as uncertainty amongst the students with respect to recalling definitions and descriptions of the various parameters involved in the expression of $f$.

In their process of appropriating the mathematical tool of harmonic oscillation the students employ semiotic means of objectification (cf. Radford, 2003) to come up with ideas and solutions to the task(s) in question. By using gestures, linguistic devices such as parameter letters, and the text book the students participate in and contribute to their shared social meaning making process. The group's process of appropriation is further nurtured by the students' efforts to interthink (cf. Mercer, 2000). By making their thinking explicit through argumentation and discussion, intersubjectivity is established which creates possibilities for individual participation and contribution to their collaborative problem solving (Rogoff, 1990). However, faced with the involved concepts and parameters in a contextual situation the students 
run into conceptually subordinate difficulties. This finding exemplifies the general position within a sociocultural perspective, that appropriation is not a straightforward and linear process where appropriated concepts and actions are without more ado transferable to new contexts. When applying concepts and parameters in a situated setting, when trying to combine in situ all the facets and subtleties that constitute the mathematical tool of harmonic oscillation, the students face difficulties. Resistance unfolds as the students try to hold everything together, application of the theoretical expression of the cosine function in order to evaluate the value of the involved parameters. Furthermore, the resistance manifests itself in their collaborative problem solving as difficulties in remembering names and conceptual elaborations of parameters. The resistance generates friction within the appropriation process (Wertsch, 1998), friction revealed as discrepancy and incongruities in the students' reasoning.

The students' appropriation process is further characterised by resistance unfolding as emerging impediments the students experience when seeking to coordinate their knowing. They use deictic words as semiotic means of objectification (cf. Radford, 2003) in their discussions which I in this case interpret as signalling uncertainty and inaccuracy as regards recalling definitions and descriptions of the various parameters. Since two of the parameters are not directly observable from the graph, the students' are bogged down with conceptually subordinate mathematical calculations while at the same time coordinating their knowing of the cosine function and harmonic oscillation. The mathematical tools under scrutiny are intimately situated within the context the tools are applied. The intimacy and situated use of tools such as harmonic oscillation release resistance to emerge in the appropriation process.

\section{NOTES}

[1] Transcription codes: (Comments by the author), Under emphasised words, CAPS loud utterance.

[2] According to the Norwegian tradition of making text books in mathematics, generally the correct answers to the tasks would be presented at the end of the book, called "the Answer section".

\section{REFERENCES}

Carlsen, M. (2010). Appropriating geometric series as a cultural tool: A study of student collaborative learning. Educational Studies in Mathematics, 74, 95-116.

Erstad, G., Heir, O., Bjørnsgård, I., Borgan, Ø., Pålsgård, J., \& Skrede, P. A. (2002). Mathematics 3MX [Matematikk 3MX], Oslo: Aschehoug.

Hannula, M. S. (2006). Motivation in mathematics: Goals reflected in emotions. Educational Studies in Mathematics, 63, 165-178.

Linell, P. (1998). Approaching dialogue. Talk, interaction and contexts in dialogical perspectives. Amsterdam: John Benjamins Publishing Company. 
Mercer, N. (2000). Words and minds: How we use language to think together. London: Routledge.

Moschkovich, J. N. (2004). Appropriating mathematical practices: A case study of learning to use and explore functions through interaction with a tutor. Educational Studies in Mathematics, 55, 49-80.

Nunokawa, K., and Kuwayama, M. (2004). Students' appropriation process of mathematical ideas and their creation of hybrids of old and new ideas. International Journal of Science and Mathematics Education, 1, 283-309.

Op't Eynde, P., De Corte, E., \& Verschaffel, L. (2006). «Accepting emotional complexity»: A socio-constructivist perspective on the role of emotions in the mathematics classroom. Educational Studies in Mathematics, 63, 193-207.

Radford, L. (2003). Gestures, speech, and the sprouting of signs: A semiotic-cultural approach to students' types of generalization. Mathematical Thinking and Learning, 5, 37-70.

Rogoff, B. (1990). Apprenticeship in thinking. Cognitive development in social context. New York: Oxford University Press.

Rogoff, B. (1995). Observing sociocultural activity on three planes: Participatory appropriation, guided participation, and apprenticeship. In J. V. Wertsch, P. del Río, \& A. Alvarez (Eds.), Sociocultural studies of mind (pp. 139-164). Cambridge, MA: Cambridge University Press.

Stake, R. E. (1995). The art of case study research. Thousand Oaks, CA: Sage.

Stake, R. E. (2000). Case studies. In N. K. Denzin \& Y. S. Lincoln (Eds.), Handbook of qualitative research (2nd ed.) (pp. 435-454). Thousand Oaks, CA: Sage.

Vianna, E., \& Stetsenko, A. (2006). Embracing history through transforming it: Contrasting Piagetian versus Vygotskian (activity) theories of learning and development to expand constructivism within a dialectical view of history. Theory and Psychology, 16, 81-108.

Vygotsky, L. S. (1978). Mind in society. The development of higher psychological processes. Cambridge, MA: Harvard University Press.

Vygotsky, L. S. (1986). Thought and language. Cambridge, MA: The M.I.T. Press.

Wells, G. (1999). Dialogic inquiry: Towards a sociocultural practice and theory of education. Cambridge: Cambridge University Press.

Wertsch, J. V. (1998). Mind as action. New York: Oxford University Press. 


\title{
REFLECTIONS ON UNCERTAINTY ASPECTS IN A STUDENT PROJECT ON TRAFFIC SAFETY
}

\author{
Kjellrun Hiis Hauge and Rune Herheim \\ Bergen University College
}

This paper explores uncertainty concepts from post-normal science together with Skovsmose's concepts on reflective knowing. In particular, it focuses on the characterising of uncertainty in students' knowledge production and on how uncertainty can be linked to reflective knowing. A student project on traffic safety in their local area is described and analysed. The community where this took place has experienced cars driving off the road and into the sea. The findings suggest that the students handle different sorts of uncertainty, they demonstrate reflective knowing and are able to link mathematical aspects to normative values. Thereby, they practice key competences for critical citizenship. The uncertainty concepts are concluded to be useful, but may be even more useful for analysing issues involving higher complexity than the analysed student project.

Key words: Critical reflection, uncertainty typology, critical citizenship

\section{INTRODUCTION}

Skovsmose $(1992$; 1994) argued that reflective knowing is a key democratic competence for critical citizenship, where reflective knowing relates to the understanding about mathematics and its use. He offers the concept of mathemacy, defined to include mathematical, technical and reflective knowing. One aspect of reflective knowing is the recognition that mathematics has a 'formatting power' in society in that "new insights may change interpretations, but also in the sense that mathematics colonizes part of reality and rearranges it" (Skovsmose, 1992, p. 6). Context and normative value aspects consequently become an essential attribute to mathematics.

There are several documented examples where real-life problems have been explored in classrooms to facilitate reflective knowing. The authenticity of contexts and their relevance for students are often considered a key feature. Examples include discussions on racial justice of mortgage opportunities (Gutstein, 2013), fairness of government programs to support beneficiary farmers (Barbosa, 2006), energy rations (Barbosa, 2009) and aspects of shopping and consumption (Pais et al., 2012).

In parallel with the literature on critical mathematics education, there is a related discussion on how natural scientists should assess and communicate uncertainty in numerical results, allowing citizens to think critically about science for policy. Postnormal science (Funtowicz and Ravetz, 1993) is a normative philosophy of science and its role in complex and controversial societal issues. It adds uncertainty and value perspectives (personal, societal and ethical values) as new dimensions to science. Since a particular way of handling uncertainty can favour one interest to another, 
uncertainty and normative value perspectives are interlinked. These dimensions should therefore be brought to the centre of debates, and citizens should be involved in evaluating how expert knowledge is relevant to the issue of concern (Funtowicz and Ravetz, 1993).

The role of uncertainty in traditional science has been something to control, either by reducing it or by quantifying it through statistical measures. However, Funtowicz and Ravetz $(1990$; 1993) argue that uncertainty cannot be controlled through quantitative measures when issues are complex. They divided uncertainty in three categories to give an impression of the degree of control: inexactness (technical uncertainty), unreliability (methodological uncertainty) and border with ignorance (epistemic uncertainty). Inexactness denotes quantifiable uncertainties and probabilities with known statistical distributions. In such cases, uncertainty is controllable. Unreliability represents uncertainty in cases where, for example, a system is understood, but the uncertainty associated with the parameters cannot be precisely quantified. Border with ignorance denotes unknowable uncertainties; either what you know you don't know or what you don't know you don't know (Funtowicz \& Ravetz 1990; 1993). Knowledge uncertainty can be associated with a mix of these sorts of uncertainties.

From what we know, mathematics education does not use comparable uncertainty concepts per se, but Skovsmose (1992, p. 9) operates with six steps of reflective knowing, which all are implicitly about uncertainty: "(1) Have we used the algorithm in the right way? (2) Have we used the right algorithm? (3) Can we rely on the result from this algorithm? (4) Could we do without formal calculations? (5) How does the actual use of an algorithm (appropriate or not) affect a specific context? (6) Could we have performed the evaluation in another way?" The first two steps refer to the mathematical tool while (3) and (4) focus on the relation between the tool and its purpose. Skovsmose further argues that (5) and (6) are crucial for achieving insights about the formatting power of mathematics.

Few have tried to bridge critical mathematics education and post-normal science. Barwell (2013) recognizes similarities between the two philosophical stances, such as critical citizenship and value and uncertainty aspects of mathematics and science in society. He suggests applying concepts from both traditions to develop mathematics education for discussing climate change in the classroom. Hauge (2013) had a related approach, where she suggests a series of characteristics to look for when reflecting on risk assessments, borrowed from literature on post-normal science. These include value and uncertainty aspects.

To our knowledge, there have been no attempts to apply concepts from post-normal science in classroom situations. It also seems that mathematics education gives little attention to uncertainty concepts (apart from statistical concepts). In this paper, we present a student project on traffic safety where we seek to apply uncertainty concepts from post-normal science (Funtowicz \& Ravetz, 1993) and Skovsmose's (1992) six steps of reflective knowing in the analysis. 
The project we observed included students from lower secondary school (12-13 years old). They collected and processed data on the height of concrete roadside barriers and traffic counts on a stretch of road where cars had happened to drive off the road and into the sea. The overall issue of this paper is whether uncertainty concepts from post-normal science can be useful tools for critical mathematics education related to critical citizenship. The research questions we address are: What sorts of uncertainty are the students coping with associated with the knowledge they are producing? What kind of reflective knowing is expressed in association with these uncertainties?

The student project, the collection of data and the analytical tools are described in the following. Findings are presented and analysed related to uncertainty and critical citizenship. These findings are finally discussed in accordance with the research questions and the overall issue of the paper.

\section{THE SCHOOL PROJECT ON TRAFFIC SAFETY}

A school teacher at a lower secondary school in a rural area invited the authors of this paper to observe a student project she had developed on traffic safety. The project involved several teachers and three 8th grade classes (12-13 years old). The local community had experienced several incidents where cars had driven off the road and into the sea. The year before, there had been a death accident, and earlier, the grandmother of one of the students had survived a similar accident. This stretch of road consisted of several relatively sharp curves where concrete roadside barriers were placed to prevent accidents. The school bus passes this stretch every day. The student project can be described as follows: The mathematics teacher developed and presented the project idea to the students. Her idea was to let the students carry out a traffic count, measure the heights of the barriers in five of the exposed curves and let the students evaluate traffic safety using mathematics based arguments. She defined the categories for the traffic frequency table, but included the students in a discussion on how many measurements they should take. Then the students carried out the fieldwork. They split into groups and did traffic counts and measured barrier heights. Teachers and parents were involved as drivers, and the local police were in charge of the students' safety during the fieldwork. The local newspaper made an article on the project. Back in class, the students punched the collected data and spent some time on repeating statistical concepts. Later, the students worked with the punched data in pairs. They used spreadsheet software to systematize the data, calculate statistical measures and to make charts. When all students had finalized these tasks, some of the pairs presented their charts in plenary and received feedback from the other students and the teacher. The last stages involved a meta-discussion on whether the students had appreciated the project and why.

\section{DATA AND METHOD}

The data are collected through video recording, observation and interview. Three classroom sessions were observed by the authors and video recorded: (1) a session 
where the students analysed the data in pairs, where two pairs were recorded, (2) the plenary presentation where they presented their charts and the meta-discussion. Two cameras were in play: directed towards the two pairs in the first session, towards the presenters at the second session and towards the teacher and the front of the classroom during the last session. The cameras were placed to avoid recording of the students which had not given permissions to record them. The teacher was interviewed about the student project to provide information about what had happened prior to our visit. Both authors of this paper were present during the recorded sessions and performed the interview with the teacher. Additional material includes the story in the local newspaper, the students' field notes, their spreadsheet files and their learning logs. The two pairs' discussions, the presentation session, the classroom discussion and the interview with the teacher are transcribed.

For our analysis, we apply the uncertainty typology developed by Funtowicz and Ravetz $(1990 ; 1993)$ to get an insight in what sorts of uncertainty the students were dealing with. We further apply Skovsmose's six steps of reflective knowing to analyse the students' reflections linked to uncertainty aspects. The combination of uncertainty typology and reflection steps may assist us in recognizing students' potential for critical citizenship and give us insight into whether the uncertainty typology may be a useful analytical tool.

The classroom recordings and the teacher interview were transcribed. In order to address what sorts of uncertainty the students were coping with, we searched the parts of the transcription that we found were related to uncertainty and categorised these in accordance with inexactness, methodological uncertainty and border with ignorance. The same parts were categorised using Skovsmoses's six reflection steps in order to explore similarities and differences between these analytical tools.

\section{RESULTS AND ANALYSIS}

In the following we present examples where the students reflected on uncertainty or were given such opportunities. These are categorised in accordance with our analytical tools. The examples are organised by themes. The first situations are related to the measurements of the concrete roadside barriers and the second to the vehicle categories for the traffic count. Within both themes several situations are presented, each accompanied by an analysis. The parts marked by " indicate that these are citations, either from the teacher interview or the classroom recordings.

\section{Uncertainty associated with the height of the concrete roadside barriers}

The first two situations are drawn from the interview with the teacher. She explained that she had invited the students to discuss and decide several aspects regarding the measuring of barriers. One such aspect had been how to measure the height of the barriers in the absence of right angles. The barriers were narrow at the top and broader at the ground level. To facilitate the measuring, a right-angled wooden device was made by the arts and crafts teacher. A second aspect had been how accurate the 
measurements should be. The teacher and students had decided on $0.5 \mathrm{~cm}$. The teacher further explained that the students still had measured to the mm during field work, removing moss to increase precision.

These examples involve uncertainty in the category of inexactness, as each measurement has inexactness as a source of uncertainty. Although we do not have direct access to what was expressed in the classrooms, the discussions in themselves were explicitly about the accuracy of the measurements. The question is whether methodological uncertainty and border with ignorance are relevant to characterize the associated uncertainty. The measurements are taken by using a tool, which could provide unreliable measures if not properly used or if incorrectly crafted. The teacher tells us that she had addressed the importance of right angles and that the two strips of wood used to improve the measuring accuracy had to be perpendicular. Yet, our interpretation is that methodological uncertainty is probably less significant for characterising the uncertainty in this case.

We assume that both situations above triggered reflections related to the mathematics itself: Whether the heights were correctly measured and whether the right algorithm was used to measure the heights, i.e. Skovsmose's reflection steps (1) and (2). The discussion on choice of accuracy may also be interpreted as linking the tool to the purpose (whether it is possible or whether it makes sense to measure to the $\mathrm{mm}$ ), which indicate step (3). We note, however, that the students consider the accuracy aspect differently during fieldwork.

The following situation is also obtained from the teacher interview. She referred to a discussion with the students on how many measurements they needed to take and on the distance between them in order to get valid results. The teacher explained that they settled for every $30 \mathrm{~cm}$. The students had presumably argued that one $\mathrm{cm}$ between each measurement would have been preferable, but that it was too time consuming and that it was no point in taking that many measurements. They had considered one meter as well, but it had been argued they could miss out on humps and bumps.

This task is associated with more complexity as it involves a model to represent the height of a barrier, and because the model can influence how the safety of the passing people and vehicles is perceived. Other models than the average height could have been chosen. Since the choice of model might have had consequences for whether the barriers would have been replaced, the associated uncertainty could be classified as methodological uncertainty or even border with ignorance. However, the system in this case (the barriers and whether the height(s) prevent accidents) may not be sufficiently complex for highlighting these categories.

The question on how many measurements are necessary requires reflections on the relation between the tool (the model for measuring the height) and the task (to measure the height). They are related to whether the way the height is measured is reliable, step (3), although this seems to be only implicitly discussed. We do not have 
data suggesting that the students reflected on possible implications of the decided tool, i.e. step (5).

\section{Uncertainty in categorizing traffic data}

The teacher informed us that she had pre-made the categories for the traffic count. These were "car", "motorcycle", "bicycle", "large vehicle" and "other". In the following, two situations are presented where the categories were an issue.

During the interview, the teacher tells us that a student had showed her his observation sheet for traffic count where he had indicated four sheep in the "other" category. Initially she had perceived it as a funny joke, but the student had argued that sheep in the road constitute a risk for passing vehicles. Later, in class, a video recording shows that the teacher invites two students to discuss this when working in pairs on presenting the traffic data in charts. She asks whether they would include sheep in "a formal letter about traffic safety". One of the students first responds negatively and concludes that "sheep don't matter". He then seems to change his mind when he explains how sheep can generate risk: "They can walk on the road and then you can crash into them".

Uncertainty lies implicit in the students' critique of the teacher's choice of categories, i.e. uncertainty related to the choice of categories. The uncertainty is not about exactness in the traffic count. The student's expression can be interpreted as a critique of the model's (the categories') inadequacy. The uncertainty can therefore be characterised as methodological uncertainty. Since the student indicates that adding the sheep category can affect people's understanding of the involved risk, his reflections can be categorised as Skovsmose's step (5).

The last situation is taken from the classroom session where student pairs present their charts on traffic counts and explain their choices. One of the students raises his hand and presents a suggestion: "When I look at what we have counted, then I think that we should have had a separate category for buses". Some of his classmates respond to the suggestion with support by arguing that there are more people in busses compared to cars and trucks. Similar to the previous example, this situation involves a critique of the categories and reflections related to how the choices of categories can affect an understanding of risk. The addressed uncertainty can thus be categorised as methodological uncertainty and the student reflections as step (5).

\section{DISCUSSION}

Starting with the first research question, the analysis suggests that the students were coping with all sorts of uncertainty in accordance with Funtowicz and Ravetz' (1993) uncertainty typology: inexactness, methodological uncertainty and border with ignorance, although the latter may not have been significant. When they were dealing with the measurements of the barrier heights, inexactness seemed to be the dominant sort. However methodological uncertainty was involved when they discussed the 
model for barrier heights. Unfortunately, these discussions are not recorded, so the actual utterances related to uncertainty are not known, but the situation implies that the students dealt with these categories of uncertainty. When the students were suggesting and discussing new categories for the traffic count, we find that methodological uncertainty was the dominant one. The student discussion implied a critique of the models' adequacy.

The question remains on whether it is appropriate to claim that the students coped with ignorance. If they had explicitly addressed whether certain heights would have prevented a vehicle from running into the sea, such a claim would be fair. A barrier's effectiveness would probably depend on its height, the vehicle's height, weight, speed and direction. Also, if the students were discussing how the traffic count itself might affect the perception of the traffic safety, they could have dealt with ignorance. However, there are no explicit examples in the data that the students discussed unknown factors or complex relationships.

Regarding the second research question, the analysis suggests that several of Skovsmose's reflection steps were covered during discussions related to uncertainty. When inexactness was dominant, the first two or perhaps three reflection steps categorized the reflections, which deal with the performance of the mathematics itself. When methodological uncertainty was involved, the reflections were characterised as step (5), i.e. reflections on how the algorithm (in this case the model for categorising vehicles) affects the understanding of the traffic safety problem.

A relevant question is whether the detected connection between the sorts of uncertainty and Skovsmose's reflection steps is factual or whether it is a coincidence. It might be expected that reflections on the correctness of computations and procedures are dominant when dealing with inexactness. It might also be expected that students reflect on the consequences of applying knowledge when the knowledge is thought incomplete or when perspectives are missing, as with the vehicle categories. However, it is still possible to imagine that that inexactness could cause reflections on how it would affect an understanding of a problem. It is also possible that identified ignorance or limited knowledge does not affect how a problem is perceived. To illustrate the last case, we can picture two situations: one where the student (or teacher) does not manage to see a connection between uncertainty and its implications, another where the stakes are too low so that the uncertainty doesn't affect how the problem is perceived.

The importance of uncertainty increases with higher stakes (Funtowicz \& Ravetz, 1993). This is why multiple voices are called for. The uncertainty typology and the reflection steps are developed because the authors believe critical citizenship is important (Funtowicz \& Ravetz, 1993; Skovsmose, 1992). How, then, can uncertainty and critical citizenship be connected in the traffic safety project? Through the project, students gathered experiences relevant for critical citizenship in several ways: (1) the students experienced that choices of the mathematical approach can 
influence the quality and relevance of the product, (2) some students exercised critique to an authority by suggesting improvements to the teachers' choice of data categories, and (3) the project itself was an exercise of developing and expressing critical reflections and arguments which could be addressed to authorities. An elaboration of these points now follows.

The discussion on how to model the heights of the barriers and the critique of the vehicle categories gave the students opportunities to see that choices need to be made when they conduct investigations. This may be a necessary experience for understanding that numbers used in society (a) are not necessarily associated with the certainty and exactness as most mathematics activities in school are, and (b) numbers in society may be based on choices and assumptions which can affect how the addressed problem is perceived.

The students who gave the critique on categories expressed such insight. Experiences like these may help students prepare for critical citizenship and being able to review expert knowledge and its use. In fact, the students' critique can be regarded as a review itself, a review of the teacher's choice of model for categorising passing vehicles for the traffic count.

This brings us to a key aspect of the idea of critical citizenship: the allowance of multiple perspectives and voices. The teacher did not only allow the students to give input and critique, she also encouraged the students to change the categories in their chart presentations. The project thus included situations of equality between the teacher and the students. In addition, the students' local knowledge about the road was probably useful for the project: the fact that sheep was not uncommon on the road and that students and teacher knew where the accidents had been.

The student project can be regarded as a critique to authorities, where the students evaluated the quality of the existing safety, of which the authorities have the responsibility. Although they didn't formulate a letter to the authorities, there were several utterances suggesting that they thought of the safety as a problem and that they were capable of providing arguments. The critique of the teacher's categories indicates that the students regarded the actual situation as a safety problem.

During the meta-reflection session where the students' gave their opinion about the project, one of the students gave the following reason for why he had liked the project: "You influence society in a positive way because you can save lives ... a car drives off, and that might be prevented with higher barriers". The authenticity of the project had naturally increased if the students had actually sent a letter to the authorities, but this student's input suggests that he did actually place himself in the role of a critical citizen.

A relevant question is whether uncertainty concepts and reflection steps are useful, and for whom? None of the concepts (including uncertainty) and steps has in this case been introduced to the students or the teacher. It may be sufficient for the students to 
work with uncertainty, and together with the teacher develop a capacity for reflecting on its nature and implications, perhaps without introducing the typology. Uncertainty in itself is a difficult concept, but useful for students when dealing with stochastic and complex situations. Teachers, on the other hand, may benefit from understanding that uncertainty can take different forms. The six steps may be useful for the same reason. By being aware of differences in uncertainties and reflections, the teachers can create opportunities where students get exposed to different sorts of uncertainties and can reflect on their characteristics and consequences. The reflection steps and uncertainty typology can thus be guidance to the teacher's choice of student projects and how to stimulate reflections on uncertainty and in accordance to different steps. Offering rich contexts and focusing on uncertainty can facilitate students' critical thinking. Ignoring uncertainty aspects may restrain students' critical thinking.

The uncertainty typology adds another dimension to the reflection steps, which suggests that it is useful for research related to critical citizenship and classroom studies. The idea of post-normal science is that quantified bases for decisions in controversial issues require an involvement of stakeholders and citizens, especially when uncertainty goes beyond inexactness. The purpose of the involvement is to become aware of possible ways quantified information can shape the perception of the problem. This way, the uncertainty typology in post-normal science can be linked to Skovsmose's reflection step (5). However, the uncertainty typology had probably been more useful in more complex project or if complexity had been given more attention in this project. More research is called for on the significance of the uncertainty categories for classroom studies and on links to concepts from critical mathematics education.

\section{REFERENCES}

Barbosa, J. C. (2006). Mathematical modelling in classroom: a critical and discursive perspective. Zentralblatt für Didaktik der Mathematik, 38(3), 293-301.

Barbosa, J.C. (2009). Mathematical modelling, the socio-critical perspective and the reflexive discussions. In M. Blomhøj \& S. Carreira (Eds.), Mathematics applications and modelling in the teaching and learning of mathematics Proceedings from Topic Study Group 21 (pp. 133-143). Mexico: ICME.

Barwell, R. (2013). The mathematical formatting of climate change: critical mathematics education and post-normal science. Research in Mathematics Education. DOI: 10.1080/14794802.2012.756633.

Funtowicz, S.O., \& Ravetz, J.R. (1990). Uncertainty and Quality in Science for Policy. Dordrecht: Kluwer academic publishers.

Funtowicz, S.O., \& Ravetz, J.R. (1993). The Emergence of Post-Normal Science. In R. von Schomberg (Ed.), Science, Politics and Morality, (pp. 85-123). The Netherlands: Springer. 
Gutstein, R. (2013). Home Buying While Brown or Black. In: E. Gutstein \& B. Peterson (Eds.), Rethinking mathematics - teaching social justice by the numbers. USA: Rethinking schools.

Hauge, K. H. (2013). Bridging Policy Debates on Risk Assessment and Mathematical Literacy. Paper presented at Eighth Congress of European Research in Mathematics Education. Retrieved from http://cerme8.metu.edu.tr/wgpapers/WG5/WG5_Hauge.pdf .

Pais, A., Fernandes, E., Matos J.F., \& Alves, A.S. (2012). Recovering the meaning of "critique" in critical mathematics education. For the learning of mathematics, 32 (1), 28-33.

Skovsmose, O. (1992). Democratic Competence and Reflective Knowing in Mathematics. For the Learning of Mathematics, 12 (2), 2 - 11.

Skovsmose, O. (1994). Towards a critical mathematics education. Educational Studies in Mathematics, 27 (1), 35-57. 


\title{
MATHEMATICAL AGENCY IN A TRAFFIC SAFETY PROJECT
}

\author{
Rune Herheim, Toril Eskeland Rangnes \\ Bergen University College, Norway
}

The paper concerns students' mathematical agency and teachers' facilitation of such agency in a multidisciplinary project on traffic safety. The concept of agency is explored. The conversations between students and a teacher are analyzed, with emphasis on students' empowerment and the two concepts 'shared agency' and 'dance of agency'. Characteristics of students' agency and teacher's facilitation of agency are identified and reflected upon with a focus on critical argumentation.

Keywords: Mathematical agency, critical argumentation, real-life context

\section{INTRODUCTION}

The paper concerns students' mathematical agency and teachers' facilitation of agency. This agency concerns how mathematical data is gathered, interpreted, understood, and used in a real-life setting. The context is a multidisciplinary project on traffic safety. A mathematics teacher at a lower secondary school in a rural area invited researchers from Bergen University College [BUC] to observe and do research on a project she had initiated on traffic safety. The project involved the students in three $8^{\text {th }}$ grade classes and their teachers in mathematics, Norwegian, and social sciences. The local community had experienced several traffic incidents, some of which resulted in cars driving off the road and into the sea. Concrete roadside barriers are placed on critical sections to prevent accidents on these winding roads, but the previous year there had been a fatality. The school bus uses these roads every day. The idea was to let the students carry out traffic counts and measure heights of barriers on six critical sections between the school and the students' homes. The students should use mathematical argumentation to evaluate and increase the traffic safety.

The teacher's and the researchers' purposes are based on a critical pedagogical perspective. Balasubramanian and Gutstein (2013) argued that such a critical perspective implies that socio-political realities and students' lived experiences can be powerful and meaningful contexts for students to learn mathematics and take actions in the society.

The focus in this paper is on students' agency, on the characteristics of their mathematical agency, and on how teachers can facilitate and encourage students' agency. A focus on agency in school mathematics naturally brings about a focus on critical mathematical argumentation (Andersson \& Norén, 2011; Skovsmose, 2005). Critical mathematical argumentation is seen as an operationalization of agency. The purpose is to explore students' agency and the teachers' facilitation of agency by identifying and reflecting upon the characteristics of their critical mathematical argumentation. 


\section{The traffic safety project - six phases}

The traffic safety project is described by six phases. First, the mathematics teacher presented the idea to the students. Her aim was to stimulate her students' critical mathematical argumentation and to empower them. Initially she planned that the students should make their own frequency tables and categories. However, due to practical limitations she had to make the categories: large vehicles, cars, motorbikes/ATVs, bikes, and other. Second, the students carried out the field work. They split into groups and did the traffic counts and measured heights of barriers. Two local police officers took responsibility for the traffic safety during the height measurements, and they were frequently engaged in discussions on traffic safety with the students. Third, the students plotted their data into spreadsheets and reviewed statistical concepts to prepare for the next phase. Fourth, the students worked in pairs with the data in the classroom. They used spreadsheet software to systematize the data and to make diagrams and graphs that could communicate their results well. Fifth, each pair of students presented their figures for the class. The presentations were discussed, and strengths and limitations of the figures were pointed out and discussed. Sixth, follow up work which involved meta-discussion of the experience of doing a project like this, the writing of learning logs, working with ingresses in Norwegian language, and participating in an article for the local newspaper. The project also included a plan for writing a letter to authorities. Although the letter was not realized, it influenced the conversations and actions in the classroom.
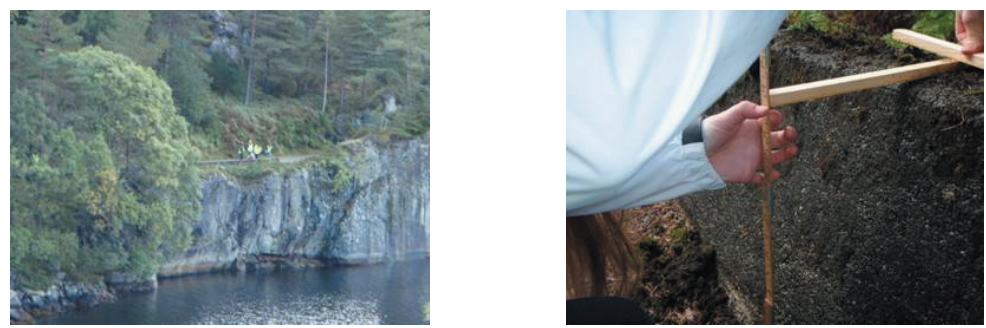

Pictures: Critical road section to the left and measuring to the right

\section{THE CONCEPT OF AGENCY}

Purpose, intention, and will are key factors of agency in the theory of action, and in this paper we emphasize in particular the concept of intention. All three of these factors can be regarded as individual, but Hegel (2007), a pioneer in the theory of action, argued against the atomic and individual view on agency. He underlined activities as actions in a context and that actions have to be seen in a holistic perspective. An agent is an individual who acts in a social structure and represents something or someone. One can negotiate on behalf of someone or oneself, one can be a negotiator. Agency is also a continuum. Students can have agency to a certain extent in one situation. They can have genuine agency in one particular context but not in another. Agency is contextual, as Hegel argued. 
A student's agency exists in and depends on relationships to the other students and the teacher. Agency has thus an individual dimension since it is about a student's possibilities to influence what happens in a group. However, agency is largely a social concept since it is about the possibilities students collectively are given by other students and teacher(s) to influence the course of events. The social dimension of agency concerns two aspects. There is agency as group agency, for instance students' collective agency in a school class, and there is agency as an individual agency effectuated in a social setting. Roth's (2004) concept of shared agency is relevant in this respect as it accentuates two relevant aspects for the social dimension of agency: the importance of joint commitment to the activity and the ability to act according to another's intentions.

Power and empowerment are key aspects of agency. Ernest (2002, pp. 1-2) used three different but overlapping domains where mathematics can be empowering: mathematical (mastering the mathematical language), social ("the ability to use mathematics to better one's life chances in study and work and to participate more fully in society through critical mathematical citizenship"), and epistemological (the ability to construct new knowledge and to have the power to assess it). Stemhagen (2009) used the term genuine mathematical agency to denote the type of agency made possible through genuine social and epistemological empowerment. Students' genuine agency involves the capacity and possibility to act and make choices according to their own will and intentions in a school setting. It is their space to say and do according to their wants and aims.

Valero (2004) underlined that power often is taken for granted and not explicitly defined. Mathematics is seen as a powerful tool in itself, without any further argumentation. One example is how OECD describes and uses mathematical literacy whereby mathematics knowledge is seen as empowering in itself. Valero argued that if there is a lack of awareness and critical reflection concerning how mathematics can be used in argumentation, then mathematical knowledge is not enough to develop empowerment. Power can also be regarded as a relational capacity where students can position themselves in different situations and use a variation of resources related to power. This includes, Valero argued, that power is not an inherent and permanent characterization of social actors. Power is situated, relational and in constant transformation, and such transformations occur through participation in the construction of a discourse. This derives from Foucault's (1972) discussion of power and negotiation of discursive practices. Following Foucault's ideas, Norén (2013) described how agency implies that individuals act according to their intentions and thereby create positions in a discursive practice. Agency, she argued, is a result of social practices embedded in different discourses that frame classroom culture, e.g. public discourses and the exercise discourse (Mellin-Olsen, 1991). Andersson (2011) underlined that learning can be expressed not only through the subject mathematics but also through the power of mathematics in society. 
Pickering (1995) described two kinds of agency in addition to human agency: material and disciplinary agency. Material agency is the way humans can be affected by "the outside", e.g. the laws and forces of nature or computers in the classroom. Does the computer program the student or is it vice versa, as Papert (1981) asked. Disciplinary agency concerns how factors like the classroom culture, dominant ways of communicating, and relationships between students and between teacher and students can influence and possibly afford and constrain students' agency. Pickering introduced the metaphor dance of agency to illustrate the interplay between material and human agency and between disciplinary and human agency. This paper focuses on the latter. Rewriting Wagner's (2007, p. 43) description of the interplay between mathematicians' agency and the agency of the mathematics discipline, gives the following: When students "follow the established patterns of their disciplines [the classroom discourse] they surrender to disciplinary agency". When students "take initiative with open-ended modelling [e.g. a traffic safety project] and crossdiscipline conversation [critical argumentation] they extend present cultural and conceptual practices and, in so doing, demonstrate their human [student] agency". In a dance of agency there is a shift between who is in control, between free and forced moves. It is, as Pickering (1995, p. 22) said, a "dialectic of resistance and accommodation". Roth's (2004) shared agency concerns agency between humans, while Pickering's dance of agency concerns how human agency is challenged by material or culturally governed agency. The two metaphors complement each other.

Students' agency is in the following analyses understood as contextual and social actions whereby empowerment and critical argumentation are key factors. Agency is a complex concept and involves interplay between a group and an individual, and between humans and disciplinary traditions.

\section{METHOD}

As a part of the research project CDCompM (Critical Democratic Competence and Classroom Discussions in Mathematics), the researchers from BUC followed a school project on traffic safety. Research data were collected through video recording, screen recording, observation, and interview. Two student pairs' data handling and preparations for class presentation were video recorded and observed. Their computer activities were recorded by screen recording software. Plenary presentations and discussions were observed and video recorded with two cameras. The teacher was interviewed before and after the pair-work and plenary sessions, and this was audio recorded. An article in the local newspaper, and the students' field notes, spreadsheet files, and learning logs served as additional material.

The two pairs' discussions, the full class discussions and the interviews with the teachers were transcribed. The communication analysis emphasizes students' agency, mutual meaning-making, and teacher's facilitation of agency, and is influenced by a pragmatic perspective (e.g. Austin, 1962; Searle, 1969). The analysis focuses on language function in a context. The analysis is also inspired by Bakhtin's dialogical perspective (Herheim, 2012; Høines, 2002; Rangnes, 2012). 
The teacher served as a consultant whenever there was doubt or missing information. The following excerpt is chosen because its' content is referred to in different activities: during the students' field work, the pair-work in the classroom, the presentations, and during the interviews with the teacher. The refining of categories is a recurring topic which provides an opportunity to gain a better understanding of students' agency and the teacher's facilitation of agency.

\section{RESULTS AND DISCUSSION}

In the following, we analyze and discuss data from phase four (the pair work), phase five (the presentations), and phase six (the meta-discussions) of the students' project.

\section{Phase four, the pair work}

The excerpt is from a conversation between a pair of students, Mark and John, and the teacher. They work on their own data as well as data collected by the other students, and they prepare for their presentations in class. The two students and the teacher have, prior to this excerpt, discussed the concept of frequency, and the students realize that they need to make a table to better communicate the results from the traffic counts:

Mark: $\quad$... so then we need to make a table out of this.

Teacher: Yes, but then you have to consider ... you know what "other" [a category] is, right?

Mark: $\quad$ Mhm.

Teacher: Do you remember what it was?

Mark: It was ...

Teacher: Some sheep he [a classmate] had counted?

Students: Yes. (In chorus and with a tentative laugh)

Teacher: Yes. Is that something you want to show? Is that something you want to include, to show?

John: $\quad$ Nnn ... (Starts on a "no" but does not finish it)

Teacher: In a serious letter?

John: Noo. (drawn out)

Mark: $\quad$ Noo. (drawn out)

Teacher: Why not?

John: Because “other" ... those sheep don't matter ... or? They can walk in the road and then you can crash into them.

Mark: $\quad$ Yes, it is, then you have to ...

Teacher: It describes a bit how the roads are and that there also are animals in the road. 
Mark: "Wild sheep" [a breed of sheep].

Teacher: Is that a threat to traffic safety?

Students: Yes. (In chorus)

The excerpt starts with Mark ascertaining that they need to make a table. The teacher confirms this. In the following utterances she directs the students' attention towards the "other" category, the sheep counted by a classmate. The students remember the sheep, and the teacher goes on asking the students if that is something they want to include in their results. At first the students say a drawn out "noo" with a tone of voice indicating some uncertainty. The teacher then asks "why not?" The first half of John's answer is an argument for why they should not include the sheep. In the middle of his utterance he stops and asks "or?" In the second half he goes on by commenting his own question saying that sheep can in fact walk in the road and cars can crash into them. Mark agrees with a "yes", and the teacher says that animals in the road also are a part of the picture. Mark specifies that they are talking about wild sheep. The teacher asks if the students think that is a threat to traffic safety, and the students answer "yes" in chorus.

The teacher's choice of words "is that something you want to include ... in a serious letter", and her tone of voice, indicate that she was doubtful to the relevance of the four sheep. The teacher had, when they returned to the school from the traffic counts, briefly discussed the relevance of the sheep with the student who had counted them. In the interview the teacher confirms that she during that discussion, and initially in the conversation with Mark and John as well, thought that the students should not include the sheep neither in their presentation nor in a letter to authorities. Even so, she goes on by asking "why not" in order to encourage the students' argumentation. The students respond, and John argues against what the teacher and the students initially thought. The teacher is open-minded and encourages the pupils to argue for why the sheep should or should not be included. Her questions invite and facilitate students' agency. The teacher, in particular with her "why not" utterance, facilitates students' critical argumentation, and by that she also demonstrates her teacher agency. She does not surrender to disciplinary patterns such as IRF (initiativeresponse-feedback) communication.

John's "or" is a key utterance in this excerpt with regard to students' agency and critical argumentation. Up until this point, the students as well as the teacher view the counting of sheep to be more of a fun thing than a relevant observation. The smiles and tentative laughs and the teacher's phrase "in a serious letter" indicate that they think they cannot use the sheep in a formal mathematical argumentation with authorities. This completely turns around when John reflects on consequences of sheep in the road. When the teacher at the end asks if the sheep is "a threat to traffic safety", the students respond in chorus and with a clear "yes". During their presentation in class, Mark and John extend their argumentation in this respect: "sheep go in the middle of the road - a person doesn' $t$ ". 


\section{Phase five, the presentations}

The students use the vehicle categories made by the teacher, and they are critical, in particular with regard to "the large vehicle" category. This is evident during the presentations. In the middle of Mark and John's presentation, a student bursts out: "When I look at what we have counted, I think that we should have had a separate category for buses". The student simply takes the word without being invited to do such a reflection by the teacher. The remark might come as a consequence of Mark and John's refining of the "other" category. The classmates then support this suggestion by arguing that there are more people in buses than in cars and trucks. The students include consequences in their argumentation. This is an example of how, first the individual student and then a group of students, can influence the course of events. It is shared agency where students and teacher are in joint commitment to the discussion and act according to each other's intentions.

The students discuss school road, vehicles, and sheep. The discussions are linked to local contexts and everyday language. When the categories pre-made by their teacher are critically evaluated, when they refine the categories and apply them on their data, they use everyday knowledge. The teacher facilitates such space by including a category termed "other" and by emphasizing questions and encouraging students' argumentation. When the teacher in the example from phase four says "it describes a bit how the roads are and that there also are animals in the road" she shows that she acknowledges the students' view on the relevance of the sheep. Acknowledging consequences of students' agency is crucial in making students' agency genuine. The teacher acts according to the students' intentions, and she participates in refining the categories she made herself. When the students shift from excluding to including the sheep, they accept the teacher's invitation to make arguments and act independently, and they use the opportunity to take agency.

The large vehicle category is refined and the sheep are included in the "other" category. The teacher says in the interview, when commenting on the students' sheep arguments, that it is "wonderful to have students that have the guts to say something else than the teacher". Neither the teacher nor the students are restrained by a dominant disciplinary agency. They do not follow a disciplinary argumentation pattern such as the IRF pattern. Furthermore, if the students had been stronger influenced by disciplinary agency, then this project could easily been yet an example of Mellin-Olsen's (1991) concept the exercise discourse. The students could have used the categories as something given and with no need for discussion. They did not "have to" critically evaluate the categories. However, the teacher invites the students to a dance of agency when she encourages them to argue and reflect upon the categories, the figures, and the use of them. The students take initiative regarding how to count and categorize vehicles, and how to support their choices with arguments. They do so even if it means they have to challenge or refine something their teacher has said or done. The power balance varies and they share agency. The teacher's open-mindedness incites the students' agency. 


\section{Phase six, the meta-discussions}

During the meta-discussion succeeding the presentations, the teacher asks if the project is worthwhile, and if so, why? One student says: "Better to work like this because then we know what we are going to use mathematics for in real life". The student uses the comparative adjective "better" without saying what it is better than. It is implicitly understood that the student experiences the traffic safety project as better than what they normally do in their mathematics lessons. By saying "... we know what we ...", in which the pronoun "we" is used twice, the student shows ownership and includes classmates as well. The choice of the words "real life" highlights the potential of mathematics as social empowering.

Another student says: 'I think it's more fun because you don't have to work in a text book which only makes random tasks ... is meaningless, but we go and get the tasks ourselves. Measure it, write it, make it on spreadsheet". This student as well makes a comparison by saying "more fun" and explicitly compares the project with working with text books. The utterance "... a book which only makes random tasks" assigns the book an agency. The "book" has material agency. Working with random tasks is described as "meaningless" by the student, and can be an expression of a lack of student agency and a distance to the context a textbook can offer. The student adds “... but we go and get the tasks ourselves". Making tasks oneself is an expression of ownership and power. The verbs used at the end of the quote, "measure it, write it, make it ..." are active verbs and indicate that the students also regard themselves as active individuals - with agency. The student alternates between using "you" and "we". When he talks about the book, he uses "you". That indicates distance. When he refers to the project he uses "we" and "ourselves", and such use of pronouns indicates an identification and ownership with the project.

A third student adds: "And when you do this [the project], you know that it matters whether you do right or wrong. In the book it's not very important whether you do right or wrong". This student uses "you" and generalizes by that his utterance. The phrase "... you know that it matters ..." indicates the student's engagement regarding the importance of their findings. This issue of importance influences the communication of their traffic safety results (cf. "in a serious letter"). This student as well compares the project with text book work: "In the book it's not very important whether you do right or wrong". It is easier to identify errors when the students own the tasks and the numbers (raw data) because they are familiar with conditions and context. Text book work gives no other consequences than the teacher's assessment, and when the tasks and the numbers are given, it can be hard to generate strong enough ownership to be able to critically evaluate answers. How students understand the relevance of the tasks makes conditions for their ability to show critical reflections and take mathematical agency.

A fourth student says: "You influence society in a good way because you can save people ... a car can drive off the road, and that might be prevented with higher barriers". The student argues for the importance of the project, it can influence 
society by saving lives, and hereby she expresses an experience of agency. The agency points forward towards responsible participation in society. The student concretizes the consequences if nothing is done, "a car can drive off the road", and that can be prevented by higher barriers. In fact, shortly after the project finished, several barriers were repaired and made higher.

These four utterances show students' empowerment and agency. They have the ability and the power to assess the project in terms of critical citizenship, and in terms of how a socio-political reality as traffic safety can provide a meaningful context for applying mathematical knowledge. It exemplifies how social and epistemological empowerment can generate genuine student agency.

\section{CONCLUDING REMARKS}

The paper identifies characteristics of students' agency by investigating interplay between students and between students and teacher in a social-political context. It explores students' critical argumentation and empowerment when mathematics is used in a real-life context. Such an approach is important for students' attitudes towards mathematics as something relevant for them and their lives. The students' agency is illustrated by their critical reflection and argumentation concerning their data and the teacher's categories. The students' meta-reflections show how they take ownership and have the power to assess the importance of their project. They argue for change in society, and using mathematics "to better one's life chances" (Ernest, 2002 , p. 1) is social empowerment, literally as well as metaphorically, in this project.

To choose a project on traffic safety on the roads between the students' homes and their school adds fuel to students' agency and critical argumentation. It is a project that goes beyond the exercise discourse. The teacher encourages their critical argumentation by emphasizing the role of questions - for her as well as the students. By focusing on the students' independent and critical argumentation, she facilitates the students' empowerment and agency. The teacher's facilitation of students' agency is also an expression of her teacher agency. This double-sidedness deserves further investigations, but that is beyond the scope of this paper.

\section{REFERENCES}

Andersson, A. (2011). Interplays between context and students' achievement of agency. In M. Pytlak, T. Rowland \& E. Swoboda (Eds.), Proceedings of the 7th Congress of the European Society for Research in Mathematics Education (pp. 1399-1408). Rzeszów: University of Rzeszów.

Andersson, A., \& Norén, E. (2011). Agency in mathematics education. In M. Pytlak, T. Rowland \& E. Swoboda (Eds.), Proceedings of 7th Congress of the European Society for Research in Mathematics Education, CERME 7 (pp. 1389-1398). Rzeszów: University of Rzeszów.

Austin, J. L. (1962). How to do things with words: the William James lectures delivered at Harvard University in 1955. London: Oxford University Press. 
Balasubramanian, A., \& Gutstein, R. (2013). The complexity of interweaving mathematical and sociopolitical content. In M. Berger, K. Brodie, V. Frith \& K. le Roux (Eds.), Proceedings of the 7th International Mathematics Education and Society Conference (MES 7) (Vol. 1, pp. 203-212). Cape Town, MES 7.

Ernest, P. (2002). Empowerment in mathematics education. Philosophy of Mathematics Education Journal, 15. Retrieved from http://people.exeter.ac.uk/PErnest/pome15/ empowerment.htm

Foucault, M. (1972). The archaeology of knowledge. London: Tavistock Publications.

Hegel, G. W. F., \& Inwood, M. J. (2007). Hegel's philosophy of mind. Oxford: Clarendon press.

Herheim, R. (2012). Pupils collaborating in pairs at a computer in mathematics learning: investigating verbal communication patterns and qualities. (Doctoral dissertation), Bergen: University of Bergen

Høines, M. J. (2002). Fleksible språkrom: matematikklcering som tekstutvikling [Flexible spaces of language: mathematics learning as text development]. (Doctoral dissertation), Bergen: Universitetet i Bergen.

Mellin-Olsen, S. (1991). Hvordan tenker loerere om matematikkundervisning? [How do teachers think about mathematics teaching?]. Bergen: Høgskolen i Bergen.

Norén, E. (2013). Tvåspråkig matematikundervisning [Bilingual mathematics teaching]. Tangenten, 24(3), 20-26.

Papert, S. (1981). Mindstorms. Children, Computers and Powerful Ideas. Brighton: Harvester.

Pickering, A. (1995). The mangle of practice: time, agency, and science. Chicago, IL: University of Chicago Press.

Rangnes, T. E. (2012). Elevers matematikksamtaler. Laering $i$ og mellom praksiser [Students' mathematical conversations - Learning in and between practices]. (Doctoral dissertation), Kristiansand: University of Agder.

Roth, A. S. (2004). Shared Agency and Contralateral Commitments. The Philosophical Review, 113(3), 359-410. doi: 10.2307/4147974

Searle, J. R. (1969). Speech acts: an essay in the philosophy of language. Cambridge: Cambridge University Press.

Skovsmose, O. (2005). Travelling through education: uncertainty, mathematics, responsibility. Rotterdam: Sense Publishers.

Stemhagen, K. (2009). Social justice and mathematics: rethinking the nature and purposes of school mathematics. In P. Ernest, B. Greer \& B. Sriraman (Eds.), Critical issues in mathematics education (pp. 337-350). Charlotte, NC: Information Age Publishing Inc. \& The Montana council of teachers of mathematics.

Valero, P. (2004). Socio-political perspectives on mathematics education. In P. Valero \& R. Zevenbergen (Eds.), Researching the socio-political dimensions of mathematics educanalation (pp. 5-24). Boston, Mass.: Kluwer Academic Publishers.

Wagner, D. (2007). Students' critical awareness of voice and agency in mathematics classroom discourse. Mathematical Thinking and Learning, 9(1), 31-50. 


\title{
MATHEMATICS IN A LITERACY PERSPECTIVE: META AWARENESS FOR ALL PUPILS
}

\author{
Bodil Kleve \\ Oslo and Akershus University College of Applied Sciences
}

In this theoretical article, the increasing social inequalities in Norwegian educational system are recognized and it is argued for higher meta awareness and meta knowledge for all pupils. Taking a didactic literacy perspective, the argument is presented on three levels, which together build on the perspective of meta awareness. First, the level of discourse, primarily concerning cultural relations and communities of meaning, is considered. The next level is genre, concerning both common cultural texts and practices and how meanings are framed in linguistic forms. Finally, arguments regarding syntagmatic and paradigmatic modes of thought are considered. This is substantiated by data from own classroom research in order to argue that both modes of thought are needed for all pupils in mathematics.

KEYWORDS: Social inequalities, primary and secondary discourse, genre

\section{INTRODUCTION}

In 2006 a new curriculum reform, The Knowledge Promotion, was introduced in Norway. The overall goal for this new curriculum was to raise the knowledge level of all pupils in school. An explicit goal was to change school in order to make the impact of family background on pupils' school results less. However, no earlier reforms has succeeded in this work, neither has the Knowledge Promotion.

In Norway, education is a democratic right and social background should not be a reason for lack of education. Yet, despite the democratisation which has taken place since the last world war, social inequalities are increasing within the Norwegian educational system as in many parts of the world: educated parents foster educated children (Bakken, 2004; Bordieu, 1995; Zevenbergen, 2001).

\section{DIFFERENT SOCIAL BACKGROUNDS AND MATHEMATICS LEARNING POSSIBILITIES}

In an earlier article, we have argued that cross-curricular perspectives may be important steps towards improving the impact of schooling for all pupils, but that teachers need to understand the literacy demands of cross-curricular work itself (Kleve \& Penne, 2012). Having recognised the increasing social inequalities, I now suggest that a higher meta awareness (which involves thinking about thinking and awareness of what Discourse you are in) of both language and modes of thought will increase all pupils' possibilities for learning. My argument is based on Bruner (1986) and on other theorists who have developed his theories further. One of Bruner's main arguments is that we learn through the use of language and meta awareness which involves being aware of the learning situation (Bruner, 1996). Olson (1994) argues that to master a school subject is to develop the ability to manipulate different texts: 
To be literate it is not enough to know the words; one must learn how to participate in the discourse of some textual community. And that implies knowing which texts are important, how they are to be read and interpreted, and how they are to be applied in talk and action (p. 273).

According to this, mathematical literacy implies knowing how to read, interpret and manipulate mathematical symbols, and knowing how mathematical texts and symbols are to be applied in discussions and activities.

Gee (2012) emphasises the difference between acquisition (acquiring something more or less subconsciously) and learning (conscious knowledge gained in a learning situation and through teaching), reminding us that what many pupils already have acquired before they start school, others have to actively learn. This is a problem which has been neglected in many pedagogical reforms. The slogan "responsibility for own learning" which has been central in Norway for many years, is one example of such neglect. Teaching, which is mainly based on acquisition through pupils' activities and not on metalinguistic awareness, will reinforce the differences which are already there. Thus, school can be looked upon as a reinforcement of social inequalities. Acquisition and learning will be further discussed in the next section.

Metalinguistic awareness and literacy competence characterise the "winners" in the Norwegian school (Bakken, 2004; Penne, 2006) as they do in other countries. Bruner (1996), whose work on "modes of thought" I return to later, makes this his main point in discussing inequalities in school, emphasising that:

If the limits imposed by the languages we use are expanded by increasing our "linguistic awareness", then another function of pedagogy is to cultivate such awareness. [...] In sum then, "thinking about thinking" has to be a principal ingredient of any empowering practice of education (p. 19).

In this article I discuss all pupils' learning possibilities in mathematics in a literacy perspective. The argumentation will take place on three theoretical levels: I explore mathematics on the level of discourse, then I turn to the level of genre, and third I examine the implications of Bruner's (1986) concept of "modes of thought" in terms of ways of thinking and reasoning in mathematics. First, however, I will discuss and emphasise the impact of social background for pupils' mathematics learning, and the role of their prior understanding about "the meaning" of typical classroom activities, that is, of playing the school game (Olson, 1994). The starting point for this discussion is Gee's (2012) argument that "social groups that are deeply affiliated with formal schooling often incorporate into the socialization of their children practices that resonate with later school-based secondary Discourses" (p. 154). With regard to mathematics, this is especially crucial because mathematics belongs to a Discourse, which is very different from everyday or primary Discourse. Children who have not benefited from such socialisation may therefore meet greater difficulties in learning mathematics in school. 


\section{LITERACY AND PRIMARY AND SECONDARY DISCOURSES}

Pupils start school with different prior understandings about its activities and goals. They have different experiences with books, literature and calculation, and different affinities in relation to letters and numbers. These prior understandings, which encompass experiences, language, habits, affinities and feelings, constitute what Gee (2012) calls their "primary Discourse"

Primary Discourses constitute our first social identity, and something of a base within which we acquire or resist later Discourses. They form our initial taken-for-granted understandings of who we are and who people "like us" are, as well as what sorts of things we ("people like us") do, value, and believe when we are not in public (p.165).

The primary Discourse is a "value Discourse" and is part of different networks of meanings. It may, or may not, support school activities. Some pupils feel comfortable at school because of a match with their primary Discourse, while for others school may be foreign. This is a challenge in a learning context. School is more or less about constant meetings with new and different thinking and texts, what Gee calls "secondary Discourses". Ideally, the purpose of schooling is to encourage openness to unfamiliar and new secondary Discourses. Mathematics belongs to a secondary Discourse which is especially foreign for pupils since the subject in many ways differs dramatically from their everyday or primary Discourse. Harel and Sowder (2007) carried out a study on students' understanding of proofs in mathematics, finding that students' use of numerical examples, as a way of proving, was prominent. In everyday Discourse "no rule without exceptions" and "the exception proves the rule" are accepted ways of arguing for or "proving" something. However, if students try to prove mathematics through using these rules from their everyday Discourse, they will fail. In the classroom data presented later in this article, numerical examples were not accepted as proof, because mathematical thought concerning proof is different from thought in all other knowledge domains. A teacher's move between concrete examples and generalization is illustrated in the data excerpt later in this article.

Literacy is mastery of a secondary Discourse (Gee, 2012). Mastery of performance, for example carrying out routine procedures in mathematics, is based on acquisition. Gee argues: "Time spent on learning and not acquisition is time not well spent if the goal is mastery in performance" (p. 174). Thus if the goal is mastery of routine procedures in mathematics, Gee argues for what he calls the Acquisition Principle. In discussing the difference between acquisition and learning, Gee (2012) emphasises meta knowledge.

\footnotetext{
${ }^{1}$ The term "Discourse" (with a big "D") is for Gee meant to cover important aspects of what others have called

"discourses". Discourses, for Gee, crucially involve:

"-ways of performing and recognizing characteristic identities and activitites

-ways of coordinating and getting coordinated by other people, things, tools, technologies, symbol systems, places and times;

-characteristic ways of acting -interacting-feeling-emoting-valuing- gesturing-posturing-dressing-thinkingbelieving-knowing-speaking-listening (and in some Discourses, reading -and writing, as well)" (Gee, 1999, p. 38).
} 
According to The Learning Principle, "Meta knowledge is best developed through learning, though often learning applied to a Discourse one has to a certain extent already acquired" (p. 174). Related to this Gee introduced the concept liberating (powerful) literacy which is a particular use of a Discourse and not a particular Discourse. Liberating literacy almost always involves learning and not just acquisition. According to Gee (2012), comparing Discourses should be part of the learning process which develops meta knowledge. He writes:

Teaching that leads to learning uses explanation and analyses that break down material into its analytic bits and juxtaposes diverse Discourses and their practices to each other. Such teaching develops meta-knowledge. While many "liberal" approaches to education look down on this mode of teaching, I do not; I have already said that I believe that metaknowledge can be a form of power and liberation (p. 175).

Similarly, Zevenbergen (2001) focuses on the potential difficulties pupils will meet in mathematics classrooms. Like Gee, she emphasises that pupils enter school and mathematics classrooms with different social backgrounds and correspondingly different language backgrounds. Drawing on Bourdieu, she argues that some pupils are "predisposed" (p. 47) to learn mathematics, not because of innate abilities but rather because of their family habitus. These pupils are better equipped to cope with the mathematical culture and to "position themselves more favorably in the eyes of their teachers" (p.47). For others the opposite will happen, and success will be more elusive. This initial habitus is also recognisable in Norwegian classrooms (Penne, 2006).

Also, Moschkovich (2003) discussed the distinction between everyday Discourse and mathematical Discourse and thus emphasised the role of students' social background in their taking part or not in mathematics discussion.

\section{DISCOURSES, GENRES AND MODES OF THOUGHT- THREE LEVELS IN THE TEACHING/LEARNING PROCESS}

In order to discuss the challenges pupils' different social backgrounds play for mathematics teaching and learning I consider mathematics on three levels. First, The level of Discourse, which primarily encompasses cultural relations and communities of meanings in school. Second, the level of genre, which concerns recognisable common cultural texts and the frames of reference, which support their understanding. Finally, on the level of paradigmatic and syntagmatic modes of thought (Bruner, 1986) which are necessary for learning within mathematics.

\section{The level of Discourse}

A Discourse is a kind of "community of meaning", of ways of thinking to understand the world or a part of the world. Discourse gives meaning, a feeling of inclusion and identity, for example in the profession of teaching. Within a Discourse, some frames may be obvious while others are in motion, formulated by Gee (2001) as follows:

We can think of Discourses as identity kits. It's almost as if you get a tool kit full of specific devices (i.e. ways with words, deeds, thoughts, values, actions, interactions, objects, tools, 
and technologies) in terms of which you can enact specific activities associated with that identity (p. 720).

Mathematics teachers are located within a Discourse or "identity kit" as does the textbook in the subject. To mathematics teachers the Discourse is creating an implicit world of knowledge or experience. However, from some pupils' point of view, what is obvious to teachers may not be certain. Some have a background providing them with access towards unfamiliar Discourses or secondary Discourses, but others will not recognize these without support from the teacher. Solomon (2009) emphasises the teacher's role in supporting mathematical literacy, and I agree that this can only be facilitated through intervention from the teacher which makes rules, language and nature of arguments in the subject more explicit. The only way pupils can become party to what is frequently implicit knowledge is through awareness of mathematics as a secondary Discourse.

Dowling (2001) presents an example of how complicated these nuances can be in mathematics classrooms. He distinguishes between two approaches representing two different interpretive frameworks or domains of mathematical activity: a practical or public domain and what he calls an esoteric domain. To be successful in mathematics, pupils need to work at the level of language, rules and principles, on what he calls "the level of discourse" (p. 182). He places this formal level, which defines and relates mathematical objects, in the esoteric domain of mathematical activity. In school, however, formal mathematics from the esoteric domain is often projected onto a practical task for the low attaining pupils, for example shopping, in the public domain. As Walkerdine (1988) pointed out, the use of numbers in shopping is not the same as studying number relationships in mathematics in the esoteric domain. Thus mathematics presented in an everyday discourse may be embedded in practical tasks and low attaining pupils will not gain the desired access to the subject. As a result, pupils' predispositions for mathematics, or lack of such, will be reinforced at school.

Similarly, Kleve (2007) reported that pupils with perceived low abilities were taught mathematics differently from high ability pupils in Norway. Low ability pupils were confronted with more rote learning and focus on methods and procedures, in comparison with pupils who were perceived to be more able. Furthermore, the low ability students were not challenged in the same way to make connections between different areas of mathematics.

\section{The genre level and pupils' prior understanding}

There is much discussion in the literature about the relationship between discourse and genre (see for example Ledin, 2001). Here I will adhere to Hyland's (2003) definition of genre as follows:

Genre refers to abstract, socially recognized ways of using language. It is based on the assumptions that the features of a similar group of texts depend on the social context of their creation and use, and that those features can be described in a way that relates a text to others like it and to the choices and constraints acting on text producers (p. 21). 
Although a variety of genres are expressed in our curriculum, and teachers themselves draw on these genres, research suggests that genres are rarely made clear for pupils, who may lack the same control of genre. They lack a cognitive frame or interpretive lens for developing their thinking within a genre (Feldman \& Kalmar, 1996). The challenge for teachers is to teach genres explicitly - as Cochran-Smith's (1994) work in English literacy suggests, successful pupils have established sufficient preunderstanding for genres while others need the teacher's help to consciously establish sufficient understanding. Martin, Christie, and Rothery (1994) refer similar examples from mathematics. Successful pupils come to school with sufficient pre-understanding of genres. Less successful pupils need the teacher's assistance to understand the implicit rules of genre in the subject.

Prior understanding opens up the text's meaning as linked to a cultural community of meaning. It is the same issue in mathematics. Solomon (2009) refers to English language classrooms in her call for awareness of genre, and emphasises the importance of awareness of genre also in mathematics. Despite not being evident in mathematics classrooms a wide range of genres are being used. In mathematics, we are using graphs as expressions. Graphs are means of communicating information and express meaning. Also, mathematical definitions, proofs, equations, algorithms and statistical tables are considered as expressions of genre. In the mathematical part of the curriculum in Norway (Ministry of Education and Research, 2013) these are integrated as competence aims, which encompass a variety of genres in line with the description presented by Marks and Mousley (1990):

In solving problems, writing reports, explaining theorems and carrying out other mathematical tasks, we use a variety of genres...Events are recounted (narrative genre), methods described (procedural genre), the nature of individual things and classes of things explicated (description and report genres), judgments outlined (explanatory genre), and arguments developed (expository genre) (p. 119).

Genres may be discursively expressed, but they will always be more than this. On one hand, they represent different textual traditions. On the other hand genres are part of successful pupils' prior understanding; they are frames for understanding, necessary for academic development and may be used as interpretive lenses (Bruner, 1986; Feldman \& Kalmar, 1996). Many pupils need a specific prior understanding to decode the genre signs necessary for a relevant interpretation of the text (Cochran-Smith, 1994).

The research reviewed here demonstrates the importance for pupils to gain awareness of mathematics discourse as well as learning about genre in the subject. Discourse and genres make mathematics what it is.

\section{Awareness of different modes of thought in mathematics}

As a last point, awareness of different modes of thought as a prerequisite for learning is discussed. Suggesting that it is necessary, but not sufficient to work on the level of discourse and genre, and building on Bruner's (1986) distinction between paradigmatic 
and syntagmatic modes of thought, I suggest that working in mathematics requires both modes of thought, or 'modes of apprehension'.

For Bruner, the paradigmatic mode of thought is linked to a scientific way of thinking that requires arguments based on decontextualized generalizations and explanations (as in the case of mathematics). It requires the acknowledgement of an unchangeable, permanent, abstract system. The syntagmatic mode of thought is primarily narrative and requires hermeneutical ways of reasoning, and as such contextualized interpretations. Bruner (1986) writes:

Let me begin by setting out my argument as baldly as possible, better to examine its basis and its consequences. It is this. There are two modes of cognitive functioning, two modes of thought, each providing distinct ways of ordering experience, of constructing reality. The two (though complementary) are irreducible to one another. Efforts to reduce one mode to the other or to ignore one at the expense of the other inevitably fail to capture the rich diversity of thought (p. 11).

The syntagmatic mode communicates an 'experienced' world, and is more or less subjectively based and therefore cannot communicate absolute truth but, rather, verisimilitude. We therefore have to interpret within contexts, within which parts can be explained in the light of wholes and vice versa. In communicating and thinking in the syntagmatic mode, the narrative structure is the most pervasive cognitive schema (Bruner, 1986, 1990, 1996; Lakoff \& Johnson, 1999; Vygotsky, 1987). For Bruner it is unrealistic to suppose that the two modes can be separated and that we can choose the one over the other. Thus, in what follows, I will discuss generalisations, argumentation and proofs in mathematics and link the discussion to the two modes of thought, emphasising the importance of both, and illustrate with data from a mathematics lesson.

\section{GENERALISATION AND ARGUMENTATION IN MATHEMATICS}

Although, as Mason (2004) points out, people deal with generalisations and abstractions all the time, in mathematics generalisations are expressed in a succinct notation from which further conclusions, particular or general, may be drawn: "Mathematics deals with relationships per se, and so context is of the least importance; hence the prevalence of abstractions in mathematics" (p. 132, my emphasis). Oatley (1996) refers to Bruner's 'two modes of thought' claiming that objects expressed in the syntagmatic mode slips easier into the mind whereas the mind is more resistant to objects expressed in the paradigmatic mode, and emphasises the need for both modes of thought in physics and mathematics. In order to support the claim that also mathematics needs both modes of thought I will refer an episode from a mathematics lesson, in a mixed ability $10^{\text {th }}$ grade class, to show how generalisation was used. The data are from Kleve (2007).

The starting point was the following task from a test: "The length of a rectangle is increased by $15 \%$ and the breadth is reduced by $20 \%$. How many percent does the area of the rectangle change?" Proof and generalisations are central genres in mathematics. 
On the test, the pupils had worked out the task with concrete examples, and some pupils claimed that showing the same change in three different rectangles, was sufficient in order to generalise. The teacher took those examples as a starting point and thus offered the pupils mediating tools to solve the task. The relation to something known for the pupils was established, before a shift in discourse took place. The context was of least importance. Generalisation was the core in this task.

1 Cecilie: The length in a rectangle is increased by $15 \%$ and the breadth is reduced by $20 \%$ how many per cent does the area of the rectangle change? And the way everybody who answered that task did it, was that you chose a rectangle. Let us take this rectangle in which the length is 20 and the breadth is 5 (she drew it on the board). What is the area of the rectangle?

2 pupils: Hundred

3 Cecilie: It is hundred. The area is hundred. And then the task was: The length is increased by $15 \%$, how much will the new length be?

4 Leif: Twenty-three

5 Cecilie: Very good, Leif, very good mental calculation. The new length becomes twenty-three, and when the breadth is reduced by $20 \%$, what is the new breadth then?

6 Baard: Four

7 Cecilie: Yes, and what is the area?

8 Baard: It is ninety-two, right?

9 Cecilie: Right. How many percent is the area reduced?

10 Baard: Eight per cent

11 Cecilie: Yes, it is. If it was hundred per cent earlier, then it is ninety-two per cent now, an eight per cent reduction. Then the question is: are you sure it is applicable for other rectangles as well? This was for one special rectangle.

In this episode, they started in a syntagmatic mode, working with concrete examples, and in turn 11 we can see a shift in discourse, a shift in thinking: Is it applicable for other rectangles? A move to the paradigmatic mode of thought was initiated. After this episode, later in the lesson, and as also discussed by Harel and Sowder (2007), the teacher emphasised that, on the test, it had not been sufficient to show numeric examples of the percentage change for concrete rectangles. She required a way to find out if the change was $8 \%$ in any rectangle. A shift to a paradigmatic mode of thought was taken. The discrepancy between everyday thinking and mathematics thinking, and that this task not could be solved using everyday Discourse, was emphasised. Meta knowledge was needed in order to gain liberate or powerful mathematics literacy. In mathematics, generalisations play a crucial role, and use of algebra, which does not belong to students' everyday Discourse, is a way of carrying out generalisations. Later in this lesson, a pupil suggested using algebra: $1.15 \mathrm{a} \cdot 0.8 \mathrm{~b}=0.92 \mathrm{a} \cdot \mathrm{b}$, which is $0.08=8 \%$ change related to $a \cdot b$. That way they had proved that the change was $8 \%$ beyond all concrete examples. 


\section{META AWARENESS IN THE LEARNING PROCESS, WHY IS IT SO IMPORTANT?}

I have argued for meta awareness for all pupils. The starting point was social inequalities and pupils' different learning possibilities as a result of their social background, their primary Discourse. Meta awareness and literacy competence characterise the winners in school (Bakken, 2004; Penne, 2006). However, meta awareness should not be reserved for those whose social background, or 'value Discourse' supports school activities. To decrease the school's reinforcement of social inequalities, teaching should be based on meta awareness rather than acquisition through pupils' activities. My argument has been on three levels; discourse, genre and modes of thought. On the level of Discourse, I have argued that the only way pupils can become party to implicit knowledge is through awareness of mathematics as a secondary discourse. The teacher plays a crucial role in this work. Also, it is important that the "less able" pupils not only should be presented mathematics in an everyday discourse, because then they will not gain the desired access to the subject. On the level of genre, it is important for the teachers to be explicit about genres and to help pupils establish sufficient pre understanding. Finally, the argument has been that both modes of thought, paradigmatic and syntagmatic are necessary for all pupils in the mathematics learning process.

\section{REFERENCES}

Bakken, A. (2004). Økt sosial ulikhet i skolen? Tidsskrift for Ungdomsforskning, 4(1), 83-91.

Bordieu, P. (1995). Distinksjonen. Oslo: Pax forlag.

Bruner, J. (1986). Actual minds, possible worlds. Cambridge, London: Harvard University Press.

Bruner, J. (1990). Acts of meaning. Cambridge, MA: Harvard University Press.

Bruner, J. (1996). The culture of education. London: Harvard University Press.

Cochran-Smith, M. (1994). The making of a reader. New Jersey: Ablex Publishing.

Dowling, P. (2001). Reading mathematics texts. In P. Gates (Ed.), Issues in mathematics teaching (pp. 180-196). London: RoutledgeFalmer.

Feldman, C. F., \& Kalmar, D. A. (1996). Autobiography and fiction as modes of thought. In D. R. Olson \& N. Torrance (Eds.), Modes of thought, explorations in culture and cognition. Cambridge: Cambridge University Press.

Gee, J. P. (1999). An introduction to discourse analysis. Theory and method. London: Routledge.

Gee, J. P. (2001). Reading as situated language: A sociocognitive perspective. Journal of Adolescent \& Adult Literacy, 44(8), 714-725.

Gee, J. P. (2012). Social linguistics and literacies: Ideology in Discourse (4th ed.). New York: Routledge Falmer.

Harel, G., \& Sowder, J. (2007). Toward comprehensive perspectives on the learning and teaching of proof. In F. Lester (Ed.), Second handbook of research on mathematics. Dordrecht: Kluwer. 
Hyland, K. (2003). Genre-based pedagogies: A social response to process. Journal of Second Language Writing, 12(1), 17-29.

Kleve, B. (2007). Mathematics teachers' interpretation of the curriculum reform, L97, in Norway. (Ph. D), Doctoral thesis, nr 5, Kristiansand: Agder University College.

Kleve, B., \& Penne, S. (2012). Crosscurricularity in a literacy perspective: Contrast, confrontation and metalinguistic awareness. International Journal of Educational Research, 55, 48-56.

Lakoff, M., \& Johnson, G. (1999). Philosophy in the flesh. The embodied mind and its challenge to western thought. New York: Basic Books.

Ledin, P. (2001). Temaintervju "Reflexioner kring genre av fyra nordiska forskare". Rhetorica, Scandinavica, 18 (Juni 2001), 2-8.

Marks, G., \& Mousley, J. (1990). Mathematics education and genre: Dare we make the process writing mistake again? Language and Education, 4(2), 117-135.

Martin, J. R., Christie, F., \& Rothery, J. (1994). Social processes in education: A reply to Sawyer and Watson (and others). In B. Stierer \& J. Maybin (Eds.), Language, Literacy and Learning in Educational Practice. Clevedon: The Open University.

Mason, J., \& Johnston-Wilder, S. (2004). Fundamental constructs in mathematics education. London: RoutledgeFalmer.

Ministry of Education and Research (2013). The 2006 knowledge promotion reform. Oslo: The Norwegian Directorate for Education and Training.

Moschkovich, J. (2003). What counts as mathematical discourse? In N. A. Pateman, B. J. Dougherty \& J. T. Zilliox (Eds.), Proceedings of the 27th Annual Meeting of the International Group for the Psychology of Mathematics Education (PME) (Vol. 3, pp. 325-331). Honolulu: University of Hawaii.

Oatley, K. (1996). Inference in narrative and science. In D. R. Olson \& N. Torrance (Eds.), Modes of Thought. Explorations in Culture and Science (pp. 123-142). Cambridge: Cambridge University Press.

Olson, D. R. (1994). The world on paper. The conceptual and cognitive implications of reading and writing. Cambridge: Cambridge University Press.

Penne, S. (2006). Profesjonsfaget norsk $i$ endringstid. A konstruere mening, selvforståelse og identitet gjennom språk og tekster. (Dr. polit), Dr. polit avhandling, UV-fakultetet, Universitetet i Oslo, nr 63.

Solomon, Y. (2009). Mathematical literacy. Developing indentities of inclusion. London and New York: Routledge.

Vygotsky, L. (1987). Thought and language. Cambridge, MA: The MIT Press.

Walkerdine, V. (1988). The mastery of reason, cognitive development and the production of rationality. London: Routledge.

Zevenbergen, R. (2001). Language, social class and underachievement in school mathematics. In P. Gates (Ed.), Issues in mathematics teaching (pp. 38-50). London: RoutledgeFalmer. 


\title{
SUPPORTIVE MATHEMATICS LEARNING COMMUNITY
}

\author{
Jónína Vala Kristinsdóttir \\ University of Iceland
}

The implementation of the policy of inclusive education in Iceland and the growth of migration has welcomed previously excluded students into schools. As a consequence, teachers are currently faced with new challenges to differentiate teaching. This qualitative collaborative inquiry into mathematics teaching aims at learning to understand how teachers develop their mathematics teaching through a co-learning partnership with a teacher educator. The narrative presented here is of a special education teacher who works with classroom teachers and is representative of the learning that developed within our community. The results indicate that she gained confidence in teaching mathematics as she participated in workshops and that collaborative research can support teachers in developing their practice when meeting new challenges in their work.

Keywords: Teacher development, community of inquiry, mathematics learning

\section{BACKGROUND}

The focus of this paper is on a special education teacher who teaches mathematics to students who have difficulties in learning mathematics. She participated in a collaborative project in which she was researching her practice together with me, and her colleagues. The findings are from a three-year collaborative study with the purpose of deepening our understanding of how teachers meet new cultural and mathematical challenges. In addition, I wanted to learn how participation in a learning community with colleagues and a teacher educator leads to changes that can be valuable for the work in schools.

In designing the study, I drew on my earlier experiences within the field of education both as a teacher and researcher collaborating with general classroom teachers at the primary level. These teachers find it difficult to teach mathematics in diverse classrooms in ways that are coherent with the goals of the national curriculum guidelines. Their own experience as mathematics learners was typically as passive receivers who practiced rules and procedures introduced by teachers and textbooks. Consequently they lack experience in investigating, communicating, reasoning and making connections with mathematics. Additionally, they felt incompetent in using these approaches in inclusive schools (Guðjónsdóttir \& Kristinsdóttir, 2011).

However, if given opportunities to collaboratively investigate with mathematics and solve mathematical problems, teachers can discover how the different experiences they bring into the community contribute to their understanding of the mathematics involved and how people learn mathematics (Gunnarsdóttir, Kristinsdóttir \& Pálsdóttir, 2013). Our results are thus in tune with the results of Boero, Dapueto and 
Parenti (1996) and Crespo and Sinclair (2008), who also found that problem-solving activity may help teachers to experience and discuss difficulties similar to those met by students in class and to understand the importance of evaluating the process in mathematical activities.

To learn more about the work of classroom teachers at the primary level, I contacted two neighboring schools with diverse groups of students. The teachers had no former experience of researching their practice, but expressed a desire to develop their own mathematics teaching. One of the teachers was educated as a social pedagogue and special educator. Her educational background thus differed from the other participants.

The main research question for the project is: What characterizes the learning processes that emerge through collaborative inquiry between classroom teachers and a teacher educator? In this paper the focus is on the special education teacher who participates in the project. The research question that I am working with here is: In what way does the special education teacher perceive how participation in the project is reflected in her teaching?

\section{DEVELOPING AS A MATHEMATICS TEACHER}

Investigation into ones own teaching and reflection on pupils learning is an important part of teacher development. Boaler (2002) emphasizes that a focus on mathematical practices in classrooms helps researchers and teacher researchers to understand the identities students develop, and the different ways they know and use mathematics. The idea of identity builds directly from studies of practice: students develop identities through the practices with which they engage. The teachers' focus on their students' development of identities and their co-learning in the classroom is an important component in their own development as teachers (Boaler, 2002). The teachers in this project engage with mathematics and with developing their mathematics teaching by focusing on their pupils' development of identity.

Teaching children mathematics requires teachers to understand how their students learn mathematics, and they need to be skilled both in mathematics and pedagogy, as well as the pedagogical content knowledge - i.e. the knowledge that combines knowing about teaching and knowing about mathematics (Ball, Thames, \& Phelps, 2008). Teachers need to know mathematics in ways useful for making mathematical sense of student work and choosing powerful ways of representing the subject so that it is understandable by students. Most important is knowing the mathematics required in teaching and being able to use it in practice. Niss (2004) outlined a model for mathematics teacher competency in which both the competencies of working with students, and working with others towards professional development are identified. It is important to note that development of teaching in classrooms is dependent both on the teachers' knowledge and their ability to learn together with others, both their students and colleagues. 
Mathematics educators emphasize the importance of teachers researching their own teaching. Stiegler and Hiebert (2004) claim that teachers have a central role to play in building a useful knowledge base for their profession. They need to analyze what happens when they try something new in their own teaching, record what they are learning, and share that knowledge with their colleagues. Artigue (2009) stresses the importance for research within schools to respect factors internal to the development of the field itself. The progression of research has made it increasingly evident that research methodologies have to take into account the situational, institutional, and cultural dimensions of learning and teaching processes. Research within schools where teachers are active participants in the research process, meets these requirements.

Cochran-Smith and Lytle (2009) emphasize the importance of teacher initiatives in research and in their work. Practitioners are deliberate intellectuals who constantly theorize practice as a part of practice itself, and the goal of teacher learning initiatives is the joint construction of local knowledge, the questioning of common assumptions, and thoughtful critique of the usefulness of research generated by others both inside and outside contexts of practice. Norton (2009) discerns between pedagogical developments and pedagogical research. The former includes activities that have a practical focus and aims at generating practical information that teachers may find useful in their daily practice. Pedagogical research has a more theoretical focus and is a more formal inquiry with accepted research methodology. It aims at generating theories that may work within schools but are not likely to have effects on school culture if they are not presented to teachers in a way that is accessible to them. My goal in researching together with teachers is to build a bridge between theory on mathematics teaching and learning and the practice within schools where teachers are engaged in working with children. These teachers may neither have time nor interest in reading theoretical papers on research findings or write about their work.

\section{COLLABORATIVE INQUIRY}

The study is a collaborative inquiry into mathematics teaching and learning (Goos, 2004), and the aim is to build a co-learning partnership between teachers and a researcher in promoting classroom inquiry (Jaworski, 2006). In an attempt to make explicit the 'practice' in which teachers and researchers participate when collaborating, Jaworski (2003) suggests shifting from the notion of community of practice to that of 'community of inquiry', where teaching is seen as learning-todevelop-learning. In such a community, teachers and researchers both learn about teaching through inquiring into it.

For three years I worked with seven teachers on a monthly basis at 90-minute workshops. The focus of the workshops was on reflection on mathematics, and on mathematics teaching and learning. To help the teachers develop their own understanding of mathematics, we worked with problems that had the potential to 
promote mathematical activity and thinking as well as to stimulate collaboration where discussions and sharing thinking was meaningful. We also discussed new research on mathematics education as well as stories from the teachers' classrooms, reflected on their pupils learning and how their mathematical thinking developed.

The workshops were videotaped, and the teachers collected data from their mathematics classes as well as from mutual visits to each other's classrooms. Interviews with teachers were audiotaped and notes kept from visits to their classrooms. Inga participated in 15 out of 17 workshops. I interviewed her four times and observed four mathematics lessons where she taught 10 to 12 years old children.

Narrative inquiry is used as an analyzing tool to study Inga's learning in participating in this project. The narrative inquiry is a way of understanding and researching into experience through collaboration between a researcher and participants. It is a mode to research with practitioners their lived experience as a source of their knowledge and understanding. The inquiry is collaborative and begins and ends with respect for lived experiences, asking participants to open up their practice and tell their stories (Clandinin, 2013). Narrative inquiry is based on the premise that as human beings we come to understand and give meaning to our lives through stories. The stories Inga told about her work at the workshops and in interviews are the basis of this narrative inquiry. They are first person-identity stories (Sfard \& Prusak, 2005) of Inga, told by her to people who worked with her within the project. Stories about Inga's work, based on my observation of her work with her pupils and in the workshops, are thirdperson identity stories (Sfard \& Prusak, 2005) told by me. In order to understand what was taking place, the data were extracted from the process and analyzed, unfolding special events and scenarios (Hunter, 2010) that were vital in the developing process.

\section{FINDINGS}

The teachers that participated in the research project were all educated as teachers for compulsory schools (children are from age 6 to16) except for Inga. Her educational background was in social pedagogy and she originally worked as a social pedagogue for a communal diagnostic and counseling center. She later added to her education as a special educator and was on her second year as a special education teacher when she joined this project. She had specialized in working with children who have behavior problems, and assisted the teachers in her school in diagnosing behavioral problems and planning intervention programs. She was concerned about how little knowledge of mathematics teaching and learning she had in her background, as this was not addressed in her education in social pedagogy. Furthermore, her special educator program neither emphasized mathematics teaching and learning. In the outset of our project she expressed the view that she was happy to have the opportunity to join this project and attend the workshops. 


\section{Collaboration}

The first year of our collaboration Inga joined a team of $5^{\text {th }}$ grade teachers in her school. Dóra and Pála were the classroom teachers for the two $5^{\text {th }}$ grade classes and Inga joined them for mathematics and Icelandic lessons. The children were streamed into three ability groups and Inga taught the children that struggled with mathematics. These children also had other learning problems as well as behavior problems. When I visited Inga's classroom at the beginning of our collaboration, she emphasized cooperative learning and supported the children in taking responsibility for their learning. Inga gave them three problems to work on in groups and while the children were working with the problems, Inga took turns discussing with the groups. Her main focus was on the students' role as participants in a group and less on the mathematics they were working on.

In our first workshop Inga was quiet and did not take initiative in the problem-solving process. When the teachers discussed their solution strategies she often referred to her pupils and how they might have solved the problem with support of manipulatives.

Later, when we were working with concept cartoons (pictures of children who had solved a problem and each gave their answer with an explanation), Inga was quick to realize that her pupils would gain from working with the cartoons: "They will work out each solution. They need to try. I think that many of them would work themselves to the right answer. There are so many of them that doubt that they can, and here they get some clues to start with".

In the third workshop, Inga, Dóra and Pála told about their work with their $5^{\text {th }}$ graders and discussed how they solved a proportional problem on the weight of animals. The children worked in groups and the teachers emphasized cooperative learning. Inga told us that she expected the problem to be too difficult for the children in her group, but she wanted to see if they could approach it: "I was most curious to see what they do. They don't need necessarily to solve the problem. I wanted to see if they had the imagination to try, and it turned out that they didn't".

Inga told us that the children were passive in their groups and did not have a clue how to address the problem. Finally she decided to go through the problem, step by step, with the whole group. Inga stressed that she needed to put more effort into teaching them collaboration and the responsibility of each person in a group:

I didn't assign them any roles in the group work and that was a mistake. I noticed a lot of things I need to do differently next time. This is a group with special needs children and they need much more preparation. They need to learn about their roles in the groups.

\section{Experimenting with groupings}

Inga did not give up on supporting the children to collaborate on math problems. A few months later she discussed her work with us in a workshop. She had grouped the children in pairs to avoid that some of them would be passive. But often only one child in a pair was active and she realized that the 'weaker' child tended to let the 
'stronger' child do the work. Instead of allowing them to choose a partner she decided to pair children that were at the same ability level:

I saw a lot, I saw a positive change. I have newer seen all of them so active. I have never seen them talk so much about the mathematics. It was great. And also those that are inactive; one of them said: "Wow I solved it". He just needed to tell us all about it. This lesson was such a victory at this time.

Inga then told us how the children discussed in pairs and supported each other in understanding their solution strategies: "He described his thinking, did this systematically and wrote down for every number, and then the next one". She was satisfied with the progress the children were making and that they were gradually becoming more independent in working on mathematical problems.

In an interview after the first year of our collaboration, Inga said that she was beginning to see 'the big picture'. To begin with, she felt that she was going back and forth but now the children were becoming more independent and did not rely as much on her as they did before. She said, "When we start a new project and I see that they have a 'light bulb moment', and are capable of relating to what we have worked on before, then we can start from there. This does not always happen, but quite often".

Inga expressed that she was satisfied with the participation in the research project and felt that she gained much from working with us and also in learning more about mathematics teaching and learning, as this was not addressed in her education. She found the collaboration with Dóra and Pála helpful and they were able to support each other by planning together and visiting each other classrooms. She had not experienced such close collaboration with classroom teachers before.

\section{Using mathematical concepts}

During the second year the project was running, Inga was concerned about her pupils when the school started. She felt that the enthusiasm she had seen by the end of the first year had vanished and the children were not interested at all: "They find everything we do is boring and I'm continuously going back to where we were last year. I see a huge difference from when they finished school last year".

Inga wanted to improve her mathematics teaching and decided to audiotape her lessons to be able to understand better what was happening in her classroom. When she listened to the first recording she was struck by the fact that she did not use mathematical concepts when talking about the mathematics. "We were working with fractions and I talked about the numbers above and below". She was concerned that she was trying to make the mathematics simpler for her special education group by using everyday language. Her experience was that if she used mathematical terms her pupils did not understand her and then she tried to make it simpler by explaining with everyday language. "But they need to learn the concepts. How can I intertwine them 
in my teaching?" Later in our discussions about her recording she asked herself: "Am I underestimating them by not using the concepts. I need to think about that too?"

Inga was pleased to hear on the recording how much she discussed with individual children while they were working with their problems and how she tried to understand their thinking when supporting them in their work. However, she was concerned that she did not give the children enough time to think and found that she was too quick to answer her own questions in a whole class discussion.

\section{Listening to children}

In the following workshops it was evident that Inga was becoming more and more aware of how her pupils were thinking when solving mathematical problems. When we were discussing a story that Pála told us about one of her pupils' misinterpretation of a fraction problem, Inga was prompted to discuss a similar situation in her class.

Something similar happened in my class as we were working with the metric system. Then one starts to think, wait, what is he thinking? He said that $4 \mathrm{~m}$ equals $4000 \mathrm{~cm}$ and he did not understand my explanation. ... So I just, why do you say 4000? I did not understand him and then the lesson was finished.

Inga told us how worried she was about not understanding the boy's justification and how she understood that her explanation that $4 \mathrm{~m}$ equals $400 \mathrm{~cm}$ made no sense to him. Her interest in understanding her pupils' development in mathematical thinking was growing and also in how they discussed their work.

I enjoyed this morning's lesson. ...We were working on a whale project. The boys got the task to draw the Blue Whale. They went outside with a measuring wheel to visualize how big he is. ... Atli started to draw on the pavement, had done the mouth and everything. Then Hilmar said: "This is a bit small mouth for all this whale". Atli just started to draw and did not think that he needed to draw in scale with the total length. Hilmar is the slowest in this group.

Inga discussed further how this instance helped her look closer for what the children are capable of doing instead of always searching for what they can not do. "One is always thinking; do they find a way? ... We are more aware of the small steps we are taking. One is more aware of the development".

\section{Explaining one's thinking}

In the third year of our collaboration, Inga was not collaborating with Dóra and Pála but still wanted to participate in our project. She was teaching in grades eight to ten and felt that her participation in the workshops helped her in teaching those children. She used tasks from our workshops and found that they supported her in awakening her pupils' interest and in making sense of the mathematics. She said: "These kids show so little initiative and they are so doubtful about their ability to learn". In the final interview with Inga, she proudly told me that she is consistent with asking her pupils to explain their thinking to her. She was collaborating with a mathematics 
teacher in the tenth grade and when this teacher was interrupting a boy who calculated differently from what he was expected to do, "I said, tell me what you are doing, and he could explain it". Inga then discussed how she believes that the children who have problems with learning mathematics are constantly reminded that they do things the wrong way and are not capable of doing things properly. Instead of getting the chance to explain their thinking, the teachers tend to explain to them again and again in a way that they do not understand. This makes them uncertain about themselves and they want the teacher to tell them what to do. But when the teacher listens to them they feel that they are capable of explaining their thinking like other children.

\section{CONCLUSIONS}

When the research project started, Inga was confident in teaching children with learning problems but felt that her own knowledge of mathematics was vague. She wanted to learn more about mathematics learning and teaching in order to be able to support her pupil's mathematics learning. In my first visit to her classroom she was consistent in teaching the children learning habits that would support them in their learning. When her pupils told her about their mental calculations she did neither respond to their discussions nor encourage them to share their thinking with the other children in class. As her mathematical competence developed through participating in the workshops she became more confident in discussing mathematics with her pupils as stressed by Niss (2004). This was evident in my final visit to her classroom. The atmosphere differed from my first visit. The children were more confident with their work and were eager to express their mathematical thinking. Inga was more secure in her role as mathematics teacher and required the children to discuss their thinking when working with the mathematics. She urged them to explore with reflection and make their own pictures with different kinds of techniques. The children all engaged in the project and eagerly explained their work by using mathematical concepts.

The collaborative explorations with mathematics strengthened Inga's pedagogical content knowledge as found by Ball, Thames and Phelps (2008). To begin with she was hesitant to express her thinking about the mathematics we were working on at the workshops but gradually she became more confident in discussing her ideas. She often referred to her pupils and how they might solve the problems we dealt with at the workshops. Her background as a social pedagogue supported her in listening to her pupils and when our collaboration proceeded, her confidence as mathematical problem solver and a mathematics teacher grew and she felt that working with us at the workshops improved her ability to discuss mathematics with her pupils.

Inga was conscious of her development as a mathematics teacher and the focus on her pupil's development in mathematical thinking supported her as Boaler (2002) found in her research. When Inga decided to record her lessons, she discovered that she did not use mathematical concepts in her discussions with the children. She was 
concerned that she was underestimating them by not using the concepts and that this was a sign that she did not believe that they would understand her. She was nevertheless satisfied that she heard herself discuss mathematics with individual students and tried to understand their thinking. The opportunity to share her work with other teachers and a teacher educator at the workshops had a profound impact on her work as Jaworski (2003) and Stiegler and Hiebert (2004) find important.

Inga's concerns that her pupils got the feeling that they were incapable of learning mathematics, supported her in keeping on trying to understand their thinking. She noticed when Hilmar was quick to realize that Atli's drawing of the Blue Whale's mouth was too small. This instance supported her in trusting that he understood more mathematics than he was able to express when solving problems with paper and pencil. Inga is aware of how important it is for her pupils to work with mathematical problems that make sense to them and help them develop their mathematical understanding.

Inga gained confidence in her development as mathematics teacher through participation in the research project, and her ability to discuss mathematics with her pupils has grown. Throuch participating in a collabortive inquiry into matheamatics teaching and learning she is gradualluy learning to notice how her pupils' mathematical thinking develops and research her own practice. The results support other research findings on teacher participation in developmental projects that research with teachers into their own teaching can add to the knowledge base of teaching in schools and teacher development (Cochran-Smith \& Lytle, 2009; Norton, 2009). The mutual learning of the participants, the primary school teachers and the teacher educator, that developed within the project, needs to be explored further and the analysis of the other participants that participated in this research project will give more insight into factors that were vital in the developmental process. As Artigue (2009) emphasised, research with teachers in school help researchers to take into account factors internal to the field itself, and as learned in this research project, the teachers develop their competence in teaching mathematics.

\section{REFERENCES}

Artigue, M. (2009). Didactical design in mathematics education. In C. Winsløw (Ed.) Nordic Research in Mathematics Education. Proceedings of NORMA08 (pp. 716). Rotterdam: Sense Publishers.

Ball, D. L., Thames, M. H., \& Phelps, G. (2008). Content knowledge for teaching: What makes it special? Journal of Teacher Education, 59(5), 389-407.

Boaler, J. (2002). Exploring the nature of mathematical activity: using theory, research and 'working hypotheses' to broaden conceptions of mathematics knowing. Educational Studies in Mathematics, 51(1/2), 3-21. 
Boero, P., Dapueto, C., \& Parenti, L. (1996). Didactics of mathematics and the professional knowledge of teachers. In A. J. Bishop (Ed.), International handbook of mathematics education (pp. 1097-1121). Dordrecht: Kluwer Academic Publishers.

Clandinin, D. J. (2013). Engaging in narrative inquiry. Walnut Creek, CA: Left Coast Press.

Cochran-Smith, M., \& Lytle, S. L. (2009). Inquiry as stance. Practitioner research for the next generation. New York, NY: Teachers College Press.

Crespo, S., \& Sinclair, N. (2008). What makes a problem mathematically interesting? Inviting prospective teachers to pose better problems. Journal of Mathematics Teacher Education, 11(5), 395-415.

Goos, M. (2004). Learning mathematics in a classroom community of inquiry. Journal for Research in Mathematics Education, 35(4), 258-291.

Guðjónsdóttir, H., \& J. V. Kristinsdóttir. (2011). Team teaching about mathematics for all: Collaborative self-study. In S. Schuck \& P. Pereira (Eds.), What counts in teaching mathematics (pp. 29-44). Dordrecht: Springer.

Gunnarsdóttir, G. H., Kristinsdóttir, J. V., \& Pálsdóttir, G. (2013). Professional development in mathematics teacher education. (In C. Smith (Ed.). Proceedings of the British Society for Research into learning Mathematics, 32(3), 85-90.

Hunter, S. (2010). Analyzing and representing narrative data: The long and winding road. Current Narratives, 1(2), 44-54. Retrieved from http://ro.uow.edu.au/currentnarratives/vol1/iss $2 / 5 /$

Jaworski, B. (2003). Research practice into/influencing mathematics teaching and learning development: Towards a theoretical framework based on co-learning partnerships. Educational Studies in Mathematics, 54(2/3), 249-282.

Jaworski, B. (2006). Theory and practice in mathematics teaching development: Critical inquiry as a mode of learning in teaching. Journal of Mathematics Teacher Education, 9(2), 187-211.

Niss, M. (2004). The Danish KOM-project and possible consequencesfor teacher education. I. R. Stræsser, G. Brandell, \& O. Helenius (Eds.), Educating for the future. Proceedings of an international symposium on mathematics teacher education (pp. 179-190). Stockholm: The Royal Swedish Academy of Sciences.

Norton, L. S. (2009). Action research in teaching \& learning: A practical guide to conducting pedagogical research in universities. London: Routledge.

Sfard, A., \& Prusak, A. (2005). Telling identities: In search of an analytical tool for investigating learning as culturally shaped activity. Educational Researcher, 34(4), $14-22$. 
Stigler, J. W., \& Hiebert, J. (2004). Improving mathematics teaching. Educational Leadership, 61(5), 12-17. 


\title{
BUILDING A LOCAL THEORY FOR THE LEARNING OF EXPERIMENTAL PROBABILITY
}

\author{
Per Nilsson \\ School of science and technology, Örebro University
}

The approach of this paper builds on the assumption that there is a need to develop local, domain specific instructional theories for the learning of probability. The aim of the present paper is to explore the qualitative hypothesis of building such a theory on the combination of students' own experimentations with samples and principles of variation. By using data from 12-13-year old students investigating the probability of obtaining a certain colour when picking, at random, one piece from a bag with six different colours of the candy, the paper shows how variations in students' own experimentations with samples can be used as means to explore and support students' understanding of critical features of experimental probability.

\section{INTRODUCTION}

Much of previous research on probability learning has investigated students' understanding in relation to the classical interpretation of probability. The classical interpretation is based on the assumption that each outcome of a random process is equally likely (Batanero, Henry, \& Parzysz, 2005) and, based on this view, many authors have derived useful examples for instruction from the seemingly simple random dependent situations involved in games of chance (Gal, 2005). However, although equiprobability is clear when tossing a symmetric coin or a die, this assumption is rarely possible to apply to functional or every-day situations (Gal, 2005). To act as conscious citizens of a modern society, we need to be able to express an opinion on the outcome of random events based on the observed frequencies of the event.

The present paper should be considered an initial step towards a local, domain specific instructional theory (diSessa \& Cobb, 2004) for the learning of experimental probability. Theories of this type are conceived local as they are situated close to practice and to specific mathematical domains, and are typically associated with particular instructional sequences. The building of a local theory entails the "conceptual analysis of a significant disciplinary idea (e.g., density, sampling distribution) together with the specification of both successive patterns of reasoning and the means of supporting their emergence" (diSessa \& Cobb, 2004, p. 83). Previous research on the learning of probability has been student-oriented. Central to the tradition has been to distil students' prior knowledge and intuitive ideas about probability in the form of framework or profiles (Jones \& Thornton, 2005). From a perspective on learning which stresses the importance to base instruction on students' own ideas and conceptions, the importance of this research cannot be overstated. However, focus has been on products, i.e., student' conception(s) of a probability idea or principle. Less focus has been given to the underlying processes of learning 
and the means that are designed to support that learning (Pratt, 2000; Nilsson, 2009). In the present study the disciplinary focus is on experimental probability. The focus is particularly on how patterns of variation (Marton, Runesson \& Tsui, 2004), established from students' sampling experimentations, can be used as an instructional means to understand and support students' reasoning in classrooms discussions on experimental probability.

\section{Aim of study}

The purpose of the present study is to investigate how variations in students' experimentations with samples can be used as a means to explore and support their understanding of experimental probability.

\section{THEORETICAL BACKGROUND}

\section{Conceptual analysis and the role of experimentation}

The theoretical interpretation of probability allows the calculation of probabilities before any trial is made. It implies the need for a sample space-oriented ratio-thinking (Hawkins \& Kapadia, 1984) where the probability of an event is obtained by the fraction of outcomes favorable for an event out of all cases possible (Borovenik, Bentz, \& Kapadia, 1991). The research tradition has made us aware of students' ability and inability to list all possible outcomes for an event and their understanding of how the underlying sample space regulates the probabilities of a random phenomenon (Chernoff \& Zazkis, 2011). The experimental probability is posterior in that the probability of an event is obtained from the observed relative frequency of that event in several trials (Borovenik et al., 1991). Similar to theoretical probability, empirical probability also implies ratio-thinking, but this time in terms of determining the fraction of the number of times an event appears out of all trials made.

\section{Instructional assumptions for design of learning activities}

Fischbein (1975) emphasizes the need to offer students opportunities to concretely experience randomness in the learning of probability. Working practically with random experimentations provides students an opportunity to sense random behaviour and, challenges them to make predictions and verifications of probabilities. Shaughnessy (2003), who stresses Fischbein's suggestion further, recommends that the teaching of probability not only should involve data-experimentation, but should actually start from there. In an experimentation-based teaching situation students may become engaged in formulating statistical and probabilistic questions, collecting data, analysing data, and drawing data-based conclusions and inferences (Paparistodemou \& Meletiou-Mavrotheris, 2008). In order to turn the students' attention towards experimental probability, sampling procedures, random behaviour and the role of sample size, our basic design principle will be that the underlying sample space will be hidden to the students.

On a general, epistemological level, the envisioned learning processes relate to a metaphor of considering students' understanding of a learning object on the form of a 
network of knowledge elements (Hiebert \& Carpenter, 1992). Promoting connections between mathematical ideas, Thompson (1985) stresses that a study situation should be problem based, promote reflections, raise questions that focus on the relations and structures of the subject matter and generate feed-back, against which the students can judge the efficiency of their reasoning.

In order to zoom in on mathematical relations and structures Marton, Runesson and Tsui (2004) argue that study situations should provide students opportunities to experience how different aspects of a phenomenon under investigation vary given that other aspects are kept constant. Aspects of a phenomenon that vary are more likely to be experienced than aspects that are kept invariant. The analytical focus of the present paper is particularly on how patterns of variation and invariance, which appear in a sampling activity, can be used as a means to explore and support students' understanding of experimental probability.

\section{Method}

The analysis is based on data gathered from a larger teaching experiment, which was conducted in a grade six class (ages 12-13) in a Swedish primary school. The entire teaching experiment, which is reported in Nilsson (2014), has a broad domainspecific focus, concerning the bi-directional relationship between experimental and theoretical probability. In the present study we will particularly focus on principles of experimental probability and, specifically, how issues of variation can be used as a means to explore and support students' understanding of experimental probability in experimentation-based teaching.

The students are familiar with traditional Swedish teaching of mathematics, with elements of group-work and whole-class discussions. However, experimentation is unusual; the textbook provides the basis for the teaching of mathematics. The students have not been formally introduced to probability in school. They are familiar with decimal numbers and fractions and have some experience of percentages.

The class was split in two halves (Group A and Group B) with ten students in each group. Within these groups, the students were organized in five small groups with two students in each group. The author of the paper acted as the teacher during the entire experiment and is referred to as the investigator (I) throughout the rest of the text. Except for one group, which was audio-taped, all classroom discussions were video-taped.

Four group-based lessons were conducted in the following order:

Lesson 1A, Lesson 1B, Lesson 2A, and Lesson 2B.

Lesson $1 \mathrm{~B}$ was adjusted, based on the analysis of Lesson 1A. The experiences gathered from Lesson $1 \mathrm{~A}$ and Lesson $1 \mathrm{~B}$ then served as a basis for adjusting the planned Lesson 2A. By analysing Lesson 2A, Lesson 2B was further specified. 


\section{Lesson 1}

The overall learning objective of the entire experiment was to develop students' understanding of relative frequencies and the role of sample size in making inferences about the random generator, producing the outcomes. The driving question of the teaching experiment was to determine, through experimentation, the probability of picking a piece of candy of a certain colour from a bag of candy. In Sweden, the candy is called Non Stop ${ }^{1}$. There are six different colours of candy in the bag, all pieces are the same shape, and the brand is well known to the students.

All five groups in each class received one bag of candy. The students were then asked to determine from sampling, which bag to choose to increase the chances of obtaining a yellow piece. The students were told that they were only allowed to pick one piece at a time and had to put the piece back in the bag before they picked another piece. The bags were of equal size (according to their weights) but the exact number of pieces is not determined and would probably be different between the bags. The students were first asked to record their observations in a diagram and then asked to record their data in a table (Figure 1).

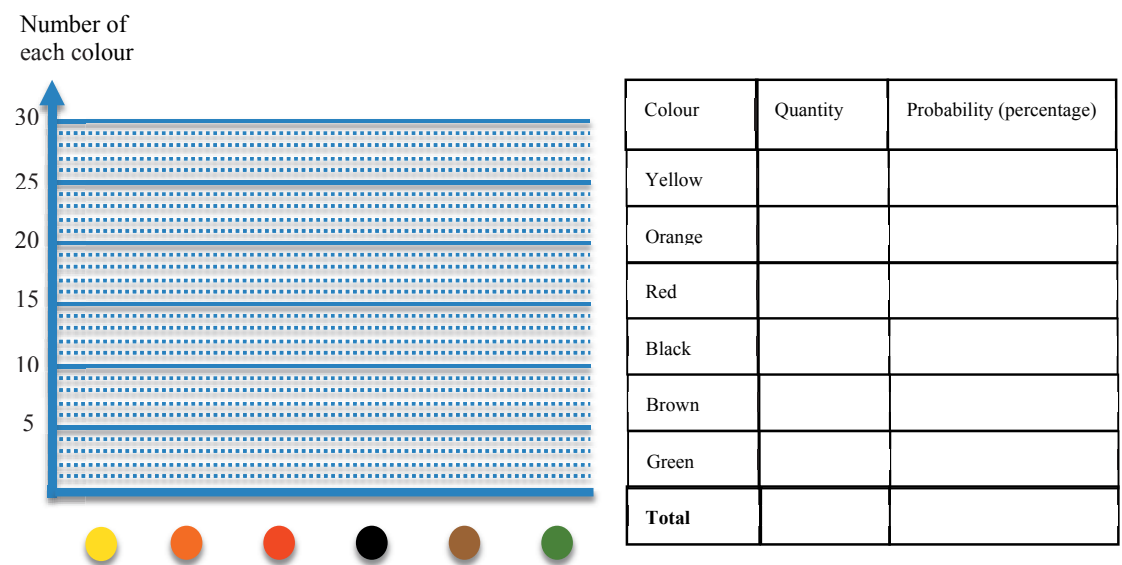

Figure 1. Diagram and table for the recording of observations

\section{Lesson 2}

The first activity in L2 followed on from L1. In the second phase of L2, the students counted the pieces of candy in their bags. They were asked to reflect on how the

\footnotetext{
1 'Non Stop' candy is similar to 'Smarties' in the UK or 'M\&M's' in the USA.
} 
proportions of the different colours in the bag correlated to the relative frequencies of the sample.

\section{Results and analysis}

The first case we will look at appears when the students are done with their sampling. The students are asked from which bags they should choose to have the best chance to obtain a yellow. They are also challenged to add arguments to their suggestions. None of the students refer to any probabilistic language for backing up their choice.

\section{Variation in context: constructing a model for comparison}

Based on the students' difficulties to come up with a probability-oriented way of comparing the bags, the investigator initiates a discussion of proportions and percentages of boys and girls in the classroom. The question he asks is what would be the probability for a random-dependent butterfly to land on a boy or a girl. Initially several students frame the situation in terms of absolute frequencies. They express an understanding of what a part is and that boys constitute one part and girls constitute another part. Still, they struggle relating the parts to a whole. Guided by the investigator, the class agree that the chance for a boy is $9 / 13 \approx 69 \%$ and the chance for a girl is $4 / 13 \approx 31 \%$ (including the investigator, the class teacher and an assistant).

Based on the butterfly situation, the class now has a numerical model for comparing the bags. All groups calculate the relative frequencies of each colour in their sample and record their results on the whiteboard (Figure, 2). Based on what the whiteboard displays, the students are asked which bag to draw from, to have the greatest chance to obtain a yellow. Carl replies "I say Lars and Sibel's, given that they have $25 \%$ and it is ... more than the others. One [group] has nine, one has 14, one 25 [Lars and Sibel's], one has 19 , one has 15 and then there is 25 , which is most."

By turning to the more 'concrete' butterfly-context, the teacher was able to zoom in the discussion on finding a way to compare the chance of random dependent outcomes. The discussion moves from part-part comparisons to part-whole comparisons. Even if we should not claim that all students completely grasp the partwhole principle, we note how the butterfly example, together with the displayed results, place the teacher in a good position for motivating and encouraging the students to calculate the relative frequencies of each of the colours in their sample and to use these numerical values as a means for comparing the chances of picking a yellow piece from the different bags. 

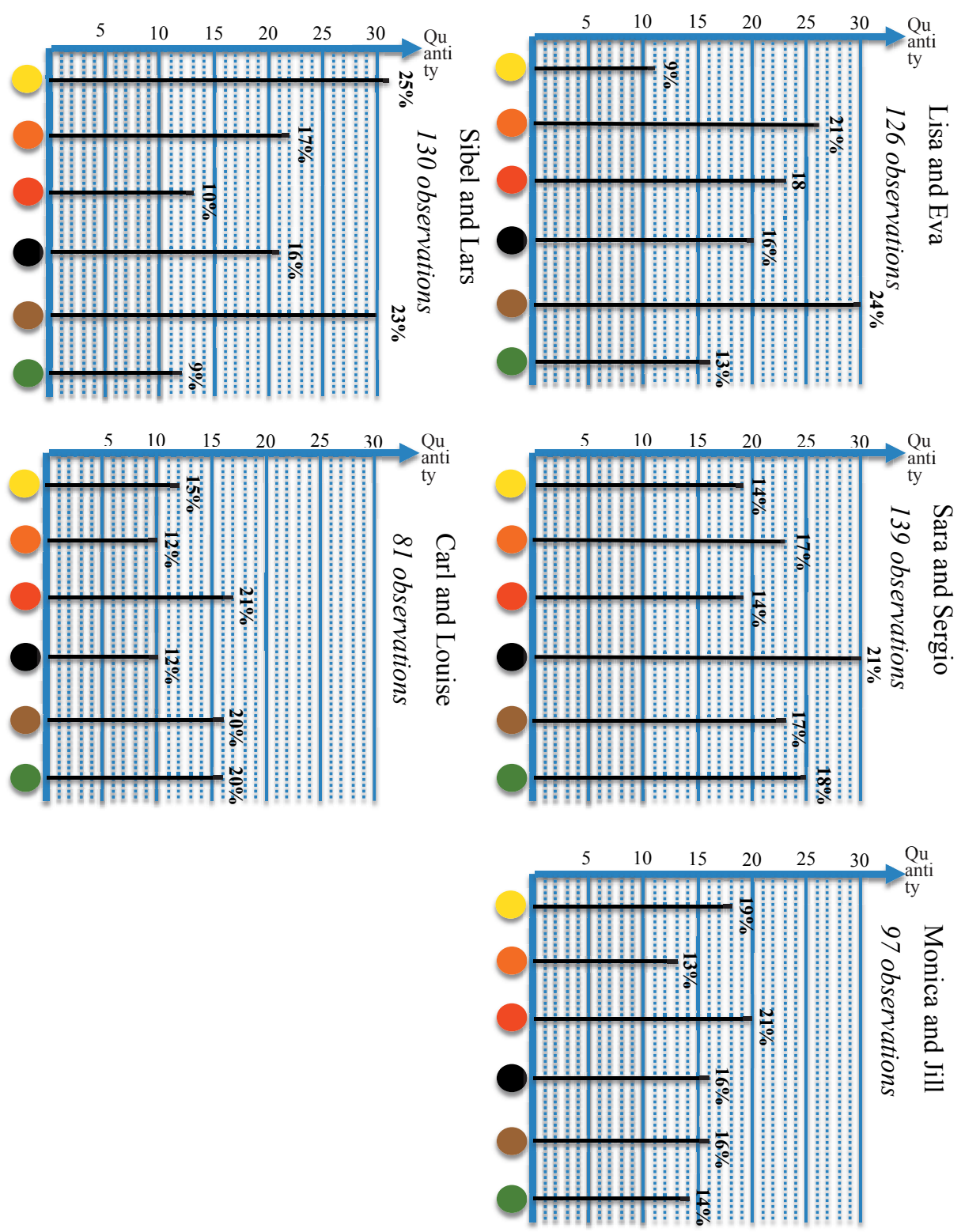

Figure 2. Groups' results from Lesson 1A 
Variation in sample size: Privileging fairness over stabilization of frequencies

One student, Monica, is, however, not completely convinced. When she reflects on the results of the five groups observations she says:

Monica: Is it actually possible to choose? Everybody has made a different quantity [of observations] or so. Many [groups] have been picking many more than others.

Investigator:Yes, continue. We say, it is impossible to choose since we have been drawing different quantities. Why should it not work do you think [asking Monica]?

Monica: Maybe one group was only picking 13 yellow and another [group] was picking 23 yellow.

Investigator: Yes.

Monica: Then the percentage will be much less in one group compared to the other [group]/.../the one [group] who had 13 might have had more if he had been aloud to continue.

Monica's reflection is interesting. At first sight, it seems as she is trapped in part-part reasoning: focusing on the part of yellow without any explicit considerations that the total also increases as the sample increases. However, it might also be the case that she is aware of that an outcome may be overrepresented in short runs and that the proportions between outcomes stabilize in long runs. The investigator does not pick up on this issue. Instead he asks the students if it would have mattered if all groups had developed a sample of six observations or 139 observations. The question was also an attempt to introduce the theme of the next lesson on the role of sample size. However, this rather extreme variation does not challenge Carl enough to questioning Monica's interpretation:

Carl: No, but really, if everyone draws the same then all have the same to compare with.

Pratt (2000) speaks about fairness as a resource for judging whether a random generator produces outcomes with an equal chance. Carl's reasoning implies similarities with the fairness resource. However, this time it is not about an equal chance, but about equal conditions for making a fair judgment from data. Such an understanding of fairness is in conflict with the formal idea of the law of large numbers and confidence intervals. Comparing two samples with only six observations each is less fair than comparing a sample of 100 observations with a sample of 200 observations. We can express an opinion with a higher degree of certainty in the latter case.

As I suggest above, Monica is focusing on the quantity of one particular outcome. She does not take into consideration that the quantity of the whole sample also 
changes so that, in the end, it might be the case that the proportions in a sample stay the same as the sample size grows. However, the situation offers some instructional possibilities to zoom in on one of the basic ideas of random behaviour, that the stabilization of relative frequencies requires pretty long series. Think of a perfectly balanced coin. In the short run, randomness can have quite a significant impact on the results of a certain outcome. It could be rather long intervals of only heads or of only tails during a series. But, if the coin is perfect, the proportions of long and short sequences of heads and tails will be balanced in the long run. So, if we compare a sample of 100 trials, of which 19 are yellow, with a sample of 50 trials, of which 5 are yellow, then it would be highly relevant to ask whether the low proportion of yellow in the latter case is mainly an effect of chance or if there is a real difference between the colours in that bag. Even if not Monica's or Carl's contributions disclose such an understanding, we can say that the variations presented on the board, together with what Monica suggests, offer certain instructional means for exploring and supporting students' understanding of this subject matter principle.

\section{Variation in proportions: Discerning relative frequencies}

In Lesson 1B, the investigator asked the students to reflect on the difference in chance of picking a yellow candy from a bag of 200 pieces with 25 yellow or from a bag of 250 pieces with 26 yellow. Supported by this contrast-oriented question, class B came to an agreement that they should favour part-whole comparisons over partpart comparisons. Encouraged by this positive experience, the investigator used questions of a similar type to engine the discussions of L2. The questions took advantage of the students' work in L1. The following two questions were constructed for L 2A:

1) Suppose that you would like a piece of brown candy. You are only allowed to pick one piece without looking from Sara and Sergio's bag or from Carl and Louise's bag. Which of the bags would you choose? Explain you answer.

2) You would like a piece of red candy and you can choose which bag you want it from. Which of the groups' bags would you choose? What is the probability of getting a red piece from the choice you made?

The colours and the groups are not selected randomly. Sara and Sergio reached a larger absolute value in comparison to Carl and Louise. But the relative frequency of Carl and Louise's value is larger. In interacting with these two tasks, most students realize that a group may have got more of one colour because they repeated the sample more times. They realize that they cannot only look at how many times a colour was observed. They have to consider how many times it appeared in relation to the total number of observations Lars and Sibels' discussion illustrates the situation in coming to an agreement on the first task:

Lars: $\quad$ There is a higher chance for us to get it [a brown] here [pointing to Carl and Louise's diagram]

Sibel: $\quad$ Yes 
Lars: $\quad$ They only had 81 !

Sibel: Yes.

Lars: But, they [Sara and Sergio] drew more [brown], but that was because they had almost 50 more observations.

The first task was limited to elaborating on two particular groups' results. The instructional idea behind this choice was that this would increase the chances that the students would really pay attention to the desirable part-whole comparison. The students then used the same approach in the next task, which had a more open character. Hence, the lesson we draw is how situations that open up for variations can be used to construct tasks with different degrees of complexity and, thereby, to increase the chances to guide students' attention towards desirable domain specific structures.

\section{CONCLUSION}

This paper should be considered as an initial, explorative step in the building of a domain specific instructional theory (local theory) (diSessa \& Cobb, 2004) for the teaching and learning of the bi-directional relationship between theoretical and experimental probability and the role of sample size in this relationship. In the present paper the focus has been restricted to aspects of experimental probability. Building a local, domain specific theory basically implies characterizing a learning trajectory and specifying central means supporting this trajectory (diSessa \& Cobb, 2004). In the present case focus has been on instructional means, in terms of focusing on how patterns of variations in students' experimentations with samples could be used to explore and support their understanding of experimental probability.

A specific finding of the present analysis was how students struggled with the role of sample size for determining the experimental probability. Articulated by Monica and Carl, we saw how a notion of fairness in sample size was prioritized over the principle of stabilization of relative frequencies in the long run. Based on my reading, I can't find this conception systematically documented in previous research on the teaching and learning of probability and statistic and, on account of that, I would suggest future research to investigate this kind of reasoning further.

The three cases highlighted in the analysis show how students' own experimentations with samples offer teachers certain possibilities to use patterns of variation (Marton et al., 2004) to explore and support the students' understanding of experimental probability and sample size. However, it is not only patterns of variation, which should be proposed as the basic instructional means for a local theory on learning probability in experimental settings. The solution is not either to just ask students to conduct experiments. What the present study suggests for the building of a local, domain specific theory for the teaching and learning of experimental probability is the combination of experimentation and systematic variation. 


\section{REFERENCES}

Batanero, C., Henry, M., \& Parzysz B. (2005). The nature of chance and probability. In G. A. Jones (Ed.), Exploring probability in school: Challenges for teaching and learning (pp. 15-37). Springer Science +Business Media.

Borovcnik, M., Bentz, H.-J., \& Kapadia, R. (1991). A probabilistic perspective. In R. Kapadia, \& M. Borovenik (Eds.), Chance encounters: Probability in education (pp. 27-71). Netherlands, Kluwer.

Chernoff, E. \& Zazkis. R. (2011). From personal to conventional probabilities: from sample set to sample space. Educational Studies in Mathematics, 77(1), 15-33.

DiSessa, A. A. \& Cobb, P. (2004). Ontological innovation and the role of theory in design experiment. Journal of the learning sciences, 13(1), 77-103.

Fischbein, E. (1975). The intuitive sources of probabilistic thinking in children. Dordrecht, The Netherlands: Reidel.

Gal, I. (2005). Towards "probability literacy" for all citizens: Building blocks and instructional dilemmas. In G. A. Jones (Ed.), Exploring probability in schools: Challenges for teaching and learning (pp. 39-64). New York: Springer.

Hawkins, A. \& Kapadia, R. (1984). Children's conception of probability - a psychological and pedagogical review. Educational Studies in Mathematics, 15, 349-377.

Hiebert, J., \& Carpenter, T. P. (1992). Learning and teaching with understanding. In D. A. Grouws (Ed.), Handbook of Research on Mathematics Teaching and Learning (pp. 65-98). New York: Macmillan.

Jones, G \& Thornton, C. (2005). An overview of research into teaching and learning probability. In G. A. Jones (Ed.), Exploring Probability in School: Challenges for Teaching and Learning (pp. 65-92). New York: Springer

Marton, F., Runesson, U., \& Tsui, A. (2004). The space of learning. In F. Marton \& A. Tsui (Eds.), Classroom discourse and the space of learning (pp. 3-40). Mahwah, NJ: Lawrence Erlbaum.

Nilsson, P. (2009). Conceptual variation and coordination in probability reasoning. The Journal of Mathematical Behavior 29(4), 247-261.

Nilsson, P. (2014). Experimentation in probability teaching and learning. In E. J. Chernoff \& B. Sriraman (Eds.), Probabilistic Thinking: Presenting Plural Perspectives (pp. 509-532). Netherlands: Springer.

Paparistodemou, E., \& Meletiou-Mavrotheris, M. (2008). Developing young student's informal inference skills in data analysis. Statistics Education Research Journal, 7(2), 83-106.

Pratt, D. (2000) Making sense of the total of two dice. Journal for Research in Mathematics Education, 31, 602-625. 
Shaughnessy, M. (2003). Research on students' understandings of probability. In J. Kilpatrick, W. G. Martin \& D. Schifter (Eds.), A Research Companion to Principles and Standards for School Mathematics (pp. 216-226). Reston, VA: National Council of Teachers of Mathematics.

Thompson, A. (1985). Experience, problem solving, and learning mathematics: Considerations in developing mathematics curricula. In E. Silver (Ed.), Teaching and learning mathematical problem solving: Multiple research perspectives (pp.189-236). Hillsdale, NJ: Erlbaum. 


\title{
HOW TO SOLVE IT: STUDENTS' COMMUNICATION WHEN PROBLEM SOLVING IN GROUPS
}

\author{
Hanna Palmér, Jorryt van Bommel \\ Linnaeus University Sweden, Karlstad University Sweden
}

The focus of this paper is on communication amongst students working on problemsolving activities in groups. Episodes from the experience of two groups of students working with the same problem-solving task are analysed. The two episodes occurred during a design research study of examining the implementation and development of mathematics teaching through problem solving in lower primary school. The analysis foregrounds the interaction between the problem solvers rather than the learning of each individual problem solver. Prioritising interaction implies analysing the discursive intention of the students and the effectiveness of their communication. The results show that students' expectations about the meta-discursive rules of the activity influence the effectiveness of the group members' communication.

Keywords: problem solving, effective communication, meta-discursive rules

\section{INTRODUCTION}

Problem solving in mathematics plays a significant role in syllabuses in many countries, but there are few countries in which mathematics teaching through problem solving has seen substantial implementation in classrooms or in which research on problem solving has had a sustained effect on school practice (Cai, 2010; Lester \& Lambdin, 2007; Lesh \& Zawojewski, 2007). The basis for this paper is an on-going design research study on the implementation and development of mathematics teaching through problem solving in Swedish lower primary school. Design research was chosen in order to involve primary school teachers in the design and implementation of problem-solving tasks with the purpose of increasing the likelihood that the experience would have a lasting effect on school practice. The seven-year-olds in the study were attending first grade in the Swedish school system.

According to the Swedish syllabus for primary school, students must develop their skills to formulate and solve mathematical problems, as well as to evaluate the strategies and methods they use (Skolverket, 2010). This emphasis in the syllabus can be understood as a reaction to a national inspection of mathematics teaching conducted in 2009 that reported that mathematics teaching in Sweden is dominated by individual counting and characterised by limited opportunities for students to develop their problem-solving abilities (Skolinspektionen, 2009). Problem solving is not new in the Swedish syllabus; however, how and why students are to be taught 
problem solving have changed through the years. The emphasis has slowly shifted from a view in which students first need to learn mathematics in order to become problem solvers to a view in which problem solving is taught as content itself and finally to today's view that problem solving is a strategy for acquiring new mathematical knowledge (Wyndhamn, Riesbeck \& Schoultz, 2000).

There are three main themes regarding the role of problem solving in mathematics teaching: problem solving as a context, problem solving as a skill, and problem solving as an art (Stanic \& Kilpatrick, 1988). In the design research study reported in this paper, the aim was to implement and further develop problem solving as a context for learning mathematics. This is done by focusing on problem solving as a skill that can be applied later when learning mathematics. Problem solving as a skill is not to be confused with attempts to teach students general problem-solving strategies, which have proved unsuccessful since problem solving is never content- or context-independent (Lesh \& Zawojewski, 2007). Instead, focusing on problem solving as a skill implies focusing on meta-cognitive strategies whereby students' communication, interpretations, representations, and reflections are prioritised. Of these, the focus of this paper is communication between students when problem solving in groups.

The importance of group discussions in mathematics teaching is widely acknowledged; interaction amongst group members "provide[s] opportunities for individuals' understandings to be tested, integrated, differentiated, extended, revised or rejected" (Lesh \& Zawojewski, 2007, p. 790). However, simply having students discuss mathematical ideas does not guarantee that meaningful learning will occur (Sfard, 2001). In the design research study considered here, groups were used in most of the problem-solving lessons. However, quite early in the process, a question emerged as to why the interactions in some groups were productive while those in others were not. Even if all the groups finally, in one way or another, completed the problem-solving tasks, the processes in the groups differed a great deal. The attempt to understand those differences, their causes, and their effects is elaborated on in this paper. Thus, the focus is the interaction between the problem solvers rather than each problem solver's individual learning.

\section{THEORETICAL FRAMING}

As learning problem solving is embedded in the content and context of the situation (Lesh \& Zawojewski, 2007), the theoretical frame for the study is learning as participation. This implies learning as the development of ways in which individuals participate in well-established communal activities (Sfard, 2001 \& 2008). According to Sfard (2008), mathematics is a discourse about mathematical objects of which problem solving is understood as a part. Based on that idea, the discourse of the design research study, its well-established communal activity, is the activity of problem solving. Further, the focus is the growth of mutual understanding and coordination between the learner and the discourse. 
Sfard (2001 \& 2008) defines a discourse as an instance of communication in a constant flux without well-defined borders. The communication in discourses is both intrapersonal (individual thinking) and interpersonal (between persons involved in communication: interlocutors). As the focus of this paper is interaction between problem solvers, we concentrate on interpersonal communication. Interpersonal communication in discourses is an attempt to make other people act or feel in a way that accords with one's intentions; in this way, it concerns the interplay between one's own and other's intentions (Sfard 2001 \& 2008). According to Sfard (2001) communication in discourses encloses two levels: the object level and the meta level. Communication on the object level involves visible mediating tools, such as content, language, symbols, and text. Communication on the meta level involves the metadiscursive rules that enable and guide the general course of communicational activities, as well as the interlocutors' concern about the way the interaction is managed and about the relationship between them. The effectiveness of interpersonal communication depends on the degree of clarity in the discursive focus. If a receiver's response is in tune with the sender's expectations, the purpose of communication is fulfilled. In effective communication, participants seem to know what the others are talking about and feel confident that all the parties involved are referring to the same things when using the same words.

Ryve (2006) has shown that students develop personal goals that are not always compatible and that such variation accounts for difficulties in establishing effective communication. Based on this finding, Ryve (ibid.) has emphasised the importance of particularly taking into account the personal goals and problems the students develop in an activity when analysing effective communication in collaborative activities. Participants bring to discourses their own use of words and their own expectations regarding the meta-discursive rules of the activity to take place (Sfard, 2001). The shape of the exchange in the discourse is the result of the interaction of the expectations of all the interlocutors. Task variables (for example, content, context, structure) alone do not account for each individual's interpreting problem-solving situations differently (Lesh \& Zawojewski, 2007). In a mathematics group activity, individual students can be ascribed a different focus that reflects their discursive intentions and what each individual student is engaged in (Sfard, 2001). According to Sfard (2001), there are two different ingredients when analysing students' focus: pronounced and attended foci- that is, the focus of the students can be indicated by speaking (pronounced) or by acting (attended). For effective communication to take place, students working in groups need to experience concord in their focus.

The analysis of the students' focus considers whether their communication takes place on the object level or on the meta level, along with the effectiveness of their communication. Both the effectiveness of communication and the ascription of discursive intentions depend on personal interpretation; this is why it is important to be explicit about whose perspective is being considered (Sfard, 2008). In this paper 
we have interpreted the effectiveness of the communication based on how individuals' responses seem to align with the sender's expectations. Similarly, we have ascribed discursive intentions based on what the students said (pronounced foci) and did (attended foci). However, we do not claim to know how the students themselves perceived the effectiveness of their communication.

\section{METHODOLOGICAL ISSUES AND IMPLEMENTATION}

Educational design research is a methodology for researchers that seeks to increase the impact, transfer, and translation of education research into practice. It is a cyclic process of designing and testing interventions in an educational context. In addition, it stresses the importance of theory building that guides, informs, and improves both practice and research (Anderson \& Shattuck, 2012; The Design-Based Research Collective, 2003).

The educational context in the design research study presented in this paper involves 20 students in grade one (age seven) of the Swedish school system. The episodes to be analysed took place on the second occasion students were asked to complete a problem-solving task in groups. As mentioned, the aim of this part of the cyclic process was to develop our (researcher-teachers') understanding regarding the productiveness of the groups' interactions. The task chosen was one of the same type the students had completed one week earlier. The set-up is as follows: every task consists of four clues written on separate note cards. In addition to the clue, the question to be answered by the group is written at the bottom of every note card. When working with the task, each student in the group gets one clue. The underlying idea is to promote all the students' involvement in finding the solution, since all four clues are needed to answer the question. The question students were given in this case was How many fish do the children have all together? The following clues were given (on the notes, the different clues were not marked with characters, but characters are used in this paper to differentiate the clues in discussion): (A) Anton has two fish. (B) Sara has two fish more than David. (C) Lisa has half as many fish as Sara. (D) David has twice as many fish as Anton. The students worked in groups of four; there were five groups in total.

The composition of the groups was arranged by the teacher and was the same as that implemented a week earlier. One group at a time worked with the task in a room next to the classroom. The teacher was not present, but one researcher was. Before the students were given the task, the researcher asked them whether they remembered what they had done the previous week. Thus, the students had an opportunity to talk about the earlier task and solution. The researcher, however, did not add anything to this. In addition, while students worked with the new task, the researcher was rather passive, intervening only when the students asked for something or when a group stopped working with the task. Field notes were taken focusing on the interpersonal communication in the groups (both verbal and non-verbal). Students' solutions were also collected in cases where they used pen and paper. 


\section{RESULT AND ANALYSIS}

The following paragraphs analyse episodes in which two groups of students worked with the problem-solving task described above. These episodes were selected because they illustrate the differences we found when analysing all the episodes in this part of the cyclic process. Based on the theoretical framing, the analysis posed the following questions: What are the discursive intentions of the students? Does the communication in the groups take place on an object level or a meta level (or both)? Is the communication effective?

\section{Group 1}

The first episode took place in the group comprising Hadon (Clue A), Jack (Clue B), Tess (Clue C), and Mary (Clue D). Students and researcher were seated around a round table; the researcher sat between Hadon and Mary. (Italics in the dialogue indicate that the student is reading from the note card.) On the table were paper, pencils, a box with buttons, and a box with Centicubes.

1. Hadon: I'll start because I seem to have a good one. Anton has two fish.

2. Jack: Sara has two fish more than David. How many does David have?

3. Tess: Lisa has half as many fish as Sara.

4. Mary David has twice as many fish as Anton.

5. Hadon: Then David has four fish.

6. Mary: And Sara has six.

7. Tess: Sara has six. Lisa has the half of Sara's fish. Then she has three. You had two. (Looks at Hadon) Two and four is six. Six and six is twelve.

8. Jack: And then there are six more.

9. Mary: What do you mean? (Looking at Jack)

10. Tess: Six plus six plus three. Six and six is twelve. (Looking at Hadon) And then plus three is fifteen. (Hadon and Mary nod.)

11. Researcher: OK; are you sure?

12. Tess: Let's write. Let's read the one we are most sure of.

13. Hadon: Anton has two fish.

14. Tess: Then we'll have to start with Anton. (Tess turns towards Mary, who has picked up a pen. Mary writes the four names of the children in the clues on a piece of paper, starting with Anton at the top and followed by David, Sara, and Lisa. Each time she writes a name, Tess says a number to write after the name. Hadon and Jack look at them and at Mary's writing. They nod after every number Tess says and after each time Mary writes.)

15. Tess: Let's start with the largest one.

16. Mary: It's fifteen.

17. Tess: Six and six is twelve. It's fifteen.

Hadon's [1] discursive intention seems to be solving the problem. He expresses a strategy when he says he will start because he "seem[s] to have a good one." His communication is on the object level. Jack continues by reading his clue [2], but this does not respond to Hadon's invitation to read a clue related to his "good one." Jack's discursive intention might be reading his clue, or it could also be that it is not clear to 
Jack that his clue is not the requested one. Whatever the case, the communication is taking place on the object level, but it is not effective (the response does not align with the sender's expectations). Jack [2] invites interpersonal communication by asking, "How many does David have?" In lines 3 and 4, Tess and Mary read their clues. Their reading does not seem to connect to either Hadon's or Jack's earlier statements but can be looked upon as their simply reading their clues aloud because the other two have done so. However, Mary's clue [4] is the one Hadon has been waiting for. In lines 5-7, solving the problem becomes the joint discursive intention, and the communication is effective. In line 8 Jack interrupts the effective communication by saying something unexpected. Mary tries to keep the focus on solving the problem by saying "What do you mean?" Tess [10] does not answer Jack or Mary but continues solving the problem, picking up where she was before Jack interrupted. This prompts Mary and Hadon to move their attended foci from Jack and instead to confirm Tess's solution. The communication between Hadon, Mary, and Tess is effective interpersonal communication on the object level. When the researcher asks whether the students are sure of their solution [11], Tess [12] introduces a new mediating tool (object level): writing. Here she also responds to Hadon's [1] statement that they are to read the one they are "most sure of." Hadon gives the expected response [13]. The communication is still effective on an object level. As they continue [14], Tess is the one directing, and Mary does the writing. Tess remembers how many fish each of the names in the task has without asking the others, and Mary gives the expected response to her utterances by writing the numbers. Hadon and Jack are not saying anything but nod as confirmation. In line 15 Tess introduces new content to the communication, indicating how to add the four numbers. Mary's answer [16] is not the expected one (though it is correct in relation to the task), and Tess herself [17] answers her own question.

To summarise this episode, the discursive intention is the same for the group almost throughout the entire exchange (object level), and the communication is mostly effective.

\section{Group 2}

The second episode reflects the experience of a group comprising Fiona (Clue A), Tracy (Clue B), Annie (Clue C), and Nellie (Clue D). Students were seated around a round table, and the researcher sat between Nellie and Tracy. On the table were paper, pencils, a box with buttons, and a box with Centicubes. When the group was asked whether they remembered what they had done the previous week, Tracy and Nellie started discussing which of them had solved the earlier problem. The researcher intervened in the discussion, saying that to solve the problem the whole group is needed and responsible. After that, the following episode took place.

18. Fiona: Who will start to read? 
19. Nellie:

20. Annie:

21. Fiona:

22. Tracy:

23. Annie:

24. Tracy:

25. Nellie:

26. Annie:

27. Nellie:

28. Nellie:

29. Nellie:

30. Nellie:

31. Nellie:

I'll start. David has twice as many fish as Anton. (After reading, looks at Annie, sitting on her right)

Lisa has half as many fish as Sara. (Turns towards Fiona, who is on her right)

\section{Anton has two fish.}

Sara has two fish more than David.

Anton has two. David four. That's six.

Sara has two.

It's twelve.

Or sixteen. We can write all the names. (When Annie has said this, Tracy and Nellie start to argue about which of them is going to write. The researcher decides that Annie can do the writing. After this, Tracy turns around and for the remaining time she does not participate in the work of the group. She is looking in the other direction, at a wall. Annie takes the pen and writes "David" on the paper.)

Four. (Annie writes "4." Then she writes "Anton" on the paper. Fiona is watching but does not say anything.)

Two. (Annie writes "2." Then she writes "Lisa" on the paper. Fiona is watching but does not say anything.)

Three. (Annie writes "3." Then she writes "Sara" on the paper. Fiona is still watching in silence.)

Six. (Annie writes “6.”)

Then it's fifteen. (Annie writes "15," and then the three girls look at the researcher, indicating that they are finished.)

Initially [18], Fiona's discursive intention seems to be meta level (referring to metadiscursive rules of interaction and relationships): Who is going to start? She does not refer to the content of the clues, but instead the question is open. Nellie [19] in a way gives an expected answer by saying, "I'll start." Nellie's clue is not the best one to start with in relation to solving the task; however, she may not be aware of that. Her answer seems to be meta level (still focusing on meta-discursive rules); it seems she wants to be the first one to read a clue. In the following [20-22] exchanges, the focus on the meta level is visible as the students read their clues based on how they are seated. Then Annie [23] moves the dialogue in a new direction, starting to solve the problem. She introduces a new discursive intention, and the communication changes to the object level. Tracy [24] answers Annie but not with the expected content, since she has not understood her clue correctly. Nellie [25] does not respond to Tracy or Annie but expresses her solution to the problem. Annie [26] answers Nellie but suggests another answer. Thus, in lines 23-25 a joint discursive intention is apparent, solving the problem, and the communication is interpersonal on the object level. However, the communication is not effective, as the students do not answer one another's utterances. Annie eventually [26] introduces a new mediating tool (writing) on the object level. Nellie's and Tracy's reactions to this exhibit their new discursive intention: Who is going to write? Their communication again moves to the meta level. When the researcher interrupts and decides who will write, Nellie returns to the discursive intention of solving the problem, while Tracy stops interacting with the others. Her discursive intention remains on the meta level of Who is going to write? 
The other three students [27-31] continue solving the problem. The order in which Annie writes the names on the paper (David - Anton - Lisa - Sara) is not the easiest or the most logical in relation to the content of the clues. However, Nellie does not seem to have a problem with this; therefore, their communication can be regarded as effective interpersonal communication on the object level.

To summarise this episode, the first discursive intention took place on a meta level as the students all read their clues. Then the communication moved to the object level but was not effective; a second segment of communication on the meta level (Who is going to write?) took place. Finally, three of the four students returned to effective communication on the object level.

\section{CONCLUSION AND DISCUSSION}

In these two episodes, both groups completed the task but demonstrated differences in the effectiveness of their communication. Variation amongst students is considered important for stimulating productive relationships, but at the same time variations can be counterproductive if the differences are too great (Cobb, 1999). Since each participant comes to discourses with his or her own use of words and expectations regarding the rules of the activity to take place, the shape of the exchange in discourses is the result of the expectations of all the interlocutors (Sfard, 2001). Based on the preceding analysis, it seems that the expectations of the students regarding the meta-discursive rules of the activity sometimes overshadow the teacher's (or researcher's) intentions.

As shown in the analysis, discursive intention variations amongst students can exist on the object level or the meta level. In group 1, meta-discursive rules did not become an issue in communication, as all the students seemed to have the same expectations regarding the rules for interaction. Their focus shifted to the object level: solving the problem. This joint discursive intention guided their interactions in reading their clues. They focused on the content of the clues (object level), not on the order in which to read them (meta level). In the second group, expectations regarding the meta-discursive rules of the activity did not harmonise. When they started working on the task, this group focused on fairness in reading the clues (meta level). It took some time before the group's joint discursive intention moved to the object level, and because they did not respond to what others were saying but worked individually (for example, 23-25), their communication did not become effective. When Annie [26] introduced writing, her suggestion at first resulted in discursive intentions on the meta level for Nellie and Tracy, who became concerned with who would write. Again, the students had different expectations regarding the metadiscursive rules of the activity; this kept their communication on the meta level and did not allow them to focus on solving the problem. Finally, three of the students continued to solve the problem, and then the communication became effective on the object level. Perhaps the most important variation amongst students for stimulating 
productive relationships is variation on the object level; variation on the meta level seems to be counterproductive. When students have the same expectations regarding the meta-discursive rules of the activity, this scaffolds their communication on the object level. However, variation on the object level also seems to inhibit participation for some students (for example, Fiona in group 2 and Jack in group 1).

In the two episodes, the students who seemed to control the mediating tools on an object level were the ones most visibly active. Writing as a mediating tool on the object level was introduced by students in both groups. Writing is not to be seen as "the right or wrong way to do in order to solve the problem[s]; rather [writing] serve[s] a function of communicating ... and of helping to improve the mathematical interpretations" (Lesh \& Zawojewski, 2007, p. 794). On the object level, writing seems to help interlocutors to gather around a joint discursive intention. In group 2, however, the question Who is going to write? became problematic because the discursive intention that the question elicited differed for at least two of the students. For one, the question reflected the object level, as explained above; for Tracy and Nellie, however, the question moved to the meta level. When the question was not addressed as such, their struggle and resistance started; the two levels caused an internal conflict.

Finally, as mentioned, the aim of the part of the cyclic process presented in this paper was to develop our (researcher-teachers') understanding regarding the productiveness of the interaction in the groups. What does a productive group problem-solving interaction entail, and what does this analysis bring to the next cycle in the intervention? Both groups presented in this paper successfully completed the problem-solving task, but the interaction amongst the interlocutors differed. As seen in the two episodes, individual students' discursive intentions are seldom pronounced but are attended, making their expectations regarding the meta-discursive rules of the activity very important. When expectations regarding those meta-discursive rules are the same, they remain unnoticed, and the focus of the group moves to the object level. But when expectations regarding the rules of the activity are not the same, the focus remains on the meta level. The meta level is closely related to problem solving as a skill in terms of successfully working in groups. The analysis of the two episodes indicates that learning problem solving as skill entails focusing more on the metadiscursive rules of problem solving. Students participate in any mathematical practice activity in a variety of qualitatively different ways and need to recognise that working in a group means learning from others and taking advantage of others' ideas and the results of their investigations. For students to comprehend this, the teacher (or researcher) cannot be passive (as in the episodes reported here) but must be active in making visible both the object level and the meta level such that students' communication, interpretations, representations, and reflections are foregrounded. If meta-discursive rules are made clear at the beginning of the problem-solving process, then students may have the same expectations regarding the rules of the activity, 
allowing their discursive intentions to move to the object level. And as emphasised by Sfard (2001), one should be careful when grouping students for collaborative learning.

\section{References}

Andersson, T. \& Shattuck, J. (2012). Design-Based Research: A Decade of Progress in Education Research? Educational Researcher, 41.

Cai, J. (2010). Commentary on problem solving heuristics, affect, and discrete mathematics: A representational discussion. In: B. Sriraman \& L. English (Eds,), Theories of Mathematics Education: Seeking New Frontiers (pp. 251-258). Dordrecht: Springer.

Cobb, P. (1999). Individual and collective mathematical learning: The case of statistical data analysis. Mathematical Thinking and Learning, 1, 5-43.

Lesh, R. \& Zawojewski, J. (2007). Problem Solving and Modeling. In: F.K. Lester (Ed.), Second Handbook of Research on Mathematics Teaching and Learning (pp.763-799). Charlotte: National Council of Teachers of Mathematics \& Information Age Publishing.

Lester, F.K. \& Lambdin, D. (2007). Undervisa genom problemlösning. In J. Boesen (Ed.), Lära och undervisa i matematik - internationella perspektiv (pp.95-108). Göteborg: Nationellt Centrum för Matematikutbildning.

Ryve, A. (2006). Making explicit the analysis of students' mathematical discourses: Revisiting a newly developed methodological framework. Educational Studies in Mathematics, 62, 191-210.

Sfard, A. (2001). There is more to discourse than meets the ears: Looking at thinking as communicating to learn more about mathematical learning. Educational Studies in Mathematics, 46, 13-57.

Sfard, A. (2008) Thinking as Communicating. Human Development, The Growth of Discourses, and Mathematizing. New York: Cambridge University Press.

Skolinspektionen (2009). Undervisningen I matematik - utbildningens innehåll och ändamålsenlighet. Kvalitetsgranskning rapport 2009:5. Skolinspektionen: Stockholm.

Skolverket (2011). Läroplan för grundskolan, förskoleklassen och fritidshemmet, Lgr11. Stockholm: Skolverket.

Stanic, G. M. A. \& Kilpatrick, J. (1988). Historical Perspectives on Problem Solving in the Mathematics Curriculum. In: R.I. Charles \& E.A. Silver (Eds.), The Teaching and Assessing of Mathematical Problem Solving 8pp.1-22). Reston VA: National Council of Teachers of Mathematics

The Design-Based Research Collective (2003) Design-based research: An emerging paradigm for educational inquiry. Educational Researcher. 32(1) 5-8

Wyndhamn, J, Riesbeck, E. \& Schoultz, J. (2000). Problemlösning som metafor och praktik. Institutionen för tillämpad lärarkunskap, Linköpings universitet. 


\title{
TASKS OF TEACHING MATHEMATICS IN KINDERGARTEN
}

\author{
Reidar Mosvold and Per-Einar Sæbbe
}

University of Stavanger

Research on the knowledge for teaching mathematics in school has received much attention in the last decades. In comparison, research on kindergarten teachers' mathematical competence has been scarce. In this paper, we discuss the extent to which the theories of mathematical knowledge for teaching (MKT) can inform studies of Norwegian kindergarten teachers' mathematical competence. Based on discussions of a vignette from a Norwegian kindergarten context, we argue that tasks of teaching can serve as a foundation for studies of kindergarten teachers competence as well as the development of a theory of teaching in kindergarten.

\section{INTRODUCTION}

Ever since Shulman (1986) ignited researchers' interest in teacher knowledge, numerous studies have been made to investigate various aspects of teachers' professional knowledge. In the U.S., researchers have developed a practice-based theory of mathematical knowledge for teaching - often referred to only by the acronym MKT (Ball, Thames, \& Phelps, 2008). Results from large-scale measurements indicate a connection between teachers' MKT, the quality of instruction and students' achievements. Other researchers have developed different theories of teacher knowledge that focus on the knowledge used in teaching (e.g., Rowland \& Ruthven, 2011); many build upon the work of Shulman.

In a kindergarten context, there has traditionally been a stronger focus on children's learning and development than on kindergarten teachers and their knowledge. Much of the research on children's mathematical development has followed a Piagetian tradition (e.g., Sæbbe \& Mosvold, 2013). Based on a review of research, Baroody, Lai and Mix (2006) contend that it is important to facilitate children's mathematical development - in particular their number sense - before they enter school age. The responsibility of facilitating children's learning and development in kindergarten lays with the kindergarten teachers, and this responsibility demands a particular kind of knowledge (Ministry of Education and Research, 2013). There is a disparity, however, between the seeming agreement about the importance of kindergarten teachers' mathematical knowledge on the one hand and the lack of research in this area on the other. A few studies have been made concerning kindergarten teachers' knowledge of mathematics (e.g., Lee, 2010), but such studies often build on the assumption that teaching mathematics in kindergarten is similar to teaching mathematics in school (Ginsburg \& Amit, 2008). In correspondence with such views, researchers have measured kindergarten teachers' mathematical knowledge by using measures that were developed for measuring elementary teachers' mathematical knowledge for teaching (e.g., Lee, 2011). 
Kindergarten traditions differ across countries, and a distinction is often made between a so-called "social pedagogy" tradition and a "pre-primary" tradition (OECD, 2006). The former is common in the Nordic countries, whereas the latter is more common in the U.S. and several other countries. When Ginsburg and Amit (2008) argued that teaching mathematics in kindergarten is similar to teaching mathematics in school, this might be true in a pre-primary kindergarten tradition. The Norwegian kindergarten belongs to a social pedagogy tradition, and this tradition has a strong emphasis on free play and informal learning (Alvestad, Johansson, Moser, \& Søbstad, 2009). Recent research in early childhood education indicates that free play is not enough to learn mathematics; intentional teaching is necessary (Ginsburg \& Ertle, 2008). A challenge, then, is that "teaching" itself is a term not commonly used in a Norwegian kindergarten context. For decades, a professional language has been called for that describes the professional work that teachers do (e.g., Lortie, 1975). Such a professional language is also needed to describe the work that kindergarten teachers do. Some early attempts have already been made to investigate the work of teaching mathematics in Norwegian kindergartens (Mosvold, 2012), and concerns have been raised that differences in kindergarten cultures might lead to different challenges of teaching mathematics across kindergarten cultures (Mosvold et al., 2011). Such preliminary results call for further and more systematic investigations of the work involved in teaching mathematics in a Norwegian kindergarten context. This paper aims at contributing to this discussion by pointing at the investigation of mathematical tasks of teaching as a potential starting point. We use a vignette from a Norwegian kindergarten context as an entry point for a theoretical discussion of how investigations of tasks of teaching might inform the efforts to develop a theory of the work of teaching mathematics in kindergarten and thereby contribute to the development of a professional language of teaching. When we discuss "tasks of teaching" in this paper, we refer to the challenges that kindergarten teachers meet in their work of teaching.

So far, we have mainly used the concept of "knowledge", whereas others prefer "competence". Niss and Højgaard (2011, p. 49), for instance, describe mathematical competence as "a well-informed readiness to act appropriately in situations involving a certain type of mathematical challenge". These researchers refer to knowledge as part of competence; knowledge is something you mainly have, whereas competence is a more compound readiness to act. Ball and colleagues (2008) seem to have a different use of the terms when they define MKT as the "mathematical knowledge needed to perform the recurrent tasks of teaching mathematics to students" (ibid., p. 399). We follow Ball and colleagues in our paper, and we therefore do not distinguish between knowledge and competence in the same way Niss and Højgaard seem to do. Before we initiate our main discussion, we make a brief presentation of some of the foundations of the framework for the practice-based theory of mathematical knowledge for teaching (MKT). Using a vignette from the Norwegian kindergarten context as a case, we then discuss how this theory might inform research on kindergarten teachers' mathematical knowledge in this context. 


\section{MATHEMATICAL KNOWLEDGE FOR TEACHING}

When Ball and colleagues at the University of Michigan developed their practicebased theory of MKT, a main focus was on identifying mathematical knowledge that was needed for teaching on the basis of analyses of the mathematical challenges or tasks that occur in the work of teaching mathematics (Ball, Thames, \& Phelps, 2008). A foundation for their theory is the understanding of teaching. Whereas researchers who analyse teaching across countries often focus on the practices of the teacher within the classroom (e.g., Hiebert et al., 2003), Ball and colleagues use the term "work of teaching" to refer to teaching in a broader sense. Their view of teaching then includes "everything that teachers must do to support the learning of their students" (Ball, Thames, \& Phelps, 2008, p. 395). When we investigate kindergarten teachers and their "teaching" of mathematics in this paper, we adopt the same broad definition of teaching. Teaching mathematics in kindergarten can thus be defined as everything kindergarten teachers do in order to support children's learning and development of mathematics. It should also be noticed that Ball and colleagues focus on teaching and not on teachers. Their approach to investigate teaching includes two main steps: 1) analyses of the tasks or challenges that are involved in teaching mathematics, and 2) design of measures of MKT. When MKT is discussed and criticized, the second step seems to get most of the attention; we therefore want to focus our attention on the first step.

In their work of teaching mathematics, teachers are faced with different mathematical challenges. Figure 1 presents a list of some of the mathematical tasks of teaching that were identified by Ball and colleagues (2008).

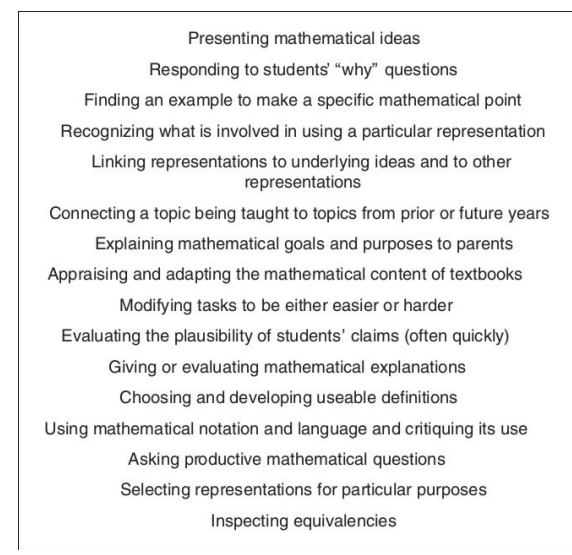

Figure 1. Mathematical tasks of teaching (Ball, Thames, \& Phelps, 2008, p. 400). 
As a second step in their analyses of the work of teaching mathematics, Ball and colleagues designed survey items to measure MKT. In correspondence with this, they distinguished between several aspects of MKT - often depicted in the "egg". Building on the theories of Shulman (1986), Ball and colleagues suggested that MKT consisted of subject matter knowledge and pedagogical content knowledge as two main categories. Each of these categories was divided into three sub-categories. Items were developed to measure teachers' knowledge of different categories of MKT, and results from large-scale measurements of teachers' knowledge were used to test their assumptions concerning the categories and dimensions of MKT. The development of items was not only useful for testing their hypotheses, however, but Ball and colleagues (2008) also described the development of items as integral to the development and refinement of the theory. It should be noted that two underlying assumptions to such research efforts are: 1) an understanding of knowledge as something that can be categorized and measured, and 2) a focus on increasing the efficiency of teaching. Since this paper has a main emphasis on tasks of teaching, we do not go into a detailed discussion of the categories of MKT or the measures. Such discussions can be found elsewhere (e.g., Ball et al., 2008).

\section{A VIGNETTE FROM NORWEGIAN KINDERGARTEN}

As a starting point for our discussion, we use the following vignette from a Norwegian kindergarten context. The situation takes place when the kindergarten teacher lets the children play with tessellation tiles in a group of ten children. "John", a 3-year old boy, is one of the oldest children in the group. In this group of children, they had worked with shapes for some months. They could recognize and name several shapes, and they had already played with the tiles a couple of times before. One of the authors (Reidar) is sitting on the floor, playing with John. This entire situation only lasts about 30 seconds, and it is initiated by Reidar's question about how they can make a star with the tiles (a shape that some of the other children had been making already):

Reidar: How, then, could we make a star?

John: Hey, are we going to destroy these afterwards?

Reidar: (Doesn't respond to John's question) Do you think we should use those? [See figure 2] (Points at one of the pink hexagon shapes)

John: This. (holds up another one of the pink hexagons)

Reidar: $\quad$ Yes. And then, what else do we need?

John: (looses his balance and tumbles around on the floor)

Reidar: Should we use (a short pause while he finds a white triangle-shaped tile) these $=$ 
John: $\quad=$ Quadrangles and triangles (singing)

Reidar: Yes. Should we find some?

John: (nods)

Reidar: $\quad$ Yes. (moves his hand over the tiles and finds another white triangle. Places it on the floor in front of them)

John: $\quad$ This is a quadrangle (picks up a green square tile)

Reidar: That is a quadrangle (points at it with his finger). What is that then? (has found a white triangle and holds it up in his hand)

John: $\quad$ Triangle. (takes it away from Reidar's hand)

Reidar: That was a triangle. We needed that. And then we need ... (looking for some more tiles) those, and this one (finds some more triangle-shaped tiles while John is placing one of the white triangles close to one of the edges of the hexagon, and a green square towards another edge) [See figure 3]

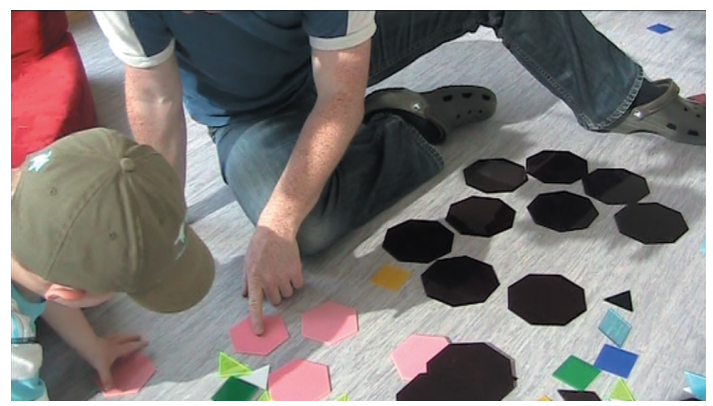

Figure 2. "Do you think we should use those?"

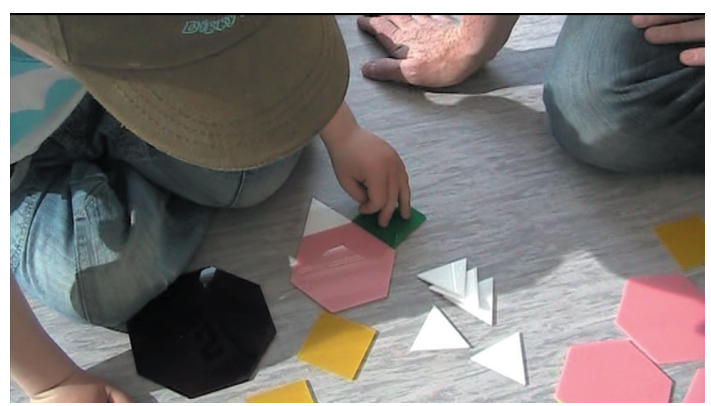

Figure 3. John starts building with the tiles 
In this vignette, we can identify some tasks of teaching that were similar to the ones Ball and colleagues (2008) identified, and we can also observe differences. In the present paper, our focus is on the theoretical argument, and we limit our discussion to three particular tasks of teaching. With these examples, we illustrate tasks that are similar in school and kindergarten, tasks that are different and possible new tasks that are unique to the kindergarten context.

An example of a mathematical task of teaching that Ball and colleagues identified, and which is also relevant in a Norwegian kindergarten context, is that of presenting mathematical ideas. With the given tiles, Reidar suggests that they build a star shape. In the discussion, the concepts of triangle and quadrangle are also used, and it appears that John is already familiar with these concepts. Although contexts and situations differ, we argue that presenting mathematical ideas is among the most important mathematical tasks of teaching in kindergarten as well as in school.

Some of the tasks of teaching identified in the American school context are different from the Norwegian kindergarten context. One example is that of adapting mathematical content from textbooks. Mathematics textbooks are not commonly used in Norwegian kindergartens, and adapting content and tasks from textbooks is thus of little relevance to Norwegian kindergarten teachers; adapting games, activities and use of manipulatives, however, is more common. This difference in the task of teaching, we argue, is related to the differences in the kindergarten cultures. In a preprimary kindergarten tradition, the use of textbooks is more common. This task of teaching is more relevant in such a kindergarten context.

The second task of teaching in the list (see figure 1) is about answering children's "why" questions. As we can see from the vignette, John did not pose a lot of questions relating to the understanding of mathematical content, and neither did the other children in his group. On the contrary, the questions and comments often seemed to be directed away from the mathematical content rather than towards it. This points towards another challenge that was not identified by Ball and colleagues (2008): achieving joint attention. Bruner (1983) and others discussed this in relation to small children's learning and language development, and the discussion between Reidar and John seems to be about achieving joint attention. Reidar initiates the situation with a question that aims at focusing John's attention in a certain direction: How can we make a star with these tiles? John does not respond to the question; instead he asks Reidar if they are going to destroy it afterwards. Reidar ignores the question and continues to try and direct John's attention towards the making of a star. When children are asked questions, they often answer or make suggestions that go in a different direction than the kindergarten teacher intended. Kindergarten children are in the process of developing language and communication skills, and this challenge of achieving joint attention, we argue, is therefore a task of teaching mathematics that is particularly relevant in kindergarten. Given such questions from children, the kindergarten teacher is still faced with the challenge of providing proper explanations regarding the mathematical content and underlying ideas. 
Some of the tasks of teaching that can be identified in this vignette are related to the age of the children (in this case: John, 3), the mathematical content and level, and some are related to the particular kindergarten context. This situation took place while the kindergarten teachers were sitting on the floor with the children. Although the kindergarten teachers had planned to use the tiles in order to stimulate children's development of understanding about shapes and pattern, the situation described here can still be described as spontaneous and informal. Kindergarten teachers are faced with challenges of presenting mathematical content in planned as well as spontaneous activities (Björklund, 2012). In this example, the possibilities of the material had been discussed in advance, but Reidar could still not be fully prepared for what took place even in this short half-minute situation. Similar spontaneous situations often occur in a school context also. The work of teaching in this kindergarten context differs from the traditional mathematics teaching in school, one might argue, in that it is more focused on facilitation than instruction. When we adopt the more broad definition of teaching from Ball and colleagues (2008), however, facilitation and direct instruction are both part of the work of teaching mathematics - in kindergarten as well as in school. The vignette illustrates some particular mathematical tasks of teaching, and these tasks relate to certain mathematical knowledge that the kindergarten teachers need (cf. Ball et al., 2008). Kindergarten teachers face different mathematical tasks of teaching in their work, and we argue that the identification of such tasks of teaching can be a starting point for investigating the knowledge needed for teaching mathematics in kindergarten. In relation to the vignette, the kindergarten teacher needs mathematical knowledge to pose questions and "guide" the conversation in the proper direction in order to support children's learning. The identification of the content and nature of this mathematical knowledge needed is not straightforward, but we suggest that the identification of mathematical tasks of teaching is a potential starting point.

\section{CONCLUDING DISCUSSION}

This short vignette illustrates a number of challenges related to kindergarten teachers' work of teaching mathematics: How can we select appropriate activities and material for a diverse group of children? How can we facilitate children's learning - while at the same time allowing the children to be active participants in the activities? How can we use children's play as a context for learning without destroying the play situation? How can we evaluate the children's learning from such informal learning situations and at the same time respect the directive to not assess children individually? We suggest that the approach used by Ball and colleagues (2008) can inform research on mathematics teaching in kindergarten in analysing the work of teaching mathematics in kindergarten, and such analysis should focus on the recurrent tasks of teaching.

Much of the international research on mathematics teaching in kindergarten has been made in a pre-primary kindergarten tradition (e.g., Ginsburg \& Amit, 2008). The 
Nordic kindergarten culture is different. There is a strong focus on play, and learning has only recently received increased attention (Alvestad, Johansson, Moser, \& Søbstad, 2009). The work of teaching seems to receive even less attention. The framework plan for Norwegian kindergartens focus on kinds of activities that kindergarten teachers should facilitate in order to ensure that children experience numbers, mathematical concepts, shapes and patterns, etc. (Ministry of Education and Research, 2012). The framework plan is also specific about what the kindergarten teachers must do in order to achieve these goals. The work of teaching thus seems to be about facilitating different activities. This seems to be prevalent in research too. When Björklund (2012), for instance, investigates mathematics teaching in kindergarten, she focuses on kindergarten teachers' awareness and ability to reflect upon one's own and children's actions. She suggests that reflection on the interaction between the kindergarten teacher and the child is essential to improving practice. The analysis has "a strong focus on the educator's experiences and interpretations of the learning process she and the child take part in" (Björklund, 2012, p. 512). Like many other researchers in the Nordic context, Björklund uses variation theory as a theoretical framework. Although variation theory arguably has a number of benefits, it is still a theory of learning rather than a theory of teaching. There is a need to develop a theory of teaching (mathematics) in kindergarten, and we suggest that analyses of the work of teaching mathematics - which entails the identification of mathematical tasks of teaching - is a viable starting point for development of such a theory of teaching.

A possible approach for further research would then be to conduct naturalistic investigations of the mathematical knowledge kindergarten teachers use in their work, how they are conscious about using proper language to describe mathematical phenomena, how they reason and wonder with the children, etc. In close connection with this, it also makes sense to investigate the nature of the mathematical challenges - or tasks - that kindergarten teachers are faced with in such a context. Studies of Mosvold and colleagues (2011) indicate that there are some differences in the tasks of teaching mathematics in Norwegian kindergartens as compared to teaching mathematics in school. Such differences indicate that we should be careful about adopting the entire framework of MKT for use in a Norwegian kindergarten tradition. We argue, however, that tasks of teaching - along with a broad definition of teaching - is a relevant focus in studies of Norwegian kindergarten teachers' mathematical competence. Mosvold (2012) made some attempts to study kindergarten teachers' tasks of teaching - and these previous attempts provide certain useful indications for future research. Further studies are needed, however, to investigate the work of teaching mathematics in Norwegian kindergartens, and we suggest that a focus on tasks of teaching might be valuable.

A possible result of such studies might be that the work of teaching mathematics in kindergartens in a social pedagogy tradition is found to be significantly different from teaching mathematics in school - or even in a pre-primary kindergarten tradition. If 
the work of teaching is significantly different, it can be argued that the mathematical knowledge needed for teaching is different too. Due to the strong social pedagogy tradition in Norwegian kindergartens, the question of what mathematical knowledge is "needed" for teaching mathematics itself can be described as a misnomer. It might be more relevant to approach a study of the mathematical knowledge used by kindergarten teachers when facilitating and scaffolding children's learning of mathematics. On the other hand, the focus of research in this area should not only be on whether or not the tasks of teaching in kindergarten are similar or different from the tasks of teaching that Ball and colleagues (2008) identified in American schools. Naturalistic inquiry with a focus on tasks of teaching can provide relevant information about the work of teaching mathematics in (Norwegian) kindergartens, and it can also provide insight into the knowledge used by kindergarten teachers. In light of the agreement both researchers and policy makers seem to have regarding the importance of kindergarten teachers' knowledge, such an increased insight should be exceedingly important.

\section{REFERENCES}

Alvestad, M., Johansson, J.E., Moser, T. \& Søbstad, F. (2009). Status og utfordringer i norsk barnehageforskning. Nordisk Barnehageforskning, 2(1), 39-55.

Ball, D.L., Thames, M. H., \& Phelps, G. (2008). Content knowledge for teaching: What makes it special? Journal of Teacher Education, 59(5), 389-407.

Baroody, A.J., Lai, M.L. \& Mix, K.S. (2006). The development of young children's early number and operation sense and its implications for early childhood education. I B. Spodek \& O.N. Saracho (Eds.), Handbook of research on the education of young children (Vol. 2, pp. 187-221). London: Routledge.

Björklund, C. (2012). One step back, two steps forward - an educator's experiences from a learning study of basic mathematics in preschool special education. Scandinavian Journal of Educational Research, 56(5), 497-517.

Bruner, J. (1983). Child's talk: Learning to use language. Oxford: Oxford University Press.

Ginsburg, H.P. \& Amit, M. (2008). What is teaching mathematics to young children? A theoretical perspective and case study. Journal of Applied Developmental Psychology, 29(4), 274-285.

Ginsburg, H.P. \& Ertle, B. (2008). Knowing the mathematics in early childhood mathematics. In O.N. Saracho \& B. Spodek (Eds.), Contemporary perspectives on mathematics in early childhood education (pp. 45-66). Charlotte, NC: Information Age Publishing. 
Hiebert, J. et al. (2003). Teaching mathematics in seven countries - results from the TIMSS 1999 video study. Washington, D.C.: National Center for Education Statistics (NCES), US Department of Education.

Lee, J. (2010). Exploring kindergarten teachers' pedagogical content knowledge of mathematics. International Journal of Early Childhood, 42(1), 27-41.

Lee, J.E. (2011). A study of pre-kindergarten teachers' mathematical knowledge for teaching. (Unpublished doctoral dissertation). The University of Texas at Austin, Austin, Texas.

Lortie, D.C. (1975). Schoolteacher: A sociological study. Chicago, IL: The University of Chicago Press.

Ministry of Education and Research (2012). Framework plan for the content and tasks of kindergartens. Oslo: Kunnskapsdepartementet.

Ministry of Education and Research (2013). Framtidens barnehage. (St.meld. nr. 24, 2012-2013). Oslo: Kunnskapsdepartementet.

Mosvold, R. (2012). Førskolelærerens utfordringer knyttet til arbeidet med antall, rom og form i barnehagen. In M. Alvestad \& T. Vist (Eds.), Laeringskulturer $i$ barnehagen: flerfaglige forskningsperspektiver (pp. 92-114). Oslo: Cappelen Damm Akademisk.

Mosvold, R., Bjuland, R., Fauskanger, J. \& Jakobsen, A. (2011). Similar but different - investigating the use of MKT in a Norwegian kindergarten setting. I M. Pytlak, T. Rowland, \& E. Swoboda (Eds.), Proceedings of the Seventh Congress of the European Society for Research in Mathematics Education (pp. 1802-1811). University of Rzeszów, Poland.

Niss, M. \& Højgaard, T. (2011). Competencies and mathematical learning: Ideas and inspiration for the development of mathematics teaching and learning in Denmark. Retrieved December 18, from https://pure.au.dk/portal/files/41669781/THJ11_MN_KOM_in_english.pdf

Rowland, T. \& Rutvhen, K. (Eds.) (2011). Mathematical knowledge in teaching. Dordrecht: Springer.

Shulman, L. (1986). Those who understand: Knowledge growth in teaching. Educational Researcher, 15(2), 4-14.

Sæbbe, P.E. \& Mosvold, R. (2013). "Han går oppover mens han går nedover!" Femåringers refleksjoner om vertikal forflytning i forbindelse med klatring. Nordisk Barnehageforskning, 6(18), 1-15. 


\title{
COORDINATING THE IC-MODEL WITH A FRAMEWORK ON COMMUNICATION IN ANALYSING STUDENT-TO-STUDENT INTERACTIONS IN MATHEMATICS
}

\author{
Marie Sjöblom \\ Malmö University
}

The aim of this paper is to investigate possibilities for coordinating two theories in order to analyse interactions in a group of four students completing a mathematics task in upper secondary school. The investigation suggests that the theories can be coordinated, but their interpretations of the interactions provide information on different levels. Alro and Skovsmose's IC-model gives a more general picture of what is happening in the interaction between students, whereas Fuentes's framework gives details to what is happening in the different dialogic acts in the IC-model.

Keywords: student-to-student interaction, student communication, coordinating theories, educational design research, communication frameworks

\section{INTRODUCTION}

In mathematics education research many studies have been conducted on giving students opportunities to talk mathematics, both in whole-class situations and in small group work. Alrø and Skovsmose (2004) claimed that "the qualities of communication in the classroom influence the qualities of learning mathematics" ( $p$. 11). This paper focuses how quality and quantity in students' mathematical communication can be studied with help of two theories on student interaction, namely the IC-model (Alrø \& Skovsmose, 2004) and Fuentes's (2013) framework for analysing student communication. Both theories have previously been used for examining students' interactions, but the theories have not been connected to each other. In a previous paper (Sjöblom, 2014), I described how the IC-model (Alrø \& Skovsmose, 2004) was used to design mathematical tasks with the aim of increasing student-to-student interaction in an upper secondary class. However, the IC-model (Alrø \& Skovsmose, 2004) was not developed as an analytical tool for understanding small group work, so when analysing the student communication, a need for more theory on student interaction occurred (Sjöblom, 2014). Therefore, in this paper, possibilities for coordinating the IC-model (Alrø \& Skovsmose, 2004) with Fuentes's (2013) framework are investigated in order to understand how capable the theories are and if coordinating them can help studying the quality and quantity in students' mathematical reasoning. If the theories can be coordinated, it will help to answer the research question: How do student interactions and perceptions change over time when different tasks are provided to increase student-to-student interaction?

There can be several reasons for connecting frameworks or theories in mathematics education research. According to Prediger, Bikner-Ahsbahs and Arzarello (2008), connections can contribute to gaining "increasing explanatory, descriptive, or prescriptive power" (p. 169). In my project, when designing different tasks to 
increase student-to-student interaction, there is a need for a theoretical base to justify why the tasks are designed the way they are and also for how data is analysed. A connection of the IC-model (Alrø \& Skovsmose, 2004) and the Fuentes's (2013) framework gives possibilities to explain and describe what happens in the communication between students from two different starting points and hence a possibility to evaluate improvements in the quality and quantity of the students' interactions. This can be done amongst other methods through looking at which mathematical questions that students ask each other and see how these questions are treated within the groups of students. One of the reasons for why the IC-model (Alro \& Skovsmose, 2004) and Fuentes's (2013) framework are chosen amongst other communication theories is that both theories address mathematical questions. They also have other equalities in their structures and can both be used for studying student-to-student interaction. A more detailed comparison of the structures is made after the theories are introduced.

\section{ALRØ AND SKOVSMOSE'S IC-MODEL}

The IC-model was developed by Alrø and Skovsmose (2004) to describe how teachers and students can work together to explore a landscape of investigation. This means that students instead of working individually with textbook exercises are introduced to a scene setting in which they can ask questions and choose directions for what they want to investigate (Alrø \& Skovsmose, 2004). The students are active participants in an inquiry process with mathematical content. The IC-model can also be applied to students' inquiry processes in which a teacher not is present at all times (Alrø \& Skovsmose, 2004). When students discuss mathematics in small groups, they are given possibilities to make use of each other's contributions assuming that they have different previous knowledge and different ways of interpreting and dealing with mathematical tasks. This can be connected to the students' zones of proximal development, that is the possibility students have to learn more together with a teacher or more capable peers compared to working alone (Vygotski, 1978). Also Goos, Galbraith and Renshaw (2002), have studied how zones of proximal development could be established through students' interactions in small group work, but they preferred to use the term collaborative zone of proximal development when describing student collaboration in order to differ it from what is happening when students talk to a teacher.

In the IC-model there are eight dialogic acts, namely: getting in contact (prepare for interaction), locating (understand the problem), identifying (find the mathematics in the problem), advocating (examine ideas), thinking aloud (make perspectives and thoughts visible), reformulating (clarify and rephrase), challenging (question) and evaluating (look back at the problem). The acts do not appear in linear order, and sometimes in conversations only some acts are present. Alrø and Skovsmose (2004) found that fully developed IC-models are rare. This could affect the quality as well as quantity of mathematical communication and learning as Alrø and Skovsmose (2004) 
considered that "the IC-model not only represents qualities of communication, it also constitutes an important resource for learning" (p. 67).

In the IC-model, mathematical questions are important parts of the inquiry process. When exploring a landscape of investigation, questions about what to do, why and how need to be addressed. Some questions can be connected to acts in the IC-model. According to Alrø and Skovsmose (2004), tag-questions that students ask at the end of an utterance to reassure that other students are with them, are part of getting in contact. Further, when students are locating the problem, they need to ask what-ifquestions and inquiring questions in order to explore different perspectives. Alrø and Skovsmose (2004) stated that when a what-if-question is followed by a why-question, then locating turns into identifying, and answers to why-questions when students give suggestions to how to solve problems, can be connected to advocating. Also the other acts can include questions, for instance, reformulating, can start with "do you mean..." and challenging is often an act of questioning mathematical statements. In all the acts in the IC-model, it is important that students are active in the interaction.

In order to be able to study the quality and quantity of what is happening in the different dialogic acts in the IC-model, one possibility can be to look at other theories concerning communication between students working together in groups. Therefore, in the next section, Fuentes's (2013) framework is presented.

\section{FUENTES'S FRAMEWORK ON STUDENT COMMUNICATION}

Fuentes (2013) conducted a series of interventions in a practitioner action research project on students' collaborative work. She claimed that it is important for students to evaluate each other's reasoning and found three categories of issues that hindered effective student communication: lack of communication between all students in a group, poor communication patterns and norms that impede student learning (Fuentes, 2013). In order to analyse what happened in the student communication, Fuentes (2013) extended a framework by Dekker and Elshout-Mohr (2004) to contain eight question/comment-response pairs used to analyse student interaction. Fuentes (2013) classified what happened in conversations between students with help of the question/comment-response pairs and then identified common interaction patterns between the students, which she used for promoting student-to-student discourse.

\begin{tabular}{|l|l|}
\hline Question/Comment & Response \\
\hline 1. A asks B to show work & 1. B shows own work \\
\hline 2. A asks B to explain work & 2. B explains own work \\
\hline 3. A criticises B's work & 3. B justifies own work \\
\hline 4. A rejects B's justification & 4. B reconstructs own work \\
\hline 5. A asks B to evaluate work & 5. B evaluates A's work \\
\hline 6. A suggests a strategy to the group & 6. The group tries the strategy \\
\hline
\end{tabular}




\begin{tabular}{|l|l|}
\hline 7. A asks B a content question & 7. B answers A's question \\
\hline 8. A asks B a clarification question & 8. B answers A's question \\
\hline
\end{tabular}

Table 1: Framework for analysing student communication (from Fuentes, 2013, p. 54)

In Table 1, the first four question/comment-response pairs are from Dekker and Elshout-Mohr (1998), while question/comment-response pairs 5-8 are Fuentes's (2013) elaboration. Fuentes (2013) used the framework for analysing student communication in order to design teacher interventions that promoted student-tostudent discourse, both for when the teacher was present and when the students worked by themselves in groups. The interventions were made to "model and foster activities such as asking questions, sharing and comparing strategies, listening to explanations, and assessing methods and solutions" (Fuentes, 2013, p. 69).

There are many similarities between this framework and the IC-model. Since a need to deeper analyse the dialogic acts in the IC-model was found in Sjöblom (2014), in the next section, an investigation of coordinating the theories is conducted.

\section{COORDINATING THEORIES}

Prediger et al. (2008) gave examples of different strategies to connect theories in mathematics education research, which stretched from ignoring other theories to unifying globally. Between these two extremes, there are different networking strategies: understanding others, making understandable, contrasting, comparing, combining, coordinating, synthesizing and integrating locally. In this paper focus is on coordinating theories, since this strategy enables "a networked understanding of an empirical phenomenon or a piece of data" (Prediger et al., 2008, p. 10). Coordinating also enables triangulation of data (Prediger et al., 2008). This is valuable in a study of students' communication, since then the communication could be looked at from two different perspectives, which gives more possibilities to study both the quality and quantity of students' interactions.

Wedege (2010) combined Prediger et al.'s (2008) networking strategies with Radford's (2008) morphology of theories in which theories in mathematics education are seen as triplets $T=(P, M, Q)$, where $P$ is a system of principles, $M$ is a methodology supported by $P$, and $Q$ is a set of research questions. Wedege (2010) claimed that it is important when using Prediger et al.'s (2008) networking strategies, to look at how the triplets $T$ of the theories are interrelated as well as the goal of the connection, so that these do not contradict each other.

Wedege (2010) claimed that Prediger et al.'s (2008), coordinating of theories was a connection strategy:

The term coordinating is used when a conceptual framework is built by well fitting elements from different theories: elements e.g. from the basic principles $P$, are chosen and put together in a more or less harmonious way to investigate a certain research problem. (Wedege, 2010, p. 67) 
In this paper, an investigation of the possibility to coordinate the IC-model and the Fuentes's framework is made, since a coordinating of them would help to analyse how students' interaction change when different tasks are introduced to increase the student-to-student interaction. Now the different elements in the triplets $T=(P, M, Q)$ for the two theories are discussed.

\section{System of principles, $P$}

The first step is to look at the basic principles, $P$, of the theories. $P$ includes "implicit views and explicit statements that delineate the frontier of what will be the universe of discourse and the adopted research perspective" (Radford, 2008, p. 319). A first comparison of the system of principles show that they both build on sociocultural views that learning mathematics is connected to working together and using language to express thinking.

A second principle for both theories is that they can be applied to communication between students and that they intend to say something about the quality of the communication. Counting how often the acts in the IC-model or the question/ comment-response pairs occur also opens up for a qualitative analysis.

A third principle that is similar is that both theories assume that students are active participants in the communication and that students together build up the mathematical conversation.

Finally, a fourth principle is that both theories focus questions. In the IC-model, the different dialogic acts contain questions when students work together with the inquiry process and questions are also an important part of Fuentes's framework.

\section{Methodology, $M$}

The second step is to look at the methodologies $M$ of the two theories. Both theories assume that there will be a communication about mathematics going on between students. In Fuentes's framework communication can be analysed by looking at question/comment-response pairs. In the IC-model, communication can be analysed by looking at the different dialogic acts. The data needed for these analyses is the same and the data collection can be made in similar ways, for instance through audio or video recordings.

\section{Set of research questions, $Q$}

The third step involves identifying the research questions $Q$ that are possible to ask when working with Fuentes's framework or the IC-model. For both theories, questions can be asked concerning student communication and interaction. It appears that both theories aim at addressing issues to deepen the understanding for students' communication. In my study both theories could be used for answering the research question on how interactions and perceptions change over time when different tasks are provided to increase the student-to-student interaction. 


\section{Possibilities for coordinating theories}

From looking at the triplets $T=(P, M, Q)$ for the IC-model and Fuentes's framework, many similarities in the structures for the theories can be found regarding all three parts $P, M$ and $Q$, and the theories do not appear to contradict each other. It therefore seems plausible to coordinate them. Now an example of how a coordinating could be applied to a piece of data concerning student communication is given. First a short description to the background of the project from where the data originates is given.

\section{METHOD AND AN EXAMPLE OF THE ANALYSIS PROCESS}

Utilising educational design research methods (McKenney \& Reeves, 2012), different tasks to increase student interaction are introduced in a first year, upper secondary mathematics class in a city in Sweden. Education design research is a cyclic method in which tasks are tried out and evaluated in cycles. The results from each cycle are incorporated into the planning of the next cycle. Each cycle has a theoretical base from which the choices of tasks and settings for the designs are made. The theories are used in both designing and evaluating the results of the tasks and thus provide an analysis of data that provides information about the research questions.

In the first cycle (Sjöblom, 2014), a mathematical group task was designed to promote some of the dialogic acts in the IC-model. The analysis of interactions between the students in the group was performed through categorizing student communication within the different acts. Results from the first cycle showed that students were active communicators in their small groups. However, the communication was not very structured. For instance, students did not seem to use mathematical questions deliberately as a part of the problem solving process, and a question list, given to the students as a support mean in the group work was not really utilised. Consequently it was decided to focus more on mathematical questions in the second cycle. Here Fuentes's framework for analysing students communication was considered an option and therefore in this paper, coordinating it with the IC-model is explored in order to understand how capable these theories were. A coordinating of the theories could provide a better theoretical base for answering the research questions, since a more detailed analysis of the interactions would be possible to conduct in the coming educational design research cycles.

Below is a transcript from a group with four students: Azad, Mohammed, Amal and Nour, who are working collaboratively on a mathematical task concerning loans and interests. The transcript was chosen to illustrate how communication can be related both to the IC-model and Fuentes's framework for analysing student communication. In the rightmost column in Table 2, connections are made to both these theories. When there is a number after a comment, question or response in Fuentes's framework, this refers to the corresponding line in Table 1. For instance response1 means that a student is showing another student his/her work (line 1 in Table 1).

The task that the students was given by their teacher Johannes was: 
Marie and Johannes have one loan each. Marie's loan has an interest of 3\% and Johannes's loan has an interest of $6 \%$. Each month they pay the same amounts on their loans. How much money is it possible that they have borrowed?

When the students had read the task, they worked with it individually. Azad and Mohammed chose to discuss some possible solutions before the group discussion began. Azad saw the solution straight away, but Mohammed misinterpreted him or rephrased Azad's solution incorrectly when the following conversation began:

\begin{tabular}{|c|c|c|c|}
\hline & Student & Conversation & $\begin{array}{l}\text { IC-act and/or question/ } \\
\text { comment/response }\end{array}$ \\
\hline 1 & $\begin{array}{l}\text { Moham- } \\
\text { med }\end{array}$ & $\begin{array}{l}\text { (To Amal and Nour:) Have you } \\
\text { understood the task? Johannes has } \\
\text { borrowed twice as much as Marie. }\end{array}$ & $\begin{array}{l}\text { getting-in-contact } \\
\text { comment6 }\end{array}$ \\
\hline 2 & Azad & $\begin{array}{l}\text { Wait, let's start like this: Which } \\
\text { questions do we need to ask to solve } \\
\text { the task? }\end{array}$ & comment6 \\
\hline 3 & Nour & $\begin{array}{l}\text { (To Mohammed:) But that will not } \\
\text { be as much. If I take an example: } 50 \\
\text { Swedish kronor and } 100 \text { Swedish } \\
\text { kronor. But then she will pay } 5 \ldots \\
\text { what was it? }\end{array}$ & $\begin{array}{l}\text { challenging } \\
\text { comment6, response6 } \\
\text { comment3 } \\
\text { question8 }\end{array}$ \\
\hline 4 & Amal & She pays $3 \% \ldots$ & response8 \\
\hline 5 & Nour & She pays $3 \%$. & rephrasing \\
\hline 6 & Amal & $\begin{array}{l}\text {... but still just as much, but he pays } \\
6 \% \text {. }\end{array}$ & locating \\
\hline 7 & Nour & Yes, and that will be... & \\
\hline 8 & Amal & $\begin{array}{l}\text { So it is she that has borrowed two } \\
\text { times as much?! }\end{array}$ & $\begin{array}{l}\text { advocating } \\
\text { comment6 }\end{array}$ \\
\hline 9 & Azad & $\begin{array}{l}\text { If they pay the same amount, then } \\
\text { she must pay more than him, twice } \\
\text { the amount, but I am not sure. }\end{array}$ & $\begin{array}{l}\text { advocating, } \\
\text { reformulating } \\
\text { response6 }\end{array}$ \\
\hline 10 & $\begin{array}{l}\text { Moham- } \\
\text { med }\end{array}$ & Yes, yes, that is right. & \\
\hline$\cdots$ & $\cdots$ & $\cdots$ & $\cdots$ \\
\hline 32 & Nour & $\begin{array}{l}\text { Wait a little; is it not Marie that pays } \\
\text { more? }\end{array}$ & question2 \\
\hline
\end{tabular}




\begin{tabular}{|l|l|l|l|}
\hline 33 & Azad & $\begin{array}{l}\text { Yes, Marie pays more since her } \\
\text { percentage is less. }\end{array}$ & response2 \\
\hline 34 & Amal & $\begin{array}{l}\text { But still... she pays the same amount } \\
\text { as him? }\end{array}$ & $\begin{array}{l}\text { challenging } \\
\text { question3 }\end{array}$ \\
\hline 36 & Azad & $\begin{array}{l}\text { Yes, she must pay more so that it can } \\
\text { balance. Johannes pays more. No. } \\
\text { They pay the same amount. }\end{array}$ & $\begin{array}{l}\text { thinking aloud } \\
\text { response3 }\end{array}$ \\
\hline 37 & $\begin{array}{l}\text { Aut her loan is bigger, or, I don't } \\
\text { know. }\end{array}$ & $\begin{array}{l}\text { She has lower interest, but she has } \\
\text { loaned more money. That's it. What } \\
\text { do you think Mohammed? }\end{array}$ & $\begin{array}{l}\text { reformulating } \\
\text { response3, comment6 } \\
\text { evaluating } \\
\text { question5 }\end{array}$ \\
\hline
\end{tabular}

Table 2: Transcript of interaction between Amal, Nour, Mohammed and Azad.

In the next section, results from the coordinating of theories are made.

\section{RESULTS FROM THE COORDINATING OF THEORIES}

In the short excerpt of the conversation between the students, several acts from the IC-model as well as questions that can be connected to Fuentes's framework were found. Alrø and Skovsmose (2004) stated that, the acts often do not appear in linear order, and all acts do not need to be present. This also seemed to be the case in this example. It also seemed that the questions related to Fuentes's framework did not occur the linear order that they appeared in Table 1. Even though a comment6 often is followed by a response6, it might be that while the students are advocating about how to solve the task, they might suggest a lot of strategies but do not carry all of them through. Then comment 6 acts as a suggestion rather than a command.

In Table 2, the interactions could be analysed separately with the IC-model or Fuentes's framework. Both models give information to what is happening in the communication between students. Coordinating the theories, however, gives an opportunity to look at data from two different perspectives that complement one another. Thus connecting the theories gives a possibility to show in more detail how the quantity and quality of the student-to-student interaction could be expanded.

Starting with Fuentes's framework, it is possible to categorize what is happening in the different utterances between students. Adding the IC-model here gives a more general description about what the communication is about when categorizing it into different dialogic acts. For instance, an identification of questions with help of Fuentes's framework gives clear suggestions to what acts in the IC-model that the 
students work with, which can facilitate understanding of what kind of advocating or challenging that is going on and the quality of the advocating or challenging.

It is also possible to start with the IC-model and look at what dialogic acts the students are working with. The IC-model then gives an opportunity to understand the context and reason for why different questions are asked. Adding Fuentes's framework here could give details to what type of question/comment-response pairs that students are using in the different dialogic acts.

Further analysis of the second cycle, indicates that some of the acts in the IC-model and Fuentes's framework are closely interrelated. For instance, challenging questions can be connected to question3/comment3; advocating often contains suggestions to how to solve the problem, which also is done in question6/comment6 and response6; and the act of evaluating can be connected to question5/comment5 and response5. Question7 and question8 are asked throughout the conversation and seem to be connected to the acts of getting in contact, locating or identifying.

These connections seems to provide a strong basis for identifying how both the quality and quantity of mathematical questions change over time when other tasks for promoting student-to-student interaction are introduced in further design cycles.

\section{CONCLUSION}

Analysing student-to-student communication is very complex, but yet an important and central question within mathematics education research. To deal with the complexity, Prediger et al. (2008) claimed that coordinating theories could provide "a networked understanding of an empirical phenomenon" (p. 174). In my study, a coordinating of the IC-model and Fuentes's framework gives opportunities for studying changes in the quality and quantity of students' interaction. Through the ICmodel, the dialogic acts in the conversation can be found, while Fuentes's framework gives details to what is happening in the different dialogic acts in the IC-model. A coordinating of the theories can provide for instance answers to how questions are handled in the students' conversation with the goal to see how interactions change over time when different tasks are introduced to increase the student communication.

The results from coordinating the IC-model with Fuentes's framework will be used for the next cycle in my project. In the first cycle, when only the IC-model was used, it was sometimes difficult to find out what was problematic for instance when students tried to advocate a suggested strategy. With Fuentes's framework, it is more clear that when strategies are suggested (comment6) and that when questions are asked, it is not always that they follow the pattern in Fuentes's framework, that is a question/comment6 is not always followed by a response6. This was interpreted that students need to be more aware of the questions they are asking each other, why they are asked and how they are answered. In this way coordinating the theories do not only give a theoretical base for how to design tasks, but also a way to find strategies for promoting interaction and giving students support means for how to work together in their collaborative zone for proximal development (Goos et al., 2002). 
A principle $P$ that can be considered problematic with both the IC-model and Fuentes's framework is the assumption that students are active participants in the interaction. It will therefore not be possible to analyse all types of students' communication with these two theories, for instance it is difficult when students choose not to participate in the group work. More research is needed to find theories for analysing different kind of interaction between students and to see which theories that are best to connect in order to give a theoretical base for promoting, understanding and analysing student-to-student interaction.

\section{REFERENCES}

Alrø, H. \& Skovsmose, O. (2004). Dialogue and learning in mathematics education. Intention, reflection, critique. London: Kluwer Academic Publishers.

Dekker, R. \& Elshout-Mohr, M. (1998). A process model for interaction and mathematical level raising. Educational studies in mathematics 35(3), 303-314.

Dekker, R. \& Elshout-Mohr, M. (2004). Teacher interventions aimed at mathematical level raising during collaborative learning. Educational studies in mathematics 56(1), 39-65.

Fuentes, S. (2013). Fostering communication between students working collaboratively: results from a practitioner action research study. Mathematics teacher education and development 15(1), 48-71.

Goos, M., Galbraith, P., \& Renshaw, P. (2002). Socially mediated metacognition: creating collaborative zones of proximal development in small group problem solving. Educational Studies in Mathematics, 49(2), 193-223.

McKenney, S. \& Reeves, T. (2012). Conducting educational design research. New York: Routledge.

Prediger, S. Bikner-Ahsbahs, A., \& Arzarello, F. (2008). Networking strategies and methods for connecting theoretical approaches: first steps towards a conceptual framework. ZDM 40(2), 165-178.

Radford, L. (2008). Connecting theories in mathematics education: challenges and possibilities. ZDM 40(2), 317-327.

Sjöblom, M. (2014). Designing tasks and finding strategies for promoting student-tostudent interaction in mathematics. Paper accepted for publication in the proceedings of the conference MADIF9.

Wedege, T. (2010). Connecting theories in mathematics education: from bricolage to professionalism. Nordic studies in mathematics education 15(1), 59-78.

Vygotsky, L. (1978). Mind in society. The development of higher psychological processes. London: Harvard University Press. 


\section{Symposium papers}




\title{
POSITIONING OF GIRLS AND BOYS IN A PRIMARY MATHEMATICS CLASSROOM
}

\author{
Eva Norén \\ StockholmUniversity
}

This paper deals with how various discourses impact on girls and boys positions as active and engaged mathematics learners in a first grade classroom. Students and teachers may themselves adopt a position exercising a specific discourse, or they may assign positions to others. The discursive practices in this classroom encouraged the boys' positions as engaged mathematics learners more than the girls even though girls' experiences from out of school were valued as starting points for learning mathematics.

\section{INTRODUCTION}

My purpose with this paper is to illuminate some of the complexity regarding gender issues and the positioning of boys and girls in in a primary mathematics classroom. Acknowledging the sociocultural location of much of the research on gender in mathematics education (for example Boaler, 1997, 2009; Forgasz \& Leder, 2001; Yelland, 2001), the study reported here is inspired by studies in mathematics education research such as Walkerdine $(1988,1998)$ and Palmer $(2010)$. I draw on Foucauldian inspired research in mathematics education that identifies discourses in everyday mathematics practices in school, while Foucault (1991) identified larger scale discourses under different historical epochs.

This paper aims to understand how girls and boys act and is positioned by exploring discursive practices, particularly enacted discourses, in primary mathematics classroom. My guiding questions have been:

How do various discourses, in relation to classroom interaction, girls and boys, operate in a primary mathematics classroom?

How do these discourses differentiate in the positioning of girls and boys?

\section{GENDER EQUITY AND EDUCATION IN SWEDEN}

Equity issues have been on the agenda in Swedish national curriculums for a while. The latest national curriculum for compulsory school (Skolverket, 2011) articulates:

Compulsory school's responsibility to work for gender equality is clear: "Schools should actively and consciously promote equal rights and opportunities for women and men; equal rights and opportunities for females and males. The way in which girls and boys are treated and assessed in school, and the demands and expectations imposed on them, contribute to shaping their perceptions of what is feminine and what is masculine. The school has a responsibility to counteract traditional gender patterns. It should therefore provide space for students to test and develop their abilities and interests, regardless of gender. (p. 8, my translation)[1] 
A concrete example of what a teacher can do in the classroom is to ensure that girls and boys have equal impact over and scope for teaching. As the students in this paper are first graders just starting school I have prefaced with a short review on research regarding gender issues in preschool.

\section{Research on gender issues in Swedish preschools}

Alva Myrdal (1936) wrote that parents or educators shouldn't make a difference when it comes to boys' and girls' toys or select the activities. Many of the later studies relating to daycare and preschool (5/6-åringar) report on how children position themselves and how daily routines and play relate to gender and gender equality, and the development of a more gender-sensitive teaching (Nyström, 2010). Much of the research shows that girls and boys face different conditions in preschool (see eg Kärrby, 1987; Odelfors, 1996; Månsson, 2000; Eidenvald, 2009). In summary it can be said that teachers in preschool as an institution tend to reinforce gender stereotypes. As a counterpoint to this several projects throughout Sweden have been initiated to make a change. The work is often called gender education or gender pedagogy, and the aim is to create better conditions for children to live their life without limits that normative traditional belief on gender may have (Dolk, 2013). Preschool is considered as a first instance in a long-term gender equality project, and the child is put in the center of this.

\section{Research on gender issues in Swedish schools}

The type of school where most studies have been identified are from compulsory school (children/youth 7-15/16 år), however, there are also studies in secondary school (students aged between 16/17-18/19 years). Classroom research is common with studies on relationships between students and the exercise of power that can be evident in different ways. In compulsory school, a number of projects have been started over the years with the aim of modifying the pedagogical/didactic work in relation to gender. Likewise, there are examples of studies with approaches based action research methodologies (Nyström, 2010). A variety of publications highlight "differences" between boys and girls or differences between them in relation to social class, parental educational background or ethnicity. This includes several studies relating to school performance and educational choices. Other studies focus on studying how sex and gender is affected in speech and practice in school (Nyström, 2010). Butler, who in turn is inspired by Foucault, influences several of the studies in gender and education. Butler (1993) argues that gender is a response to interactions that emerge in practices, thus gender is viewed as constructed rather than a fixed set of human properties.

\section{DISCOURSE, POWER RELATIONS AND POSITIONING}

In discourse theory (Foucault, 1971, 1977, 2003) discourses are recognized as practices structured through power relations that enact different activities, identities and positions. I focus on the relationships between discourses that are enacted in the discursive practices in one first grade mathematics classroom. In so doing I construe 
mathematics education not only as a sociocultural practice but also as a political practice in that power operates at all levels in society in general (Foucault 1971, 1980) and in teacher/student interactions in particular. According to Foucault (1980) power relations are often unequal and relatively stable, although these relationships change and the change occurs as a result of a complex interaction. In a Foucauldian sense, power is a relational capacity of social actors to position themselves and others in different situations through the exercise of various discourses. In considering power relations, Foucault (1982, p. 217-221) says:

What characterizes the power we are analysing is that it brings into play relations between individuals or between groups. [...]. The exercise of power consists in guiding the possibility of conduct and putting in order the possible outcome [...].

Defining power in this way provides a means for studying existing practices in classrooms in which people interact with each other (Öhman, 2010). Power is a mechanism (Foucault, 1991) that enables people to act. Power is exercised through people's intentions, through strategic trade-offs they make in their daily lives. In mathematics classrooms discursive practices enable or disable girls' and boys' positions as engaged mathematics learners.

Practises in an institutionalized field, such as mathematics teaching in school, can be understood in terms of positioning. Davies and Harré (1990) indicate that discourses create individuals while at the same time those individuals are manipulators of discourses. Discourses provide possibilities and boundaries for what we can or cannot do or say, and we may ourselves adopt a position exercising a specific discourse, or we may assign positions to others.

Learning mathematics relies on how students position and describe themselves as mathematics learners in the classroom (Solomon, 2007). Consequently, I see school mathematics as embedded in the enacted, ever-changing discourses in the classroom. In other words, exercise of various discourses creates social and gender positions and negotiates power relations.

\section{DISCOURSES IN THE MATHEMATICS CLASSROOM}

The data for this paper has previously been analysed from a perspective of learning mathematics using a second language (Norén, 2010). While the analysis was being conducted, input from a colleague (Anna Palmer) suggested the data could be analysed from a gender perspective. This is the focus of this paper. The data considers 12 mathematics lessons in a classroom with 22 second language learning students aged seven and eight years old. In this paper one lesson is chosen, as it is indicative of what usually occurs in the classroom. I took the role of participant observer to get close to daily communication and activities in the mathematics classroom (Emerson et al, 1995). Field notes were taken at each observation and rewritten later. The interpretations of my findings were structured as categories and later discourses regarding how students' experiences and initiatives were valued and taken in as resources for learning mathematics. Later, the categories were elaborated 
to enable comparisons of girls' and boys' engagement in various discourses. Data also incorporated interviews with the mathematics teacher, before and after observed lessons at six occasions, to obtain data on how the teacher thought about mathematics teaching and learning and how the lessons were planned. The interviews with the teacher were audio taped and notes were taken during the interviews.

Discourses were identified in the earlier study (Norén, 2010), and will be used for analysing girls and boys positioning in this paper. Two of the discourses enacted by the teacher and students were a reform-oriented mathematical discourse and a language sensitive discourse. Other discourses enacted in this classroom were social relational, inclusion of students' out of school experiences; some of the discourses already identified worked as normalizing. Normalizing discourses promoted independent learners, Swedish-ness, and specific mathematical argumentation in relation to learning when using Swedish as a second language.

Anna[2], the teacher, organized the content as well as time and space in relation to reform-oriented practices. The students' work regularly involved mathematical tasks that were solved in small groups or pairs. Students were urged to communicate about what they discovered. After students completed their work in groups, the teacher and the students discussed the mathematics involved, in groups, in half or in full class discussions. The language sensitive teaching in mathematics that was going on has similarities with reform-oriented mathematics teaching, characterized by the emphasis on communication and collaborative work (Moschkovich, 1999).

\section{GIRLS AND BOYS POSITIONING IN DISCOURSES}

I will use mathematics activities from the classroom to illustrate how girls and boys were positioned within various discourses. Anna valued students' out-of-school experiences as starting points for learning mathematics. She engaged in a language supportive discourse that "allowed" her to include certain experiences of students, those that related to Swedish language and mathematics. When incorporating students' experiences that were related to mathematical issues she displayed reformoriented mathematical discourse. In the following activities both discourses were enacted.

Every morning Anna greeted her students one by one when they entered the classroom. It was a practice that had emerged as an opportunity when out of school experiences could be shared. Sometimes the morning ritual ended up with Anna changing her plans for the mathematics classroom activities. I interpret the changes as being based on students' actions, as a result of this particular social practice. In a first grade classroom like this, power naturally is not equally distributed, but due to students' positions within different discourses power relations were moving.

One specific morning the moving of power relations was observably pronounced when two girls on their way to school, Liljana and Amina, have been discussing if it is necessary to become "fussy[3]" when becoming a teenager. Amina starts telling 
Anna that one of their teenage sisters and some neighbour girls are fussy. The two girls say they never want to become fussy themselves. Amina is positioning herself as a transmitter of experiences from out of school and turns to Anna[4]:

7. Amina:

Do you really have to become fussy when you become a teenager?

8. Anna: What do you mean? Do you know anyone that is fussy?

9. Amina: My neighbour, she has strange clothes and ...

10. Liljana: My sister and cousin as well ...

11. Anna: How old are they then? How old are you when you are a teenager? What is a teenager?

12. Amina: They can be 15 or 19 .

13. Liljana:

Between 12 and 14.

In simultaneous exercise of a language supportive discourse and a reform oriented mathematical discourse, Anna decides to use the girls' conversation to explore their number sense and what the girls knew about the suffix - teen (utterance 11). The girls don't know that teenagers' age is derived from the words in the number line from thirteen to nineteen (utterance 12 and 13). The discourse exercised promotes the girls' daily life experiences as starting point for learning mathematics. Amina's initial question (utterance 7) and the girls' on going performance in their interactions with Anna and each other resulted in the change of lesson plans and the focus of the mathematical content, as a base for shared knowledge production. By changing content of the mathematics lesson power relations are moving, and Anna positions the girls as independent actors while exercising a reform-oriented school mathematical discourse. At the same time the positioning of the girls maintains the discourse. Anna is also enabling of a discourse promoting students' daily life experiences as resources for their learning of mathematics. In exercise of such discourses students were commonly positioned as engaged and competent mathematics learners, though it varied how boys and girls were positioned.

Anna is concerned about how the students conceptualise -teen, in relation to the Swedish language, and asks the students how old a teenager can be. Anna gets suggestions, but none of the students show that they know. Tony then says: "I just guessed before. Now I know!" Power relations are moving while enacting a reform oriented mathematical discourse and positioning himself as mathematically competent. He asks Anna to write the numbers from eleven to nineteen "with letters" on the white board and so she does. In so doing, Tony exercises language sensitive discourse alongside reform oriented mathematical discourse. When Anna asks him why he wanted her to write those numbers he answers, "Ten is not a teen". When writing the numbers on the white board, Anna is positioning Tony as a knowing student. What he says is put as a resource for further learning for Tony, but also the other students. Anna is not struggling for authority and by the positioning of Tony; power relations are at play while shared knowledge is produced. 
Anna again turns to the group of students, pointing to the white board and a few of the written -teen suffixes. She asks the students if they can tell what these numbers are all about, now referring to "we", the students as a group and not individual answers: "What can we say about these number?" None of the students responds. Anna looks at Tony, once again positioning him as competent in the mathematical discourse, and asks him to come to the whiteboard. Amina seems to be in her own thoughts, still worrying about teenagers being fussy. She talks a little to herself, and is not participating in the mathematical discourse, and Anna is not trying to get her involved in the interaction. Anna acknowledges a particular school mathematical practice by empowering a boy not a girl. Walkerdine (1998) found it common in school mathematics practices, for boys to be encouraged more than girls.

Tony shows engagement more clearly, when, on his way to the whiteboard, he takes another initiative and picks up a pointer. Tony points to all of the -teen names written on the white board, saying:

14. Tony:

There it says teen, there it says teen, /.../ there it says teen it says teen the whole row.

Tony is not pointing to eleven and twelve. His performance can be interpreted as though he is positioning himself as an engaged and knowing student who is coconstructing knowledge or he is taking up the teacher's role, with both interpretations appropriate within a language-supportive discourse. Anna authorizes his position by nodding. This is interpreted as an obvious moment of knowledge production, in which the relational power in a discursive practice is dynamic. Anna positions Tony as an engaged and active learner, and he does the same. Anna writes the word teenager [tonåring] on the board. At this point Tony loosens his engagement in the discourse, he says: "My sister is almost a teenager." By saying this he is positioning himself as mathematically competent in a mathematical discourse, knowing that twelve is not a "teen-age-word".

The content of the lesson so far is built on the conversations of Liljana and Amina. The issue about sisters, cousins and girl teenagers being fussy or not, came from the girls and is transformed into a joint exploration of mathematical words' multiple meanings in a language-supportive discourse. However, Anna, through Tony's and other boys' agentic interactions, reconstructs the exploration into a "project" in relation to her expectations about what the content of the lesson should be: mathematics learning related to Swedish language learning. In that reconstruction boys are more encouraged than girls.

Liljana acknowledges that she has understood how old a teenager might be: "So now it is, when you are a teenager!" Liljana's action exercises a language-supportive discourse. Amina still declared she did not want to become a teenager now but maybe later. It could be that Amina chose to reject the socialisation into a school mathematical discourse. She positioned herself within an out-of school-discourse, outside both the mathematical and the language supportive discourses operating in 
the classroom, yet she was the one who initiated the change of content focus and lesson plans (utterance 7). She instead focused on what her own future as a teenager might be. The situation might have changed if Anna had invited her and other girls to participate in the exploration of mathematical words' multiple meanings in a language-supportive discourse.

Another boy who affects power relations by positioning himself as a competent learner in knowledge production is Melvin. He contributes to the mathematical interaction by engaging in a language supportive discourse. Anna positions him as an engaged mathematics learner when changing direction of the lesson once more. Melvin suggested that $\operatorname{ton}[5]$ could designate something else:

But ... this thing about ton, one ton, two tons, three tons ... what is that? It is like this ... (he points to the table). This weighs a ton

Anna positions Melvin as engaged in his learning while valuing his question as having an important focus for further learning on issues about tons as a unit for measuring weight. Melvin enacts a language supportive discourse, by showing language awareness connected to Swedish and mathematical content. Anna confirms Melvin a position as competent in the discourse by showing that she is happy about his utterance and question, with smiles and encouraging nods. Again she supports a boy's position in mathematical and language activities. Melvin, positioning himself as a committed learner, suggests that it is possible to weigh oranges and flour. Within the discourse, Anna's following question makes it possible for Melvin to move around the classroom and pick up a scale[6], which has been placed on a table in the classroom. Anna asks him what he thinks oranges can weigh?

16. Melvin: (quietly to himself) One kilogram, two kilogram's ... (Melvin puts the scale on the table were the students were sitting).

Anna repeats Melvin's suggestion and writes 1 kilo [1 kg] on the whiteboard. At this point another girl, Muna, says: "There are degrees ... I am thinking of degrees."

Her question did not make Anna change direction of the lesson, as knowledge production was focusing formal mathematical words for weighing. Muna's question displays she is positioning herself in a reform mathematical discourse, giving voice to an individual mathematical thought. Her question made Liljana, also positioning herself in a reform oriented mathematical discourse, to ask another one, referring to "four grams of butter" when making cakes. Anna, though, is strongly enacting a Swedish language supportive discourse, not acting on the girls' comments.

17. Anna:

Actually, it is like this ... kilogram (writes the word kilogram on the whiteboard, points to the end of the word and draws a line below the suffix of the word -gram, Anna is not acting towards the girls' utterances).

18. Amir: $\quad$ You have to look at and connect the first letter (Anna does not pay attention to what he is saying either, changing to an exercise of a mathematical discourse). 
Amir (utterance 18) on the other hand is deeply involved in a language supporting discourse, and thus Anna follows up his trail of thoughts:

19. Anna:

The unit (that you use) when we weigh is called a kilo. We say kilo. What do we say when we talk about an elephant, what do we use when we weigh an elephant? Can I say gram (write $g$ on the whiteboard) or am I going to say kilo (writes kilo) or gram (points to g) when I speak about elephants?

Melvin was the first one to answer "ton", positioning himself as a committed learner in mathematical and language supportive discourses, which were exercised side by side. In the discourses exercised Anna may have positioned Melvin as the most mathematically competent child as she turned to him while speaking. Cecilia claimed an individual voice, saying she wanted "to think about it, she hasn't decided yet". But it was ignored or not listened to by Anna, even though she promoted all students to give individual answers and ask questions. In a power relational knowledge production, it was Melvin who was set in a certain position that "endorsed" most of the other students to give the same answer as he did. What the girls were saying was not taken into the knowledge production on kilograms and which unit to use when measuring.

\section{DISCUSSION}

In the first grade mathematics classroom I regularly encountered power relations shifting and boys and girls differently positioned in the mathematical discursive practices. While enacting reform oriented mathematical and language sensitive discourses, boys acting as independent learners was encouraged whereas girls were more often left to themselves or positioned in a social relational discourse. The boys' actions as "teacher" in reform oriented mathematical and language sensitive discourses take form despite their institutional positions. The Foucauldian defining of power as relational, dynamic and moving enabled the analysis of the discursive practices in the classroom, and the boys positioned as engaged mathematics learners in reform oriented mathematical, and language sensitive discourses. Even though girls' experiences from out of school were valued as starting points for learning mathematics and the Swedish language, the enactment of social relational discourse did not challenge power relations and did not enable girls to move into the positions as engaged mathematics learners. In the interactive nature of classroom power relations, boys more than girls found space for actions that kept the mathematics lessons interesting and positioned them as engaged and competent learners.

\section{NOTES}

1. Grundskolans ansvar för att arbeta för jämställdhet är tydligt: "Skolan ska aktivt och medvetet främja kvinnors och mäns lika rätt och möjligheter. Det sätt på vilket flickor och pojkar bemöts och bedöms i skolan, och de krav och förväntningar som ställs på dem, bidrar till att forma deras uppfattningar om vad som är kvinnligt och manligt. Skolan har ett ansvar för att motverka traditionella könsmönster. Den ska därför ge utrymme för eleverna att pröva och utveckla sin förmåga och sina intressen oberoende av könstillhörighet.

2. All names are fictitious.

3. In Swedish, fjantig. 
4. Translations from Swedish to English by the author.

5. In Swedish, ton is the same word as the suffix in thirteen, fourteen ... nineteen [tretton, fjorton ... nitton].

6. Used for measuring for example flour or sugar when baking or cooking.

\section{REFERENCES}

Boaler, J. (1997). Reclaiming school mathematics: the girls fight back. Gender and Education, 9(3), 285-305.

Boaler, J. (2009). Paying the price for "Sugar and Spice": Shifting the analytical lens in equity research, Mathematical Thinking and Learning, 4(2-3), 127-144.

Butler, J. (1993). Bodies that matter: On the discursive limits of "sex". London: Routledge.

Campell, P. B. (1995). Redefining the "girl problem in mathematics". In W. G. Secada; E. Fennema; L. Byrd, \& L. Byrd-Adajian, (Eds.), New directions for equity in mathematics education. Cambridge: Cambridge University Press.

Davies, B., \& Harré, R. (1990). Positioning: The discursive production of selves. Journal for the Theory of Social Behaviour, 20(1), 43-63.

Dolk, K. (2013). Bångstyriga barn: Makt, normer och delaktighet i förskolan (Doctoral dissertation, Stockholm).

Eidevald, C. (2009). Det finns inga tjejbestämmare: Att förstå kön som position $i$ förskolans vardagsrutiner och lek. Jönköping: Högskolan för lärande och kommunikation.

Forgasz, H. \& Leder, G. (2001). "A+ for Girls, B for Boys": Changing perspectives on gender equity and mathematics. In (Eds.), B. Atweh, H. Forgasz, \& B. Nebres. Sociocultural research on mathematics education: An international perspective (pp. 347-366). Mahwah, New Jersey and London: Lawrence Erlbaum Associates, Publishers.

Foucault, M. (1971). Orders of discourse. Social science information, 10(2), 7-30.

Foucault, M. (1972). The archaeology of knowledge. Trans. AM Sheridan Smith. New York and London: Routledge.

Foucault, M. (1977). History of systems of thought. In D. F. Bouchard, Language, counter-memory, practice: Selected essays and interviews by Michel Foucault (pp. 119-204). Ithaca, New York: Cornell University Press.

Foucault, M. (1980). Power/knowledge: Selected interviews and other writings, 1972-1977. Random House Digital, Inc.

Foucault, M. (1982). After the word: the subject and power. In H. Dreyfus, \& P. Rabinow, Michel Foucault: Beyond structuralism and hermenutics. London: The Harvester.

Foucault, M., \& Rabinow, P. (1991). The Foucault reader: An introduction to Foucault's thought. Ed. P. Rabinow, Penguin. 
Foucault, M. (2003). The essential Foucault: Selections from the essential works of Foucault, 1954-1984. P. Rabinow \& N. Rose (Eds.). New York, NY and London: The New Press

Kärrby, G. (1987). Könsskillnader och pedagogisk miljö i förskolan. Institutionen för Pedagogik, Göteborgs Universitet.

Moschkovich, J. (1999). Understanding the needs of latino students in reformoriented mathematics classrooms. Changing the faces of mathematics: Perspectives on latinos (March 1999): 5-12.

Myrdal, A. (1936). Riktiga leksaker. Kooperativa förbundets bokförlag.

Månsson, A. (2000). Möten som formar: Interaktionsmönster på förskola mellan pedagoger och de yngsta barnen i ett genusperspektiv. Institutionen för pedagogik, Lärarhögskolan, Malmö.

Odelfors, B. (1996). Att göra sig hörd och sedd: Om villkoren för flickors och pojkars kommunikation på daghem. Stockholm: Stockholms universitet.

Norén, E. (2010). Flerspråkiga matematikklassrum: Diskurser i grundskolans matematikundervisning (Doctoral dissertation, Stockholm).

Nyström, E. (2010). Nordisk forskning om genus och jämställdhet $i$ skola och utbildning: 2005-2009. Oslo Norden, Nordiskt institut för kunskap om kön NIKK

Palmer, A. (2010). Att bli matematisk: Matematisk subjektivitet och genus $i$ lärarutbildningen för de yngre åldrarna (Doctoral dissertation, Stockholm).

Skolverket [National Agency of Education]. (2011). Curriculum for the compulsory school, preschool class and the leisure-time centre 2011. Stockholm: Skolverket.

Solomon, Y. (2007). Experiencing mathematics classes: Ability grouping, gender and the selective development of participative identities. International Journal of Educational Research, 46, 8-19.

Yelland, N. (2001). Girls, mathematics, and technology. In (Eds.), B. Atweh, H. Forgasz, \& B. Nebres. Sociocultural research on mathematics education: An international perspective (pp. 393-410). Mahwah, New Jersey and London: Lawrence Erlbaum Associates, Publishers.

Walkerdine, V. (1988). The mastery of reason: Cognitive development and the production of rationality. Taylor \& Frances/Routledge.

Walkerdine, V. (1998). Counting girls out (Vol. 8). Psychology Press.

Walshaw, M. (2007). Working with Foucault in education. Sense Publishers.

Öhman, M. (2010). Analysing the direction of socialisation from a power perspective. Sport, Education and Society, 15(4), 393-409. 


\title{
WHY SARAH LEFT ACADEMIA
}

\author{
Lovisa Sumpter \\ School of Education and Humanities, Dalarna University, Sweden
}

This paper explores why some Swedish female mathematicians decide not to work in academia. The stories of four women were merged into one narrative. Sarah describes the life as a female PhD student in a mathematics department as a positive experience. The reasons why she decided not to stay at the university were (1) the difficulty of getting a job, and (2) her wanting to work with applications and problem solving more than developing theory.

Keywords: Conceptions, female mathematicians, gender, higher education, post-PhD

\section{INTRODUCTION}

Some years ago, Watt (2008) asked the following question: "Why do men and women frequently end up in different kinds of careers" (Watt, 2008, p. 3). The question is still a relevant one especially looking the lack of women in mathematics departments. Watt (2008) concluded that women are both less likely to enter mathematics and more likely to leave. Women seem to 'disappear' through the grades and following academic professions. Looking at Sweden, we have 50-50 division at the most mathematical intense upper secondary school programme, but at undergraduate level, one third of all students in mathematics or other mathematics intensive courses including engineer and teacher education are female (Brandell, 2008). This is a similar situation as in many western countries e.g. USA (Herzig, 2004) and the UK (Burton, 2004). Moving up in the career ladder, the number of women lectures or professors decreases even more. In USA, a postdoc is a strong factor for the possibility to get a tenure track and the number of women doing a postdoc is far less than the number of graduate students (Nerad \& Cerny, 1999). Looking at the UK, only $2 \%$ of the professors in mathematics in 2002 were women (Burton, 2004). In 2007, the number of female post-docs in mathematics in Sweden was $6 \%$, senior lecturers 21\%, and professors 7\% (Lindberg, Riis \& Silander, 2011), but there is a difference in which area these professors worked in. In 2008, the distribution of 13 female professors in mathematics was the following (Wedege, 2011): mathematical statistics $(n=5)$, mathematics education $(n=3)$, applied mathematics $(n=2)$, pure mathematics $(n=2)$ and numerical analysis $(n=1)$. At the same time, there were 138 male professors and 67 of them worked in pure mathematics. This means that some areas are more male than others. Hence, even within a subject (here mathematical sciences), men and women end up in different kinds of careers and this in a country described as a "society in which gender equity is highly valued at societal and political levels" (Brandell, 2008, p. 659). 
In general, women are in majority at under graduate level not only in Sweden but also in many other countries (UNESCO, 2007). However, higher education has a strong gender structure and the number of women is reduced when you move up the hierarchy. In EU, on average, $45 \%$ of all $\mathrm{PhD}$ graduates were women in 2006 (European Commission, 2009). About one third of the world's researchers are women, but the number of professors is lower (UNESCO, 2007) and the proportion of women is the smallest (18\%) looking at grade A academic staff in EU (European Commission, 2009). Focusing on Sweden, the Glass Ceiling Index (GCI) is higher compared to the average of the EU (European Commission, 2009) implying that 'glass ceiling' is lower. The main problem seems to be number of women disappearing especially between $\mathrm{PhD}$ and further careers. Why do women leave? This paper aim to explore female mathematicians' expressed conceptions about their decisions. The research question posed is "What reasons do female mathematicians give for leaving mathematics as an academic profession?"

\section{BACKGROUND}

I will here shortly discuss the two main concepts for this paper: gender and conceptions.

\section{Gender}

In this paper, gender is understood as a social construction more than a consequence of a biological sex (West \& Zimmerman, 1987). It refers to what is thought of "as socially constructed differences between men and women and the beliefs and identities that support difference and inequality" (Acker, 2006, p. 444). Damarin and Erchick (2010) concluded that gender is best described or viewed as a dynamic process meaning that the attributions, beliefs, identities etc. are not static. An example of such a process is that in Sweden in the 1970s, the thought of femininity and masculinity in the school discussion were understood as sex roles or sex-value roles (Hedlin, 2013), a view that is far more limited than the definition given above.

The concept gender can be divided into four different aspects (Bjerrum Nielsen, 2003): structural, symbolic, personal, and interactional gender. Structural gender refers to gender as part of a social structure alongside with other factors e.g. ethnicity and class. The number of female PhD students in mathematics in Sweden in relation to male students or the percentage that gets an academic profession are examples of structural gender. Symbolic gender stems from these structures such as that symbols and discourses are attributed to a specific gender creating norms and trajectories that tell us what is normal and what is deviant, e.g. the idea of mathematics as a male domain (Brandell, Leder \& Nyström, 2007) or what girls and boys are thought of as mathematics students (Walkerdine, 1998). The third aspect is personal gender. It focuses on for instance how the individual perceive the structure with its symbols, e.g. girls' different views of themselves as students in mathematics (Mendick, 2002) or female professional mathematicians description what it is like to work in a 
mathematics department (Burton, 2004). It can also be about how a person develops gender within a structure (e.g. Walls, 2010). Personal gender and symbolic gender do not have to overlap and can even contradict each other, e.g. girls are considered insecure in mathematics but don't feel insecure themselves (Sumpter, 2012). The structure and its symbols can influence in a constant ongoing process. Solomon (2012) studied women undergraduate students in mathematics and she concluded that they were forced to work with their identity, their self-concept as 'a woman in mathematics', including how they talk about themselves and their situation. The fourth aspect is interactional gender. This is when we see gender through social interaction, how people interact with each other or how the structure is created e.g. studies that focus on situated learning. Compared to personal gender, which more could describe gender as something we "are", interactional gender is something we "do" (Wedege, 2011). The symbols, self-concepts, and interactions shape the structure and the structure produces norms. Connell (2006) calls this overall dynamic pattern of gender relations within an organisation for gender regime that "provides the context for particular events, relationships, and individual practices." (Connell, 2006, p. 839). These four aspects on gender are not separate components, but more an analytical tool used to highlight different sides of the same phenomena.

In organisations, gender together with class and race create the base for inequality (Acker, 2006). For a long time, gender and class were often integrated in many organisations but this has changed. Gender is still a main factor for women participation at work. When studying Swedish bank workers, Acker (1994) saw that men 'aspiranters' (those aspiring to a career in the bank world) were trained for managerial work whereas the women were given tasks such as answering the phone or work as tellers. Thereby a filter for further careers was created, similar to the chance to have a post doc position and the probability to get a tenure track (Nerad \& Cerny, 1999). In this way, gender structures are created. Other factors that are related to the structure are norm-controlled self-selections and internal and external factors such as how research grants and other funding are distributed (Lindberg, Riis \& Silander, 2011). Husu (2005) concluded that in higher education, female professors and female colleagues were important sources for support for female researchers. Similar ideas have been expressed by female mathematicians (Henrion, 1997). You need help if you want to move on. This seems to be true for undergraduate studies too. Undergraduate students in mathematics at English universities point out how important the relationship is with the tutors (Solomon, Lawson \& Croft, 2011). Tutors could be 'good' but also be described as having power and authority and thereby working as a gate. If to look at obstacles, the lack of support and discrimination (both explicit or hidden) are two main factors behind women struggle to advance in their careers especially when the work situation often are uncertain (Husu, 2005; Husu, 2013). This has also been noticed in mathematics (Henrion, 1997) and in other STEM subjects (Heilbronner, 2013). It seems like that if a woman 
is less integrated in her department and in scientific networks, she will have (more) problems to pursue a career in research.

\section{Conceptions}

This paper studies female mathematicians' conception. Conceptions are here defined as "conscious or unconscious beliefs, concepts, meanings, rules, mental images, and preferences" (Thompson, 1992, p. 132), meaning that conceptions may have both affective dimensions as well as cognitive dimensions. As parts of conceptions you have beliefs such as beliefs about yourself (Schoenfeld, 1992) and self-identity (or self-concept). Self-identity can be viewed as "a person's perceptions of him- or herself" (Marsh \& Shavelson, 1985, p. 107) including dimensions as your capacity or your role in different situations (Devos \& Banaji, 2003). Gender is then part of your self-identity. Conceptions should be viewed, just as gender, as a dynamic concept that is developed and changed through interactions and experiences.

\section{METHOD}

A written questionnaire was sent out to nine female mathematicians from six different Swedish universities (different sizes; north to south) that finished their $\mathrm{PhD}$ in mathematics during the years 2002-2012. Mathematics is here interpreted as mathematical sciences such as pure and applied mathematics, mathematical statistics, computational mathematics and optimization but excluding mathematics history and mathematics education. The author knows four of the women and the other five were found through a mutual contact or the Swedish network 'Women and mathematics', a sub-organisation of IOWME. Since the answers to the questionnaire were kept anonymous, and the respondents were aware of this, the assumption is that the difference connections did not affect the objectivity or the quality of the replies. The respondents were instructed that they could write as much or as little as they wanted. Four main questions were posed: (1) Why did you become a mathematician/ Why mathematics?; (2) How come you did a PhD in mathematics?; (3) How was it to be a (female) PhD student in mathematics?; and, (4) You have a career outside the university. How come? To each of theses four questions, several optional subquestions were listed. The respondents were also encouraged to write something about their background. The answers were sent back within two weeks. A first analysis of the data showed that four of them had similar answers describing a slightly more positive experience whereas the remaining five shared a more negative view. In this paper, I will focus on the first four. They come from three different universities. These replies constitute the base of for the story presented as Sarah's. In another paper (Sumpter, submitted) I have performed a similar analysis on the other five responses. 
The method of analysis used in this paper is collective narrative: one story is created by interweaving the (written) answers from several respondents. It is a tool to emphasize meaning of responses (patterns) in a collective context rather than to show individual's replies (Mendick, 2002). Here, the collective narrative analysis shares similar goal as content analysis with the aim to identify traits of the material (Smith, 2000). In this paper, the traits are told by a fictive voice creating sharing 'her' story. This also helps to keep the respondents anonymous especially in a small community such as female mathematicians in Sweden. As common in narrative analysis, my own voice is part of the story (Smith, 2000) although I've tried to minimize it as much as possible by using the respondents' own formulations. Using respondents' own formulations when expressing shared ideas enables to present traits that are common with 'their' voice. In some cases, the formulations have been joined together to one sentence and when needed I've changed the context (e.g. seminars have become lessons) to make sure that the specific person/ situation can't be identified. In both these cases, the meaning of the replies remains the same.

This is a qualitative study that aims to describe some female mathematicians' voices with no aim to generalise or trying to grasp over all their conceptions including their self-concept. Since self-concept can have both descriptive and evaluative dimensions, e.g. I am angry or I am bad at mathematics (Marsh \& Shavelson, 1985), the respondent's answers can have both these characteristics. These expressions can differ from other evaluative constructs e.g. grades. It falls under the personal aspect of gender focusing on women's own expressed conceptions in the role of 'female non-academic mathematician'.

\section{RESULTS}

I will here present the result of the analysis in the format of a story created by four female mathematicians replies. In this story, their conceptions have been melted into one trait.

\section{Sarah}

Sarah was born and grew up in a middle size town in Sweden. (She can also have been born in another country and immigrated to Sweden as a young adult.) She studied the most mathematical intensive program at upper secondary school (age 1619), the natural Science Programme. Sarah's parents have always supported her, but they didn't work in mathematics themselves. When she was 25-30 years old, she started her $\mathrm{PhD}$ almost right after her undergraduate studies (which was in mathematics/applied mathematics/mathematics statistics combined with engineering/ physics/ statistics; 4-5 years). During her PhD, she had no children and therefore did not experience what it was like to be on parental leave. Sarah finished her PhD when she was around the age of 30-35. This is now 1-10 years ago. She had both female and male supervisors (where the most common situation was only male supervisors). 
Sarah is now working as a mathematician/ researcher in a private corporation or at a council/governmental institute. Why did Sarah choose mathematics in the first place?

I have always liked math already from an early age. When I succeeded in school, the subject became more fun. It worked liked a positive spiral. After graduating from upper secondary school, I didn't know what to choose so I went for subjects that I liked: math and physics. With time, my interest for physics decreased and my interest for math increased especially for applied mathematics/mathematics statistics. It surprised me how versatile the subject is! You can work in so many different areas. And I like the logic behind it.

The step to do a $\mathrm{PhD}$ was pretty straightforward but there were also people who expressed negative opinions:

When you study, there are so few students so you get both good contacts with the other students and with the teachers, but also a look into the world of academia. So, with some encouragement from my male supervisor that I had when I wrote my final essay, I applied for a PhD and I got a position. There were some individuals that thought that I wasn't clever enough, but it didn't effect me.

Sarah got a $\mathrm{PhD}$ position at the same department where she had done her undergraduate studies. Her main topic was applied mathematics/mathematics statistics. How was it then to be a (female) $\mathrm{PhD}$ student in a mathematics department?

I enjoyed being a $\mathrm{PhD}$ student. It was mainly a positive experience. There were several female $\mathrm{PhD}$ students when I started (in my group) so there were no hinders [left] because of that. I learnt a lot from my supervisors, not just science. And I worked close to other groups both outside mathematics and the university, which meant that I got valuable insights in how things can work in different places in and outside academia. Even if women and men were treated differently at the department, I didn't notice/experience anything. I sat in deciding boards at the department as a $\mathrm{PhD}$ student and I always felt they listened to what I said. But later I've heard what have happened to others. I didn't have any children while I was a PhD student. During the first years, it wasn't on the agenda, and later I found it hard to be on parental leave.

Sarah had a positive experience from the mathematics department. However, staying in academia was not really an alternative. She explains:

I didn't want to stay in academia and I had no plan to stay. I wanted to apply my knowledge. I like my work a lot. I get so solve problems, which is the most fun part of research, but I do not have to pursue my own research project. I find this work much more meaningful - to apply - than to do theoretical work.

It is the application of mathematics and the problem solving Sarah emphasizes. But there are things Sarah misses from the academia.

What I can miss from the university is the freedom: the freedom to choose your work and the flexible work situation such as working hours. My job now is more based on commissions. But overall it felt so unsafe with employments at the university. It is so hard to get a permanent position [at the university]. Also, you had to go abroad and do a 
post doc and that didn't work for me since I wanted to have children. And you have to apply for grants, which you are most likely not to get.

Sarah also talks about the view of mathematics as a closed subject:

In Sweden, for some reason, there is little interest in that researchers changing between the university world and outside academia. There are not many mathematicians that decide to work with other subjects (such as biology and medicine). Instead, you meet researchers [in other subjects] struggling with models they don't fully understand. As I see it, you should encourage researchers in mathematics that like applications to work in other subjects, to collaborate with other people.

\section{Summary}

Sarah gives two main reasons for why she is working outside academia. The first reason is the lack of full-time, long-term jobs in academia. The jobs available are short-term contracts with little security. The other reason is the nature of the work. Sarah is interested in the applications of mathematics and to use mathematics to solve problems. She thinks that mathematics (in a mathematics department) is a closed world and it would be better if mathematicians open up their eyes for other subjects.

\section{DISCUSSION}

This paper started by showing the decreasing numbers of female participation in mathematics when moving upwards in the career ladder. The aim is to try to give a voice to the women who 'disappear', here between $\mathrm{PhD}$ and further academic research and teaching professions. In another paper, I addressed a more negative story. For Sarah, even though she enjoyed being a $\mathrm{PhD}$ student in a mathematics department, staying in academia was not part of her plan. The first explanation Sarah gives for not working in a mathematics department is the difficulty of getting a permanent position. This is related to structural gender. The types of job, the uncertainty of getting them and short-term contracts seems to create a filter that has been noticed before for women scientist (Husu, 2005). Women who like to pursue a career at the same time having and/or providing for a family find it hard to take such work contracts. No one mentions the size of the salary, but it is the knowing that you have a salary that matters. Sarah continues describing this filter by saying that a postdoc abroad was not an alternative since she wanted to stay in Sweden starting a family. Post doc seems to be a filter for further career not only in USA (Nerad \& Cerny, 1999) but also in Sweden and thereby working as a norm-controlled selfselection, based on gender, in the structure (Lindberg, Riis \& Silander, 2011). Those who are not willing to take such work contracts or want to stay time abroad have no future in mathematics as an academic. In this case, this applies to women. Other factors are the application for grants, grants that you are most likely not to get. The system of applying for grants is a structural problem that has been reported as a 
general problem for women in STEM subjects (Xu, 2008). The result from this system is that if you want to pursue research in academia you need research grants, and to get research grants you need support. Sarah is not interested in applying and managing her own research project. Therefore a life in academia was not an option.

The second explanation is based in the nature of the work and the subject itself (as it is created). Sarah wanted to apply her knowledge, to use her skill, in other contexts. She was never interested in theoretical work in that way. She describes mathematics as slim scoped or perhaps a bit narrow when keeping to them selves. As a result, she experiences that other researchers are struggling with the mathematics. Sarah would rather see more cooperation between mathematics and other subjects. She emphasis the collaboration with other subjects and outside academia partners both during her $\mathrm{PhD}$ and now in her profession as a positive thing.

Sarah had a positive experience as a (female) $\mathrm{PhD}$ student. She mentions that there were already several women in her group when she started. As several already have concluded (eg. Henrion, 1997; Husu, 2005) female colleagues are important when it comes to support. Sarah describes this support such as that some obstacles were gone. It shows an awareness of that the situation has been different, or that other mathematical subjects/departments may have another climate. It is interesting to note that the four women that create Sarah's story all work in mathematical sciences focusing on applications. Do certain areas in mathematics have better working environments for women? This question has not been addressed in this paper, but it is plausible to think that different micro-climates are created in different mathematical subjects in different universities.

\section{REFERENCES}

Acker, J. (1994) The gender regime of Swedish banks. Scandinavian Journal of Management, 10, 117-130.

Acker, J. (2006). Inequality regimes. Gender, class, and race in organizations. Gender \& Society, 20(4), 441-464.

Bjerrum Nielsen, H. (2003). One of the boys? Doing gender in Scouting. Génève: World Organization of the Scout Movement.

Brandell, G., Leder, G. \& Nyström, P. (2007). Gender and mathematics: recent development from a Swedish perspective. ZDM, 39(3): 235-250.

Brandell, G. (2008). Progress and stagnation of gender equity: Contradictory trends within mathematics research and education in Sweden. ZDM, 40 (4), 659-672.

Burton, L. (2004). Mathematicians as Enquirers: Learning about Learning Mathematics. Dordrecht: Kluwer.

Connell R. (2006) Glass ceilings or gendered institutions? Mapping the gender 
regimes of public sector worksites. Public Administration Review, 66(6), 837-849.

Damarin, S., \& Erchick, D. B. (2010). Toward clarifying the meanings of gender in mathematics education research. Journal for Research in Mathematics Education, 41 (4), 310-323.

Devos, T. \& Banaji, M.R. (2003). Implicit self and identity. In M.R. Leary \& J.P. Tangney (Eds.), Handbook of self and identity. (pp. 153-175). New York: Guilford.

European Commission (2009). She Figures 2009. Statistics and indicators on gender equality in science. Report EUR 23856 EN.

Hedlin, M. (2013). Swedish schools and gender equality in the 1970s. International Education Studies. 6. 76-87.

Heilbronner, N.N. (2013). The STEM pathway for women: What has changed?. Gifted Child Quarterly, 57(1), 39-55.

Henrion, C. (1997). Women in Mathematics: The addition of Difference. Bloomington: Indiana University Press.

Herzig, A. H. (2004). "Slaughtering this beautiful math": Graduate women choosing and leaving mathematics. Gender and Education, 16(3), 379-395.

Husu, L. (2005) "Women's Work-Related and Family-Related Discrimination and Support in Academia". Advances in Gender Research, 9,161-199.

Husu, L. (2013)."Recognize Hidden Roadblocks". Nature 7; 495(7439), 38.

Lindberg, L., Riis, U. \& Silander, C. (2011). Gender equality in Swedish higher education: patterns and shifts. Scandinavian Journal of Educational Research, 55(2), 165-179.

Marsh, H.W., \& Shavelson, R. (1985). Self-concept: its multifaceted, hierarchical structure. Educational Psychologist, 20(3), 107-123.

Mendick, H. (2002). Narratives of gender and maths. In P. Valero \& O. Skovsmose (Eds.), Proc. $3^{\text {rd }}$ International MES Conference. (pp. 1-13). Copenhagen: Centre for Research in Learning Mathematics.

Nerad, M. \& Cerny, J. (1999). Postdoctoral patterns, career, advancement, and problems. Science, 285, 1533-1535.

Schoenfeld, A. (1992). Learning to think mathematically: problem solving, metacognition and sense-making in mathematics. In D. Grouws (Ed), Handbook of Research in Mathematics Teaching and Learning (pp.334-370). New York: Macmillan Publishing Company.

Smith, C.P. (2000). Content analysis and narrative analysis. In H. T. Reis \& C. M. Judd (Eds.), Handbook of research methods in social and personality psychology (pp. 313-335). New York: Cambridge University Press. 
Solomon, Y., Lawson, D. \& Croft. T. (2011). Dealing with 'fragile identities': resistance and refiguring in women mathematics students. Gender and Education 23(5), 565-583.

Solomon, Y. (2012). Finding a voice? Narrating the female self in mathematics. Educational Studies in Mathematics, 80, 171-183.

Sumpter, L. (2012). Upper secondary school students' gendered conceptions about affect in mathematics, Nordic Studies in Mathematics Education, 17(2), 27-47.

Sumpter, L. (submitted). Why Anna left academia, submitted conference paper.

Thompson, A.G. (1992). Teachers' beliefs and conceptions: a synthesis of the research. In D. Grouws (Ed), Handbook of Research in Mathematics Teaching and Learning (pp.127-146). New York: Macmillan Publishing Company.

UNESCO (2007) "Women in Science: The Missing Links", Unesco Courier 2 (2007). http://www.unesco.org/new/en/unesco-courier/archives/.

Walkerdine, V. (1998). Counting Girls Out. London: Falmer press.

Walls, Fiona (2010). Freedom to choose? Girls, mathematics and the gendered construction of mathematical identity. In H. J. Forgasz et al. (Eds.), International perspectives on gender and mathematics education (pp. 87-110). Charlotte, NC: Information Age Publishing.

Watt, H. M. G. (2008). Gender and occupational outcomes: An introduction. . In H.M. G. Watt \& J. S. Eccles (Eds.), Gender and occupational outcomes: Longitudinal assessments of individual, social, and cultural influences (pp. 3-24). Washington, DC: APA books.

Wedege, T. (2011). Doing gender in mathematics education. In G. Brandell \& A. Pettersson (Eds), Matematikundervisning: Vetenskapliga perspektiv [Mathematics education: Scientific perspectives] (pp. 92-114). Stockholm: Stockholms universitets förlag.

West, C. \& Zimmerman, D. H. (1987). Doing Gender. Gender \& Society, 1(2), 125151.

Xu, Y.J. (2008). Gender disparity in STEM disciplines: A study of faculty attrition and turnover intentions. Research in Higher Education, 49(7), 607-624. 


\title{
CHOOSING MATHEMATICS IN NORWAY AND ENGLAND: DISCOURSES OF GENDER, EQUITY AND CHOICE
}

\author{
Katarina With ${ }^{1,2}$, Yvette Solomon ${ }^{2,3}$ \\ ${ }^{1}$ Veitvet Skole, Oslo Norway ${ }^{2}$ Høgskolen i Oslo og Akershus, Oslo Norway \\ ${ }^{3}$ Manchester Metropolitan University, Manchester UK
}

In many countries, including Norway and England, there is a concern about the low number of students continuing with post-compulsory mathematics, and especially the low number of girls. Drawing on socio-cultural perspectives on the construction of identity, this paper explores the role of cultural models in choosing post-compulsory mathematics in the context of contrasts between Norwegian and English education systems, practices and policies. Specifically, we seek to interrogate the extent to which a Norwegian public discourse of egalitarianism, particularly gender equity, impacts on girls' and boys' accounts of choosing mathematics. We conclude that there are more similarities than differences between the two countries, and note the potential impact of neo-liberal discourses in eroding Norwegian equity discourses.

Key words: gender; post-compulsory mathematics; cultural models; equality; choice

\section{GENDER AND MATHEMATICS IN NORWAY AND ENGLAND}

In many countries, including Norway and England, there is a concern about the low number of students continuing with post-compulsory mathematics, and especially the low number of girls (see Bøe on Norway in 2012, and Noyes on the UK in 2009). Sociocultural and discursive theorists have addressed this issue by highlighting the link between identity and the social practices of school mathematics, arguing that girls and women experience traditional competitive mathematics classrooms negatively (Boaler \& Greeno, 2000; Paechter, 2001; Solomon, 2009) or that there is a lack of discursive spaces in which they may comfortably identify as mathematically inclined (Solomon, 2012). Writing about the UK, Mendick (2005) emphasises that girls' under-participation in post-compulsory mathematics is not due to characteristics of girls themselves, but to the practice of mathematics: 'masculinity' and 'femininity' are 'fluid properties of practices not people' (p. 240) such that doing mathematics is 'doing masculinity' (p. 235).

However, school systems and educational ideologies in Norway and England are very different; in particular, as Wedege (2007) has suggested, mainstreaming of gender issues in Norway and Denmark means that 'whether the issue is gender difference or gender equity, in the Nordic countries the underlying issue will always be equal opportunity' (2007, p. 252). This is inscribed in the Norwegian school system such that 'everyone can choose an educational path and a vocation that suits their own interests and abilities, irrespective of traditional gender role expectations' (Ministry of Education and Research, 2007, p. 22). In Norway the historically dominant ideology focuses on equal rights in education, mixed ability teaching which disallows permanent streaming, and late specialization, although this emphasis on 
egalitarianism is under pressure from travelling neo-liberal discourses (Braathe, 2012). In England, however, the school system operates explicitly within these discourses. Accountability, market competition, testing and ability grouping are commonplace and accepted as "common-sense", even in the primary years. This is particularly so in mathematics, where such practices are perceived as essential despite arguments that the system reproduces cycles of disadvantage and fails to teach for understanding (Solomon, 2009). While compulsory schooling England has a high profile system of public examinations, culminating in GCSE at age 16 in (typically) 8-10 subjects, Norwegian students in Year 10 (the final compulsory year) will have only one national written exam and only one locally given oral exam. Moving into the post-compulsory years, students in Years 12 and 13 in England will move to specialisation, typically studying towards between 3 and 5 'A'-levels, with public examinations in all subjects in both years ${ }^{1}$. Norwegian students in the equivalent years 11-13 will have varying experiences according to what type of programme they follow, but a typical experience will be that in Year 11 only $20 \%$ of the students will have an examination which can be either written or oral, in Year 12 all students will have either a written or an oral examination, and in Year 13 all will have one written exam in Norwegian. They will also have two other written exams and one oral. The students do not know which subjects they will have exams in, and these are randomly drawn (Norwegian Directorate for Education and Training, 2013).

In this study, we were interested to explore the ways in which these differing educational and discursive contexts might shape students' accounts of choosing mathematics. In particular, Wedege's observations raise the issue of the potential influence of Norwegian equity discourses: would mathematics be less likely to be seen as a gendered choice in Norway? Would students draw on different cultural models of mathematics and how it is learned? To investigate these questions, we draw here on Sfard and Prusak's (2005) and Holland, Lachicotte, Skinner and Cain's (1998) accounts of narrative identity. From Sfard and Prusak we take the suggestion 'that identities may be defined as collections of stories about persons or, more specifically, as those narratives about individuals that are reifying, endorsable, and significant' (2005, p. 16, original italics). Of particular use here is their concept of a designated identity, a 'story of the self' which emanates from significant others and has many authors: 'Identities are products of discursive diffusion - of our proclivity to recycle strips of things said by others ...' (p. 18). Such narratives can ossify into accounts of academic success and failure: 'On their way into designated identities, tales of one's repeated success are likely to reincarnate into stories of special "aptitude," "gift," or "talent," whereas those of repeated failure evolve into motifs of "slowness," "incapacity," or even "permanent disability" (p.18).

As Holland, Lachicotte, Skinner and Cain (1998) point out, our social existence means that we must draw on cultural resources or tools in order to author ourselves. The stories we tell, how we tell them, to whom and in what context we tell them, are products of the figured worlds in which we live, where "particular characters and 
actors are recognized, significance is assigned to certain acts, and particular outcomes are valued over others' (p. 52). Elsewhere, Gee (2012) introduces the concept of a cultural model as synonymous with a figured world, and we use this term here:

A cultural model or figured world is a picture of a simplified world that captures what is taken to be typical or normal. What is taken to be typical or normal, of course, varies by context and by people's social and cultural group... (p. 99)

With this focus on narrative and its use of cultural models, we explore here the differences and similarities in Norwegian and English students' self-authoring as mathematics students, in terms of their use of cultural models of gender and mathematics, and their self-positioning within discourses of equity and competition.

\section{THIS STUDY}

Nine $13^{\text {th }}$ Grade Norwegian students, four girls and five boys from three schools in different areas of Oslo, volunteered to participate following an introduction to the study by With or by their own teacher or headteacher. In England, three girls and three boys in Year 13 were recruited from a school in Manchester via initial contact with a teacher educator from Manchester Metropolitan University who was working at the school. The students were selected by their mathematics teacher in advance of our arrival, apparently with the aim of providing a diverse group with different social backgrounds and range of A-level subjects.

All students in the study were interviewed by With; in Oslo, interviews were in Norwegian and in Manchester they were in English. Interviews were semi-structured and covered the following topics: students' reasons for choosing post-compulsory mathematics, their reflections on what constitutes being good at mathematics, their peers' and family members' perceptions and experiences of mathematics. Towards the end of the interview, they were also asked direct questions about gender, unless they had brought this topic up themselves, in which case they were asked earlier; questions included 'are there any differences between boys and girls studying mathematics?' or 'do you think there are any differences between what boys and girls choose to study?'. These direct and explicit questions about gender enabled us to analyse how students referred to gender discourses in their responses. All the interviews were recorded and transcribed, in their original language. Initial phases of the analysis were carried out by With, seeking to identify emerging themes and discourses. Later stages of organisation of the analysis involved discussion between both authors; translation of the Norwegian data quoted here was undertaken by With in cooperation with Solomon, and aimed to capture the meaning of the original while producing 'natural' English, hence requiring extended discussion.

\section{ANALYSIS: THE COMPLEXITY OF CHOICE}

Students' initial responses to the question 'why mathematics' were straightforwardly 'rational', for example 'it's a good thing for the future' and 'I like it'. However, ideas about their own enjoyment and interest were frequently connected to generalised 
statements about people and about mathematics itself, and more or less explicit statements about themselves as people. Thus Mathias (Norway) expands on the idea of interest to talk about particular qualities which he attributes to mathematics students, as distinct from students who choose other subjects:

... so I would say that it has to do with interest in doing it, and maybe it has to do with how willing you are to not give up, how stubborn you are, because those who don't do it, they might have given up too soon, and don't care to try, or they are not interested in it.

Also in Norway, Camilla approached the question about who chooses and who does not choose to continue with mathematics in a slightly different way, drawing on a 'natural ability' discourse: if you don't need mathematics for your future choices, then why should you choose to continue with it when you're not good at it?

So I think people have different abilities in it, and some can't do it and some can do it. That's the way it is in all subjects. So I understand why they don't want to continue with it, and especially if you don't need it, then it's not necessary.

Many of the students said that they had chosen to continue with mathematics because they liked it and they enjoyed working with it. Emily (England) connects this enjoyment with a personal history of 'always' having been good at it ('...ever since I was a little kid ... I've always been consistently good at maths..') and an implicitly negative comparison with other subjects which draws on a cultural model of mathematics as 'harder', because it can't be memorised:

it's always just been fun, ... and then as it got harder, I sort of liked the challenge. ... I decided to go for maths because I genuinely enjoyed maths and I don't find it hard enough, and I wanted to do further maths cause it would help me with engineering, cos that's what I'm applying for. And I didn't like memorizing stuff so much, so that's why I dropped biology .... you learn maths, you can't really memorize it ...

Beyond the straightforward stories about usefulness, enjoyment and interest, there are, then, hints of a cultural model of mathematics in both groups that denotes the student who chooses it as hardworking and always ready to take on the challenges which demand (natural) ability. As we shall show in what comes next, further complexities of choice emerged as students positioned themselves within circulating stories of the kinds of people they were, and within the spaces afforded by competing discourses of equality, ability and competition, and gender.

\section{Circulating stories and mathematics identities}

Many of the students talked about the influence of parents, friends and teachers. In an explicit description of circulating family stories, Sara (Norway) says that mathematics is in the nature of her family and in her own nature; in fact, her father would have thought it was 'weird' if she had chosen not to continue with mathematics because she has done well in it:

So I feel that most of my family see me as science-minded - they think that 'she will become something like that'. 
In England, Emily talks similarly about how her family likes mathematics, and how her parents and sisters encourage her, and she works hard for them:

it's motivating I'd say, cause sometimes when you do some work, cause they know it's not the easiest thing ever, and it gets hard and you think "you know what? There's so many people believing in you, man I'm gonna do it for them". So it helps.

In Norway, Camilla identifies as a particular type of person in her story of not giving up mathematics. She says that it had 'always been her subject' and that she is 'better at thinking logically'; she also talks about her parents' positioning of her as 'managing the best' in mathematics when it came to choosing her subjects:

... mum and dad have been very on about that I should continue with mathematics - they know that it is what I manage the best - so they have kind of been on that I should continue with it - and also they know that I want to study engineering too so they say that 'yeah, you have to do that' and that I shouldn't quit mathematics.

Other people contribute to Camilla's positioning as good at mathematics; she remembers meeting her primary school teacher, who asked only how she was doing with mathematics. In an ironic tone, Camilla says, 'thank you for remembering me'. She underlines her self-positioning as a reluctant or 'different' mathematics student with a comment that her (female) friends say she is 'crazy' for studying mathematics.

\section{Positioning within competing discourses of ability, competition and equality}

Both groups of students drew on similar discourses about the nature of mathematics, drawing on cultural models of mathematics as 'hard' and as an indicator of 'cleverness' or being 'special' in comparison with others. For example, Louise (Norway) talks about how other students see those who study mathematics:

no, I think they think that "you're smart" or they think it is a bit impressive that you have $\mathrm{R} 2$, because it is a very difficult subject - it's a common view that it is the most difficult in year 13, so I don't know, I think it is actually is a bit cool just that you have it.

In England, Annie identifies as a 'hard working' student of mathematics in contrast to her friends who have chosen (implicitly) easier subjects and see her as a geek:

I think I'm a bit more hard working than them, because I guess maths is a subject where you have to work a lot harder than some of the others that they do. So I probably work a bit more .... they'll call me a little maths geek ...

Doing mathematics increases her specialness:

There are lots of skills that are involved in maths, that like bring on a good character .... I think it shows you've got a good train of thought...

However, other aspects of their accounts appeared to reflect the different educational systems and ideologies in their countries. While Louise's comment is quite usual among the Norwegian students, they also took some care when talking about differences between students, frequently referring to public discourses of equality in choice and opportunities. They also appeared to be influenced by the Scandinavian 
'Law of Jante' (Sandemose, 2000) which emphasizes the collective and devalues individual success and achievement and disallows claims to be better than others. For example, despite his emphasis on the value of mathematics and its role in 'prestigious occupations such as doctor and maybe engineering' Ruben (Norway) is anxious to point out that there are a lot of higher education subjects which do not require it at all. Indeed, he appears conscious of the desirability of not devaluing those who get lower grades - this does not automatically make someone bad at mathematics:

... because there are many who cram a lot and knows the answers to the questions in the book, but they don't know why it's like that - so maybe there are many who sit there and maybe are on a 3 or 4 that can do [problems] better than many others..

Also in Norway, competing discourses of ability versus equality are visible in Cecilie's attempt to sympathise with students who get poorer grades, and her ambivalence over her own position in the grades hierarchy:

... you can feel a bit of sympathy with those who get bad grades, at least if you know that they have worked really hard for it and they don't get it in the end, but there are many who you understand that in a way don't care to try or use their abilities and then it is kind of their own fault. And those who get good grades, of course, you look up to them, and they are maybe people who you measure yourself with ... there are many who know that I do well in mathematics, so in a way maybe a bit more are concerned with what I get than what others get, which can both be annoying and nice.

Although ability grouping is not a sanctioned permanent practice in Norway, it can be used temporarily. In Year 12 the students at Jonatan's school were divided into two groups for mathematics, one for the high achievers and one for the low achievers, and he was placed in the higher group. It was intended that students could change from one group to another if they wanted to. Jonatan reflects on being in the higher group:

I think it has to do with that you learn different things and that you enjoy different things - I who like mathematics, I learn it easier because I think it's fun to work with.

However, he connects mathematics and ambition, thus undoing his attempt to recognise difference rather than deficit:

those who have the easier mathematics is of course somebody that do not have big ambitions, and don't think far enough ahead and you feel that in the group I am in which is the hardest there is - everyone has targets and everyone knows what they want.

Sara has participated in mathematics groups for specially gifted students. While she says that it is good to be challenged, and not to have to wait for the lower achievers, she also voices an emphasis on equal opportunities in mixed ability classrooms:

I felt actually in a way it can be a bit bad, especially for those who are really good - but at the same time for those who are average or those who are bad - I don't really know if they get a lot better when they don't have others around that are interested - that maybe can give a bit of motivation to get better - I think it's good with differences. 
In contrast, the educational discourses of ability and competition as raising standards for all were more clearly voiced by the English students. Emily makes an undiluted and unquestioning case that ability grouping and grade prediction will motivate all students to work harder and get better grades via an increase in competitiveness:

I think it's a really good system, because people lower down in the set, they'd sort of get annoyed that they weren't higher up, so that's made some of the people work harder, and people in the top set would think "I'm good enough, so I can work harder" - so I really like that system.

This is not to say that students in England never question the system, but the discourse which links ability and progress is powerful. For example, Tarik says that ability in mathematics could be a 'genetic thing', and that ability groups are useful, although he recognises the impact this might have on the achievement of lower sets:

I think - they are useful in some sense that they can categorize people so that you can be with similar people of level of maths, so that you can like thrive together, but I think it is sort of like labelling people, and for the sets lower down feel like they're like stuck there and they can't like accomplish more, so in that sense it's not great.

\section{Mathematics and gender within equality discourses}

In the same way that the public discourse of equality was cross-cut by competing discourses of ability in the Norwegian accounts, the analysis revealed how discourses of gender equity competed with more traditional discourses of gender difference. Camilla makes explicit reference to gender equity issues in order to explain patterns in subject choice. She notes the dominance of men in certain subjects and the university's positive discrimination policy, which she intends to capitalise on:

I think that engineering and things like that are more male dominated, that is why NTNU [Norwegian University of Science and Technology] have to give extra points for girls ... there is of course subjects that are more dominated by gender than others.

However, other students do not talk in these terms. Cecilie draws on a familiar traditional discourse of boys as naturally able versus girls as mere hard workers:

... I think that those who are the very best are boys, for example, but ... those who come next under that, who are very good are girls, and then it is those who are maybe a bit worse are boys. [Why?] Well, you can wonder about that - it is also there I feel the 'genius thing' comes in, because it is often those who are the very best are in a way maybe also extremely good at many things, just understand everything very easy, and I don't really have any explanation for why that is boys. That girls come in the middle has probably more to do with their work ethic - with working a lot with mathematics.

Louise also attributes girls' success to hard work, but implies that boys will catch up:

... yes, I think at least at our age, girls work more than boys. I feel that girls do more homework, they do more tasks, and work a bit more than boys do now, but that later on when they start studying and when they've figured out what they want to specialize in, 
then I think they will work even harder. But I think that more girls work more now ... at least I feel in our class that very many girls are better than the boys.

As a boy, Bjarne is wary of going as far as to say that girls are not able to do mathematics, but he makes the same point by invoking boys' 'natural' engagement:

I don't dare to say they don't have the head for it, but there's probably more engagement from boys when it comes to things like mathematics - it's more natural with boys.

Jonatan connects ambition and gender, noting that fewer girls choose mathematics even though they usually have better results than boys in school; while he deduces that this is because they are less ambitious, he notes the contradictions in his position:

... of course they have the exact same opportunities, but I feel that more boys have ambitions to get into more demanding education ... But I think it's kind of weird, because ever since primary school, it is kind of the girls who are always the best.

In England, there was similar evidence of competing discourses. Emily talked in terms of outdated stereotypes and equal opportunities - nowadays, 'anything goes':

... before it was sort of like ... "oh, girls are more into that textilesy stuff, English, talk about their feelings, guys are more logical thinking, just doing maths, science". I wouldn't say that stereotype exists any more, cos I don't see it as much, it's sort of equal opportunity, if a girl does maths it's like “yeah, cool”, if a guy's gonna do English, it's "yeah, cool". No one really does any sort of stereotyping anymore.

Kevin suggests that low self-esteem can restrict some girls' options:

[Can girls' confidence restrict their possibilities in maths?] Probably yeah, cos [my girlfriend] enjoys it and she doesn't think she'll do as well - her target's an A, but she doesn't think she'll get that, whereas my sister's confident ...I think she is more likely to want to do maths, cos she thinks she can do it because she's more confident.

He also recognises that his 'mathsy' family, including a father who is good at mathematics, will have made a difference. But at the same time that he voices this version of an equality discourse, he also draws on a discourse of natural ability:

All my family seem to be quite clever at maths ... so we probably got some a bit natural..

Other students' accounts were more clearly dominated by traditional discourses. Annie identifies as a mathematician in the future, who would like to 'be known as a clever maths person'. But she finds it difficult to picture a female mathematician:

... for some reason I always picture a man, and never a woman, when I think of a mathematician, I don't know why, but yeah for some reason it's a man.

Indeed, her friend Kaitlin appears to agree with this viewpoint:

... my friend Annie, you know, she's a girl and it comes natural to her - it just seems like an utter oxymoron, it seems unfair.

Kaitlin subscribes to the discourse of male natural ability versus female effort: 
... boys maybe feel more comfortable doing maths, I don't think girls feel uncomfortable, but I think, I'm not sure if it's true, but ideas of how the brain works, it sort of fits better into boys' psychology to be able to do maths, rules, laws [...] maybe it's the people who it comes easier to are generally the boys, maybe the girls are the ones who have to put more effort in to get there, but you know girls are determined, we'll put the effort in.

Kaitlin attempts to confront the stereotypes, but only by drawing on a traditional cultural model of femininity in describing a charity supporting girls in science:

... there's a charity ... and they have some images of scientists and these clever girls who are gorgeous looking as well as clever ... maybe there should be more famous female mathematicians who look gorgeous and awesome at maths at the same time.

\section{DISCUSSION}

We conclude that there are more similarities than there are differences between the two groups of students. They drew on familiar cultural models of mathematics, as difficult, challenging and indicative of the 'good' student. Many drew on the idea that hard work can create someone who is good at mathematics, but only those who are born good at mathematics can be 'brilliant'. These cultural models were often incorporated into circulating stories about their own positioning as good at mathematics, and their accounts of choice in particular.

There were, however, some notable differences reflecting their different cultural backgrounds and their experience of growing up in two fundamentally different educational systems. Discourses of ability and the legitimacy of competition within a system of ability grouping and performance were more powerful in the English students' stories, and were not necessarily even questioned. In contrast, the Norwegian students were more obviously careful in their accounts of ability and their limited experience of ability grouping. Drawing on discourses of equality and the Law of Jante, they tried to avoid devaluing other students, even though they also drew on the 'international' discourse of mathematics as a marker of cleverness. Their attempts to 'juggle' these competing discourses were very evident.

Our final interest in this paper is the role of gender equality discourses in what our two groups of students said, and how this relates to choosing mathematics. We found that students in both Norway and England clearly positioned themselves within discourses of ability and gender. While some subscribed unquestioningly to traditional discourses, many struggled to reconcile these with competing equality discourses, and to understand contradictions in their actual experiences. For the girls, the suggestion that women do not traditionally study mathematics did not appear to threaten their choice of studying mathematics, but it did appear to feed a potentially limiting self-positioning as 'just' a hard worker. Overall, we conclude that the presence of traditional gender discourses and cultural models of mathematics in our students' accounts demonstrates the complexity of choice as a product of negotiation with, and navigation through, competing discourses. We would also add that the additional complexity of neo-liberal discourses of competition and ability is 
something which Norwegian mathematics educators need to be vigilant about in the context of an increasing emphasis on competition in Norwegian schooling.

\section{REFERENCES}

Boaler, J., \& Greeno, J. (2000). Identity, Agency and Knowing in Mathematics Worlds. In J. Boaler (Ed.), Multiple Perspectives on Mathematics Teaching and Learning Ablex Publishing.

Braathe, H. J. (2012). Discursive positioning in Norwegian teacher education: Shifting from cross-curricularity to skills-based subject specialization. International Journal of Educational Research (55), 26-35.

Bøe, V. M. (2012). Science Choices in Norwegian Upper Secondary school: What Matters? Science Education, 96(1), 1-20.

Gee, J. P. (2012). Social linguistics and literacies: ideology in discourses. London: Routledge.

Holland, D., Lachicotte, W., Skinner, D., \& Cain, C. (1998). Identity and agency in cultural worlds. Cambridge MA: Harvard University Press.

Mendick, H. (2005). Mathematical Stories: Why Do More Boys than Girls Choose to Study Mathematics at AS-Level in England? British Journal of Sociology of Education, 26(2), 235-251.

Ministry of Education and Research. (2007). Education - from Kindergarden to Adult Education. Retrieved 19.12.2013 from http://www.european-agency.org/countryinformation/norway/norwegian-files/Gen_Education_in_Norway.pdf.

Norwegian Directorate for Education and Training. (2013). Utdanningsdirektoratet Retrieved 07.01, 2013, from www.udir.no

Noyes, A. (2009). Exploring social patterns of participation in university-entrance level mathematics in England. Research in Mathematics Education, 11(2), 167184.

Paechter, C. (2001). Gender, reason and emotion in secondary mathematics. In P. Gates (Ed.), Issues in mathematics teaching. London: Routledge Falmer.

Sandemose, A. (2000). En flyktning krysser sitt spor: fortelling om en morders barndom. Oslo: Aschehoug.

Sfard, A., \& Prusak, A. (2005). Telling Identities: In Search of an Analytic Tool for Investigating Learning as a Culturally Shaped Activity. Educational Researcher, 34(4), 14-22.

Solomon, Y. (2009). Mathematical literacy: developing identities of inclusion. New York: Routledge.

Solomon, Y. (2012). Finding a voice? Narrating the female self in mathematics. Educational Studies in Mathematics, 80(1-2), 171-183.

Wedege, T. (2007). Gender perspective in mathematics education: intentions for research in Denmark and Norway. ZDM The International Journal on Mathematics Education (39), 251-260.

\footnotetext{
${ }^{1}$ Students may follow a more vocational pathway, or leave education altogether. Here we are stating the typical traditional pathway, which is that followed by the students in this study.
} 
Working groups 


\title{
WORKING GROUP ON RESEARCH ON CURRICULUM MATERIALS
}

\author{
Guðný Helga Gunnarsdóttir and Guðbjörg Pálsdóttir \\ University of Iceland
}

A Nordic network on research on mathematics textbooks was established in 2011 with funding from NordForsk. The network has created opportunities for researchers in this field to discuss and collaborate on their research. At the conference participants arranged 80 minutes slot to introduce the network and discuss the possibilities to continue the collaboration.

A network for research on mathematics textbooks in the Nordic countries has been operating during the last three years (2011-2014). The network has been funded by NordForsk. The network consists of researchers from Estonia, Finland, Iceland, Latvia, Norway, Sweden and some international experts from the Netherlands and Germany. The network has been led by Professor Barbro Grevholm, University of Agder. The network has collaborated and organized seminars and workshops on mathematics textbooks research every year and the last workshop was held in Reykjavík in May 2014.

The main aim of the network was to increase the Nordic and Baltic collaboration in research on mathematics textbooks with implications for teachers' teaching, students' learning, and decisions by policymakers and publishing houses. Researchers in the network have collaborated in groups in many ways and participants in the network are now working on papers to be published in a thematic issue of NOMAD.

Participants of the network are interested in continuing their collaboration and at the Norma14 conference they wanted to invite others to join the group. The aim of the working group was to provide insight into the work of the network and to discuss how researchers in this area can continue their collaboration when the period of funding by Nordforsk is finished this year. The network has gathered material and information about different aspects of textbooks and curriculum materials, their history and usage. Now when IT is getting more accessible to both teachers and students it is important to follow and do research on the development of curriculum materials.

In the working group the chairs told about the network, its aims and seminars. The network has a homepage, http://textbookstudy.wordpress.com/ where there is information accessible about the work. There have been nine seminars with some 
introductions, discussions and group work. The results can e.g. be seen at NORMA14 in four presentations from the network:

- How do teachers use teacher guides in mathematics? Guðný Helga Gunnarsdóttir og Guðbjörg Pálsdóttir

- How is matematics teacher guides used for support and inspiration in teaching? Linda Ahl, Lena Hoelgaard. Tuula Koljonen

- Teaching by the book: What kinds of classroom practice do three different teacher guides for year one promote? Lena Hoelgaard og Andreas Ryve

- Engineering students' use of web lectures in a linear algebra course. Ragnhild Johanne Rensaa

There have already been some publications resulting from the collaboration and more are in preparation. The participants of the network have found it encouraging and fruitful to meet. The funding is running out so the participants wanted to find ways to continue. It seems that it is not possible to apply for further funding in NordForsk. The participants have been attending conferences and there seems to be a growing interest in research on curriculum materials as could be experienced in a working group at PME37 in Kiel 2013

Research agenda suggested at PME 37 in Kiel 2013

- The development of e-textbooks and research on these in mutual relations of all kinds.

- Development of e-textbooks that really take advantage of the possibilities of ICT and studies of their effect.

- Continued comparative studies and studies based on content analysis from different aspects.

- More research attention needs to be paid to the role of textbook developers, policy makers, curriculum specialist, teacher educators and evaluators in the process of textbook development, adoption and use, and how they interact with each other. Development should be based on research but the development processes should also be researched.

- Future research on mathematics textbooks should aim for a more integrated view on reading and learning from textbooks.

This implies that many researchers are interested and would be willing to participate in collaboration in the field. The ICMT 2014 conference in Southampton has 
participants from many countries and the organisers of the conference have asked the Nordic network for collaboration.

The chairs raised some issues to discuss in the working group.

- Textbooks or curriculum materials in a wider sense

- Is it out of date to focus on textbooks? - Should we take on a broader view Teachers interaction with resources when preparing for their teaching ( c.f. ZDM December 2013).

- Working groups at conferences

- ICME - Studies on textbooks have been discussed in various groups - is it possible have influence here? Topic study group: Curriculum development?

- CERME9 ( http://www.cerme9.org/) There are many possibilities for discussing research on curriculum materials and other resources in working groups at CERME 9.

- PME - Interest and possibilities for a working group

- Possibilities for funding - are there any?

Around twenty conference participants attended the working group. The main discussions were on two issues, the influence of ICT on the development of curriculum materials and possible ways to apply for funding for researchers' collaboration in this field. There was an agreement on that ICT would be an intertwined part of curriculum materials in the future and that the field needed to focus on research on the development of curriculum materials. There were also discussed some ideas about possibilities of funding inside EU for some multinational collaboration. The Nordic network has had focus on creating a forum for different research interest but inside EU the participants thought it would be necessary to narrow the focus and collaborate on joint research projects. Some participants were willing to look into and take the initiative and prepare for an application for research funding (EU) with some colleagues from other European countries. 


\section{Teaching Mathematics at higher education}

\section{Simon Goodchild ${ }^{1}$ and Frode Rønning ${ }^{2}$ \\ ${ }^{1}$ University of Agder and ${ }^{2}$ Norwegian University of Science and Technology}

An increasing attention towards learning and teaching of mathematics in higher education, also in research, can be observed (Abdulwahed, Crawford, \& Jaworski, 2012). This is to some extent motivated by society's need and desire to educate more people in Science, Technology and Mathematics combined with a concern about the level of performance of students as they transfer from school to higher education. In Norway, there is evidence to support the assertion that students lack competence in several basic elements of mathematics when they enter higher education (Nortvedt, 2012) and international studies, such as the TIMSS-Advanced Study, show that both Norwegian and Swedish students ${ }^{1}$ perform well below the international average (Mullis, Martin, Robitille, \& Foy, 2009). In higher education one can observe a considerable drop out rate in study programmes requiring strong competencies in mathematics, and typically the mathematics courses in the programmes are seen as particularly challenging. This is observed in many countries and from Abdulwahed et al. (2012) and the references therein one can find examples of research showing how measures have been taken to improve the quality of mathematics teaching and learning.

Recently several new projects have been launched in Norway to address issues concerned with teaching and learning of mathematics in higher education, in particular within study programmes of other subjects such as engineering, natural sciences, economics and teacher education. Two examples of such projects are the Centre for Research, Innovation and Coordination of Mathematics Teaching: MatRIC, based at the University of Agder and run in collaboration with partners, and the project Kvalitet, tilgjengelighet og differensiering $i$ grunnutdanningen $i$ matematikk ${ }^{2}$ : KTDiM, based at the Norwegian University of Science and Technology (NTNU).

The project MatRIC, based at the University of Agder (UiA), with partners NTNU, the Norwegian University of Life Sciences (NMBU) and the National Centre for Mathematics Education (NMSO) is part of the framework for centres of excellence in education established by the Norwegian Agency for Quality Assurance in Education (NOKUT). Centres of excellence in higher education have existed internationally for several years, in Norway the first such centre (in teacher education) was established in 2012, and three new centres in 2014, MatRIC was one of these (the others were in biology education and musical instrument practice education). When framing the proposal for MatRIC it was

\footnotetext{
${ }^{1}$ No other Nordic countries participated in TIMSS-Advanced 2008.

${ }^{2}$ Quality, availability and differentiation in basic teaching of mathematics.
} 
natural to look to the international experience. The drop-in centres established, for example in the UK, first at the Universities of Coventry and Loughborough offered a strong example. However, the example did not seem to fit the local situation of UiA, or the Norwegian context.

UiA is split between two campuses separated by about $45 \mathrm{~km}$, with mathematics studied in both places; a single drop-in centre would not meet our students' needs. Norway's relatively small population is widely spread; excellence in mathematics teaching at university level is found in universities and university colleges throughout the country. A new concept for the centre of excellence, as a national centre and resource was required, and this is the goal for MatRIC.

The goal of MatRIC is to establish learning communities of university level mathematics teachers, within and across institutions and networked into the international community. We believe that our students' learning needs will be best addressed if we can learn from each other, share experience and creative and tested approaches to teaching mathematics. Mathematics teachers at all levels face many challenges, from fundamental cultural change and attitudes to education and studying, wider and more varied demands on budgets that appear to mean dwindling resources for teaching (larger classes, fewer lessons!), and technological advances that many are trying to exploit in transforming teaching and learning mathematics to meet the demands. Currently, MatRIC is focusing on four areas of innovation in mathematics teaching, the use of video (including ideas of flipped classrooms, MOOCs and on-line tutorials), digital assessment, simulation and modelling, also combinations of these approaches in blended learning. The first challenge of MatRIC is to make contact with and bring together university level mathematics teachers in Norway who are working with these innovations, with expertise and experience from other countries to establish learning communities that can serve as a national and international resource. MatRIC aims to coordinate effort in innovation, to build on accumulating experience and knowledge and avoid repeating the same mistakes in many different locations. MatRIC will also disseminate and sponsor research into teaching and learning mathematics at university level.

The project KTDiM at NTNU is in its initial phase but it builds on experience from reforms done in the courses Calculus 1 and 2 in the academic year 20132014. The overarching aim of the project is to contribute to better learning experiences for the students in the sense that they should develop a deeper understanding of mathematical concepts and processes, thereby making them better equipped for using mathematics in applications (Crawford, Gordon, Nicholas, \& Prosser, 1998; Hiebert \& Lefevre, 1986). It is expected that this will lead to better experiences for the students in terms of quality and relevance of the education. It is further expected that it will lead to a reduced dropout rate. The following points are important in order to reach the goals of the project.

- Increase student activity and involvement in all parts of the education 
- Stimulate increased and more continuous work input in the studies

- Enable closer contact between students and highly qualified teachers

- Increase differentiation so that the education is better adapted to different students' varying interest and previous knowledge of mathematics

Developing digital resources, e.g. digital assessment and video, is an important part of the project, so the project matches well the areas of innovation in MatRIC. Digital resources can be important to increase differentiation and to give the students a choice of what resources to use, and they can also be used to shift teacher time to more extended student contact.

An important part of the student-teacher contact is a drop-in centre for students. This is open all day every day and students can come at any time. Each study programme has certain times of the week where they are given priority but subject to capacity, they can come also at other times. A challenge here is the number of students. Calculus 1 alone has around 1800 students so scaling the drop-in centre in order to meet the needs of the students in a best possible way is not an easy task. From a survey of students in Calculus 1 it appears that the most important factor deciding whether students will use the drop-in centre or not is the possibility to get help fast (Rønning, in press). Given the large number of students it is natural that the pressure on the drop-in centre could vary a lot.

There is evidence to support the proposition that students come to higher education with a perception of mathematics as fragmented and that learning of mathematics involves using routine based procedures on standardised tasks (e.g. Crawford et al., 1998), a perception based upon their experiences of the subject in school (Goodchild, 2001). On-going research indicates that this perception still is present. Traditionally teaching of university mathematics has been much about presenting the subject matter, without much variety in modes of presentation. Lectures and a textbook have been the prevailing media used in teaching. Acknowledging that students come to higher education with different background and motivation, one will come to the conclusion that a stereotype way of teaching will have difficulties providing adequate education to a group of students that show increasing variation (Henderson \& Broadbridge, 2007). However, the introduction of new ways of presenting the material to be learned presents some challenges, as the students seem to prefer the traditional ways. In the survey of students in Calculus 1 at NTNU mentioned above $60-70 \%$ say that they use traditional lectures and the textbook to a large extent and 80-90\% agree that they learn a lot by attending lectures and that lectures are important for structuring the work (Rønning, 2014).

The steadily increasing range of possibilities in using technology (video, digital and web-based technologies) seems to offer interesting options when it comes to adapt to students' varying background and motivation. There are rich possibilities in using video, digital and web-based technologies in teaching, learning and assessing mathematics. And although use of computer technology 
in mathematics teaching is not a new idea (Schoenfeld, 1988), it is fair to say that it still does not play a major role in teaching mathematics in higher education.

The aim of this workshop was to discuss and work on some issues related to the teaching of mathematics in higher education, and to identify some questions that are worthwhile looking closer into. The following questions were put up for discussion.

- What are the necessary features of mathematics at higher education that distinguishes the subject from students' prior experience in school?

- How do the special characteristics of mathematics influence mathematical education at higher education?

- What are the 'conditions' of/for innovation in mathematics teaching, learning and assessment at higher education?

Another goal of the workshop was to establish a network of researchers in mathematics education who are focusing on the issues and quality of teaching and learning mathematics in higher education. MatRIC is funded as a national centre, which we hope will be used to disseminate knowledge gained from projects such as KTDiM. However, the success of MatRIC rests on both national and international collaboration, and we look first to our Nordic colleagues and friends, we hope the collaboration will be of mutual value.

\section{References}

Abdulwahed, M., Jaworski, B., \& Crawford, A. R. (2012). Innovative approaches to teaching mathematics in higher education: A review and a critique. Nordic Studies in Mathematics Education, 17(2), 49-68.

Crawford, K., Gordon, S., Nicholas, J., \& Prosser, M. (1998). Qualitatively different experiences of learning mathematics at a university. Learning and Instruction, 8(5), 455-468.

Goodchild, S. (2001). Students' goals: A case study of activity in a mathematics classroom. Bergen: Caspar forlag.

Henderson, S., \& Broadbridge, P. (2007). Mathematics for 21st century engineering students. In Proceedings of the 2007 AaeE Conference, Melbourne (pp. 1-8). Retrieved from http://ww2.cs.mu.oz.au/aaee2007/papers/inv_Hend.pdf

Hiebert, J., \& Lefevre, P. (1986). Conceptual and procedural knowledge in mathematics: An introductory analysis. In J. Hiebert (Ed.), Conceptual and procedural knowledge: The case of mathematics (pp. 1-27). Hillsdale, NJ: L. Erlbaum.

Mullis, I. V. S., Martin, M. O., Robitaille, D. F., \& Foy, P. (2009). TIMSS Advanced 2008 International Report: Findings from IEA's Study of Achievement in Advanced Mathematics and Physics in the Final Year of 
Secondary School. Chestnut Hill, MA: TIMSS \& PIRLS International Study Center.

Nortvedt, G. (2012). Rapport. Norsk matematikkråds forkunnskapstest 2011.

Oslo: Norsk matematikkråd. Retrieved from

https://www.duo.uio.no/bitstream/handle/10852/32282/NMR_rapport_for kunnskapstest_2011.pdf?sequence $=1$

Rønning, F. (2014). Future teaching of mathematics for engineers. In Proceedings from 42 ${ }^{\text {nd }}$ SEFI Annual Conference, Birmingham, UK. http://www.sefi.be/ conference-2014/0083.pdf

Schoenfeld, A. H. (1988). Uses of computers in mathematics instruction. In D. A. Smith, G. J. Porter, L. C. Leinbach, \& R. H. Wenger (Eds.), Computers and mathematics: The use of computers in undergraduate instruction (pp. 1-13). Washington, DC: The Mathematical Association of America. 


\title{
POTENTIAL USES OF SOCIAL MEDIA IN AND FOR MATHEMATICS EDUCATION RESEARCH
}

\author{
Reidar Mosvold \\ University of Stavanger, Norway
}

\begin{abstract}
"Everyone" uses social media, and Twitter and Facebook are examples of popular social networks. In this working group, possibilities and pitfalls for using social media in and for mathematics education research have been discussed. Based on the discussions during the working group session - and an investigation of Twitter as a case-implications for future research in this area are suggested.
\end{abstract}

\section{INTRODUCTION}

Social media has become increasingly popular in the last years, and academics have also (slowly) started adopting it - mainly to connect with other people (e.g., Gruzd, Staves, \& Wilks, 2012). Social media and networks are mainly about communication, and the novelty of social media lies in the virtual nature of the communities and networks in which the communication and interchange of information takes place.

Although social networks have a recent origin, the very idea of communicating in settings other than face to face is, of course, far from recent. Researchers - and human beings in general - have embraced this idea for centuries. An example is the scientific journal - although we do not always think of it as a virtual community. Indeed there are differences between publishing an article in e.g. Educational Studies in Mathematics and publishing a 140 character long message (tweet) on Twitter. The differences are, however, mainly related to the qualities of the output media - or virtual community - and not so much to the communication act itself. It can be argued, and rightfully so, that publishing a scientific article is more time-consuming and challenging than publishing brief messages on social networks like Twitter, Facebook, Google+, etc. Both activities are still, however, acts of communication, and both acts of communication take place in some kind of virtual community or network. Since our activities, as researchers, evolve around acts of communication, we should carefully consider the benefits and pitfalls of the different possible arenas in which our scientific communication can take place.

Media consumers and creators have adopted social networks en masse (Lasorsa, Lewis, \& Holton, 2012), but researchers in mathematics education seem to be more reluctant adopters. Some studies have investigated education researchers' use of social media in general (Gruzd et al., 2012; Veletsianos \& Kimmons, 2013) as well as particular social networks like Twitter (e.g., Veletsianos, 2012) and Facebook (e.g., Bicen \& Uzunboylu, 2013). In mathematics education research journals, however, little attention is given to these topics. With this background, a working group was organized at NORMA 14 with a focus on discussing potential uses of social media in and for mathematics education research. Twitter - which is one of the largest and 
most common social networks - served as a starting point (but not an end point) for the discussion. The following research question was raised as a main question in the working group:

What are the potentials (and pitfalls) of using social media in and for mathematics education research?

The working group session was initiated by a short presentation of some issues that have been raised in research on Twitter in relation to education in general - since virtually no research so far has been reported on use of Twitter in mathematics education. The following themes were highlighted:

- research on teachers' and education researchers' use of Twitter

- research on Twitter networking

- research on the content of tweets (Twitter messages)

With this overview of the existing research on Twitter use in education as a background and illustrative example, a discussion of possible uses of social media in and for mathematics education research was initiated. The following topics were proposed for discussion:

- possibilities (and pitfalls) of using social media for networking and collaboration in mathematics education

- possibilities (and pitfalls) of using social media for communication and mining of research

- possibilities (and pitfalls) of conducting research on social media (e.g., Twitter content) or uses of social media

- possible theoretical and/or methodological approaches for research on social media

An overall aim of the activities in the working group was to explore possibilities for initiating collaborative research and writing projects on the topic, and the final part of the working group session was used for discussing this.

\section{WHAT IS SOCIAL MEDIA?}

So far, we have used the term "social media" with reference to certain examples; we have not yet defined it. If it is what has been indicated when referring to the similarities and differences between articles in scientific journals and tweets - mere acts of communication - social media does not seem to represent anything new. When looking at the historical development, one might argue that the appearance of Usenet (internet discussion system) in 1979 and the emergence of email - which came even earlier - represent early examples of social media. In their attempt to define social media, Kaplan and Haenlein (2010) emphasize the need to distinguish between this term and the seemingly related terms "Web 2.0" and "User Generated 
Content". Web 2.0, they argue, developed as a term among software developers in 2004 to describe a new way of thinking about Internet content. At this time, web content changed from being static and created by individuals to being "continuously modified by all users in a participatory and collaborative fashion" (Kaplan \& Haenlein, 2010, p. 61). The static web sites of the past were gradually replaced by blogs, wikis and collaborative projects. When it comes to user generated content, some think of this as equal with social media (e.g., Mangold \& Faulds, 2009), whereas others make a distinction and looks at user generated content as a descriptor of how people use social media (Kaplan \& Haenlein, 2010). Having made this distinction, Kaplan and Haenlein (2010, p. 61) present the following general definition: "Social Media is a group of Internet-based applications that build on the ideological and technological foundations of Web 2.0, and that allow the creation and exchange of User Generated Content". In the paper, I follow this definition when using the term "social media" with reference to specific types of Internet-based applications. In the discussions and implications presented, however, the focus is more on the use of social media than on the social media applications themselves.

One of the most well known examples of social media today is Twitter. In the working group session - as well as in the present paper - previous research on Twitter usage was/is presented as a foundation for the concluding discussion and suggested implications for future research.

\section{THE CASE OF TWITTER}

Since its appearance in 2006, Twitter has become one of the most popular social networks with more than 500 million registered users (Dhir, Buragga, \& Boreqqah, 2013). Like in other social networks, a main idea with Twitter is that you can connect with others. Instead of making "friends", like on Facebook, you "follow" people on Twitter. Social networks are not only about networking, however, but it is also about contributing and sharing content. In contrast with traditional blogs, Twitter - which is often referred to as a "micro-blog" - has a restriction of 140 characters for each message or "tweet" (Lasorsa et al., 2012). User messages can be public, or they can be privately directed towards a particular user. Even public tweets can be directed towards particular users by including their @username in the message. Any message can be "re-tweeted" by other users, and particular topics can be addressed by including a "hashtag" (e.g., "\#mathematics") in the message (Lasorsa et al., 2012).

In a review of academic papers related to Twitter, Williams, Terras and Warwick (2012) found that most of the papers had a focus on the messages/content (61\%). Other papers focused on users $(21 \%)$, some focused on technology $(10 \%)$ and the final $8 \%$ had focus on conceptual issues. An example of a paper that focuses on content is the article by Waters and Jamal (2011). They used content analysis to investigate Twitter updates from non-profit organizations. An example of a study more related to the academic world is that of Thelwall and colleagues (2013). They analysed the content of tweets in which links to academic articles in four particular 
journals were shared. Their conclusion was that the main contribution of such tweets was related to publicity rather than a discussion or evaluation of the content.

Other studies focus more on users, and Veletsianos (2012) is an example of this. In his study, he investigated the participation and practices of higher education scholars who used Twitter. His findings indicate, among other things, that some use Twitter to share work-related content, whereas others used Twitter for networking and participating in a social commentary. Another example of a study focusing on usage is the literature review of Dhir and colleagues (2013). Unlike Veletsianos (2012), they focused on the use of Twitter as a tool for learning in the classroom. They argue that Twitter has a positive influence on informal learning as well as the classroom environment, students' motivation, etc. They also conclude, however, that "the role of Twitter in the education field is scarcely investigated" (Dhir et al., 2013, p. 679).

\section{CONCLUDING DISCUSSION}

An increasing number of mathematics education researchers seem to be using social media, but a review of literature indicates that potential uses of social media in and for mathematics education research is still under-explored. There still seems to be a lack of interest among mathematics education researchers to approach a serious and critical investigation of the potentials and pitfalls of social media. Our conclusion is therefore that this working group has an important agenda.

Based on previous research related to social media use in other areas, as well as our own experience and opinions, we suggest that the following issues need to be investigated further:

- What types of social media do mathematics educators (both teachers and researchers) use, how do they use social media, and what rationale does these users have for using social media?

- How can social media - including both open and more closed networks - be used in mathematics education (at all levels)?

- What are the potentials of combining aspects from social networks with use of more traditional resources like (electronic) textbooks?

In addition, it would be relevant to investigate and analyse the user-contributed content related to mathematics in different types of social networks (e.g., Twitter, Facebook, Google+, Linkedin, etc.).

\section{REFERENCES}

Bicen, H. \& Uzunboylu, H. (2013). The use of social networking sites in education: A case study of Facebook. Journal of Universal Computer Science, 19(5), 658671. 
Dhir, A., Buragga, K., \& Boreqqah, A.A. (2013). Tweeters on campus: Twitter as a learning tool in classroom? Journal of Universal Computer Science, 19(5), 672691.

Gruzd, A., Staves, K., \& Wilk, A. (2012). Connected scholars: Examining the role of social media in research practices of faculty using the UTAUT model. Computers in Human Behavior, 28, 2340-2350.

Kaplan, A. M., \& Haenlein, M. (2010). Users of the world, unite! The challenges and opportunities of Social Media. Business horizons, 53(1), 59-68.

Lasorsa, D.L., Lewis, S.C., \& Holton, A. (2012). Normalizing Twitter: Journalism practice in an emerging communication space. Journalism Studies, 13(1), 19-36.

Mangold, W. G., \& Faulds, D. J. (2009). Social media: The new hybrid element of the promotion mix. Business horizons, 52(4), 357-365.

Thelwall, M., Tsou, A., Weingart, S., Holmberg, K., \& Haustein, S. (2013). Tweeting links to academic articles. International Journal of Scientometrics, Infometrics and Bibliometrics, 17. Paper 1.

Veletsianos, G. (2012). Higher education scholars' participation and practices on Twitter. Journal of Computer Assisted Learning, 28(4), 336-349.

Veletsianos, G. \& Kimmons, R. (2013). Scholars and faculty members' lived experiences in social networks. Internet and Higher Education, 16, 43-50.

Waters, R.D. \& Jamal, J.Y. (2011). Tweet, tweet, tweet: A content analysis of nonprofit organizations' Twitter updates. Public Relations Review, 37, 321-324.

Williams, S.A., Terras, M.M., \& Warwick, C. (2013). What do people study when they study Twitter? Classifying Twitter related academic papers. Journal of Documentation, 69(3), 384-410. 
Suomen

ainedidaktinen

tutkimusseura 